Andrews University

Digital Commons @ Andrews University

1975

\title{
A Handbook of Supplementary Reading Methods and Job Sheets for Childen with Learning Disabilities
}

May-Ellen Colon

Andrews University

Follow this and additional works at: https://digitalcommons.andrews.edu/theses

Part of the Elementary Education Commons

\section{Recommended Citation}

Colon, May-Ellen, "A Handbook of Supplementary Reading Methods and Job Sheets for Childen with Learning Disabilities" (1975). Master's Theses. 172.

https://dx.doi.org/10.32597/theses/172

https://digitalcommons.andrews.edu/theses/172

This Thesis is brought to you for free and open access by the Graduate Research at Digital Commons @ Andrews University. It has been accepted for inclusion in Master's Theses by an authorized administrator of Digital Commons@ Andrews University. For more information, please contact repository@andrews.edu. 


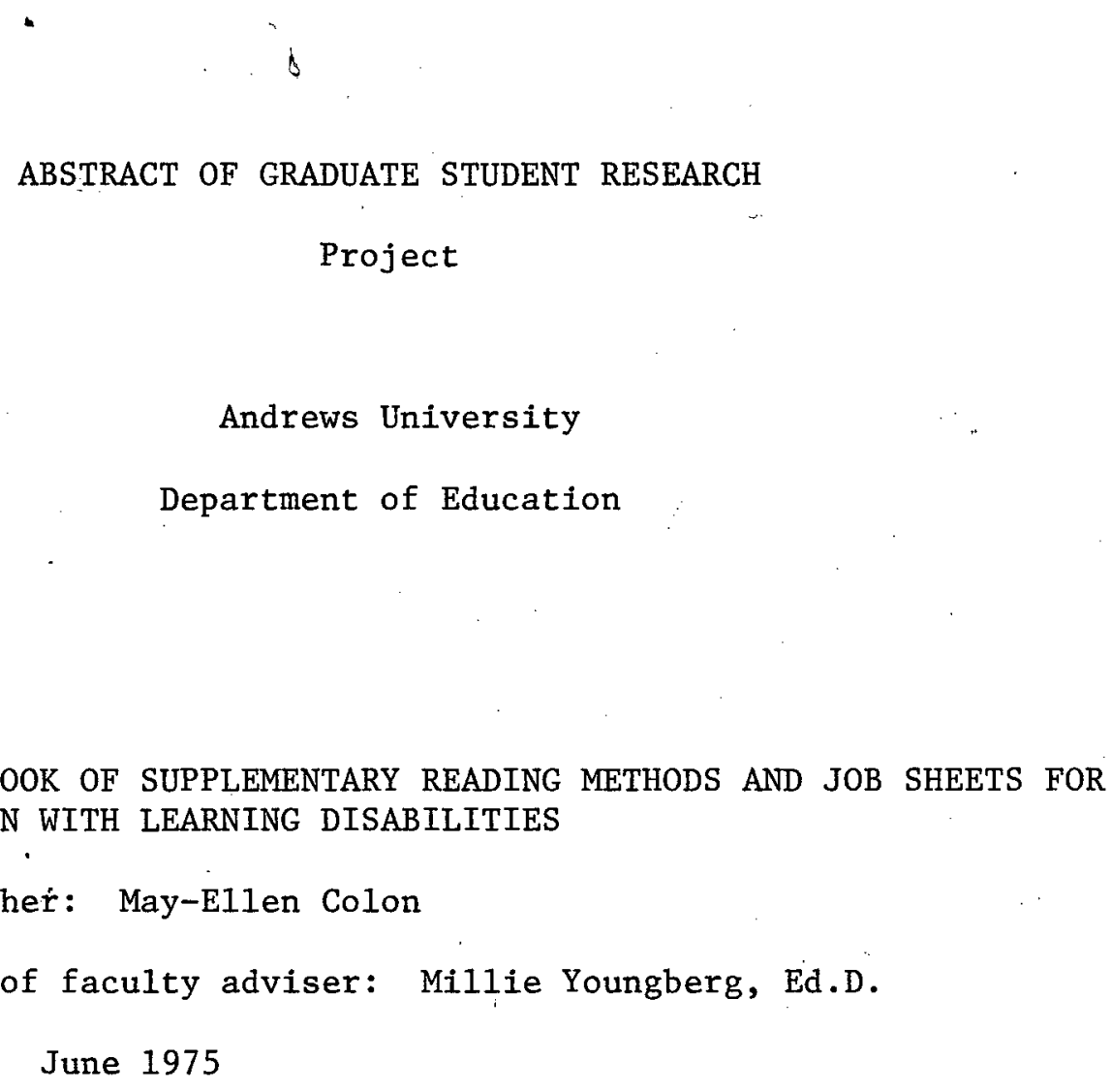

Title: A HANDBOOK OF SUPPLEMENTARY READING METHODS AND JOB SHEETS FOR CHILDREN WITH LEARNING DISABILITIES

Name of researcher: May-E1len Colon

Name and title of faculty adviser: Millie Youngberg, Ed.D.

Date Completed: June 1975

Problem

An important concern of educators today is the prevalence of children with reading disabilities. There are many methods and materials with which to help these children. The problem is to coordinate some of these techniques and to find the best approach. Therefore, the purpose of this project was to combine the best from a number of methods into a new set of useable materials for learning disabled children.

\section{Method}

Several books and materials on teaching learning disabled children were read for background and information. Ideas obtained from the methods studied were then combined to form three different types of job sheets: (a) Auditory-Visua1-Tactile reinforcement (AVT Method), (b) Visual-AuditoryKinesthetic-Tactile reinforcement (VAKT Method--reading, tracing, and writing), and (c) additional reinforcement (workbook-type exercises). A Teacher's Maiual was prepared to help the teacher use these materials more effectively. It includes instructions and dictation sentences. 


\section{Conclusions}

The Supplementary Job Sheets in this project can be very profitable for the learning disabled child since they are multisensory and carefully structured. Each new lesson is built on the preceding lessons. Success experiences are made possible because there is no guessing. The child is not held responsible for words with sounds he has not yet had. New sounds are learned, and consonant-vowel blending becomes natural through the use of the adapted AVT (Auditory; Visual, Tactile) job sheets. Each new sound is then reinforced with the VAKKT (Visual, Auditory, Kinesthetic, Tactile) job sheets. For further reinforcement, workbook-type job sheets are provided. The whole child is involved in learning to read as he does these exercises.

It is recommended that other materials be developed and included in this handbook. Some suggestions äre reading comprehension, vocabulary, a1phabet, dictionary, and affix exercises, more syllabication and spelling rule job sheets, and perceptual and readiness activities. For diagnostic purposes, an informal inventory may be prepared to accompany the checklist in this project. 


\title{
Andrews University
}

School of Graduate Studies

A HANDBOOK OF SUPPLEMENTARY READING METHODS AND JOB SHEETS FOR CHILDREN WITH LEARNING DISABILITIES

\author{
A Project \\ Presented in Partial Fulfillment \\ of the Requirements for the Degree \\ Master of Arts
}

by

May-E1len Colon

June 1975

Approva1 


\section{PREFACE}

This project emerged from a desire to blend the good points from various reading methods into one workable supplementary program for children with learning disabilities. The AVT Method by Frank Lang of Chattanooga, Tennessee, and the Traub Method found in Recipe for Reading were the main programs drawn from, supplemented by materials and methods from Orton, Gillingham, Durbrow, Plunkett, Bloomfield, and others. There is much more that can be done on this project, but for the time being, it is limited to job sheets on the most common phonemes encountered in reading and spelling.

The writer expresses appreciation to Mrs. Connie Wade for the cursive handwriting on the job sheets, to Mr. Ed Wright for the artwork, to Miss Judy Robinson for her help on some of the job sheets, and to Mr. Frank Lang for permission to use his diagrams of the speech organs. 
TABLE OF CONTENTS

Chapter

Page

I. INTRODUCTION $\ldots \ldots \ldots \ldots \ldots \ldots \ldots \ldots \ldots \ldots \ldots \ldots \ldots \ldots \ldots \ldots \ldots \ldots$

Statement of the Problem $\ldots \ldots \ldots \ldots \ldots \ldots \ldots \ldots \ldots \ldots \ldots$. 1

Purpose of the Study $\ldots \ldots \ldots \ldots \ldots \ldots \ldots \ldots \ldots \ldots \ldots \ldots$

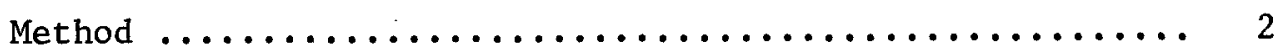

Limitation of the Project $\ldots \ldots \ldots \ldots \ldots \ldots \ldots \ldots \ldots \ldots, 2$

Definition of Terms $\ldots \ldots \ldots \ldots \ldots \ldots \ldots \ldots \ldots \ldots \ldots \ldots \ldots$

Suggestions for Further Study $\ldots \ldots \ldots \ldots \ldots \ldots \ldots \ldots \ldots$

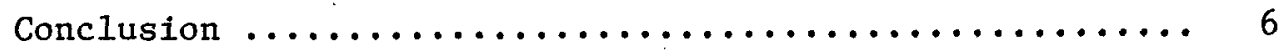

II. REVIEW OF LITERATURE $\ldots \ldots \ldots \ldots \ldots \ldots \ldots \ldots \ldots \ldots \ldots \ldots \ldots \ldots$

Definitions of Learning Disability $\ldots \ldots \ldots \ldots \ldots \ldots \ldots$

The Need--A Special Approach for Learning Disabled Students ........................ 11

Causes of Learning Disabilities ................ 12

Symptoms of Learning Disabilities ............. 15

III. METHODS FOR LEARNING DISABLED STUDENTS $\ldots \ldots \ldots \ldots \ldots \ldots \ldots \ldots$

The AVT Method $\ldots \ldots \ldots \ldots \ldots \ldots \ldots \ldots \ldots \ldots \ldots \ldots \ldots \ldots$

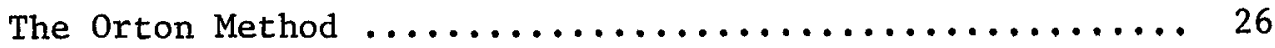

The Gillingham Method $\ldots \ldots \ldots \ldots \ldots \ldots \ldots \ldots \ldots \ldots \ldots \ldots$

Nina Traub's Method ....................... 27

The Slingerland Method $\ldots \ldots \ldots \ldots \ldots \ldots \ldots \ldots \ldots \ldots \ldots$

Clock Writing $\ldots \ldots \ldots \ldots \ldots \ldots \ldots \ldots \ldots \ldots \ldots \ldots \ldots \ldots \ldots \ldots \ldots$

Plunkett Spelling Series $\ldots \ldots \ldots \ldots \ldots \ldots \ldots \ldots \ldots \ldots \ldots . \ldots . \ldots$ 
Harold G. Maine's Multi-Sensory Phonics Workbook ....... 29

Anderson and Maine's Multi-Sensory--A Workbook of

Resource Words .......................... 29

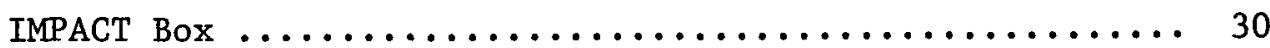

Bloomfield's Let's Read ..................... 30

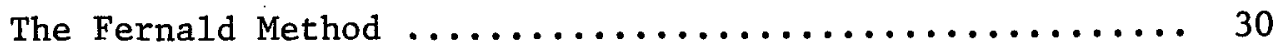

Multi-Sensory Approach to Learning Sight Words ....... 32

Student's Notebook $\ldots \ldots \ldots \ldots \ldots \ldots \ldots \ldots \ldots \ldots \ldots \ldots . \ldots \ldots$

Other Methods and Hints .................... 33

CHECKLIST AND INDEX TO THE JOB SHEETS $\ldots \ldots \ldots \ldots \ldots \ldots \ldots \ldots$

THE SPEECH ORGANS $\ldots \ldots \ldots \ldots \ldots \ldots \ldots \ldots \ldots \ldots \ldots \ldots \ldots \ldots \ldots \ldots$

IV. TEACHER' ${ }^{\prime}$ MANUAL $\ldots \ldots \ldots \ldots \ldots \ldots \ldots \ldots \ldots \ldots \ldots \ldots \ldots \ldots \ldots$

Some Special Aspects of the Supplementary

Job Sheets ............................ 39

How to Use the Supplementary Job Sheets More Effectively ....................... 44

Specific Instructions for Each Lesson ............ 50

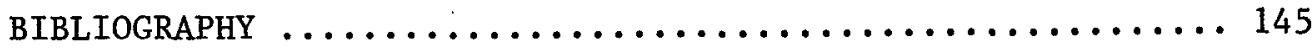

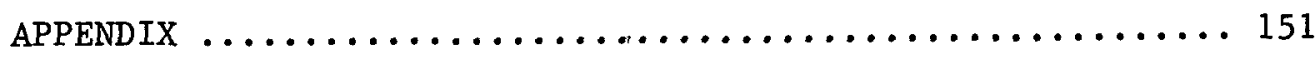

SUPPLEMENTARY JOB SHEETS 


\section{LIST OF TABLES}

Table

Page

I. Forty Ways of Saying About the Same Thing ........... 9

II. Do-It-Yourself Terminology Generator ............... 10

III. AVT - Sequence Outline ...................... 25 


\section{CHAPTER I}

\section{INTRODUCTION}

\section{Statement of the Problem}

The Secretary's (HEW) National Advisory Committee on Dyslexia and Related Disorders (1969, p.4) reports that eight million children in America's schools today will not learn to read properly. One child in seven is handicapped in acquiring essential reading skills. This problem occurs in all segments of our society. The above Committee addressed its attention primarily to "the problems manifested by those individuals who, in spite of apparentIy adequate intelligence and emotional stability, exhibit difficulties in learning to read within a teaching program that proves effective for most children (Ibid., p.6)." Their study indicates that "approximately 15 percent of the total school population conforms to this description (Idem)."

There are many methods and materials available with which to help these children. The problem is to coordinate some of these techniques and to find the best approach.

\section{Purpose of the Study}

The purpose, therefore, of this project was to combine the best from a number of methods into a new set of useable materials for learning disabled children. These materials can be used for tutoring, seatwork, and homework. 
Method

Several books and materials on teaching learning disabled children were read for background and information. Ideas obtained from the methods studied were then combined to form three different types of job sheets: (a) Auditory-Visual-Tactile reinforcement (AVT Method), (b) Visua1-Auditory-Kinesthetic-Tactile reinforcement (VAKT Method-reading, tracing, and writing), and (c) additional reinforcement (workbook-type exercises). A Teacher's Manual was prepared to help the teacher use these materials more effectively. It includes instructions and dictation sentences.

\section{Limitations of the Project}

This project was limited to the construction of supplementary job sheets for the common phonemes encountered in reading and spelling. A small number of job sheets on syllabication and affixes were also included. In addition, a few key methods for dealing with learning disabled children were inserted. There are no reading readiness or alphabet job sheets. Any other needed materials may be obtained commercially.

\section{Definition of Terms}

AVT--An Auditory, Visual, Tactile reading method originated by Frank Lang of Chattanooga, Tenn.

Blow-A-Syllable--After the student becomes proficient in Trade-ASyllable with the teacher (see Trade-A-Syllable), he trades syllables with himself, blowing between each syllable--if he cannot whistle.

Body Image--Awareness of one''s own body (conscious mental picture or subconscious knowledge of one's position in space and time) (Kaluger \& Kolson, 1969). 
Dominance--The tendency to use one side of the body for most tasks, such as using the right hand, right eye, and right foot (Kaluger \& Kolson, 1969).

Dysgraphia--Partial inability to express ideas by means of writing or written symbols. Usually associated with brain dysfunction (Ibid.).

Dyslexia--Partial inability to read, or to understand what one reads silently or aloud. Condition is usually, but not always, associated with brain impairment (Ibid.).

Experience Stories--The development of basic reading skills and abilities through experience; the use of language and reading of experience records to develop initial reading skills and abilities (Carter \& McGinnis, 1970, p.3111).

Eye-Pointer Control--Reading without a pointer, using one's eyes to coordinate articulation with the letters on the page.

Figure Ground--Involves the ability to see or hear a specific stimulus that is mingled with other stimuli.

Hyperkinetic--Hyperactive, with excessive motor restlessness (Kaluger \& Kolson, 1969).

Hypokinetic--Hypoactive, listless, diminished motor activity (Ibid.).

Kinesthetic--Pertaining to the sense by which muscular motion, position, or weight are perceived (Ibid.).

Laterality--The internal organization of the organism so that there is an awareness of sideness, left or right; also used to imply the tendency to use one side of the body for most tasks, such as using the right hand, right eye, and right foot (Ibid.).

Learning Disability--A specific deficit in perceptual, integrative, or expressive processes which severely impairs learning efficiency. Deficits may be specified in the visual-motor channel, auditoryvocal channel, auditory decoding, visual decoding, auditory-vocalassociation, visual-motor-association, vocal encoding, motor encoding, auditory-vocal-sequencing, visual-motor-sequencing, etc. (IMPACT).

Maturational Lag--The concept of delayed development of areas of the brain; of the perceptual process which matures according to recognized patterns longitudinally. A lag signifies irregularity in these patterns without a structural defect, deficiency, or loss * (Laluger \& Kolson, 1969). 
Minimal Brain Dysfunction--A small dysfunction of the brain that causes hidden handicaps.

Multisensory--Employing more than one of the senses. e.g. The AVT Method (Auditory, Visual, Tactile) is multisensory.

Perception--The interpretation of sensory information. The mechanism by which the intellect recognizes and makes sense out of sensory stimulation. The accurate mental association of present stimuli with memories of past experiences (IMPACT).

Perseveration--Continuing to behave or respond in a certain way when it is no longer appropriate (e.g. repetition of a word several times before going on, continuing a movement such as letterwriting even at the end of a line, bringing up an idea over and over, or writing the same number over and over) (Kaluger \& Kolson, 1969).

Phonemes--Speech sounds (Ibid.).

Phonetic Analysis--To analyze words by individual sounds.

Reversal--A transposition of letters (Kaluger \& Kolson, 1969).

Self-Pointer Contro1--The student using the stick (pointer) to guide his own articulation (Lang).

Sensory Deprivation--Being deprived of an accepting and stimulating enviroment, where one has a chance to have new experiences, someone with whom to identify, and someone to love him (Love, 1970, p.43).

Sight Words--Words that are to be recognized by sight, not by phonetic analysis.

Specific Language Disability--Usually the term is applied to those who have found it very difficult to learn to read and spe11, but who are otherwise intelligent, and usually learn arithmetic more readily. More recently any language deficit, oral, visual or auditory is referred to with this term (IMPACT).

Specific Reading Disability--Inability to acquire reading ability where there is no mental retardation or serious visual deficiency. Labeled by Morgan in 1896 as congenital word-blindness (Ibid.).

Strephosymbolia--Twisted symbols--a reversal of symbols observed in the reading and writing performance of children with learning disabilities.' e.g. was for saw (Kaluger \& Kolson, 1969).

Strict Pointer Control--The instructor moving the stick (pointer) from letter to letter to aid in coordinating the student's articulation with the letters on the printed page. As each letter is pointed 
to, the student must say the sound of that letter, and must not jump ahead to the next letter, or lag behind. In consonant digraphs such as $\mathrm{ch}$. the teacher points between the $c$ and the $\underline{h}$ to indicate that one sound should be pronounced.

Structural Analysis--To analyze words by syllables.

Tachistoscope--Instrument for providing a brief exposure of visual material (Carter \& McGinnis, 1970, p.318).

Tactile--To perceive by touch.

Trade-A-Syllable--This technique is used to teach automatic perception of the syllable as a unit, and to help the student have visual perception time. A word is broken into natural divisions for pronunciation, not necessarily for writing (e.g. di-vi-dend). The teacher says the first syllable, the student says the second, and the teacher the third, etc. A consonant must be left for the next syllable (e.g. di-vi-dend--not div-i-dend). When " $r$ " is at the end of a syllable it is spoken in the following syllable also (e.g. "Mary" is spoken as Mar-ry).

Trade-A-Syllable Solitaire--Reading by syllables, but trading syllables with one's self. (See Trade-A-Syllable.)

Unvoiced Sounds--Sounds that do not use the voice. (e.g. s, t, f, etc.)

Voiced Sounds--Sounds that use the voice in pronunciation. (erg. the 1, $\mathrm{m}, \mathrm{z}$, etc.)

Whistle-A-Syllable--After the student becomes proficient in Trade-ASyllable with the teacher (see Trade-A-Syllable), he trades syllables with himself, whistling between each syllable. TradeA-Syllable Solitaire is the next step after this. (See TradeA-Syllable Solitaire.).

Whopper Words--A sequence of consonants and vowels such as the following: momototom. This "Whopper Word" must be pronounced in one breath. No breaks in the flow of sound are allowed.

\section{Suggestions for Further Study}

1. Make an informal inventory to accompany the checklist in this project.

2. Make a study of the effectiveness of the Supplementary Job Sheets.

3. Add more syllabication and speling rule job sheets. 
4. Add reading comprehension exercises.

5. Add more job sheets on affixes.

6. Add vocabulary exercises.

7. Add dictionary exercises.

8. Add perceptual and readiness material.

9. Add alphabet job sheets.

10. Make job sheets for adults.

\section{Conclusion}

The Supplementary Job Sheets in this project can be very profitable for the learning disabled child since they are multisensory and carefully structured. Each new lesson is built on the preceding lessons. Success experiences are made possible because there is no guessing. The child is not held responsible for words with sounds he has not yet had. New sounds are learned, and consonant-vowel blending becomes natural through the use of the adapted AVT (Auditory, Visual, Tactile) job sheets. Each new sound is then reinforced with the VAKT (Visua1, Auditory, Kinesthetic, Tactile) job sheets. For further reinforcement, workbook-type job sheets are provided. The whole child is involved in learning to read as he does these exercises. 
CHAPTER II

REVIEW OF LITERATURE

\section{Definitions of Learning Disability}

Hartman \& Hartman (1973, p.684) explain that a student with a learning disability usually has average or above average intellectual potential. However, his academic achievement is lagging significant1y. Definitions of learning disability generally rule out such factors as emotional disturbance, social disadvantage, physical handicap, and mental retardation. Learning disabled children are sometimes called perceptually handicapped. John Meier (1970) says that

Children with special learning disabilities exhibit disorder in one or more of the basic psychological processes involved in understanding or in using spoken or written languages. These may be manifested in disorders of listening, thinking, talking, reading, writing, spelling, or arithmetic. They include conditions which have been referred to as perceptual handicaps, brain injury, minimal brain dysfunction, dyslexia, developmental aphasia, etc. They do not include learning problems which are due primarily to visual, hearing, or motor handicaps, to mental retardation, emotional disturbance, or to enviromental disadvantage (p.5).

Lehman and Ha11 (1966) point out that the learning disabled child is not mentally retarded, yet he is retarded in certain skills. He is not emotionally disturbed, yet emotional problems may have developed as a result of his learning difficulties. "What he is not is often more obvious than what he is." After the child is taken to doctors, psychologists, or guidance centers by his puzzled parents, the diagnosis reveals that the child has learning disabilities resulting from what the specialists call minimal brain dysfunction. This term is 
obviously disturbing to any parent, but at least it points to the brain as the center of the child's inability to read (Woodward, 1973).

According to Lehtinen (no date given), minimal brain dysfunction changes the way in which the child perceives the world "and the way in which he thinks about what he perceives." Johnson and Myklebust (1967) assert that such a problem "is one of altered processes, not of a generalized incapacity to learn (p.8)."

"Specific learning disability" (SLD) is another common term used in the definition of learning disability. Woodward (1973) explains that the word "specific" is added "because their handicap, no matter how serious or frustrating, is not the result of mental retardation or emotional imbalance."

Clark (1973, pp.30,31) maintains that many U.S. scientists prefer to use the term "specific language disability" rather than "dyslexia" since the latter expression (a Greek derivation meaning "poor ability to cope with language") 'is often confused with non specific dyslexia--or the inability to read or write--which can result from any number of causes (p.31)." For example, the child may have minimal brain damage, he may be intellectually dull, or he might have had poor teaching.

However, the term "developmental dyslexia" is internationally favored as a synonym for "specific language disability" because (1) the disability does not handicap the child until he is asked to read or write, and (2) it develops (progressively worsens) if not treated. Also, the expression "developmental dyslexia" means the same to scientists of every nation (Ibid., p.30). 
Fry (1972) concludes that there are almost as many terms for mild brain damage (minimal brain dysfunction) as there are investigators. To prove his point he made a list of some forty terms that authorities have used:

TABLE I

FORTY WAYS OF SAYING ABOUT THE SAME THING

\author{
MINIMAL BRAIN DYSFUNCTION \\ Association deficit pathology \\ Organic brain disease \\ Organic brain damage \\ Organic brain dysfunction \\ Minimal brain damage \\ Diffuse brain damage \\ Neurophrenia \\ Organic drivenness \\ Cerebral dysfunction \\ Organic behavior disorder \\ Choreiform syndrome \\ Minor brain damage \\ Minimal brain injury \\ Minimal cerebral injury \\ Minimal chronic brain syndromes \\ Minimal cerebral damage \\ Minimal cerebral palsy \\ Cerebral dys-synchronization syndrome \\ Hyperkinetic behavior syndrome \\ Character impulse disorder \\ Hyperkinetic impulse disorder \\ Aggressive behavior disorder \\ Psychoneurological learning disorders \\ Hyperkinetic syndrome \\ Dyslexia \\ Hyperexcitability syndrome \\ Perceptual cripple \\ Primary reading retardation \\ Specific reading disability \\ Clumsy child syndrome \\ Hypokinetic syndrome \\ Perceptually handicapped \\ Aphasoid syndrome \\ Learning disabilities \\ Conceptually handicapped \\ Attention disorders \\ Interjacent child (pp.321,322)


"In order to facilitate further clarification of terms, and to poke a little fun at those who pompously use big words: (Ibid.)," Fry has developed a "terminology generator" which can easily "yield 1,000 different terms with considerable specificity of meaning and degree of involvement (Ibid.). Even this leaves out additional terms such as Strauss' syndrome, neurophrenia, developmental lag, specific dyslexia, aphasiod, and many more.

TABLE II

DO-IT-YOURSELF TERMINOLOGY GENERATOR

DIRECTIONS: Select any word from Column 1. Add any word from column 2; then add any word from Column 3. If you do not like the result, try again, It will mean about the same thing.

1 2 3 Qualifier Area of involvement

Problem

Minimal
Mild
Minor
Chronic
Diffuse
Specific
Primary
Disorganized
Organic
Clumsy

Brain

Cerebral

Neurological

Neurologic

C.N.S. (Central Nervous System)

Language

Reading

Perceptual

Impulse

Behavior

\author{
Dysfunction \\ Damage \\ Disorder \\ Dissynchronization \\ Handicap \\ Disability \\ Retardation \\ Impairment \\ Pathology \\ Syndrome (p.322)
}

McCarthy and McCarthy (1974, p.1) agree that no other single label seems to connote as great a variety of "seemingly unrelated conditions" as does the term learning disabilities. Capobianco (1964) reacts,"'Perhaps the one irrefutable characteristic attributable to children with learning disabilities is their wide variety of behavior (p.187)." 
The Need-A Special Approach for

Learning Disabled Students

As previously mentioned, eight million children in American elementary and secondary schools have reading disorders. One in seven children are handicapped in acquiring reading skills. All segments of our society are affected (Report of the Secretary's HEW National Advisory Committee on Dyslexia and Related Disorders, 1969). In New York state alone, the Fleishmann Commission on Education reported that over 49,000 children in the state's public schools have specific learning disabilities. The report also exposed the fact that SLD children are the most neglected group: Only 14 percent were receiving any help at al1 (Woodward, 1973).

For a variety of neurological reasons, these children, though usually endowed with average or superior intelligence, cannot learn to read by the standard sight methods employed in most classrooms. According to Dr. R.N.M. Crosby (1968), a renowned neurologist who works with SLD children, "Reading is one of the most complex neurological tasks a person undertakes in his lifetime (p.51)." It is obvious why children with the neurological problems of SLD have such difficulty.

These children need to be identified early, and then treated properly if they are to overcome their difficulties (Report of the Secretary's HEW National Advisory Committee on Dyslexia and Related Disorders, 1969, p.8). Special techniques must be used on learning disabled children. A child who has impaired visual perception cannot learn with the whole-word or look-say method. A child with poor auditory perception would have difficulty learning with a phonic approach. 
The kinesthetic method is not likely to work for the child with poor tactile perception. Therefore, each student must be individually diagnosed, and a plan of therapy developed for remediation of his particular problem (Traub, 1973, p.2). The child has to learn new ways to learn. This involves more than practice in developing a particular process. A child who has difficulty in detecting differences in sounds may have to learn how to detect the differences through the help of touch and vision, feeling and looking at the tutor's lips, mouth, and throat when certain sounds are made. Merely listening to a set of tapes that, through example and practice, teach differences between sounds, is not likely to bring good results (IMPACT, Workshop Module, No. 47).

\section{Causes of Learning Disabilities}

Years of research have not brought clear-cut conclusions concerning the causes of learning disabilities. There is only one widely accepted conclusion: Disabilities in learning are the result of several contributing factors (Ear1y, 1957).

Malnutrition, Endocrine Disorders, Infëctions

Early (1957) claims that malnutrition, endocrine disturbances, and infections are the three factors most frequently mentioned by researchers as causes of reading disability. Smith and Carrigan (1959) add that endocrine disorders, in turn, appear to cause abnormal synaptic transmission and failure to achieve adequate longterm neural activity. Such a condition adversely affects a person's day-to-day memory. 
Maturational Lag and Weak Laterization

Vernon (1971) introduces the theory that maturational lag, "failure in the normal maturation of certain functions of the cerebral cortex (p.159)," is commonly thought to cause dyslexia. The neurologica1 patterns show slow differentiation and remain immature. Therefore, "clearly defined neurological patterns such as that of cerebral dominance have not been fully established... (Ibid.)." The result is weak laterization.

Carter (1970) suggests that studies of learning disabled children have provided some evidence that lack of dominance adversely affects reading ability. However, she also points out that there is lack of agreement on this issue. So it may be assumed that dominance is only one factor to be considered in the study of learning disability.

Trauma, Injury, High Fever, Lack of Oxygen, Noxious Reactions

Regarding causes of learning disabilities, Lehtinen suggests trauma occurring during a difficult delivery, or a severe accident. She also mentions high fever, encephalitis, or lack of oxygen. A condition of the mother such as blood incompatibility, or virus illness may have caused a noxious reaction, thus producing changes in the central nervous system which interfere with its normal growth and activity.

\section{Toxic Chemicals}

Woodward (1973) also attributes perceptual problems to high fever or trauma shortly after birth. In addition, toxic chemicals are mentioned as a cause. 
Minimal Cerebral Dysfunction and Learning Disabilities McCarthy and McCarthy (1974,p.10) refer to the label "minimal cerebral dysfunction" as the cause for the behavior responsible for learning disabilities. However, they point out that "not all types of cerebral dysfunction lead to learning disabilities (p.11)." (Neither are all learning problems to be classified as learning disabilities.) Clements (Abstract published in Special Education, 1966) says that minimal brain dysfunction such as is associated with learning disabilities "may arise from genetic variations, biochemical irregularities, peinatal brain insults, illnesses or injuries sustained during the years critical for the development and maturation of the central nervous system, or from unknown causes (pp.188,189)."

\section{Ear1y Sensory Deprivation}

McCarthy and McCarthy (1974) say that Clements does not disregard the possibility that early, severe sensory deprivation causes "permanent alterations" in the central nervous system. They indicate that study of the neurologically impaired child's history often reveals events that are presumed to cause central nervous system damage. "But," they add, "such events are also associated with the histories of children with minimal cerebral dysfunction (p.12)."

\section{Heredity}

Woodward (1973) states that perceptual difficulties have been traced to heredity. He claims that in nine out of ten cases studied, such difficulties were a dominant family trait--often inherited from the father. 
Emotional Disturbance and Learning Disabilities

Emotional disturbance is a result of learning disabilities, not its cause. Early (1957) implies this in her statement: "Since emotional disturbances may result from reading failure, continued failure aggravates these conditions. The older the retarded reader is, the more intense and deep-seated these emotional reactions may become ( $p$. 21)." Miller (1971,p.48) believes that when the reading problem is corrected the emotional maladjustment resulting from the reading disability will disappear.

\section{Symptoms of Learning Disabilities}

Clements (Minimal Brain Dysfunction in Children, 1966) compiled an exhaustive list of learning disability symptoms from over one hundred recent publications. About one hundred specific behaviors were listed. The ten behavior characteristics most frequently cited, in order of frequency, were as follows:

1. Hyperactivity.

2. Perceptual-motor impairments.

3. Emotiona1 lability.

4. General orientation defects.

5. Disorders of attention (e.g. short attention span, distractibility).

6. Impulsivity.

7. Disorders of memory and thinking.

8. Specific learning disabilities in reading, arithmetic, writing, and spelling.

9. Disorders of speech and hearing.

10. Equivocal neurological signs and electroencephalographic irregularities (p.13).

The movie, "Early Identification of Learning Disabilities, presents several behavioral symptoms of learning disabilities. For example, the learning disabled child in the movie had great difficulty with dressing. When she drew a picture of herself, parts were missing. She could des- 
scribe objects, but could not remember their names. Abstract think-

ing was difficult. e.g. Concepts of today and tommorrow were poor.

Meier (1970) presents a special test for screening learning dis-

abled children right in the classroom. This test is known as the

Individual Learning Disability Classroom Screening Instrument (ILDCSI).

It lists 80 items which may be considered symptoms of learning disabil-

ities. Some items on the test are below:

Holds book too close (6 in. or less).

Avoids work requiring concentrated visual attention.

Head forward or tilted to one side (more than $15^{\circ}$ ) when reading

or engaged in other visual tasks.

Moves head or trunk excessively during visual tasks (instead of moving eyes).

Uncontrollable rapid jumping of eyes.

Rubs eyes of ten when reading or engaged in other visual tasks.

Facial contortions with visual tasks (including squint).

Unable to copy from chalk board.

Unable to arrange letters of objects in a prescribed order.

Unable to learn the sounds of letters (can't associate proper phoneme with its grapheme).

Doesn't seem to listen to daily classroom instructions or directions.

Can't correctly recall oral directions when asked to repeat them. Doesn't seem to comprehend spoken words.

Can't name letters when they are pointed to. Can't pronounce the sounds of certain letters.

Mild speech irregularities. (Can't pronounce most words common to his grade level.)

Immature speech patterns (Still uses baby talk.)

Lips remain apart when at rest (mouth breathing).

Tongue thrust forward between teeth and often beyond lips (especially when using hands for writing, cutting, etc.).

Unable to correctly repeat a 7-10 word statement spoken by the teacher.

Errors in own oral expression--confuses prepositions such as

over, under, in, out, etc. ("put water under fire to boil it").

Transposes sounds in words. (Says "nabana" instead of "banana"). Can't recite the days of the week in correct order.

Seems confused when using visual, auditory and/or tactile inputs simultaneously. (e.g. oral reading and/or written spelling). Seems insensitive to others' feelings.

The remainder of the test follows. 


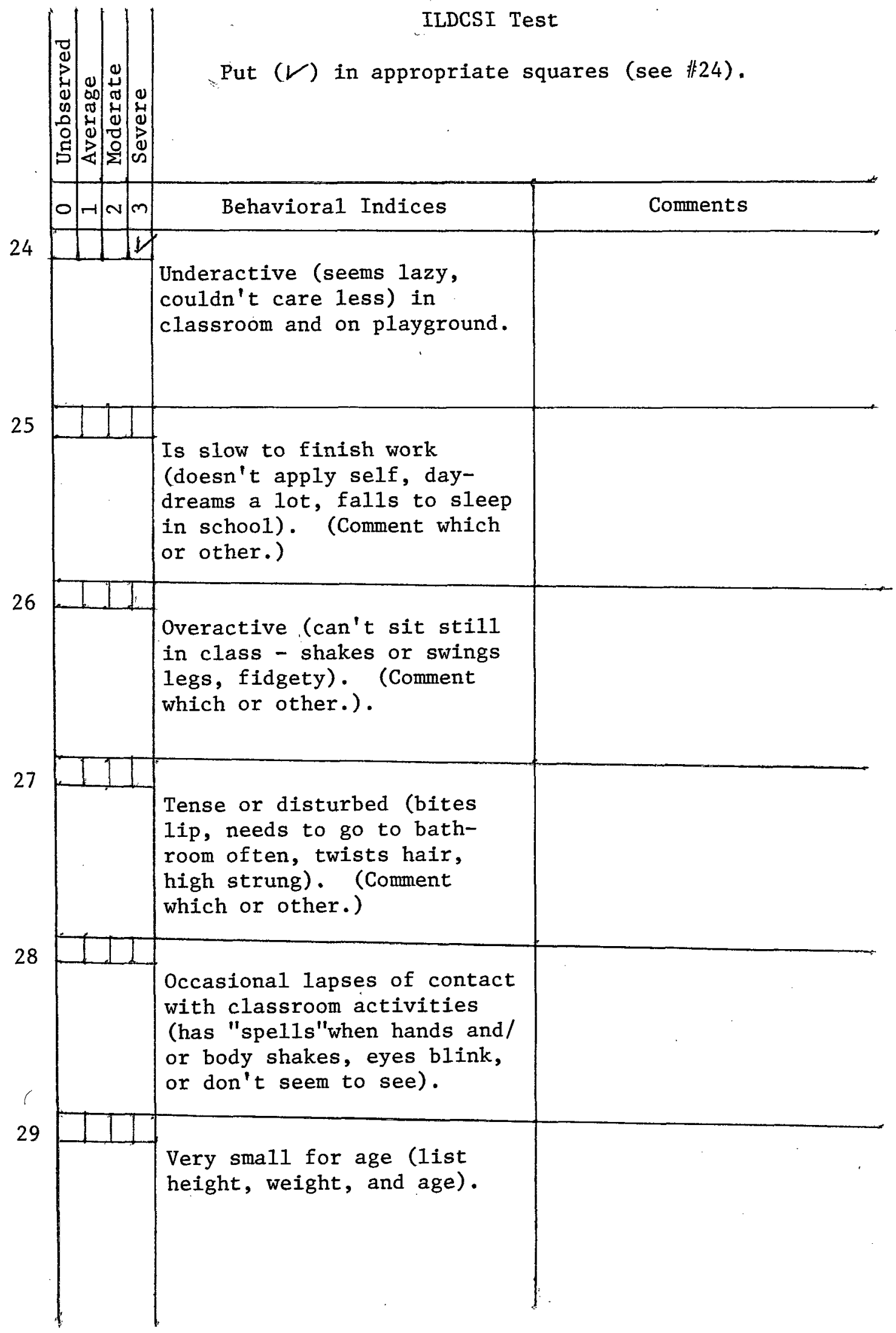




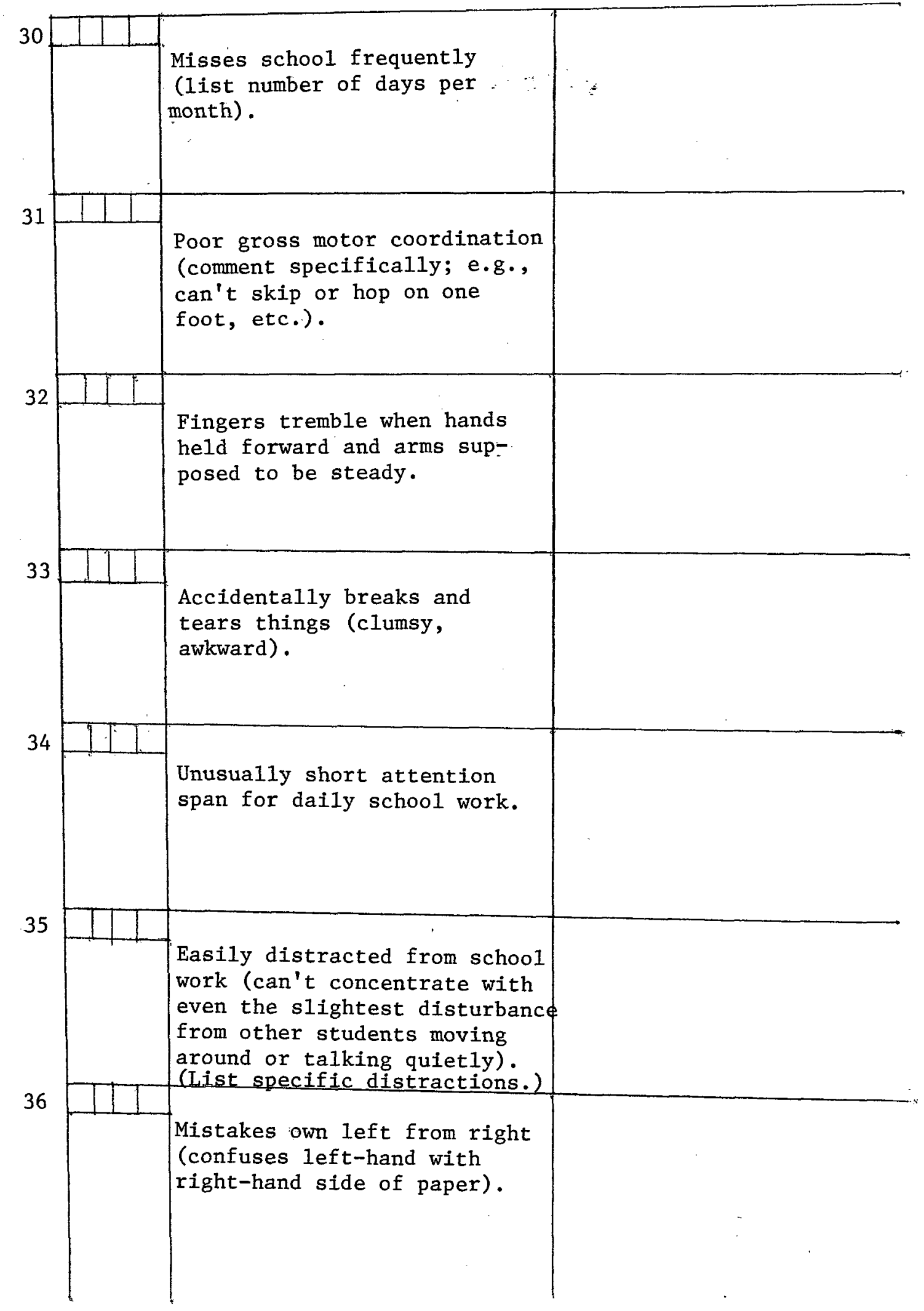




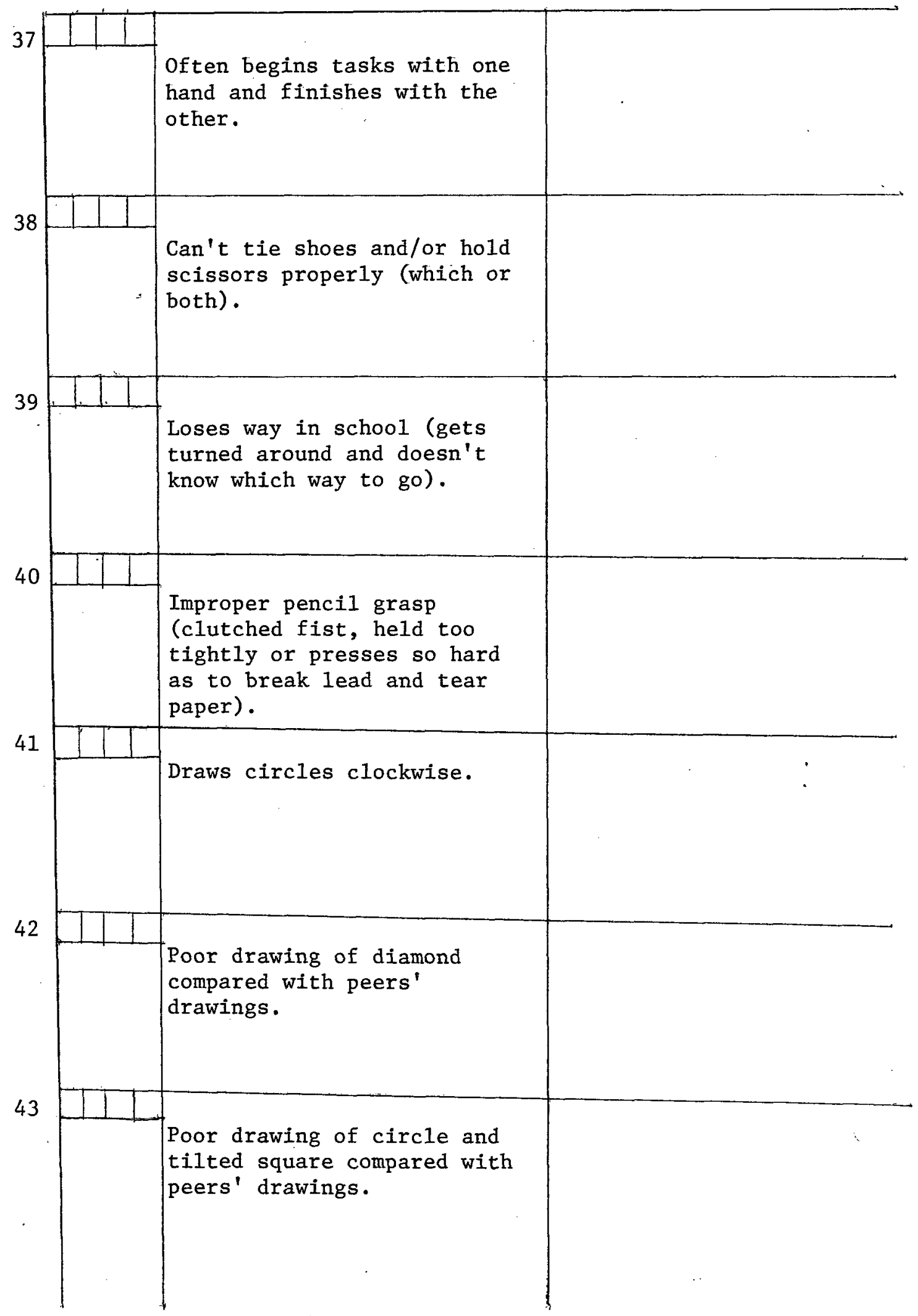




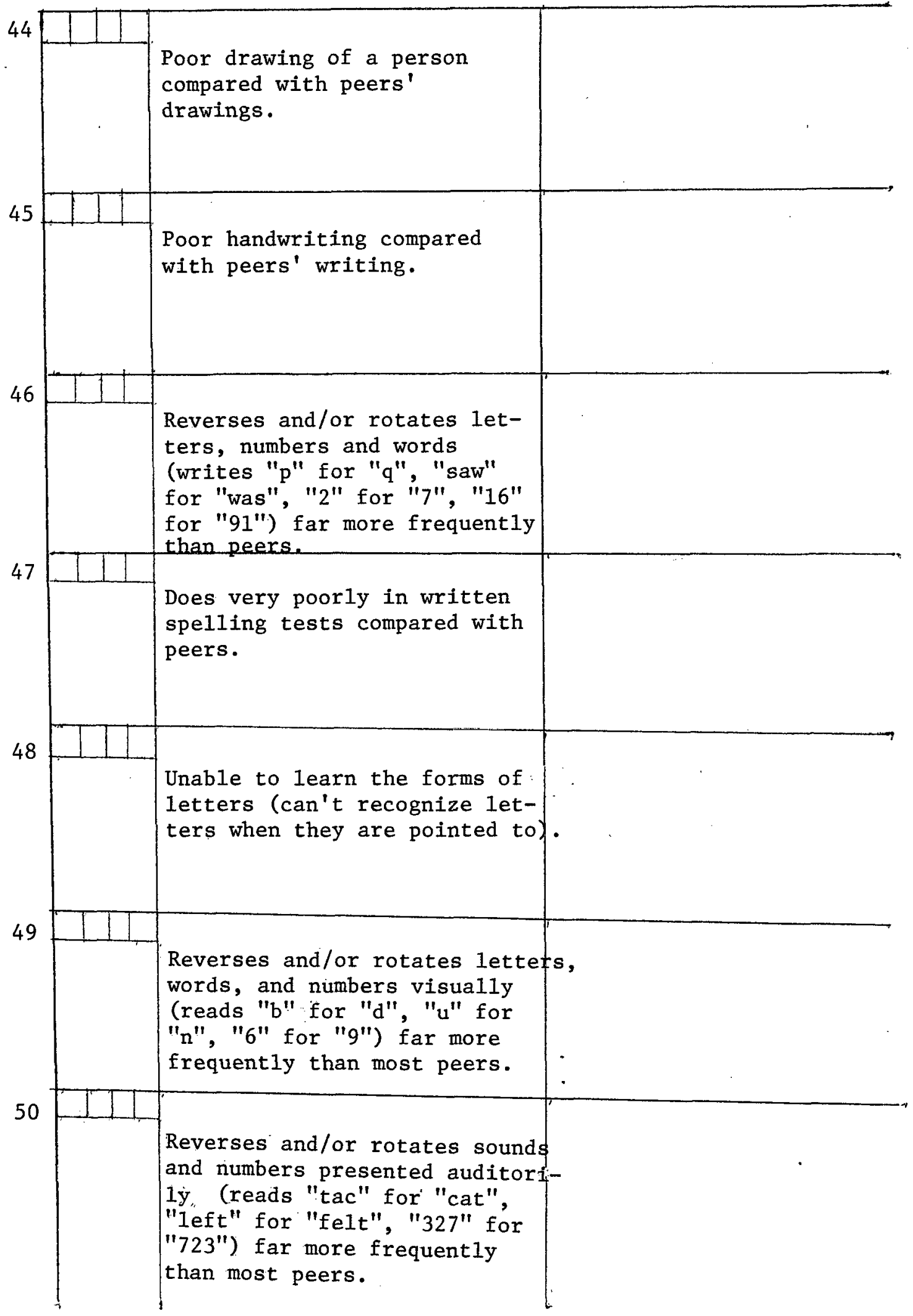




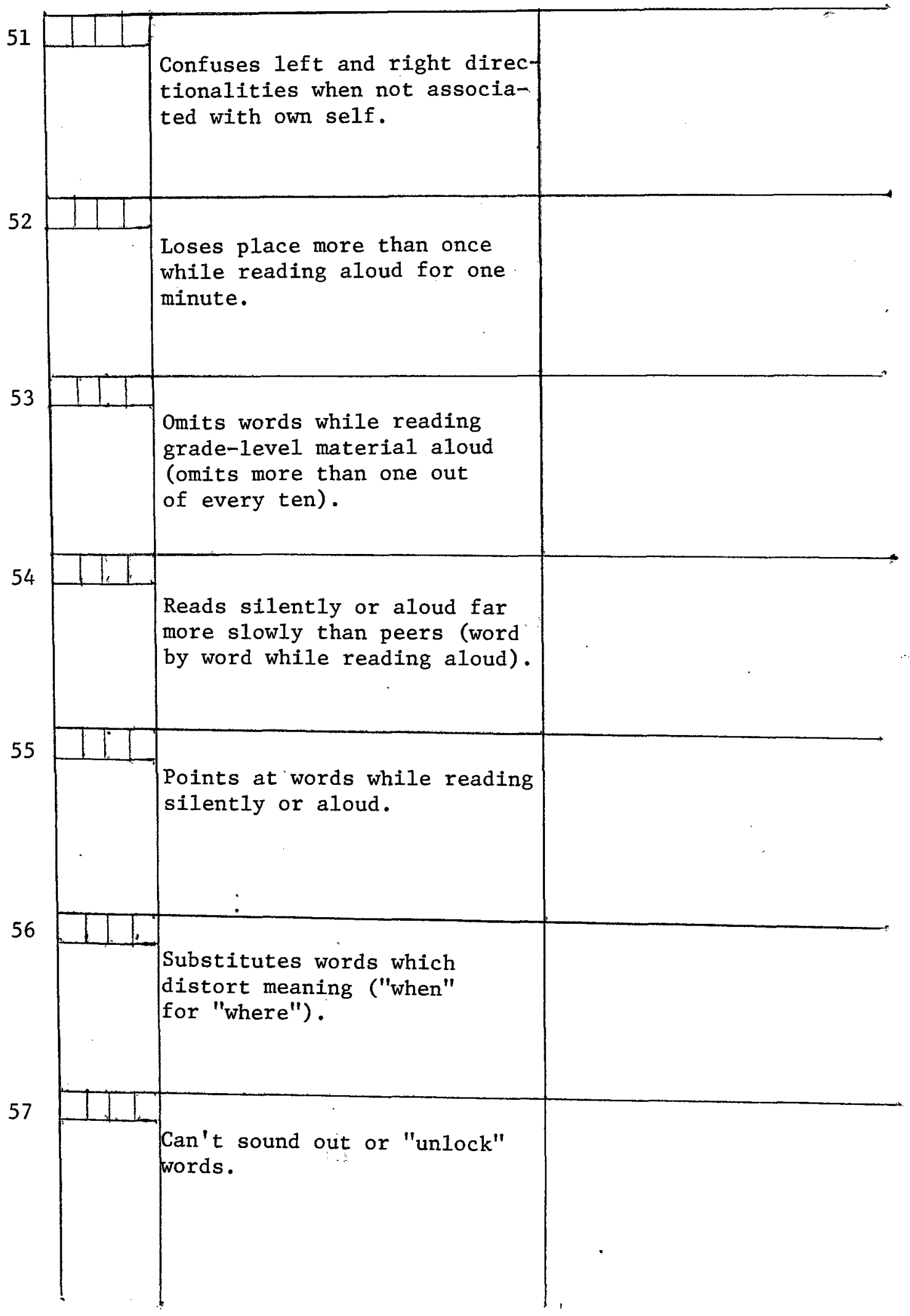




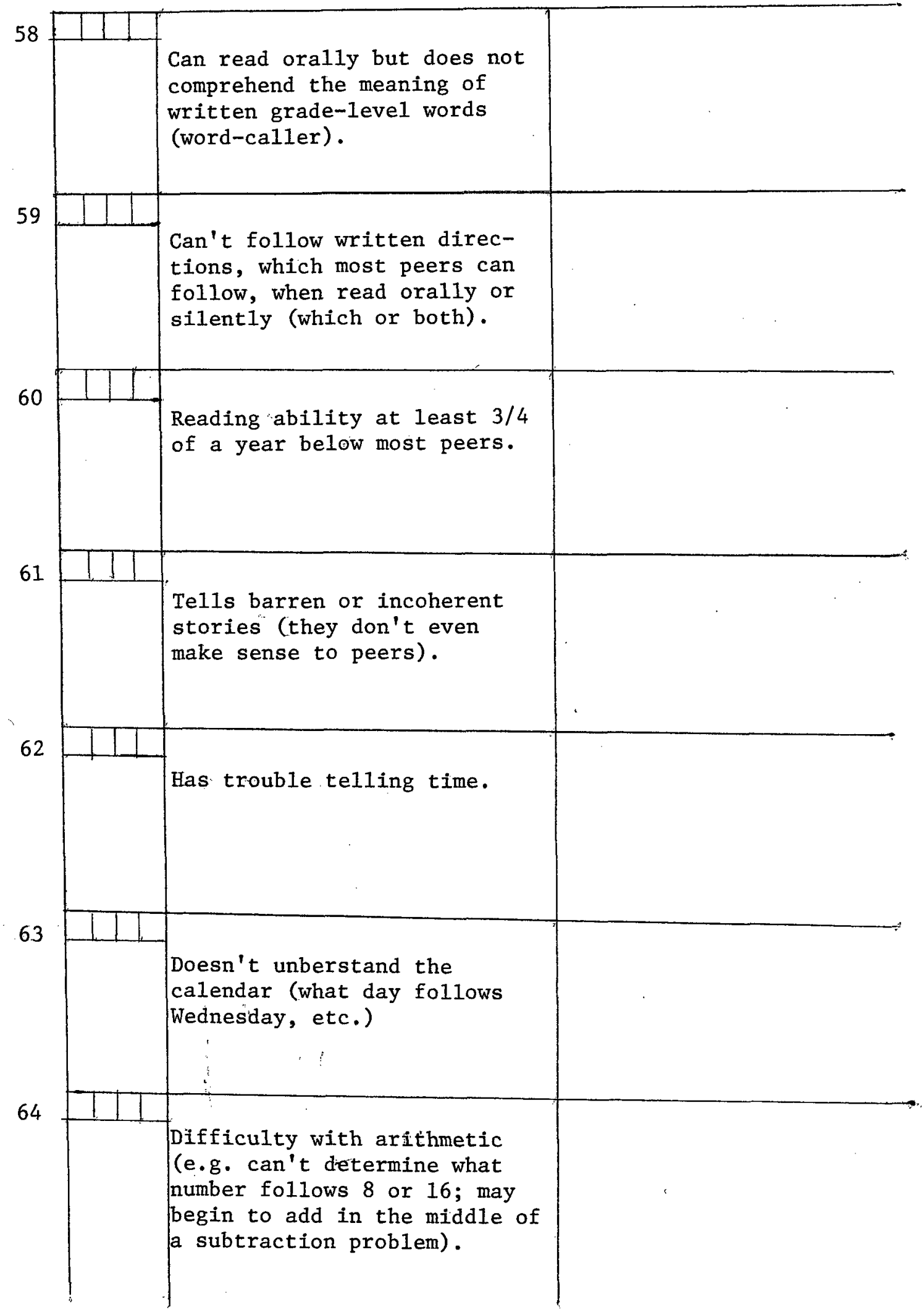




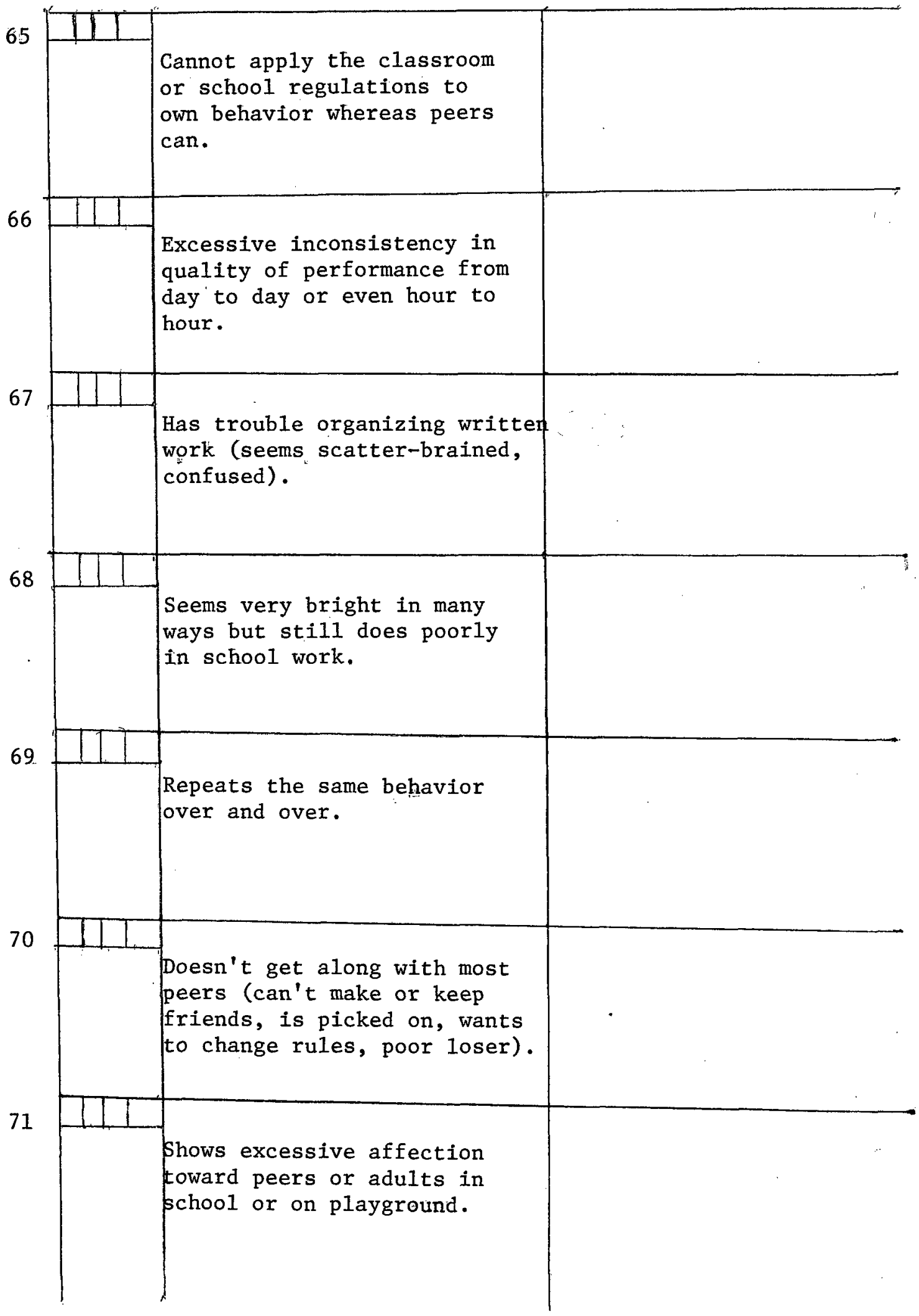




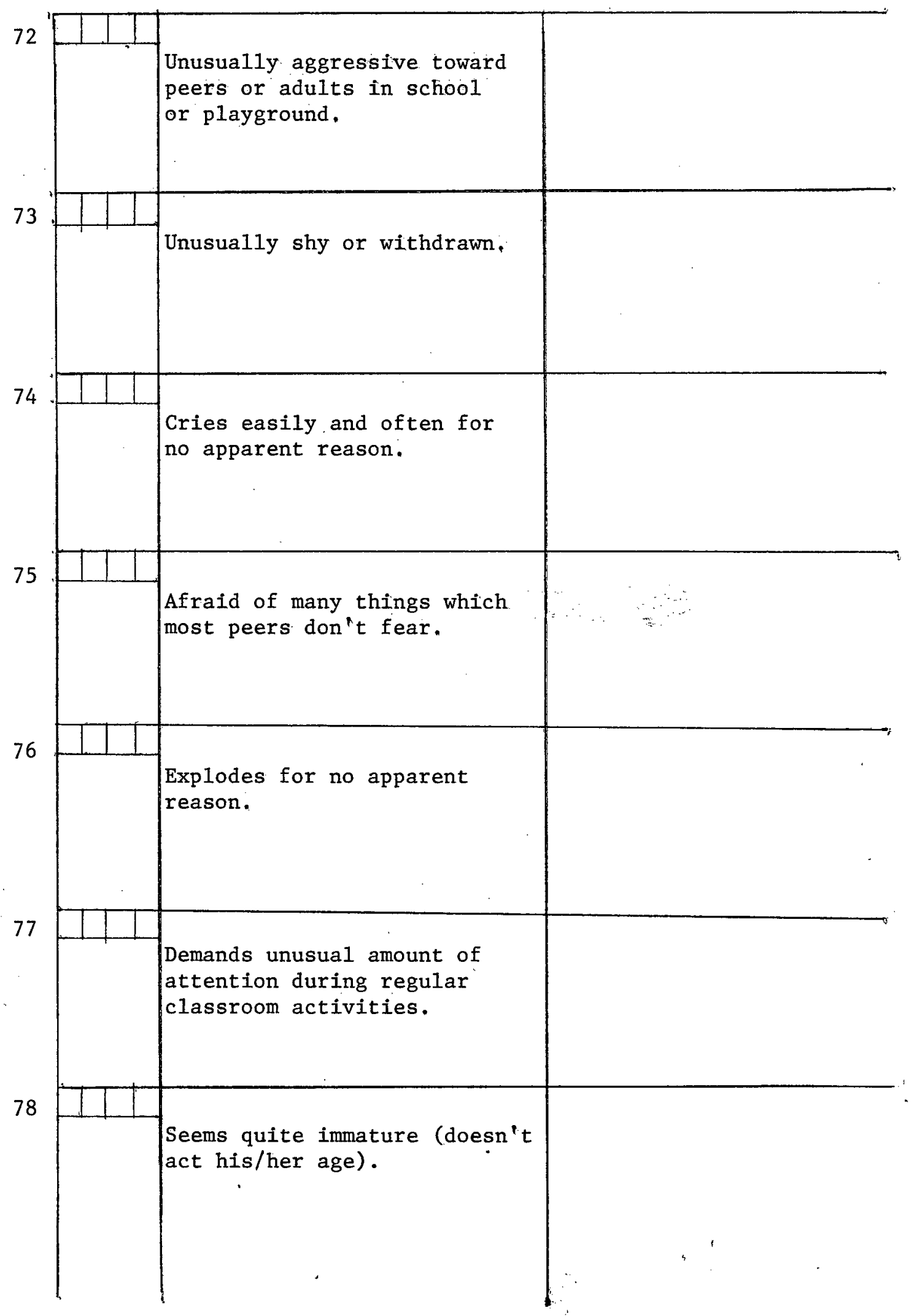


CHAPTER III

\section{METHODS FOR LEARNING DISABLED STUDENTS}

\section{The AVT Method}

The White Booklet

Frank Lang, of the AVT Educational Laboratory in Chattanooga, Tennessee, has developed a remedial reading teaching method that simultaneously involves the Auditory, Visual, and Tactile senses. A series of AVT materials are available which take the student back to the primer level of reading and steadily guide him up through college level. The first booklet, Introducing Consonant-Vowel Blending, deals with consonant-vowel blending on the primer level. The student is reminded that the letters on a printed page are "marching orders," telling his mouth ("talking machine") what sounds to produce. Articulation is described as cutting the flow of sound into pieces or articles. Vowels produce a continuous stream of sound. Consonants cut this sound off. When speaking, the mouth is open for vowels and closed for consonants. Consonant-vowel blending is achieved by sustaining the breath as it builds up pressure against each consonant (articulator) which, in turn, "explodes" into a vowe1. A pointer is used by the teacher to coordinate the student's articulation with the letters ("marching orders") on the printed page. Using a pointer is called strict pointer control. The student must follow the pointer, and should not say any other sounds except the sound that is being pointed to. In consonant digraphs such as ch, the teach- 
er points between the $\underline{c}$ and the $\underline{h}$ to indicate that one sound should be pronounced. In addition to regular words, "Whopper Words" are used for drill. A "Whopper Word" is a sequence of consonants and vowels such as the following: momomom. This sequence must be completed in one breath, using strict pointer control. In addition to the drills in the white book, a primer such as the Scott-Foresman Jr. Primer is used for further practice in consonant-vowel blending with pointer control. Each story in the primer is first read with strict pointer control. The same story is reread at natural speed. Any difficult words are decoded with pointer control.

The Pink Booklets

The second book in the AVT series, Mastering Consonant-Vowe1 Combinations, includes second grade skills in combining consonants and vowels into words. Strict pointer control is used, along with eye pointer control. Eye pointer control is the student using his eyes as a pointer. Self pointer control (the student using the stick to guide his own articulation) may also be incorporated as needed. The other pink booklet, Long and Short Vowels, teaches skills in distinguishing between long and short vowels. For example, the first lesson presents short "a" words, followed by the second lesson presenting long "a" words with final silent "e." A few short vowel words are mingled with the long vowel lesson for contrast. Mr. Lang calls the silent "e" a permission letter. This permission letter gives the other vowel in the word permission to say. its own name. During these lessons the instructor points to the vowel and the student points to the permission letter as each word of this type is sounded out by the student. Basal readers 
are used to supplement the two pink booklets.

The Yellow Booklets

The yellow series has three booklets, employing third and fourth grade reading skills. The first booklet, Consonant Blends, gives practice in blending two or more consonants. Strict pointer control is used along with eye and/or self pointer control. The second yellow booklet deals with Vowel Digraphs. Long and Short Vowels is the third yellow booklet. The same procedure is used here as in the pink Long and Short Vowels booklet (teacher and student pointers). There is no need to finish one yellow booklet before using the next one. All three may be utilized simultaneously. At this time trade-a-syllable is introduced for use in free reading. The purpose of trade-a-syllable is to teach the student to perceive the syllable as a unit. Trade-a-syllable is done as follows: A multisyllabic word, such as "dividend" is broken into natural divisions (e.g. di-vi-dend). The teacher (T) says the first syllable, the student (S) the second, and the teacher the third, etc. (e.g. di-vi-dend). A consonant must be left for the next syllable. (e.g. di-vi-dend not div-i-dend). A second rule is that when "r" is at the end of a syllable it is repeated in the next syllable (e.g. Mary is pronounced Mar-ry). During the yellow series trade-a-syllable is used only on unknown or difficult words in the supplementary basal readers. Normal reading is used every other time.

\section{The Salmon Booklet}

Simple Prefixes and Suffixes is the next booklet in the series. This booklet is on the grade 3-5 level, and is used to prepare the way for the green series. Pointer and free reading may be used for decoding. 
The Green Booklets

Advanced Skills $=-$ Suffixes follows the salmon booklet, and is on the grade 5-6 level. Trade-a-syllable with the teacher is used on the exercises in this booklet. When doing outside reading, the student reads at normal speed until a hard word is reached. Then he does trade-a-syllable with the teacher. Whistle-a-syllable may be introduced after proficiency in trade-a-syllable is reached. Whistle-asyllable means that a student trades-a-syllable with himself, whistling between each syllable. (e.g. $\stackrel{\text { di (whistle) }}{\mathrm{S}}$ vi (whistle) $\mathrm{d}$ dend). If the student cannot whistle, he may blow-a-syllable (blowing between each syllable).

The last book in the AVT series is Advanced Vocabulary, using grade 5 to high school and college skills. In addition to trade-a-syllable, the student does trade-a-syllable solitare, if he is ready. This is simply reading by syllables, but trading syllables with himself. There is no whistling or blowing between each syllable. At this time High School and College books may be used for decoding, but not for comprehension.

Vowel Cards and Consonant Wheels

Vowel cards and consonant wheels are used during the AVT sequence to drill and review the sounds learned. Various words are made as consonants are held in the boxes. On the back of the vowel cards is a list of words for additional practice.

Vowe1

Flash

Card
Consonant Wheel

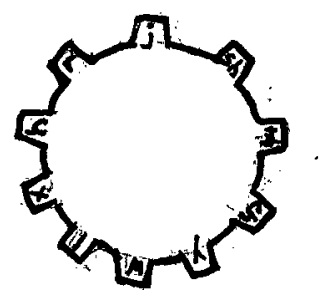


Leve1

1

2

Mastering

Consonant-Vowe1

Combinations

3

4

Consonant

Blends

5 Vowel Digraphs

6

Long and Short

Vowels

7

Simple Prefixes and Suffixes

8

Advanced Skills-Suffixes

9
Advanced
Vocabulary

Advanced
Vocabulary

Color Grade Number

White $\quad P-1$

26

Pink

2

21

Pink

2

10

Yellow 3-4

Yellow 3-4

38

Yellow 3-4

Salmon 3-5

$5-6$

30

Green

$5-6$

Green

5-6 to 30

high sch. \& college 


\section{- SEQUENCE OUTLINE}

\section{Vowe1 \\ Cards}

$\mathrm{X} \quad$ Strict Pointer Control
Supplementary Materials and Methods

Use Primer most phonetic for pointer control reading. Suggest: Scoot Foresman Junior Primer

$\mathrm{X}$ Strict Pointer Control Use other basa1 readers. Eye Pointer

X Teacher and Student Pointers

$\mathrm{X} \quad$ Strict Pointer Control Eye Pointer:

1) Free reading

2) Trade-a-syllable with teacher on unknown words

X Teacher and Student Pointers

Eye Pointer

X Teacher and Student Pointers

X Pointer and Free Reading

Use basal readers of fourth and fifth grade difficulty.

X Trade-a-Sy1lable with Teacher

X Trade-a-Sy11able Solitaire
Use basal readers of third and fourth grade difficulty.
1) Free reading

2) Use sixth grade to high school or college books for decoding practice. 
The Orton Method

The late Dr. Samuel Orton's wife, June Lyday Orton, has written A Guide to Teaching Phonics, published by Educators Publishing Service, Inc. This teacher's guide presents procedures for teaching phonics to children who have specific reading and spelling disabilities. A structured phonics approach is used, consisting of four steps:

Step One The teaching of consonants and short vowels. . Short vowels are taught in this order: a $i$ o $u$ e. The short " $i$ " and " $e$ " are easily confused, so they are learned far apart.

Step Two Long vowel sounds in their various forms are taught.

Step Three Other vowel sounds, such as dipthongs, are presented.

Step Four Word structure, including affixes and roots, is integrated throughout the other steps. Sight words are also regularly learned.

Throughout this program the student is not held responsible for any sound or word to which he has not previously been introduced. A set of phonics cards with 100 phonograms are available with this program.

The Gillingham Method

Anna Gillingham and Bessie Stillman have written a manual known as Remedia1 Training for Children With Specific Disability in Reading, Spelling, and Penmanship. This technique uses a close association of visual, auditory, and kinesthetic elements. These elements form what is called "the language triangle." The sounds of letters are taught with Phonics Drill Cards and are built into words. This program, based on Dr. Samuel Orton's neurological discoveries, is very structured. Two editions of the manual are available. 
Nina Traub's Method

Nina Traub with Frances Bloom have written a manual based on the Gillingham Method, simplified. Known as Recipe for Reading, the structured manual commences with single letter sounds and progresses to vowel digraphs, consonant blends, spelling rules and word families. The beginning lessons contain kinesthetic instruction for the correct formation of manuscript and cursive letters. Auditory, visua1, and. kinesthetic factors determine the sequence of letters taught. Phonetic readers accompany these lessons. Students are not held responsible for words with sounds not taught before the time they read. Any words with unknown sounds are underlined and the teacher pronounces them for the student. Sequence Charts, for recording individual progress, and specially lined paper are included with the manual.

\section{The Slingerland Method}

The Slingerland approach is an adaptation. of the Orton-Gillingham approach, and is intended for classroom use. A preventative or remedial program is employed with primary-grade specific language disability children. A teacher's manual is available which explains this program in detail. The title of this manual is A Multi-Sensory Approach to Language Arts for Specific Language Disability Children by Beth L. Slingerland. Two main sections comprise the manual: "The Auditory Approach.and Learning to.Write for Spelling and Written Expression" and "The Visual Approach for Reading." Numerous activity and multisensory reinforcement are used throughout the program. For example, when the teacher is presenting letters and sounds by the visual approach, she will first show the children the alphabet card. Then in- 
dividual children:

1. Name the letter seen on the card, forming it in the air with a free armswing from the shoulder.

2. Name the key word (a common object of constant form which affords a reliable cue for recall).

3. Give the sound of the letter (p.52).

This is only one of Slingerland's methods for learning sounds. She also has an auditory approach, and a kinesthetic approach.

Other characteristics of the Slingerland approach are emphasis on phrase meaning in reading, writing in manuscript instead of cursive (to minimize interference with school district policies, etc), and repetitious overlearning. As the child becomes involved with this approach, he becomes actively involved in learning.

Slingerland has also published a kit to give SLD children reading readiness training. It is called Training in Some Prequisites for Beginning Reading.

\section{Clock Writing}

Children who have dysgraphia may be helped by the "clock" method of handwriting. See Appendix A for an example of this. Students write letters on a "clock face," using the numbers to orientate them. Romalda and Walter Spaulding have published a book called The Writing Road to Reading. This book presents the "clock" in manuscript writing. Helene C. Durbrow has written a series of books, known as Learning to Write, that teach cursive writing with the "clock."

\section{Plunkett Spelling Series}

Mildred Plunkett has written a series of spelling workbooks for dyslexic students. A Spelling Workbook for Early Primary Corrective 
Work, Books I and II have lessons aimed at helping second and third graders, respectively. Spelling is taught in a meaningful way, emphasizing phonetic elements of words. Book I uses cursive writing to avoid reversal tendencies exhibited by many children. Either manuscript or cursive writing may be used in Book II.

A Spelling Workbook for Corrective Drill for Elementary Grades is for children in grades $4-6$ who have difficulty with visual recall of word configurations. Phonics drills, word groupings, and kinesthetic reinforcements are used to improve spelling ability.

Children in grades 7-12 with spelling and reading problems will find A Spelling Workbook Emphasizing Rules and Generalizations for Corrective Drill helpful. Pronunciation symbols, spelling generalizations and rules, and syllable concepts are learned through this book. Other helpful spelling, reading, and writing materials may be obtained from Educators Publishing Service.

\section{Harold G. Maine's Multi-Sensory Phonics Workbook}

The areas of reading, writing, and spelling are strengthened as this workbook is used. The student looks at the phonograms, says the guide word, and then generates in writing words that have the same sound-spelling pattern as the guide word. Sentences and paragraphs may then be written, using the words that have been generated. When the assignment is completed, the student reads his written work.

\section{Anderson and Maine's Multi-Sensory--A Workbook of Resource Words}

This versatile workbook has a variety of uses. It can be utilized as a spelling book, a diagnostic word list, a vocabulary book, or a 
language textbook. The student may say each word and mark the vowels with a macron or breve. The words in this book are listed by phonemes, and space is provided for writing each word mastered.

\section{IMPACT Box}

The Berrien County Intermediate School District in Berrien Springs, Michigan, has produced the IMPACT Box. IMPACT means Instructional Model Program for All Children and Teachers. The IMPACT Box contains indexed cards which provide the teacher with diagnostic and prescriptive materials for children with learning problems. After the assessment and prescription are made, the teacher may select materials from the box which will help the child in his weak area.

\section{Bloomfield's Let's Read}

Leonard Bloomfield firmly believed that learning the code should be the first step in beginning reading. He questioned the emphasis on meaning that was, and still is, prevalent in beginning reading instruction (Chall, 1967, p.24). He and Clarence L. Barnhart have co-authored a linguistic reading program known as Let's Read. This structured and scientific program presents words in word families. Irregular words are left until later. Like the Orton, Gillingham and Traub methods, Let's Read builds new lessons from previous lessons. Here is a sample sentence from lesson one: Can Dan fan Nan? This approach is good for SLD students.

\section{The Fernald Method}

Grace Fernald (1943) has developed a method whereby the child selects a word he would like to read. This word is learned by using 
the visual-auditory-kinesthetic-tactile senses. The word is then built into a story for him to read. As the child pregresses to the final stages he reads material other than his own stories. Briefly outlined, the four stages of this method are as follows:

Stage I--Learning words by tracing

(A) The child learns the word he has selected by saying the word as he traces it with his finger. (B) This repeated until he can write the word without looking at it. (C) A story is developed with the word and the teacher types it out (within 24 hours) for the child to read. (D) The child files his word in a word file for future review.

Stage II--Tracing eliminated

(A) Eventually the child should develop the ability to learn new words by merely looking at the word while saying it over to himself. Then he will write it without looking. (B) The child continues to write stories and to read them after they are typed.

Stage III--Reading from Print

The child now looks at the word in print (He read it handwritten before), says it to himself, and writes it without looking. He is told unfamiliar words, which he later learns.

Stage IV--Recognizing words from similarity to known words 
Multi-Sensory Approach Learning Sight Words

This method is intended to develop sequential visual imagery in children who have visual memory or spatial relation difficulty.

1. After introducing the new words, have the child read one page of a new story from a book on his instructional level.

2. List the words he cannot read.

3. Write these words on the chalkboard or on flashcards and pronounce each word as the child looks at it carefully. Tell child to underline it with his finger and say it.

4. Have him trace the letters with his finger, saying the word slowly.

5. Have him underline the word with his finger as he says it.

6. Then the child should spell the word aloud while looking at it. He says the word again.

7. Cover the word and have the child spell it out loud. Repeat steps 4-6 if he is unable to do this.

8. Cover the word and have him write it as he says it slowly. Te1l him to check to see if he wrote it correctly. Do not allow corrections of any kind, but repeat the previous steps again.

9. Have child spell the word out loud backwards while word is covered.

10. Cover word and have him write it forward, saying the word slowly as he writes.

11. Now the child should re-read the page in his reader where the words are from so that he can practice reading them in 
context.

12. The next day, check to see if the child can read the words he learned the day before. If not, repeat the steps. Otherwise, select another page from his reader and repeat the sequence.

Use this method for 15-30minutes/day, gradually increasing the number of words to be learned per session. Eventually these sessions may become unnecessary. (From the Berrien County Intermediate School District)

\section{Student's Notebook}

Students take pride in a formal notebook with definite headings where they can keep record of what they have learned. Helene C. Durbrow suggests dividing such a notebook into phonogram sections. The child then practices writing words that use that phonogram. A table of contents with the notebook page of each phonogram listed is helpful.

\section{Other Methods and Hints}

1. Child should read phonetic readers.

2. Do experience stories. Type them and make them into a book. The child may wish to draw illustrations for his stories.

3. Use music in teaching.

4. Have children use language masters, typewriters, Frostig materials, peg boards, DLM materials, puzzles, and other tactile, kinesthetic, visual, and auditory materials.

5. Use behavior modification.

6. Have learning centers.

7. Shorten assignments, if necessary. 
8. Use few verbal directions and keep them simple.

9. Praise the children when they deserve it.

10. Use visual clues with verbal directions.

11. Eliminate competition if the odds are too great.

12. Limit choices.

13. Use games to drill.

14. Block off work area with carrels, etc.

15. Do not present a new skill until the previous one is learned.

16. Allow and provide for movement.

17. Give responsibility for equipment.

18. Give oral examinations when necessary.

19. Avoid abstracts when teaching--use concrete objects to illustrate.

20. Provide for individual differences.

21. Enlist the aid of P.E. people to teach motor training and body concepts.

22. Allow for coordination activities such as walking the balance beam, rhythmical activities, obstacle course, relays, skipping, following directions such as: Go to the door, pick up the broom, and bring it to the table.

23. In general, have many manipulative materials to use. Teach through the child's strong mode, but be improving the weak mode at the same time. 24. Have a soft, big overstuffed "reading chair" for the children to use. 25. Make marks on each desk to show correct paper placement for handwriting.

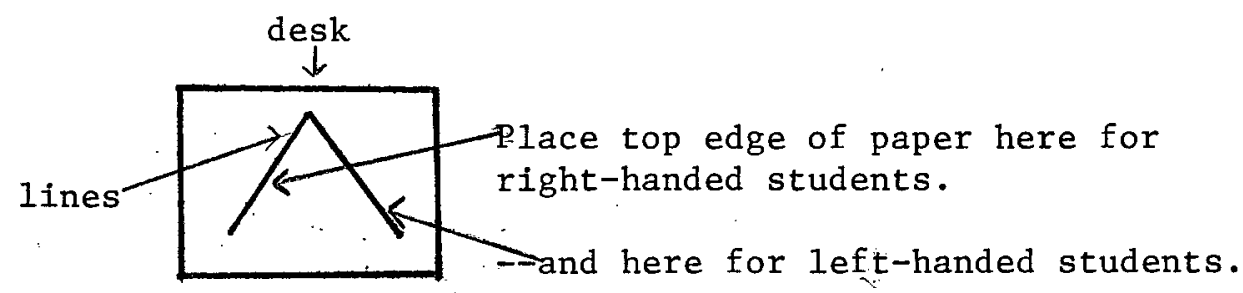


26. Use colors for letters and words that you would 1ike the child to see.

27. Tape paper on desk if your children have difficulty in keeping their writing paper straight.

28. Do not wear distracting perfume or clothes.

29. Put a green dot on the left side of the paper to indicate that the child should start writing there. Put a red "stop" dot on the other side.

30. Cut up magazines. Have the children face people, animals, cars, etc. in the correct direction for reading (facing left to right). 31. Use little tricks such as the following: For remembering "bed" make hand motions as follows: index and thumb form a circle, other fingers straight; left hand will form "b" and right hand will form "d." 32. Use picture clues for letter placement, using sky, ground, and underground. For example, " $a$ " is a ground letter, " $t$ " is a sky letter, and " $\mathrm{p}$ " is an underground letter.

33. Trace letters on the child's back,

34. End each lesson with something easy.

35. For additional ideas, methods, and materials for working with L.D. children, consult books like Games That Teach Within Your Reach, by Elaine Webber, Mott Institute, E. Lansing, Michigan; Aids to Psycholinguistic Teaching, by Bush and Giles; and Recipe for Reading, by Nina Traub. 
CHECKLIST AND INDEX TO THE JOB SHEETS

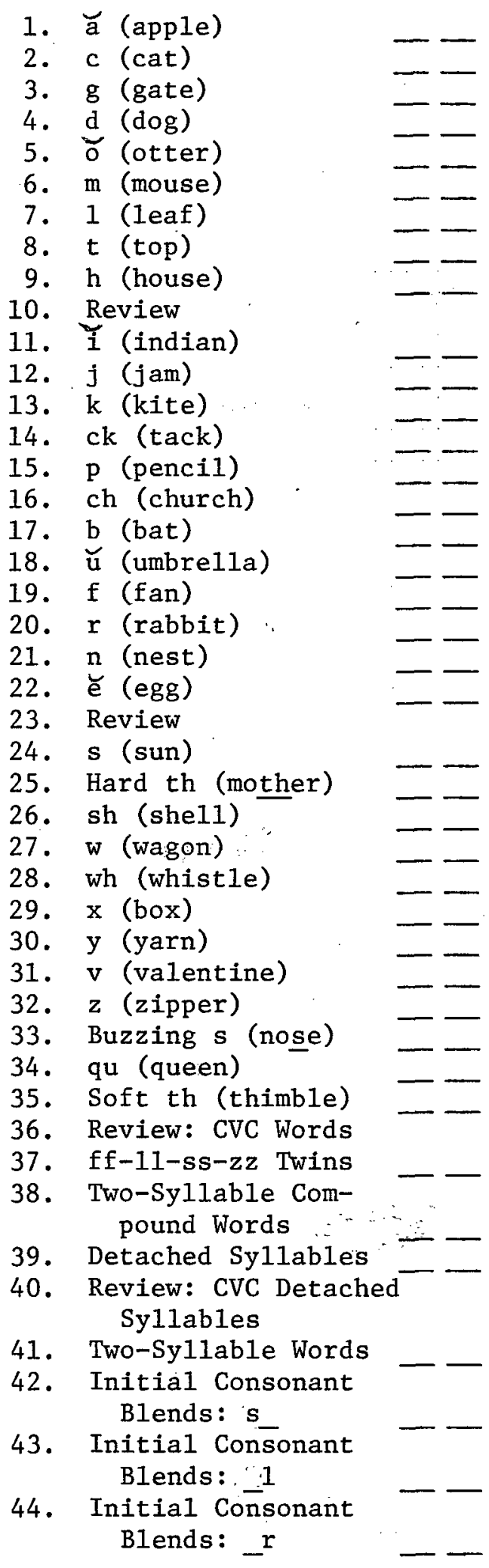

45. Initial Consonant

Blends: w

46. Final Consonant Blends

47. Adding $s$ and 's

48. ng nk

49. Review of Consonant Blends

50. Detached Syllables =with Consonant Blends

51. Two-Syllable Words Using Consonant Blends

52. ph (phone)

53. kn (knot)

54. gn (gnat

55. wr (wrench)

56. mb (thumb)

57. Review

58. a-e (cake)

59. e-e (Steve)

60. i-e (nine)

61. o-e (stove)

62. u-e (cube, flute)

63. "Magic e" Detached Syllables

64. Two-Sy1lab1e "Magic:- $\mathrm{e}^{\text {" Words }}$

65. "Magic e" Review

66. ai (pail)

67. ay (pray)

68. ea (seat)

69. ee (three)

70. oa (road)

71. oe (hoe)

72. ie (pie)

73. Review

74. Syllable Division

75. ou (cloud)

76. ow (ow1)

77. er (fern)

78. ir (shirt)

79. ur (nurse)

80. igh (night)

81. ar (car)

82. or (corn)

- 83. le (bubble)

84. Review 


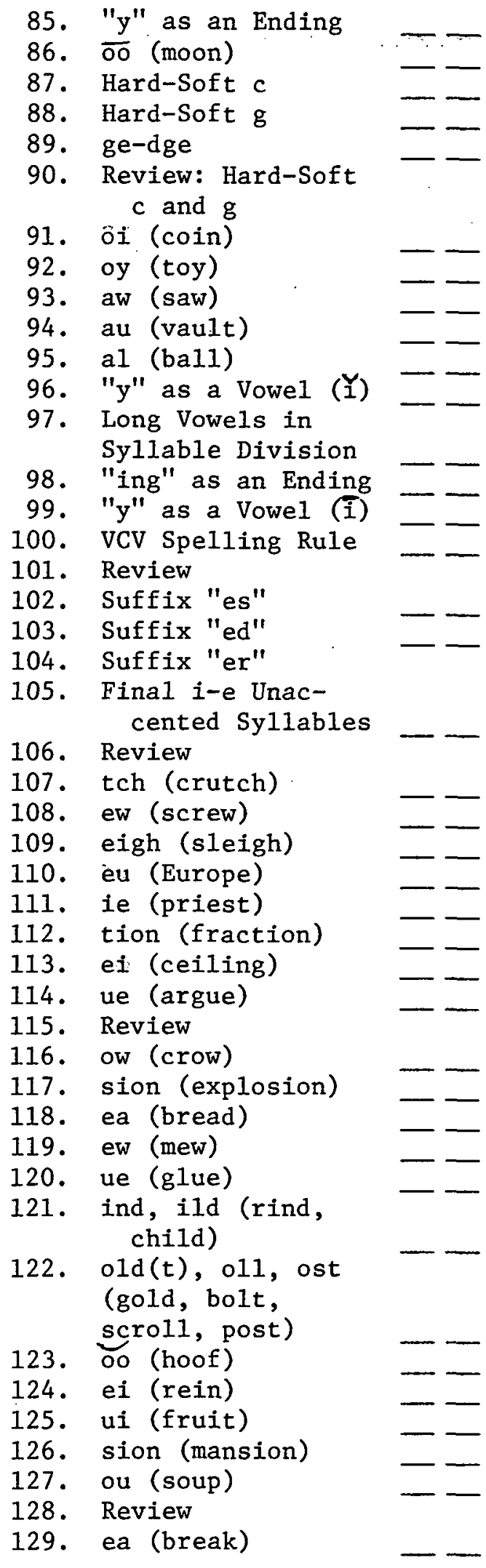

130. ou (four)

131. ie (Willie)

132. Short Vowel Sounds With_r or_rr

133. or (worm)

134. Schwa Sound ( $(\exists)$

135. ou Plus Silent " 1 "

136. o (onion)

137. ove (glove, moving van)

138. ch (schoo1)

139. ear (earth)

140. ey (monkey)

141. Review

142. ar (dollar)

143. ch (chef)

144. ou (country)

145. gh (=f,g, silent)

146. ci (glacier)

147. ey (they)

148. ui (build)

149. gu (guard)

150. a (wasp)

151. aught (daughter)

152. ought (fought)

153. Review

154. Affixes and Root Words

155. Contractions

156. Punctuation

157. Weirdo-Words
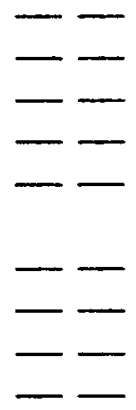

* As each lesson is completed, circle its number on this check1ist. The two blanks may be used for assessment purposes. For example, before the student begins the Supplementary Job Sheets the teacher may check his knowledge of the phonemes and other items on the checklist with an informal inventory. A check (v) is placed on the first blank after each phoneme, etc. that the student knows. The items that the student does not know are not checked. Thus the teacher can tell at a glance the student's strengths and weaknesses, and can adjust instruction accordingly. Later, the teacher can assess the student again, placing checks on the second set of blanks when the student demonstrates proficiency on an item. (The Review lessons have no blanks.) 
THE SPEECH ORGANS

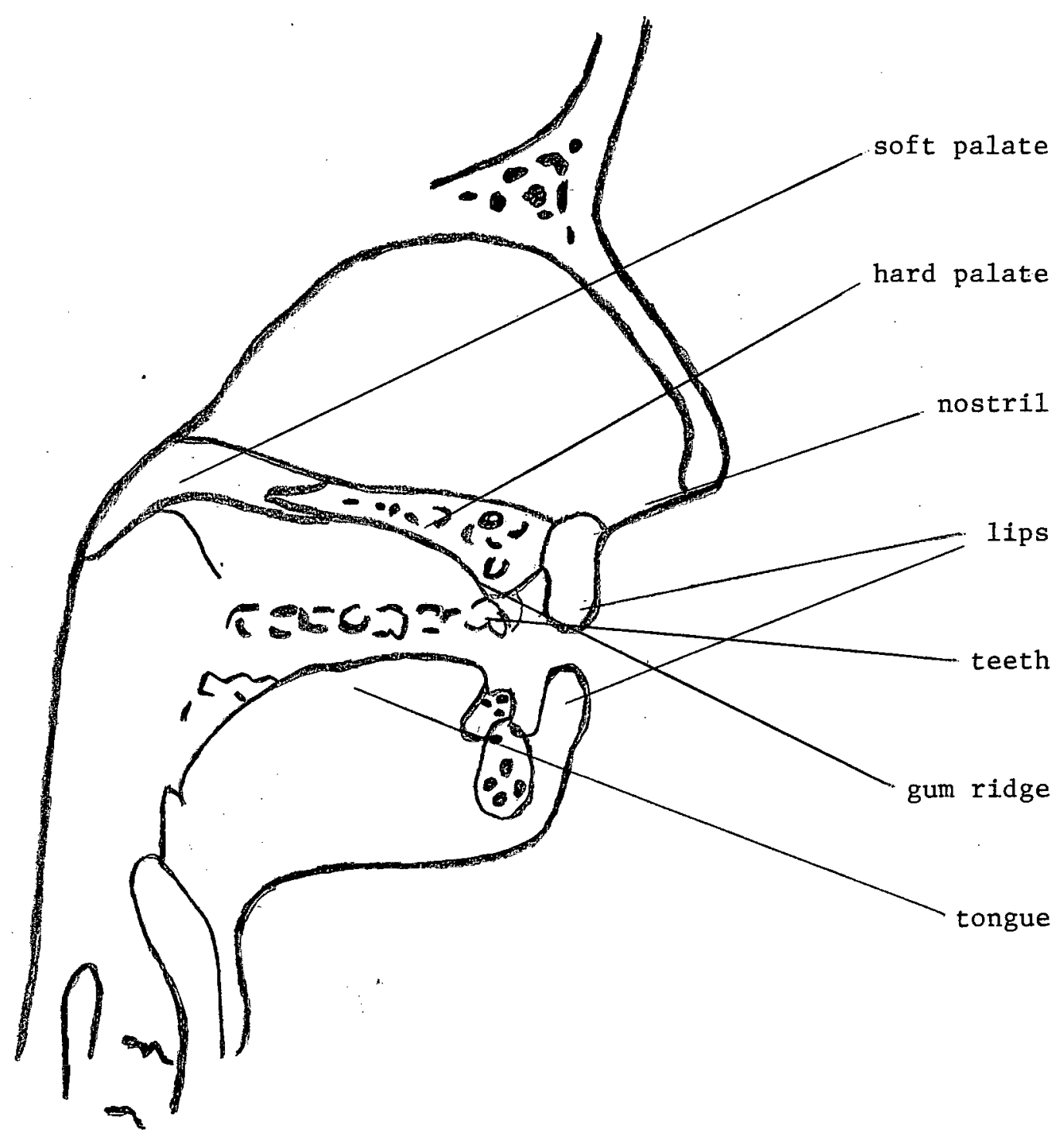


CHAPTER IV

TEACHER'S MANUAL

\section{Some Special Aspects of the Supplementary Job Sheets}

The Supplementary Job Sheets are not a complete reading program. They are mainly intended to serve as a supplementary resource for the teacher who is dealing with learning disabled students. The key features are explained below.

\section{Checklist}

A checklist is included in this manual to serve as an index to the job sheets and to record the student's progress. The teacher may also wish to use' the checklist to initially assess and record the student's knowledge of the phonemes. The second blank could be used for another checkup at a later date, or for whatever else is desired.

\section{Three Types of Job Sheets for Each Phoneme}

Each phoneme is introduced in three ways, as previously explained. The "a" job sheets are an adaptation of the AVT Method. New words are introduced as parts of "Whopper Words," and then by themselves. e.g. catacat cat. The new words are followed by other "Whopper Words" which give additional practice and review. Job sheet "a" often concludes with review words in patterns. e.g. cat mam dam strict pointer control is used at first to make the student pay attention to each sound. Later, self pointer control, eye pointer control, and trade-a- 
syllable are used as the student's skills increase. Where needed, diagrams of the speech organs are included to give the student a better body image as he forms each sound. After the eyes learn to control the mouth automatically, mouth movement will become unnecessary and silent reading takes place (Youngberg \& Lang, AVT Teacher's Manual, 1975, p.3).

The "b" job sheets use the VAKT Method. A manuscript word list presents the new words from job sheet "a" as the child would probably see them in a book. This list is followed by the same words written in cursive. Using a multisensory method, the child learns these words by tracing, spelling, and writing practice on the job sheet.

Learning is further reinforced by workbook-type exercises on the "c" job sheets. These exercises are many and varied, with fill in the blanks, unscramble the words, find the correct answer, and so forth.

Each of the three types of job sheets are entities in themselves. They may be used individually or together.

\section{Key Pictures}

Most of the "b" job sheets have a picture representing the new. sound to be learned. Space is available for the child to draw additional pictures representing the sound, so that other words will also remind him of the new phoneme, thus creating a better generalization.

\section{Cursive and Manuscript Writing}

Each "b" job sheet presents both cursive and manuscript writing 
and reading practice. Manuscript is learned because this is how the student sees the letters and words in a book. New words are pract1ced in cursive to prevent reversal difficulties.

\section{Special Lines}

To orientate the child when he is writing, specially lined paper with arrows and dots is used in the " $b$ " job sheets. The lines, adapted from Traub's Recipe for Reading, help the child to correctly position his letters in space. The upper line tells the child the highest point he may go in a high letter like "h". (Traub calls this line "the attic.") The lowest line reminds him how far down to go in letters that go below the line, such as "g". (Traub calls this "the basement.") As the job sheets progress, and the child's skills improve, the lowest line is eliminated; finally only single lines are used.

\section{Dots}

Dots are used to indicate where the child should start writing each word on the line. Each new word will be written twice, so there will be two dots on each line, except where there are long words that are too large to write twice on one line. The student should use another line or a separate sheet of paper to write these words the second time. It was felt that this would be better than asking the student to cram two long words on one line. From job sheet $\# 83$ on, the dots are discontinued.

\section{Arrows}

The " $b$ " Job sheets have arrows pointing left to right, reminding the child to write in that direction. Arrows are also used in the 
practice of letter formation to assure a correct writing procedure.

\section{Lower and Upper Case Letters}

Upper case letters are to be presented and practiced as needed. To avoid confusing the child, they are not systematically presented for practice with the lower case letters. For reference, upper case letters may be found at the top of each " $b$ " job sheet that introduces a new letter. The complete alphabet may be found in Appendix B.

\section{Multisyllable Words}

Multisyllable words are presented on the " $b$ " job sheets with $a$ space between syllables to assist the child in decoding.

\section{Dictation}

Writing a word from a spelling list is not enough. Students must learn to write words correctly in a sentence. For this reason dictation sentences are included in the teacher's manual. The teacher dictates each sentence to the student, who writes it on a separate sheet of paper. Any unphonetic word is placed on a card so that it may be copied by the student. Such words are underlined in the teacher's manual. If the child cannot cope with complete sentences, a phrase may be dictated at a time. For reading practice, the child then reads the complete sentence from cards. The unphonetic words are underlined, and the child is not responsible for them. The number of sentences to be dictated depends on the child's ability.

Sight Words

The underlined words in the sentences for dictation may be consid- 
ered sight words. Throughout the program the student will be exposed to such words, and will automatically learn some of them. Writing experience stories (the students dictates an experience to the teacher, who types it on a primer typewriter or prints it for the student to read) will expose him to a few more sight words. Greater emphasis can be placed on learning sight words when the basic phonics skills are learned. The Dolch Sight Cards are recommended for this purpose. They consist of:

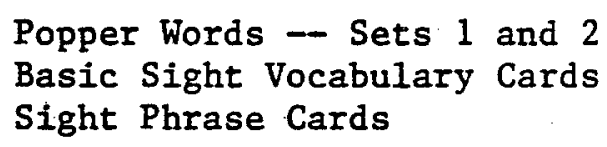

These materials can be ordered from:

Garrard Publishing Co. 1607 N. Market Street

Champaign, Illinois 61820

\section{Order of Presentation}

As in Traub's Recipe for Reading, the sequence of phonemes in the job sheets is determined by auditory, visual, and kinesthetic factors. Short $\underline{e}$ and $\underline{i}$, and $\underline{d}$ and $\underline{b}$ are presented far apart to avoid confusion. Before any job sheets are begun, nine letters $(a, c, g, d, 0, m, 1, t$, h) are presented. New words on the first nine job sheets are built from these nine letters. The student's reading and spelling vocabulary continues to grow as he progresses through the job sheets.

\section{Weirdo Words}

Unphonetic words that are not dealt with on the job sheets may be found on the "Weirdo Words" page at the end of the job sheets. This partial list of common sight words may be used by the student who wish- 
es to increase his sight vocabulary. The student or teacher may want to add more words to the list.

\section{Cover Card}

A "Cover Card" is provided so that the child can cover each listed word while he writes it from memory. The card may also be used to cover any distracting stimuli on the page.

\section{How to Use the Supplementary Job Sheets More Effectively}

Before attempting these job sheets the pupil should be acquainted with the alphabet. Otherwise, the teacher will need to adapt the program to the pupil's weakness.

\section{Additional Materials}

The teacher should make a set of flashcards with one of each phonogram introduced in the job sheets printed on each card. A set of $4^{\prime \prime} \mathrm{x}$ 6" (or 5" $\times 8^{\prime \prime)}$ cards with each sentence to be dictated is also necessary. The sentence cards may be typed with a primer typewriter or printed by hand.

\section{Perfect Practice}

"Perfect practice makes perfect" (Youngberg, 1975). The child should be supervised as he does these job sheets so that errors may be caught immediately and corrected. Otherwise he will learn errors. Repetition and overteaching are also important with learning disabled children. 
The Role of the Teacher

Establish a good atmosphere for learring. Each statement to the student should be positive. If the student does poorly on the job sheets, encourage him to do better by making statements such as, "Let me help you," or "Just make this change and it will be right." Do not cross out and write over in red ink when man is spelled nan. Instead, write on the board or show a card with the correct spelling. Have the student erase the incorrect part and rewrite the word correctly. Give him a compliment on the parts of the word that were correct (Traub, 1973, pp.7,8). Put stamps of approval on his job sheet when he does well.

\section{All or Some}

Some students may not need to complete every job sheet, while others may need to. Have each student work on the skills not mastered. He may do some job sheets with his teacher and take others home for parent help.

Figure Ground Problems

When working with children who have figure ground problems it may be helpful to cover the part of the job sheet not being worked on with a piece of paper or the "Cover Card." Adjoining words on the job sheets may need to be covered as the child reads each word.

\section{Student's Notebook}

As new words are learned it is recommended that the student record them in a notebook, as mentioned previously. This gives him additional practice and a feeling of accomplishment as he sees his notebook filling up with words that he knows. A notebook page can be allotted 
for each item on the checklist, and a table of contents added that indicates what page each item is on. Spelling rules and a glossary of language terms that the student has learned may be included in the notebook. (See Appendix C.)

\section{Memory Training}

Traub (1973, p.19) suggests the following technique for students who have difficulty remembering sentences as they are dictated during dictation exercises. The teacher gives the child a word orally, and tells him to carry it in his mind to some point in the room and then to bring it back. For example, the teacher points to a book and says, "book." The child goes to the other side of the room; touches a chair, comes back to the teacher and says, "book." Then the teacher asks, "What else can you say about the book?". The child may say, "red." He takes the "red book" in his mind, walks to the window, comes back to the teacher and says, "red book." This is expanded to "red book on the shelf," etc. until the sentence becomes too long to repeat verbatim to the teacher. Suggestions may be offered to students who cannot think of descriptive words.

Vowels in Red

The vowels and vowel digraphs in the typed words on the top half of the "b" job sheets may be traced with a red pencil or pen for additional help in decoding, or it may be done by the child as part of an exercise to find the vowel in each word.

\section{Phonetic Readers}

As each phoneme is introduced have the student read words con- 
taining that phoneme in a phonetic reader. See Lynds \& Smith, Index to Phonetic Readers, 1973. When he is reading, allow the child to point or use a marker (Traub, 1973).

\section{Key Pictures}

Since "students should not be encouraged to memorize a 'sample word' for each sound (Youngberg \& Lang, 1975, p.22), space is provided on the "b" job sheets to draw additional key pictures for each phoneme. Memorizing one sample word for each sound may cause the student to read slower because he has to recall that word before he can know the sound. It is better to directly associate the sound with its letter, eliminating intermediate steps. This is why flash card drill of each sound learned is important (Ibid.).

\section{Tachistoscope}

Some children have difficulty separating figure from ground. Therefore, reading words from a list presents a problem for them. The new words on each "b" job sheet may be presented or reviewed with a tachistoscope so that they will see only one word at a time (Traub, 1973, p. 63).

\section{Experience Stories}

As previously mentioned, the student should occasionally dictate his own story to the teacher, who then types it on a primer typewriter or prints it. Encourage the student to illustrate his story with pictures. The story is then made into a book for him to read. This book may consist of one story with one sentence at the bottom of each page, or of many stories. 
After the story is printed, the teacher may wish to place it over a few carbons. Then the child can trace the letters with a pencil and produce carbon copies of his story. Not only will he receive writing practice, but he will receive several copies of his book.

Generally a child can read his own stories at a higher level of difficulty than regular textbook material. Verbal expression and the learning of a sight vocabulary are enhanced (Ibid., p.22).

\section{Reading and Listening for Meaning}

For a time, the child's reading level will prohibit him from reading interesting, exciting materials. Therefore, an adult should read interesting stories to the child to spark an interest in reading. This reading may be done for pleasure or for reading comprehension practice. The student may be asked to listen for an answer to a question that the adult asks before reading. Later on, unanticipated questions may be asked after reading the selection (Ibid.).

\section{Spelling Review}

Periodically, a spelling test may be given over the words previously learned from the job sheets.

\section{Word Games}

Phonetic word games may be used in addition to the job sheets to reinforce learning and to replace drill.

\section{Stutterers}

Youngberg \& Lang (1975) suggest that the student who stutters should use soft breath control when pronouncing words. 
Mirrors

A mirror is useful in helping the student to see that his tongue and facial muscles are in proper position for good pronunciation of each phoneme. The student may also look in the mirror at the teacher demonstrating them. This enables the teacher to exaggerate the pronunciation without breathing in the student's face (Itid.).

Feeling the Phoneme

To better help the student "feel" the phonemes in his mouth, put a dowel rod between his teeth and have him pronounce the phoneme.

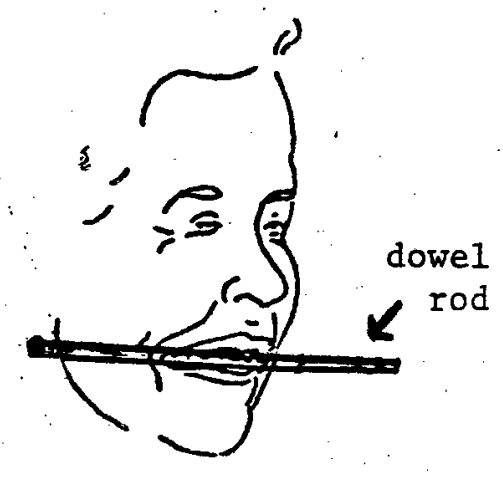

Vowel Referents

Youngberg \& Lang (1975) suggest the following vowel referents as an aid in teaching vowels:

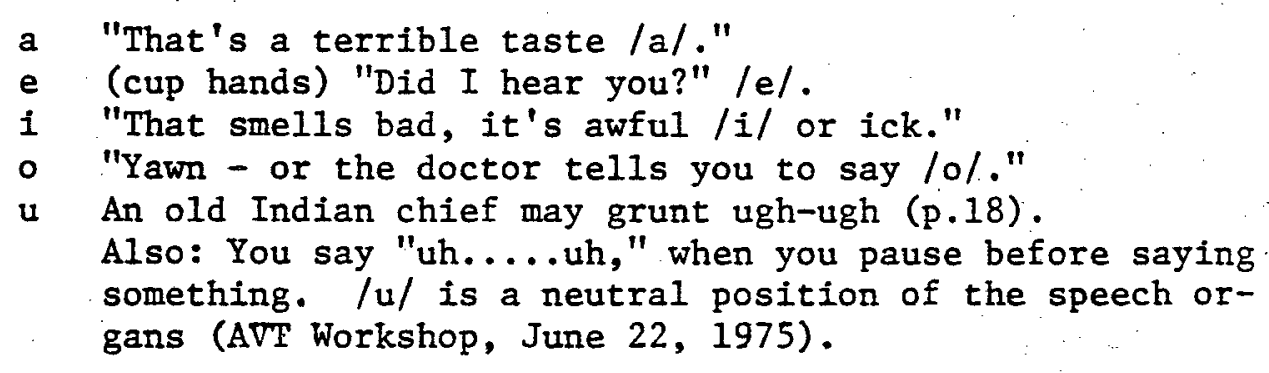

Vowel Cards

The AVT Vowel Flash Cards may be used with the job sheets at the teacher's discretion. They may be helpful for review at various points during the program.

\section{Breath Control}

Some students may need breath control exercises because they run 
out of breath during pointer control exercises. Have the student lie on his back and breathe heavily from his abdomen. Chest breathing should be discouraged. A book or dowel rod may be held against the abdomen of the student. Let him feel the rise and fall of his abdomen as he breathes. Details on breath control exercises and other information regarding AVT precedures may be found in the AVT Teacher's Manual and teaching materials. The teacher should have some training and practice in the AVT Method before using these job sheets.

\section{Spectific Instructions for Each Lesson}

Sample Lesson

1. Review known phonemes with flash cards in the manner presented below.

2. Do job sheet "a" (AVT sheet). Follow the "Five Steps in Each AVT Lesson" where applicable.

3. Do job sheet " $b$," according to the "Job Sheet ' $b$ ' Directions." *

4. Do job sheet "c." Follow directions on each individual job sheet.

5. Give the dictation sentences to the student. Remember to show each underlined word on a card that can be copied by the student. Also ask the child to read each sentence from cards when he is done writing.

6. Have the student read in a phonetic storybook. The teacher and student may wish to take turns reading sentences in the story. This gives the student a model to read by.

7. Play phonetic word games.

*At this point have the student record the new words in his notebook, as explained on pages 45 and 46 . 
Some of the preceding items may be done for homework. Be sure to inform the parents on how to use these materials. Any directions not written on the job sheets may be found in the teacher's manual. As previously stated, not all children will need to do these steps as presented. Adjust the lesson to meet individual needs.

\section{Reviewing Known Phonemes}

Before each lesson flash all the phonic sound cards that have been learned, using the following procedure:

1. Teacher flashes the phonic sound cards. Pupil gives the sound for each card.

2. Teacher shuffles the cards and gives the sound of each letter (one at a time). The pupil gives the name of the letter and writes it (Traub, 1973, p.23).

\section{Five Steps in Each AVT Lesson (Job Sheet a)}

1. Speech. Tell the student to assume an initial consonant position holding breath pressure. Demonstrate a vowel position inaudibly. Have the student release the breath through the shape opening. (vowel position) you have demonstrated.

2. Spelling drill. Give the student a pencil and paper. Dictate a word, waiting at each articulatory position until the student writes the letter symbolic of that position before moving on through the word.

3. Blackboard drill. Write a consonant on the board. Have the student assume the proper articulatory position and hold breath pressure. Next, write the vowel having the student release breath and sustain the vowel, thereby executing a consonant vowel transition. The vowel should be sustained until a final consonant or consonant combination is written. The student should then complete the pronunciation.

4. Pointer control. Using the printed lists, point to the first letter of the word. Have the student assume that articulatory position, holding breath pressure. Next, point to each letter within the word -- avoiding any particular cadence -- with the student 
transitioning from consonant to vowel to consonant throughout the word.

5. Tachistoscopic drill. Using two cards, cover the practice words. Flash them singly, allowing the student to identify each audibly. Occasionally have the student write down the flashed word and sound it out. This will assure that the student is not merely guessing through form recognition, unaware of the word's individual parts (Youngberg \& Lang,"Consonant-Vowel Blending, 1975).

Adapt these steps to each individual lesson. Further instructions are given in this manual as the student progresses through the job sheets.

\section{Job Sheet "b" Directions}

Pencil should be used so that mistakes can be erased. The student should:

1. Say the word slowly, as in AVT, while looking at it.

2. Say the word slowly, as in AVT, while he traces the letters with his finger. Say the word again.

3. Write the word in the air, saying it slowly as in AVT. Say the word at normal speed.

4. Copy the word on the job sheet, saying it slowly as in AVT. Say the word at normal speed.

5. Spell the word orally while looking at it. Say the word.

6. Look at the word and lock in memory.

7. Spell the word orally without looking at it. Check. (If he cannot spell it correctly, repeat steps 2 and 5.) Say the word.

8. Cover the word and write it on the job sheet from memory, saying the word slowly as in AVT. Say the word. Check to see if it is correct. 
9. Write the word with eyes averted. Check.

10. If incorrect, repeat the above steps.

11. Homework activity: Use each word in a sentence (orally). Parents may help the child to write it down.

*With some students it may not be necessary to do steps 3 and 9.

When beginning the next lesson, check to see if the child knows (or can read) the words from the previous lesson. If not, repeat steps 1-9, using the same words.

When the student gets to the point where he can move through steps 1-10 without error on three consecutive "b" job sheets, the steps can be reduced to 1,7 , and 8 . If an error is made, repeat on1y steps 1,7 , and 8 .

(There is another copy of job sheet " $b$ " directions in Appendix D that is suitable for photocopying. This can be sent home so that parents can work with their child on job sheet "b.")

Additional instructions for "b" job sheets with letter practice:

Trace each cursive and manuscript letter with finger. Write them three times each, starting on dots. Then write them from memory, and lastly, with eyes averted.

Use the above instructions, where applicable, for all " $b$ " job sheets marked with an asterisk (*).

Readiness for Lesson One

Before attempting these job sheets, the child should be acquainted with the alphabet. To prepare for lesson one, use the phonic flash 
cards and present the first nine letters (a, c, g, d, o, m, 1, t, h)

in the following manner:

1. The teacher shows the letter, and tells its name.

2. The pupil repeats the name of the letter.

3. The teacher makes the letter sound and the pupil repeats it. (Consult the checklist for the proper sound of each letter.)

4. Covering the card, the teacher makes the letter sound and asks the pupil to tell the name of the letter represented by the sound.

5. The teacher then makes a large copy of the letter.

6. The pupil traces the letter, copies it, writes it from memory, and finally writes it with eyes averted.

7. The teacher makes the sound of the letter and asks the pupil to write the letter that has that sound (Gillingham \& Stillman, 1960, p.41).

LESSON 1

$a=\mid \breve{a}$

Key Picture - apple

a. (Job Sheet a) The referant is "a terrible taste."

Teacher: The "Five Steps in Each AVT Lesson" may be incorporated into each lesson at the teacher's discretion. Before doing this lesson, review the pronunciation of the sounds $\underline{m}, \underline{h}, \underline{t}, \underline{\mathrm{d}}, \underline{1}, \underline{\mathrm{g}}$, and $c$. The AVT diagrams and directions for job sheets $2 \vec{a}, 3 a, 4 a$, $6 a, 7 a, 8 a$, and $9 a$ may be used, if needed, for additional explanation. Use strict pointer control on this job sheet (1a), moving the pointer from letter to letter. The student must stay with your pointer as he says the sound of each letter. Remind him to form the vowel with breath released from the preceding consonant. e.g. "dad" not "duh-a-dud." As the student articulates a consonant he explodes it into the following vowel. He may be told, "When you move from the closed place (consonant) to the open place (vowel) 
push the breath pressure hard and loudly into the vowel so the sounds will stick together with no break." Using an extra, exaggerated force of breath where there are consonant-vowel transitions avoids the break between sounds. When blending the consonant and vowel sounds in the words tam, dad, had, lad, gag, cat, etc., there is no sound from the initial consonant until it explodes into the vowel. The student merely gets his mouth into position and builds up pressure when these consonants are pointed to, letting the sound out when the pointer reaches the vowel. When the pointer touches the initial m in mat, a humming sound is made. Blend the $m$ and the vowel with an extra force of air. Vary your speed of pointing to keep the student alert. Remind him that his eyes control his "talking machine" (mouth). There should be a continuous flow of sound as each letter is pointed to. No sneak breaths are allowed. The word families at the bottom of the page should be read downward so that the pattern may be observed.

Student: When you say /ă/ it sounds like you tasted something bad. Your facial expression looks that way, too. The lips are pulled to the side, your tongue is flattened and half way between the top and bottom of your mouth, and the sides of your tongue protrude between your teeth. Say it again /ă/ (Youngberg \& Lang, "C-V B," 1975). The two squares on your job sheet represent the places for consonants.

b. (Job Sheet b) Follow Job Sheet "b" directions on pages 52, 53 .

c. (Job Sheet c) Answers: (across) bag, that, ran, Sam, sat, nap, tack, man, tan, pack, land, wag, lap, strap, cat, quack

\section{d. Dictation:}

1. I am a lad.

2. Mac had the mat.

3. The lad had a tam.

4. Dad had a cat.

5. Dad is a ham.

e. Phonetic Readers: Have the student read with strict pointer control. Then he should reread each selection at normal speed. As the student progresses through these lessons, strict pointer control may eventually be eliminated. The progress of each individual student will determine when. Adapt the suggestions listed under Supplementary Materials and Methods on page 25 (AVT Sequence Outline) to each lesson. 
LESSON 2

$c=|k|$

Key Picture - cat

a. Teacher: Use strict pointer control. Encourage the student to make a good explosion into the vowel. Remind him that no sound is made until the pointer reaches the vowel. When the "c" is pointed to, he positions his mouth and builds up pressure for the explosion into the vowel.

Student: When you make the "c" sound the back of your tongue cuts off the air at the roof of your mouth. Look at the diagram on your job sheet. Now pronounce the "c" while you look in the mirror. Notice that an explosion takes place where your tongue touches the palate in back of your mouth. The front part of your tongue tucks under (Ibid.).

b. Follow the job sheet "b" directions on pages 52,53 . Do this for every "b" job sheet marked with an asterisk (*).

Definitions of words marked with a t:

cam - a projection on a piece of machinery that imparts motion to another piece.

cad - a youth who does not act like a gentleman.

c. Answers: car, cookies, cup, can, cake, candy

d. Dictation:

1. Mac had a cat.

2. Cal is mad.

3. The cat had the mat.

4. Dad had the cam.

5. The cad had a cat.

e. Phonetic Readers: Remember to use phonetic readers as explained in lesson one. Continue this throughout the lessons.

LESSON 3

hard $g=\mid g /$

Key Picture - gate 
a. Teacher: Use strict pointer control. Review the idea that in saying vowels the mouth is opened, and when saying consonants, one closes the mouth or closes off air.

Student: The " $g$ " is made much like the " $c$. " Compare the two sounds. Say $\mathrm{CaI}$ and gal (Ibid.).

b. Follow the usual job sheet "b" directions. If there are no additional instructions for " $b$ " job sheets, this section will not be included in the manual from now on.

c. Sentences for the teacher to read:

1. Mag had a new coat.

2. Can Pat tag Nan?

3. Nan can gag Gad.

4. Nat can gag the cat.

5. She is a hag.

6. Dan did lag behind.

7. The gal was nice.

8. Gad is a son a Jacob.

9. The snakes might bite the gal.

The answers are the underlined words.

d. Dictation:

1. Gad will tag Mag.

2. The gal had a tag.

3. The hag will lag.

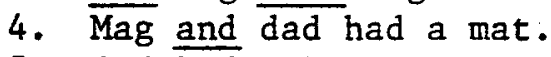

5. Gad had a hat.

LESSON 4

$d=/ d /$

Key Picture - dog

a. Teacher: Use strict pointer control.

Student: When you say /d/ notice that the tip of your tongue is touching your gum ridge behind your front top teeth. It is made almost like $/ t /$. Look in the mirror to see if your tongue is in the correct position. The /d/ is a completely closed consonant with voice. 
b. Definition:

dag - a heavy pistol, no longer used. Also: a loose hanging end.

d. Dictation:

1. Dad is mad.

2. Tad had a mad cat.

3. The lad had a mat.

4. Gad is at a dam.

5. The mad hag had a tam.

LESSON 5

$0=|\check{0}|$

Key Picture - otter

a. The referant is "a yawn."

Teacher: Use strict pointer control.

Student: The "o" says /o/ as in otter. Since your mouth is open when you say it, is it a vowel or consonant? Yes, it is a vowel. Say the $/ 0 /$ as you yawn. Show your tonsils and shape your mouth like an "o." Be sure to depress your tongue and round your throat (Ibid.).

c. Phrases for the teacher to dictate:

1. got a $\log$

2. had a tot

3. a hot cod

4. a hot $\cot$

5. got a hog

6. at a dot

\section{d. Dictation:}

1. Mom and Tom got hot.

2. The $\overline{\operatorname{dot}}$ is mod.

3. Doc had a lot.

4. The dog got a hog.

5. The $\log$ is at the lot.

Note: Words like $\underline{\log }$ and hog are pronounced differently in various areas. e.g. $10 \mathrm{~g}$ has these two pronunciations: $1 \mathrm{gg}$ - as in hot, and $16 \mathrm{~g}$ - as in law. 
LESSON 6

$\mathbf{m}=/ \mathrm{m} /$

Key Picture - mouse

a. Teacher: Use strict pointer control.

Student: When something tastes good, what do you often say? $/ \mathrm{m} /$. When making the " $m$ " sound the lips will block the air from coming out. Since the palate is open, the air produces a nasal sound through the nose. Pinch your nose and say $/ \mathrm{m} /$. What happened? The next letter after " $m$ " will be a vowel, so you will open your mouth. The "m" sound will come out with the vowel. Keep with the pointer and your eyes will not get the letters out of order. Are you ready? (Ibid.)

b. Definitions:

cam - a projection on a piece of machinery that imparts motion to another piece.

lam - to flee

(Remind the student that he knows the meaning of words that many people do not know the meaning of, so he is really smart.)

c. The teacher reads the underlined words on this, and every, "c" job sheet.

d. Dictation:

1. Mom is mad.

2. I am Tom.

3. Mom got mad at the hog.

4. Tom got Dom a mat.

5. Mom is a mam.

LESSON 7

$1=/ 1 /$

Key Picture - leaf

a. Teacher: Use strict pointer control. 
Student: Put the tip of your tongue on your gum ridge (as in the diagram) and let out a fast stream of air. Do you hear the "I" sound? This time flip your tongue down when the air is about half used up. (The result is a neutral vowel.) Now get your tongue ready at the gum ridge and flip it into the vowel shape I show you. (Teacher: Use vowels "a" and "e.") Let's do pointer control on our job sheet. When I point to the " 1 " get your tongue ready at the gum ridge, and let it go when I point to the vowel. Do not make any sound until the vowel is pointed to. The consonantvowel blend should be sharply produced. Do not forget to hold out the vowel until the pointer mives to the next consonant. No sneak breaths are allowed! (Ibid.)

b. Definition:

lam - to flee (Remember?)

c. $\frac{\text { Answers: }}{8 . \mathrm{d}} \mathrm{I}, \mathrm{g} \quad 2 . \mathrm{d}$ 3. $\mathrm{t} \quad 4.1,1$ 5.d $6 . \mathrm{d}, \mathrm{g}$ 7. $\mathrm{t,t}$

d. Dictation:

1. The lad is hot.

2. Al is a $\overline{l a d}$.

3. Cal has a log.

4. The lot has a dam.

5. The gal got. a log.

LESSON 8

$t=|t|$

Key Picture - top

a. Teacher: Use strict pointer control.

Student: We are going to try some whopper words that have the $/ \mathrm{t} /$ sound. Place the tip of your tongue tightly behind your front teeth and gums. You will hear an explosion behind your front teeth. Let's try it together. $/ t /$. You do not use your voice when making the $/ t /$. Now follow my pointer. Remember to explode the " $t$ " into the vowel. Build up pressure, but do not make any sound until the pointer reaches the vowel (Ibid.). 
d.. Dictation:

1. Dot had a tam.

2. The tot got a dot.

3. Tom will tag Dot.

4. Tod got a mat.

5. The mat has a dot.

LESSON 9

$\mathrm{h}=\mathrm{h} / \mathrm{I}$

Key Picture - top

a. Teacher: Use strict pointer control.

Student: Take a deep breath and release the " $h$ " into the vowel that I point to.

b. Defintion:

hod - a wooden tray that has a handle

d. Dictation:

1. The hag had a hot hat.

2. Hal is a hog.

3. The hog is hot.

4. The ham is hot.

5. HaI is hot.

LESSON 10

\section{Review}

Answers: (across) hat, $10 \mathrm{~g}$, cat

hog, tag, dog

dot, mat, man 
LESSON 11

$1=|\breve{i}|$

Key Picture - Indian

a. The referant is "That smells bad."

Teacher: Use strict pointer control.

Student: When you smell something bad, you may say / $\breve{i} /$. To say /I/, open your mouth slightly and press the tip of your tongue against your lower front teeth. Raise your tongue high in the front. Shape your face like the picture on your job sheet. Check with a mirror. When you let out noisy air from your throat it should have an $/ \hat{i} /$ sound. Did it? Now practice the words on your job sheet (Ibid.).

d. Dictation:

1. Tim lit a mit.

2. It is dim.

3. The mit did hit him.

4. Dig it, Tim.

5. Tim hid the mit.

LESSON 12

$j=\mid j /$

Key Picture - jam

a. Teacher: Use strict pointer control.

Student: To produce $/ j /$, put your tongue in the " $t$ " position and let out air in a / $/ \mathrm{h} /$ position (Ibid.).

c. Answers:

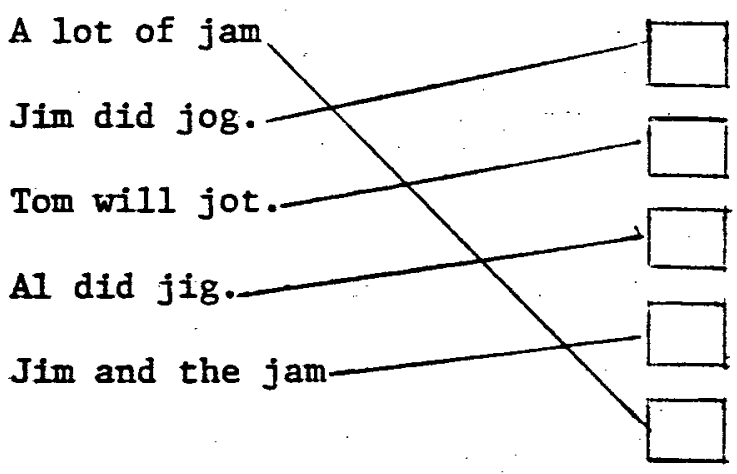


d. Dictation:

1. Jim hit the jam.

2. Tim did $j \circ g$ and $j i g$.

3. Jim had a lot of jam.

4. Dot did jot a 10t.

5. The jam is hot.

\section{LESSON 13}

$\mathbf{k}=\mid \mathbf{k} /$

Key Picture - kite

a. Teacher: Use strict pointer control.

Student: The " $k$ " sounds the same as the " $c$ " sound.

c. Answers: First tic-tac-toe game: Draw a line through kite, king, key.

Second tic-tac-toe game: Draw a line through kidney, kangaroo, keyboard.

d. Dictation:

1. The kid hit Kim.

2. Kim got a hit.

3. A kid hit a kit.

4. The kid did jig.

5. Jim got a kid.

\section{LESSON 14}

$\mathbf{c k}=/ \mathbf{k} /$

Key Picture - tack

a. Teacher: Use strict pointer control. Point between the "c". and "k" in "ck" to indicate one sound.

Student: "ck" also sounds 1ike $/ \mathrm{k} /$.

b. Further Instructions: "c" and "k" say (ck) separately and together. 
When you hear a " $k$ " sound after a short vowel in a one-syllable word it is usually spelled with ck. ck never begins a word (Traub, 1973, p.132).

c. Answers: Jack will lack a tack.

Jim will lick it.

Dick has the lock.

Jack has a dog.

The jam is hot.

d. Dictation:

1. Jack did kick the jam.

2. Dick hit the dock.

3. The tack is hit.

4. Tom did mock him.

5. Dick got a lock.

LESSON 15

$\mathrm{p}=/ \mathrm{p} /$

Key Picture - pencil

a. Teacher: Use strict pointer control.

Student: Close your mouth and build up pressure for the "p" sound. When I point to the vowel following the "p". let the "p" explode into the vowel. Do not make any sound until the pointer touches the vowel. Hold your hand in front of your mouth and feel the air pressure when the "p" explodes into the vowel. Let's try this together /pop/. Now follow my pointer on the job sheet (Youngberg \& Lang, "Consonant-Vowel Blending, 1975).

$\begin{array}{lllll}\text { c. Answers: } & \text { 1. hop } & \text { 2. pal } & \text { 3. hop 4. top 5. pat } & \text { 6. hot } \\ \text { 7. cap } & \text { 8. pig } & \text { 9. lock } & \text { 10. pal, hack }\end{array}$

\section{d. Dictation:}

1. The cop did pat the pig.

2. The pod is hot.

3. Pam had a pom-pom.

4. The top of the pad is hot.

5. The pot is hot. 
LESSON 16

$\mathrm{ch}=/ \mathrm{ch} /$

Key Picture - church

a. Teacher: Use strict pointer control. Point between the "c" and "h" in each "ch."

Student: When you put "c" and " $h$ " together you get a single new sound. To pronounce this new sound start with a " $t$ " position with the top of the tongue at the front of the gum ridge. Let out the air in a "sh" position (Ibid.).

b. Definition:

chit - a short note or letter

d. Dictation:

1. The chap had a chat.

2. The chap did chop the log.

3. Dick had a chick.

4. Did Jack and Tom chit-chat?

5. Tom did kick the chip.

LESSON 17

$\mathrm{b}=/ \mathrm{b} /$

Key Picture - bat

a. Teacher: Use strict pointer control.

Student: The letter " $b$ " is a closed consonant like the "p." The breath is closed off at the lips. Build up pressure on the "b" and explode it into the vowel. Do not make any sound when the pointer is on the " $b$ " (Ibid.).

c. Answers: Color the baby, bottle, book, ball, and bicycle

d. Dictation:

1. The back of the dam is big.

2. Dick did the job.

3. The tab is big. 
4. Bob had a bib.

5. The cob is hot.

LESSON 18

$u=/ \breve{u} /$

Key Picture - umbrella

a. The referant is "uh... uh." (Like when you pause while talking.)

Teacher: Use strict pointer control.

Student: The "u" is a very easy vowel. Relax your mouth and use your voice. Do hear the $/ \overline{\mathrm{u}} / \mathrm{\text {? }}$ Look into a mirror as you practice.

c. Answers: Did the chum lug the mud?

The jug is cut.

Cal dug it up.

Dick got a mug and a jug. or Dick got a jug and a mug.

d. Dictation:

1. The jug is up.

2. Mom dug up the mug.

3. The gum is big.

4. Dick is a chum.

5. The duck has mud.

LESSON 19

$\mathbf{f}=/ \mathrm{f} /$

Key Picture - fan

a. Teacher: So far the student has had completely closed consonants where no sound came out when the pointer was on the letter. Then he had the letter " $m$ " where the air came through the nose. Now the student will study a leaky closed letter. The "f" closes off air, but not tightly. Air leaks out while the pointer is on the letter. Extra air should be used in the consonant-vowel transition. Use strict pointer control.

Student: The "f" is a leaky consonant. To make the /f/ put your teeth against your lips and add a rush of air. See the dia- 
gram on your job sheet. A rush of air from the /f/ leakage lets the vowel out. Hold your hand in front of your mouth as you do it (Ibid.).

b. Definitions:

fob - a small pocket on men's pants

fop - a foolish or silly person

c. Answers: 1. fit 2. fib 3. fat 4. fig 5. Fog

d. Dictation:

1. The fog is bad.

2. The fig is big.

3. Did the hat fit?

4. The $f i b$ is big.

5. Did Rick pat the fat pig?

LESSON 20

$r=|r|$

Key Picture - rabbit

a. Teacher: Use strict pointer control.

Student: The " $r$ " is made by tightly sealing the sides of your tongue against your gums, so that all breath and voice must pass through an opening in the front, just behind the gum ridge. The tip of your tongue flips down as your tongue moves into a vowel position. There is a narrow groove in the middle (Ibid.).

c. Answers: 1. rod 2. rich 3. rim 4. rat 5. rip 6. Rick

d. Dictation:

1. Rich Rick is fat.

2. The rim of the rug did rip.

3. The rod and rock did it.

4. The rat bit the pig.

5. The cat did rip the rag. 
LESSON 21

$\mathrm{n}=/ \mathrm{n} /$

Key Picture - nest

a. Teacher: Use strict pointer control.

Student: The " $n$ " is pronounced by blocking the air with your tongue at the gum ridge. Leave your lips apart and use your voice. The sound comes through the nose as does the "m" sound. Practice with a mirror (Ibid.).

c. Answers: 1. not 2. nag, man 3. can, nut 4. Jan, fun 5. pin, on 6. tin

d. Dictation:

1. The man is fat.

2. Did the dog nip Nat?

3. Don is not fat.

4. The bun is big and hot.

5. The pan is tin.

LESSON 22

$e=\mid \grave{e} /$

Key Picture - egg

a. The referant is "Did I hear you?" /ĕ/

Teacher: Use strict pointer control.

Student: When an old grandpa or grandma can't hear you, what do they say? Have you ever seen them cup their hands behind their ears and say $/ \mathrm{e} /$ ? Pretend that you are old and say $/ \breve{e} /$. Look into the mirror and watch your tongue (Ibid.).

\section{d. Dictation:}

1. The pen is in the net.

2. Ten men met on it.

3. The pet can beg.

4. Rick is fed.

5. The hem is big. 


\section{Review}

Follow the directions on the job sheet. The children may wish to color their pictures.

LESSON 24

$\mathbf{s}=|\mathbf{s}|$

Rey Picture - sun

a. Teacher: Use strict pointer control.

Student: Are consonants open or closed places? Yes, they are closed places. The letter "s" has a leaky closed place, as does the "f." When you make the "s" sound the air leaks through a little hole behind your front teeth. Make sure there is some air pressure behind the leak and give an extra burst of air when you change from "s" to a vowel. Let's practice this on your job sheet (Ibid.).

c. Word 1ist for teacher to read: (Answers are underlined.)
1. Rick
4. hiss
7. sand
10. condemn
13. serious
2. sick
5. sake
8. miss
11. saddle
14. beliefs
3. pail
6. cat
9. consist 12. mam
15. silver

d. Dictation:

1. Sam is in the sun.

2. Sam is such a sad man.

3. The sun set at ten.

4. Sal did sit on the tack.

5. I can sit on the sack.

th $=/$ th/ (voiced - hard)

Key Picture - mother 
a. Teacher: Use strict pointer control. Point between the " $t$ " and "h" in "th" to indicate one sound.

Student: Place your tongue on your upper front teeth. Make a buzzing sound that tickles your tongue. You just said hard th (Ibid.).

c. Answers: That mat is on top.

Jack will pick this hat.

Rick hit them.

Jack had that cup.

They got them to cut the rug.

d. Dictation:

1. That cat is back.

2. This is a big sack.

3. Sam got them to lug the log.

4. This is a fan.

5. Then Jack got a pet.

LESSON 26

$\operatorname{sh}=/ \mathrm{sh} /$

Key Picture - shell

a. Teacher: Use strict pointer control. Point between the "s" and Student: The "sh" sound is also a leaky consonant sound. Make believe you are telling someone to be quiet by saying $/ \mathrm{sh} / \mathrm{Be}$ sure your lips protrude (Ibid.).

c. Answers: 1. th 2. ch $3 . \mathrm{sh}$ 4. sh $5 . \mathrm{sh}$

d. Dictation:

1. Dick can mash that.

2. The ship is red.

3. The shed is shut.

4. The dish is in the shop.

5. Cash the check, Dick. 
LESSON 27

$w=|w|$

Key Picture - wagon

a. Teacher: Use strict pointer control.

Student: The "w" sound (a vowel-like consonant) starts with a small opening like the vowel "oo." However, we consider it a consonant when it moves quickly away to let out a vowel (Ibid.).

\section{d. Dictation:}

1. Mick did win the ship.

2. The wig is on Sal.

3. I wish I can win.

4. Don has much wit.

5. Jack is with Ha1.

LESSON 28

wh $=/ \mathrm{hw} /$

$\underline{\text { Key Picture - whistle }}$

a. Teacher: Use strict pointer control. Point between the "w" and "h" in each / wh/.

Student: The "wh" sound is a combination of the " $h$ " and " $w$ " sounds, in that order. Make believe you are blowing out a candle when you pronounce /wh/.

b. To better acquaint the student with the dictionary, help him look up each of the new words. Read the definitions to him.

c. Answers: Pictures with /wh/: wheel, whip, wheat, whale

d. Dictation:

1. It is bad to whip a dog.

2. Which man is with dad?

3. When can Sal win the dish?

4. Which rug is in the shop?

5. When can Sam shut the shed? 
LESSON 29

$\mathbf{x}=/ \mathbf{k s} /$

Key Picture - box

a. Teacher: Use strict pointer control.

Student: " $x$ " sounds like a quick blend of $\underline{\mathrm{ks}}$. Let's say it together. Are you ready for the new words?

c. List for teacher to read: (Answers are circled.)
(1) $\mathrm{Max}$
2. tack
(5) $\operatorname{sax}$
6. exercise
9. pun
(3) $\mathrm{ax}$
7. sake
10. box
(13. fox
(14. $1 \mathrm{ax}$
11. shop
4. sack
8. cattle
(2). wax
15. sock
(16) six
(17) $\operatorname{tax}$
18. $\mathrm{mad}$
(19) vex
(20) Rex

d. Dictation:

1. Fix the ax.

2. Max can fix the box.

3. The fox is in back of the shed.

4. The ox has a big back.

5. Don is $\overline{l a x}$ and did not wax the ax.

LESSON 30

$y=|y|$

Key Picture - yarn

a. Teacher: Use strict pointer control.

Student: The " $y$ " is another vowe1-like consonant beginning in a position similar to short " $i$ " or long "e." Exaggerate the glide" between the " $y$ " and the vowel in each word (Ibid.).

b. Definition:

yak - an ox in Asia

d. Dictation:

1. Yes, Don did win.

2. Did Jack get wet yet? 
3. The yam is in the pot.

4. The dog did yap at the cat.

5. A yak is big.

LESSON 31

$v=/ v /$

Key Picture - Valentine

a. Teacher: Use strict pointer control.

Student: The " $v$ " is like the "f" but it has a buzzing sound.

(You use your voice.) Remember to exaggerate the sound so there will be no break between consonant "v" and the vowel.

c. Answers: violin - yes tree - no vacuum cleaner - yes

$$
\begin{array}{lll}
\text { bee - no } & \text { vegetables - yes } & \text { veil - yes } \\
\text { ball - no } & \text { vase - yes } & \text { fish - no }
\end{array}
$$

d. Dictation:

1. Val had a van.

2. Vic did not wish to get the vat wet.

3. The vet had a dog.

4. Val did vex the vet.

5. Which man sat on the van?

LESSON 32

$z=|z|$

Rey Picture - zipper

a. Teacher: Use strict pointer control.

Student: The " $z$ " is like the " $s$ " but it has a buzzing sound. No breaks are allowed between the " $z$ " and the vowel.

b. Definitions:

zax - a tool used for roofing 
zed - a metal box shaped like a "z"

zel - a type of cymbal

d. Dictation:

1. Jack did zip the bag.

2. Val can zig - zag.

3. Zig is a whiz.

4. Tim can fix the zel.

5. The zax can fix that.

LESSON 33

$s=|z|$

Key Picture - nose

a. Teacher: Use strict pointer control.

Student: The buzzing "s" has the same sound as the "z." (The word tis is a contraction for it is.)

c. Answers: has, nose, rose, his, foes, those, hose, pose, those, mows, lose, grows, knows, sews, close

d. Dictation:

1. That is his.

2. Jack has a van.

3. Jim has as much vim as Val.

4. 'Tis a big box.

5. His van did whiz by.

LESSON 34

$q u=. / \mathrm{kw} /$

Key Picture - queen

a. Teacher: Use strict pointer control. Point between the " $q$ " and the "u." Point out that " $q$ " and " $u$ " always go together.

Student: The letters "qu" sound I1ke /kw/ (Ibid.). 
b. Definitions:

quag - marshy land

quid - a suitable portion for chewing, e.g. a quid of tobacco

d. Dictation:

1. Val got the vet to quit.

2. The quiz is a whiz.

3. That man is quick.

4. That duck can quack.

5. Dan will quit.

th $=/$ th $/$ (unvoiced - soft $)$

Key Picture - thimble

a. Teacher: Use strict pointer control. Point between each " $t$ " and

Student: Place your tongue on your upper front teeth and let air leak between. Do not use your voice for the soft th sound.

c. Word list to be read by the teacher: (Soft th word's numbers are
1. then
2. that
(3.) thing
(4.) think
5. there
6. them
(7) three
(9) thrash
10. then
11. those
(14. thick
15. path
(17). thorn
18. truth
19. writhe
8. this
12. thaw
16. throat
20. tenth

d. Dictation:

1. The thin dog had a bath.

2. The ax hit Beth.

3. Val led the men up a path.

4. Math is fun.

5. The ax hit the rock with a thud. 
LESSON 36

$\underline{\text { Review }}$

Answers: (left to right)
hut map pen
hog whip ax

LESSON 37

The ff -11 - ss - 22 Twins

Spelling Rule: Double $\underline{f}, \underline{1}, \underline{s}$, and $\underline{z}$ in most one-syllable words after a short vowel (Orton, 1973, p.44).

a. Teacher: Now use strict pointer control on every third line, or as needed. If the student is ready, use self pointer control in between. (Self pointer control is the student using the stick to guide his own articulation.) Eye pointer control may also be used on some of the words. (Eye pointer control is the student using only his eyes as a pointer. However, he should read each letter at the same speed as in strict pointer control.) A suggested procedure, at this point, is to start the lesson with strict pointer control. Then the student can try self pointer. If he does well with this, he may progress to eye pointer. If the student makes a mistake, immediately go back to strict pointer control until he reads smoothly again. Adapt each lesson to the individual student.

\section{d. Dictation:}

1. The man fell in the pass.

2. That pill is red.

3. This doll is big.

4. The dull bell is a mess.

5. That cat will puff up. 
LESSON 38

Two-Syllable Compound Words

Key Picture - pigpen

a. Teacher: On this job sheet the student will read the first syllable of each compound word, and then the second syllable. Lastly, he will read the complete word. This is done to help the student to realize that big words aren't hard if he breaks them down. 'Use strict pointer control on every third line, or as needed. Eye and/ or self pointer may be used as explained in lesson 37 .

Student: The compound words in this job sheet each have two consonants that come right together. Sometimes one of the consonants is very quiet and you may think you have made only one sound, because when you come to each closed letter you stay closed until you reach the open letter. Only then you may let out any air (except with leaky consonants, and " $m$ " and " $n$ "). Let's practice your new words. After that, try your luck on the whopper words. If you can get your tongue around them you are ready for anything!

c. Answers will vary. Accept any feasible answer.

\section{d. Dictation:}

1. That bagman is mad.

2. Fill up the dishpan.

3. The man has a whiplash.

4. Catfish are wet.

5. Cal has a suntan.

\section{LESSON 39}

Detached Syllables

a. Teacher: Have the student read the detached syllables. Be sure he stays with the pointer. Self and/or eye pointer control may be used every other line.

Student: The syllables that you will be reading are parts of actual words. 
b. The little train with a detached car is intended to illustrate the idea of a syllable that is detached from the rest of the word.

Side one of job sheet " $b$ " has some detached syllables. The student is to read and write each syllable, starting at the dot. The teacher should say each syllable in a word. . Some suggestions may be found below:

\begin{tabular}{cc} 
Detached Syllable & Sample Word \\
\hline tel & telephone \\
tem & temple \\
mem & member \\
med & medical \\
hap & happy \\
chap & chapel \\
dif & differ \\
dis & distant \\
tum & tumny \\
lum & lumber
\end{tabular}

On side two of job sheet " $b$ " the student is to spell the syllables that are read to him. The syllables for dictation are below:
a. bum
f. vel
b. gog
g. siz
c. fas
h. suf
d. rus
1. whis
e. pov
j. ped

Ask the student to try and think of some words that use these syllables.

c. Nonsense sentences for dictation: (Additional help on punctua-

1. The lum is mem. tion may be found on job sheet

2. That hap can dif. 156.)

3. What a big gog!

4. This pov fell off that siz.

5. Can bam med?

LESSON 40

Review - CVC Detached Syllables 


\section{Syllables for Dictation:}

$\begin{array}{ll}\text { 1. jus } & \text { 6. ret } \\ \text { 2. riv } & \text { 7. hom } \\ \text { 3. fab } & \text { 8. lob } \\ \text { 4. cal } & \text { 9. chas } \\ \text { 5. dex } & \text { 10. lib }\end{array}$

LESSON 41

Two-Syllable Words

a. Teacher: Strict pointer control may be used as needed. Eye and/ or self pointer control may be used in between.

Student: The words on this job sheet have two consonants in a row, as did the compound words on job sheet 38. Remember to stay closed on each closed letter and let out air only on leaky letters and open letters. Sometimes the double consonants will make only half sounds. Are you ready?. Good luck with the whopper words!

b. For additional reinforcement, the teacher may put the two syllables of each new word on two index cards. The child reads the first card, the second card, and then the two in sequence, blending them into one word. The two syllables may be juggled and the student can arrange them into a word (Traub, 1973, p.70).

c. Answers:

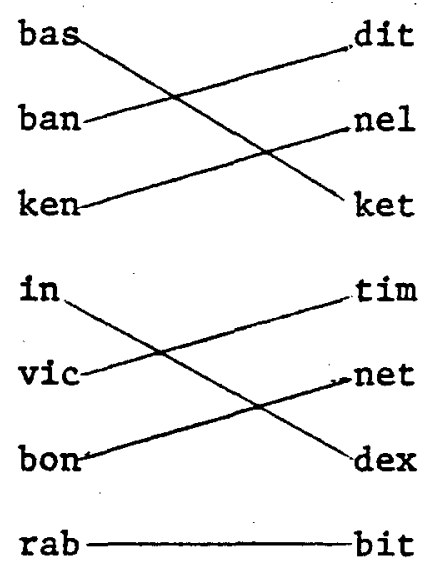

d. Dictation: After writing the dictated sentences the student is to draw a line between the syllables in each two-syllable word. (Divide between middle consonants.) 
1. The man will have a cutlet.

2. The napkin will rip.

3. Did Beth withness that?

4. The pionic is fun.

5. The basket had a tabilet in it.

LESSON 42

Initial Consonant Blends: s_

Introduction (to be explained to student): Digraphs make one sound. Each sound of a consonant blend is heard, even though they are blended together. Job sheets 42-46 will present various types of initial consonant blends. The drawing of a blender on job sheets (b) 42-46 represent the idea of blending consonants. Initial consonant blends are a group of two or three consonants blended before a vowel. The sequence used in presenting sample consonant blend words in job sheets $42-46$ is as follows:

1. Phonetic words with initial consonant blends followed by a vowel and consonant.

2. Consonant blend-vowel-consonant digraph

3. Consonant blend followed by ff-11-ss-zz twins (Traub, 1973, p. 73, 74).

a. Teacher: Use strict pointer control where needed, and self and/ or eye pointer control between.

Student: When reading the words with a consonant blend, start the "s" in the normal way. Hold your air pressure for the second consonant and keep holding it while you pucker for the "r," if any. Release the consonants into the vowel (Lang, 1974).

b. On each "b" job sheet, say the blend first and then the sample word. The teacher may dictate each consonant blend before the student reads it, if necessary. Next, follow the usual job sheet " $b$ " Instructions. The sequence of presentation corresponds to the three points mentioned above.

\section{d. Dictation:}

1. That skit was fun. 
2. The sled is on that hill.

3. Tell Bill to scrap the strap.

4. That slim man will smash the box.

5. Beth will stuff the sack.

\section{LESSON 43}

Initial Consonant Blends: 1

a. Teacher: Use strict pointer control, where needed, and self and/ or eye pointer.

Student: When reading the 1 blends, get air pressure at the lips for closed consonants, get the tongue ready at the gum ridge when the " 1 " is pointed to, and let it go when the pointer points to the vowel. There will have been no sound until that time. The consonant-consonant-vowel blend should be sharply produced. For "cl" and "gl" blends, get some air pressure at the back of the tongue. Hold it, get the tip of the tongue almost up and flip it, letting out the vowel. (Demonstrate this for the student.) Notice this in the diagram below:
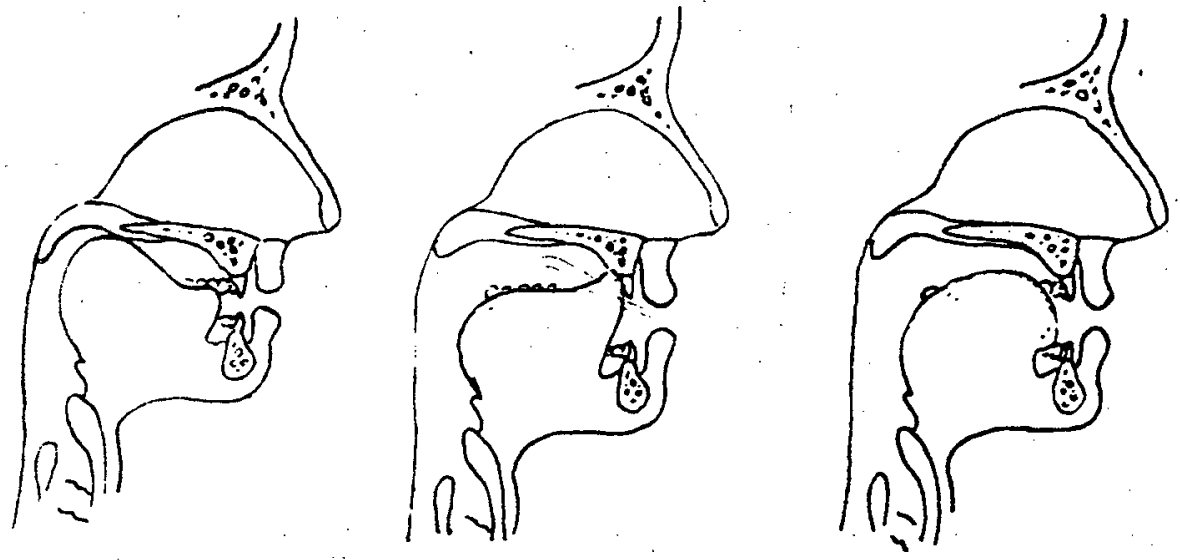

c1 and gl Blends

On leaky consonants, such as "f" and "s," keep the sound going and get your tongue ready behind the gum ridge for the "1.". Flip it and let out the vowe1 (Lang, 1974). Let's practice. 
b. Say the blend first and then the word. Continue with the usual " $b$ " job sheet instructions.

\section{d. Dictation:}

1. The class will have the sled.

2. Jack will not clap.

3. His flesh is as red as the sunset.

4. The glass fell as quick as a flash.

5. God bless you.

\section{LESSON 44}

\section{Initial Consonant Blends: $r$}

a. Teacher: Use strict pointer control, as needed, and self and/or. eye pointer control between.

Student: For br and pr blends - Whistle, puckering your 1ips. This is how you use your lips when saying these blends. Remember to tightly seal your tongue against your gums, so that all breath and voice must pass through an opening in the front, just behind the gum ridge. The tip flips down as your tongue moves into the vowel position. There is a narrow grove in the the middle (Ibid.). See the diagram on job sheet $20 \mathrm{a}$.

cr and gr blends - Get air pressure at the back of the tongue as the diagram below shows. Tighten the muscles in your neck and jaw for the "r." Make no sound until you say the vowel.
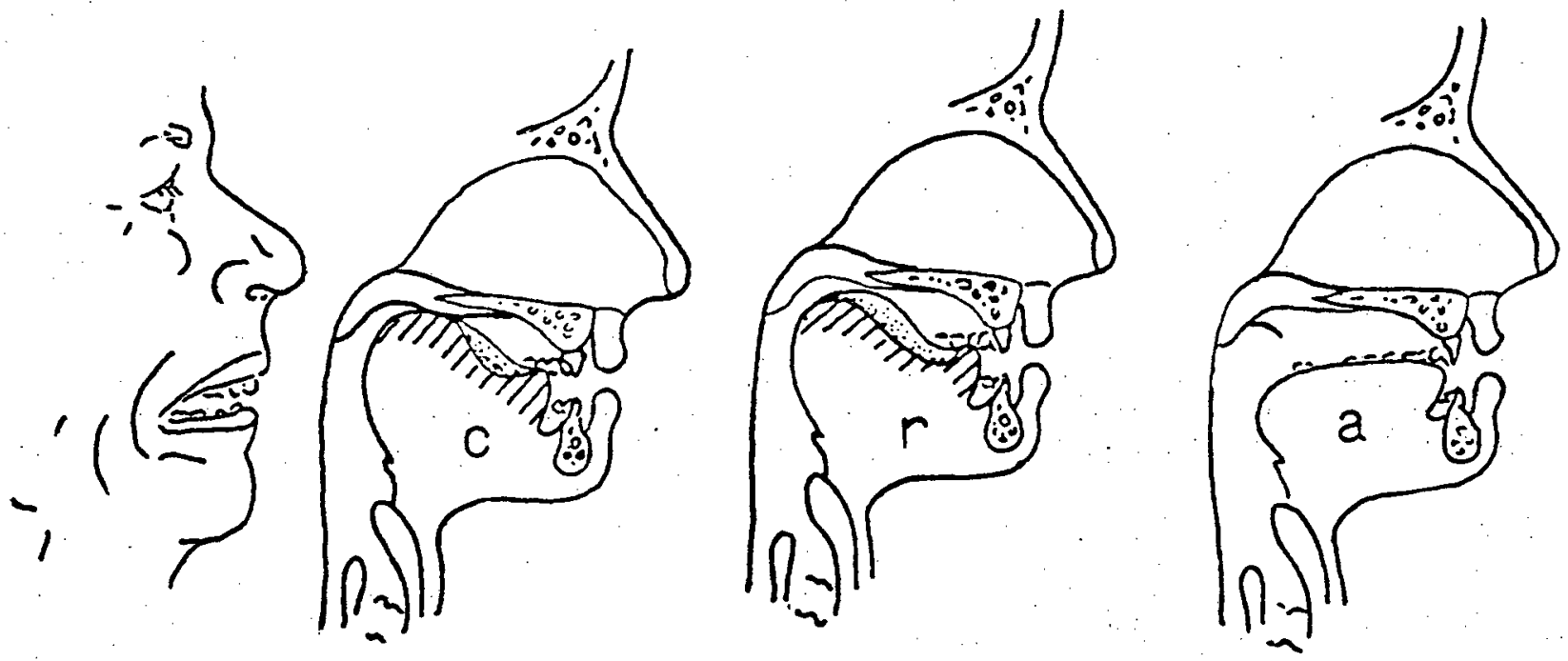
dr and tr blends - Notice the diagram below. Remember to let the sound go at the vowel, and not before.
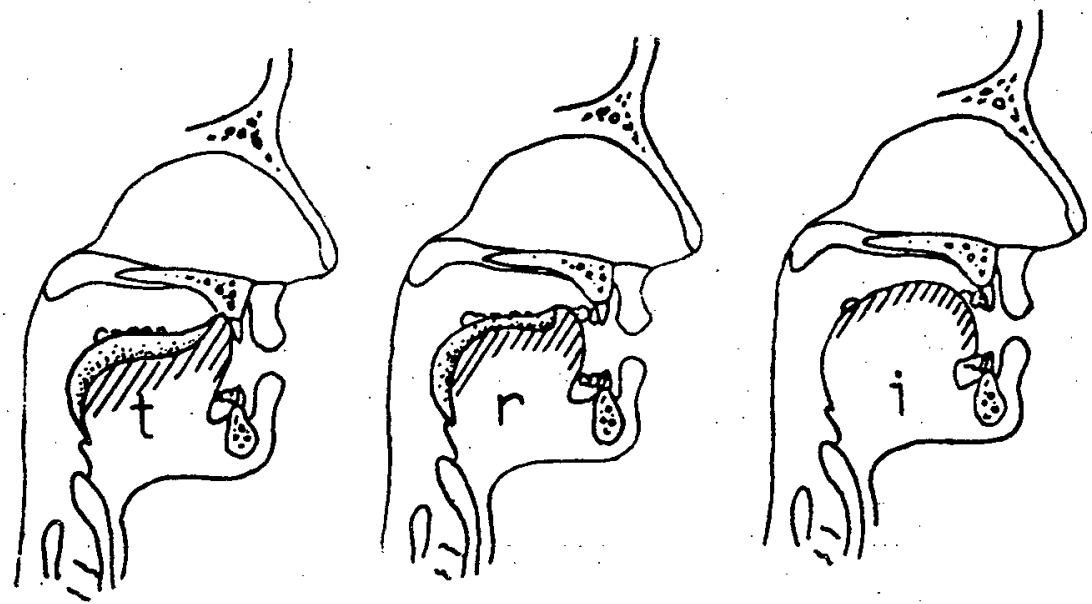

fr blends - Start the "f" and keep it going. Pucker up for the whistle position (point to the " $r$ "). Let out the vowel when it is pointed to.

thr blends - Start the "th" (tongue between teeth with air; teacher points between "the " $t$ " and " $h$ "). Keep the "th" going and pucker for the "r." (Point to the "r.") Let out the vowel.

shr blends - Start the "sh." (A little bigger opening than "s." "H" always means more breath.) Pucker for the "r." Let it out on the vowel (Lang, 1974).

b. Say the blend and then the word. Then proceed as usual.

\section{d. Dictation:}

1. The glass has a chip on the brim.

2. This grass is thin.

3. The press has a crack in it.

4. Sam will not drop that frog.

5. Trim this shrub. 
a. Teacher: Use strict pointer control as needed. Eye and/or self pointer control may be used in between.

Student: To pronounce $\mathrm{w}$ blends, get your tongue into the position of the first consonant. Then pucker your lips for the "w." Let the sound out on the vowel. Stay with the pointer.

b. Say the blend and then the word. Continue as usual.

\section{d. Dictation:}

1. The man swam to his twin.

2. The dress has a twill top.

3. Will you dwell with him?

4. The brush will swish.

5. Can you swim?

LESSON 46

Final Consonant Blends

Final consonant blends will be presented in the following sequence:

1. Words starting with a consonant or consonant digraph, followed by a vowel and a consonant blend.

2. Words starting with a consonant blend, followed by a vowel and a consonant blend (Traub, 1973, p.75).

a. Teacher: Use strict pointer control on every third line, or as needed. Use self and/or pointer control between.

Student: Since two consonants come together at the end of the words with final consonant blends, you may think you have made only one sound. Let's practice these new words.

b. Present each final consonant blend. Then dictate each sound to the student before he reads the word with that blend. The student then practices the words in the usual manner.

c. Answers: 1. sand 2. dust 3. pond 4. milk 5. desk 
d. Dictation:

1. Mom will help dad.

2. I an fond of crisp crust.

3. The rabbit went thump, thump.

4. Lift that milk jug.

5. The French spent much time in the camp.

\title{
LESSON 47
}

\author{
Adding $s$ and 's
}

a. Teacher: Use strict pointer control as needed, and self and/or eye pointer control between.

Student: Some words have an $\underline{s}$ or ' $\underline{s}$ at the end. Read the words on your job sheet. Notice that the final s sounds like the $/ z /$ after a voiced consonant, and like an /s/ after an unvoiced consonant. As you read the new words, decide whether to say the $/ \mathrm{s} /$ or $/ \mathrm{z} /$ on the final $\mathrm{s}$. Tongue movement is very slight between the last letter of the word and the added $\underline{s}$ when $\underline{t}$ comes before $\underline{s}$. The air hisses, rather than puffs out. When a leaky consonant comes after a closed letter it only opens as wide as the leaky letter (Lang, 1974). See the diagram on job sheet $a$, which gives and example of what happens when $\underline{s}$ follows $\underline{t}$.

c. Answers: Possessives - 1. This is Bob's hat.

2. Frank has Jack's dog.

3. The gals' cats are big.

4. Dan's dog has a sock.

d. Dictation

1. Dick's ship is red.

2. The tablet's are Bob's.

3. Cliff has six sleds.

4. The man's hats are back.

5. Mom's dress has frills. 
a. Teacher: Use strict pointer control, if necessary, and self and/ or eye pointer.

Student: The /ng/ is a nasal sound as in "sing." To make the /ng/ tuck your tongue behind your lower front teeth and block off the air with the back of your tongue. Open your mouth as you say /ng/. Look at the diagram (Youngberg \& Lang, "C-V B,"1975). The /nk/ sounds a1most like /ng/. The " $n$ " in the /nk/ is also made by blocking off the air with the back of the tongue. This puts the tongue into position for the release of the " $k$ " (Lang, 1974). Notice the diagram.
c. Answers: top left - king
top right - tank
bottom left - swing
bottom right - sink

\title{
d. Dictation:
}

1. Bill rang the bell and sang.

2. The king sank the ship.

3. Thank the bank for that.

4. Hank clung to the sink.

5. The hunk stank.

\author{
LESSON 49 \\ Review of Consonant Blends
}

Follow the directions on the job sheet. The student should be proficient in consonant blends before going on to the next lesson.

\section{LESSON 50}

Detached Syllables With Consonant Blends

Introduction: The detached syllables are from real words, and are presented in the following sequence:

1. Consonant Blend-Vowel-Consonant or Consonant Digraph

2. Consonant-Vowel-Consonant Blend 
c. Answers: 1. th 2. ch 3. ph 4. sh 5. ph

d. Dictation:

1. Phil is not a prophet.

2. The pamphlet has a graph.

3. Ralph sent a pamphlet to Phil.

4. The prophet will tell what will happen.

\section{LESSON 53}

$\mathrm{kn}=\ln /$

Key Picture - knot

a. Teacher: Use strict pointer control, as needed. Use eye and/or self pointer between. Point between the " $k$ " and " $n$ " in each / kn/ word. Explain that the " $k$ " is silent.

Student: The " $k n$ " makes the " $n$ " sound." Remember the block air with your tongue at the gum ridge. Leave your lips apart and use your voice.

d. Dictation;

1. Val did not knit that.

2. The knot did not help.

3. Ralph had a knapsack.

4. Phil has a knack with graphs.

5. Knock when Phil comes.

LESSON 54

$g n=|n|$

Key Picture - gnat

a. Teacher: Use strict pointer control as needed. Eye and/or self pointer control may be used in between. Explain that the " $g$ " is silent. Point between the " $g$ " and " $n$ " in each "gn" word.

Student: The "gn" also says /n/. The "g" does not say anything.

Answers: 1. gnat 2. knapsack (best answer) 3. knit knock 5. not 
3. Consonant Blend-Vowel-Consonant Blend (Traub, 1973).

In lesson 51 you will see these syllables in words.

a. Teacher: Use strict pointer control, as needed, and self and/ or eye pointer control in between.

Student: Follow the technique you have been using for initial and final consonant blends.

d. No dictation this time.

\section{LESSON 51}

Two-Syllable Words Using Consonant Blends

a. Teacher: Use strict pointer control when needed. Use self and/ or eye pointer control between.

Student: The words in this lesson have two syllables. You will recognize one of the syllables in each word.

\section{d. Dictation:}

1. Cal has nutmeg in his milk.

2. That traffic is a problem.

3. The man will inspect the windswept shed.

4. The trumpet is splendid.

5. That plastic pumpkin has an insect on it.

\section{LESSON 52}

$\mathrm{ph}=\mid \mathrm{f} /$

Key Picture - phone

a. Teacher: Use strict pointer control as needed. Eye or self pointer control may be used in between. Point between the " $p$ " and " $h$ " in each "ph" word.

Student:- Make the "ph" sound like the "f" sound. Put your teeth against your lips and add a rush of alr. 


\section{d. Dictation:}

1. The gnat will sting him.

2. The man will gnash his teeth.

3. Phil struck the gnat.

LESSON 55

$\mathbf{w r}=|\mathbf{r}|$

Key Picture - wrench

a. Teacher: Use strict pointer control when needed. Between times use eye pointer or self pointer. Mention that the "w" is silent. Remember to point between the " $w$ ". and " $r$ " in "wr" words.

Student: The "wr" makes the " $r$ " sound. Remember that this is done by tightly sealing the sides of your tongue against your gums so that all breath must pass through an opening in the front, just behind the gum ridge. The tip flips down as your tongue moves into a vowel position. There is a narrow grove in the middle of the tongue (Youngberg \& Lang, "Consonant-Vowel Blending;" 1975).

c. Tell the student to look for words with the " $r$ " sound, as in red and wrench.

Answers: rack, rap, trick, Russ, rich, rock, trap, ring, wrath, Rick, track

\section{d. Dictation:}

1. The wren will rest on the branch.

2. Jack has written the test.

3. Phil did wring his wrist.

4. That is the wrong wrench.

5. Dad's wrath is strong.

LESSON 56

$\mathrm{mb}=/ \mathrm{m} /$

Key Picture - thumb

a. Teacher: Use strict pointer control as needed. Use eye pointer 
or self pointer control in between. Point between the "m" and " $b$ " in each "mb" word.

Student: The "mb" is another way of spelling the "m" sound. Just close your mouth and hum $/ \mathrm{m} \mathrm{m} \mathrm{m} /$.

c. Answers: 1. pamphlet Ralph graph Phil

2. knit knock gnat knot gnash

3. wrap wrong wring written

4. Iamb limb thumb bomb

d. Dictation:

1. Dick has a numb thumb.

2. The dumb lamb is not big.

3. A bomb hit the truck.

4. That limb is big.

5. I have the crumbs.

\section{LESSON 57}

Review

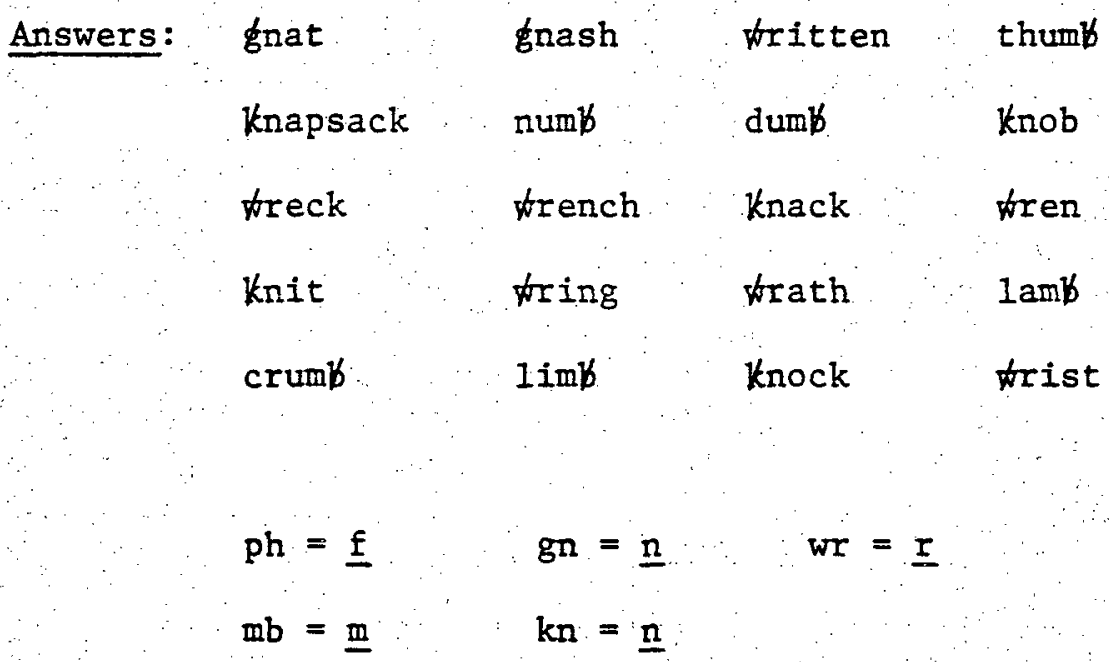


LESSON 58

$\mathrm{a}-\mathrm{e}=|\overline{\mathrm{a}}|$

Key Picture - cake

Introduction: : Explain to the student that he can do a magic trick with the letter "e." When a one-syllable word ends in "e," that "e" gives him permission to use the name of the vowel in that word. Therefore, we call " $e$ " the "permission letter." (Sometimes it is called "magic e.") When "e" serves as a permission letter, it is alsays silent.

a. Teacher: In the next few lessons (58-64) the teacher will point to the vowel in each "magic $e$ " word. At the same time the student will point to the permission letter "e." Use strict pointer control, self pointer, or eye pointer control on the other words on job sheet $a$.

Student: Read the following words. What happens when a permission letter is added to each word? e.g. at, ate.

b. In each "magic e" word, underline the vowel in red and draw an arrow from the permission letter to the vowel. The first one is done for the student. The words are then to be learned in the usual manner.

c. Answers: 1. tape 2. mad 3. hat 4. mat 5. sale

d. Dictation:

1. Jake ate the cake at the shed.

2. The fat man had a bad fate.

3. Jan got a cap and cape.

4. Can Sal take Jane to the sale?

5. That fad will fade.

LESSON 59

$\mathrm{e}-\mathrm{e}=|\overline{\mathrm{e}}|$

Key Picture - Steve

a. Teacher: The teacher points to the vowel and the student points to the permission letter as each "magic $e$ " word is read. (Teacher and student pointers). Use eye or self pointer control on the 
other words.

b. The student is to underline the vowel and draw an arrow from the "magic $e$ " to the vowel that says its own name. "Then proceed as usual. 6. Steve 7. These

d. Dictation:

1. Eve and Steve came here.

2. These men run fast.

3. Pete will eke out his living.

4. The fete was fun.

5. Zeke has a cake to bake.

LESSON 60

$i-e=|\bar{i}|$

Rey Picture - nine

a. Teacher and student pointers on "permission letter" ("magic $e$ ") words. Use strict pointer control, self pointer, or eye pointer control on the other words.

b. Underline the vowels and draw arrows from the permission letter to the vowel. Then continue as usual.

c. Answers: 1. bit 2. like 3. ride 4. win 5. pile

\section{d. Dictation:}

1. I came here nine times.

2. Pete will write when he can.

3. The prize is a ride to the next state.

4. Five miles is a long ride.

5. The bride has a big smile. 
I.ESSON 61

$0-e=|\bar{o}|$

Rey Picture - stove

a. Teacher and student pointers on "permission letter" words. Use strict, self, or eye pointer control on the other words.

b. Underline vowels and draw arrows from the permission letțer to the vowel. Then continue as usual.

$\begin{array}{llll}\text { c. Answers: } & \text { 1. smoke } & \text { 2. note } 3 \text {. hop } & \text { 4. phone } \\ \text { 6lobe } & \text { 7. bite } & \text { choke }\end{array}$

d. Dictation:

1. I hope that the rope is strong.

2. The red rose froze.

3. That stove has a note on it.

4. Jake strode home.

5. I will not quote $\mathrm{Mr}$. Jones.

LESSON 62

$\mathrm{u}-\mathrm{e}=/ \overline{\mathrm{u}} /(\mathrm{y} \overline{\mathrm{u}})$ or $/ \bar{o} /$

Key Pictures - cube (yü)

flute (oo)

a. Teacher: Teacher and student pointers on "permission letter" words. Use strict, self, or eye pointer control on the other words.

Student: Long " $u$ " has two different sounds. It sounds like "you"

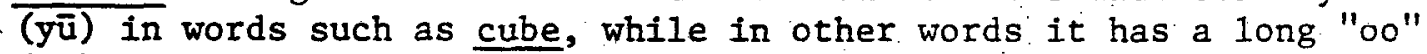
(ठठ) sound, as in flute. Sometimes it has an in-between sound-depending on the speaker (Orton, 1973).

b. The top half of the words on job sheet " $b$ " have the $/ \bar{u} /(y \bar{u})$ sound. the bottom half have the $/ \overline{00} /$ sound. Underline the vowel and draw arrows from the permission letter to the vowel. Then learn the words. 
c. Answers: 1. cut 2. duck 3. cube 4. gun 5 . use

d. Dictation:

1. The mule is cute.

2. Here is a red cube.

3. That duke was here in June.

4. The fuse gave Mike a shock.

5. The tone of the tune is not bad.

\section{LESSON 63}

"Magic e" Detached Syllables

a. Teacher and student pointers on permission letter words. Use strict, self, or eye pointer control on other words.

b. Again, the 1ittle train with a detached car symbolizes a detached syllable. Ask the student to try to think of words that have the syllables on the job sheet. Some examples are below:

\begin{tabular}{cl} 
Detached Syllable & Sample Wo \\
\hline $\begin{array}{c}\text { nite } \\
\text { buse } \\
\text { pose }\end{array}$ & ignite \\
plete & abuse \\
tate & compose \\
pede & complete \\
bine & dictate \\
pire & stampede \\
sane & combine \\
tume & empire \\
& insane \\
& costume
\end{tabular}

Now the student should learn each syllable in the usual job sheet " $b$ " manner. Have him say sentences that have words using the above detached syllables. e.g. nite - Dick will ignite the sticks.

c. Detached syllables for dictation: (Have child number his paper from 1-12).
1. cade
2. bose
3. pote
4. tude
5. dile
6. trive
7. tene
8. struse
9. nize
10. nate
11. node
12. tere 
LESSON 64

Two-Syllable "Magic e" Words

a. Teacher and student pointers on permission letter words. Use strict, self, or eye pointer control on other words. Remind the student to stay closed when he comes to two consonants in a row, releasing them both into the vowel with an explosion.

b. The little train has no detached cars because all the syllables in the job sheet are joined together, forming complete words. There are no detached syllables ("cars").

c. Answers:
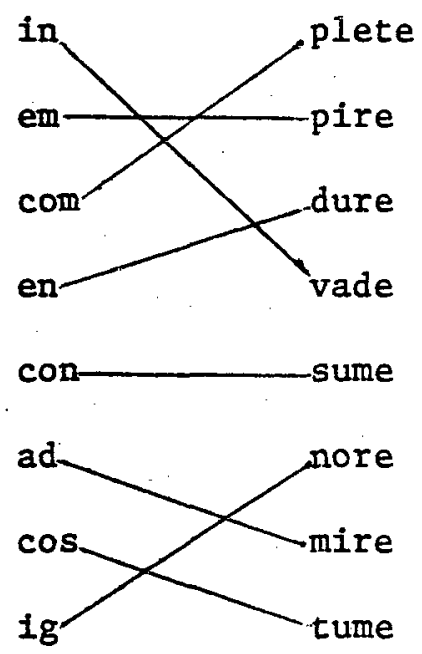

d. Dictation: (Divide the two-syllable words by drawing a line between them.)

1. I suppose the tadpole is inside the tank.

2. The entire ship is lost.

3. The bagpipe made a tune.

4. The king and his men will invade the entire empire.

5. That drink is impure.

\section{LESSON 65}

"Magic e" Review

Words to be read by teacher: 1 . kite 5. rope (Answers are underlined.)

2. flüte

3. here

4. cagge 
LESSON 66

$a i=|\bar{a}|$

Key Picture - Pail

a. Teacher: Have the student use eye pointer control. Return to strict pointer control when mistakes are made.

Student: Some vowels are formed by rapidly combining two simple vowels. They are known as "diphthongs." The two letters "ai" make a long " $a$ " sound: Long " $a$ " is a dipthong (Youngberg \& Lang, "Consonant-Vowel Blending," 1975). The rule, "When two vowels go walking, the first one does the talking" applies to lessons 66-72. The name of the first vowel is the name of the couple (Traub, 1973, p. 93). e.g. ai $=\bar{a}$. The "ai" vowel is usually found at the beginning or middle of the word rather than at the end (Ibid., p.101).

c. $\frac{\text { Answers: 1. mail 2. pain 3, pail 4. tail 5. bail }}{\text { 6. plain }}$

\section{d. Dictation:}

1. The snail has no tail.

2. The quaint shed fell.

3. This mail is Pete's.

4. Paint the chair.

5. The maid paid for the grain.

LESSON 67

ay $=|\bar{a}|$

Key Picture - pray

a. Teacher: Have student use eye pointer control.

Student: The letters "ay" also form the long"a" dipthong (Youngberg \& Lang, "Consonant-Vowel Blending, 1975). "ay" is usually found at the end of a word" (Traub, 1973, p.105).

c. Magic Squares - (Adapted from Childs, 1965.)

It is fun to make words from "Magic Squares," which use the new sound that has been learned. This is how they can be used:

1. Start in any square and move from one square to another to make a word. 
2. Do not jump over any square.

3. A letter from any square may be doubled.

\section{Scoring:}

Three points for each three-letter word

Four points for each four-letter word

Five points for each five-letter word - and so on...

He may earn two bonus points for each additional word he can think of that contains the vowel digraph on the particular magic square. These words need not be made up of the other letters on the square (Childs, 1965). (Also found in Traub, 1973, p.96).

\section{d. Dictation:}

1. The tray is in the way.

2. I must pay to take the subway.

3. Pray that Jake may say the best thing.

4. This day the hens will lay eggs.

5. Steve's playmate has clay.

LESSON 68

ea $=|\bar{e}|$

Key Picture - seat

a. Teacher: Have the student use eye pointer control

Student: The two letters "ea" are a team. In this lesson, they say long "e." When you say /ē/ you have a "sweet smile" expression. Your tongue is wide and close to the palate. The tip is at the base of the teeth (Youngberg \& Lang, "Consonant-Vowel Blending," 1975). Remember the rule "When two vowels go walking, the first one does the talking."

c. Answers: yeast, grape, peach, bean, wheat, grain, cream

\section{d. Dictation:}

1. Pete will not pick and eat the beans.

2. Please clean the seat.

3. The beach is east of here.

4. Jean will eat near the clean stream.

5. Jan will teach Jean to read. 
LESSON 69

ee $=|\vec{e}|$

Key Picture - three

a. Teacher: Have the student use eye pointer control.

Student: The "ee" team makes the same sound as "ea." Do you remember how to make this sound? c. Answers: beast, Pete, squeak, athlete, screech, cheap, green,

d. Dictation:

1. Did Jean plant the beet seeds?

2. The queen made a long speech.

3. Did Pete see the wee bee?

4. The fleet went near the street.

5. I will need to keep that jeep.

LESSON 70

$o a=\mid \bar{o} /$

Key Picture - road

a. Teacher: Have the student use eye pointer control.

Student: What sound does the "oa" team make? Remember, "the name of the first vowel is the name of the couple." You will usually find this team at the beginning or middle of a word (Traub, 1975).

c. Magic Squares - Follow directions for lesson 67.

\section{d. Dictation:}

1. The boat had a load of oats.

2. Can the foam from that soap clean this coat?

3. The goat did groan.

4. The toast made Joan groan.

5. An oak tree fell on the road. 
a. Teacher: Have the student use eye pointer control

Student: The "oe" team also says long "o," and is usually at the end of a word.

c. Answers: 1oad, mote, hole, coat, lone, soap, home, float

d. Dictation:

1. Joe weeks with a hoe.

2. Moe broke his toenail.

3. Woe to him who stands on his tiptoe.

4. The doe ate and than ran from a foe.

5. The belt is made from doeskin.

\section{LESSON 72}

$i e=|\bar{i}|$

Key Picture - pie

a. Teacher: Have the student use eye pointer control.

Student: What sound does this team make? $/ \bar{i} /$. Notice how it is produced. (Look at the diagram on job sheet a.)

c. Answers: side, cried, white, prize, died, fine, mite, inside, slide, tie

\section{d. Dictation:}

1. The pie had a top crust.

2. Joan will lie in wait for the rabbit.

3. Joe's tie is green.

4. The dog may die.

5. Ben will not lie to the man. 


\section{LESSON 73}

\section{Review}
Answers: 1. sai1
tree
6. meaI
2. play
7. road
3. pail, palle
4. seat 5. Pete's,
8. hoe, pole 9. boat, float

LESSON 74

Syllable Division

I.

Answers: tentpest

rąblbitt

cathip

suspect

boninet

adimit

subjject

tentis

bandit

sublime

tabliet

pigment

complete

hobnob

bobibin

conkrete

pulpit

muffifin

II.

happen

contest

polilen

cominit

subitract

pumpkin

kitten

combust

magnet

nutimeg

pancake

mandate

pubilic

dispute

rositrum

helimet

stampede

fossil

III.

suffix

victim

suppose

gossip

dentist

tandem 


$\begin{array}{lll}\text { sudden } & \text { consent } & \text { disrupt } \\ \text { napkin } & \text { dictate } & \text { splendid } \\ \text { picnic } & \text { vampire } & \text { conclude }\end{array}$

LESSON 75

ou $=/ o u /$

$\underline{\text { Key Picture - cloud }}$

a. Teacher: Present the ou and ow cards together as the two ow's. Then teach the first one of the two in this lesson (Ibid.). Have the student use eye pointer control.

Student: If I pinched you, what would you say? (Pinch the student gently, if appropriate.) "Ouch" has our new sound right in the beginning of the word.

c. Answers: 1. ground, South 2. found, stout, scout, house 3. count, hounds 4 . trout 5. cloud, round 6. sour 7. snout, flour

\section{d. Dictation:}

1. Our house is in the South.

2. The proud grouch sat on the couch.

3. His mouth made a pout.

4. Our milk is sour.

5. The round cake fell on the ground.

\section{LESSON 76}

ow $=$ ou

Key Picture - owl

a. Teacher: Have the student use eye pointer control.

Student: This is the second ow. The sound is identical to ou.
c. Answers: 1. clown
2. crowd, shout, loudly
3. Brown, down, 
town 4. mouth 5. down South 6. crown 7. pout, out

d. Dictation:

1. Can an owl grow1?

2. The clown made the crowd scowl.

3. The cows will come in now.

4. How did dad plow the town?

5. The man will drown.

LESSON 77

er $=|\dot{e r r}|$

Key Picture - fern

a. Teacher: Present the er, ir, and ur cards together. Introduce them as the three er's (Ibid.). Have the student do eye pointer control.

Student: This lesson has er words. er is the most frequently used of the three er's. (Ibid.). When doing eye pointer control, remember to treat er as one sound.

c. Answers: (Samples - Answers will vary.) 1. sister 2. whiskers 3. driver 4. singer 5. silver 6. paper 7. plumber

d. Dictation:

1. Her fern is green.

2. Bert will plant some herbs.

3. Herb found the subject and verb.

4. Perhaps the hermit will linger.

5. The stern sister had a temper.

Note: The word herb has two pronunciations - /èrb/ and /hèrb/.

LESSON 78

ir $=|\dot{e} r|$

Key Picture - shirt

a. Teacher: Have the student use eye pointer control. 
Student: ir has the same sound as er. The ir is the second most commonly used of the three er sounds (Ibid.).

c. Magic Squares - Have fun!

d. Dictation:

1. Those birds like to chirp.

2. The girl will take three skirts.

3. The dirt made the third girl squirm.

4. The first shirt is a birthday gift.

5. The birds like the birch tree.

LESSON 79

$u r=|\dot{e r}|$

Rey Picture - nurse

a. Teacher: Have the student use eye pointer control.

Student: ur is the least commonly used of the three er's (Ibid.). Remember to treat ur as one sound when doing eye pointer control.

c. Answers: 1. third, Burns 2. bird, "Chirp, chirp." 3. first, girl, birds. 4. Bert 5. fern, under 6. stern 7. hurt, silver

d. Dictation:

1. Turn left at the curve.

2. Do not disturb us.

3. Ben will burn leaves near the curb.

4. Pete will furnish his house.

5. The spur will rip the fur. 
a. Teacher: Have the student use eye pointer control.

Student: The Igh is sometimes called the three-letter " $i$, "for the three letters make the " $\vec{i}$ " sound when they are combined. Treat these three letters as one sound when doing eye pointer control.

c. Answers: top left - light top right - all right

bottom left - night bottom left - flight

d. Dictation:

1. This night is a sight.

2. The flight had a slight problem.

3. The high winds are nigh.

4. A bright light might help.

5. It is not right to fight.

LESSON 81

ar $=|a r|$

Key Picture - car

a. Teacher: Have the student use eye pointer control.

Student: When " $r$ " teams up with "a," the "a" sounds different. We call this " $r$ " bossy "r." Do you know why? Let 's say the "ar" sound together.

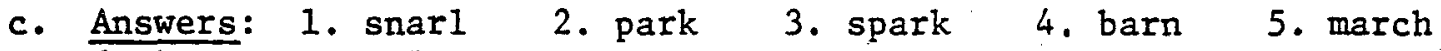
6. harmless 7. hard

\section{d. Dictation:}

1. The car did not go far.

2. Here are his marks.

3. The dog made a sharp bark.

4. A harp will not harm his ears.

5. The park has an art display. 
a. Teacher: Have the student use eye pointer control.

Student: Bossy " $r$ " makes "o" sound different, too. Say the /or/.

\section{d. Dictation:}

1. Bert will order the cord for the porch.

2. The horn is worn out.

3. A stork was born last week.

4. A storm hurt the corn.

5. Jack went home for the torch.

a. Teacher: Present the endings ble, tle, ple, fle, dle, kle, zle, gle--each on a separate card--before the student reads this exercise with eye pointer control. Note: "When these endings follow a short vowel sound, the first letter of the ending is usually doubled (Ibid., p.124)." That accounts for bottle, sniffle, puzzle.

Student: The "le" sound is a syllable ending. It says $\partial 1$ (ŭl).

b. If the student still has trouble reading the "le" words on this job sheet, have him cover the ending with his thumb, read the first syllable, and then the entire word.

\section{c. Answers:}

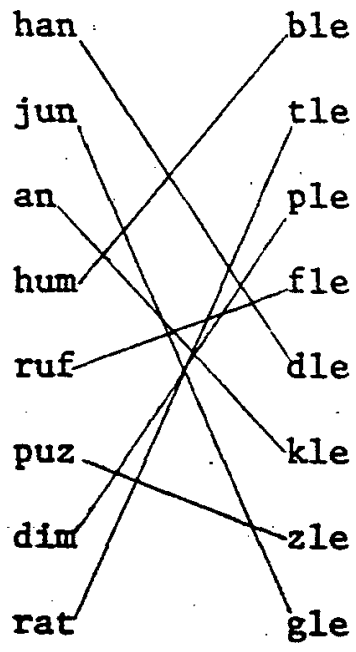




\section{d. Dictation:}

1. The little bottle has apple drink in it.

2. The bundle fell and made a rumble.

3. The puzzle made the man with a fiddle giggle.

4. The handle of the paddle will wiggle.

5. Do not tattle and meddle.

\section{LESSON 84}

\section{Review}
Words for dictation: 1. star tle 2. for gave 3. in sight 4. jun gle 5. out side 6. fur nish 7. sight less 8 . her mit 9. dis turb 10. arm chair 11. or bit 12. snif fle

\section{LESSON 85}

"y" as an Ending

$y=a$ sound between $/ \breve{i} /$ and $/ \bar{e} /$

Key Picture - candy

a. Teacher: Present the appropriate endings on separate cards before each word is read with eye pointer control. e.g. Show the "Iy" card and say the sound. Then the student should read the sound and the word, "manly." Next, show the "by"! card. Have the student read this sound and the word, "hobby."

Sounds for separate cards: 1y, by, vy, dy, fy, ty, my, ny, sy, py, ky. "When these endings follow a short vowel sound, the first letter of the ending is usually doubled (Ibid., p.130)."

b. Have the student read each typed new word without the ending. (He may cover the ending with his thumb.) Then he should read the whole word. Continue with the usual job sheet "b" instructions.

For older children: The " $1 y$ " may be introduced as a suffix. Definition of suffix - an ending attached to a word that will change the meaning of the word. The suffix "ly" means "in a certain way, or like." e.g. goodly - in a good way. An adjective becomes an adverb when " $1 y$ " is added. e.g. sad - sadly (Ibid,, p. 
131). Have the student do this to other words.

d. Dictation:

1. Daddy is happy with mommy.

2. The funny man is short and stubby.

3. Bobby ate the chunky, crispy candy.

4. That shelf is dusty.

5. The frisky dog is dirty.

\section{LESSON 86}

$00=/ \overline{0 O} /(\mathrm{u})$

\section{Key Picture - moon}

a. Teacher: Have the student read with eye pointer control.

c. Answers: top left - broom ...top right - stool

bottom left - spool bottom right - mushrooms

\section{d. Dictation:}

1. That room is too big.

2. The cartoons are funny.

3. The zoo has a coon and a baboon.

4. This pool is cool.

5. That poodle fell off the roof.

\section{LESSON 87}

Hard - Soft c

$c=|k|($ hard $)$

$c=\mid s /($ soft $)$

$$
\begin{array}{r}
\text { Key Pictures - cup (hard) } \\
\text { circle (soft) }
\end{array}
$$

a. Teacher: Explain to the student that " $c$ " is usually pronounced like a " $k$," except when it is followed by "e," " $i$, " or "y." Then it is pronounced like an "s." Take the student through the lesson, and have him read the words with eye pointer control, giving the 
proper sound of the " $c$ ". and the reason. After the student understands the reason, tell him to abbreviate the reason to "natural" or the name of the cue vowel ( $e, i, y)$. After this exercise have the student read the lesson in a normal manner (Lang, 1974).

b. There are no hard " $c$ " words on this job sheet because job sheet \#2 gives practice with hard " $c$ " words. Hard "c" words are reviewed on job sheet " $a$ " of this lesson. Job sheet " $b$ " is intended to offer practice on new soft " $c$ " words.
c. Answers: 1. c 2. $\mathrm{k}$ 3. $\mathrm{c}$ 4. $\mathrm{k}$ 5.k $6 . \mathrm{c}$ 7. c 8. $\mathrm{c}$ 9. $\mathrm{k}$ 10. c 11. c 12. k 13. k 14. $\mathrm{k}$ 15. c 16. c 17.c 18. k 19. c 20.c 21.k 22.k 23. c 24. $k$ (Note: This rule does not always hold. e.g. circle.)

d. Dictation:

Hard "c"-

1. The car came close to the curb.

2. This corn is in a can.

3. The clip is cute.

Soft "c"-

1. That nice game is ten cents.

2. Nancy has a fancy fence.

3. Val hurt her face at the circus.

\section{LESSON 88}

$g=/ g /$ (hard

$g=/ j /($ soft $)$
Key Pictures - glass (hard)
page (soft)

a. Teacher: " $g$ " is usually pronounced as in gate, except when followed by "e," " $i$, " or "y." Then it is pronounced as "j." Have the student read the words in this lesson with eye pointer control, giving the proper sound of " $g$," and the reason. After he understands the reason, tell him to abbreviate the reason to "natural" or the name of the cue vowel $(e, i, y)$. Then he may reread the lesson in a natural manner (Ibid.).

b. Hard "g" words were learned on job sheet \#3. This lesson merely 
reviews hard " $\mathrm{g}$ " words, and is intended to offer practice with new soft " $g$ " words.

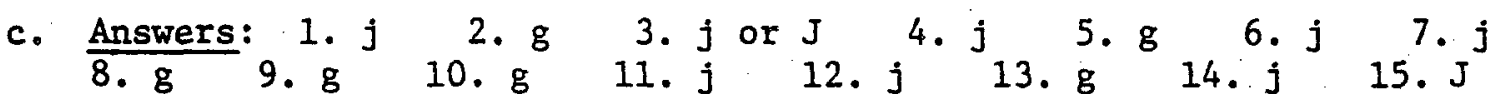
16. $\mathrm{J}$

d. Dictation:

Hard "g"-

1. Gus had a grin on his face.

2. The gate is near a grape vine.

3. I gave the glass to Mrs. Green.

Soft "g"- (All the "j" sounds are spelled with "g.")

1. The ginger cake is huge.

2. Roger did not tell the age of the gem.

3. The cage is on the stage.

LESSON 89

ge - dge

ge - dge $=|j|$

a. At the end of a word the "j" sound is usually spelled with ge or dge (Traub, 1973).

Teacher: Have the student read the ge and dge words with eye pointer control.

Student: Notice the rules for ge - dge on your job sheet.

c. Answers: 1. smudge 2. forge 3. fudge 4. bridge 5 . badge 6. strangely 7 . large

d. Dictation:

1. The badge is large.

2. Herb will lodge here.

3. The strange judge had a grudge. 
4. The huge cage is near the hedge.

5. Mom will urge Jack to cross the bridge.

\author{
LESSON 90 \\ Review - Hard-Soft $c$ and $g$
}

Follow the directions on the job sheet.

\title{
LESSON 91
}

oi $=\mid o i /$

Key Picture - coin

a. Teacher: Present the oi and oy cards together. Mention that oi is usually within a word and $\frac{o y}{1 s}$ usually at the end of a word (Ibid.). Begin trade-a-syllable (with teacher) in this lesson. In trade-a-syllable a word is broken into natural divisions for pronunctation, not necessarily for writing (e.g. di-vi-dend). The teacher says the first syllable, the student says the second, and the teacher the third, etc. A consonant must be left for the next syllable (e.g. di-vi-dend-not div-i-dend). When " $r$ " is at the end of a syllable it is spoken in the following syllable also (e.g. "Mary" is spoken as Mar-ry).
c. Answers: 1. $\mathrm{f}$
2. $s$
3. sp
4. $\mathrm{p}$
5. $\mathrm{m}$
6. j.
7. b

d. Dictation:

1. Joe will oil the joint.

2. Do not join that club.

3. The tinfoil is moist.

4. The point will spoil the coil.

5. This check is void. 
a. Teacher: Do trade-a-syllable with the student.

c. Answers: 1. Roy, toy 2. broil 3. Joyce, choice 4. boy,
5oin 5. coil 6. Roy, employ, boy 7. oyster

d. Dictation:

1. The little boy might like the nice toy.

2. Roy will enjoy soy beans.

3. Mike found an oyster in Troy.

4. The convoy is near.

5. Jack will employ the boy.

LESSON 93

$\mathrm{aw}=\mid \hat{\mathrm{o}} /$

Key Picture - saw

a. Teacher: Present the aw and au cards together as the two aw's

(Ibid.). aw is used for a final sound, or before a consonant. au is used before a consonant (Orton, 1973, p.88): Do trade-a-syllable with the student.

d. Dictation:

1. I saw a hawk at dawn.

2. The ice will thaw soon.

3. I saw the squaw draw.'

4. The claws on the cat's paw made Val squawk.

5. The law has a flaw.

LESSON 94

$\mathrm{au}=|\hat{o}|$

Key Picture - vault

a. Teacher: Tell the student that au is the second of the two aw's. Do trade-a-syllable with the student.

c. Answers: 1. hawk 2. straw 3. gnaw 4. Paul's fault 

5. haul, lawn
6. raw
7. Paul, jaw

d. Dictation:

1. Paul will haul the vault.

2. The cat may maul the dog.

3. Saul will launch a boat.

4. It is Paul's fault.

5. Will the graveyard haunt him?

LESSON 95

$a 1=|\hat{o}|$

Key Picture - ball

a. Teacher: Use trade-a-syllable.

c. Answers are underlined:

A phone call came when I was at the mall. While there, I put salt on a small dish of French fries and ate them. After I had a malt drink and some walnuts, I left for home. My boy met me and told about the call. I went in the house to return the call, and had a nice talk.

Now I will clean the chalk off my dress and sprinkle the cornstalks.

d. Dictation:

1. The small boy will call you.

2. Is that all?

3. Do not salt the malt.

4. The walnut cake is at the mall.

5. Do not talk now.

LESSON 96

"y" as a Vowel (í) 
a. Teacher: Use trade-a-syliable.

c. Answers: 1. It, is, myth, is, in 2. 1ynx, cyst, his 3. will, gyp, Dick, system 4. Syntax, is, English 5. cymbals, Jill 6. Oxygen, is, important 7. Iyric, is

\section{d. Dictation:}

1. The myth is funny.

2. This gym has a basketball goal.

3. The song lyric is nice.

4. The cymbals are loud.

5. This system needs help.

\section{LESSON 97}

\section{Long Vowels in Syllable Division}

a. Teacher: Remind the student that syllable division helps him to decode words. Review the rules that (1) a word has as many syllables as it has vowel sounds, and (2) when two consonants come between the vowels, syllable division occurs between the consonants.

Now introduce words that are divided after a long vowel. First, teach the following short, familiar words where " $e$ " and "o" say their name (long vowel sound) at the end of the word:

be we he she me go no ho so

Tell the student that the vowel at the end of a syllable will usual1y say its own name (long vowel sound). This rule does not apply to"magic $e^{\prime \prime}$ words. With this in mind, have the student do trade-asyllable with you on the new words on job sheet "a."

\section{c. Answers: 1ilac}

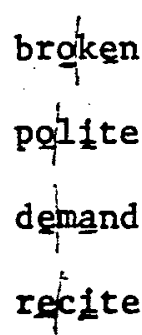
proftect hựan

crisis

program

sẹcret

behave

Item spoken

erect

donate

Ajax

climax

fgcus (Traub, 1973). 
a. Dictation:

1. The apron is at the hotel.

2. A basin can be found under the sink.

3. Did you begin the term paper?

4. Do not omit this pupil from the trip.

5. This is a time to rejoice.

\author{
LESSON 98 \\ "ing" as an Ending
}

a. Teacher: Use trade-a-syllable with the student. If he has any difficulty, have him cover the ending with his thumb, and read the first syllable. The teacher then reads the second syllable, and so on.

*Note: Technically (according to the dictionary), sour and flour are one-syllable words. If they were divided, where could you divide them? (sou/r flou/r?) That would not work, for every syllable needs a vowel. Yet, they are pronounced as two syllable words. Compare: flour, flower.

When adding "ing" to a "magic $e$ " word, we usually drop the silent "e" before adding "ing." e.g. bake, baking, stroke, stroking.

\title{
d. Dictation:
}

1. Stop that banging and honking.

2. Jack's fishing pole is long.

3. The yelping dog was tossing a ball.

4. The plane is landing soon.

5. The bell is ringing and ringing.

LESSON 99

"y" as a Vowel

$y=|\bar{i}|$

Key Picture - eye

a. Teacher: Use trade-a-syllable.

Student: "Y" also has a long " $i$ " sound." 
c. Answers: (Column 1)-my try spry (Column 2)-Mike pie why
sigh type (Column 3)-fly glide deny prime tie light
(Column 4)-satisfy style shy

\section{d. Dictation:}

1. My eye hurts.

2. The sly fox will try to sleep.

3. That type of dress is nice.

4. The spy got a lock.

5. Last July; a fly bit my arm.

LESSON 100

VCV Spelling Rule

Be sure the student understands what root words and suffixes are. For additional practice in this, use worksheet 非154.

$$
\text { The "One - One - One" Rule }
$$

Words of one syllable ending in one vowel and one consonant double the consonant before adding a suffix beginning with a vowel (Orton, 1973, p.62). This is the Vowel-Consonant-Vowel (VCV) Spelling Rule. Exceptlons: Never double "w" and "x."

Answers: 1. rûf lng

2. big ést

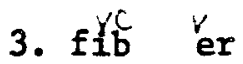

4. màd ěst

5. scót is

6. drồ ing

7. sún $\forall$

8. stư 识g
9. bbat

10. dưnk

11. blush

12. stajc

13. creep

14. stố

15. plunk

16. 011

17. black

18. load
19. $\mathrm{C}$

20. 苗ent

21. less

22. Ing

23. กิess

24. $\frac{v}{y}$

25. énce
32. ènt

26. er

27. en

28. ish

29. able

30. ed

31. est 

33. $\tan +$ ing = tanning
38. big + est $=$ biggest
34. rust + ed $=$ rusted
39. run $+e r=$ runner
35. $c l a n+i s h=$ clannish
40. spoon + ed $=$ spooned
36. skin $+y=$ skinny
41. claim + ing = claiming
37. $\operatorname{man}+1 y=\operatorname{manly}$
42. drift + ed $=$ drifted

LESSON 101

Review

\begin{tabular}{|c|c|c|c|c|}
\hline Answers & & soil & employ & coin \\
\hline & & boil & oyster & soy \\
\hline & & joint & convoy & spoil \\
\hline & & foil & Roy & hoist \\
\hline & & hawk & vault & Paul \\
\hline & & lawn & flaw & law \\
\hline & . & launch & crawl & haul \\
\hline Bottom & $101_{2}:$ & $\mathrm{pa} / \mathrm{per}$ & $\mathrm{ba} / \mathrm{sis}$ & $\mathrm{re} /$ turn \\
\hline & & ho/tel & be/gan & \\
\hline
\end{tabular}

- LESSON 102

Suffix es

es $=|e z|$

a. Teacher: Tell the student that es is added instead of $\underline{s}$ after $\underline{s}$, $\underline{z}$, sh, ch, and $x$. (es is pronounced /ez/.) Use trade-a-syllable. 


\begin{tabular}{|c|c|c|c|}
\hline Answers: & tack $\underline{\underline{s}}$ & noses & jazzes \\
\hline & bumps & waxes & nests \\
\hline & crutches & latches & dishes \\
\hline & paths & hisses & paws \\
\hline & trees & churches & misses \\
\hline & Iedges & Iunches & trips \\
\hline & bubbles & clowns & beans \\
\hline
\end{tabular}

\section{d. Dictation:}

1. The taxes are high in this town!

2. Those churches have benches outside.

3. Quizes are fun if you prepare for them.

4. The brushes are all right.

5. Dick rushes home each day.

LESSON 103

\section{Suffix ed}

ed $=/$ ĕd $/, / \mathrm{d} /, / \mathrm{t} /$

a. Teacher: Explain that when something happened in the past you add ed to the verb. Remind the student that if you can touch it, it is a noun. If you can do it, it is a verb (Traub, 1973, p.162). ed has three sounds: /ëd/, /d/, and $/ t /$.

1. / ĕd/: a separate syllable after d or t. e.g. melt, melted; hint, hinted.

2. $/ d /$ : a blended final sound after a voiced consonant (or a final vowel sound). e.g. sail, sailed; pray, prayed.

3. $/ t /$ : a blended final sound after an unvoiced consonant. e.g. jump, jumped; whip, whipped. (Orton, 1973, p.61).

Explain the above rules; then use trade-a-syllable. The job sheets have two sample words for each of the three sounds of ed. 
b. The numbered groups of words on job sheet " $b$ " correspond to the numbered rules on page 114.

c. Answers will vary.

\section{d. Dictation:}

1. The butter melted last night.

2. Jack spelled the name incorrectly.

3. Mr. Smith rushed home.

4. The clip pinched me.

5. That play lasted too long.

LESSON 104

Suffix er

er $=|\dot{e} r|$

a. Teacher: Use trade-a-sy1lable.

c. Answers: boy - boyish

$$
\begin{aligned}
& \text { settle - settled, settler, settlement } \\
& \text { big - bigger, biggest, bigness } \\
& \text { drink - drinker } \\
& \text { complete - completed, completeness } \\
& \text { wax - waxes, waxed, waxer, waxless }
\end{aligned}
$$

\section{d. Dictation:}

1. The farmer will farm this year.

2. The boiler may boil over.

3. This beginner will begin next week.

4. The skater will skate fast.

5. The same complainer may complain soon. 
LESSON 105

Final i-e Unaccented Syllables

a. Teacher: Before doing this lesson, the student should be acquainted with the idea of accented and unaccented syllables. Refer to the schwa sound. Job sheet 134 will give additional practice, if needed. Use trade-a-syllable. Note that the "permission letter" e is not working this time. If the student has difficulty deciding whether to give the final syllables an /i/ or $/ \equiv /$. (uh) sound, consult job sheet $105 \mathrm{~b}$.

Student: Final i-e unaccented syllables often have a short "i". sound (sometimes "uh") for the vowel (Orton, 1973, p.71).

c. Answers: 1. native 2. exquisite 3 . famine . 4. office 5. massive 6. justice 7. examine

\section{d. Dictation:}

1. The native is very active.

2. A famine bothered the whole nation.

3. The massive problem seemed too big to help.

4. Examine the contents of that box.

5. Justice will be done.

LESSON 106

Review

Follow directions on the job sheet. Answers will vary.

LESSON 107

$\operatorname{tch}=/ \operatorname{ch} /$

Key Picture - crutch

a. Teacher: Use trade-a-syllable.

Student: At the end of a word or syllable, following a short vowel, tch is usually used instead of ch. Exceptions to this rule are 
words like sandwich, such, Iich, attach, much, which, and ostrich.

c. Answers: 1. chin 2, pitch 3. march 4, hatch 5. pitcher 6. branch 7. blotch 8. ouch 9. chop 10. cIutch 11. starch 12. thatch

d. Dictation:

1. Fill the pitcher with liquid.

2. The bug made Jack's arm itch.

3. The pants need a patch over the blotch.

4. The witch swept the steps with her broom.

5. Make a sketch of a Dutch girl.

I.ESSON 108

ew $=/ \overrightarrow{00} /(i i)$

Key Picture - screw

a. Teacher: Have the student read the one-syllable words at normal speed. Use trade-a-syllable on two-syllable words.

Student: The ew in this lesson has an $/ \overline{00} /$ sound, as in moon.

c. Answers: 1. The player threw a ball. 2. Jack blew the bubble. 3. Those birds flew south. 4. He has a new screw. 5. Chew that food well.

d. Dictation:

1. The new crew flew west.

2. Jake threw the screw down a hole.

3. The man slew the lamb.

4. Do you chew gum?

5. The wind blew hard. 
a. Teacher: Have the student read the one-syllable words at normal speed. Use trade-a-syllable on two-syllable words.

c. Answers: 1. weight 2. tail 5. freight 7. eighth 9. sleigh 10. apron 11. weigh 12. plate 13. cake

\section{d. Dictation:}

1. My neighbor has eight cats.

2. The freight cars are large.

3. This sleigh goes fast.

4. James is underweight.

5. Mike weighs eighty-eight pounds.

a. Teacher: Use trade-a-syllable.

Student: All our new words have the /yü/ sound except sleuth, which has the $/ \overline{00} /$ sound.

b. Definitions:

euphony - a sound that pleases the ear

sleuth - a detective

c. Answers: 1. cute 3. feud 5. neuron 7. neutral 8. compute 10. feudal 11. confuse 12. euphony 13. flute (According to Orton [1973, p.74] the / $\overline{00 /}$ sound in flute is a type of long "u" sound.)

\section{d. Dictation:}

1. The man was neutral on the subject.

2. Sam went to Europe last year.

3. The three nations had a feud.

4. This man will read the eulogy.

5. A euphony has a pleasing sound. 
LESSON 111

$i e=|\bar{e}|$

Rey Picture - priest

a. Teacher: Use trade-a-syllable where appropriate.

Student: The words in this lesson follow the rule: "i before e except after c.." Mnemonic: The $\underline{i}$ comes first - "I am the chief (Traub, 1973, p.166)."

c. Answers: 1. field 2. Pete 4. seat 6. yield 7. brief 9. street 10. relief 11. wheat 12. sleep 13. chief

d. Dictation:

1. The priest gave a brief talk.

2. The thief stole eighty gems.

3. Our belief is not new.

4. Her shriek is too loud.

5. Yield the right of way.

LESSON 112

tion $=/$ shun $/$ (sometimes /chun/, as in question) Key Picture - fraction

a. Teacher: Use trade-a-syllable.

c. Answers: 1. ration 2. plantation 3. section 4. mention 5. friction 6. lotion 7. station

d. Dictation:

1. This tire has no traction.

2. Turn right at the junction.

3. The nation will ration food.

4. We must take quick action.

5. This lotion smells sweet. 
LESSON 113

ei $=|\bar{e}|$

Key Picture - ceiling

a. Teacher: Use trade-a-syllable.

Student: Do you remember the rule, "i before e except after $\underline{c}$ ?" The first six words in lesson follow that rule. The last four words are exceptions to the rule.

c. Answers: 1. ceiling 2. chief 3. receive 4. field 5. conceive 6. thief 7. tier 8. belief 9. conceit 10. priest 11. deceit 12. yield 13. deceive 14. grief

d. Dictation:

1. The man might deceive her.

2. Neither Rick nor Tom had a vacation.

3. We will receive it Sunday.

4. The weird man may seize it.

5. Never practice deceit.

ue $=/ \bar{u} /(y \ddot{u})$

Key Picture - argue

a. Teacher: Use trade-a-syllable.

Student: The ue in this lesson has the $/ \vec{u} /$ (yiu) sound, as in you, NOT the $/ \overline{0 O} /$ sound, as in moon.

c. Answers: 1. Mom and dad did not argue.

2. We will continue that later.

3. Please rescue the drowning swimmer.

4. Remember to give me a cue.

d. Dictation:

1. The boys will argue.

2. The lifeguard did rescue the girl.

3. Continue your classes.

4. That cue is fine.

5. The value of the gem is high. 
LESSON 115

Review

\begin{tabular}{|c|c|c|c|c|}
\hline Answers: & $\begin{array}{l}\frac{t c h}{\text { catch }} \\
\text { latch } \\
\text { sketch }\end{array}$ & $\begin{array}{l}\frac{\text { el }}{\text { either }} \\
\text { neither } \\
\text { conceit }\end{array}$ & $\begin{array}{l}\frac{\text { eigh }}{\text { freight }} \\
\text { eight } \\
\text { weight }\end{array}$ & $\begin{array}{l}\text { ew } \\
\text { slew } \\
\text { threw } \\
\text { strew }\end{array}$ \\
\hline & $\begin{array}{l}\frac{\text { ue }}{\text { argue }} \\
\text { value }\end{array}$ & $\begin{array}{l}\frac{\text { le }}{\text { relief }} \\
\text { priest } \\
\text { bellef }\end{array}$ & $\begin{array}{l}\frac{\text { eu }}{\text { euphony }} \\
\text { eulogy } \\
\text { Europe }\end{array}$ & $\begin{array}{l}\text { tion } \\
\text { diction } \\
\text { action } \\
\text { notion }\end{array}$ \\
\hline
\end{tabular}

a. Teacher: Use trade-a-syllable.

c. Answers: 1. load 2. note 3. show 6. know 8. hoe
9. rode 10 slow 14. crow

d. Dictation:

1. I know that the snow will blow.

2. Do not throw the bowl out.

3. The plant grows slowly.

4. Show me the window.

5. The shadow is made by his elbow.

LESSON 117

sion $=/ 2$ hun $/$

Rey Picture - explosion

a. Teacher: Use trade-a-syllable. 


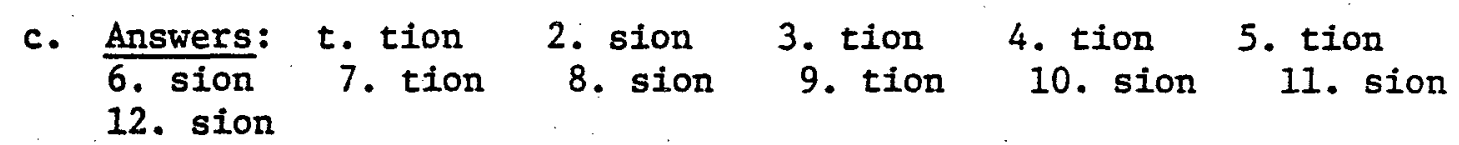

\section{d. Dictation:}

1. Try this division problem.

2. The confusion came at the conclusion.

3. Jack needed a transfusion.

4. The explosion is a surprise.

5. The invasion caused confusion.

LESSON 118

$e a=|\breve{e}|$

Key Picture - bread

a. Teacher: Use trade-a-syllable where appropriate. You may wish to have the student read one-syllable words at normal speed.

d. Dictation:

1. The man liked the bread.

2. That thread is heavy.

3. I wish he had better health.

4. This dead man is deaf.

5. He meant everything he said.

LESSON 119

$\mathrm{ew}=/ \overline{\mathrm{u}} /(\mathrm{y} \ddot{\mathrm{u}})$

Rey Picture - "Mew, Mew"

a. Teacher: Whistle-a-syllable may be introduced at this point. The student will read each syllable, whistling between each syllable. If he cannot whistle, he may blow between each syllable. e.g. ex (whistle or blow) plo (whistle or blow) sion. There is no need to whistle or blow between one-syllable words.

Student: The ew in this lesson has the $/ \bar{u} /($ yii) sound, NOT the $/ \overline{00} /$ sound. 
c. For contrast and review, most of the ew words in sentences 1-6 have the $/ \overline{00} /$ sound. When the student writes his own sentences at the bottom of the job sheet, tell him to use ew words that have the $/ \bar{u} /$ sound, as in mew.

Answers: 1. screw, brew 2. crew, flew, yew 3. blew, stew 4. chew 5. slew, threw 6. drew

d. Dictation:

1. A few boys will hew the logs.

2. The grass is wet with dew.

3. This stew is nice.

4. The new kittens mew.

5. The vacation will renew his health.

LESSON 120

ue $=/ \overline{0 o} /(i \mathrm{i})$

Rey Picture - glue

a. Teacher: Have the student do whistle-a-syllable (or blow-a-sy1-

Student: Notice that the ue words in this lesson have the $1 \overline{00} /$ sound instead of the $/ \bar{u} /(y \bar{u})$ sound.

$\begin{array}{lll}\text { c. Answers: avenue } & \text { pursue } \\ \text { blue } & \text { rue } \\ \text { construe } & \text { subdue } \\ \text { flue } & \text { sue } \\ \text { glue } & \text { true } \\ \text { misconstrue } & \end{array}$

\section{d. Dictation:}

1. The blue sky is overhead.

2. Is that the true story?

3. Glue this for me.

4. Sue will pursue her.

5. The fine is due. 
LESSON 121

Ind, ild $(i=/ \bar{i} /)$

Key Pictures - rind, child

a. Teacher: Have the student do whistle-a-syllabie (or blow-asyllable).

c. Answers:

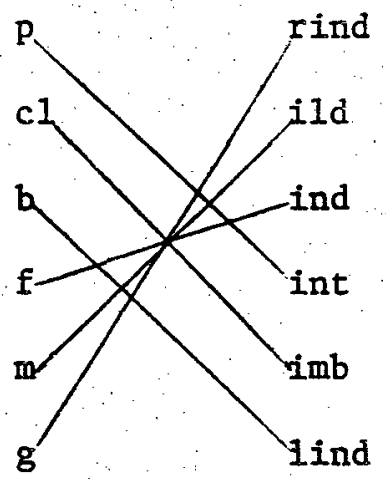

d. Dictation:

1. The wild child is not mild.

2. He will grind it for her.

3. The blind man is also deaf.

4. Did the kind man find it?

5. Order three pints of drink.

LESSON 122 .

old, olt,

ol1, ost $(0=/ \bar{o} /)$

Key Pictures - gold, bolt scroll, post

a. Teacher: Have the student do whistle-a-syllable (or blow-asyllable).

c. Answers: (Answers are underlined.)

The old man took a stroll down the street. He met a bold

colt who ran by, giving the man a jolt. Most old men would scold such a bold colt, but this old man did not. 
d. Dictation:

1. The old man will scold her.

2. Be bold when you go.

3. The colt gave me a jolt.

4. He will stroll in the park.

5. The dog did roll over.

LESSON 123

$00=/ \check{0} /(\dot{u})$

Key Picture - hoof

a. Teacher: Have the student do whistle-a-syllable (or blow-asyllable).

c. Answers: 1. booked 2, goodness 3. hoodless or hooded 4. hookless or hooked 5. looker or looked "6. footless or footed 7 . wooded 8 , crooked

d. Dictation:

1. The book shook him up.

2. Hestood on his sore foot for ten seconds.

3. The cooking is good.

4. Jack took some new fishhooks.

5. Look at that.

LESSON 124

ei $=|\bar{a}|$

Key Picture - reins

a. Teacher: Have the student do whistle-a-syllable (or blow-asyllable).

b. Definition:

skein - A quantity of silk, yarn, thread, etc. put up after it is taken from the reel.

d. Dictation: 
1. The reins came off.

2. $\therefore$ Her veil had white lace.

3. The king will reign for a long time.

4. Did he like the chowmein?

5. His vein is sore.

LESSON 125

$u i=|\vec{u}|$

Key Picture - fruit

a. Teacher: Have the student do whistle-a-syllable (or blow-asyllable).

\section{d. Dictation:}

1. This fruit is good.

2. Did you bruise his arm?

3. Jack has ten suits.

4. The army will recruit them.

5. Apple juice is good:

sion $=/$ shun $/$

Key Picture - mansion

a. Teacher: Have the student do whistle-a-syllable (or blow-asyllable).

c. Answers: tension, pension, pretension, compulsion, propulsion, suspension, extension, expansion

\section{d. Dictation:}

1. The tension in his job is small.

2. How is the propulsion in the jet?

3. The old man has his pension.

4. The church has a new extension.

5. The expansion of the club is large. 
$o u=/ \overline{o o} /(i)$

3. Teacher: Have the student do whistle-a-syllable (or blow-asyllable).

Student: Route and wound are sometimes pronounced with the ou sound, as in cloud. In this lesson, pronounce them with the $1 \overline{0 o} /$ sound.

c. Answers: 1. Louis joined the youth group.

2. Baby Lou has the croup.

3. The soup tastes good.

4. The salt water made the wound sting.

5. The circus troupe followed the southern route.

6. The clay was soupy.

d. Dictation:

1. That soup is not good.

2. This group is made up of youth.

3. The wound is sore.

4. Lou likes soupy things.

5. The route is hard to trace.

LESSON 128

Review

\begin{tabular}{|c|c|c|c|c|c|}
\hline Answers: & ę & $\underline{i}(\overline{00})$ & ō & $\bar{i}$ & $\underline{\mathrm{a}}$ \\
\hline & $\begin{array}{l}\text { tension } \\
\text { dead } \\
\text { nephew } \\
\text { meant } \\
\text { pension }\end{array}$ & $\begin{array}{l}\text { bruise } \\
\text { due } \\
\text { glue } \\
\text { fruit } \\
\text { soup } \\
\text { new } \\
\text { croup }\end{array}$ & $\begin{array}{l}\text { most } \\
\text { cold } \\
\text { jolt } \\
\text { toll }\end{array}$ & $\begin{array}{l}\text { climb } \\
\text { find } \\
\text { wild } \\
\text { pint }\end{array}$ & $\begin{array}{l}\text { reign } \\
\text { vein } \\
\text { ü(ơ) } \\
\text { wool } \\
\text { shook }\end{array}$ \\
\hline
\end{tabular}


a. Teacher: Trade-a-syllable solitaire may be done by the student at this point. He will say words by syllables, trading syllables with himself instead of with his teacher. e.g. (stu.) (stu.)(stu.) mis con strue

\section{d. Dictation:}

1. The great chief is here.

2. Break the link if you need to.

3. This steak is broken.

4. At daybreak, the trip began.

5. Beefsteak is sold at the store.

a. Teacher: Have the student do trade-a-syllable solitaire.

d. Dictation:

1. Fourteen men went to court.

2. Pour the milk this way.

3. He sings with soul.

4. The course is hard:

5. Do not mourn for him.

$i e=\mid \bar{e} /$ (as an ending)

a. Teacher: Have the student do trade-a-syllable solitaire.

d. Dictation: 
1. Millie and Willie came late.

2. That is Susie.

3. Frankie is going now.

4. Here is Dickie.

5. Winnie joined the Brownies.

\section{LESSON 132}

Short Vowel Sounds with $\_$or $\_r r$

a. Teacher: Have the student do trade-a-syllable solitaire.

Student: In some cases, "r" does not modify vowels. (It is not

"bossy.") This lesson has some words that have short vowel sounds in spite of the " $r$ " that follows.

c. Answers: 1. carrot $\begin{array}{lll}\text { 2. ferry } & \text { 3. sparrow } & \text { 4. berry }\end{array}$

Unscrambled words: irritable

irrigate

iridescent

d. Dictation:

1. The man will carry that.

2. This berry is very nice.

3. The farmer will irrigate his crops.

4. That carrot is old.

5. Sparrows sing a lot.

LESSON 133

or $=|\dot{e} r|$

Key Picture - worm

a. Teacher: Have the student do trade-a-syllable solitaire.

c. Answers: worse, mayor, worth, worry, world, worst, word 
d. Dictation:

1. This word is not hard to read.

2. When did Jake go to work?

3. The worst is over.

4. The world is round.

5. Why worry? It could be worse.

LESSON 134

Schwa (a) - The Lazy Vowel

$\partial=\mid \tilde{u} /$

Teacher: Draw a schwa on the board as you say something like the following: "This is the symbol for the schwa. You may think of it as a lazy vowel. It is found in words that have more than one syllable. Say banana. Did you hear an./uh/? Say banana again and listen. Did you hear it? The /uh/ is the schwa sound. You would expect the a in banana to say /a/ and not /uh/, wouldn't you. You will find the /uh/ (a) in the syllables that are not stressed. Which syllables are not stressed in banana? Write an accent mark (') on the stressed syllable. Notice that the unstressed (unaccented) a's in banana are so lazy that they just say /uh/. What does the a in the accented syllable say? /ă/. Find the schwa sound in table. Now do your job sheet.

Answers:

$$
\begin{array}{ll}
\text { sep' a rate } & \text { dam' age } \\
e^{\prime} \text { qual } & \text { hu' man } \\
\text { mod' el } & \text { ap' ple }^{\prime} \\
\text { dis' tant } & \text { pick' le } \\
\text { cab' in }^{\prime} & \text { a bout' } \\
\text { con fuse' } & \text { a'pron } \\
\text { a round' } & \text { a lone' }
\end{array}
$$


LESSON 135

ou - Plus Silent 1

$\mathrm{ou}=/ ð 0 /(\dot{u})$

a. Teacher: Have the student do trade-a-syllable solitaire. Explain contractions if the student is not familiar with them. Job sheet \#155 will help.

d. Dictation:

1. She could not go.

2. Should I bake the bread now?

3. He wouldn't do that.

4. Couldn't I p $\overline{l a y}$ ball?

5. Ned would do that soon, if he could.

LESSON 136

$0=/ \mathrm{u} /$

Key Picture - onion

a. Teacher: Have the student do trade-a-syllable solitaire.

c. Answers:

The month of May marks the time when summer begins to come. Early on a Monday morning a dozen sons meet in front of a house. All of them are going on a wonder trip to the beach. The sons will enjoy making a pile of sand that seems to weigh a ton. Before day is done, the sun will get hot, so the boys will need a cover. Mother will be happy when the children come home.

\section{d. Dictation:}

1. The son drove a two ton truck.

2. No wonder he is late.

3. Three dozen eggs will be fine.

4. Would Jack cover the news this month?

5. Come here right now. 
LESSON 137

"ove" Words

ove $=/ \mathrm{uvv} /$ or $/ \overline{\text { ovv }} /$

Key Pictures - glove, moving van

a. Teacher: Have the student do trade-a-syllable solitaire. The first row of new words has the "u" sound, the second row, the "סo" sound.

Student: "ove" words have two sounds: $/ \overline{\mathrm{u}} /$ as in love, and $/ \overline{00} /$ as in move.

c. Answers:

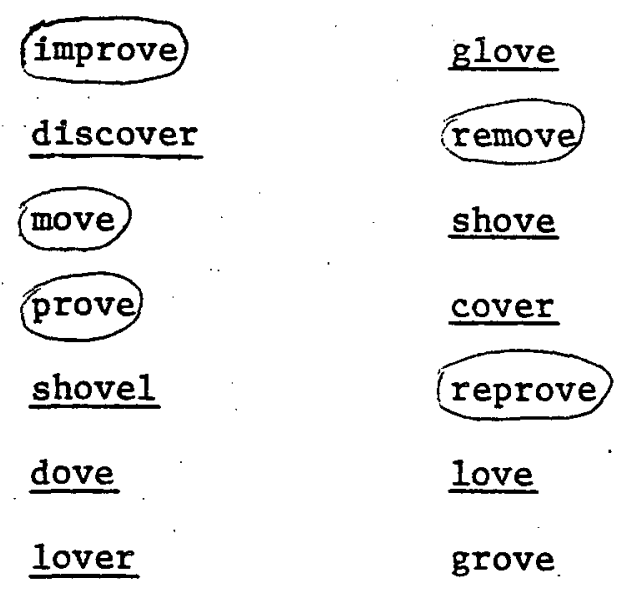

d. Dictation:

1. I love those gloves.

2. Do not cover.

3. Joe will move next week.

4. Things might improve if he moves.

5. Cover the jars before the ants discover them.

LESSON 138

$\mathrm{ch}=/ \mathrm{k} /$

Key Picture - school

a. Teacher: Have the student do trade-a-syllable solitaire.

c. Answers: 1. Christmas, Christ 2. schoolboy, chorus 3. Chrome, headache 4. schools, schoolroom 5. scheme 6. ache 


\section{d. Dictation:}

1. The school chorus is great.

2. The schoolboy devised a scheme.

3. His headache is bad.

4. The chrome fender is dented.

5. The schoolroom has a Christmas tree.

a. Teacher: Have the student do trade-a-syllable solitaire.

c. Answers: 1. earn 2. heard 3. pearl 4. Earl 5. early 6. earnest 7. learn 8, earth 9. search

\section{d. Dictation:}

1. Earl heard a good story.

2. Joe will earn a prize.

3. What on earth is he doing?

4. Jack will search earnestly.

5. Earl will go early.

a. Teacher: Have the student do trade-a-syllable solitaire.

\section{d. Dictation:}

1. The monkey ate the honey.

2. How much money is that?

3. This donkey eats too much.

4. The journey is long.

5. The honey is too sweet for Earl. 


\section{LESSON 141}

Review

\begin{tabular}{|c|c|c|c|}
\hline \multirow{8}{*}{ Answers: } & great/est & spar/row & beef/steak \\
\hline & poul/try & wor/ry & mon/key \\
\hline & $\mathrm{ir} / \mathrm{ri} /$ gate & ear/1y & may/or \\
\hline & shov/el & im/prove & cov/er \\
\hline & ear/nest & day/break & four/teen \\
\hline & won/der & hon/ey & $\mathrm{dis} / \mathrm{cov} / \mathrm{e}$ \\
\hline & Christ/mas & Ann/ie & head/ache \\
\hline & Brown/ie & ber/ry & jour/ney. \\
\hline
\end{tabular}

ar $=$ ièr $/$

Key Picture - dollar

a. Teacher: Have the student do trade-a-syllable solitaire.
c. Answers:
1. $\operatorname{ard}$
8. 1ar
2. 1 ar
3. 1 ar
4. ward
5. 1ar
6. gar

d. Dictation:

1. His collar is on backward.

2. The scholar will charge ten dollars.

3. The beggar is by the pillar.

4. The lizard climbed the poplar tree.

5. The custard is standard. 
a. Teacher: Have the student do trade-a-syllable solitaire.

\section{d. Dictation:}

1. The chef is in Chicago.

2. He had a chevron on his sleeve.

3. This chef has a mustache.

4. The chic gentleman is from Michigan.

5. That chic gentleman wears a mustache.

\section{LESSON 144}

$\mathrm{ou}=/ \breve{u} /$

Key Picture - country

a. Teacher: Have the student do trade-a-syllable solitaire.

c. Answers: 1. country 2. couple 3. cousin 4. double 5. famous 6. southern 7. touch 8 . trouble 9. young 10. youngster

d. Dictation:

1. The boy made double trouble.

2. A couple ropes will touch the plant.

3. His cousin is young.

4. The youngster loves the country.

5. The young singer is famous.

$g h=/ f /, / g /$ and silent

a. Teacher: Have the student do trade-a-syllable solitaire.

Student: The gh combination has three sounds: /f/ as in rough, /g/ as in ghost, and it's silent in words such as dough. (Perhaps you could call that two sounds.) Job sheet "b" has the new words catagorized under the proper gh sound. 
c. Answers: 1. silent 2.f $3 . g \quad 4 . f \quad 5$. silent $6 . \mathrm{f}$ 7. $\mathrm{g}$. silent 9. g 10. $\mathrm{f}$

d. Dictation: (All g sounds are spelled gh.)

1. The ghetto is rough and tough.

2. That is enough dough.

3. Jack says he saw a ghost.

4. His laugh is ghastly.

5. Although he is late, he did enough.

LESSON 146
$c i=/ \mathrm{sh} /$
Key" Picture - glacier

a. Teacher: Have the student do trade-a-syllable solitaire.

c. Answers: The Queen of England is a special person in her country. She is gracious and kind. At special times she wears an ancient crown that is made with precious jewels. At social parties the people appreciate her happy smile. It would be nice to have sufficient money to be able to visit her castle. The Queen must have a good conscience to handle the financial matters of her country.

\section{d. Dictation:}

1. The special official is here.

2. Joe has financial problems.

3. That ancient vase is precious.

4. He has a clear conscience.

5. The gracious lady appreciates the social outing.

LESSON 147

$\mathrm{ey}=|\overline{\mathrm{a}}|$

Key Picture - they

a. Teacher: Have the student do trade-a-syllable solitaire. 
c. Answers: 1. Whey 2. "Hey," they 3. Frey, grey hound
4. survey, obey 5. convey

d. Dictation:

1. Hey, how are they?

2. She threw out the whey.

3. Will he obey the sign?

4. The bird flew after its prey.

5. The survey showed a need for study.

LESSON 148

$u i=\mid \breve{i} /$

Key Picture - build

a. Teacher: Have the student do trade-a-syllable solitaire.

d. Dictation:

1. This builder built that building.

2. The guild started the art show.

3. He felt no guilt for taking the quilt.

4. The new guitar was just built.

5. Did she feel guilty?

LESSON 149

$g u=\mid g /$

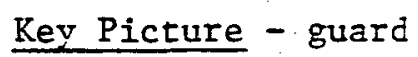

a. Teacher: Have the student do trade-a-syllable solitaire.

$\begin{array}{llll}\text { c. Answers: } 1 . \text { guard, guitar, guards } & \text { 2. guide } & 3 \text {. guild }\end{array}$

d. Dictation:

1. I guess he will guide them.

2. The guard will not let him out.

3. The guest will be here late. 
4. The beach has a new lifeguard.

5. The swindler uses guile.

$a=/ \hat{o} /(a w)$ or $/ \breve{o l}$

Key Picture - wasp

a. Teacher: Have the student do trade-a-syllable solitaire.

Student: The "a" has a special sound in the "wa" combination. (Notice that the "qu" in squash sounds like / kw/.) Sometimes this "a" is pronounced as $/ \hat{\sigma} /$, and sometimes as $/ \zeta /$.

\section{d. Dictation:}

1. They want the squash.

2. That swan is sleeping.

3. The man will wash the rag.

4. Jack walked near the swamp.

5. Do not wander away from home.

LESSON 151

aught $=1 \hat{o} /+t$

Rey Picture - daughter

a. Teacher: Have the student do trade-a-syllable solitaire.

Student: The gh is silent in aught words.

c. Answers will vary on this exercise. Some possible answers are below:
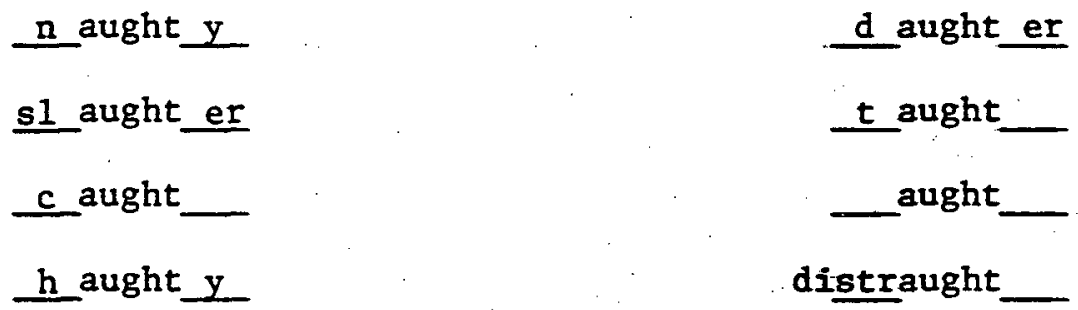

distraught 
d. Dictation:

1. They were caught by the officer.

2. The haughty man taught the class.

3. The daughter was naughty.

4. The lamb went to the slaughter.

5. This man is very distraught.

LESSON 152

ought $=|\partial|+t$

Key Picture - They fought.

a. Teacher: Have the student do trade-a-syllable solitaire.

Student: ought sounds the same as aught.

c. Answers: 1. aught 2. bought 3. brought 4. caught

5. daughter 6. distraught 7 . fought .8 . haughty

9. naughty 10. ought 11 . slaughter 12. sought

13. taught 14. thought

d. Dictation:

1. They ought to go home.

2. Jane bought a new quilt.

3. Jack and Jill fought after they fell.

4. I thought that he had brought it.

5. The boys sought for it all night.

LESSON 153

Review

\begin{tabular}{|c|c|c|c|}
\hline Answers: & young $\underline{\underline{u}}$ & taught $\widehat{0}$ & guide $\underline{I}$ \\
\hline & guest $\underline{\mathrm{e}}$ & though $\overline{0}$ & sought $\widehat{0}$ \\
\hline & hey $\overline{\mathrm{a}}$ & prey $\bar{a}$ & 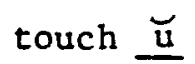 \\
\hline & guild I & guile $\dot{I}$ & bought $\hat{o}$ \\
\hline & ghost $\overline{0}$ & rough $\underline{u}$ & laugh $\underline{a}$ \\
\hline
\end{tabular}




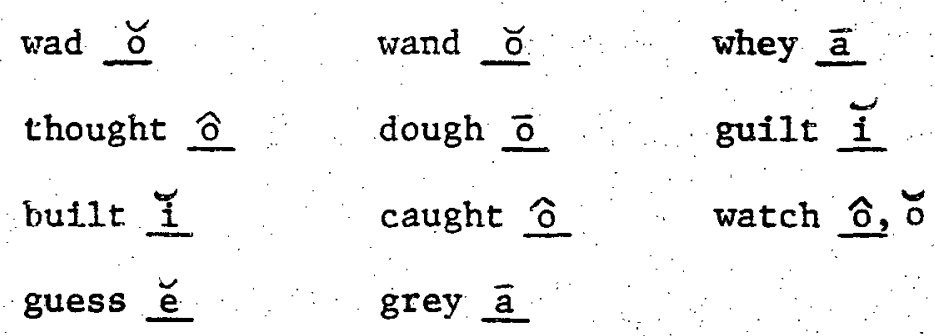

Note: The words that have $\hat{\underline{o}}$ as the answer are sometimes pronounced with an $\underline{o}$ sound; and vice versa. It varies from area to area. Accept ô or o.

Note: At this point, it is recommended that the student do the exercises in the following AVT Booklets:

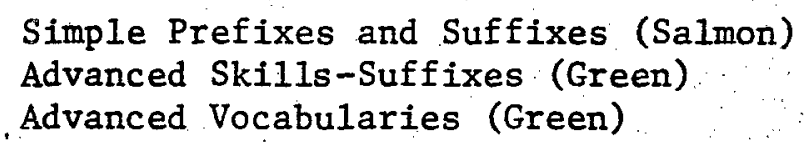

Vowel sounds may be reviewed with the AVT Vowel Flash Cards. Be sure to read the instructions that come with the cards. 



\section{BIBLIOGRAPHY}

Anderson, C. Wilson, and Maine, Harold G. A Workbook of Resource Words. Minneapolis: T. S. Denison and Company, Inc., 1973.

Bishop, Margaret, M. Phonics with Write and See. New York: AppletonCentury-Crofts, 1968.

Bloomfield, Leonard, and Barnhart, Clarence L. Let's Read. Detroit: Wayne State University Press, 1961.

Buchanan, Cynthia D. A Programmed Introduction to Linguistics. Boston: D. C. Heath and Company, 1963

Bush, Wilma Jo, and Giles, Marian Taylor. Aids to Psycholinguistic Teaching. Columbus, Ohio: Charles E. Merrill Publishing Company, 1969.

Capobianco, R. F. "Diagnostic Methods Used with Learning Disabilities Cases." Exceptional Children 31 (December, 1964): 187.

Carter, Homer L. J., and McGinnis, Dorothy J. Diagnosis and Treatment of the Disabled Reader. New York: The Macmillan Company, 1970.

Chall, Jeanne. Learning to Read: The Great Debate. New York: McGrawHill Book Company, 1967.

Childs, Sally, and Childs, Ralph de S. Magic Squares. Cambridge: Educators Publishing Service, Inc., 1965.

Clements, Sam D. Abstract in Special Education: Strategies for Educational Progress. 44th CEC Convention Papers: 188-189.

Crayon, Sr. Ann. "Multi-Sensory Reading Activities." Andrews University.

Crosby, R. M. N., and Liston, Robert. The Waysiders. New York: Delacorte Press, 1968.

Durbrow, Helene C. Learning to Write - Book II: Swing Into Letters. Cambridge: Educators Publishing Service, 1968.

Early Identification of Learning Disablities. Motion picture. Churchill Films Production.

Early, Margaret J. "What Does Research Tell the Classroom Teacher About the Basic Causes of Reading Disability and Retardation?" in Arnt Jewett, ed. Improving Reading in the Junior High School. Bulletin 
No. 10. Washington, D. C.: United States Printing Office, 1957.

Fernald, Grace M. Remedial Techniques in Basic School Subjects. New York: McGraw-Hill Book Company, 1943.

Flesch, Rudolf. Why Johnny Can't Read. New York: Harper and Brothers, 1955.

Forbes, Celeste T. Graded and Classified Spelling Lists for Teachers Grade 2-8. Cambridge: Educators Publishing Service, Inc., 1968.

Fry, Edward. Reading Instruction for Classroom and C1inic. New York: McGraw-Hill, Inc., 1972 .

Gillingham, Anna, and Stillman, Bessie W. Remedial Training for Children with Specific Disability in Reading, Spelling, and Penmanship. 7th ed. Cambridge: Educators Publishing Service, Inc., 1960.

Green, Georgie F. Alphabetic Phonics. Cambridge: Educators Publishing Service, Inc., 1971.

Halverson, Mabel; Meighen, Mary; and Pratt, Marjorie. Phonics We Use. Book D. Chicago: Lyons and Carnhan, Inc., 1966.

Hartman, Nancy C., and Hartman, Robert K. "Perceptual Handicap or Reading Disability?" The Reading Teacher 26 (April 1973).

Helson, Lida, and Fiske, Ahna. Building Language Skills. Cambridge: Educators Publishing Service, Inc., 1973.

IMPACT. "Workshop Modules." Berrien Springs, Michigan: Berrien County Intermediate School District, 1973.

Johnson, Doris J., and Myklebust, Helmer R. Learning Disabilities: Educational Principles and Practices. New York: Green and Stratton, 1967.

Johnson, Warren T. The Johnson Handwriting Program. Cambridge: Educators Publishing Service, Inc., 1972.

Kaluger, George, and Kolson, Clifford J. Reading and Learning Disabilities. Columbus, Ohio: Charles E. Merrill Publishing Company, 1969.

Krane, Louis. Phonics is Fun. 2 books. Cleveland, Ohio: Modern Curriculum Press, 1970.

Lang, Frank. AVT Teaching Materials. Chattanooga: AVT Educational Laboratory, 1974,1975 .

Learner, Janet W. Children with Learning Disabilities. Boston: Houghton Mifflin Company, 1971. 
Lehnan, Eileen F., and Hal1, Robert E. "Who Is This Child?" American Education. April, 1966.

Lehtinen, Laura E. "Have You Ever Known a Perceptually Handicapped Child?" A reprint from the bulletin of the Fund for Perceptually Handicapped Children, Inc. Learn. Evanston, Illinois.

Love, Harold D. Parents Diagnose and Correct Reading Problems. Springfield, Illinois: Charles C. Thomas, Publisher, 1970.

Lynds, Barbara K., and Smith, Carolyn. Index to Phoretic Readers. Cambridge: Educators Publishing Service, Inc., 1967.

Maine, Harold G. Multi-Sensory Phonics Workbook. Minneapolis: T. S. Denison and Company, Inc., 1972.

McCarthy, James J., and McCarthy, Joan F. Learning Disabilities. Boston: Allyn and Bacon, Inc., 1974.

McEathron, Margaret. Your Child Can Learn to Read. Buffalo: Kenworthy Educational Service, Inc., 1952.

Meier, John H. Administration, Scoring, and Interpretation - A Manual for the Individual Learning Disability Classroom Screening Instrument. Bethesda, Maryland: ERIC Document Reproduction Service, ED $065515,1970$.

Miles, M. B., and Simmons, R. W. My First Letters. Cambridge: Educators Publishing Service, Inc., 1968.

Miller, Wilma H. Identifying and Correcting Reading Difficulties in Children. New York: The Center for Applied Research in Education, Inc., 1971 .

Monroe, Marion; Aaron, Ira; and Schiller, Andrew. Spelling Our Language. Books 1-8. Glenview, Illinois: Scott, Foresman \& Company.

Murphy, John F. Listening, Language, and Learning Disabilities - A Guide for Parents and Teachers. Cambridge: Educators Publishing Service, Inc., 1970.

Orton, June Lyday. A Guide to Teaching Phonics. Cambridge: Educators Publishing Service, Inc., 1973.

Plunkett, Mildred B. A Spelling Workbook Emphasizing Rules and Generalizations for Corrective Dril1. Cambridge: Educators Publishing Service, Inc., 1961.

- A Spelling Workbook for Corrective Drill for Elementary Grades. Cambridge: Educators Publishing Service, Inc., 1961. 
P1unkett, Mildred B., and Peck, Caroline A. A Spelling Workbook for Early Primary Corrective Work. Books 1 and 2. Cambridge:

Educators Publishing Service, Inc., 1960.

Report of the Secretary's (HEW) National Advisory Comittee on Dyslexia and Related Disorders. Reading Disorders in the United States. August, 1969.

Saunders, Roger E.; Gialas, Angeline; and Hofler, Donald B. LINCS to Writing, Reading and Spelling. Cambridge: Educators Publishing Service, Inc., 1973.

Schoolfield, Lucille D. Better Speech and Better Reading. Magnolia, Massachusetts, 1951.

Slingerland, Beth $\mathrm{H}$. A Multi-Sensory Approach to Language Arts for Specific Language Disability Children. Cambridge: Educators Publishing Service, Inc., 1974.

- Training in Some Prerequisites for Beginning Reading. Cambridge: Educators Publishing Service, Inc., 1967.

Smith, Donald E. P., and Carrigan, Patricia M. The Nature of Reading Disability. New York: Harcourt, Brace and Company, 1959.

Spaulding, Romalda Bishop, with Spalding, Walter T. The Writing Road to Reading. New York: William Morrow and Company, Inc., 1969.

Steere, Amey; Peck, Caroline Z.; and Green, Linda Kahn. Solving Language Difficulties. Cambridge: Educators Publishing Service; Inc., 1971.

Stiefel, Nancy, and Dew, Joan. "Multi-Sensory Approach fo Learning Sight Words." Berrien County Intermediate School District, Berrien Springs, Michigan, 1972.

Traub, Nina, with Bloom, Frances. Recipe for Reading. Cambridge: Educators Publishing. Service, Inc., 1973.

Vernon, M. D. Reading and Its Difficulties. Cambridge: Cambridge University Press, 1971.

Weber, Elaine. Games That Teach Within Your Reach. E. Lansing, Michigan: Mott Institute.

Wingo, Charles E., and Hletko, Mary C. Sounds, Letters, and Words. Chicago: J. B. Lippincott Company, 1960.

Woodward, Kenneth L. "When Your Child Can't Read." McCalls, February, 1973. 
Youngberg, Millie, and Lang, Frank. "AVT Teacher's Manual." Andrews University, 1975.

Youngberg, Millie, and Lang, Frank. "Consonant-Vowel Blending." Andrews University, 1975.

Zintz, Miles V. Corrective Reading. 2nd ed. Dubuque, Iowa: Wm. C. Brown Company Publishers, 1972. 


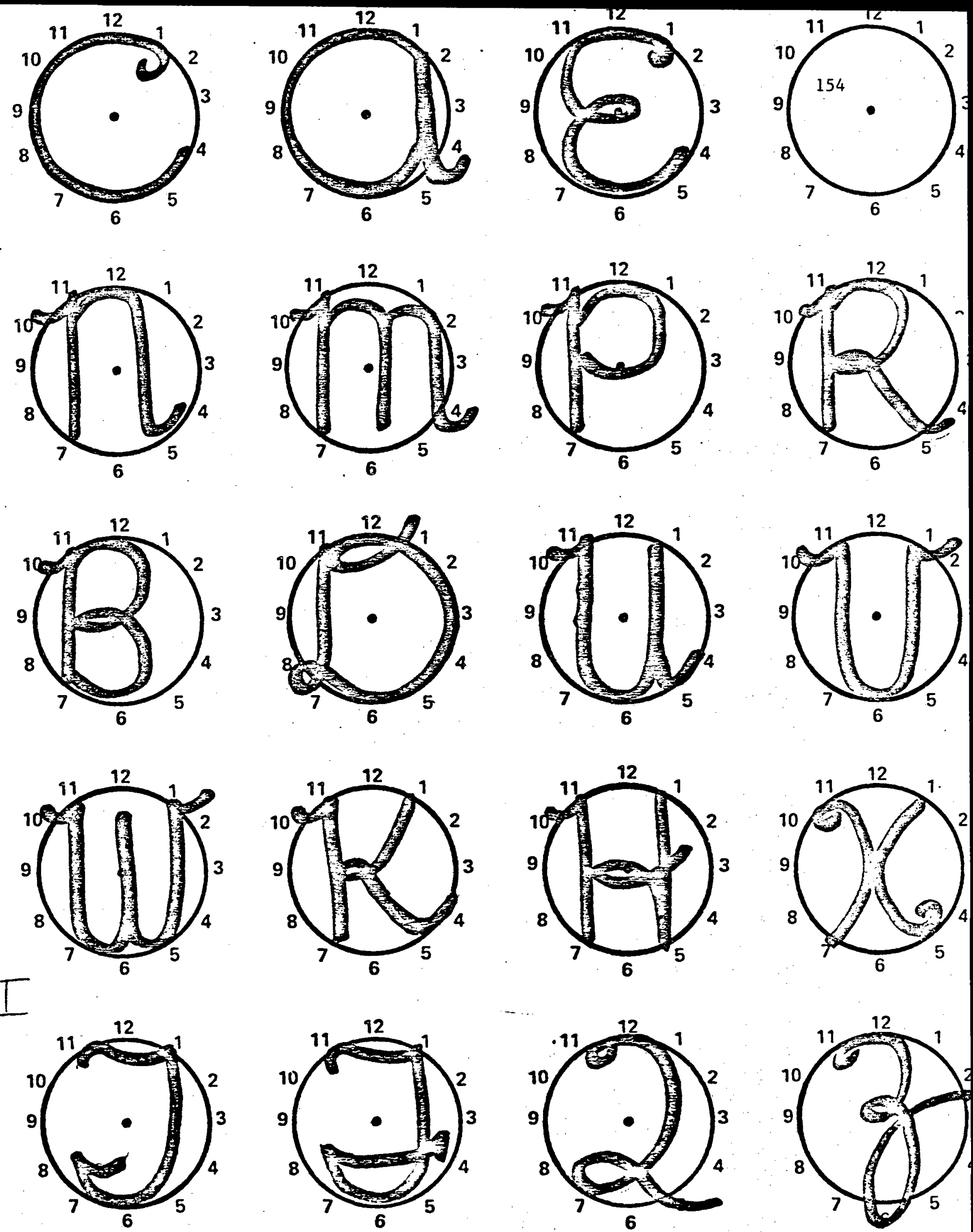

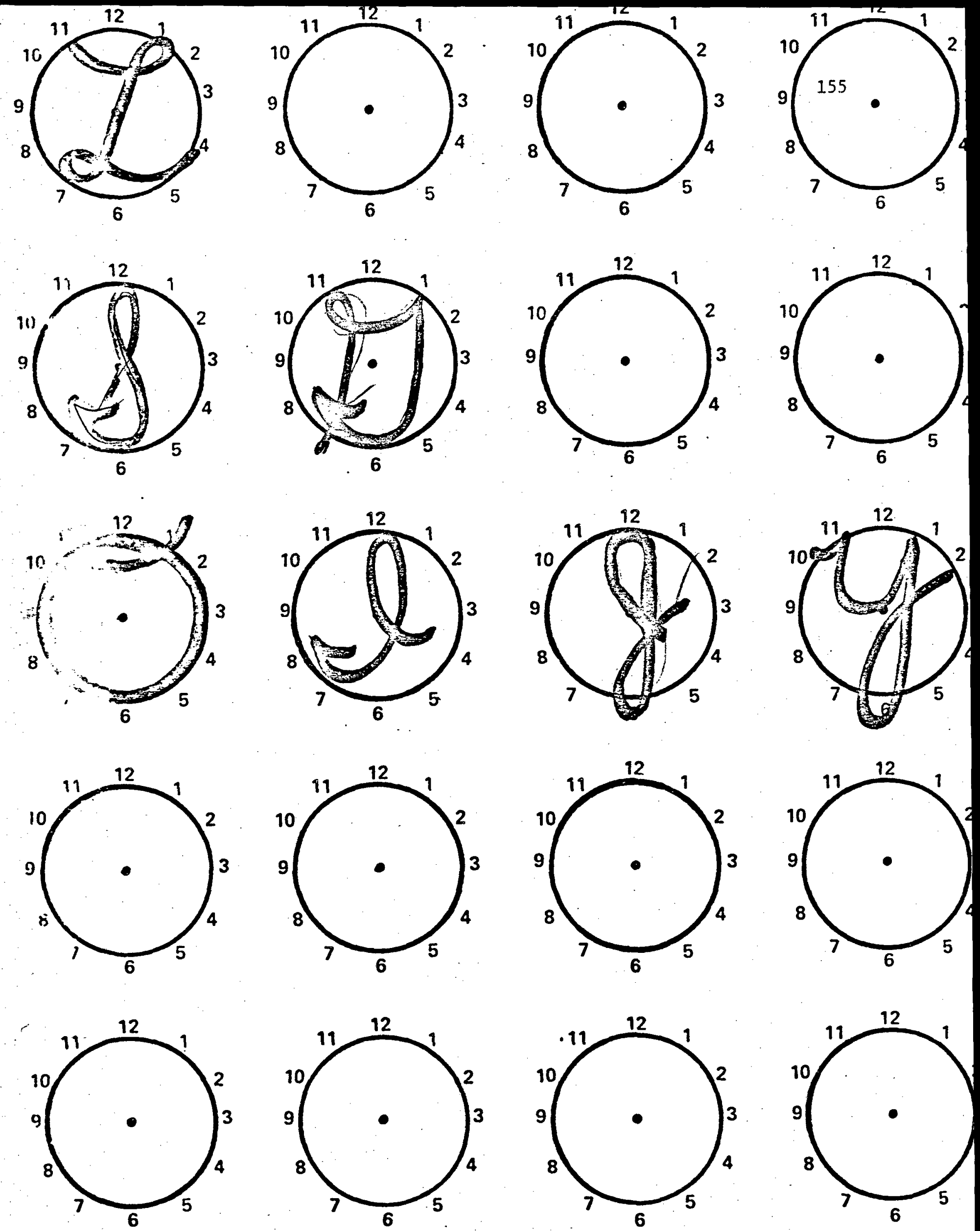

CAPITALS

Group I Swing Around Letters 


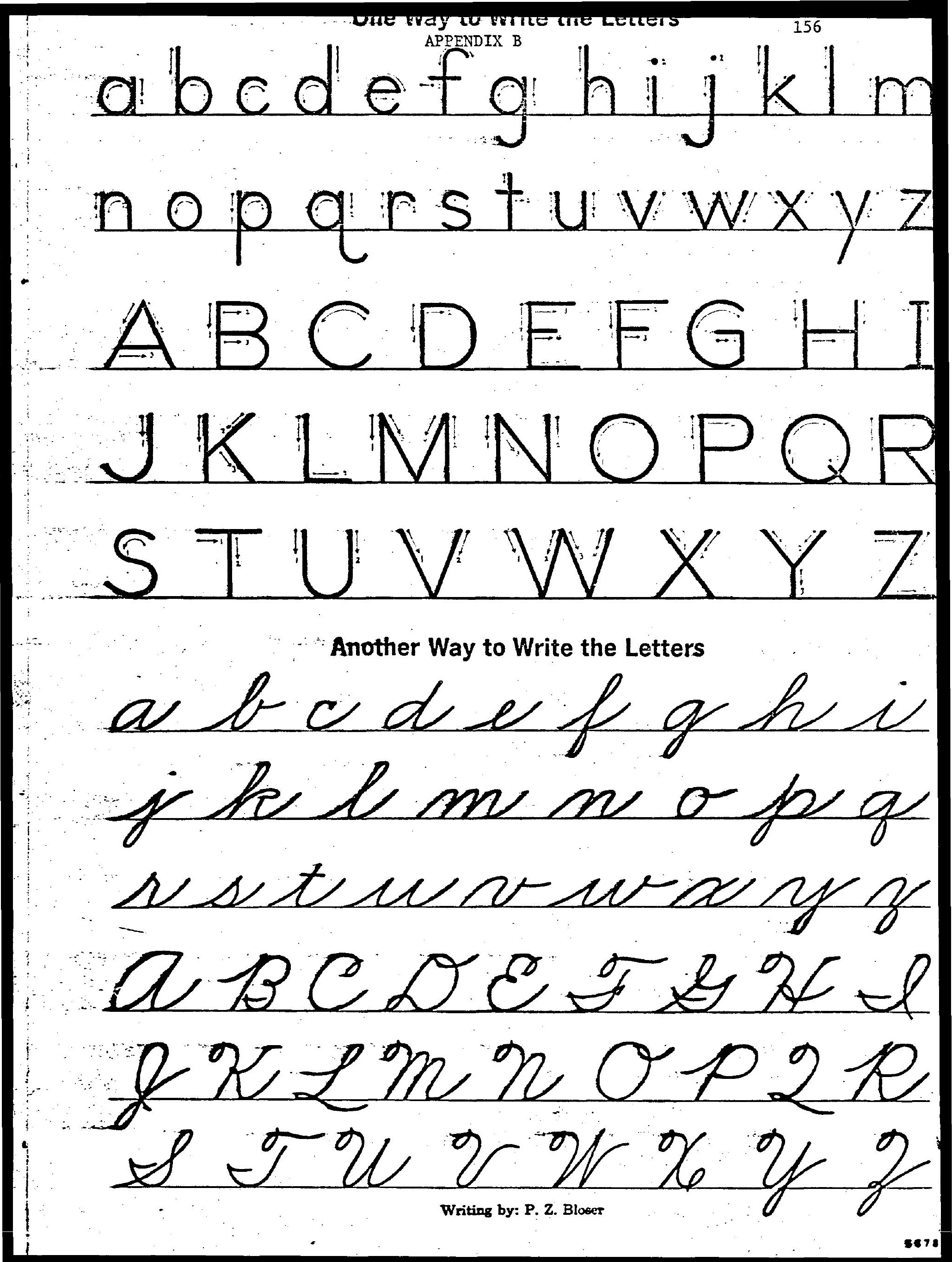


120

BULLETIN OF TIE ORION SOCIETY

APPENDIX

Double Consonants- \&ummarty

Double consonants can be expected in:. -

"Rabbit" words

1,1 (dibuards (fell)

Before suffixes

Consonant + le words-. "rabbit" type"

Chameleon" prefix words - assimilation.

Coincidental doubling

Fig. 6

Notebook page summarizing about $90 \%$ of the occurrences of "double" consonants in English spelling. 
STRUCTURE OF ENGLISH

12

Language Terms lace word. d derivative root

$$
\text { (rom } P \text { ) }
$$

- prefix

suffix,

adverb conjunction offer (roth) preposition compound wordinterjection component lend -ll - nd porto of speech consonant digraph "ph

- $\therefore$ wound digraph - ora. 1 diphthong - oi

homonymo-due -dew synonyms - little- small antony ma big little plural..

- Dimaular

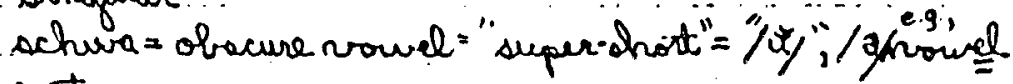
carat A

i monosyllable - manor- = 1

polyaylalle - poly. - many

- possessive.

apostrophe singular plural

mourn

- adjective article $(a, a n$, the $)$

verb

... pronoun

Fig. 7

Sine "language terms" in the order in which Dan learned them. 棺 
4. The final-e, long vouel pattern. This was not called "magic-e." It is, in fact, a signal to tell the reader, "Make the long vowel sound," and does not "make the vowel say its name." This pattern leads to the principle, or convention, that a vowel is usually given its long sound if only one consonant stands between it and the next vowel. These so-called "silent $e$ 's" were formerly sounded, but now they are kept only for their signal-value. $(\bar{r} \subset \phi)$

5. Open syllables, stressed, ending in single vowel, which is long, as in monosyllable's like $I, m c$, go (there is nowhere else for stress!), and $p^{\prime} \cdot n y$ and still longer polysyllible's, but with emphasis on two-syllable words. $\left(-\bar{v}\right.$, or $-\bar{v}^{\prime} \cdot(\cdot v)$

6. Stundurd patterns for two-syllable words. (This is casier for children than for adults, I find.)

a. $\mathrm{gam}^{\prime} \cdot$ bit (spelled as sounded), $r a b^{\prime} \cdot$ bit (sccond b silent, but a useful signal to readers). Sce principle, in 3 , above. $\left(-v_{c} \cdot(v-)\right.$

b. po' $11 y-$ see principle, in 5 . $\left(-\bar{v}^{\prime} \cdot c v\right)$

c. rob' $\cdot$ in $\left(-\breve{v} c^{\prime} \cdot v-\right)$ there are a good many of these and the fact that a given one is of the "robin-type" must be learned; they sound like "rabbit-types" but look like "pony-types." A second try gets you out of the reading problem they pose, but in spelling that may not work, because spelling depends on visual memory. "When you hear only one consonant after a stressed short vowel in a base word, as a best guess, use two-or better still, the dictionary!"

d. The o-mit' and be-gin' words are a third-choice pattern for reading but Inake no trouble in spelling-until you must recognize them when adcling suflixes-see 12 a.

7. The many 2-syllible, consunant +le words almost always follow patterns $6 a$ and $6 \dot{b}$. "That is, they are "rabbits" (rabble), if they are not "gambits" (gamble), or "ponies" ( stable). (Fig. 4)

8. Consonant spelling chuices dictated by: etymology (f or ph, etc.); convention (final ge, $v^{\prime}$ ); probability (likelihood of initial $c$ and final $k$ spellings of $/ \mathrm{k} /$, with many predictable variations); etc.

9. Other ways of signaling long and rariant rourel sounds, including diphelongs. Note: 8 and y hille many mini-sceuconces, mostly tatght carlice but structuralised here for convenience.

\section{Derivalivey}

The foregoing words were unitury, not dirivatives. In forming variants, the principle is 10 be as logical as possible in giving signals to the reader-but there are exceptions he will be expecting you to know; don't let them lirew you. (A "sct for diversily" has its values.)

10. Plurals-regularly add $s$, sometimes $c s$, (always if you hear $\mid \mathrm{ez} /$, and often using the rule develuped in $12 \mathrm{~b}$ below). 
STRUCTURE OF ENGLISH

1

Consonant -le Words

"Pony "type .... Rabbit" type .... Others.

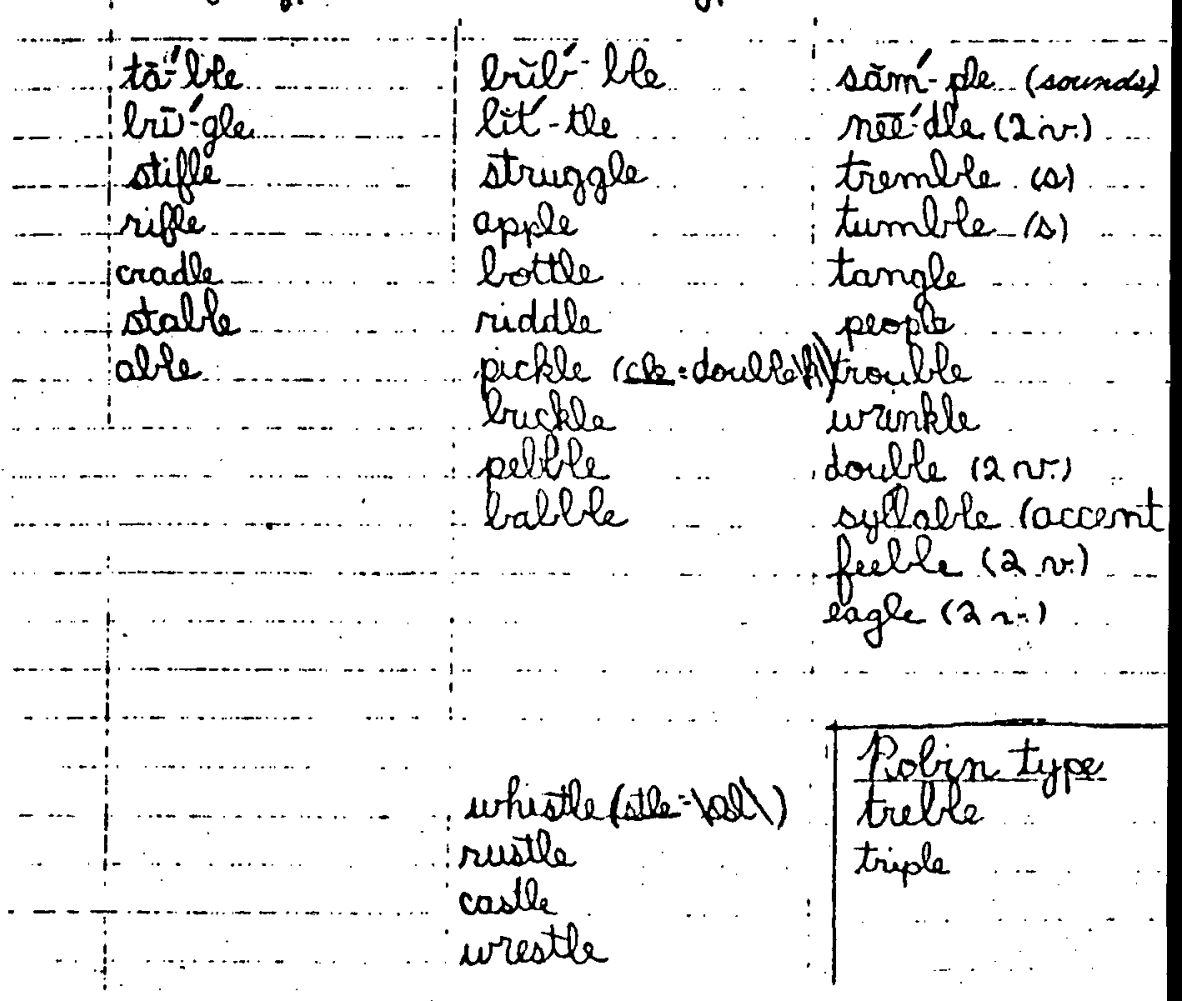

Fig. 4

Sample page from spelling notebook of Dan (sec Fig. 3), grade 7. Classification 2-syllable, consonant + le words.

$\underset{\infty}{\mathfrak{w}}$ 
APPENDIX D

Job Sheet "b" Directions

Pencil should be used so that mistakes can be erased. The student should:

1. Say the word slowly, as in AVT, while looking at it.

2. Say the word slowly, as in AVT, while he traces the letters with his finger. Say the word again.

3. Write the word in the air, saying it slowly as in AVT. Say the word at normal speed.

4. Copy the word on the job sheet, saying it slowly as in AVT. Say the word at normal speed.

5. Spell the word orally while looking at. it. Say the word.

6. Look at the word and lock in memory.

7. Spell the word orally without looking at it. Check. (If he ramot spell it correctly, repeat steps 2 and 5.) Say the word.

8. Cover the word and write it on the job sheet from memory, saying the word slowly as in AVT. Say the word. Check to see if it is correct.

9. Write the word with eyes averted. Check.

10. If incorrect. repeat the above steps.

11. Homework activity: Use each word in a sentence (orally). Parents may help the child to write it down.

*With some students it may not be necessary to do steps 3 and 9.

When beginning the next lesson, check to see if the child knows (or can read) the words from the previous lesson. If not, repeat steps 1-9, using the same words.

When the student gets to the point where he can move through steps 1-10 without error on three consecutive " $b$ " job sheets, the steps can be reduced to 1,7 , and 8 . If an error is made, repeat only teps 1,7 , and 8 . 


\section{A. Pre-primer luvel}
I. a
3. it
15. two
22. for
2.) ne
3is. said

2 and

9. jump

3.6. up

23. fun

30. ny

37. see

3. away 10. little 17. we

24. funny

31. not

33. the

4. big

11. $100 k$

13. vhere

25. help

32. one

39. yellor.

5. Blue

12. make

19. come

26. here

33. $\Gamma^{12 y}$

40. you

6. can

13. three

20. dorm

27. I

34. red

7. is

14. to

21. find

23. in

35. run

\section{B. Primer Level}

\begin{tabular}{|c|c|c|c|c|c|}
\hline 1. a11 & 10. like & 19. Black & 28. good & 37. ride & 46. what \\
\hline 2. an & 11. must & 20. broun & 29. no & 38. saw & 47. while \\
\hline 3. are & 12. new & 21. but & 30. now & 39. they & 48. who \\
\hline 4. at & 13. she & 22. came & 31. on & 40. this & 49. will \\
\hline 5. ate & 14. so & 23. did. & 32. our & 41. too & 50. with \\
\hline 6. be & 15. soon & $24 . \mathrm{do}$ & 33. out & 42. under & 51. yes \\
\hline 7. have & 16. say & 25. cat & 34. pretty & 43. want & \\
\hline 9. he & 17. that & 26 . four & 35. please & 44. ivas & \\
\hline 9. into & 13. there & 27. get & 36. ran & 45. vel1 & \\
\hline \multicolumn{6}{|c|}{ C. First Level } \\
\hline 1. af ter & S. could. & 15. has & 22. Ifve & 29. put & 36. them \\
\hline 2. again & 3. every & 16. her & 23. may & 30. round & 37. then \\
\hline 3. $\mathrm{an}$ & 10. fly & 17. him & 24. of & 31. some & 38. think \\
\hline 4. any & 11. from & 13. his & 25. old & 32. stop & 39. walk \\
\hline 5. as & 12. Elve & 19. how & 26. once & 33. take & 40. were \\
\hline 6. ast & 13. going & 20. Just & 27. know & 34. thank & 41. when \\
\hline 7. by & 14. had & 21. 1et & 23. over & 35. open & \\
\hline
\end{tabular}


1). Second tevel

\begin{tabular}{|c|c|c|c|c|c|}
\hline J. alvays & 9. ca11 & 17. first & 25. pul1 & 33. cilese & 41. why \\
\hline 2: a round & 10. $\operatorname{col} d$ & 13. soes & 26. read & 34. those & 42. wish \\
\hline 3. because & 11. does & 19. green & 27. right & 35. upon & 43. Work \\
\hline 4. been & 12. don't & 20. its & 28. $\operatorname{sing}$ & 36 . us & 44. would \\
\hline 5. befor & 13. fast & 21. made & 29. sit & 37. use & 45. write \\
\hline 6. best & 14. five & 22. many & 30. sleep & 38. very & 46. your \\
\hline 7. both & 15. Eound & 23. off & 31. tell & 39. wash & \\
\hline 3. by & 16. gave & 24. of & 32. their & 40. which & \\
\hline
\end{tabular}

E. Third level

$\begin{array}{llllll}\text { 1. about } & \text { 3. drat } & \text { 15. grow } & \text { 22. laugh } & \text { 29. own } & 36 . \text { start } \\ \text { 2. better } & \text { 9. drink } & \text { 16. hold } & \text { 23. light } & \text { 30. pick } & 37 \text {. ten } \\ \text { 3. bring } & \text { 10. eight } & \text { 17. hot } & \text { 24. long } & \text { 31. seven } & 38 \text { today } \\ \text { 4. carry } & \text { 11. fall } & \text { 18. hurt } & \text { 25. much } & \text { 32. shall } & \text { 39. together } \\ \text { 5. clean } & \text { 12. far } & \text { 19. if } & \text { 26. myself } & \text { 33. show } & \text { 40. try } \\ \text { 6. cut } & \text { 13. full } & \text { 20. keep } & \text { 27. never } & 34 \text {. six } & \text { 41. warm } \\ \text { 7. done } & \text { 14. got } & \text { 21. kind } & \text { 23. only } & 35 . \text { small } & \end{array}$




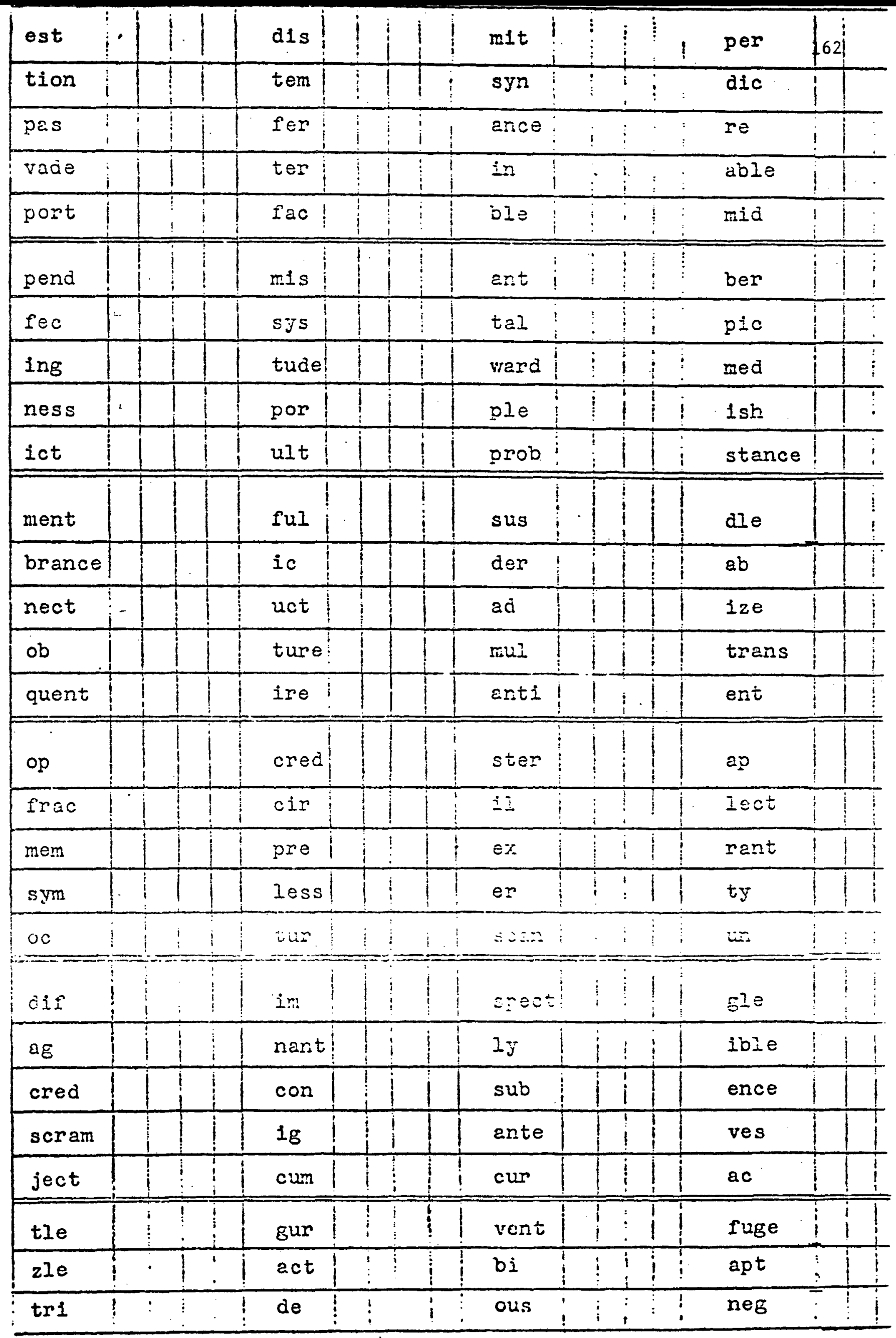




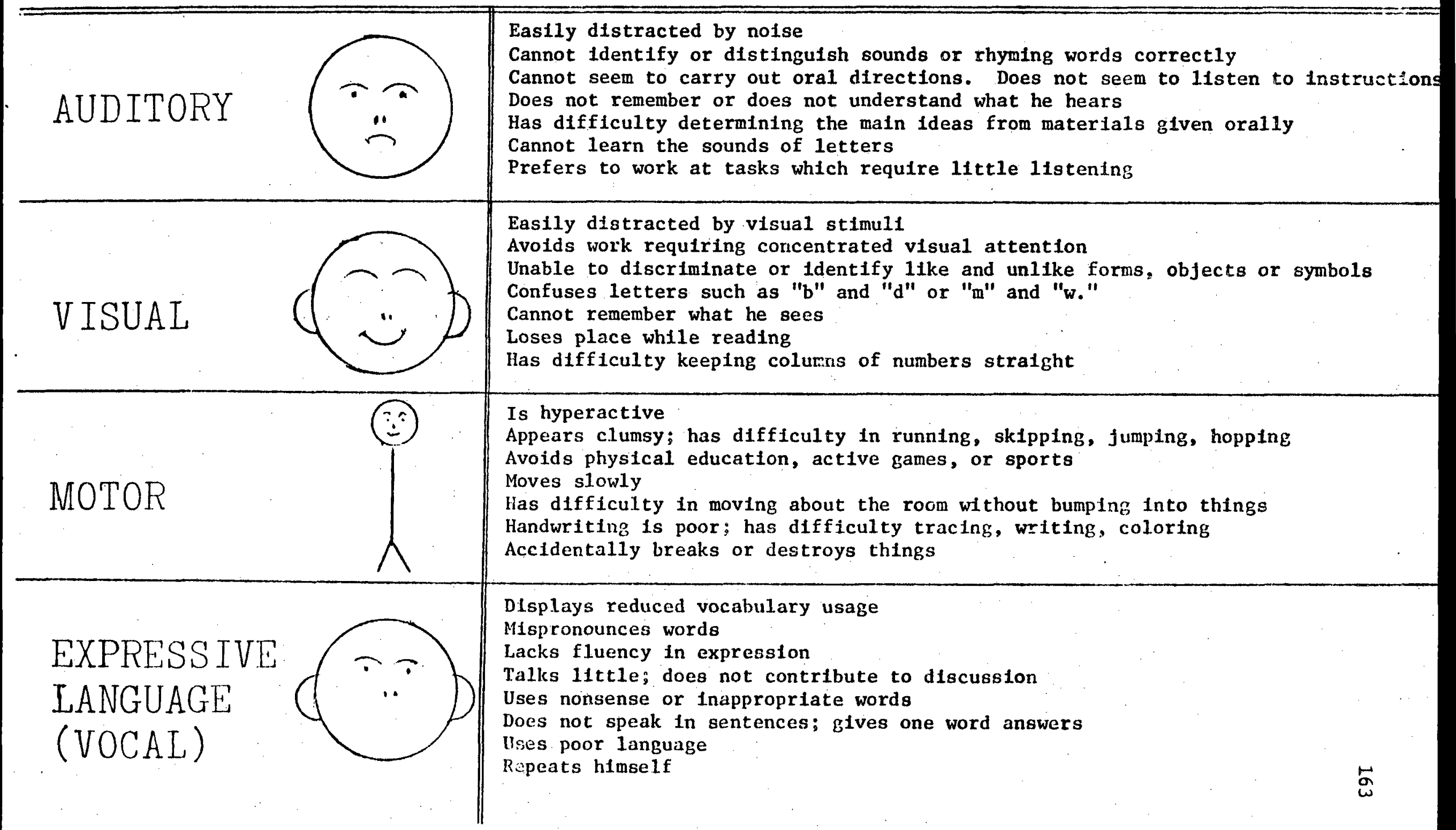




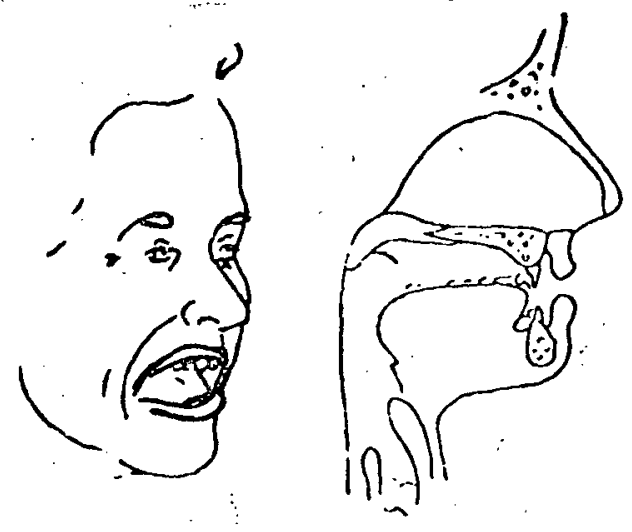

पa口

mamam am hamam ham tamam tam.

dadad dad hadad had laladad lad

atat at matat mat lagagag lag

gagag gag

adamat dagad hamad cagat tatat

lamat mamam tamam gadat hagamag

mad dam hag hat Mac Gad mam Mag cat Mag 
$1 b^{*}$

am

ham<smiles>CC1CC1C</smiles>

a Aa

tam

dad

had

lad

at

mat

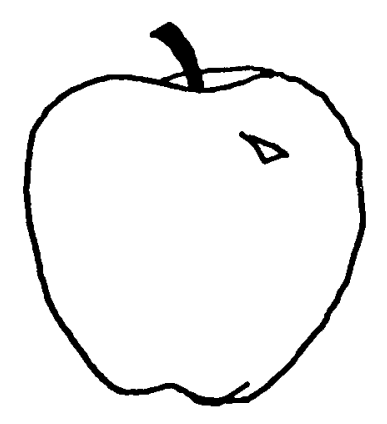

lag

gag

an

ham

tans 


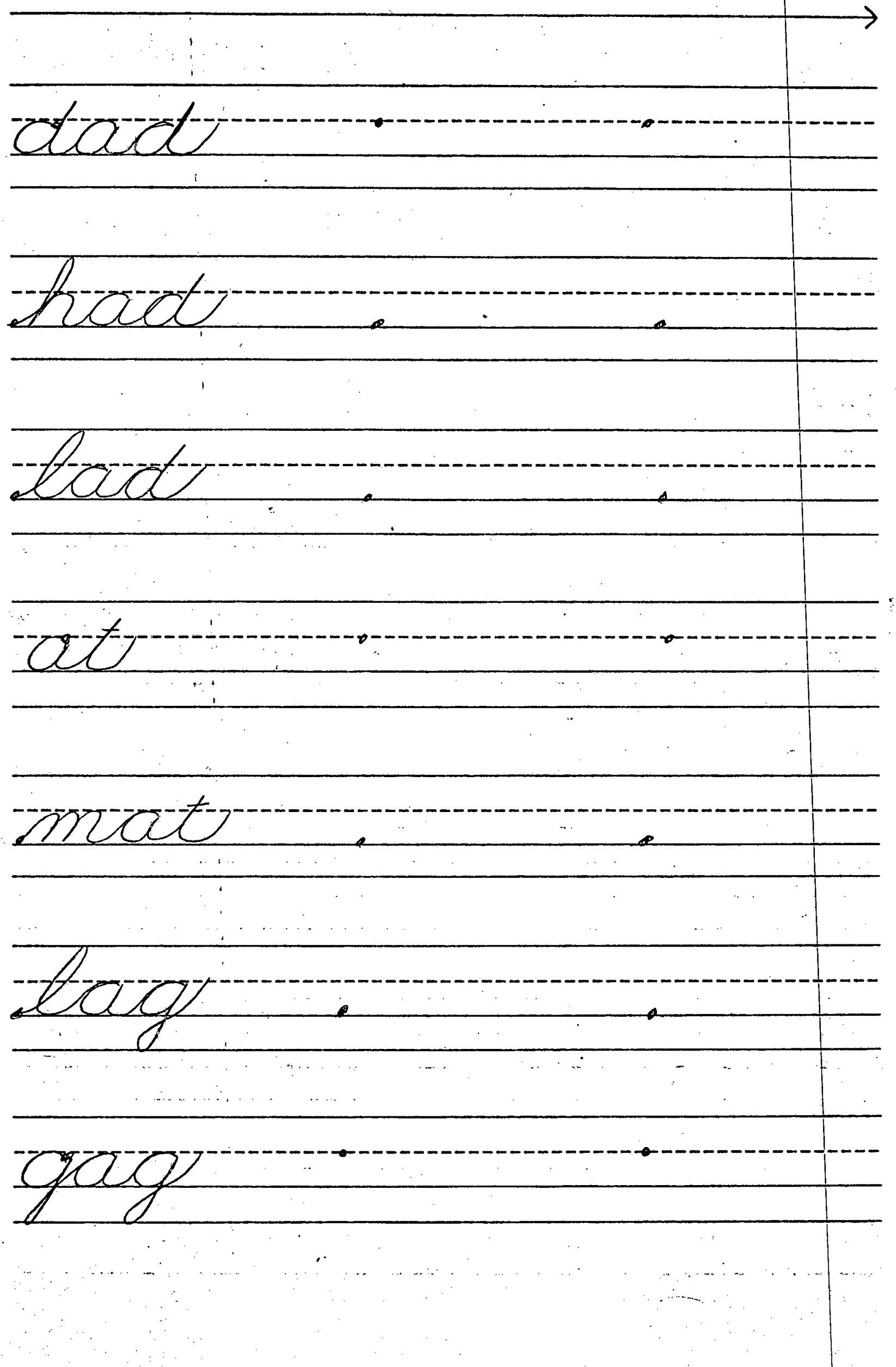


Listen as your teacher reads these words. Circle the words that have the short "a" sound. Put a (breve) over the vowel.

bag

that

ran

mate

Sam

game.

sat

take

nap

bai†

tack

man

$\tan$

fate

pack

I and

lame

wag

Kate

train

rain

I ap

strap

rake

cat

Kate

pain

break

quack

dame 

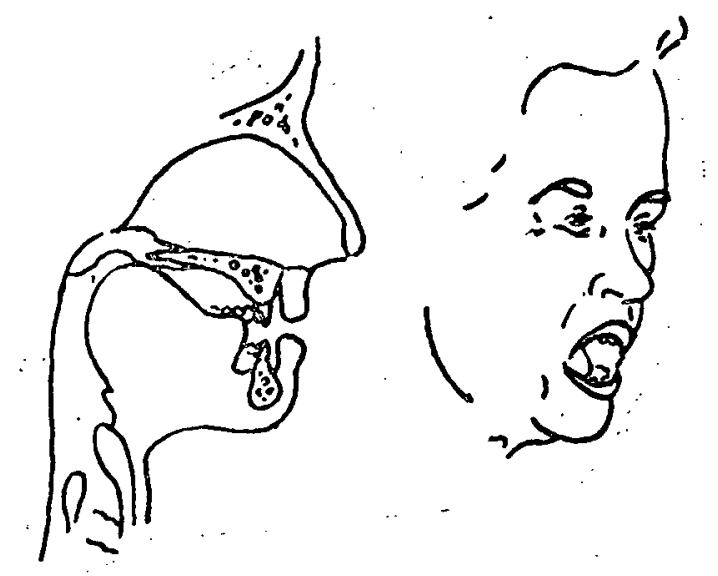

C

cacal Cal camam cam cacat cat

cadad cad mamac Mac

macam cacat cacacam calal gacag

tacad hacam catad gacat catam

ham cat Mac Cal Tad
cam mat mam gal cad




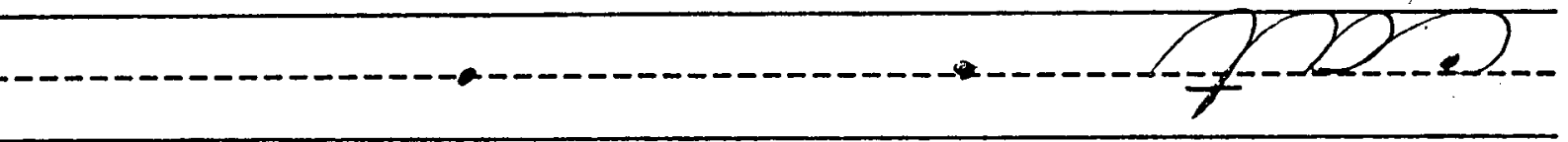

LUWLLE

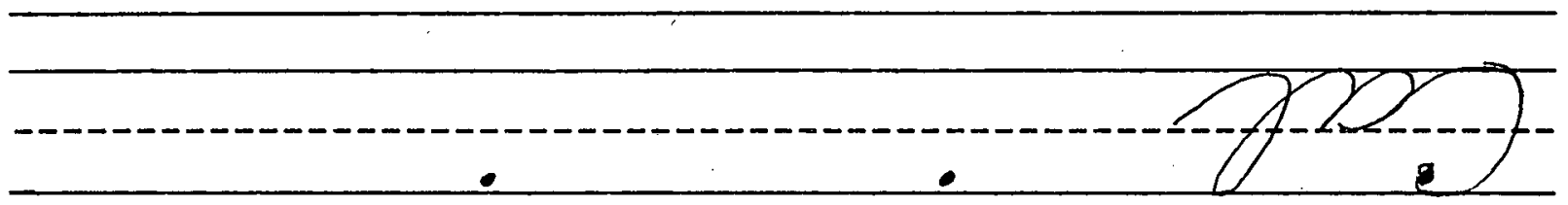

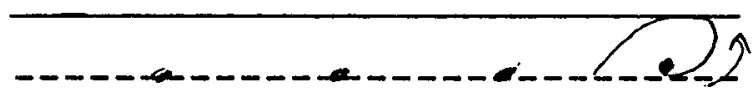

$\int_{7}^{21}$

$\leftarrow$

$\leftarrow$

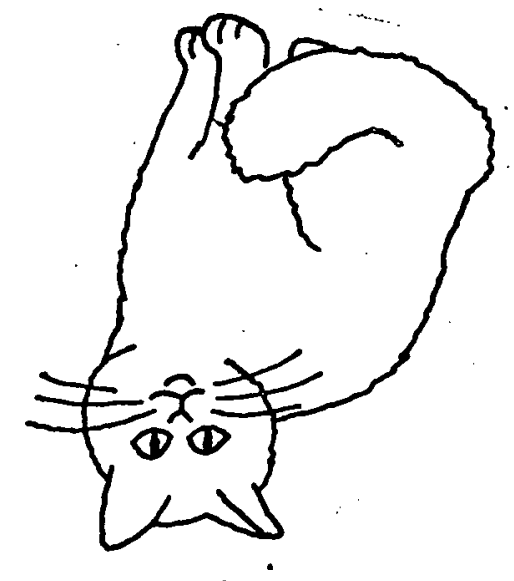

ODN + PDO tDo

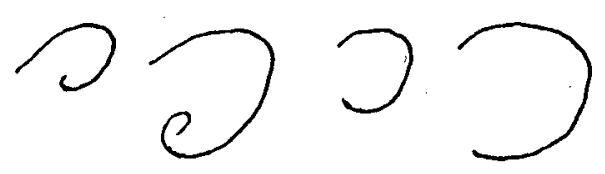
+ UDO IDO *92 
cadt................

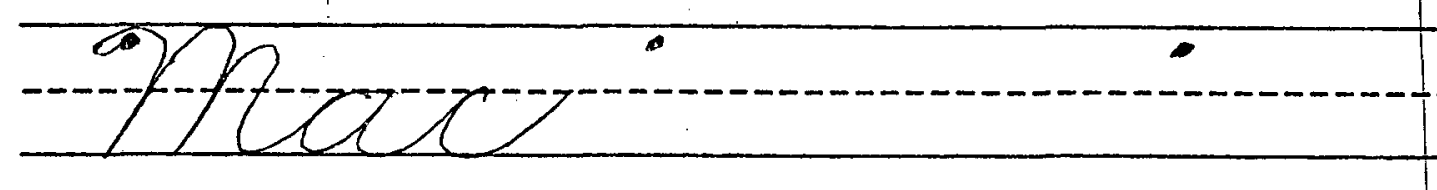


Write a "c" in the box if the name of the picture begins with the "c" sound.
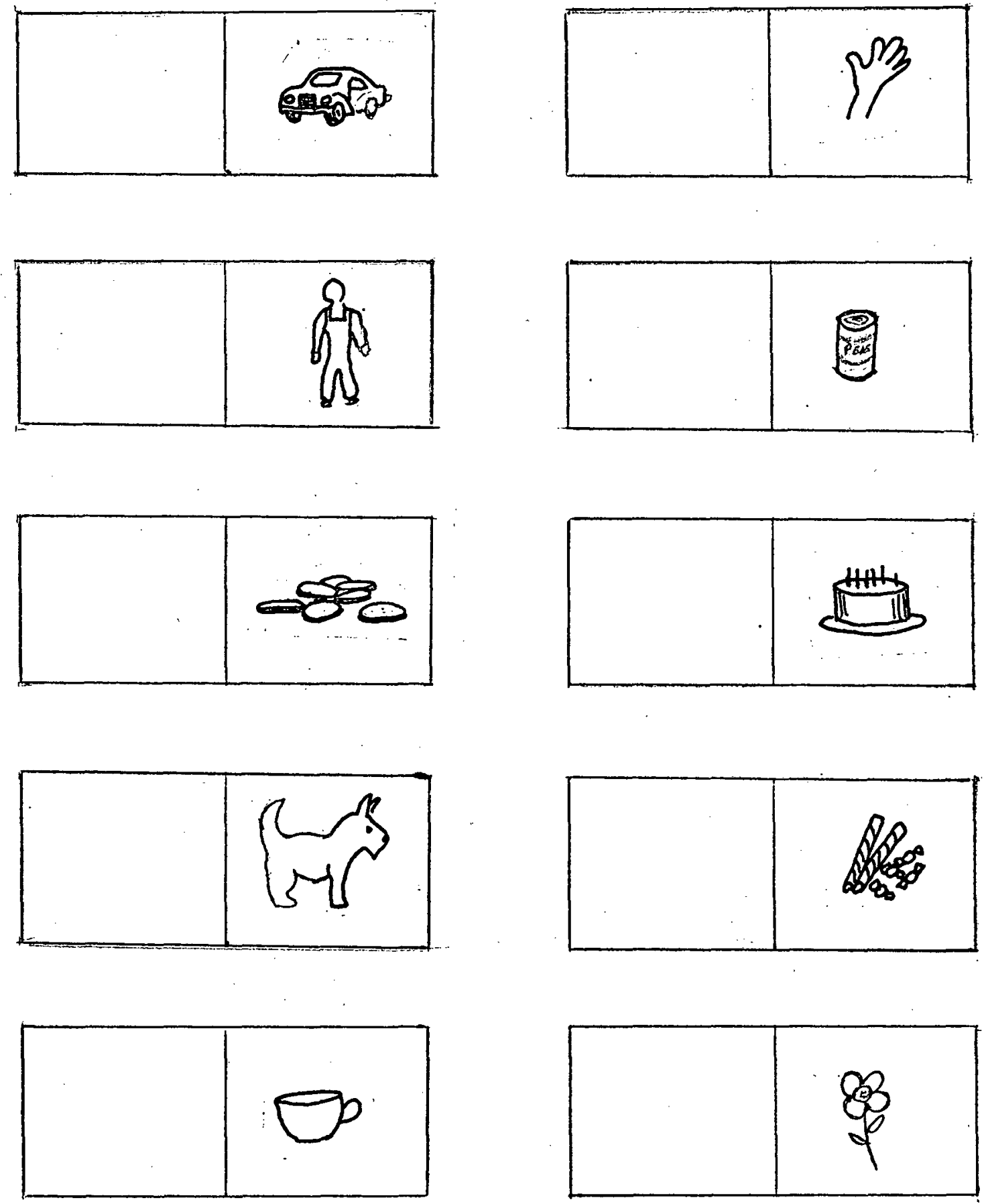


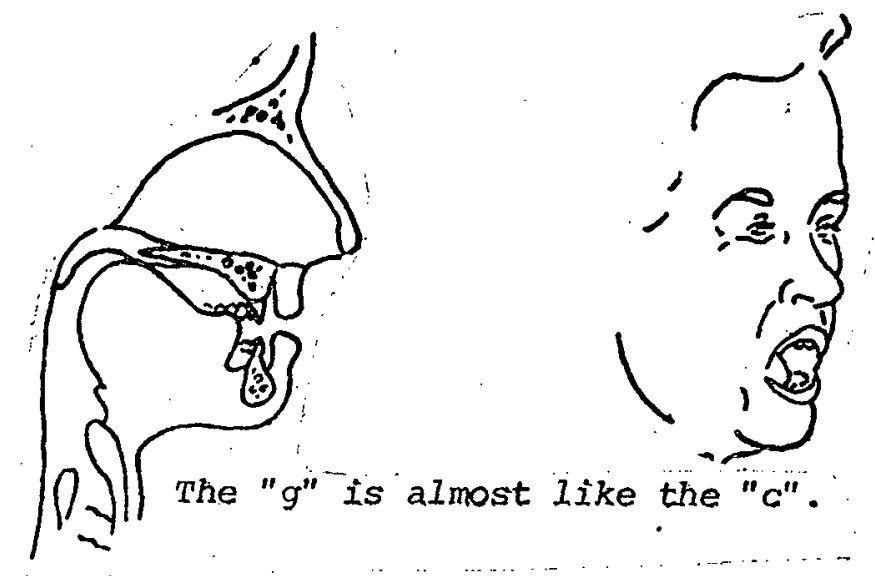

g

gadad Gad gagal gal gagag gag

mamag Mag hagagag hag lagagag

lag tatag tag

gagagag mamagag tatatat gamamam

cagacac hatagat magadad tamagad

ham Mag lad cat dam

hat mad dad mat mam 
Gad

gal

gag

$\mathrm{Mag}$

hag

l ag

tag
$\operatorname{Gg} \theta$

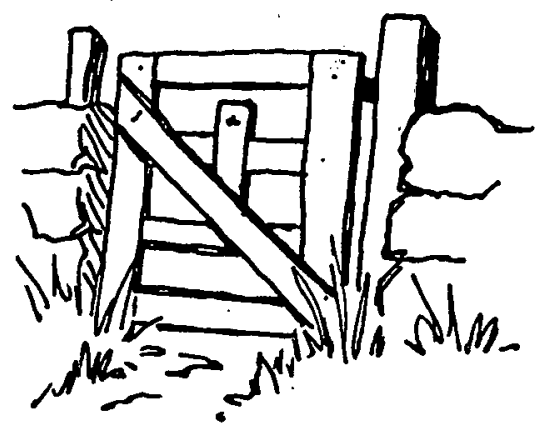

zy
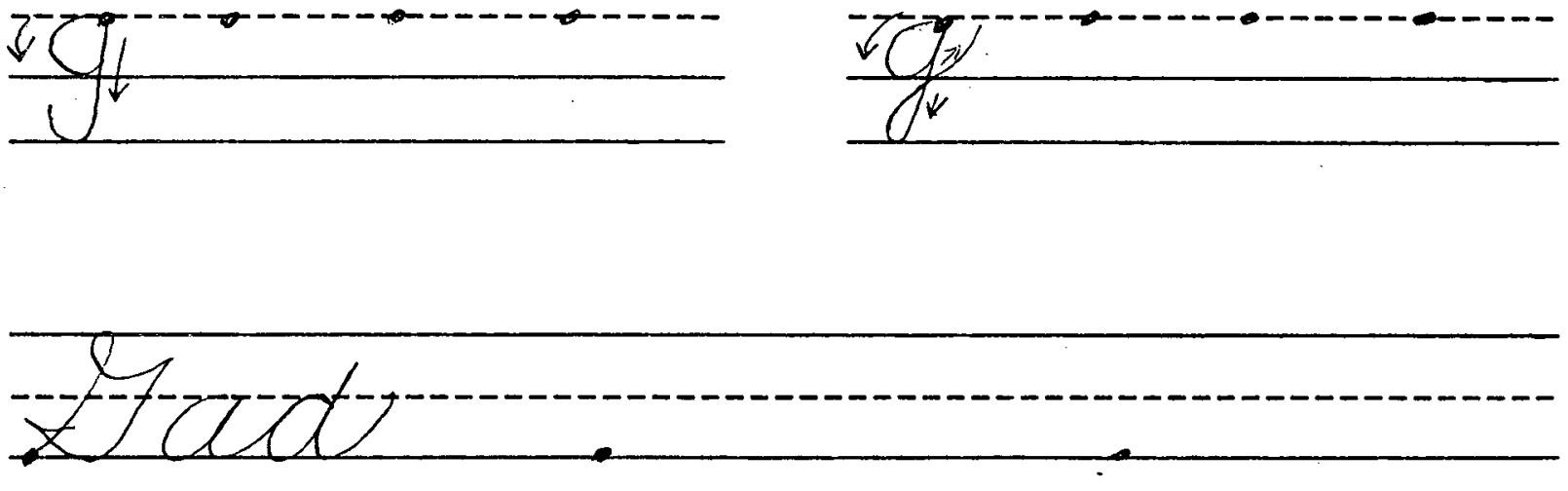

(2)

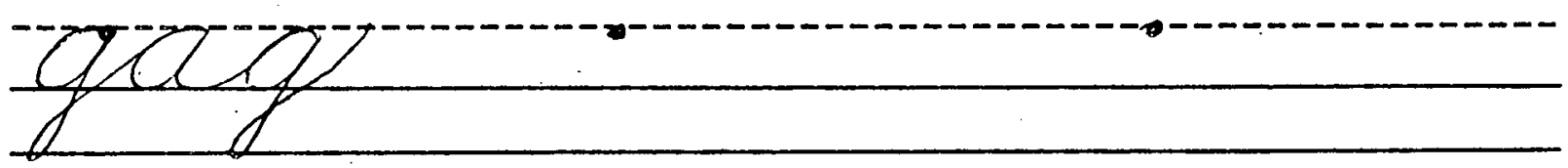


Listen to the sentences your teacher reads. Write down the words you hear with a "g" sound. 


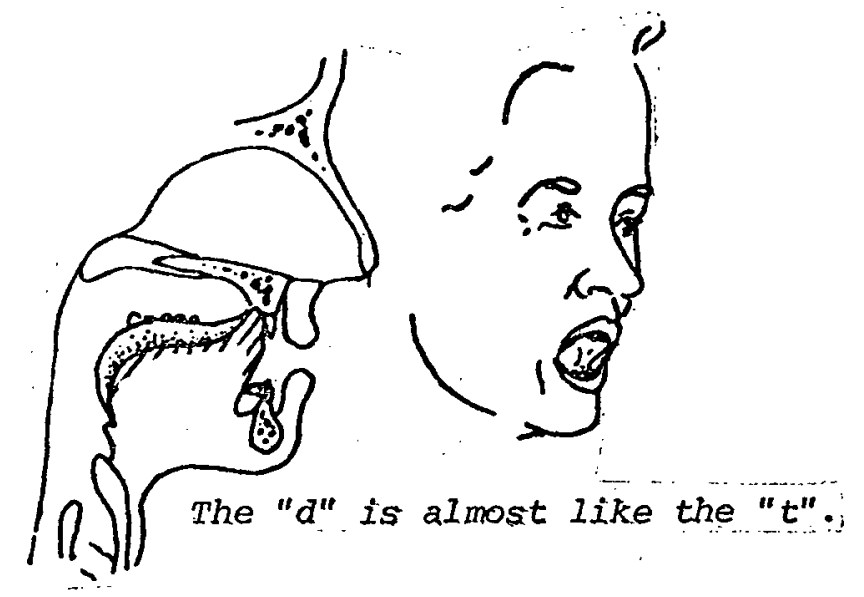

$4 a$

damadam dam dagagag dag dadadad dad gagad Gad mamad mad tadatad

Tad cacad cad hadad had I adad

lad

dadagag mamam latatag cadacad

gagagat hagatag hatamat cadad
Tad
cad
lag hat
mam
tag
cat
lad
had
dam 
dam

dag +

dad

Gad

mad

Tad

cad

had

lad
Dd $\mathscr{D} d$

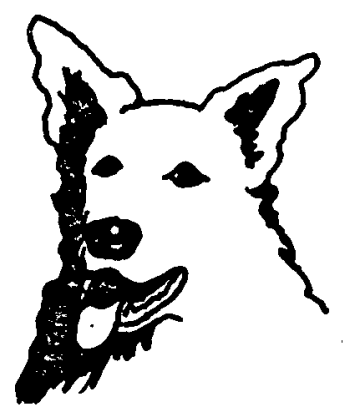

$\rightarrow$

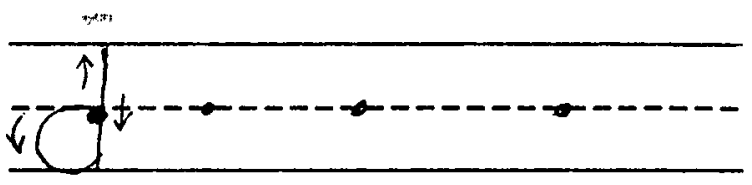

(d)

deartr

$\operatorname{atag} \cdots$

ctats 
tant

monods

Fad

cand

hode.

tact. 
$4 c$

Circle all the "d's" below.

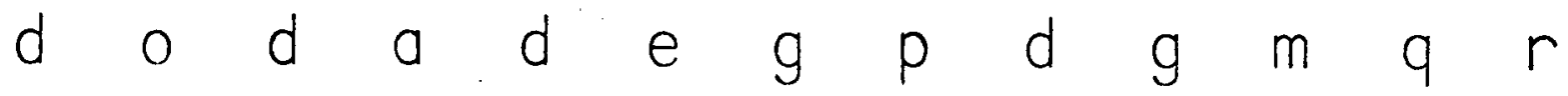

$\begin{array}{lllllllllllll}s & d & a & \dagger & c & d & f & g & g & d & p & q & u\end{array}$

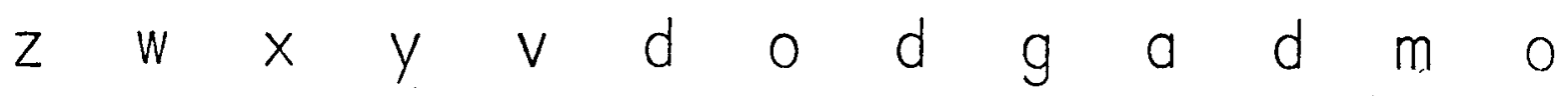

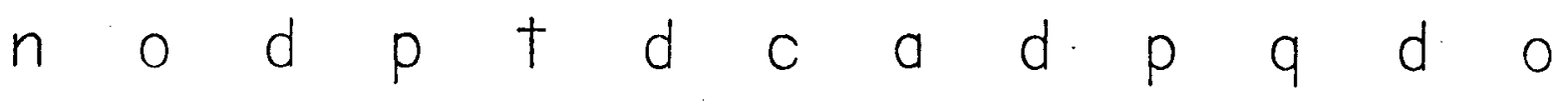

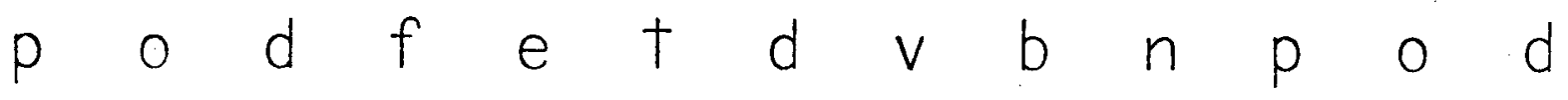

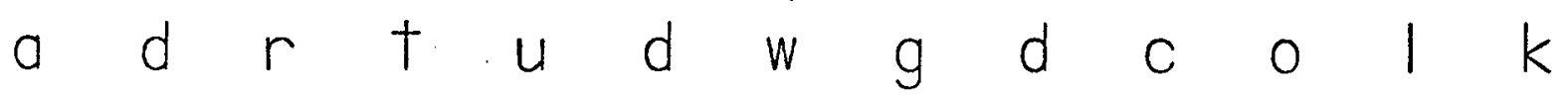

d $s a f \times g d z+y \quad i \quad p d$

d $f \quad g h$ s $d$ e 


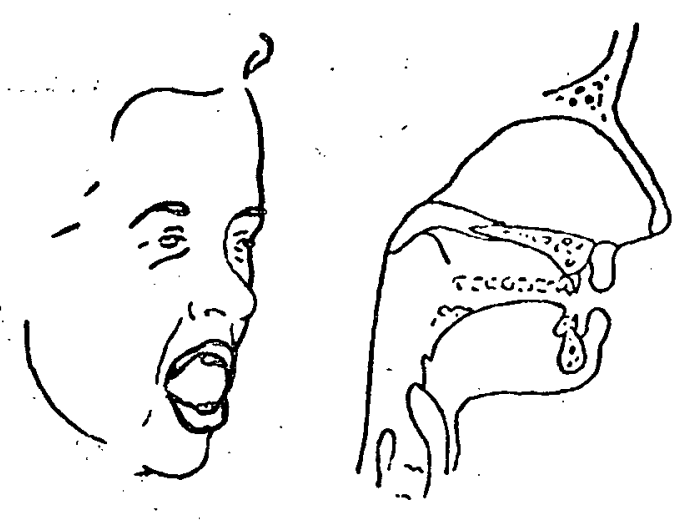

\section{DOD}

godod God todotod Tod cogog cog

hogog hog lologog log momom mom

tomomom Tom gogotot got hotot hot lototot lot

motot dogog codod lodod hodot momomom momod totod gogog cotot

tot mom dot Tod dog hot Tom cot God cog 


$$
5 b *
$$

God

Tod

cog

hog

log

mom

Tom

got

hot

lot
Oo Or

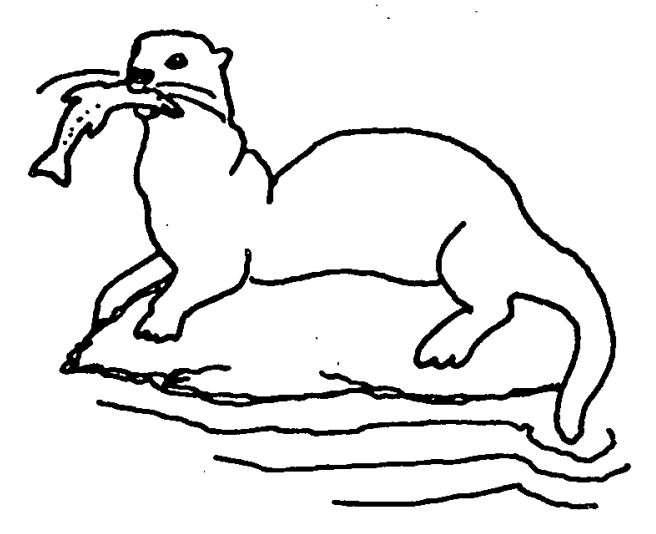

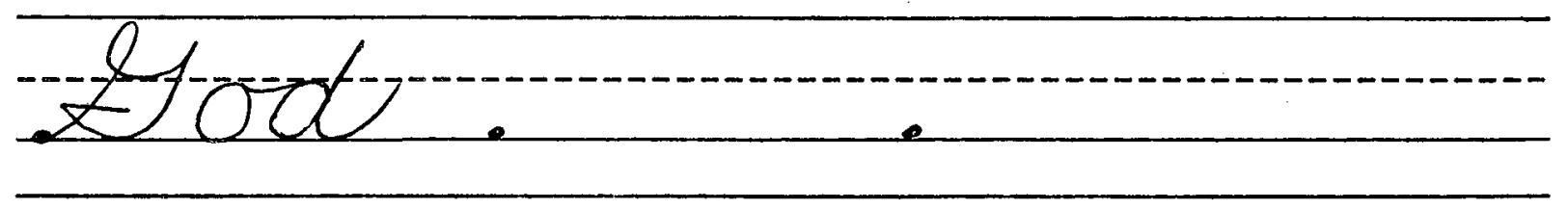

Tod

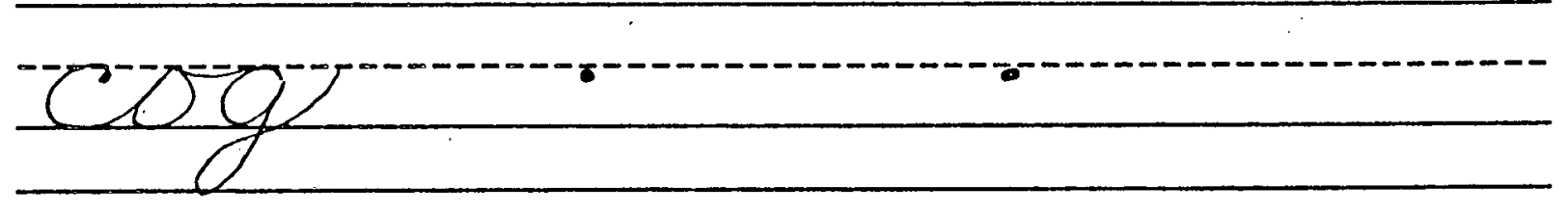




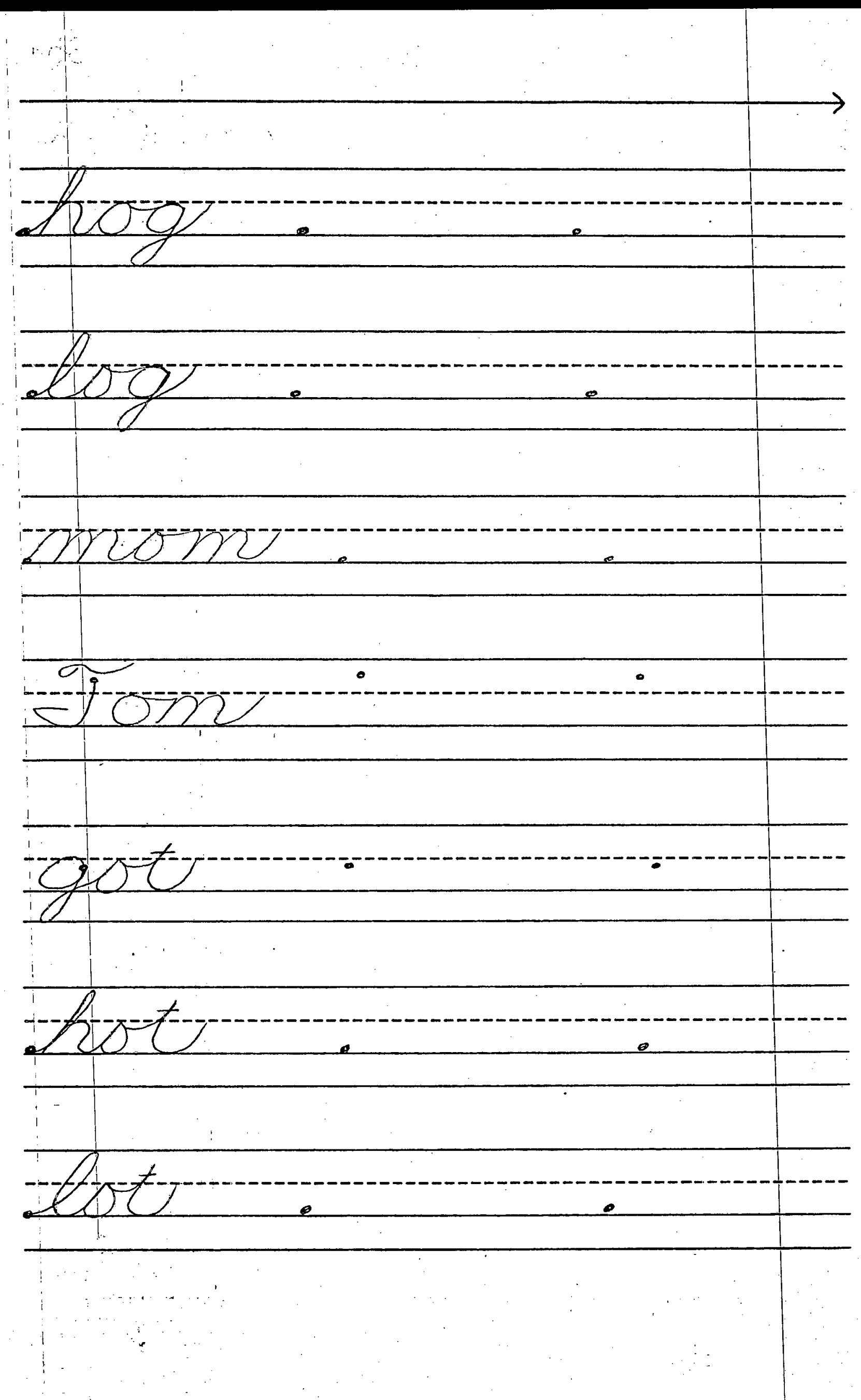


Repeat each phrase the teacher dictates. Then write it below. Read the phrase from printed cards. 
Soft palate
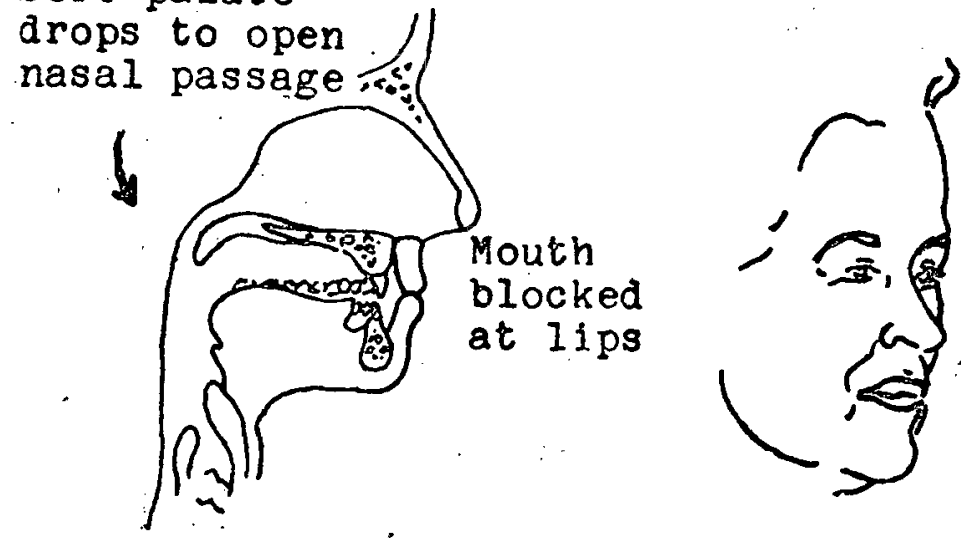

$m$

mamamad mad mamamam mam matatat

mat momomod mod momomom mom

amamam am camacam cam lalamam

lam domodom Dom totomom Tom

omomom madom domod lomomam homat

macac dacotom mototot hamod ladad

tam lot mad hat God

dam dot Gad hot cod 
mad

mam

mat

mod

mom

am

cam +

lam +

Dom

Tom
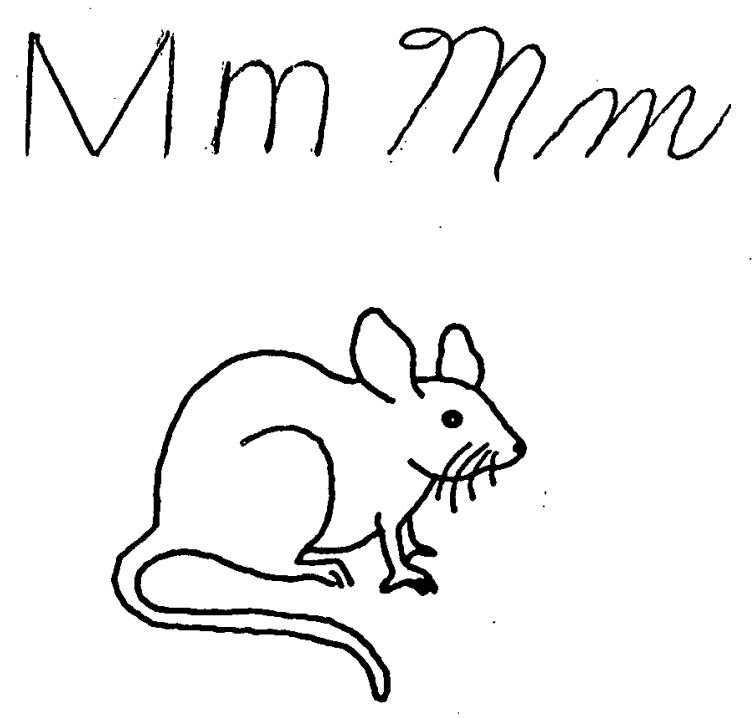

$\sqrt{10} 10$

T⿰冫欠工⿺辶.

"yndad

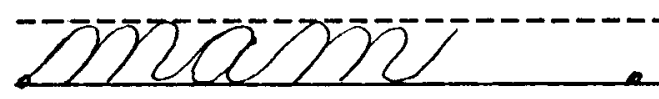

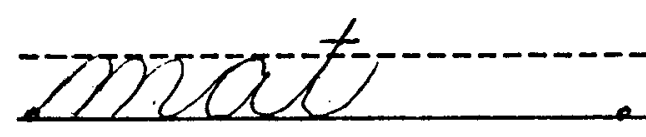


Read and copy these nonsense sentences.

Mot will mog the com.

The lom and mol will hom.

Gom was moc, hol, and gam. 

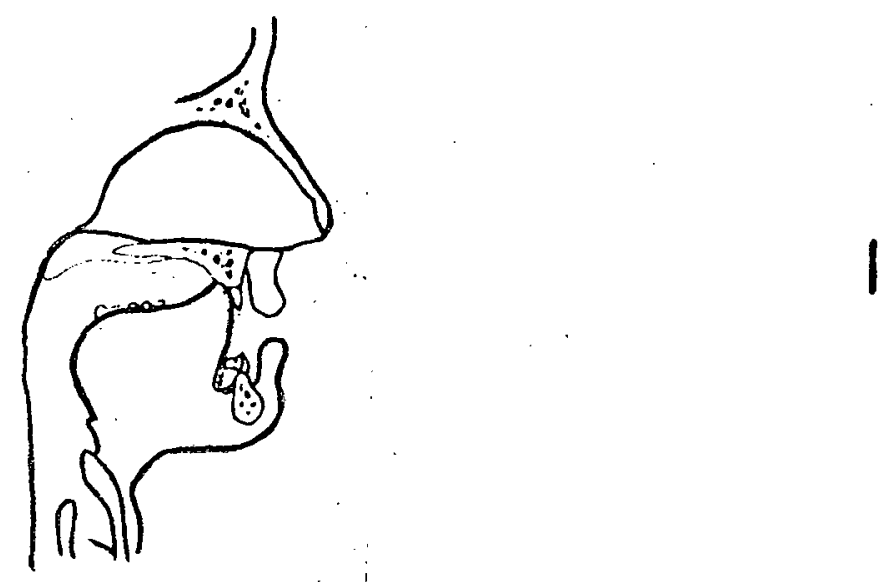

ladad lad lagag lag lamamam lam

logogog log lotot lot Alal Al

cacal Cal gagagal gal halal $\mathrm{Hal}$

daladal locococ molot homol

olototol. gagagal cagadom tamog

dad dot log cam mat

lad got hog ham cat 


$$
7 b^{*}
$$

lad

$\mathrm{lag}$

lam +

$\log$

lot

AI

Cal

gal

$\mathrm{Hal}$
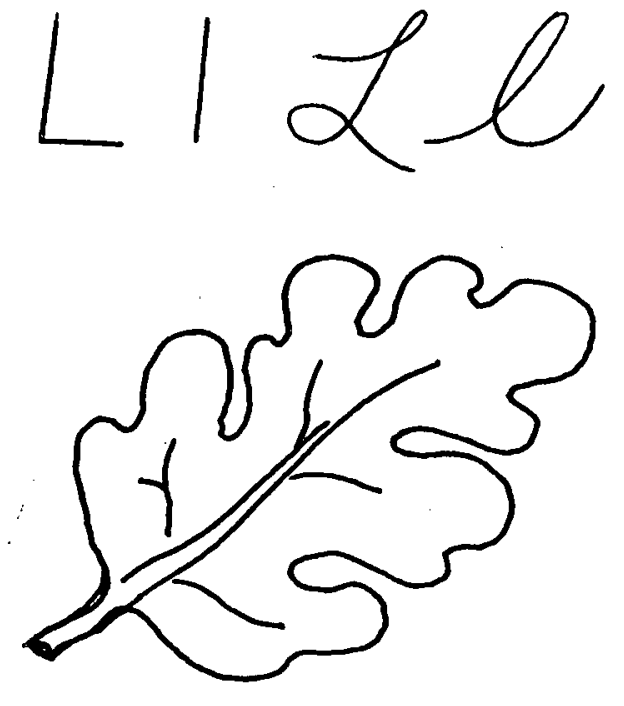
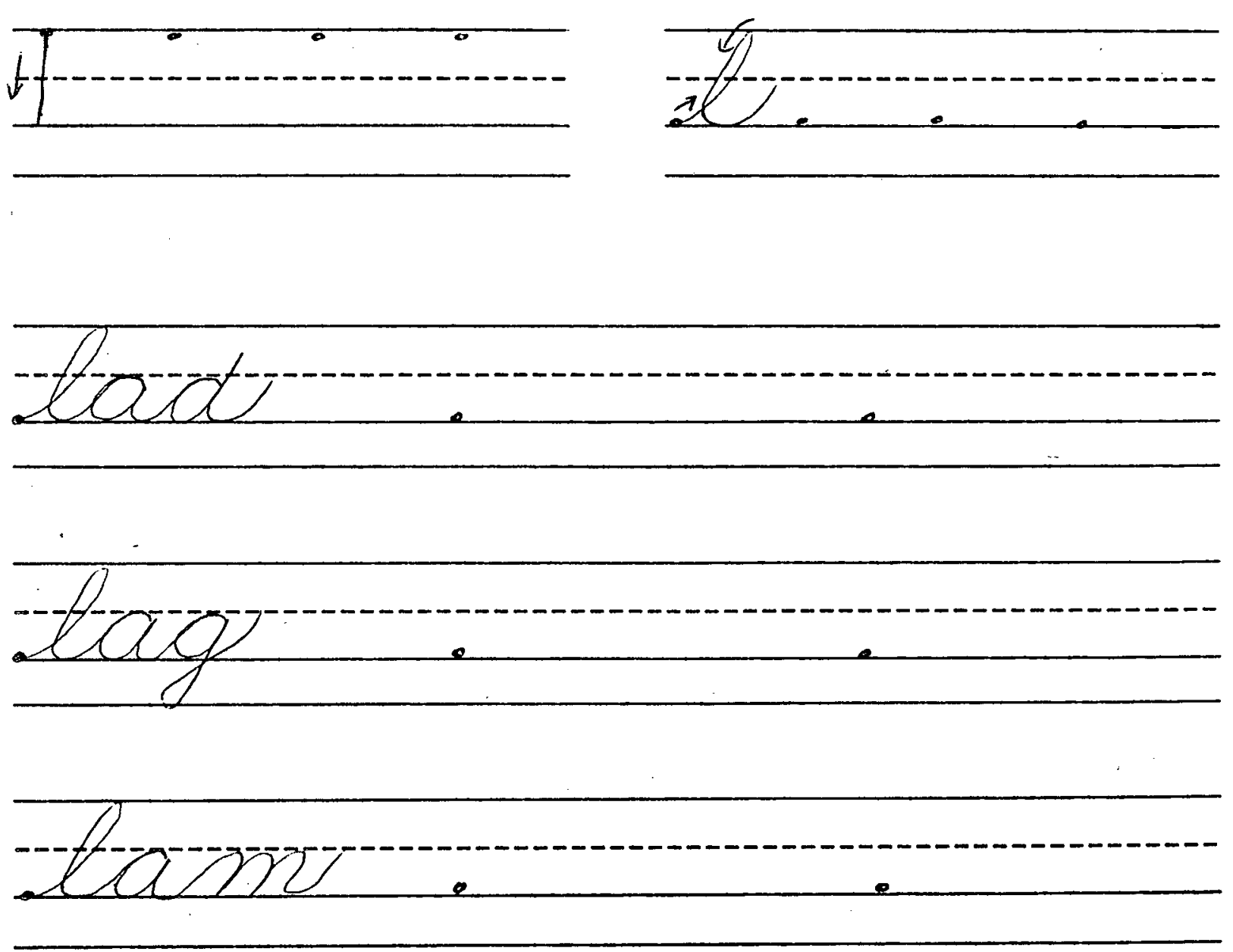


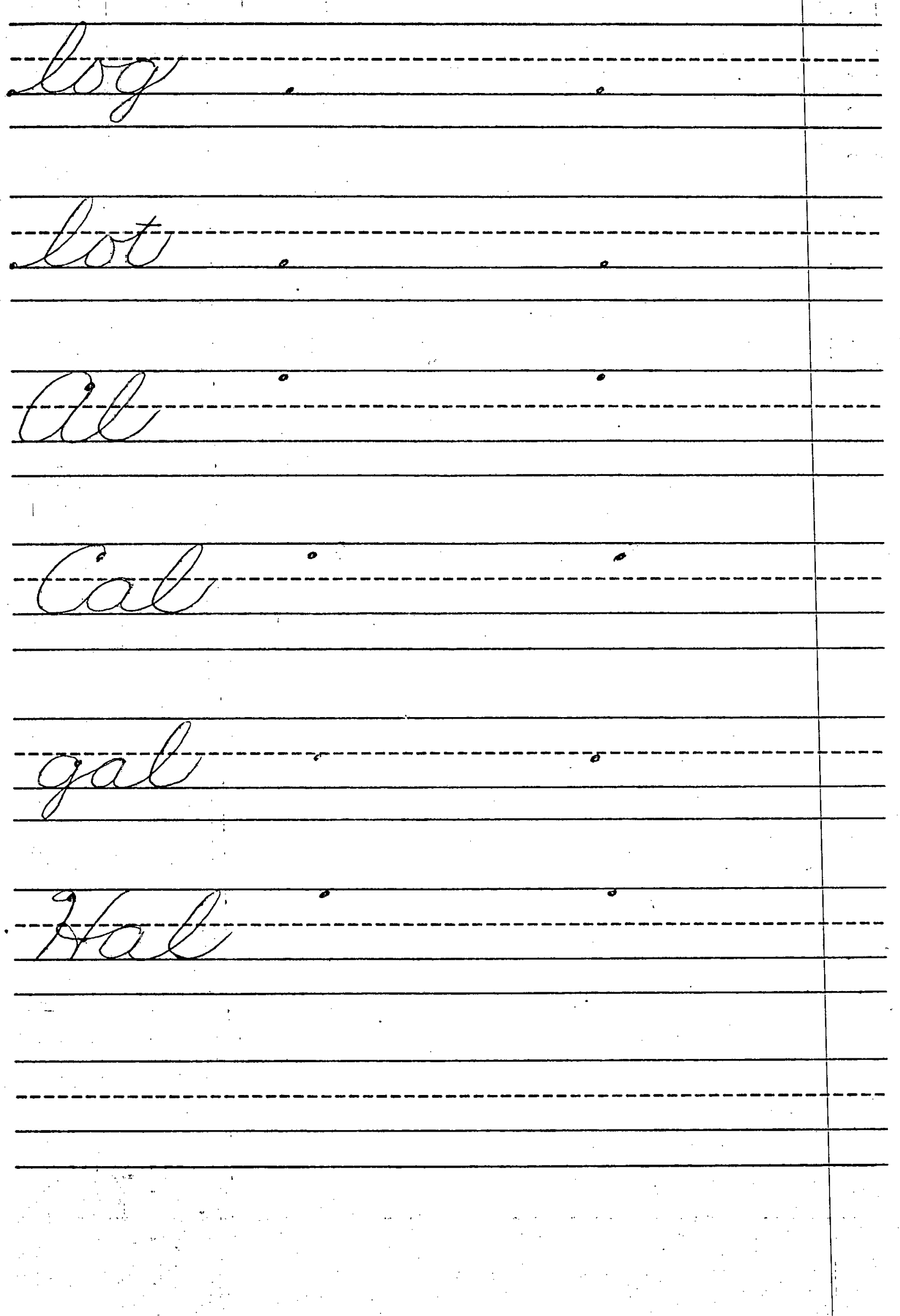


Fill in the blanks with the correct letters.

1. The lo__ $(d, g, m)$ got hot.

2. Dad got mad at the la_ $(\dagger, m, d)$.

3. Al got $\underline{a} 10 \ldots(t, m, d)$.

4. Ca_ $(g, 1, c)$ will $\operatorname{tag} \mathrm{Ha}_{-}(1, d, t)$.

5. Mag got ma_ $(t, d, m)$ at Mac.

6. Mom ha_ $(1, d, t)$ a lo__ $(g, l, h)$.

7. The ca__ $(1, \dagger, h)$ has a ma_. $(\dagger, m, 1)$.

8. Tom is a la__ $(\mathrm{g}, \mathrm{d}, \mathrm{t})$. 

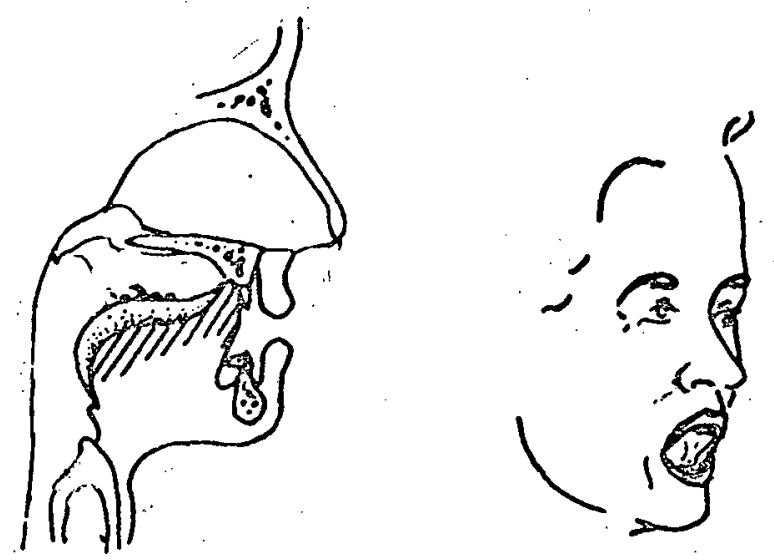

$\dagger$

tadatad Tad tagatag tag tamatam

tam todod Tod togogog tog tatom

Tom tototot tot dodotot dot

gogotot got matamat mat

tamomat gagotom cocot lotomad hatomag totacom hamamam comatad

mom lot hat gag Tod mam log cat tag mod 

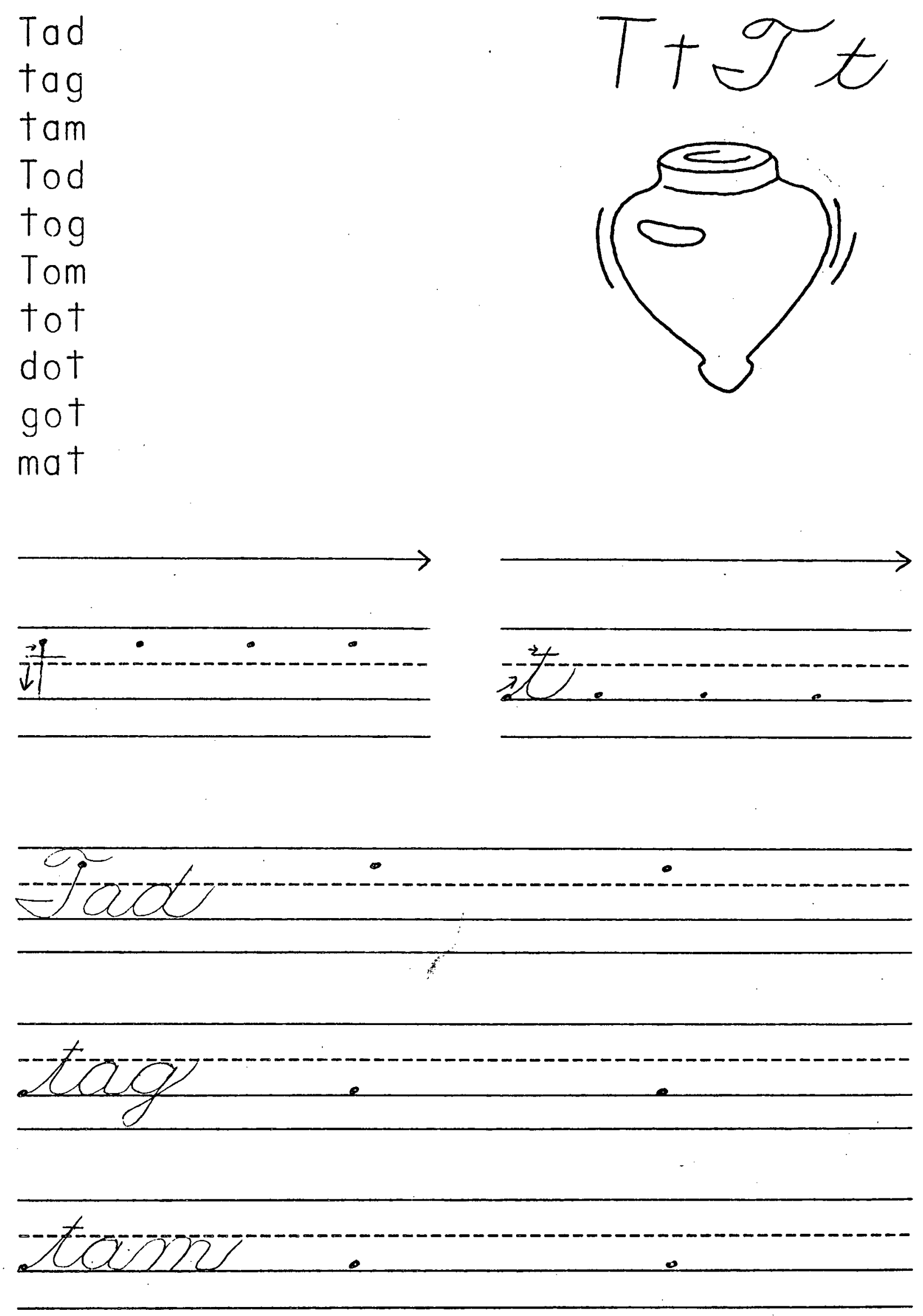
foo

tog

form

tot

dot

got

mat 
Write a new story, using your new words. They are listed below.

Tad

tam.

tog

tot

got

tag

Tod

Tom

dot

mat 
h

hadad had hagag hag halal Hal

hamamam ham hatatat hat hodod hod

hogog hog hototot hot

hacacat homomot hacamat halam

hodom hacodal lototocam matam

tam Tom gal dot God

ham mom Cal cot cod 
had

hag

$\mathrm{Hal}$

ham

hat

hod +

hog

hot

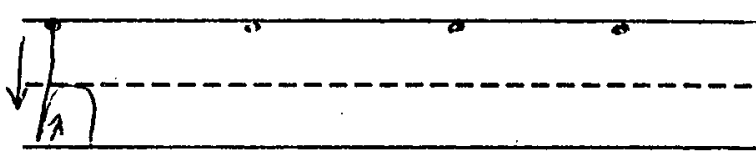

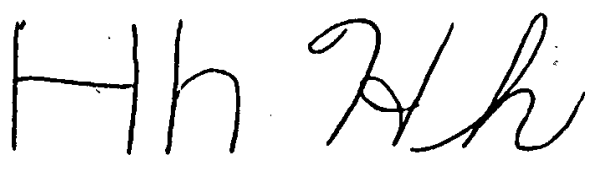

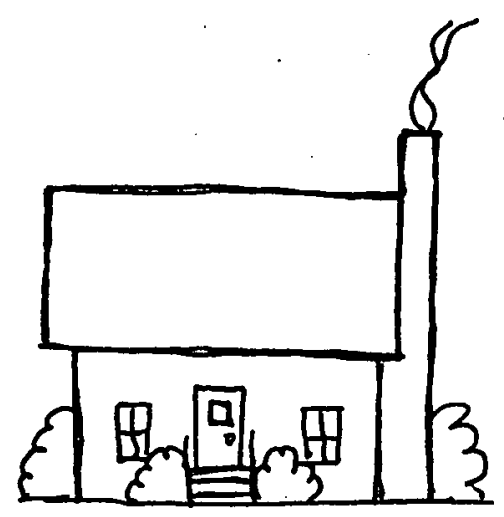

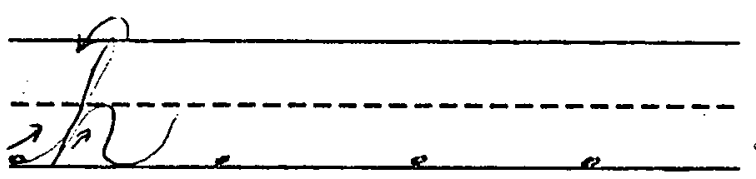
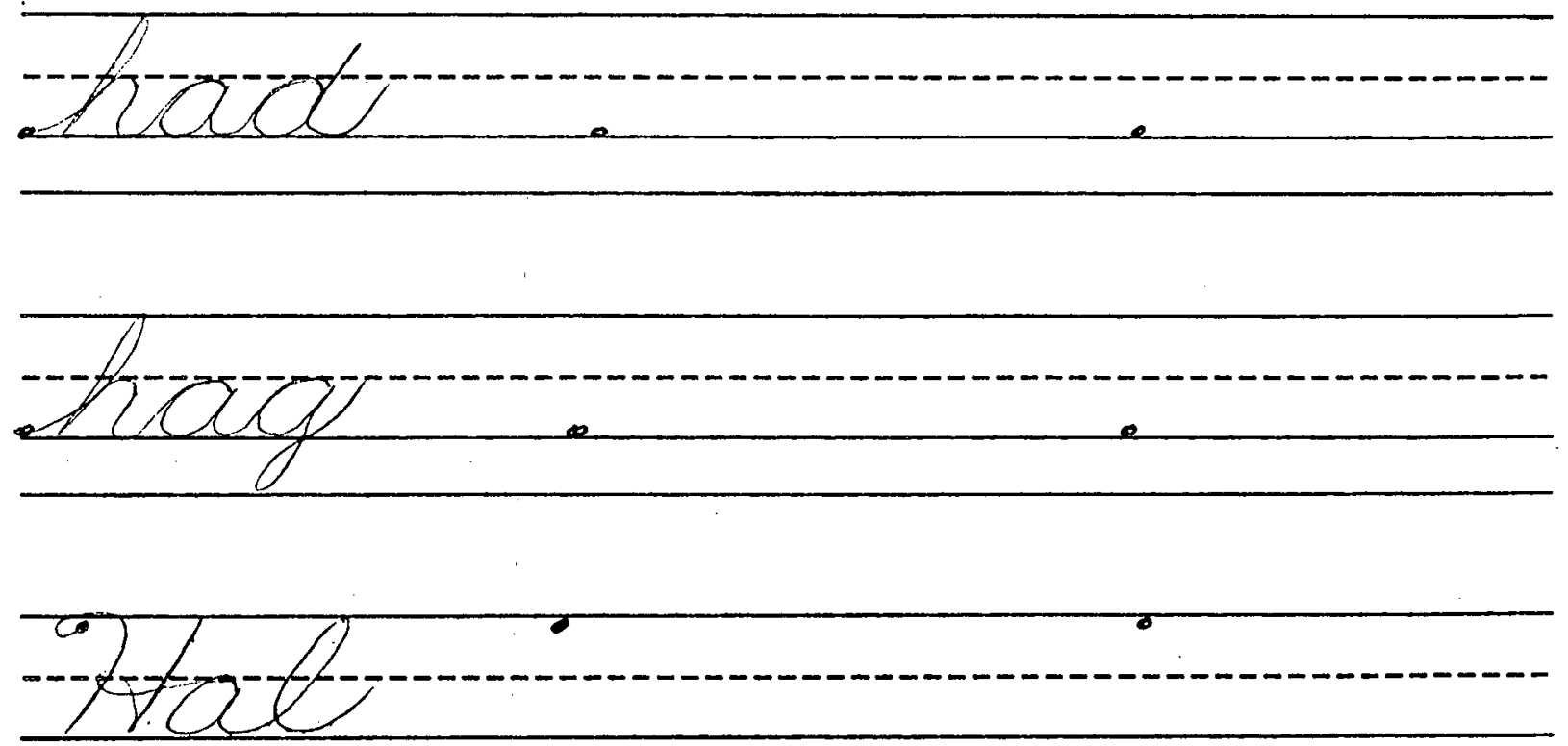


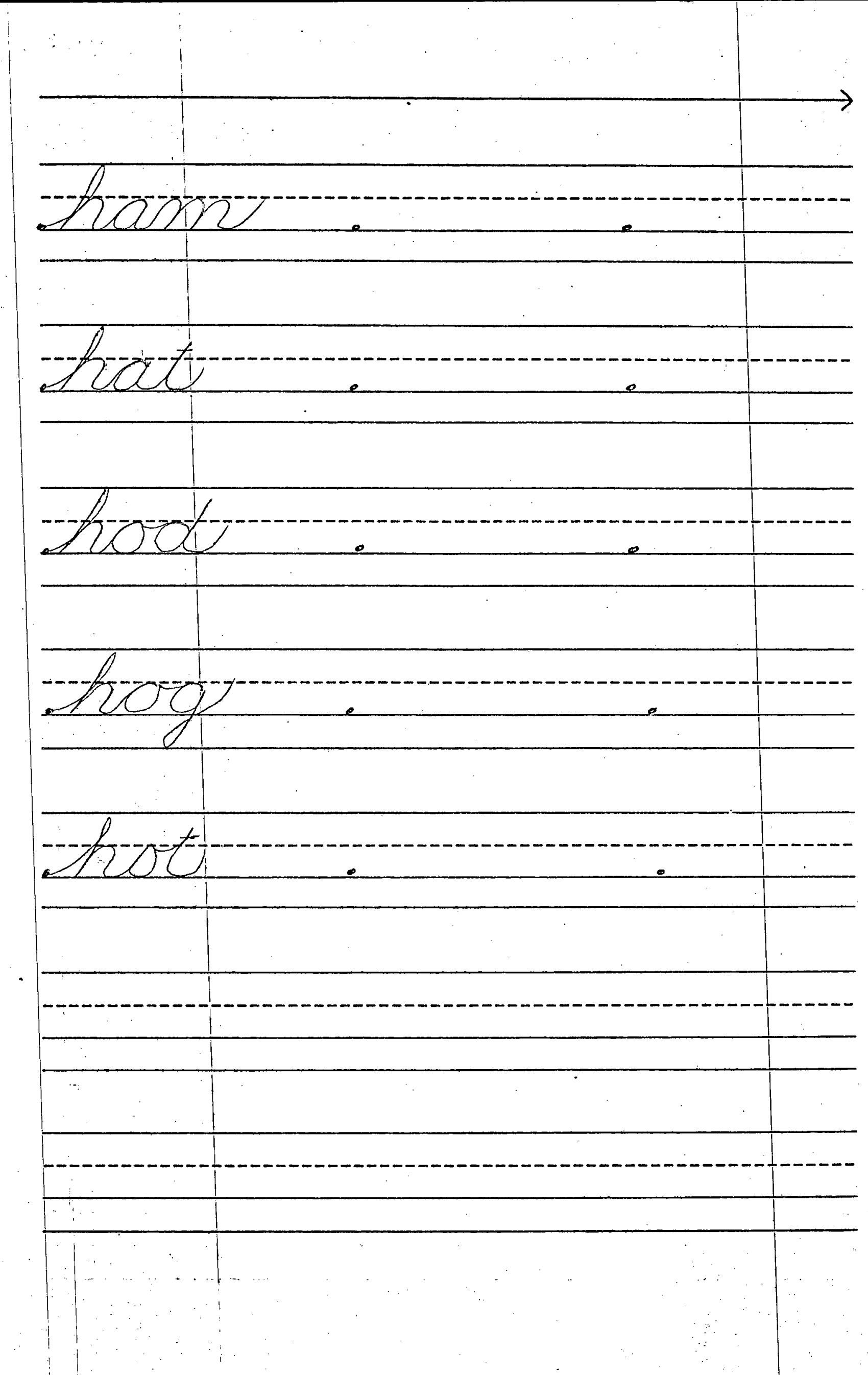


Tell a story, using as many " $h$ " words as you can. You may use this space to illustrate your story. 


\section{Review}

Write the missing beginning, middle, and ending sounds on the correct blanks below each picture. The first one is done for you.

(6)

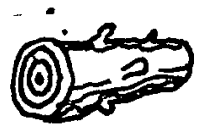

h $a+$

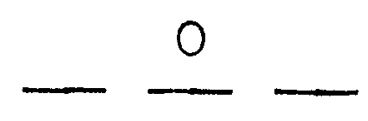

(959
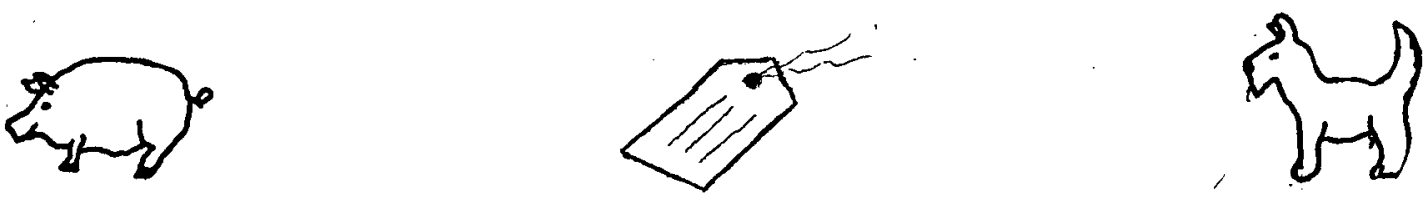

h
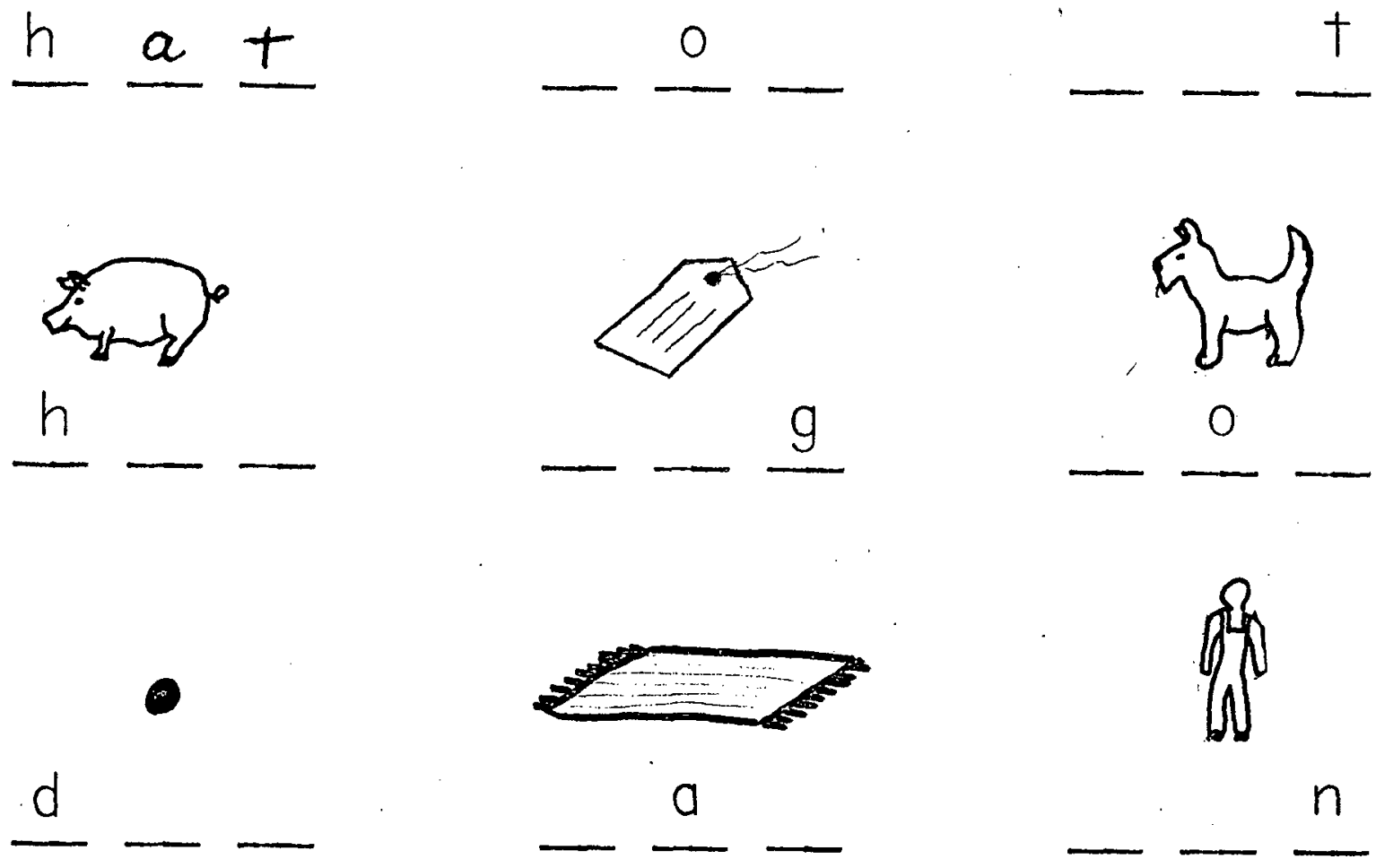

Read these words.

Tom am log mad mat lad lot Hal tam mom Tad lag dot hot 

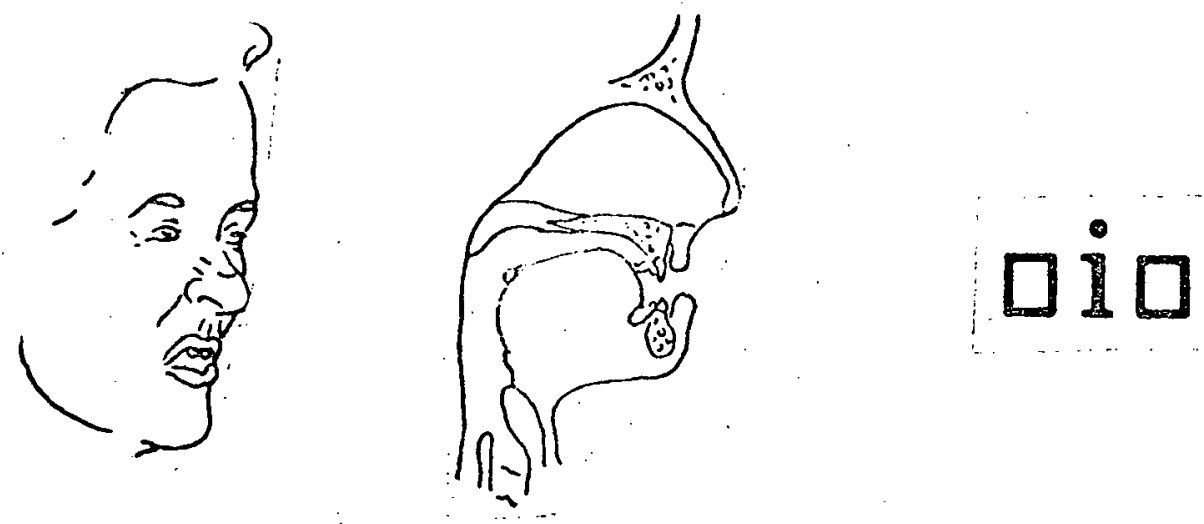

dididid did hidid hid lididid

lid mimid mid dididig dig didim

dim himim him i†i†i† i† hitit

hit mimit mi†

itimit diditim hitimim liditil

midimim ditig lididid tidimit
lid
lit
dim
$\operatorname{mid}$
$\operatorname{Tim}$
did
hit
dig
hid
dim 

did
hid
lid
mid
dig
dim
him
it
hit
mit

Ii di

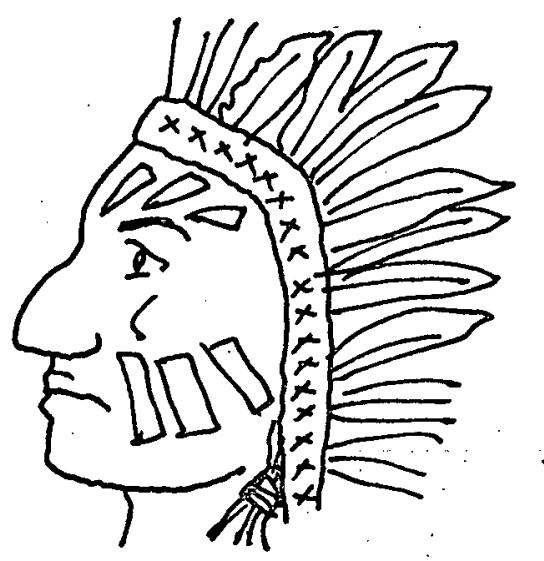

i

atict
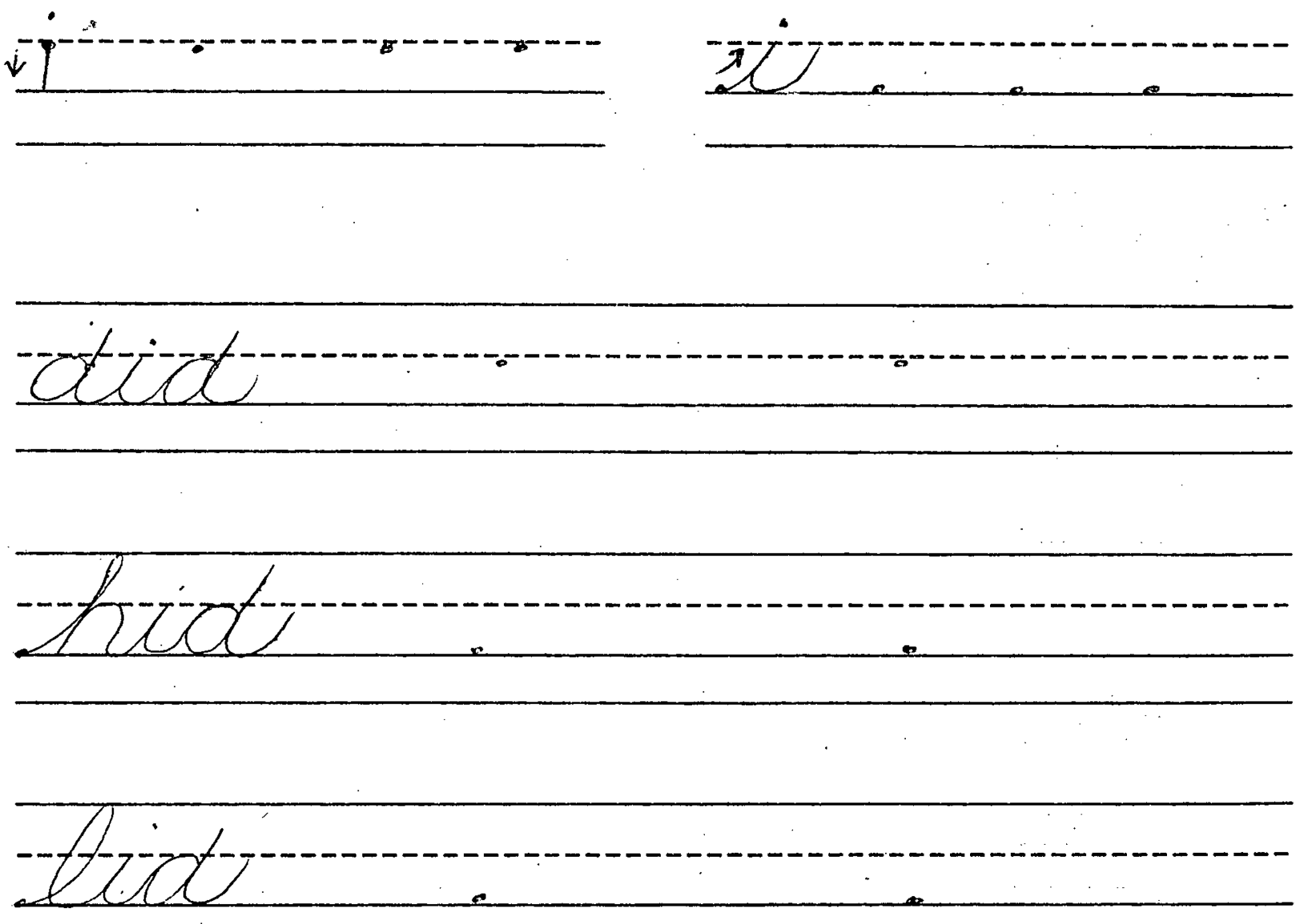

Read the story below, using pointer control.: Remember to stay with the pointer. Reread the story at normal speed.

The lad hid a lid at the dam. Tim had to dig a lot for it. Dad got him a dog to dig for him. A lad hit the dog. Tim was mad.

Draw a picture of what happened in the story: 
jagag jag jamam jam jigig jig

jimimim Jim jogog jog jotot

jo†

jitog jatim jocat jomomom jitit damamom jimadad catamal hicom mom hit log got dog mam mit lag jot cog 
$12 b *$

jag

jam

jig

$\mathrm{Jim}$

jog

jot
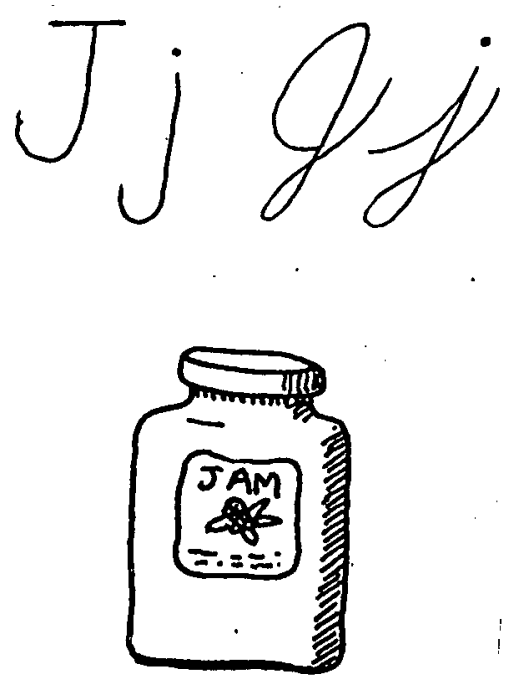

$\longrightarrow$
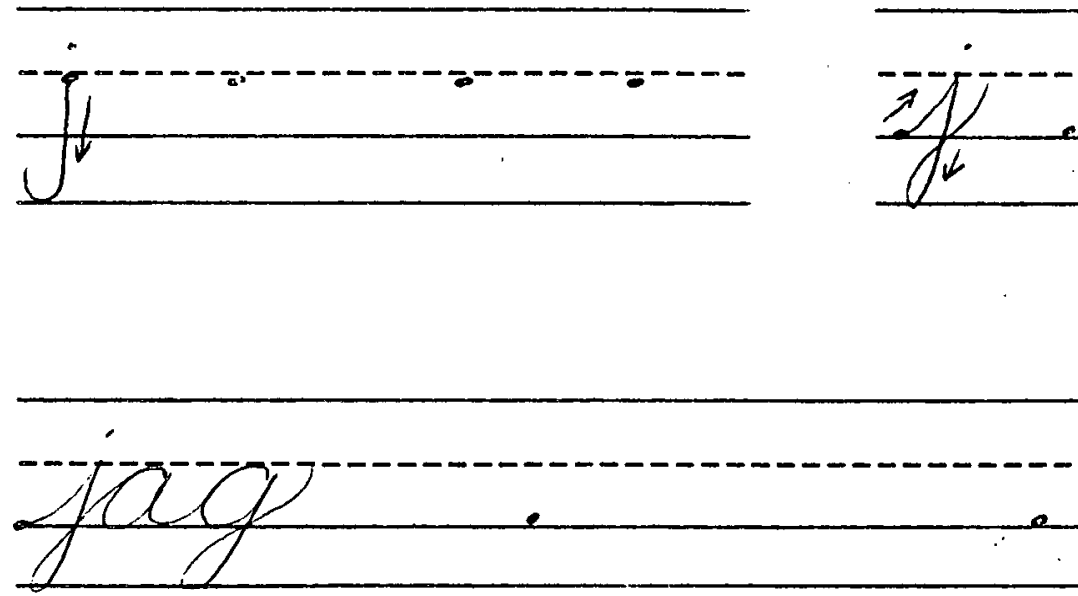

Janne-

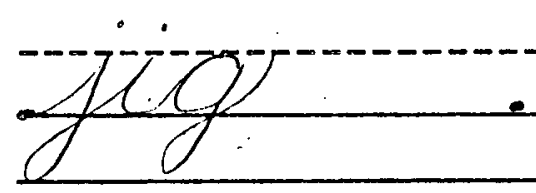




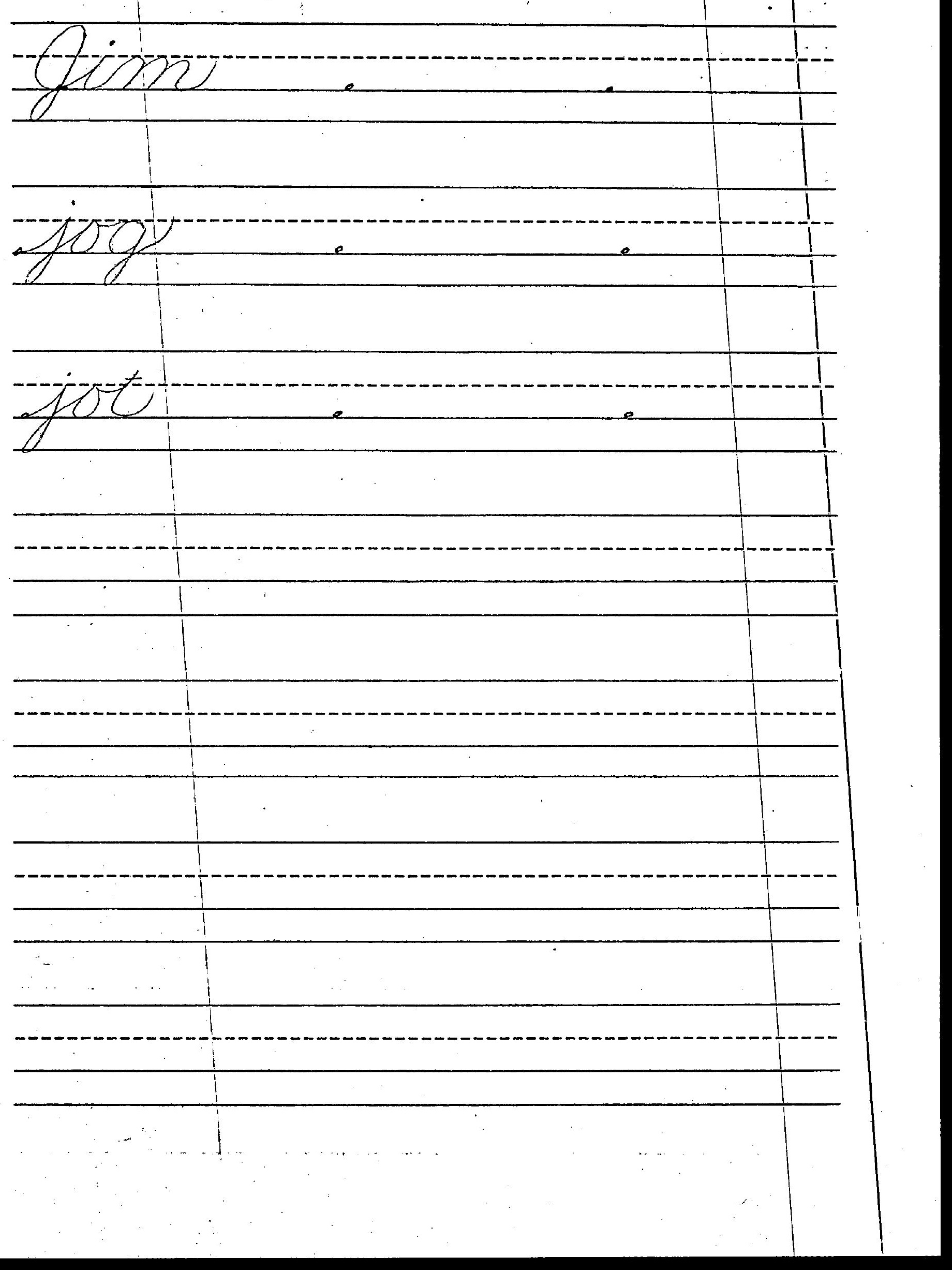


Draw a line from the sentence or phrase to the correct picture.

A lot of jam

Jim did jog.

Tom will jot.

$=\frac{9}{2}$

里

Al did jig.

Jim and the jam

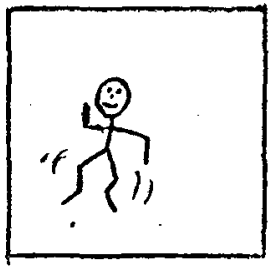

圆果

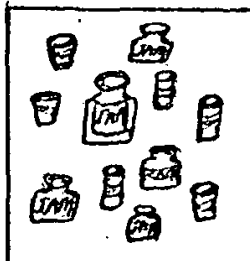


$13 a$
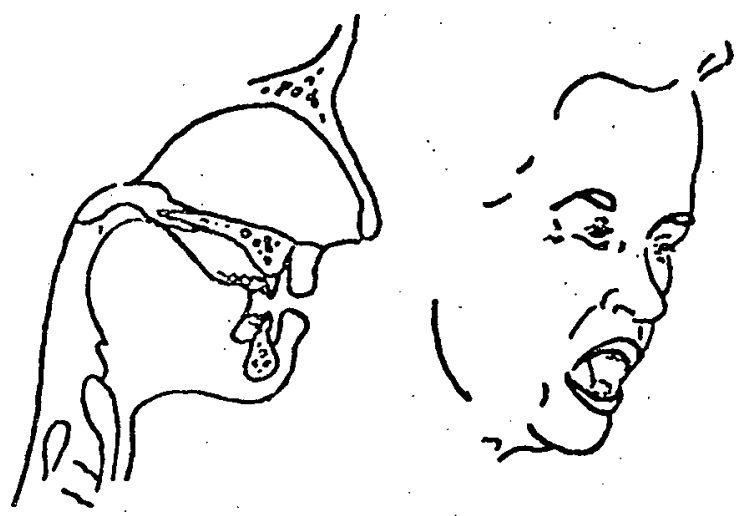

k

kikidid kit kimimim kim kitikit.

$\mathrm{ki} \dagger$

kikot kamat kotam kakat kodot

kocacom catacat komocad midacot

tag cot cat Gad mid

lag got mat God lid 
$13 b *$

kid

$\mathrm{Kim}$

$K K$

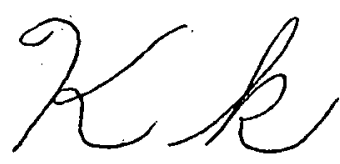

$\mathrm{kit}$
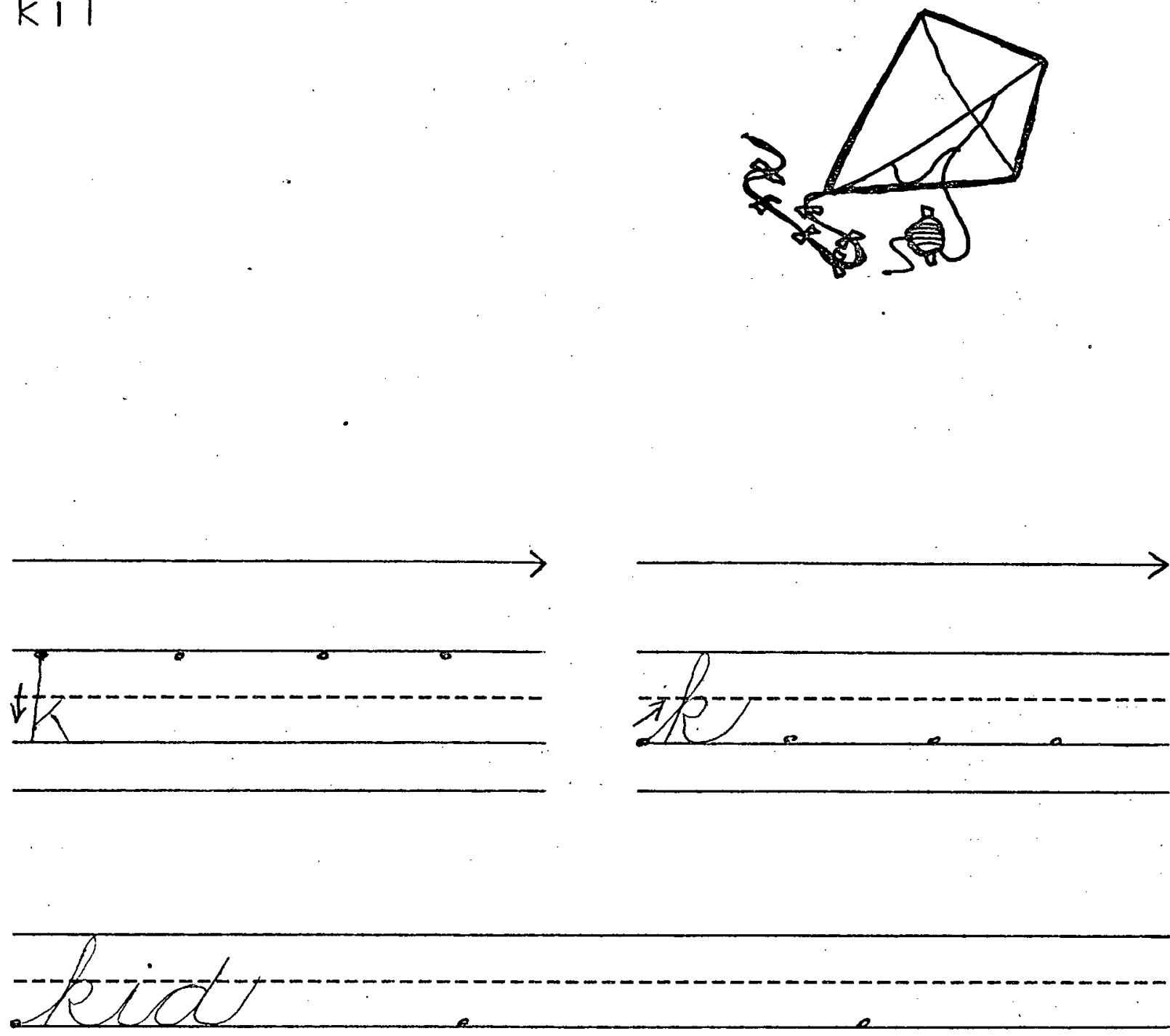

(6)

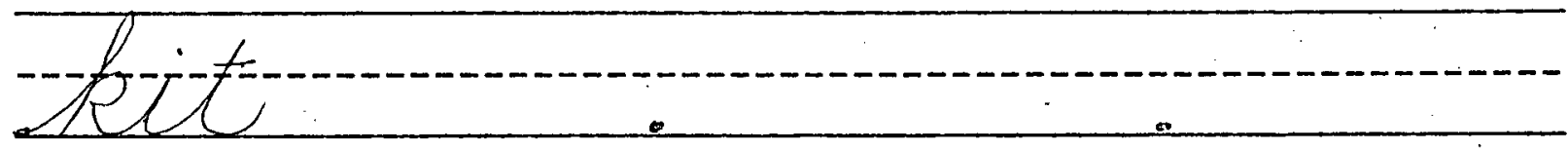



We now have two letters for the $(k)$ sound. What other letter has this sound? Some words begin with "c" and others begin with " $k$."

Draw a line through the three pictures in a row that begin with "k."
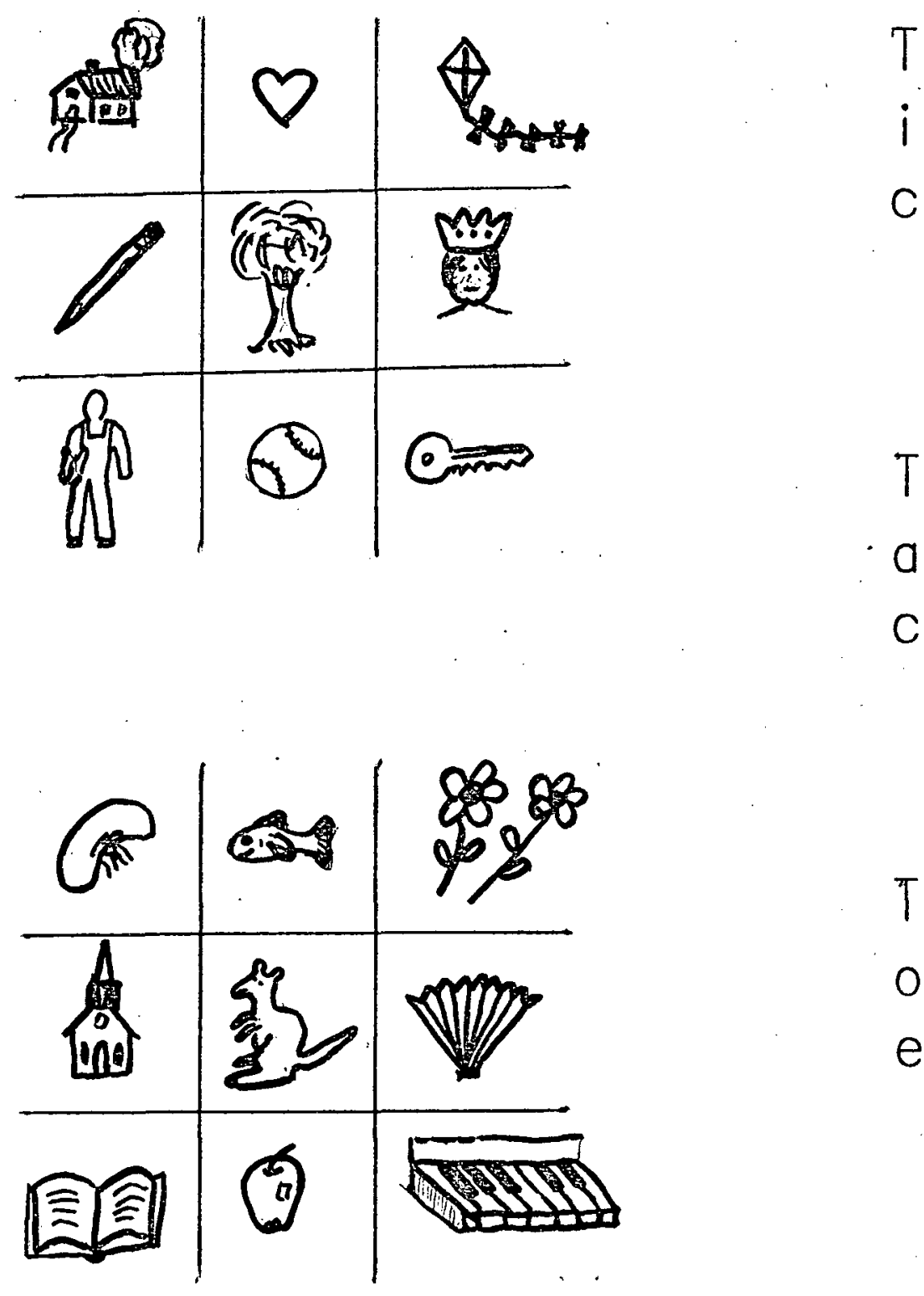

$T$
0
$e$ 
$14 a$

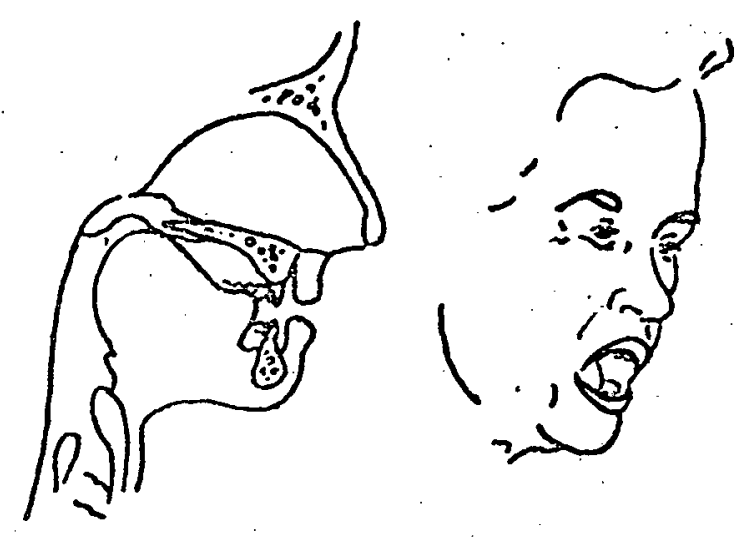

ck

hacack hack jacack Jack lacack lack tatatack tack dodock dock locock lock momock mock didick Dick likick lick titick tick jotock kotock hatack litick lamack hadack mimitim kidick

jot tick-tock mad hack dog dot Mick Tad Mack jog 
hack

Jack

lack

tack

dock

lock

mock

Dick

lick

tick
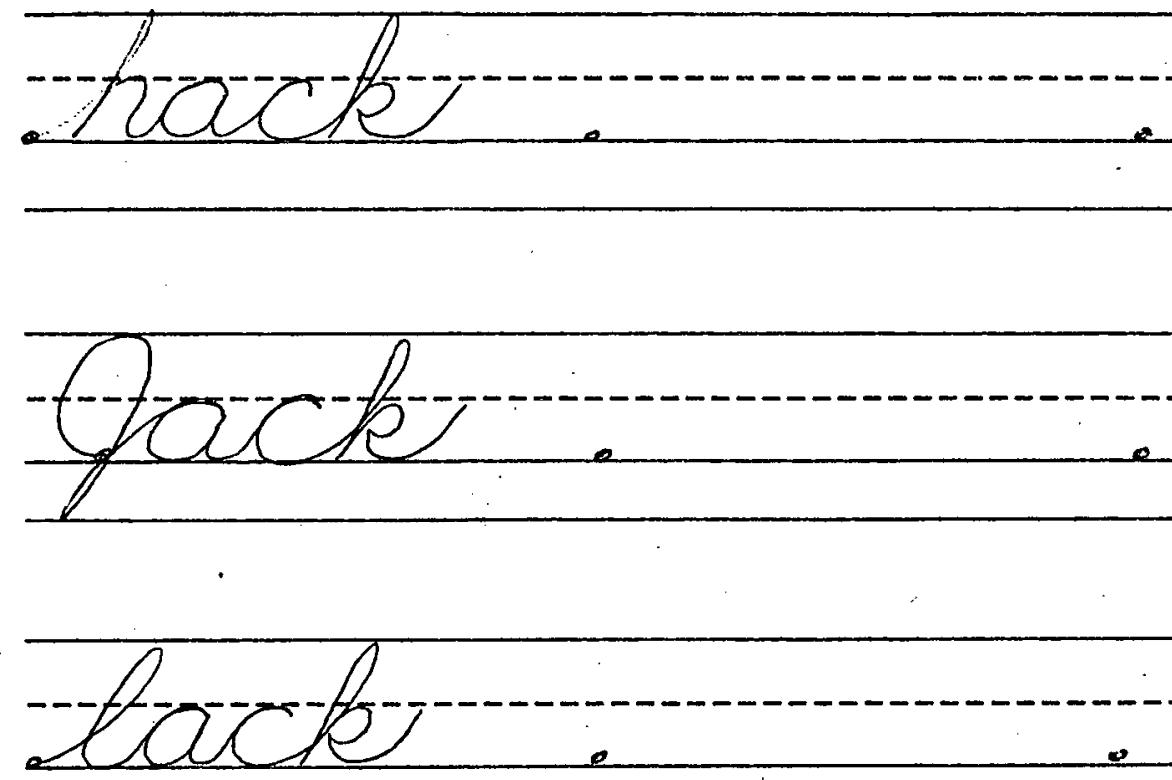

tache 
atoct

tock

mock

Fice

tick

tick. 
Complete each sentence, using all the words in the nearest box.

Jack will

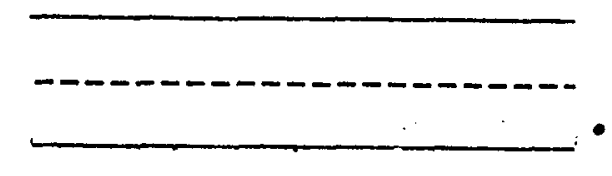

a
tack
lack

$\operatorname{Jim} \underline{w i} \mid 1$
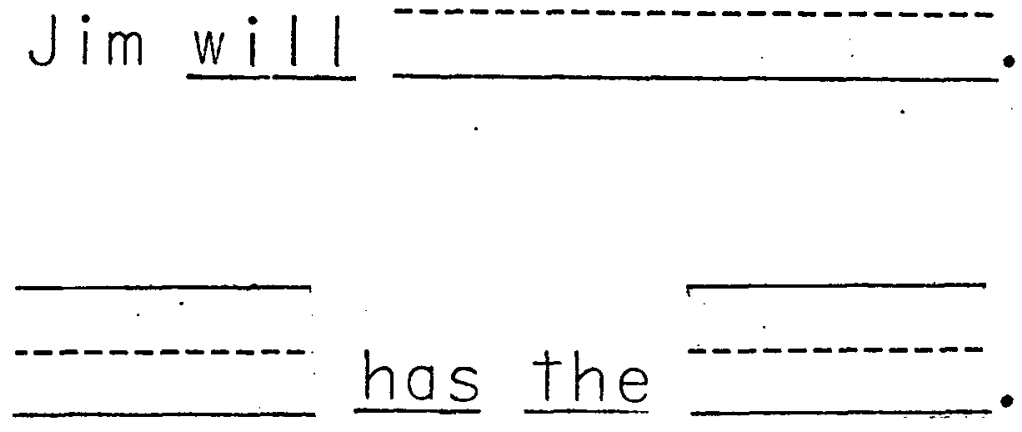

Dick lock

it
l ick .

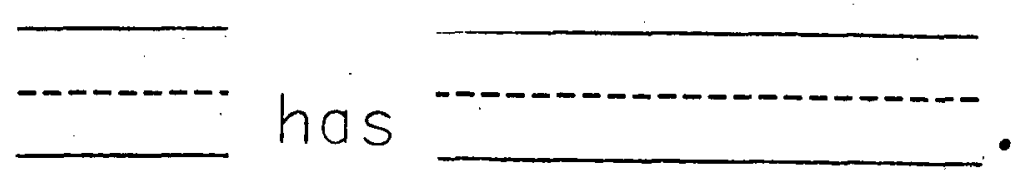

\begin{tabular}{|l|}
\hline dog \\
a Jack
\end{tabular}

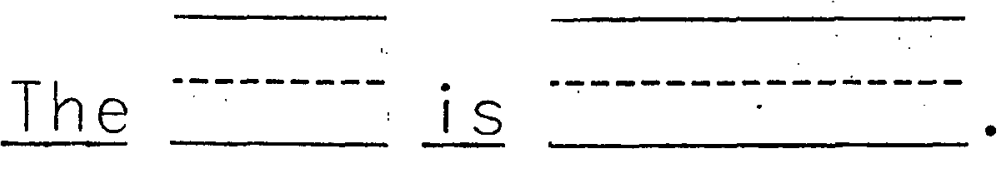

jam
hot



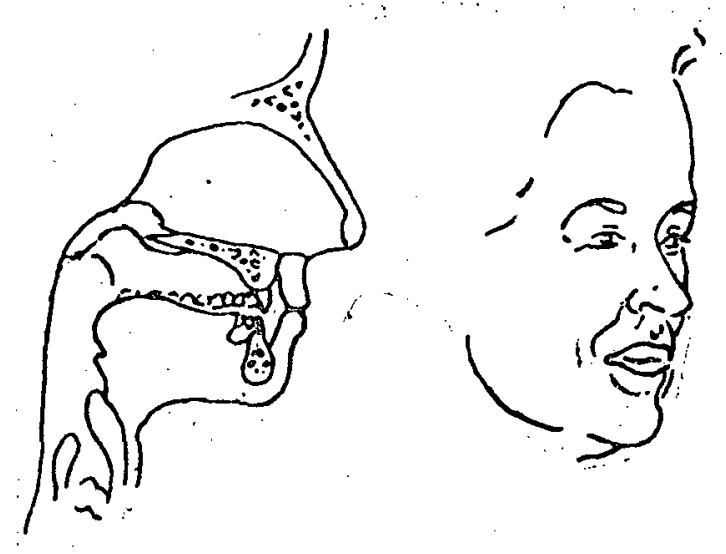

p

papadad pad papal pal pamamam

Pam patapat pat pigopig pig

popod pod pomopom pom-pom hipip

hip totop top mopomop mop

tapock mipit jopock hamap potop

popopop jicack gatamap himimick

pack mat him pot dock hack Mack Tim lot mock 
$15 b *$

pad

Pam

pig

pom-pom

hip

top

Pp Pp<smiles>C=C=C</smiles>

is

port

port

7 arno 
fort

torig

froot

$600 m=0002 \pi$.

zixp

moofs

top 
Underline the best word choice for each sentence.

1. The cat will (hop, Pam, lad).

2. Tom is a (pad, pod, pal).

3. Jimwill (hip, hop, pod).

4. The (top, mop, pad) of the pot is

5. Did Pam (pot, top, pat) the pig?

6. The pod is (hot, pal, pat).

7. Jack has a (him, cap, had).

8. The (pig, pat, pod) is mad.

9. Mom will pick the (mad, lock, Dick).

10. The (pal, Sal, had) will (hack, Pam, 
ch

chocock chock chopop chop chapap

chap chatat chat chikick chick

chipip chip chit-chat chitit chit

chamit chodop dotick mamock

chidick jamop patapam hicack

Jim chick Cal hop did dim Mick pal chop mid 


chock
chop
chop
chat
chick
chic
chitchat
chit + + ch

Chock

chop

chaps

chat 



\section{$16 \mathrm{c}$}

Add ch to the incomplete words. Then say the words and sentences.

1. Jack had a _at.

2. _op the log.

3. The _ap has a cap.

4. Pam will _it__at.

5. Jim has a _ick.

6. The _ick is mad.

7. Mick has a _ip.

8. The gal has a _it.

9. Dad will kick the _ap.

10. Al will _at. 


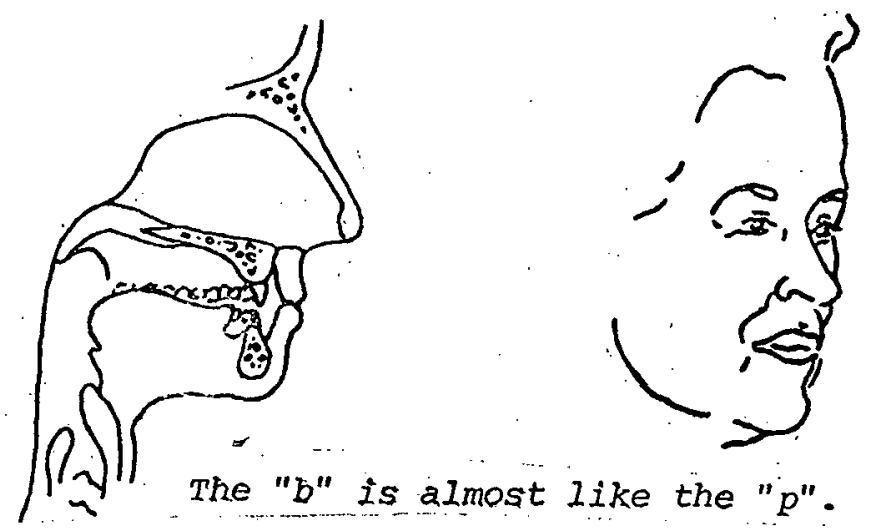

$b$

bababack back bagag bag bibibib.

bib bitibit bit bobobob Bob

bobog bog jabab jab tatab tab

cococob cob jobob job

bocock bomob mobom pobob tibab

pabib bababab mobobom timimab

did mat lag cock bib

hid chat gag mock Bob 
$17 b *$

back

bag

bib

bi †

Bob

bog

jab

tab

cob

job
$B b B b$

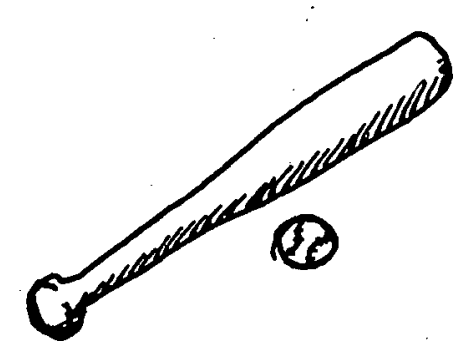

I

tract e

tag

tie 
18

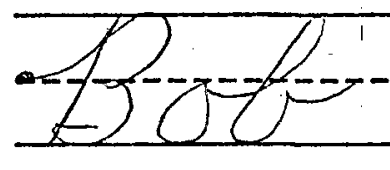

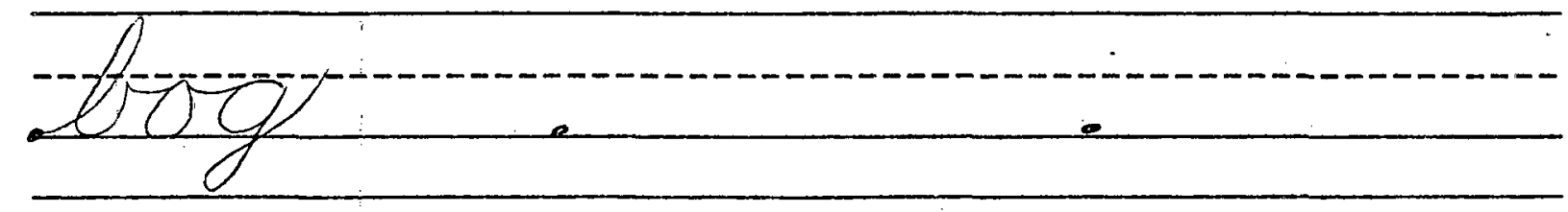

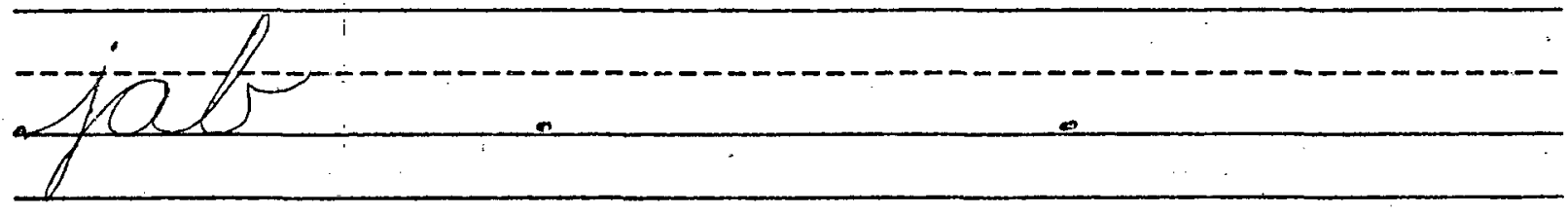

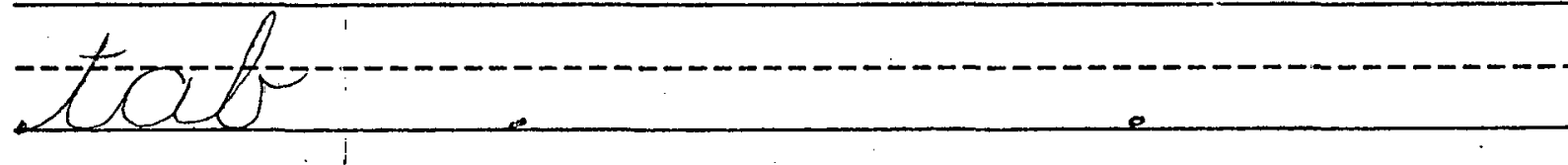

300

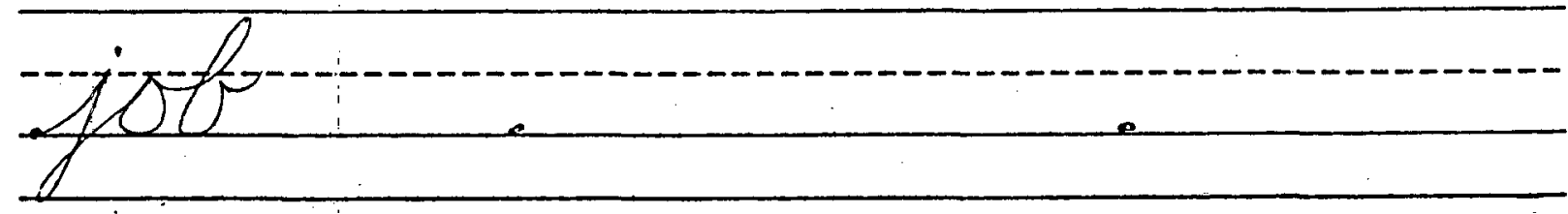


Color the objects that have the "b" sound.
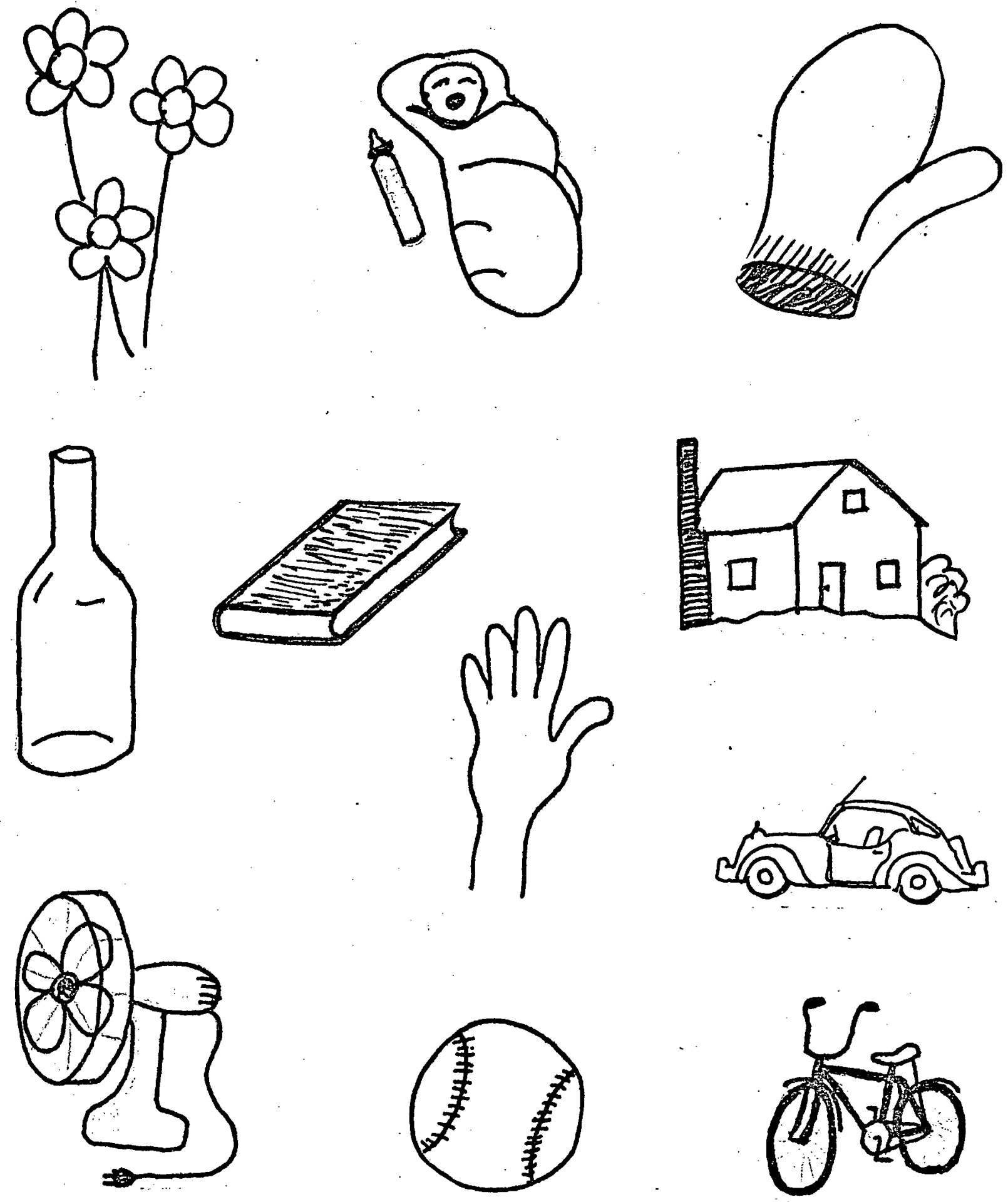
पu口

cucud cud dududud dud jugug jug

tutug tug chumum chum gumugum

gum humum hum upupup up cucup

cup bububut but

pupucup chumumum bubub chutut

bumumum gucumuck pupupum bumumum

gut much mum mug tuck
hut muck bum jug buck 


$$
18 b *
$$

cud

dud

jug

tug

chum.

gum

hum

up

cup

but
Un 20

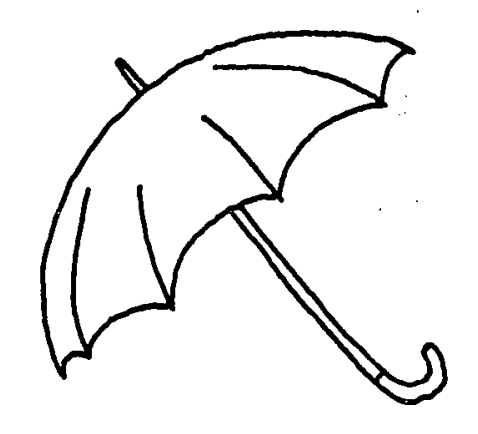

$\underline{4}$

rut

trot

jug 
trag

chumry-a

$\frac{\frac{1}{20 u m y}}{\frac{1}{1}}$

$2 x p \frac{1}{1}$

$\frac{1}{2 x+1}$

(1) 
Complete each sentence, using the words in the nearest box.
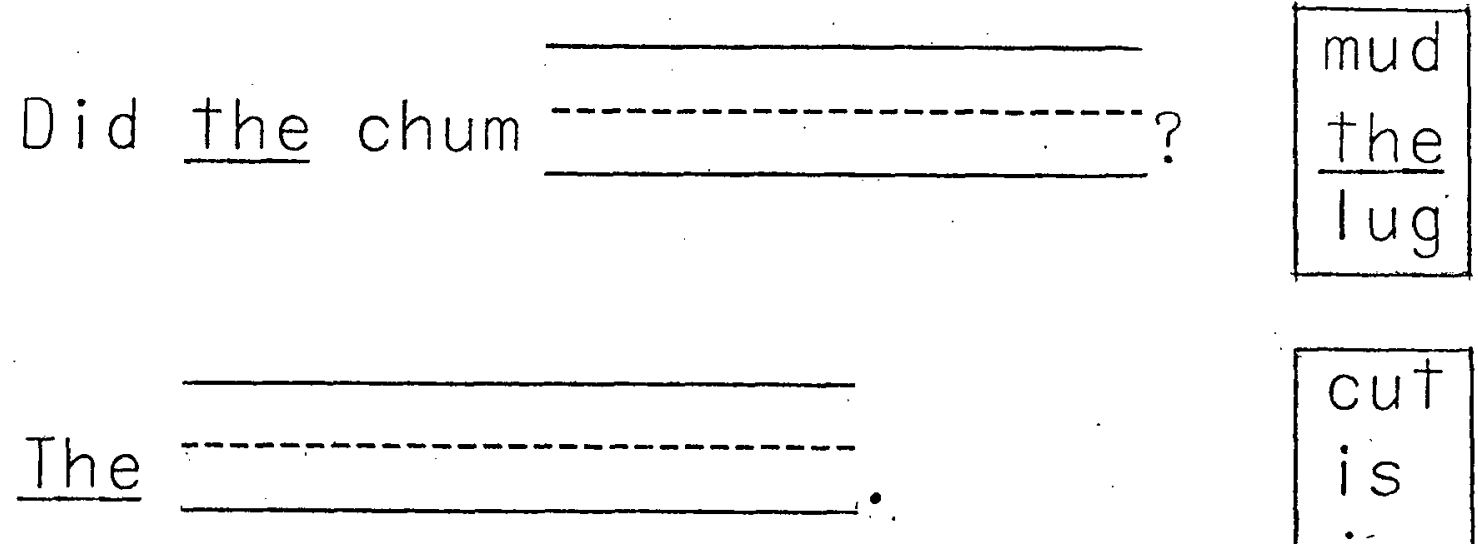

\begin{tabular}{|l|}
\hline cut \\
is \\
jug
\end{tabular}

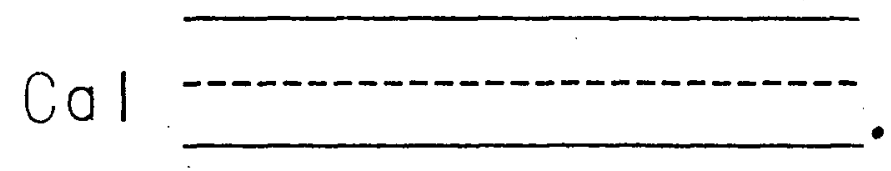

dug
up
it

Dick

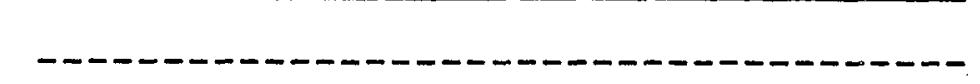


cud

dud

jug

tug

chum.

gum

hum

up

cup

but
$18 b *$

lu Q un

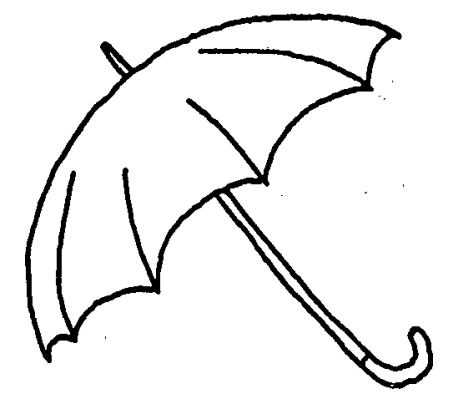

顽记。

wed

trot

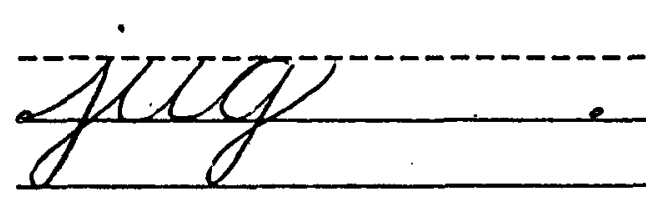




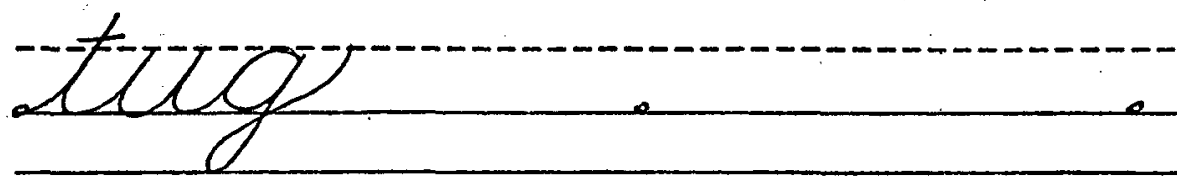

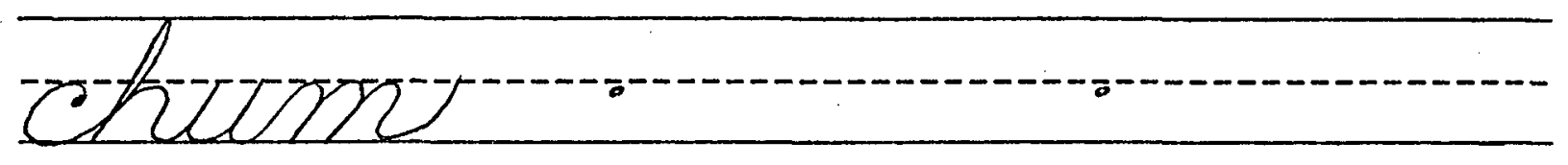

for 202

-

LCH

327

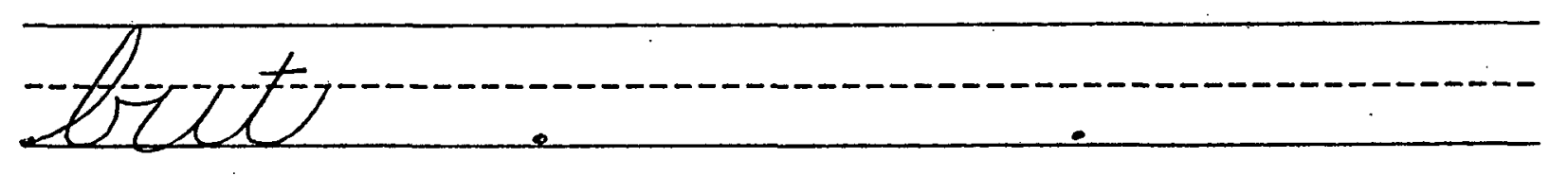


Complete each sentence, using the words in the nearest box.
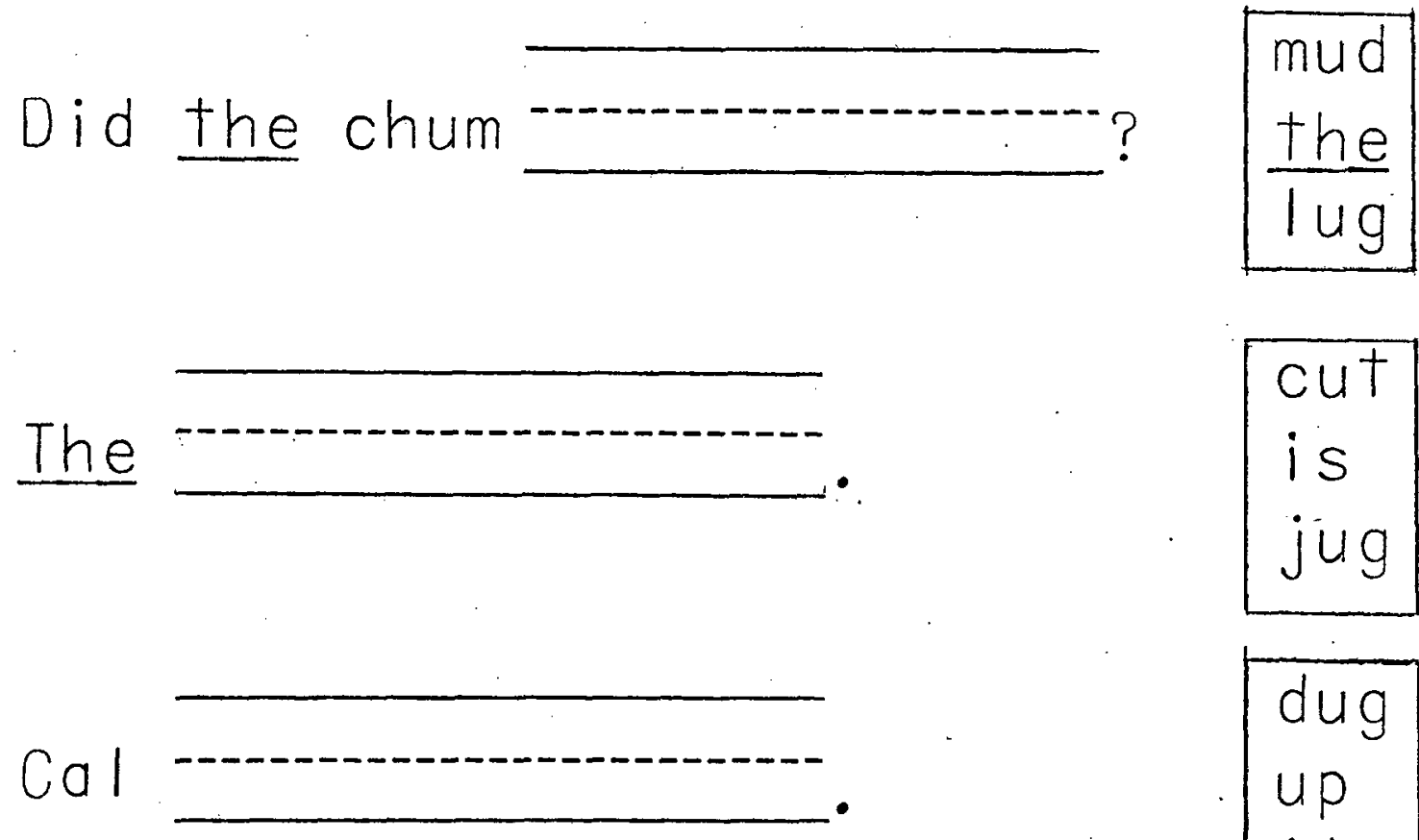

dug
up
$i t$

Dick

\begin{tabular}{|l|}
\hline got \\
jug \\
mug \\
a \\
a \\
and \\
\hline
\end{tabular}


190
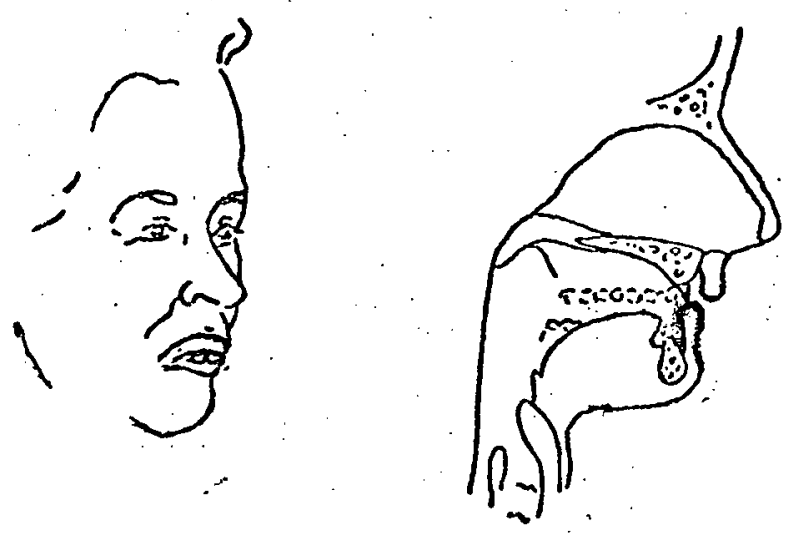

f

fafadad fad fafagag fag fatat fat fibifib fib figafig fig fitit fit fobofob fob fogog fog fopofop fop famat fomidat mutif fopopap chopob fococock chibuck fidadum bubutick

Mack chum dot puck lag back hum tot luck log 
$19 b *$

$$
\begin{aligned}
& \text { fad } \\
& \text { fag } \\
& \text { fat } \\
& \text { fib } \\
& \text { fig } \\
& \text { fit } \\
& \text { fob }+ \\
& \text { fog } \\
& \text { fop }+
\end{aligned}
$$
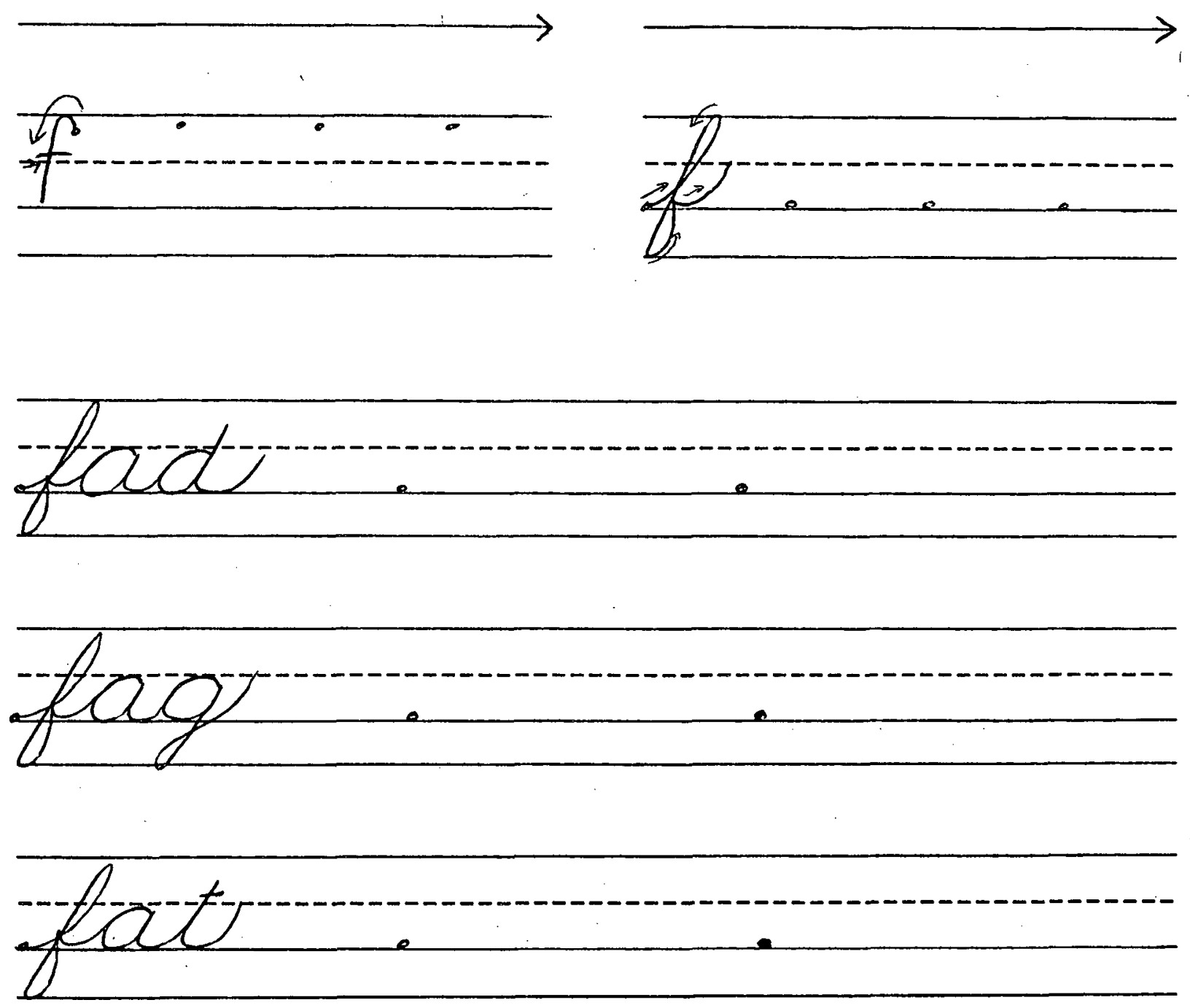

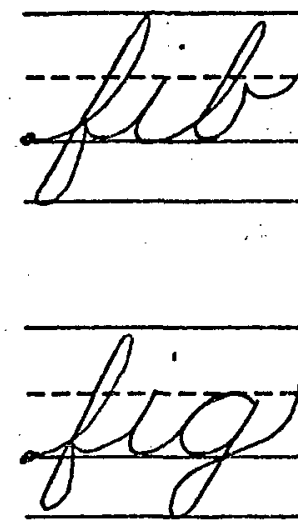

0
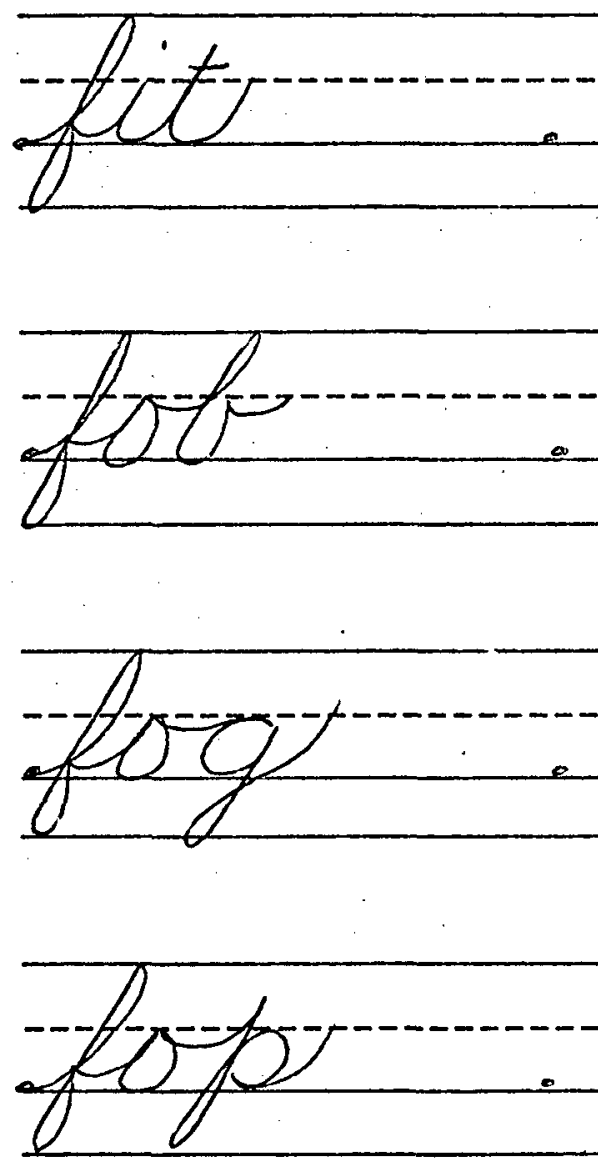
Circle the correct word.

\section{- $f i \dagger$}

1. The hat fat Jim.

fob

fat.

2. It is bad to fib.

fig.

fog.

3. The pig is fot.

4. Bob bit the big fig.

fib.

Fog

5. Fug is bad.

Fob 


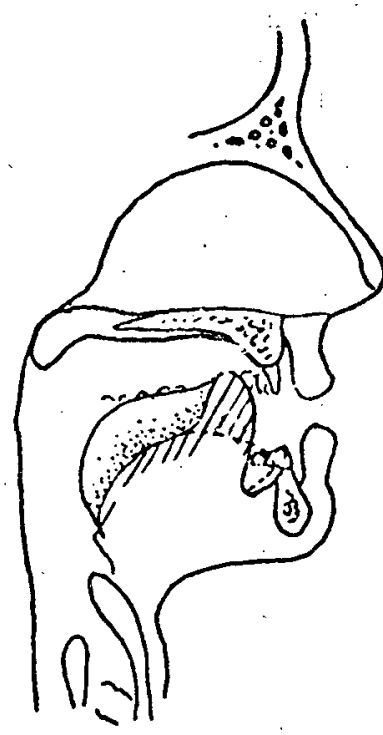

$20 a$

racack rack ramam ram rapap rap

rikich rich rikikick Rick rocock rock rodod rod rototot rot rugug rug rututut rut

romot ratal gotim mimimit cogad hidid rububub ritimim futimad hack rag lop much Kim rack rug rap muck rim 
rack

ram

$20 b *$

rap

rich

Rick

rock

rod

rot

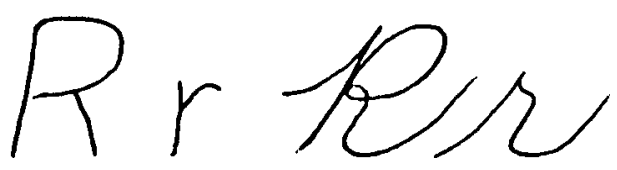

rug

rut
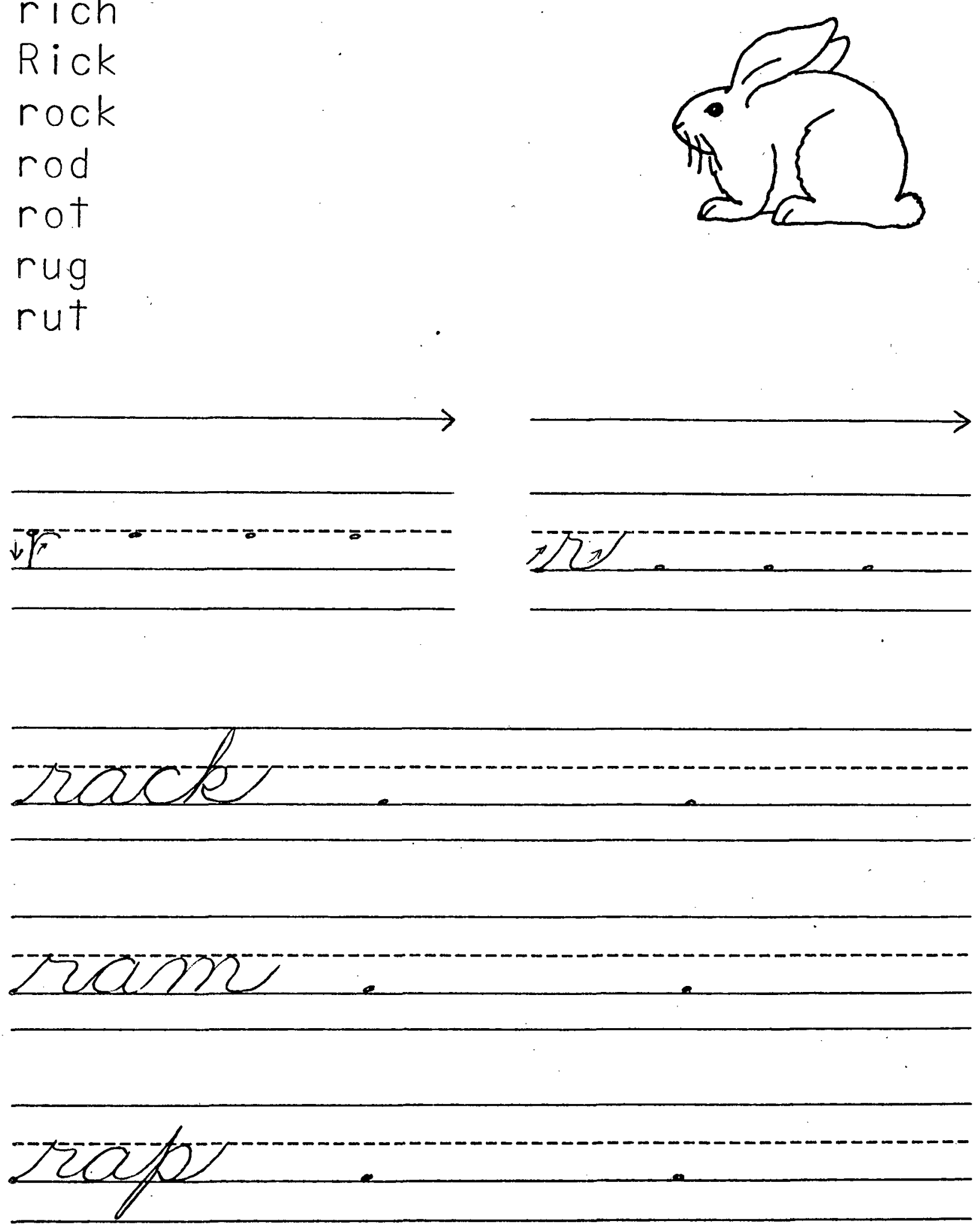
wich

Rick

rocke

2000

reot

zung

rut 
Put the following words in the blanks where they fit best: rim, rich, rod, rat, rip, Rick

1. Jack got a -...-....

2. The lad is

3. The pot has a big

4. The bit Rick.

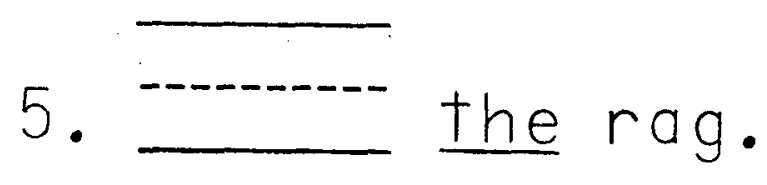

6. 
210
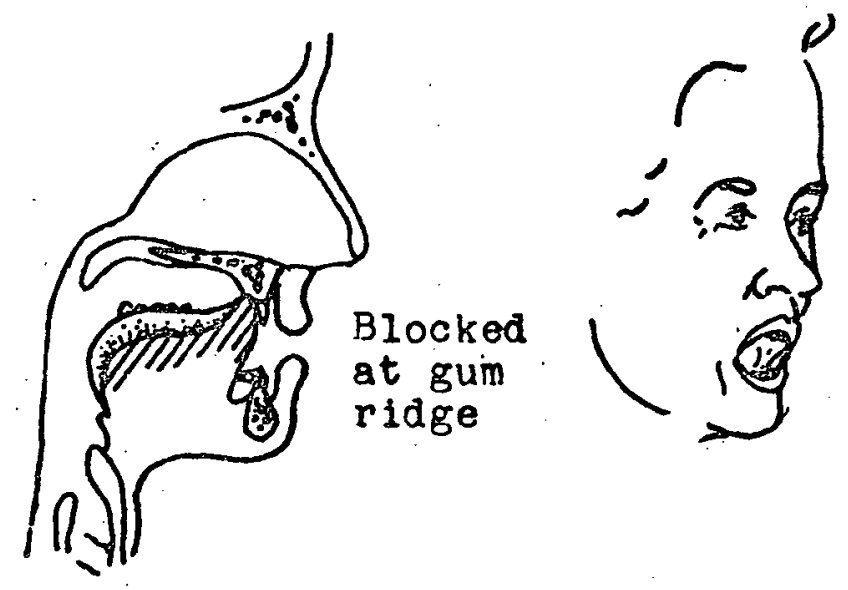

$n$

nipip nip nanat Nat nonotot not.

nununut nut fafanan fan papan pan

pipinin pin tinitin tin gunun gun

bububun bun

famal gututut fofof chutun mamom

lotot runinun chapapap minimin

Pam fun chin tack ram pan pun chum Mack ran 


$$
21 b *
$$

nip

$\mathrm{Nat}$

not

nut

tan

pan

pin

tin

gun

bun
No Nm

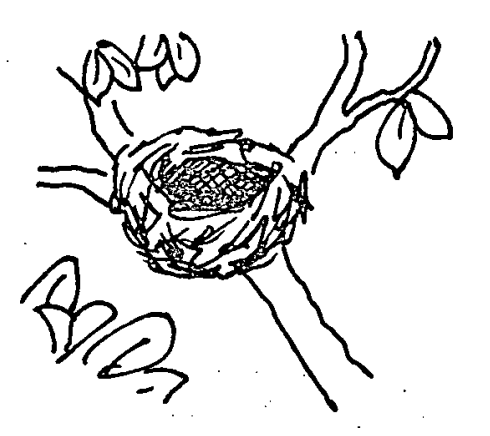

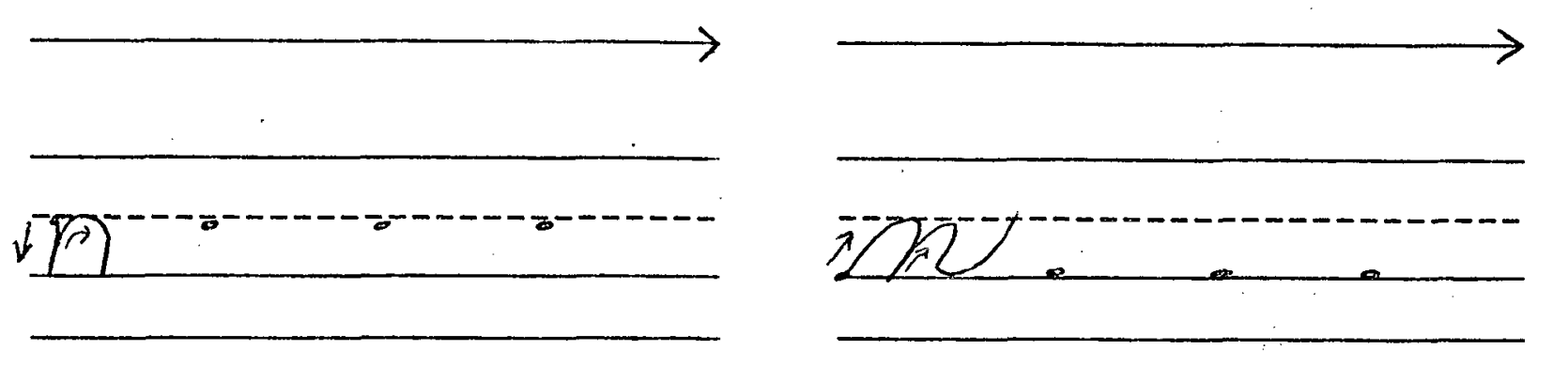

miff

tat

not 
muts

tant

c.

2

$\circ$

20

$\circ$

212

$\circ$

getnet

- 
Put the following words in the blanks where they fit best: nut, not, man, nag, can, Jan, fun, on, pin, tin.

I. J Jack will $\bar{\cdots}$ run.

2. Dan did $\cdots$ the $\bar{\cdots}$.

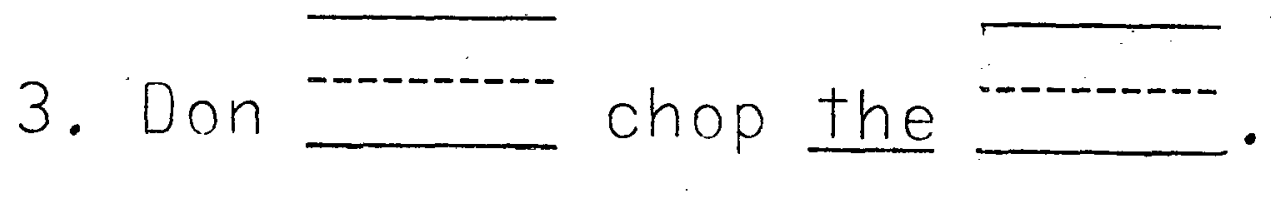

4. Rick and $\cdots$ had

5. $\bar{\cdots}$ the $\operatorname{tag} \overline{\cdots \cdots}$ Ron.

6. The can is big. 


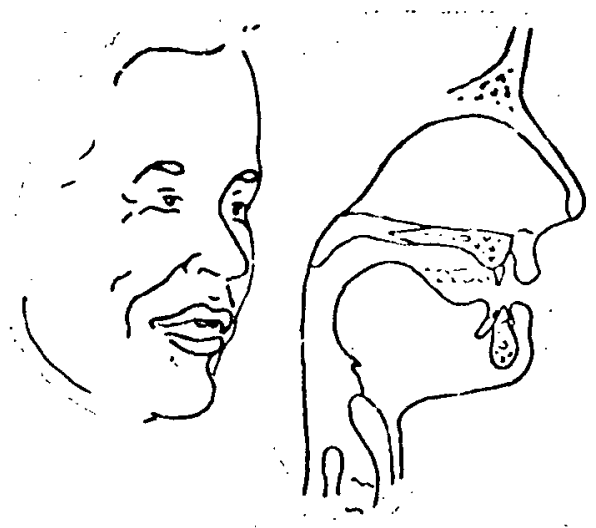

\section{aed}

fedefed fed reded red bebeg beg

legeg leg pepenen pen tetenen ten

betet bet nenet net petet pet

hememem hem

chepep memem leteten fefefef tetet

refen seseses chetetet nenenem

men beg pet jet led
hen peg let net Ned 
fed

red

beg

l eg

pen

ten

bet

net

pet

hem
$22 b *$
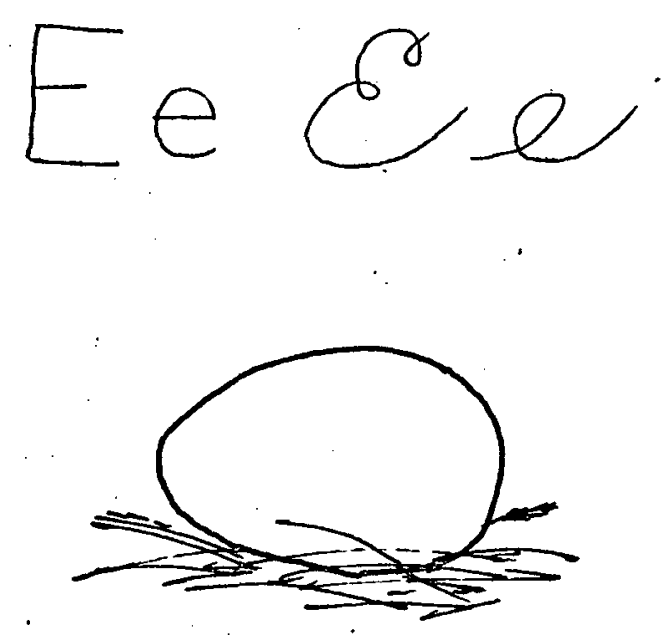

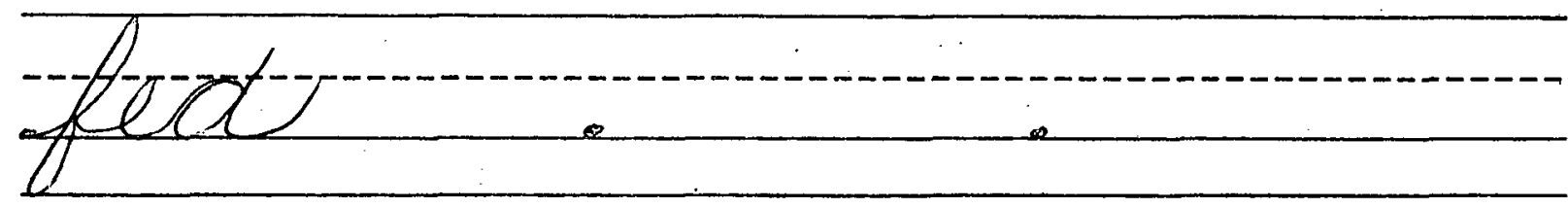

rete

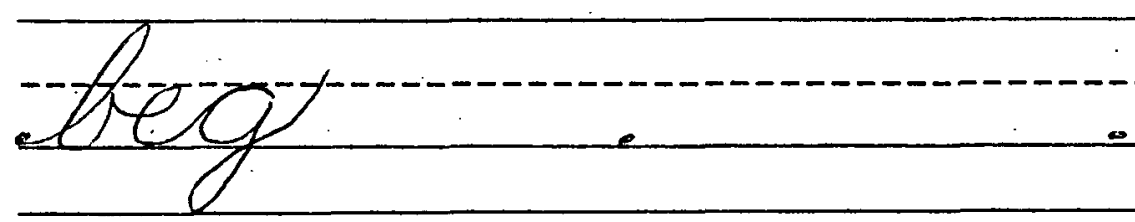



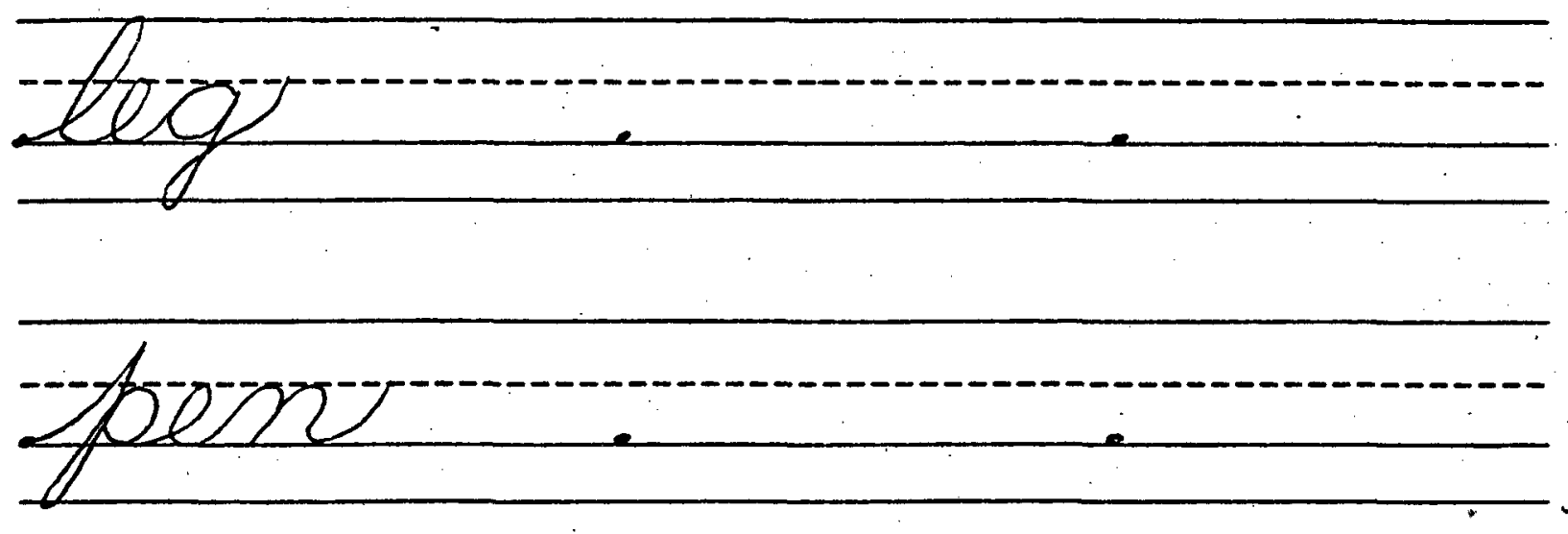

$\tan { }^{-}$

(1)

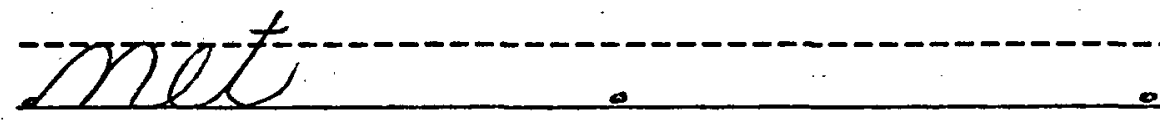

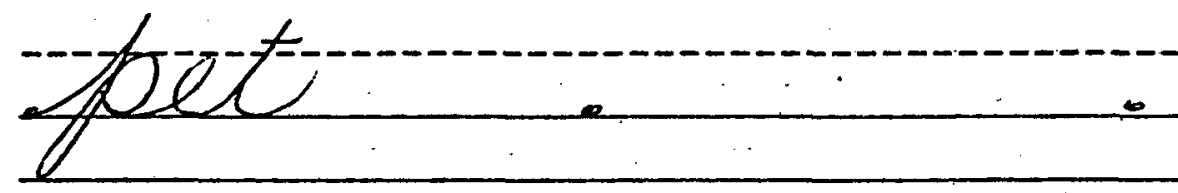

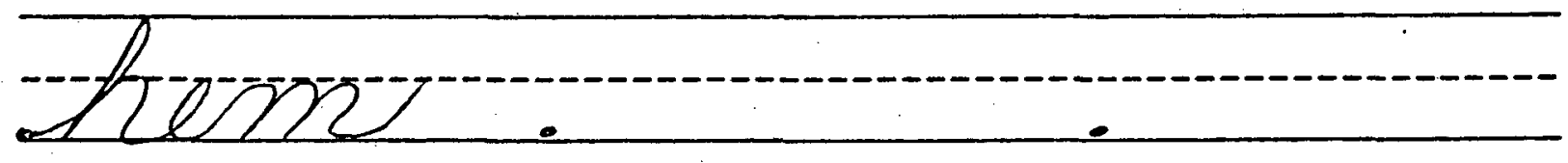


Make ten new short "e" words, using these consonants: $b, m, l, p, n, t$, $f, h, j, c k$

1.

6.

2.

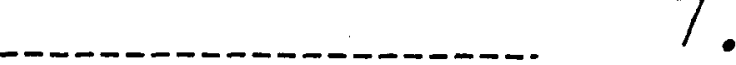

7.

8.

3.

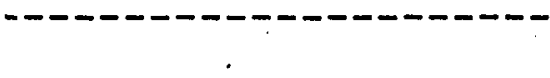

4.

9.

5.

10. 
Review

Draw a picture of each word you can read in the square.

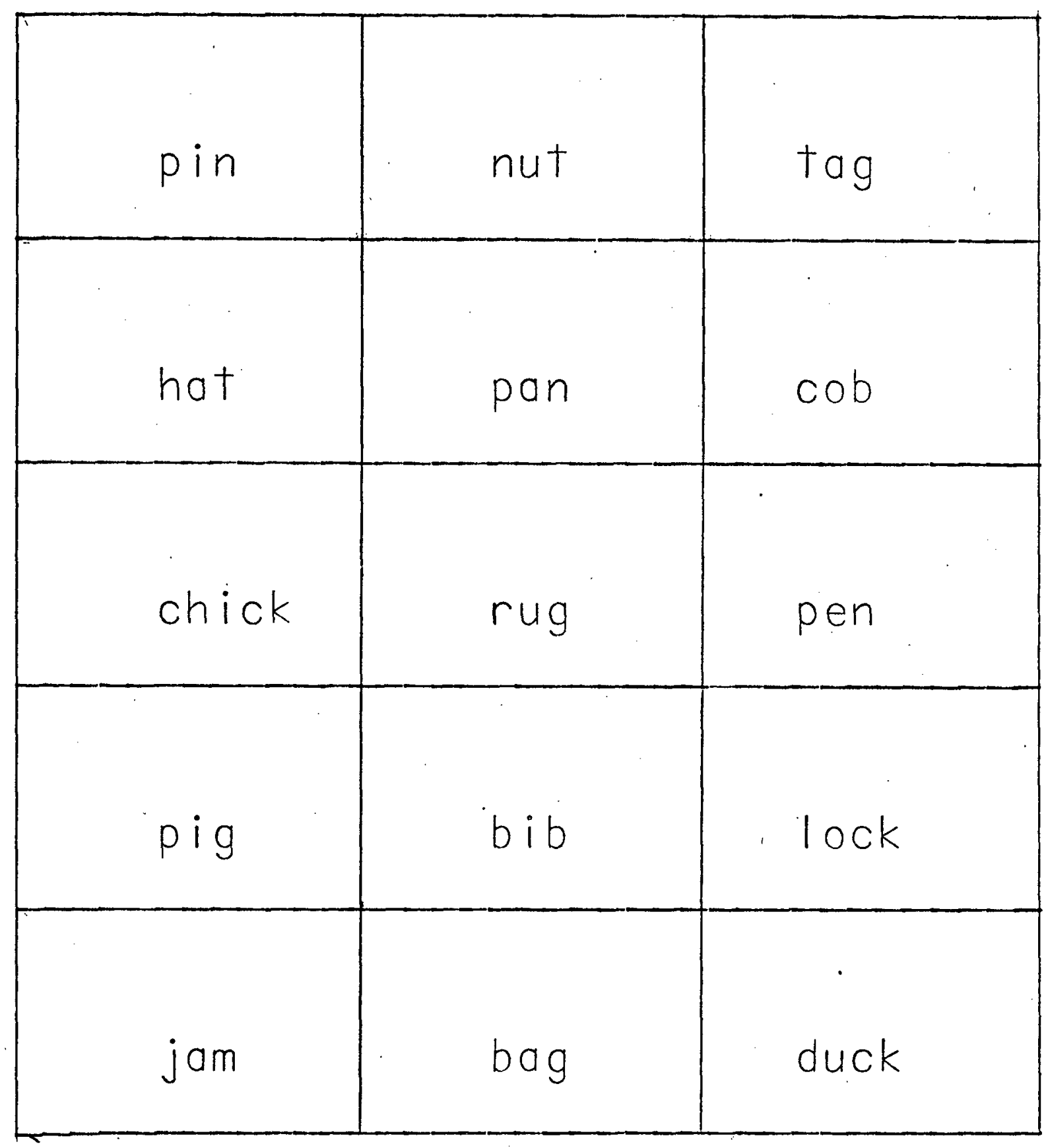




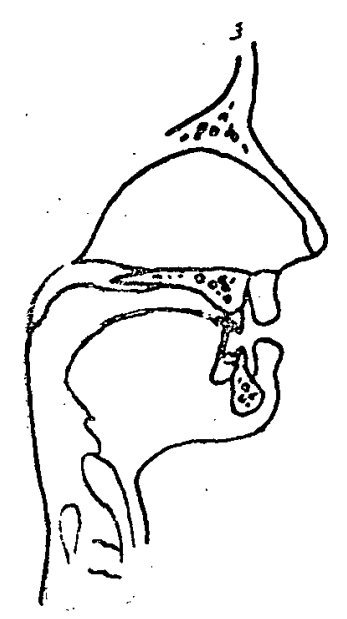

S

sasasal Sal samásam Sam sasatat

sat setet set sininisin in sisit

sit soposop sop, sububub sub susuch

such susun sun

susasos chipipip tososat ninonan

metemem lasasam cacacack riminim

kick rug up chap jet

lick chug pup rap set 
$24 b *$

Sal

Sam

$\operatorname{SSc} \alpha$

sat

set

sin

sit

sop

sup

such<smiles>CC1C(C)C(C)C(C)C(C)C(C)C(C)C(C)C(C)C(C)C1C</smiles>

sun
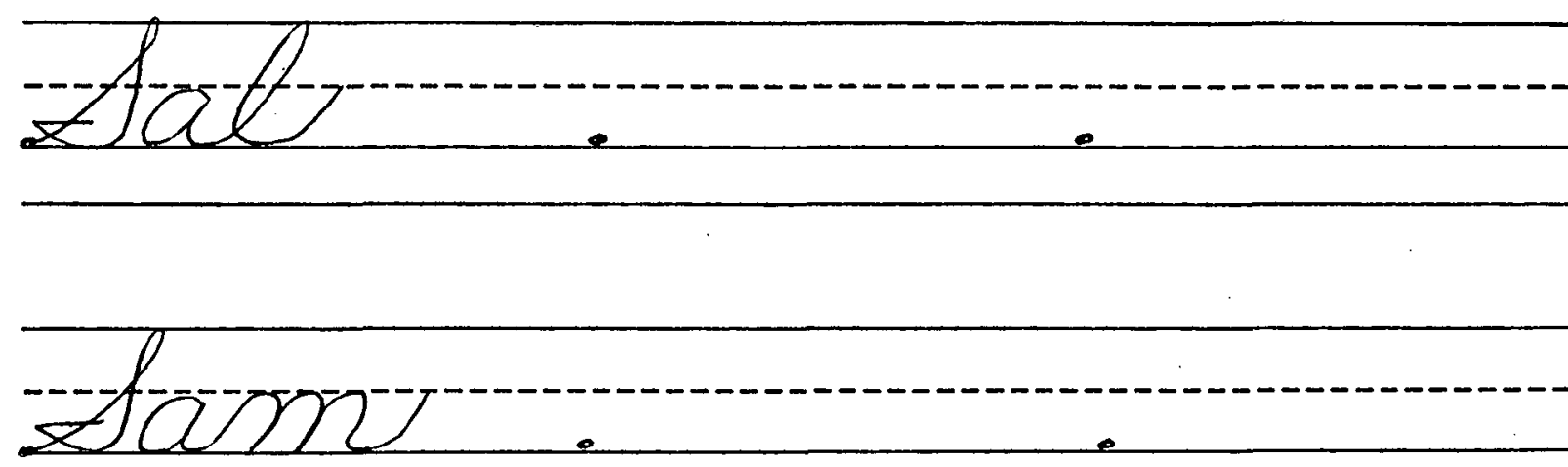

Deaf 
net

sins

sit

mach

tow 
Listen as your teacher reads some words. Write the number of each word that has the "s" sound.
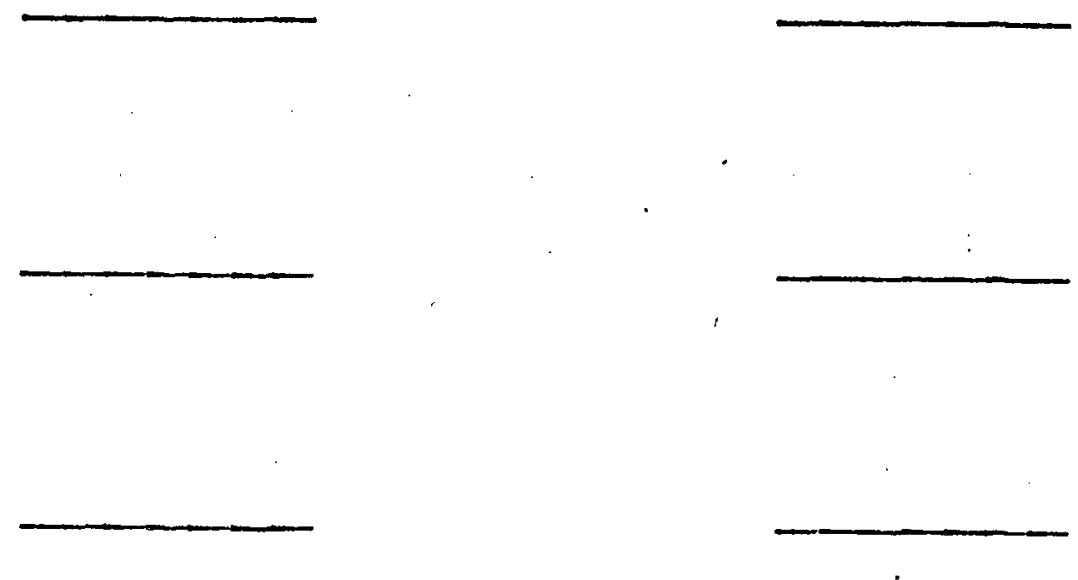

Use this space to draw pictures of objects whose names have the "s" sound. 


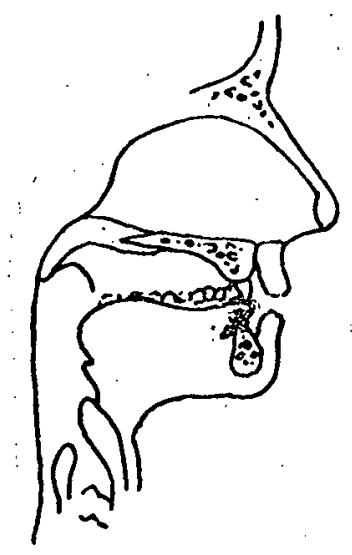

th

(hard)

thanan than thathat that themem

them thethen then thisisis this

thusuthus thus

thothoth pothop fof of thocock

somotot motof senonam chucuck

sack chat chuck mit peck rack fat buck fit pick 
than

that

hard th

them

then

this

thus

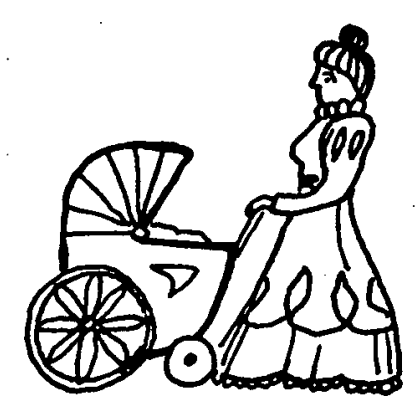

-tharñ

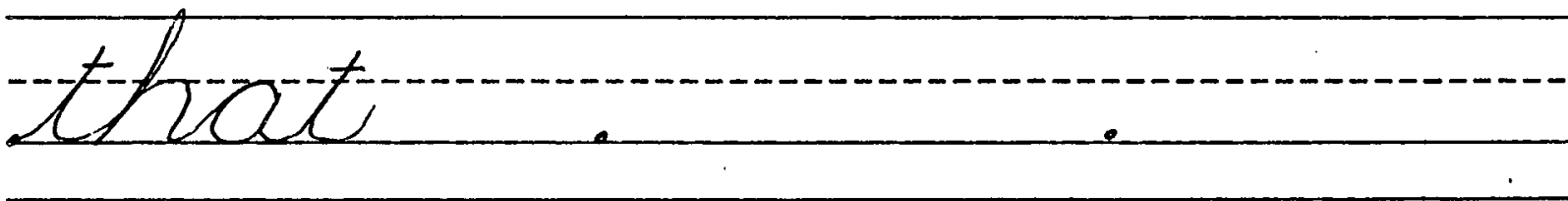

thethon

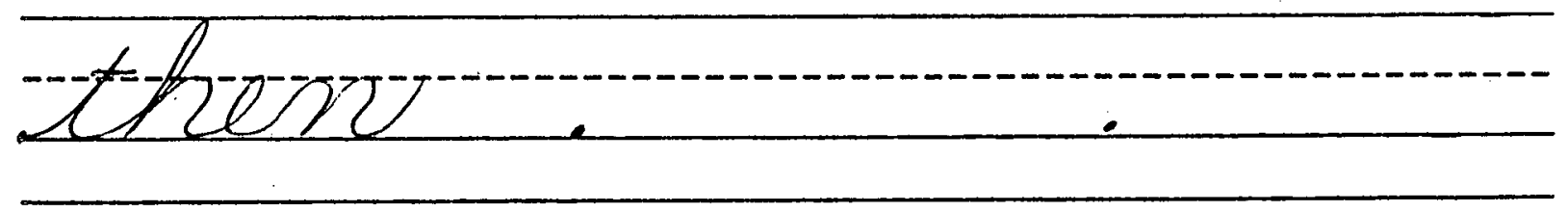




\section{$\rightarrow$}

(2)

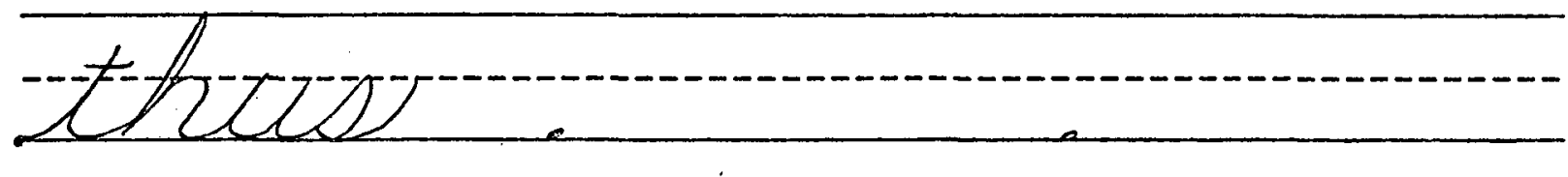


$25 c$

Arrange these words into good sentencess.

mat That on is top

pick this will Jack hat

hit Rick. them

had cup Jack that

cut got rug They to them the 


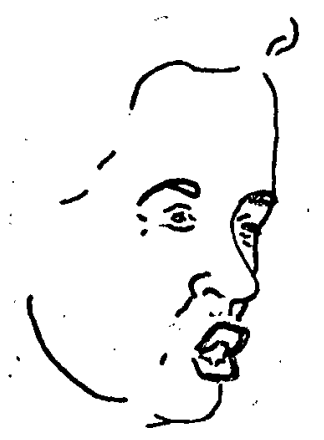

sh

shagag shag shamam sham sheshed.

shed shipip ship shopop shop

cashash cash lashash lash memesh

mesh didish dish mushush mush

chash mushuck pishish shodod

nashach ramenick mamack thuduthud

rid much ship shun shack

kid such chip sun rack 


$$
26 b *
$$

shag

sham

sh

shed

ship

shop

cash

lash

mesh

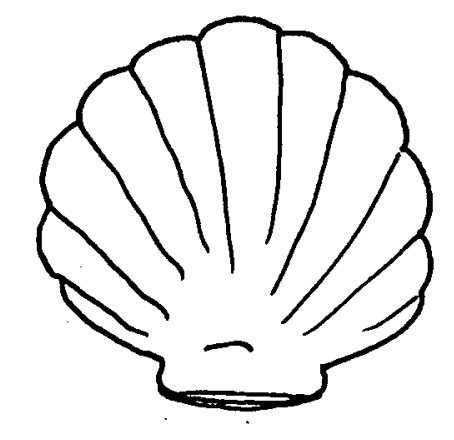

dish

mush

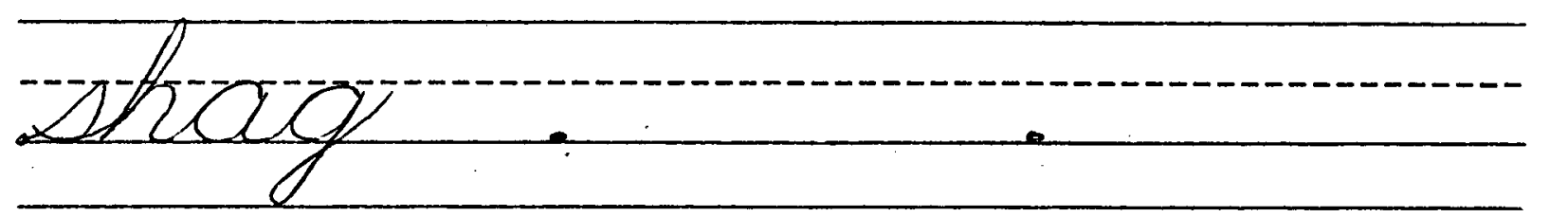

thant
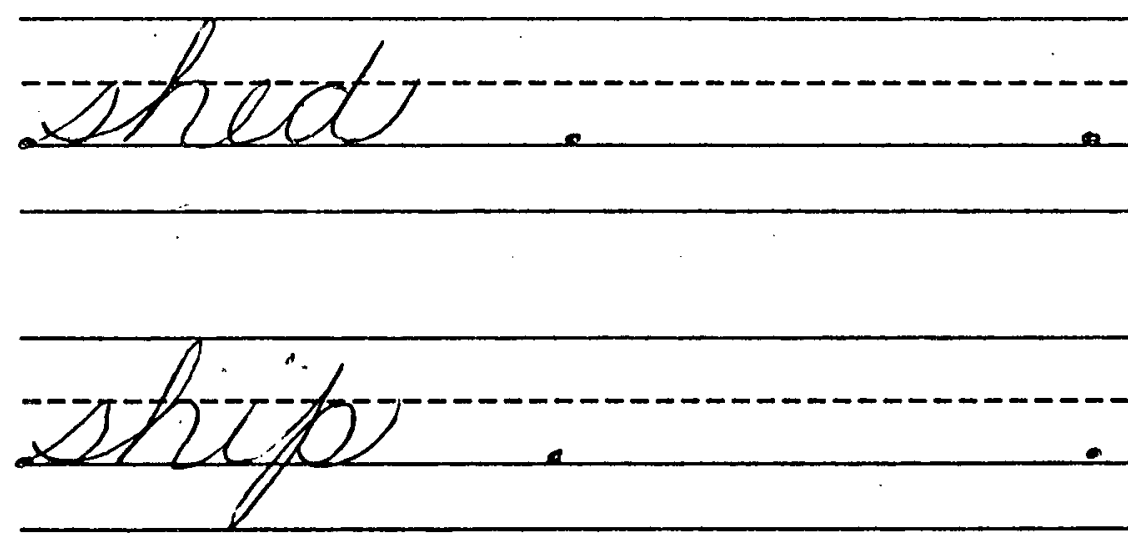

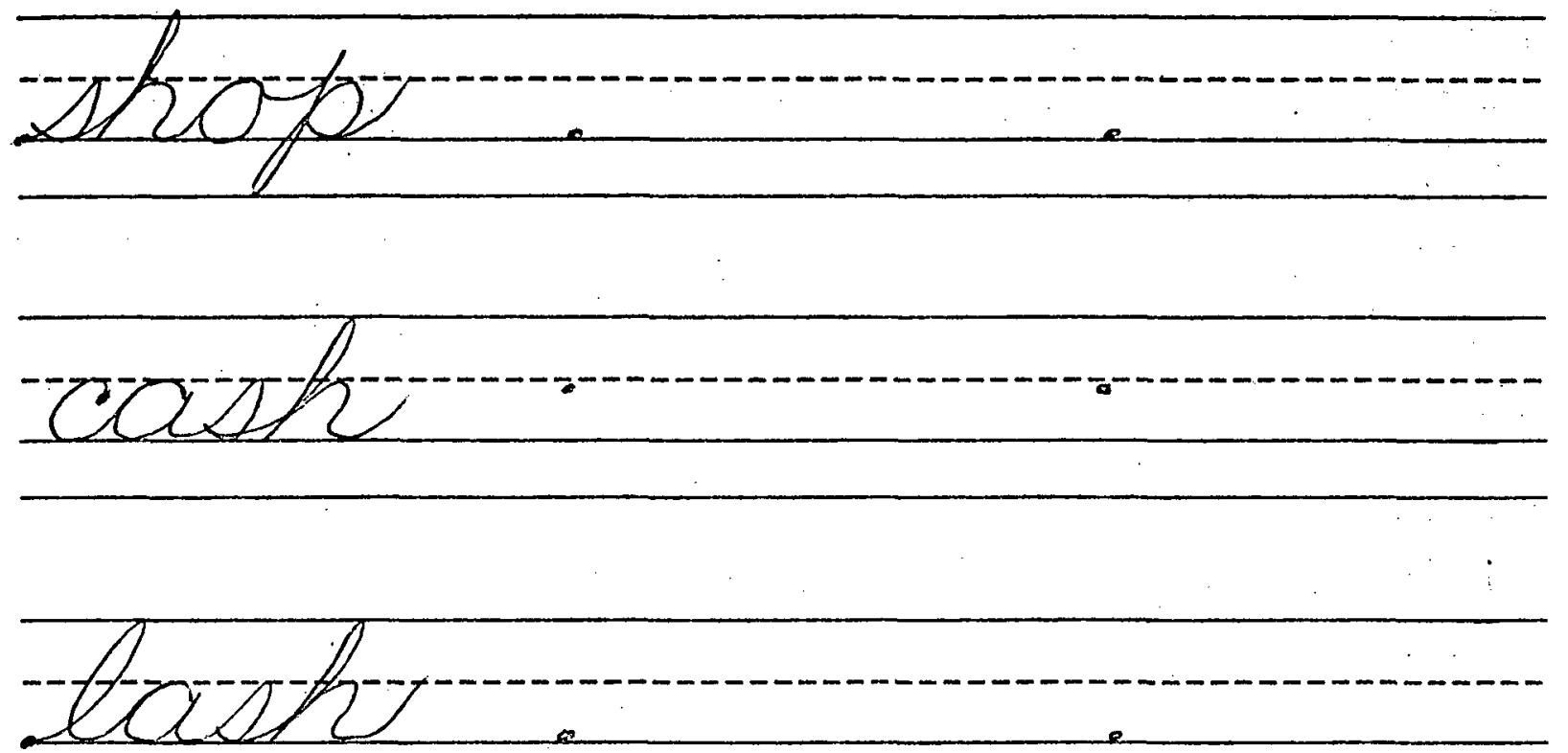

e

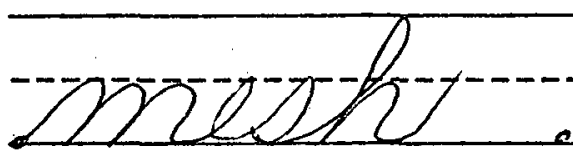

$a$

aturts

MIUTAC

2 
Choose the correct digraph to put in each blank.

ch

1. _at cat was hit. sh

th

2. The lad will _at. sh

th

3. That is a big di_.. sh

th

4. The man had ca_.. sh

th

5. The _op had a map. sh

th 


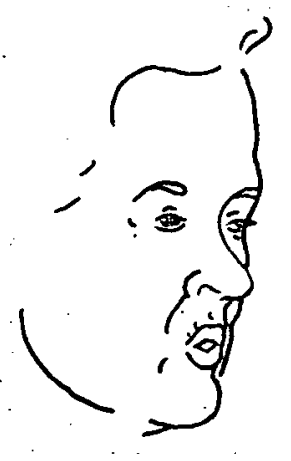

W

wagag wag webebeb web wededed wed wetetet wet wiwick wick wigig wig wininin win wishish wish witit wit withith with

womomom potom thatam sananan ratumun rutunim famamam bubun

rut chug tack gash Nat shut pug shack rash: chat 
wag

web

wed

wet

wick

$w i g$

win

wish

wit

with
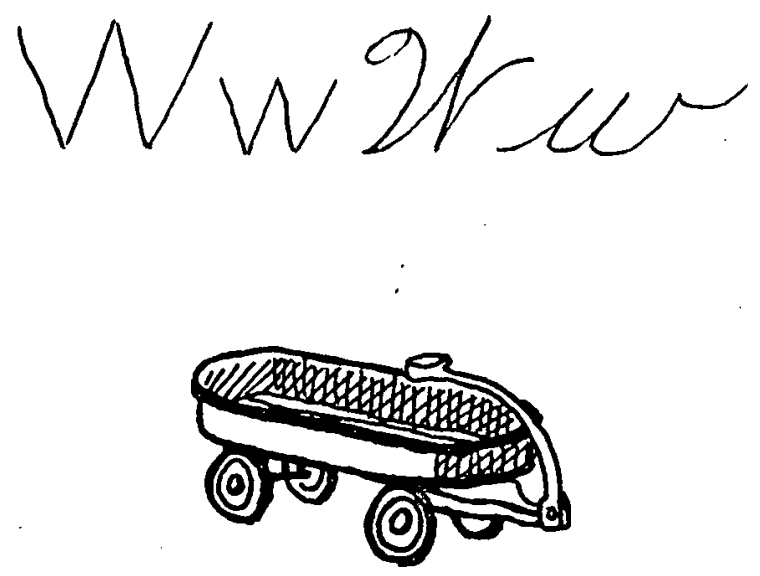

van
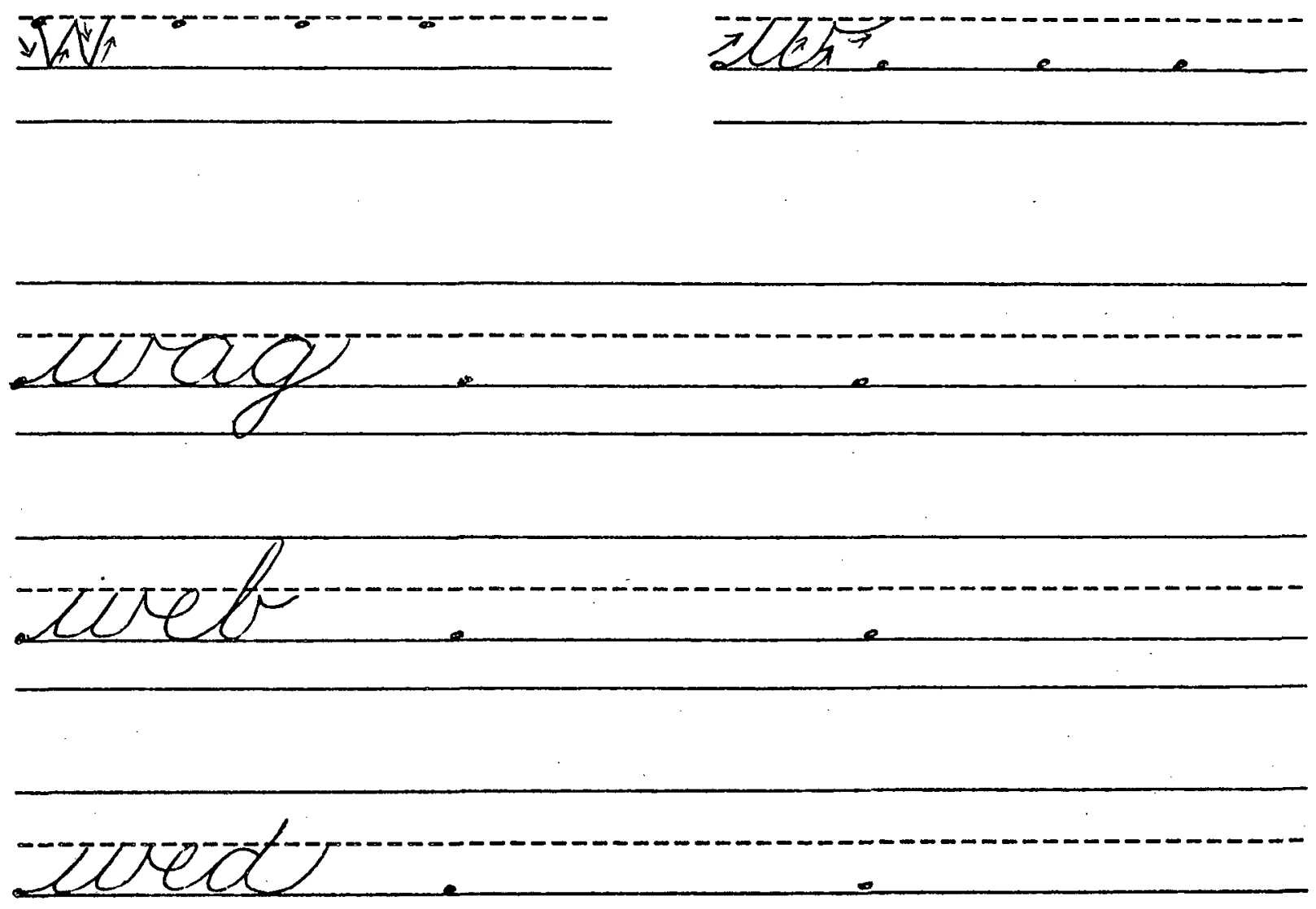

Dictate a story to your teacher, using as many "w" words as you can. You may use this space to write any of the "w" words in your story that you can spell, or you may wish to illustrate your story. 


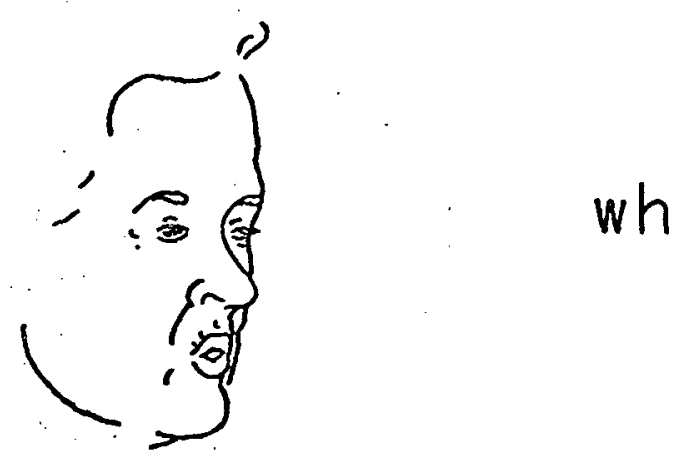

whenen when whetet whet whiwich

which whimim whim whipip whip

whishish whish whitit whit whopop

whop

waman cagoch fishich dicack kutip

pechech thopopop shushish chamam

hack run whack not than

pack pun hack shot tan 


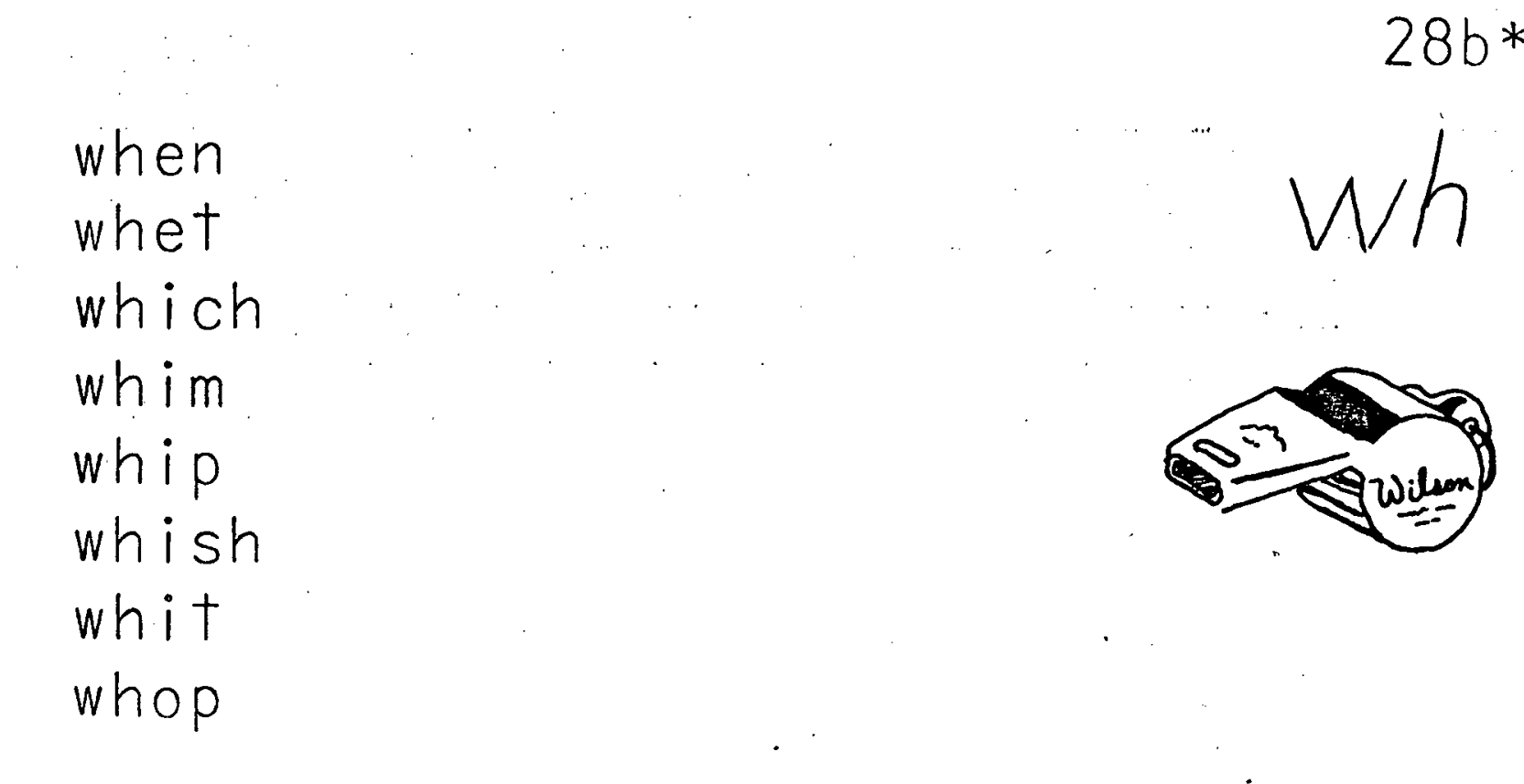

when

zohet

which:

zohise. 
(1)

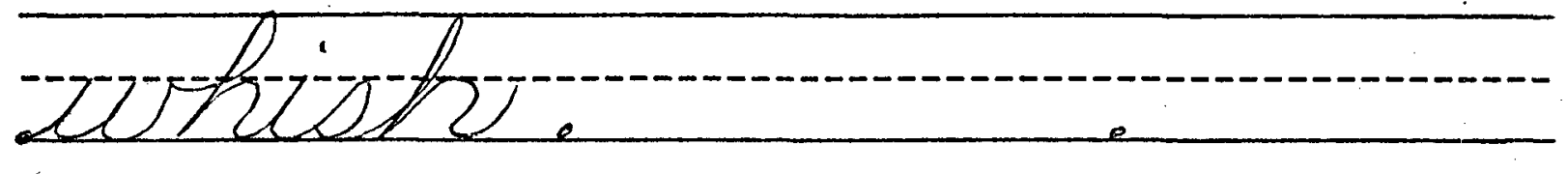

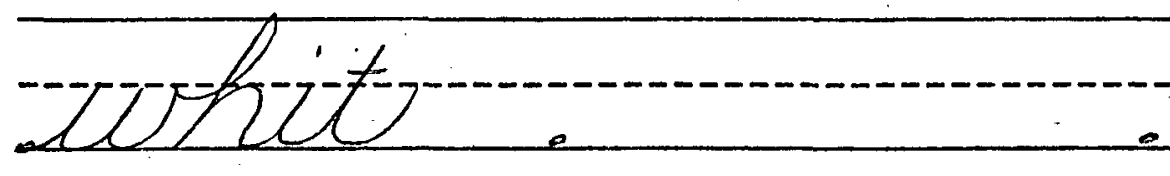

(2) 
Write "wh" in the box if the name of the picture begins with the "wh" sound.
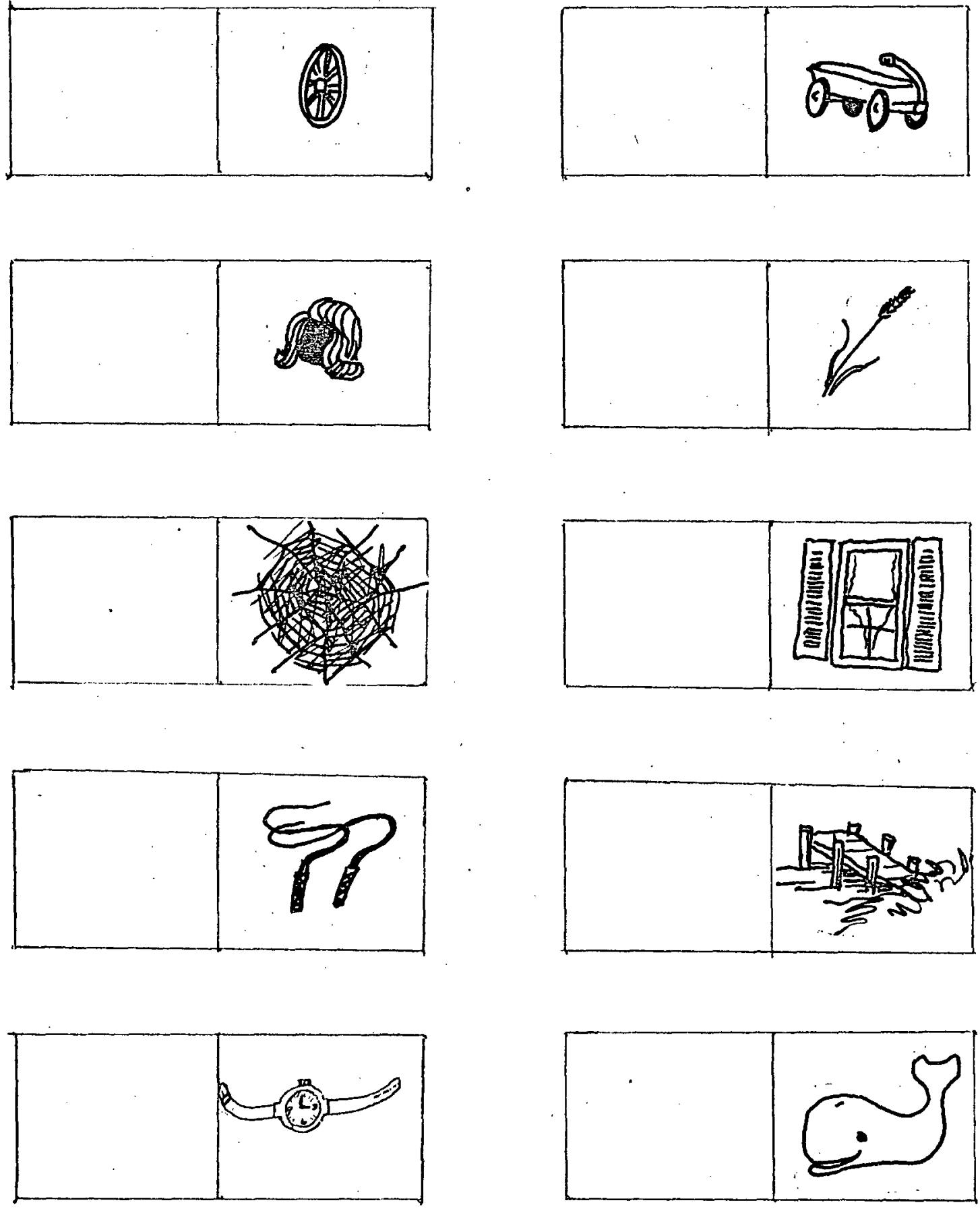
ax lalax lax tatax tax vevex vex

fifix fix mimix mix sisix six ox bobox box fofofox fox

bubax putut hoshosh taman licacock tapit whethesh chafaff siminim

lick then mush chip that tick them hush ship chat 

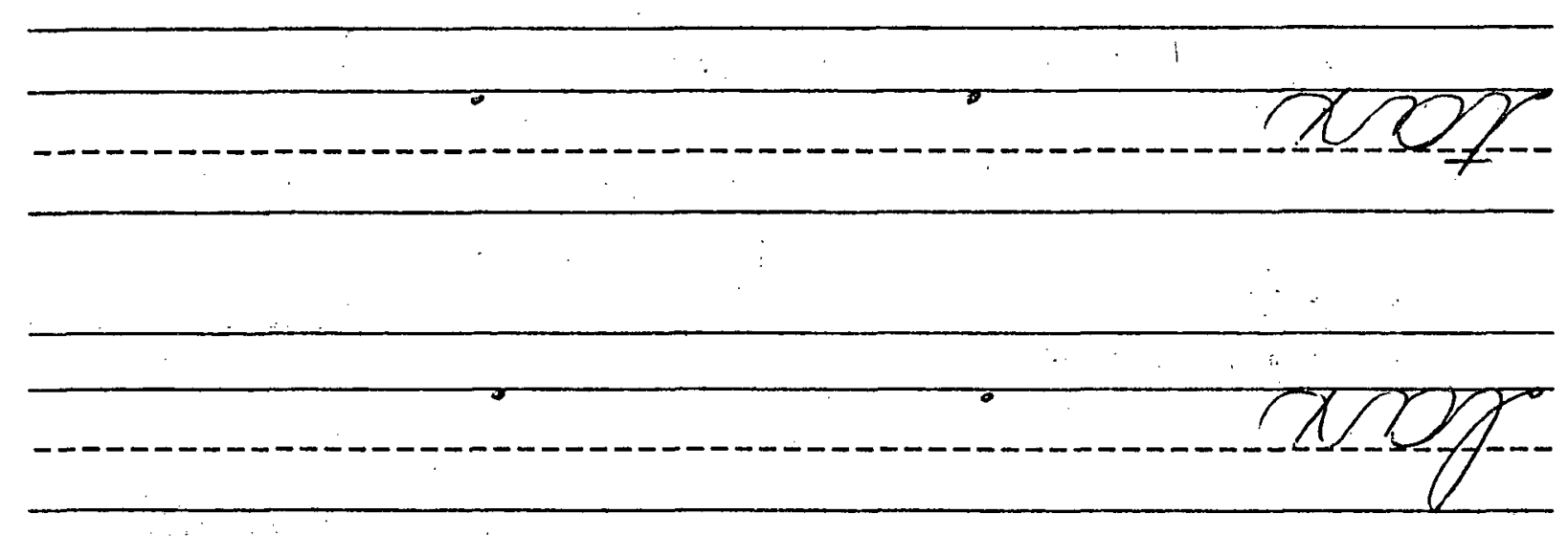

$\leftarrow$ 
$20 x$

fine

max

$x$

$0 x$

tore 


\section{$29 c$}

Listen to the words that your teacher reads. Circle the number of each word that has the " $x$ " sound.
1
2
3
4
5
6
7
8
9
10
11
12
13
14
15
16
17
18
19
20 


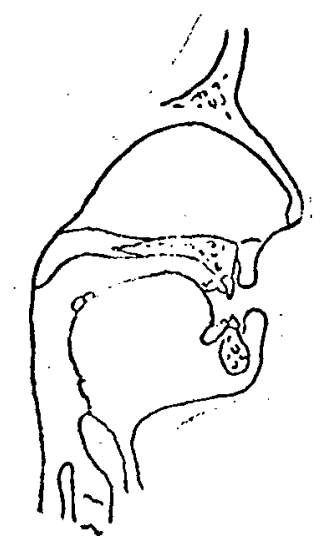

\section{y}

yakak yak yamamam yam yapapap yap

yenenen yen yeseses yes yetet yet

yipipip yip yononon yon

yech yosh bososh mapipig koshoch

micadack roshoshox thumumum boch

kick luck than when shut

sick tuck tan hen hut 


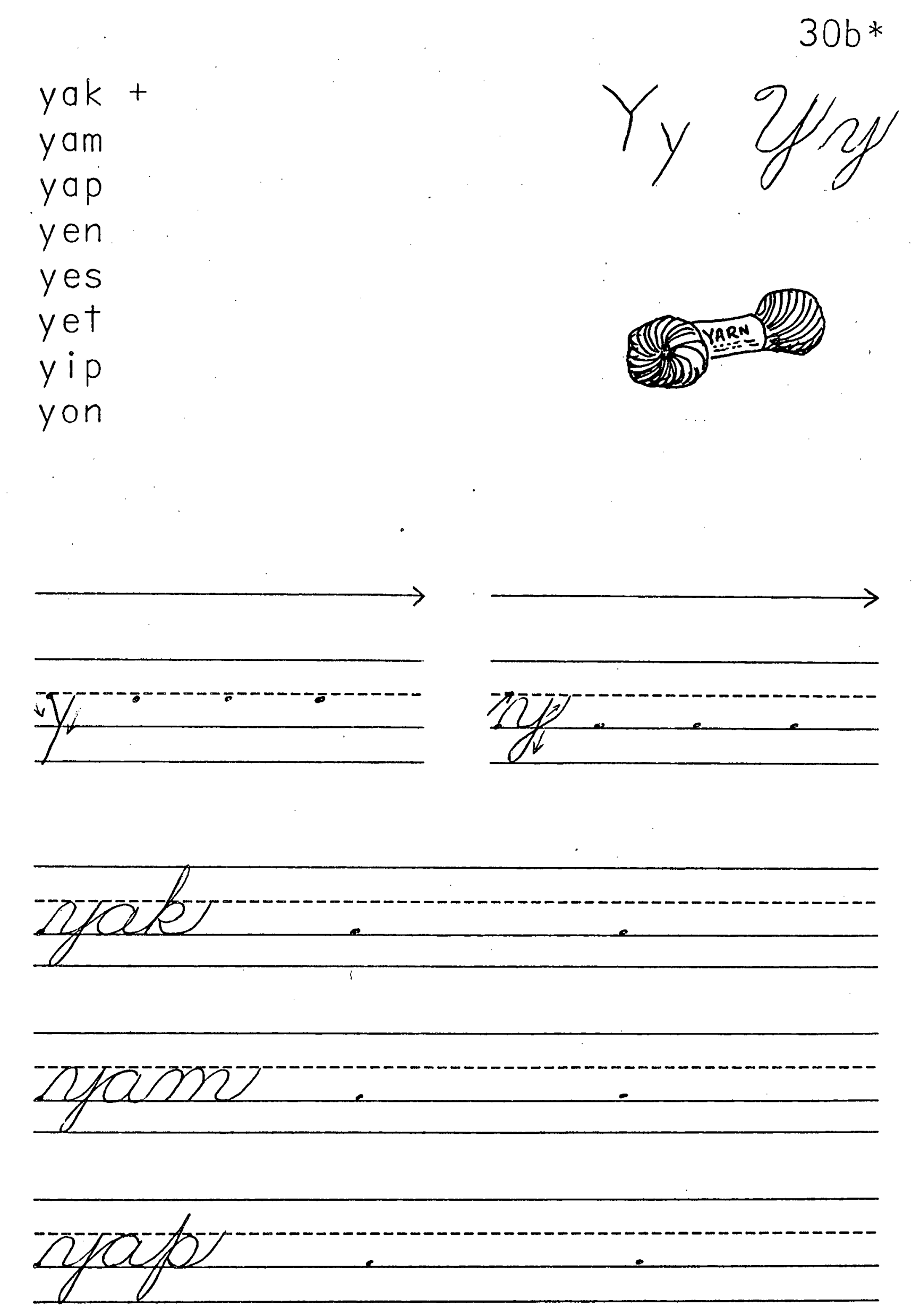


zyen

zjes

ajet

zipip

zyon 
Point to all the "y's" on a page in your reader. Use this space to draw pictures of objects whose name begins with "y." 
$31 a$
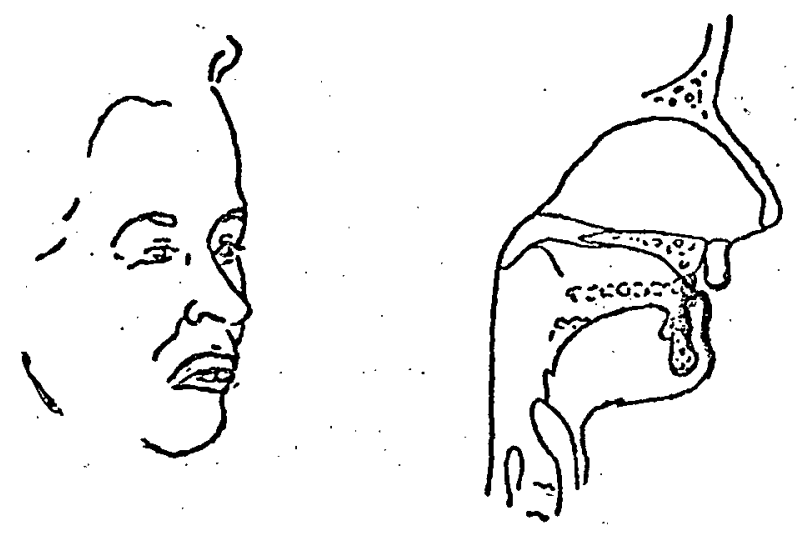

valaval Val vavavan van vavatat

vat vetevet vet veverex vex

vivivic Vic vimivim vim

fosh thock sovovov vonock voth

yamat novobom whopop homovovom

shag whet puck whit gal wag wet luck wit Sal 

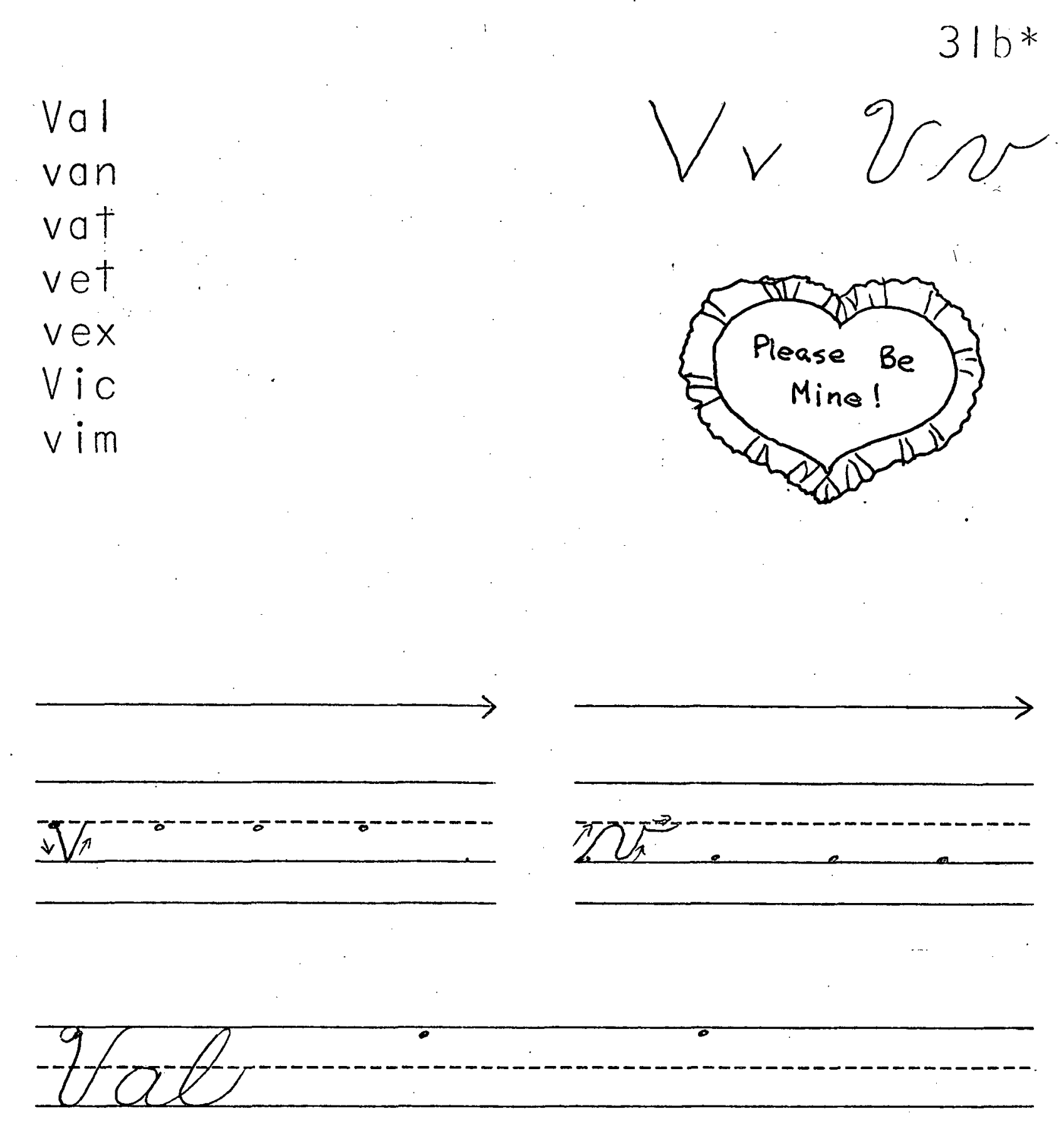

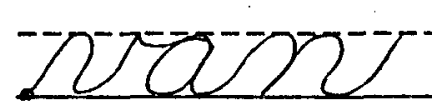

wat 
Write "yes" if the picture has a "v" sound. Write "no" if it does not.
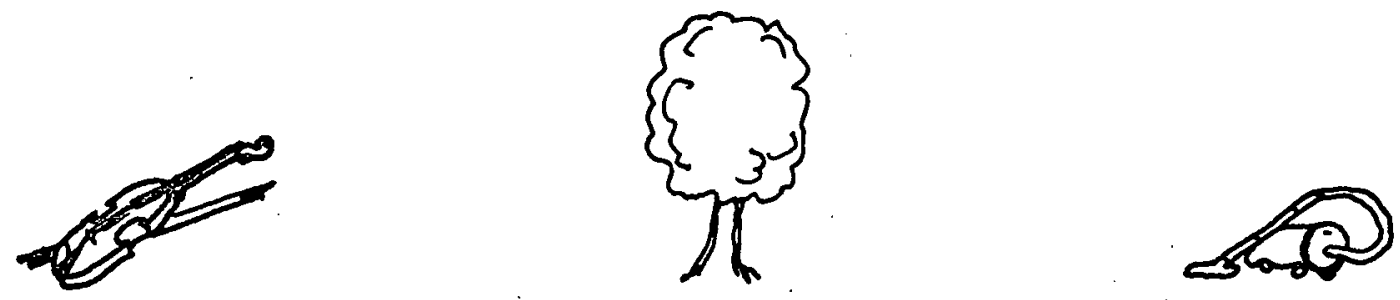

$\phi_{8-2 \cdot-2 \cdot 2}$
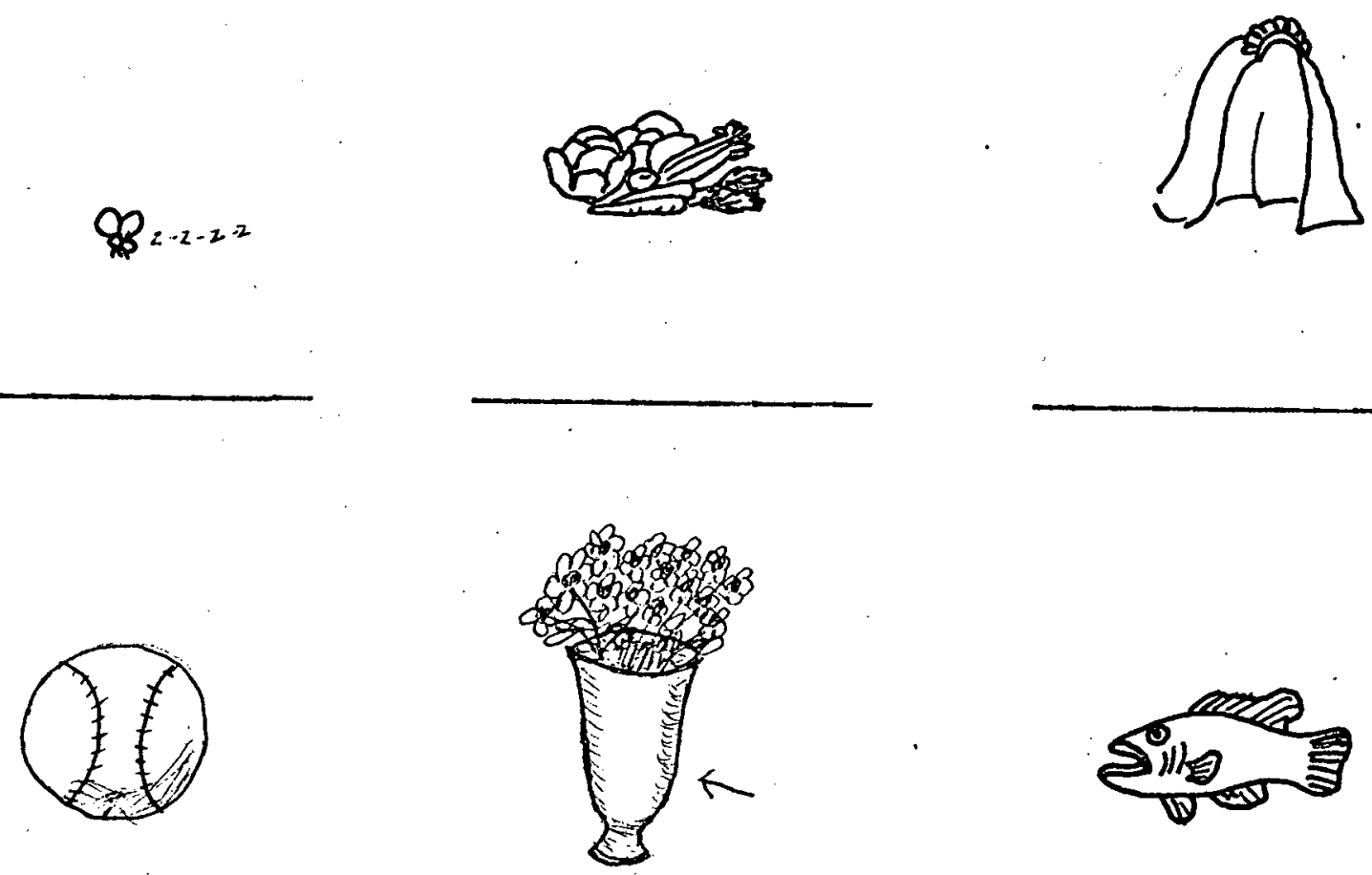
$32 a$

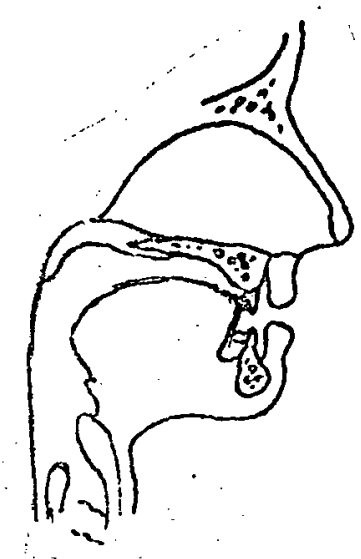

Z

zazacazax zax zezezed zed zezelel

zel zig-zag zizipip zip whiziziz

whiz

pizafivoz sozozoz novovov zosozos

zosh voth wavavax kikiziz titiz

check Jack Sam tap fun neck shack sham zap shun 
zax +

zed +

zel +

zig-zag

zip

whiz
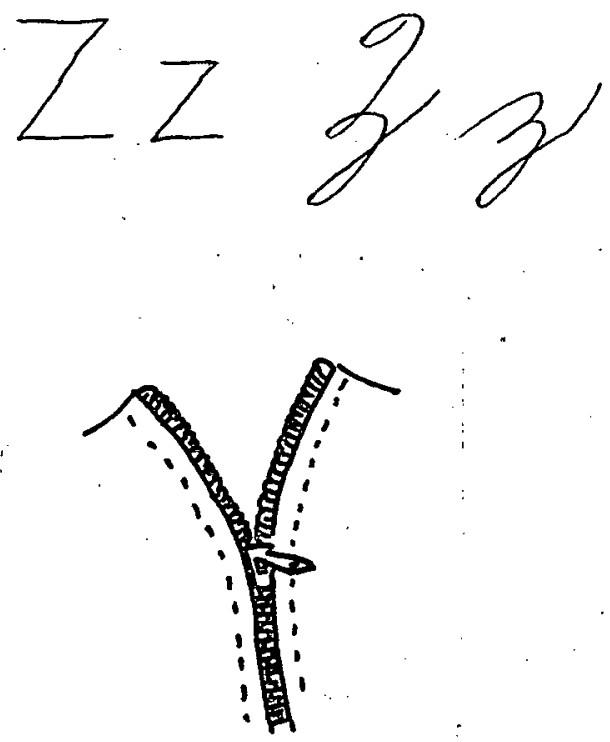
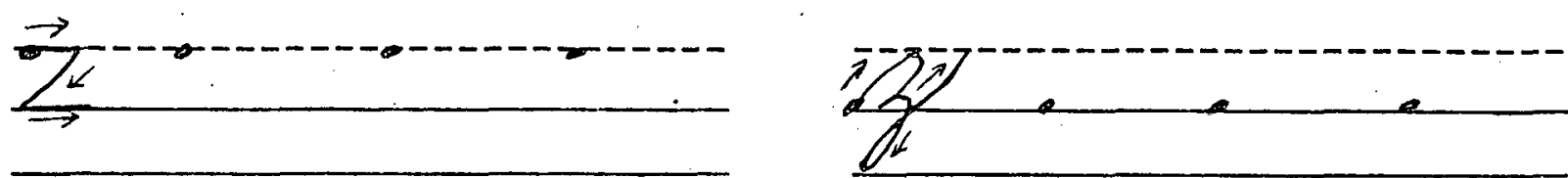

$20 x+$

zedo

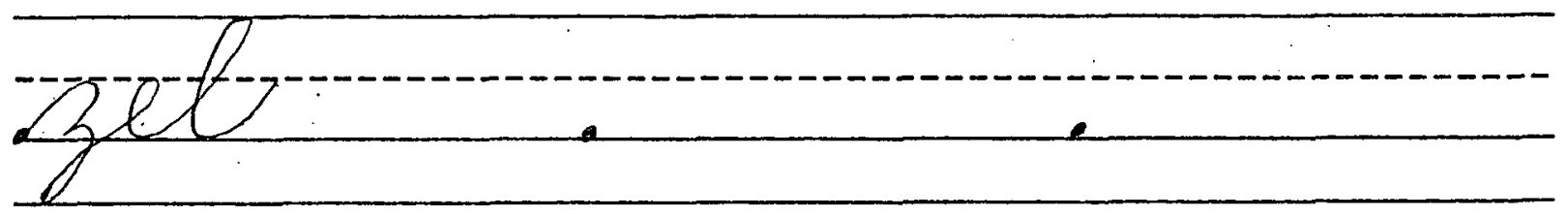


zing-zang:
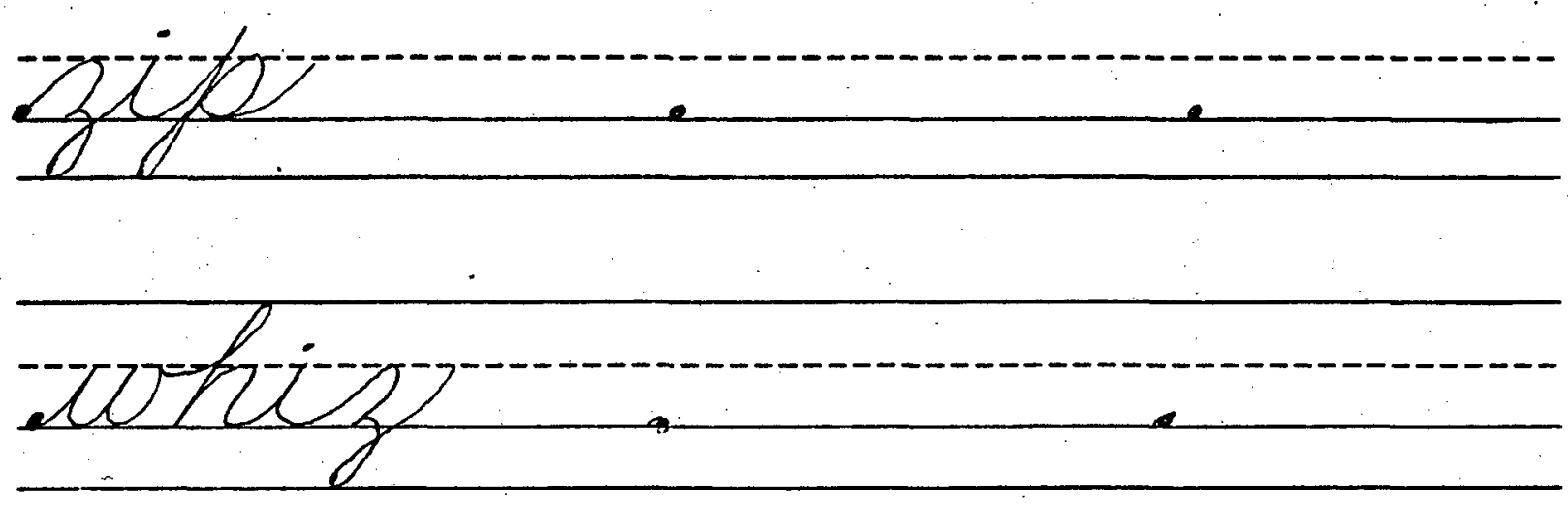
Circle each "z" below. Do it as fast as you can.

$\begin{array}{lllllllllllll} & a & b & f & l & z & p & f & z & r & s & z & \dagger\end{array}$

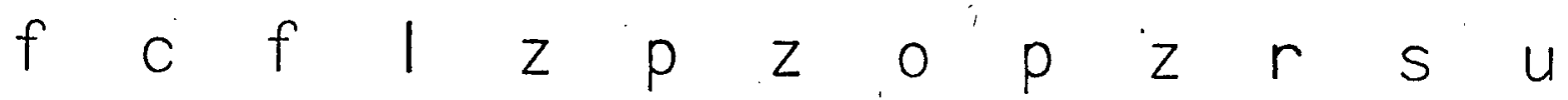

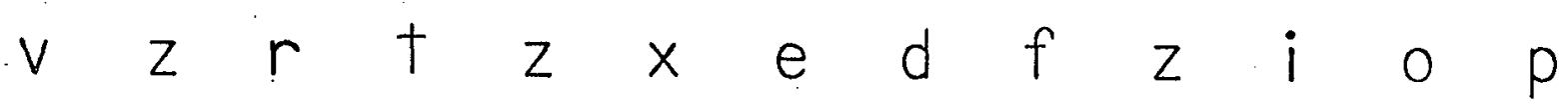

$z \quad o \quad p \quad u \quad y \quad z \quad s \quad w \quad r \quad t g r f h$

$k \quad z \quad x \quad c \quad e \quad r \quad t \quad s \quad g \quad f \quad d \quad s \quad z$

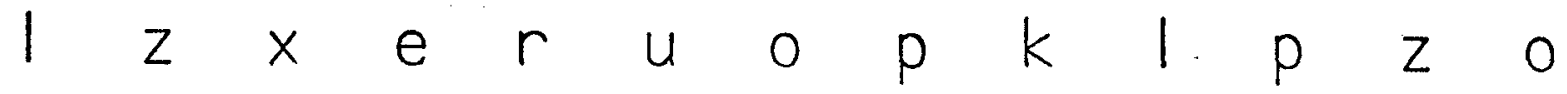

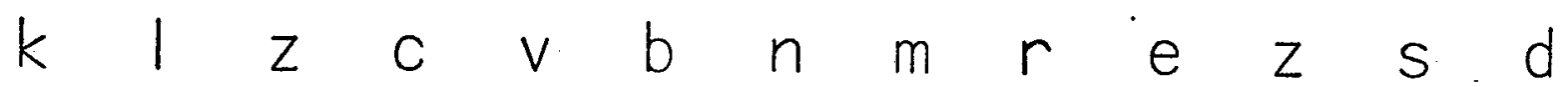

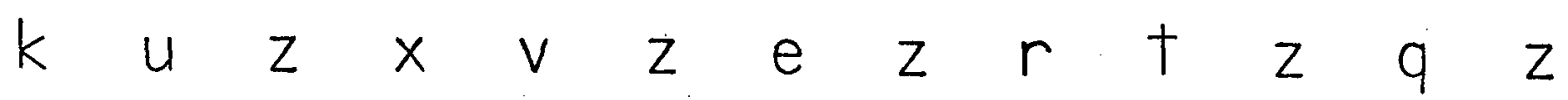

l $u+a \quad b \quad z \quad c \quad x \quad s \quad w \quad z \quad \dagger \quad y$

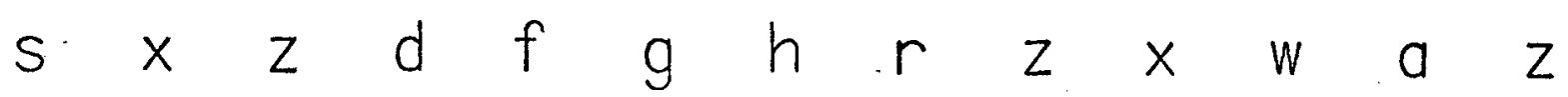

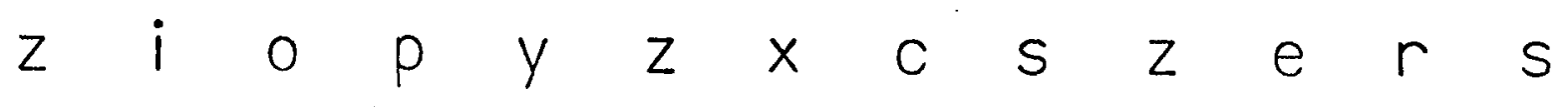




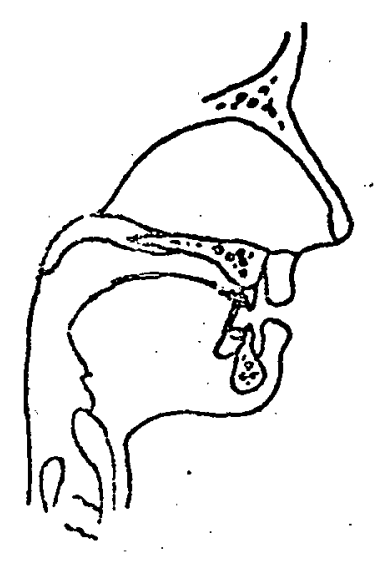

S

with a buzz /z/

as has is his 'tis as his has

as is his is 'tis as has is

siziziz patach begack ramanam

I unat potopot vovovov shoth

fix rig hack bib Sam

mix wig sack rib sham 
as

has

Buzzing $S$

is

/ z.l

his

'十is

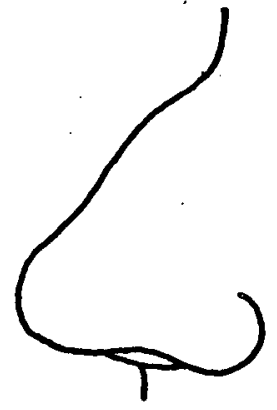

ad
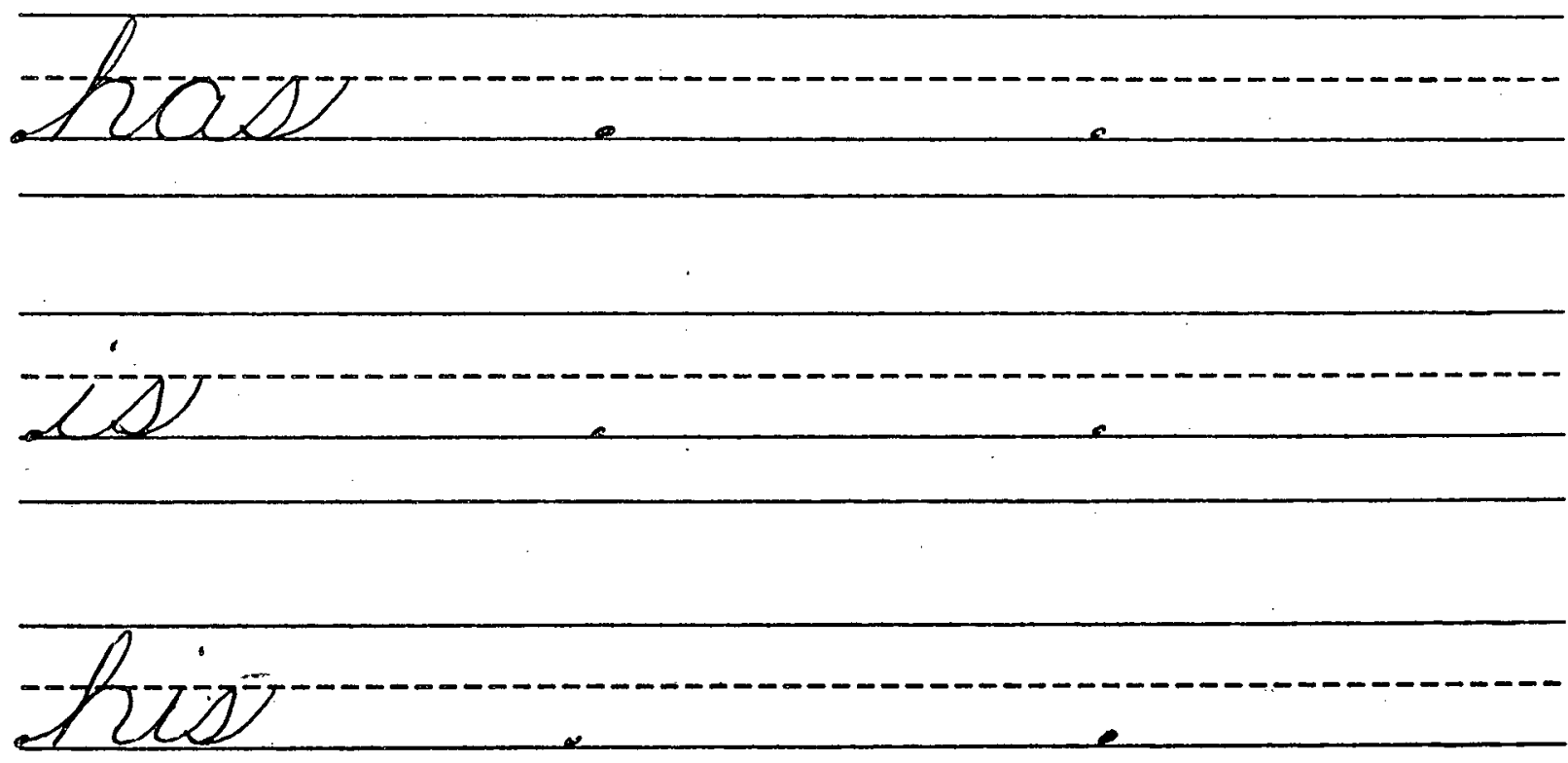


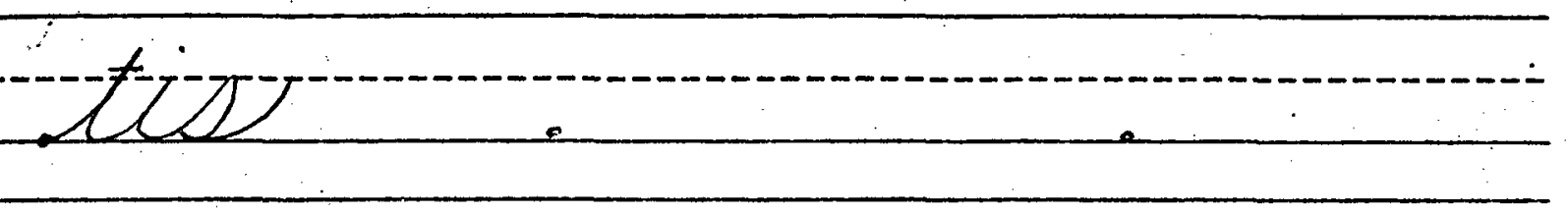


Circle the words that have the /z/ sound spelled with "s". Your teacher will read the underlined words.

this

those

grows

has

hiss

$\underline{\text { kiss }}$

$\underline{\text { nose }}$

pass

$\underline{\text { miss }}$

sis

$\underline{\text { miss }}$

knows

rose

$\underline{\text { hose }}$

sews

his

pose

looks

that's

Sam

pots

sick

those

close

dose

mows

loose

foes

lose

gas 
qu

quack quag quick quid quip quit

quiz quick quid quip quit quick

quanan pucuck locof seseset yeses

yezezez thininin quicocock vozaz

luck when fun lag that

tuck hen shun wag vat 


$$
34 b *
$$

quack

quag +

quick

quid +

quip

quit

quiz

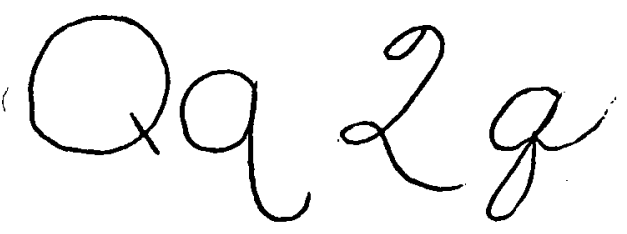

28

qu

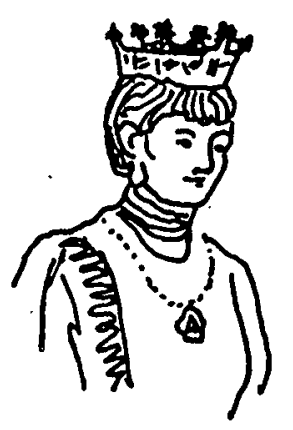

Q never does anything without $\underline{u}$.
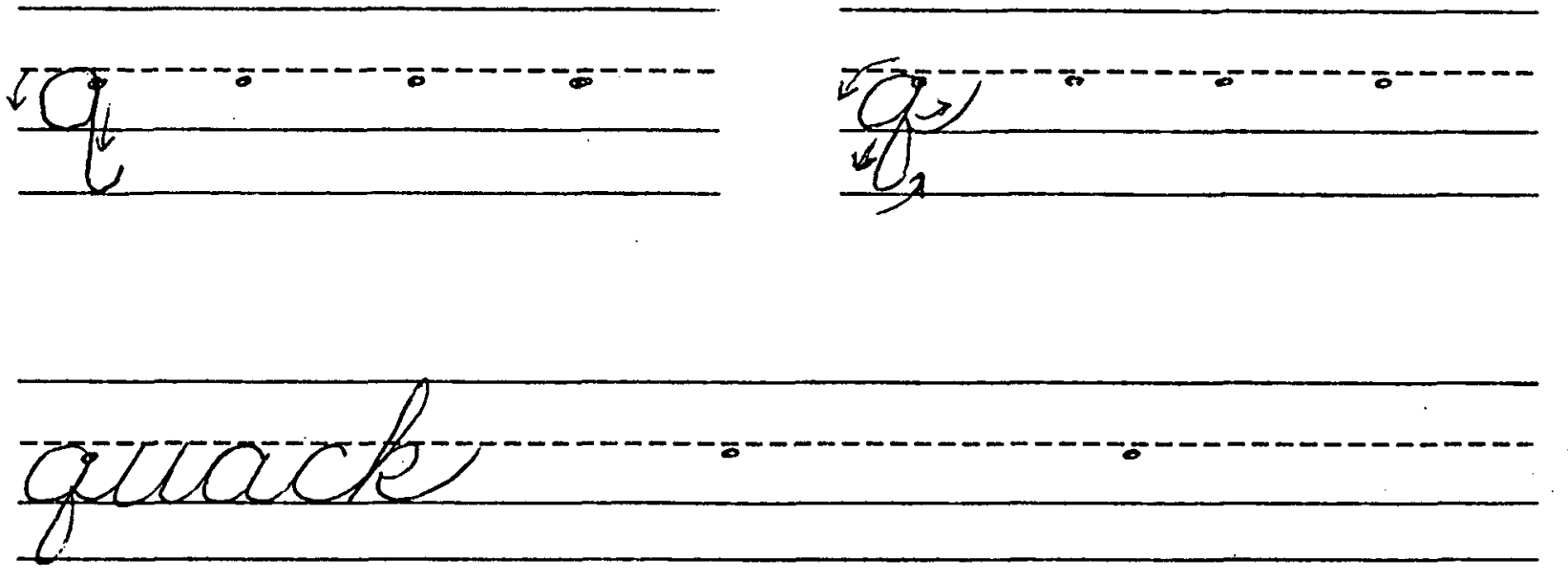

quag

quiche 
gutid

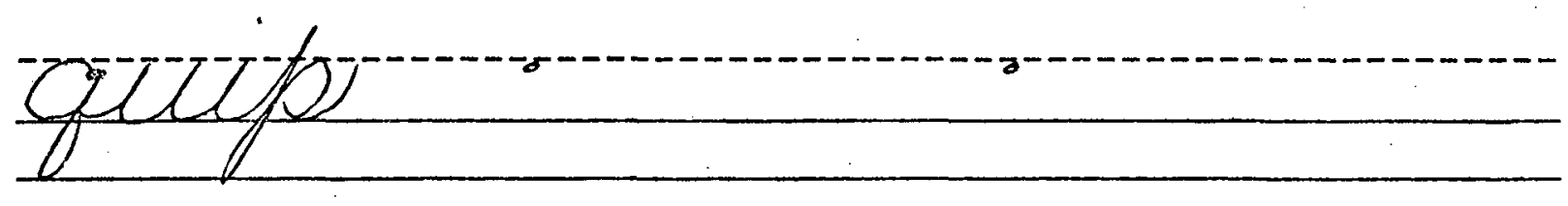

qutet

gitity - m n 
Read the sentences with the pictures. All of the picture-words begin with $q$.

Dan is not a

A is $25 \not$.

That is not a bad

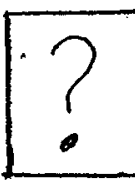

This is a set of " ".

Jack has a $\cong$ pen.

Circle each "q" as fast as you can.

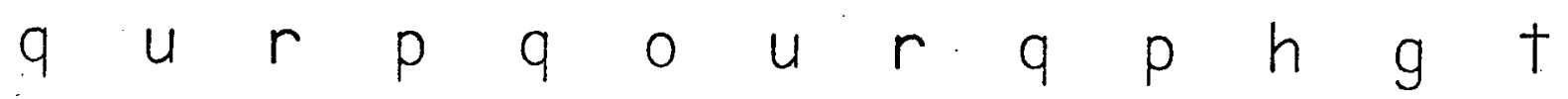

$q u+r$ s $k$ l $p g h \quad g \quad b \quad y$

$p q g d b \quad b \quad r \quad g+g f b h$

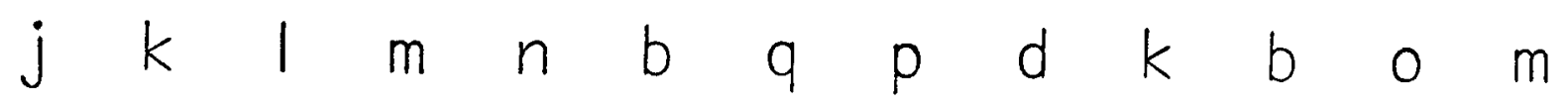

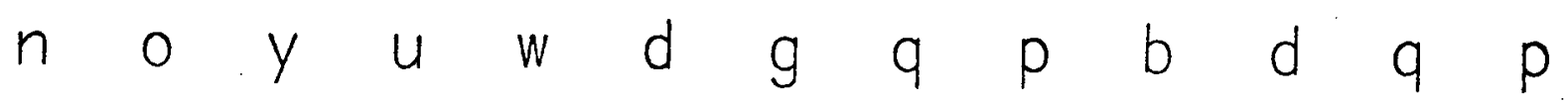




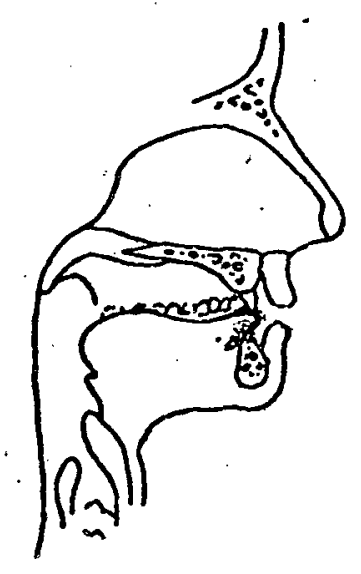

\section{th \\ $(\operatorname{sof} t)$}

thithin thin thudud thud thugug

thug bababath bath mamamath math

papapath path bebebeth Beth seseth

Seth mothomoth moth

zozozoth pacach yipix fovofor

thock zathath yivivix whimimick

sock that whim shop wax shock hat him hop sax 
thin

thud

thug

bath

math

path

Beth

Seth

moth soft th

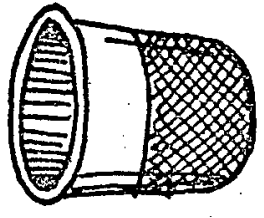

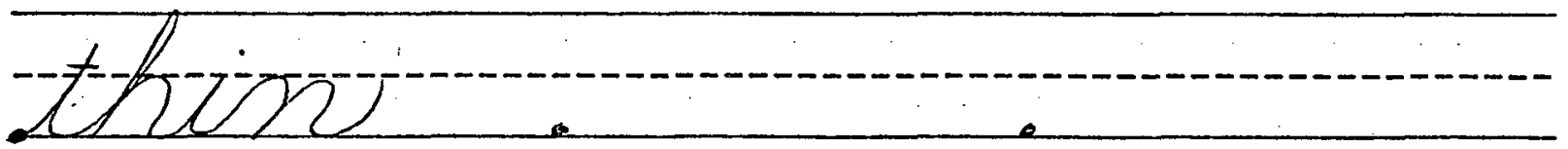
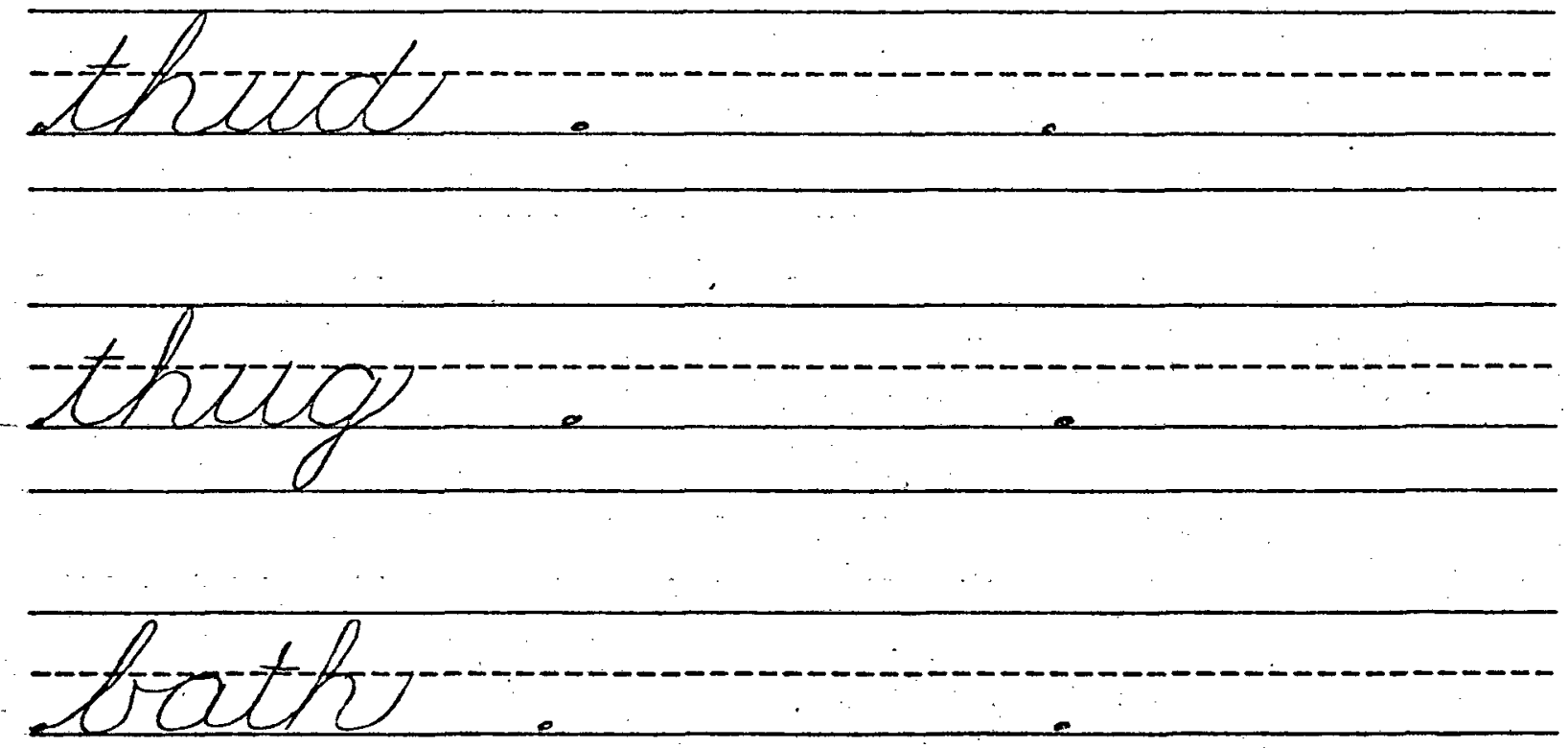
moth

poothe.

Beth

Eetho.

mothe. 
Your teacher will read a numbered word list. Circle the number of each word that has the soft th sound.

1

2

3

4

5

6

7

8

9

10

11

12

13

14

15

16

17

18

19

20

Tell a story that you have made up, using as many soft th words as you can. 


\section{Review - CVC Words}

Say the sound of each letter or digraph.

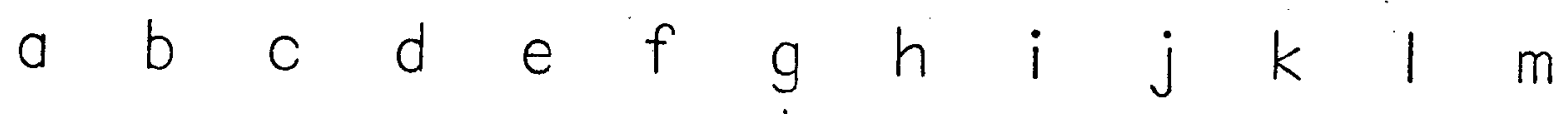
$n$ o $\quad p \quad q \quad r \quad s \quad t \quad u \quad v \quad w \quad x \quad y \quad z$ ch th-(voiced and unvoiced) sh wh

Read these words down the columns.

tan beg hid hot chum bath

can leg mid. lot hum math

fan peg rid cot gum path

them whim chock lush.

then whip chop mush

whit gush

Write the beginning and ending sounds belowseach picture.
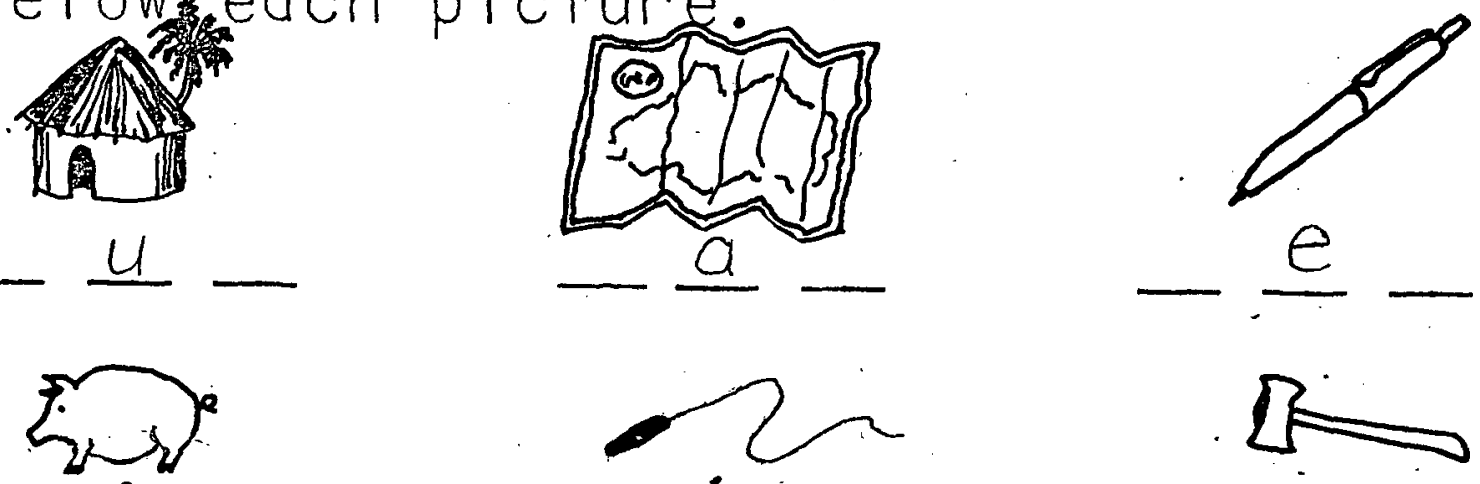

- 은

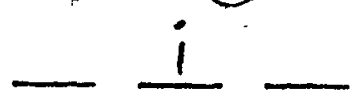

a 


$$
\text { ff-11-ss-zz Twins }
$$

dull pass puff jazz mess

buff miss doll pill fizz

thoff tosit zazazizez sazasez

chix chicacam shututox quimim

whit Jack quack box whit
whiff jazz shack fox whim




$$
37 b *
$$

buff

puff

pill

doll

dull

pass

mess

miss

jazz

fizz.

$$
\text { ff e-1t-5s-2z }
$$

Twins
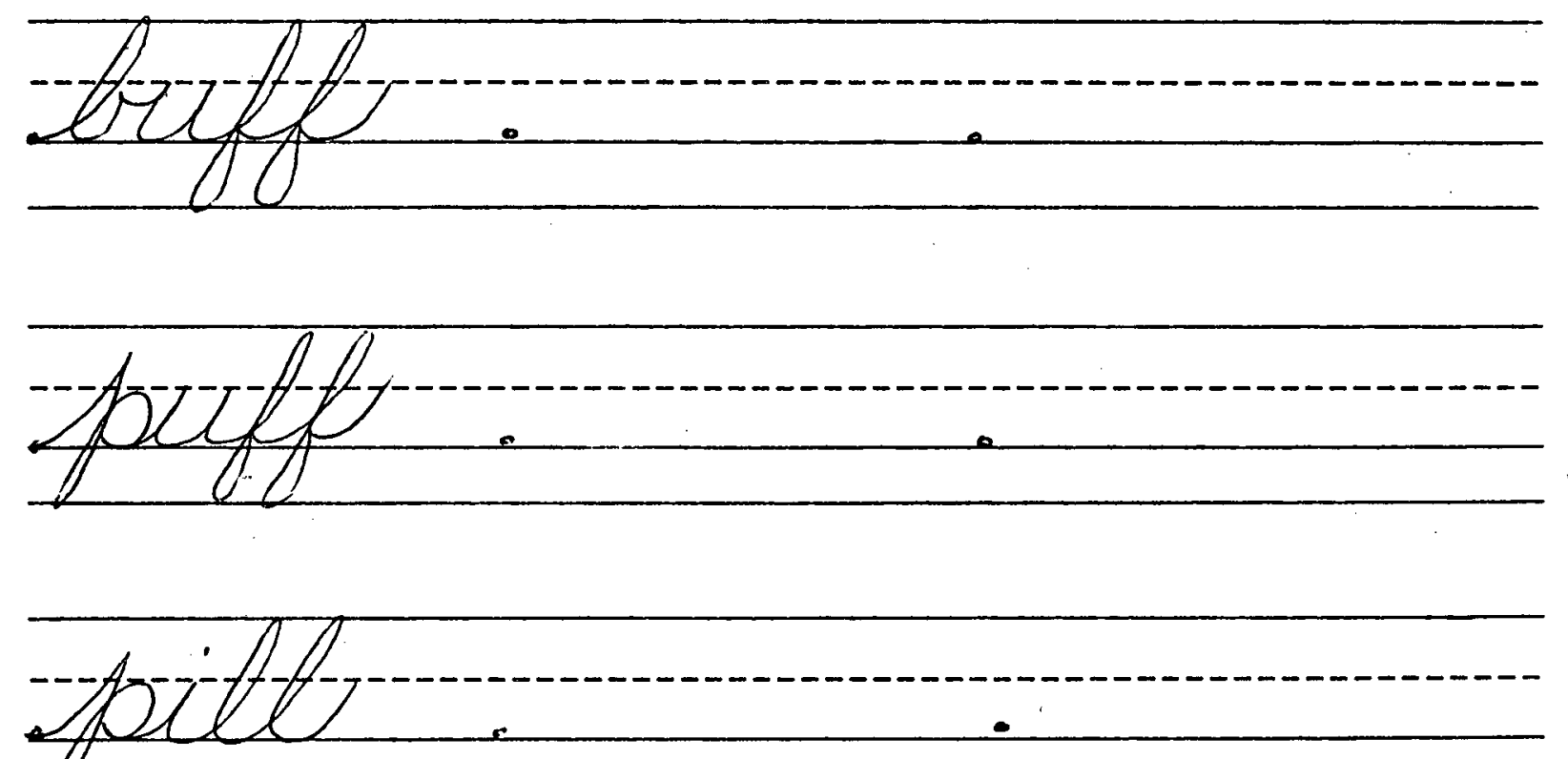

toft 


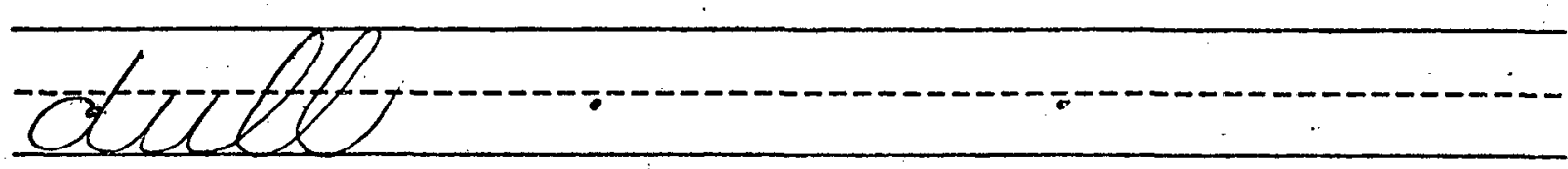

"taldy

272020
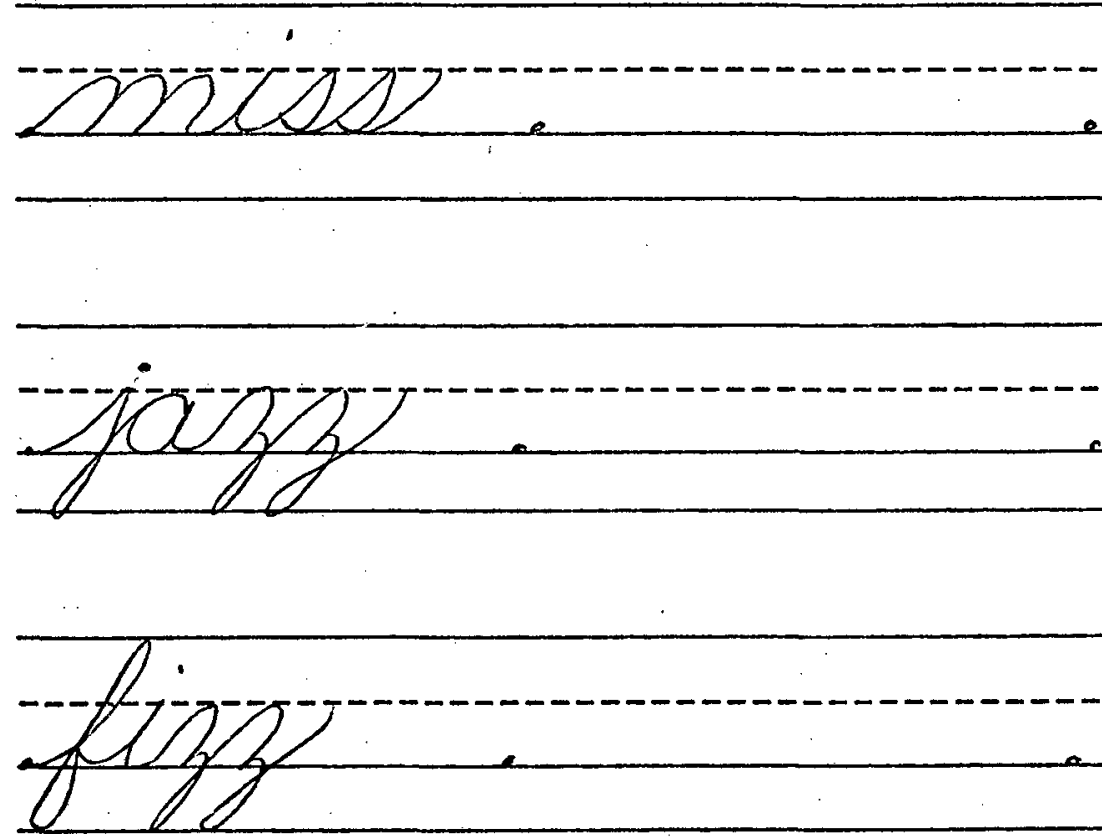
Write ten new ff-II-ss-zz words below.

1.

2.

3.

4.

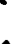

5.

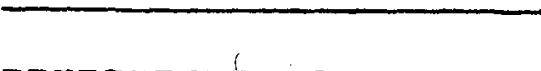

6

7 .

8.

9 .

10. 


\section{SYLLABIC TRANSITIONS}

bag man bagman up set upset

Bat man Batman can not cannot

dish pan dishpan ash can ashcan

suntan suntan cat fish catfish

sun set sunset whip lash

whiplash

optamdopmat. dzatfop casotmip

puntisaz timatfom zoshigmun 


$$
38 b *
$$

bag man

Bat man

dish pan

sun tan

sun set

up set

can not

ash can

cat fish

whip lash
Two-Sy| $|a b| e$

Compound Words

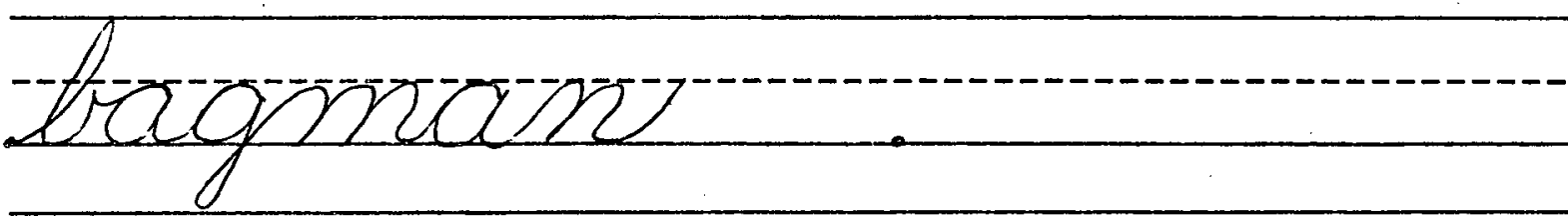

Batman

dishpan o

suntan 


$$
\underline{\underline{1}}
$$


Make new compound words with these words: fish, cat, sun, cob, with, hot, in, rod, up, mix, set. 


\section{Detached Syllables}

teleletel tel tetemem tem

memem mem mededed med hapap

hap chapachap chap dififif

dif disidis dis tumum tum

I umum I um

sen jus gog fab lin

den rus sog sab kin 


\section{Detached Syllables}

1.

tel

tem

mem

med

hap chap

dif

dis

†um

I um
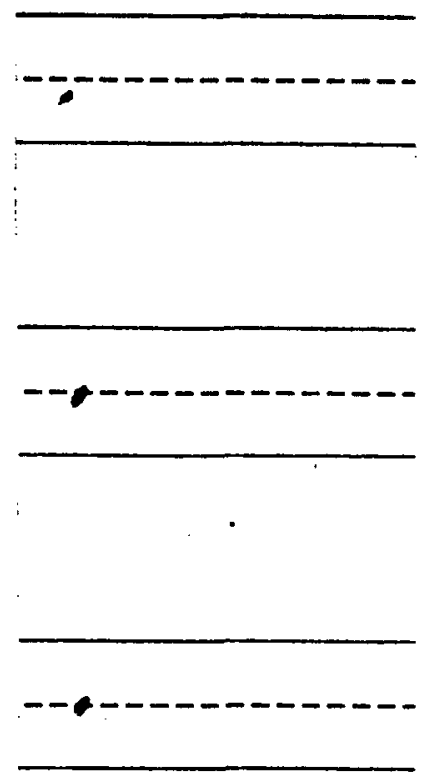
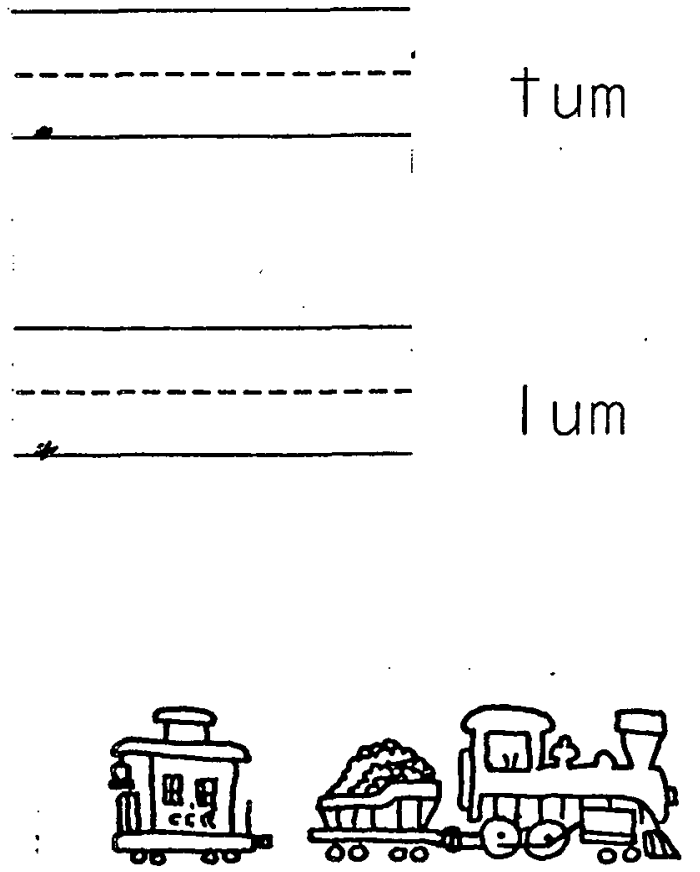
2.

(a)

(f)

(b)

(g)

(c)

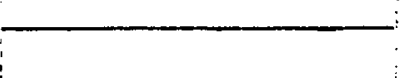

$+$

(h)

(d)

(i)

(e)

( j) 
Write the silly sentences that your teacher dictates. Be sure to use a period (.), a question mark (?) or an exclamation mark (:) at the proper time and place. Also remember to begin your sentence with a capital letter. 


\section{Review - CVC Detached Syl|ables}

Read the following syllables.

fes

dom

hap

dif

choc

sub

rus

$\mathrm{mal}$

hex

$\mathrm{col}$

whis

sem

sen

tas

doc

dis

lib

non

sev

sug

Spell the syllables your teacher dictates.

1.

6.

2.

7.

3.

8.

4.

9.

5.

10. 
Two-Syllable Words

mag net magnet tab let tablet

gob let goblet gob lin goblin

wit ness witness can did candid

ban dit bandit pic nic picnic

hic cup hiccup cactus cactus

tedandatut mitnumtum pimpadempsup

pagnutnis optictendapmic dactic

pill wit can box is
fill fit van ox his 
mag net magnet

tab let

gob let

gob $\quad$ in

wit ness

can did

ban dit

pic nic

hic cup

cac tus tablet

goblet

goblin

witness

candid

bandit

picnic

hiccup

cactus
Two-Syl|ab|e

Words

incignets.
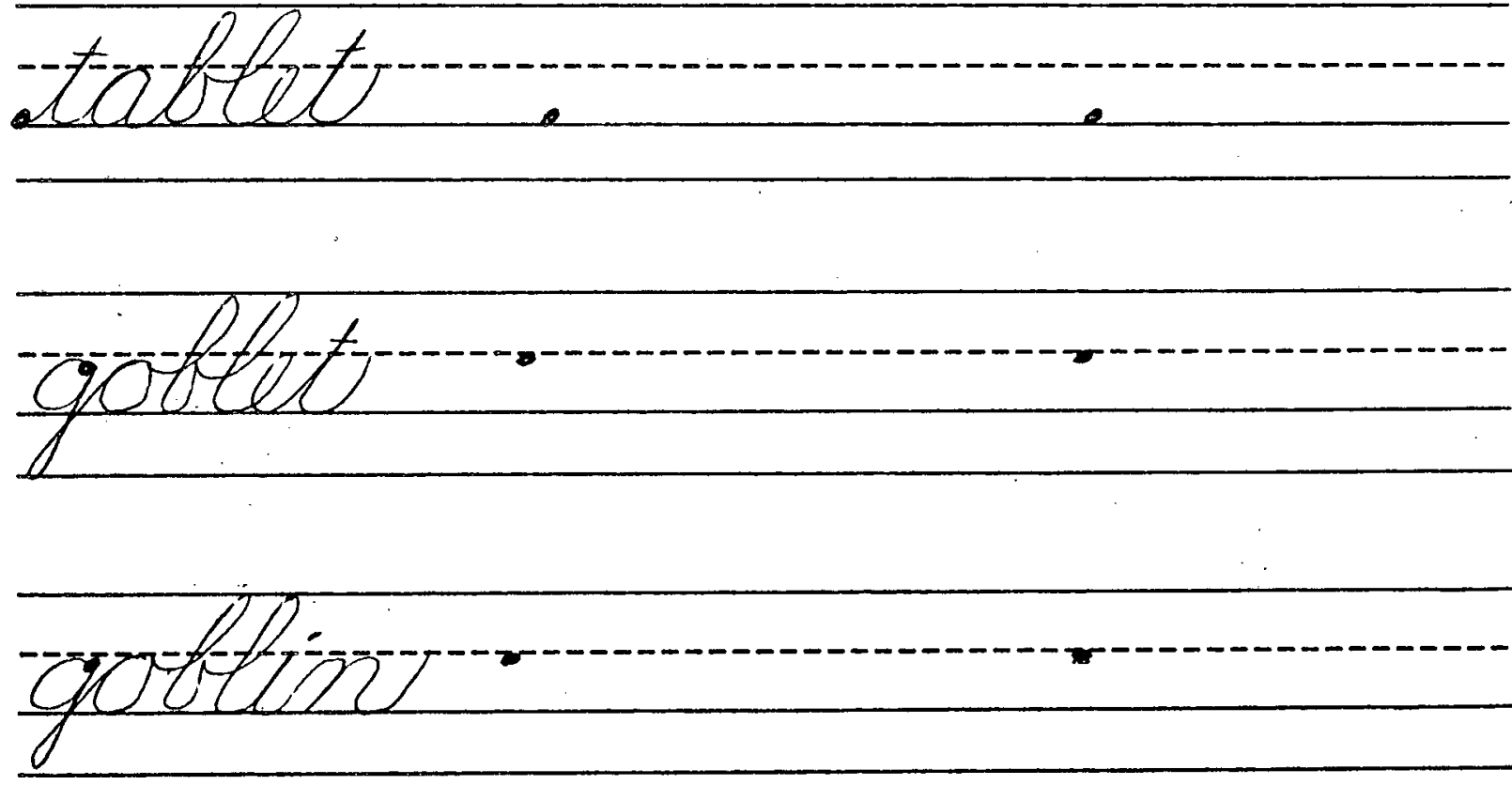
arcitneoss.

connatiot

bondit...

pionic

Zivocutp.

castus 
Make words from these detached syllables by drawing lines to the matching syllable.

bas

ban

ken

in

vic

bon

$r a b$ dit

nel

ket

†im

net

dex

bit 
s_ Blends

cat scat kit skit sim slim

sog smog nap snap pat spat

top stop sim swim lash slash

Iush slush mash smash lash

slash cuff scuff rill shrill

kill skill sell smell nuff

snuff sell spell taff staff

till still tuff stuff tress

stress well swell

stracneshpas stashrim spemitim

whignet cuctam pucnet chitnut 


$$
42 b_{1}^{*}
$$

1 .

$$
\begin{aligned}
& \text { sc - scat } \\
& \text { sk - skit } \\
& \text { sI - slim } \\
& \text { sm - smog } \\
& \text { sn - snap } \\
& \text { sp - spat } \\
& \text { st - stop } \\
& \text { sw - swim }
\end{aligned}
$$

Initial Consonant Blends
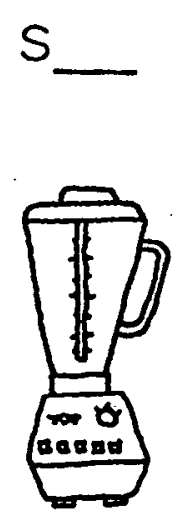
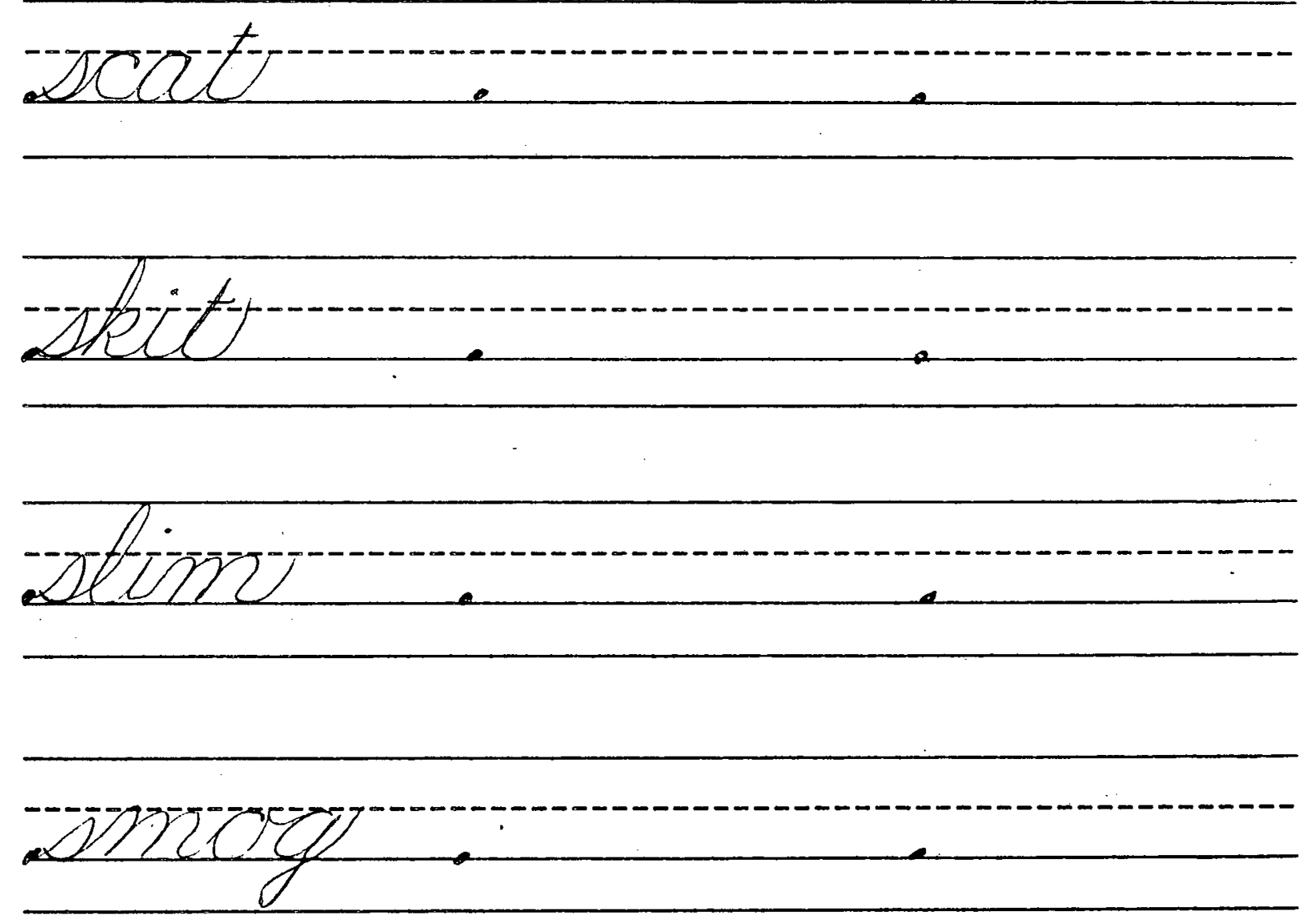

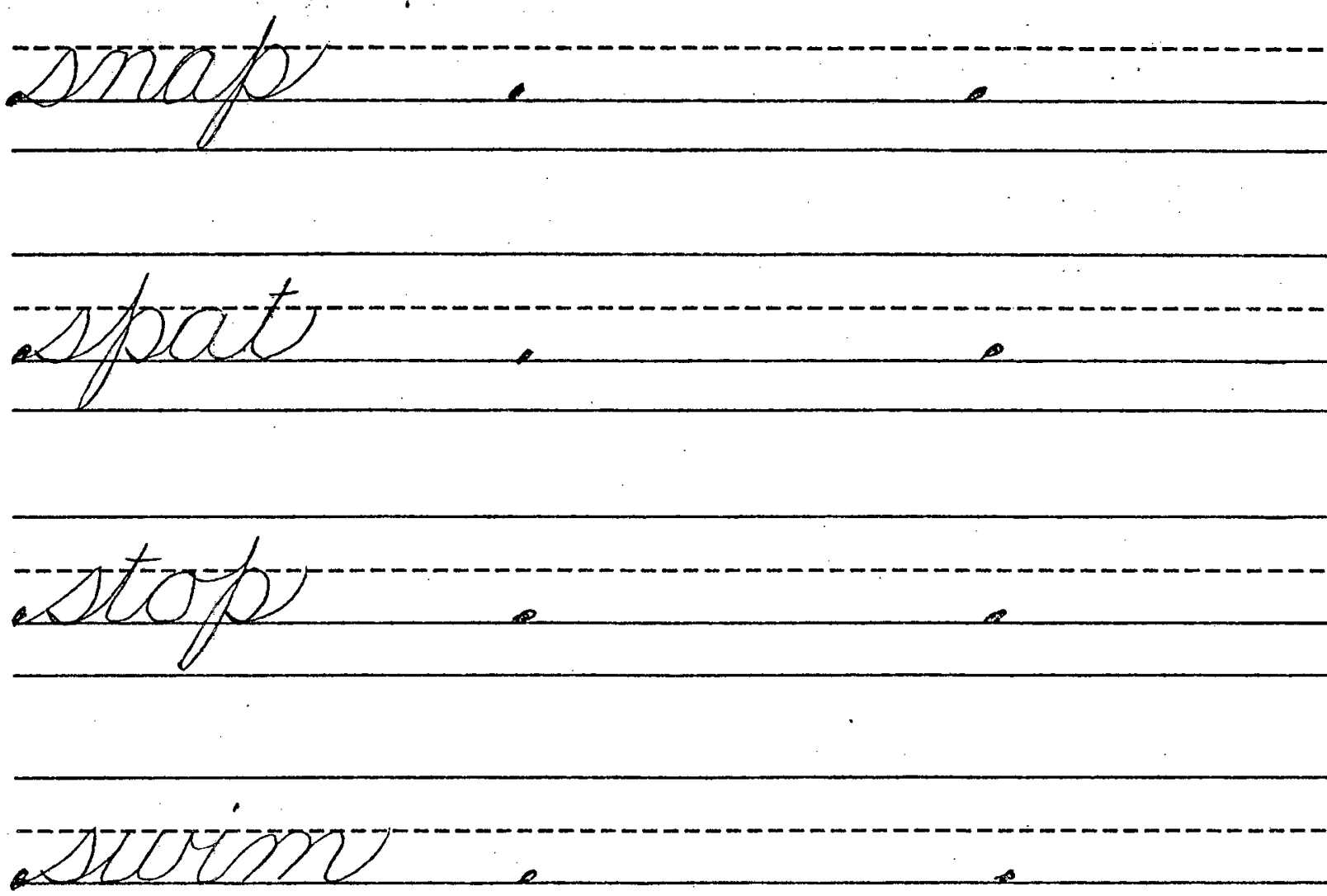
$42 b_{2}^{*}$

$$
\begin{aligned}
& \text { scr - scrap } \\
& \text { spp - sprig } \\
& \text { cpl - split } \\
& \text { squ - squid } \\
& \text { str - stream }
\end{aligned}
$$

s_ Blends
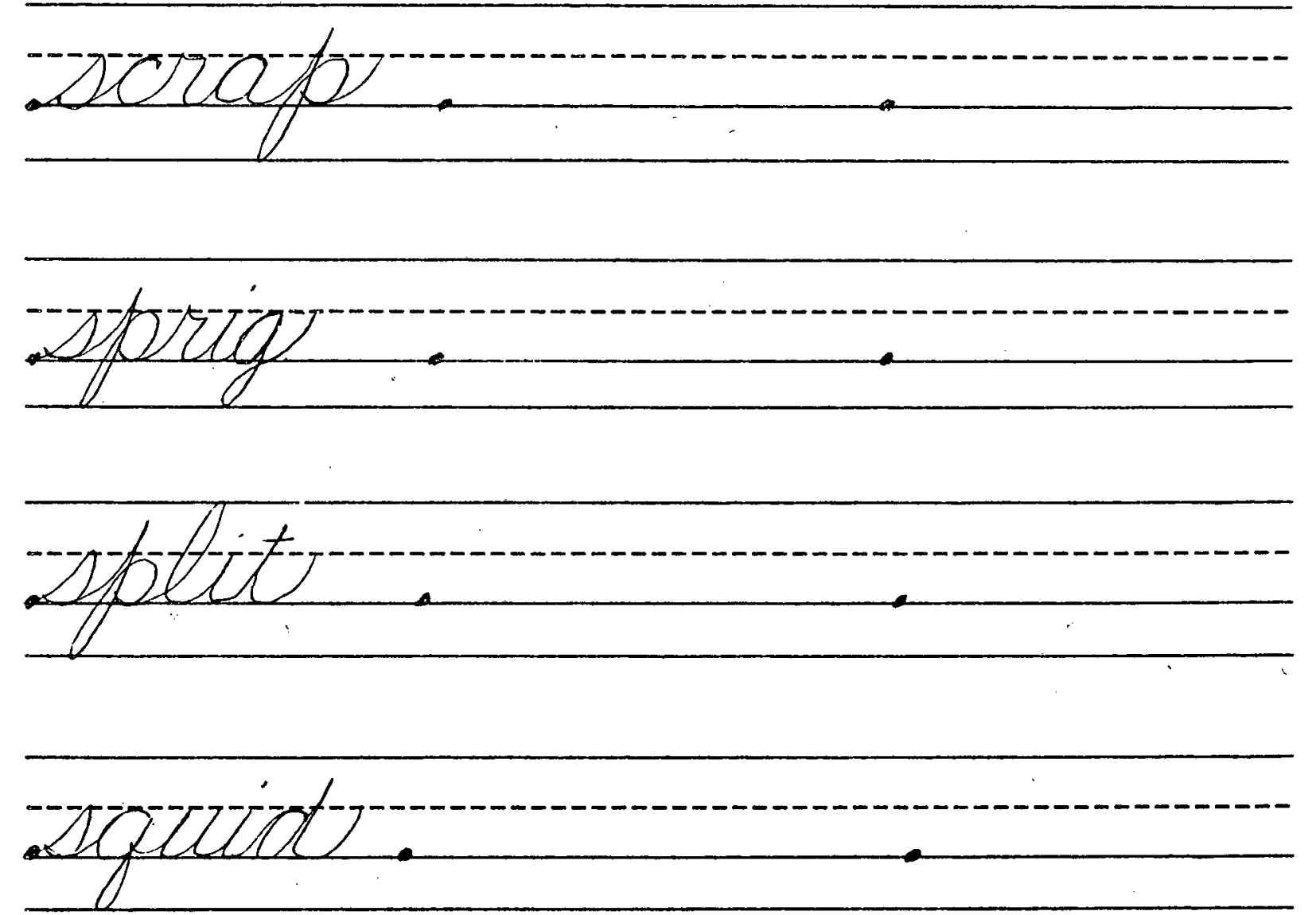
४⿻ 


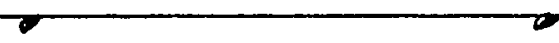

2 APDLER

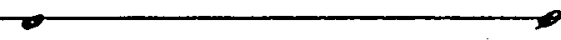

ACALZPLC

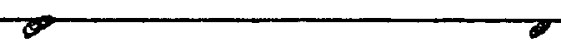

IPISPID

$<$

YSDWS

usnis

spuə|g-s

YSDIS

* ${ }^{\varepsilon} \mathrm{q}$ 力 


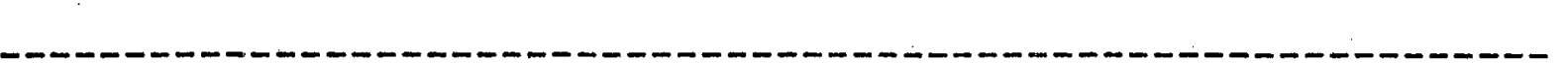


3. scuff

s_ Blends

shrill

skill

smell

snuff

spell.

staff

still

stuff

stress

swell
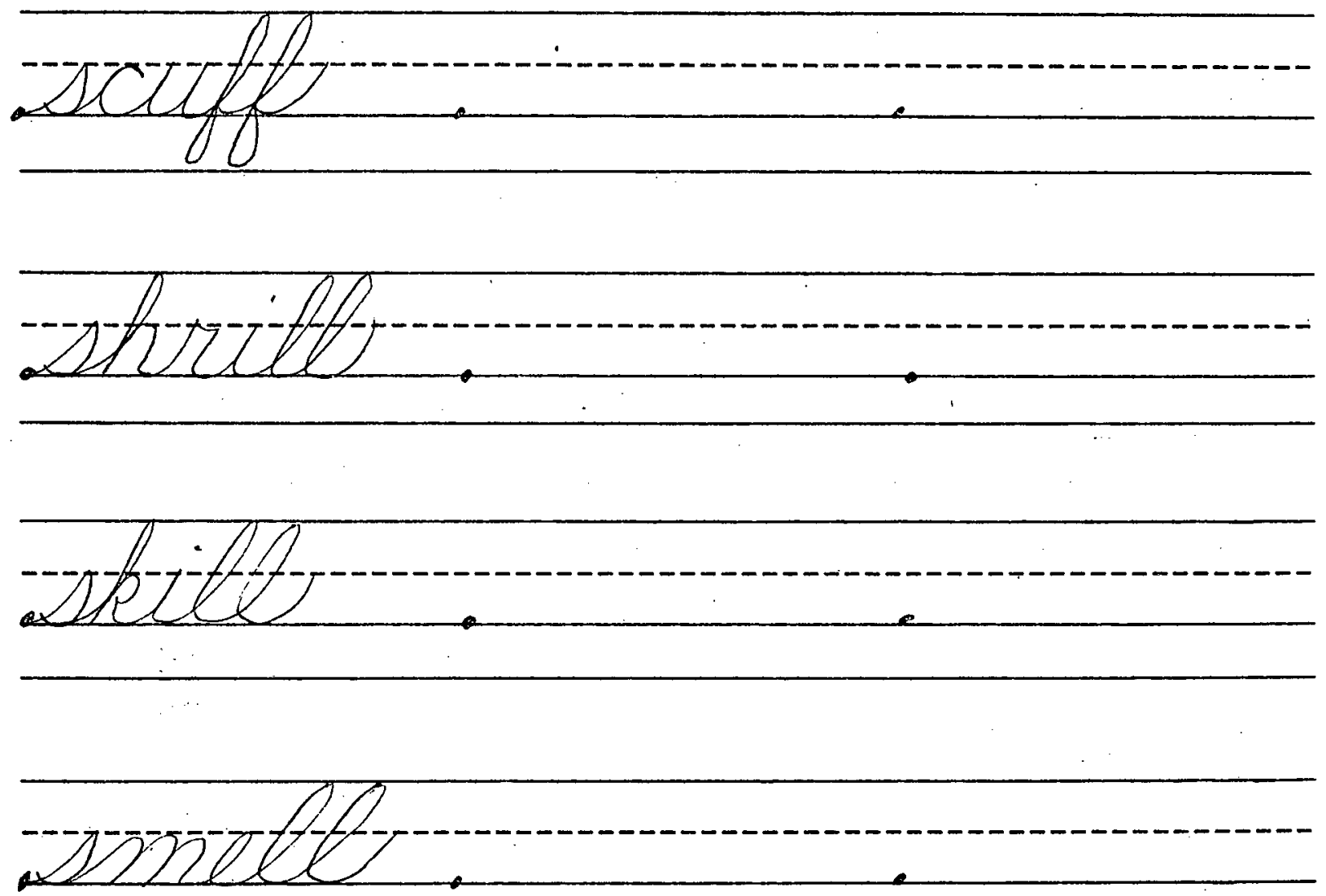

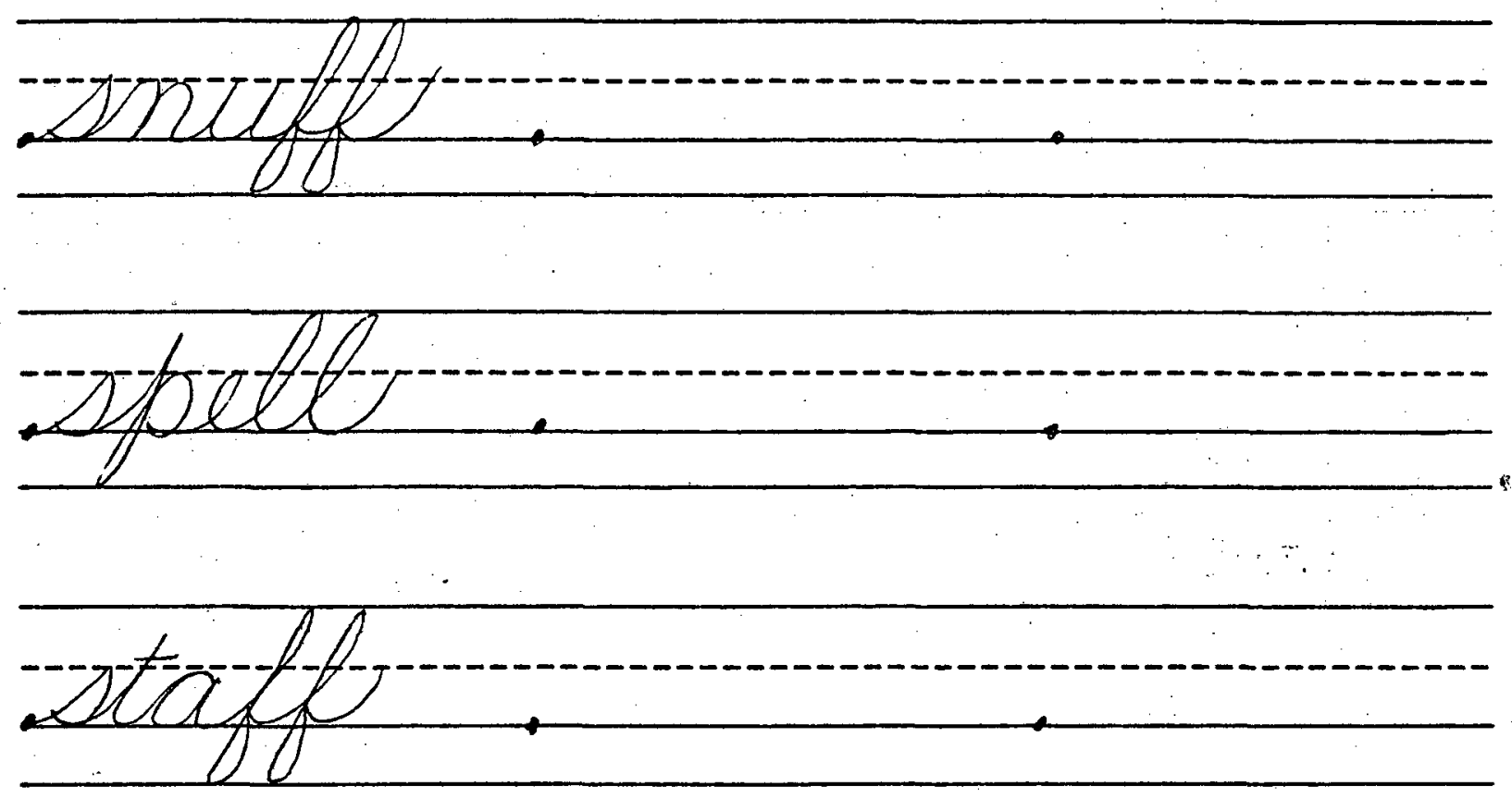

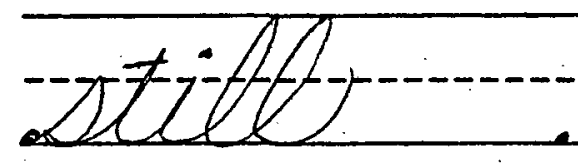

2171

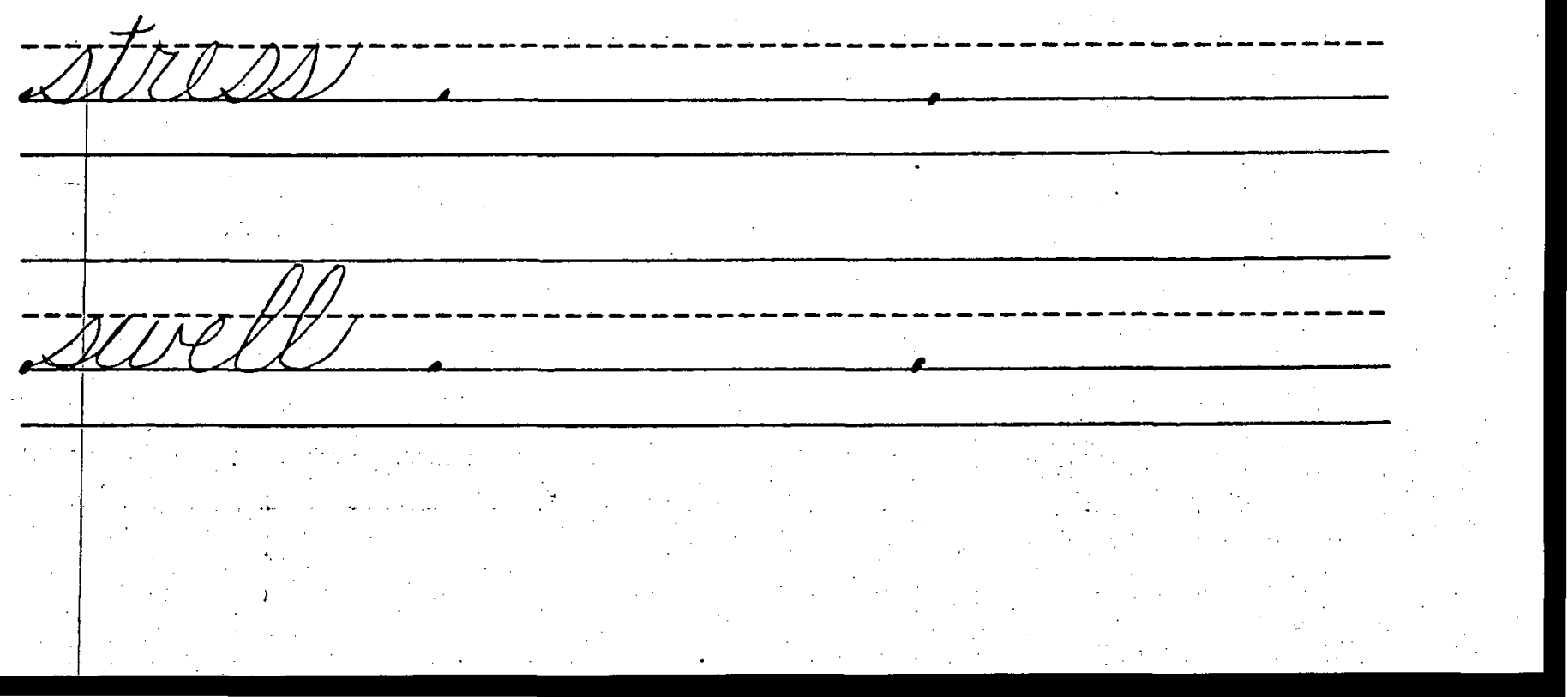


Write other words that have initial s_blends. 


\section{- 1 B I ends}

lot

blot

lip

clip

$\operatorname{lag}$

flag

gob

$g \mid o b$

I um

plum

led

sled

lash

flash

Iush

blush

Iesh.

flesh

Iush

flush

Iush

plush

lass

glass

liff

cliff

less

bless lass class

b laf I op

clapusleff

plep lapap

blebiblub

claceclucat

glaceclag 


$$
43 b_{1}^{*}
$$

1.

$$
\begin{aligned}
& b l \text { - blot } \\
& c l \text { - clip } \\
& f l-f l a g \\
& g l-g l o b \\
& p l-p l u m \\
& \text { sI -sled }
\end{aligned}
$$

Initial Consonant

Blends

$-1$

起

ac o
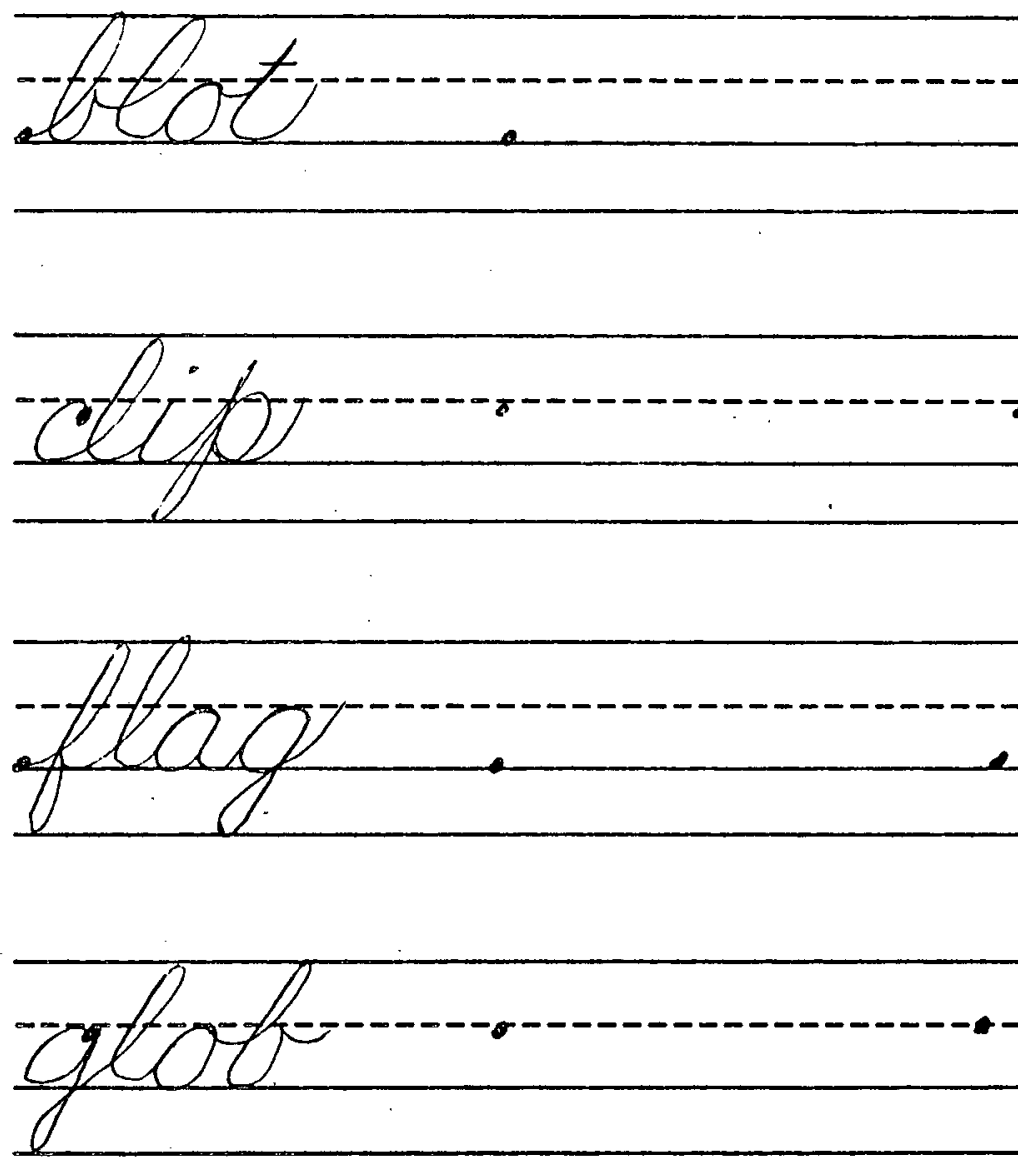


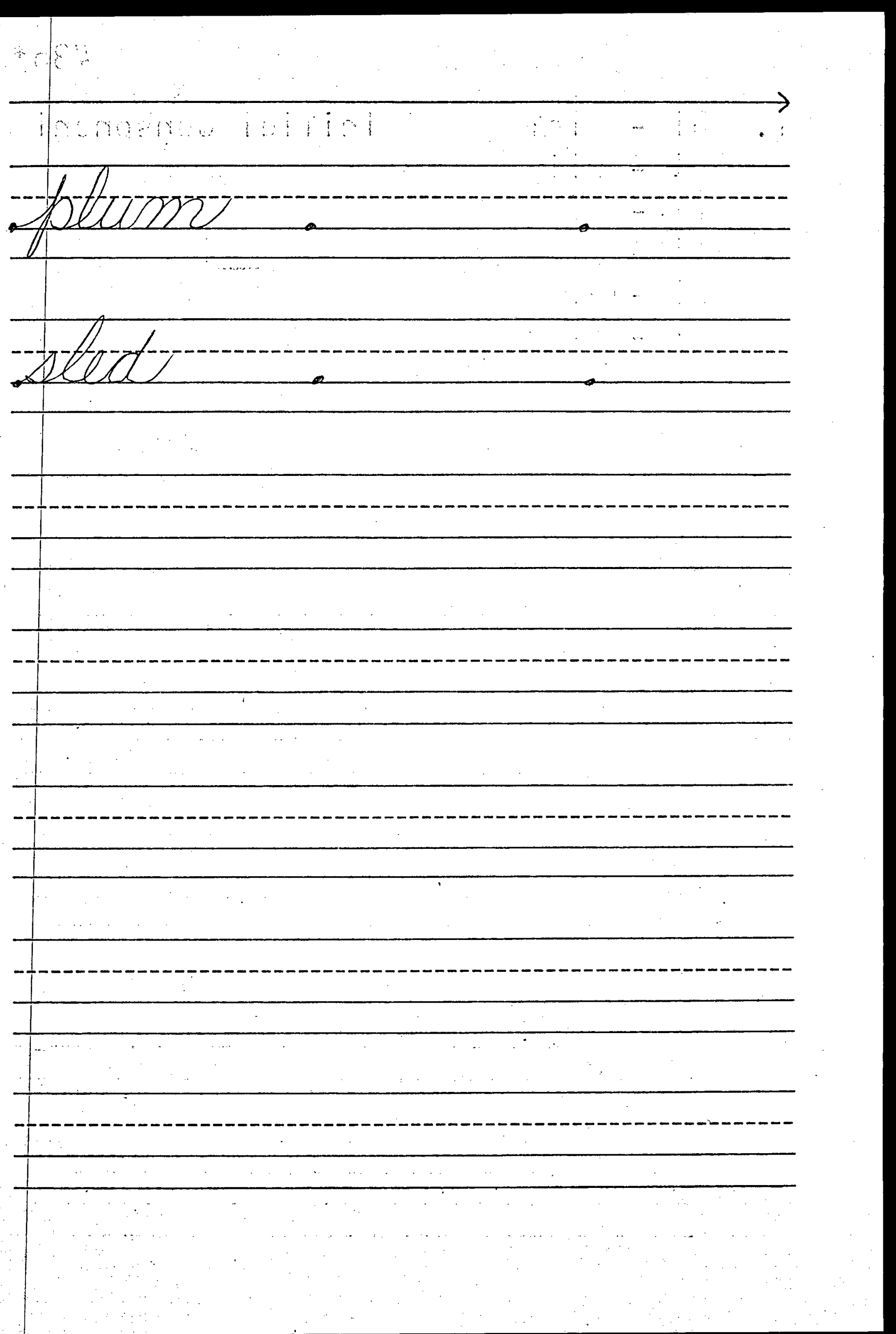




$$
43 b_{2}^{*}
$$

2. flash

blush

flesh

flush

plush
- 1 Blends
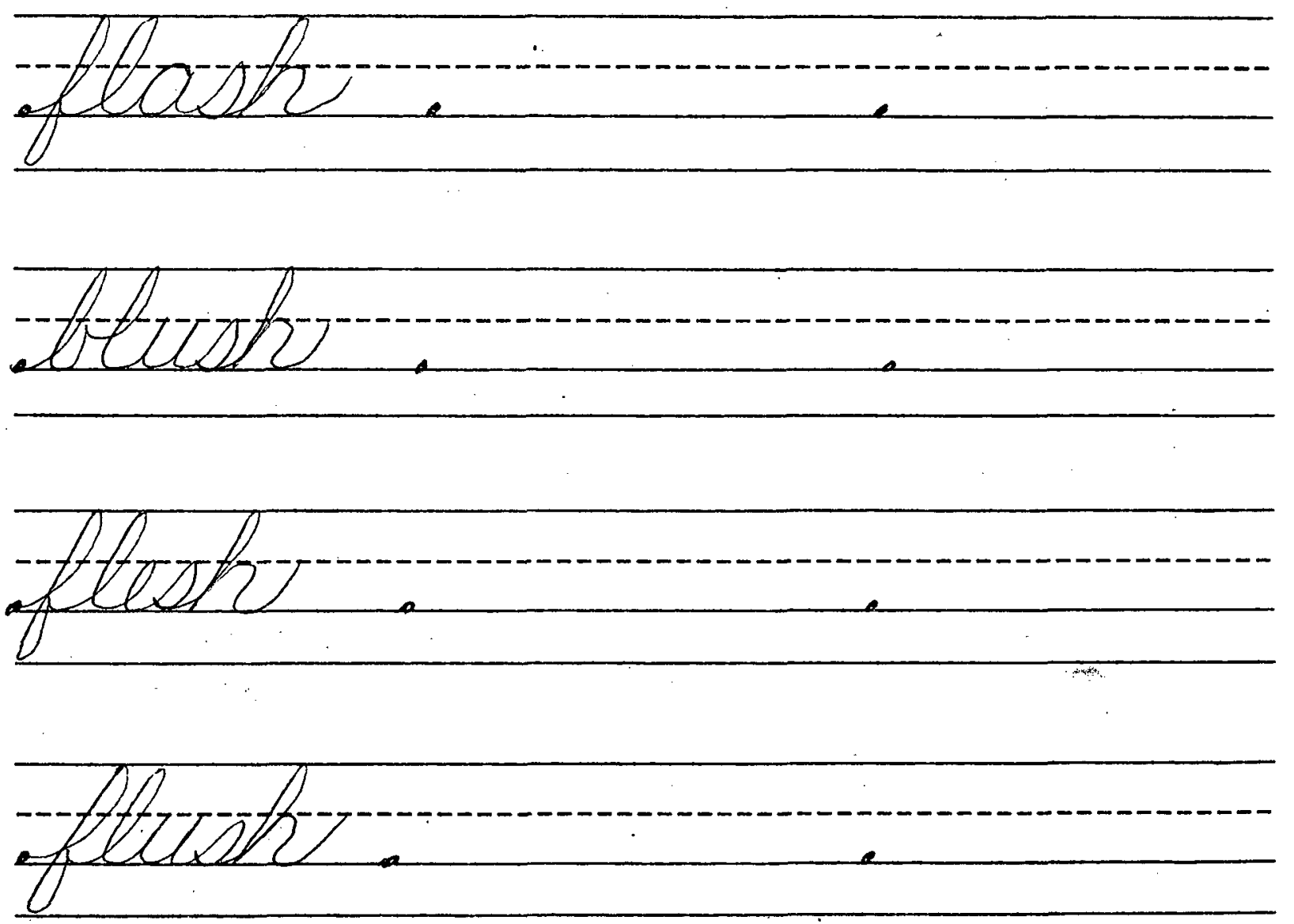


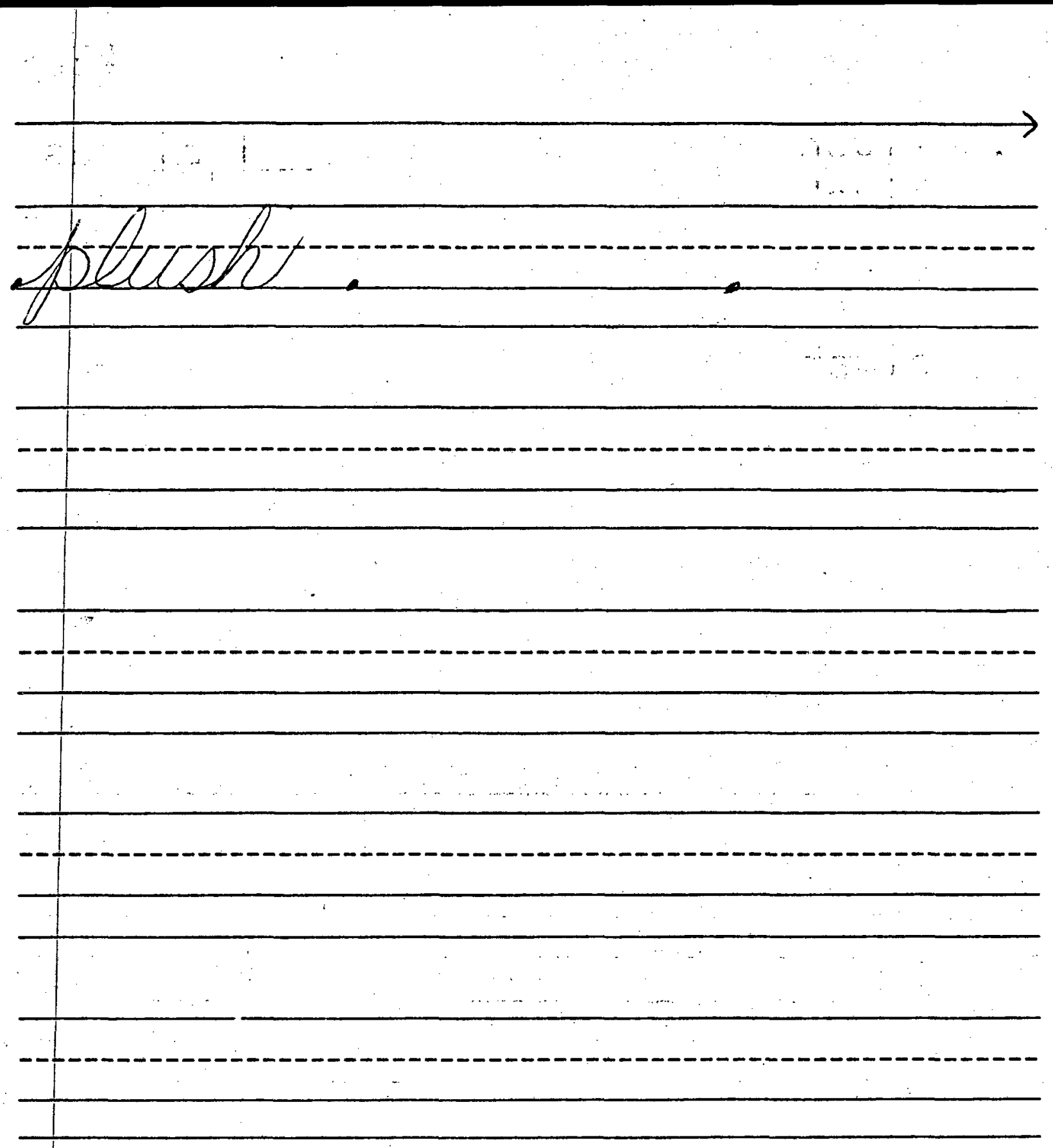


3. glass

cliff

_l Blends

bless

class
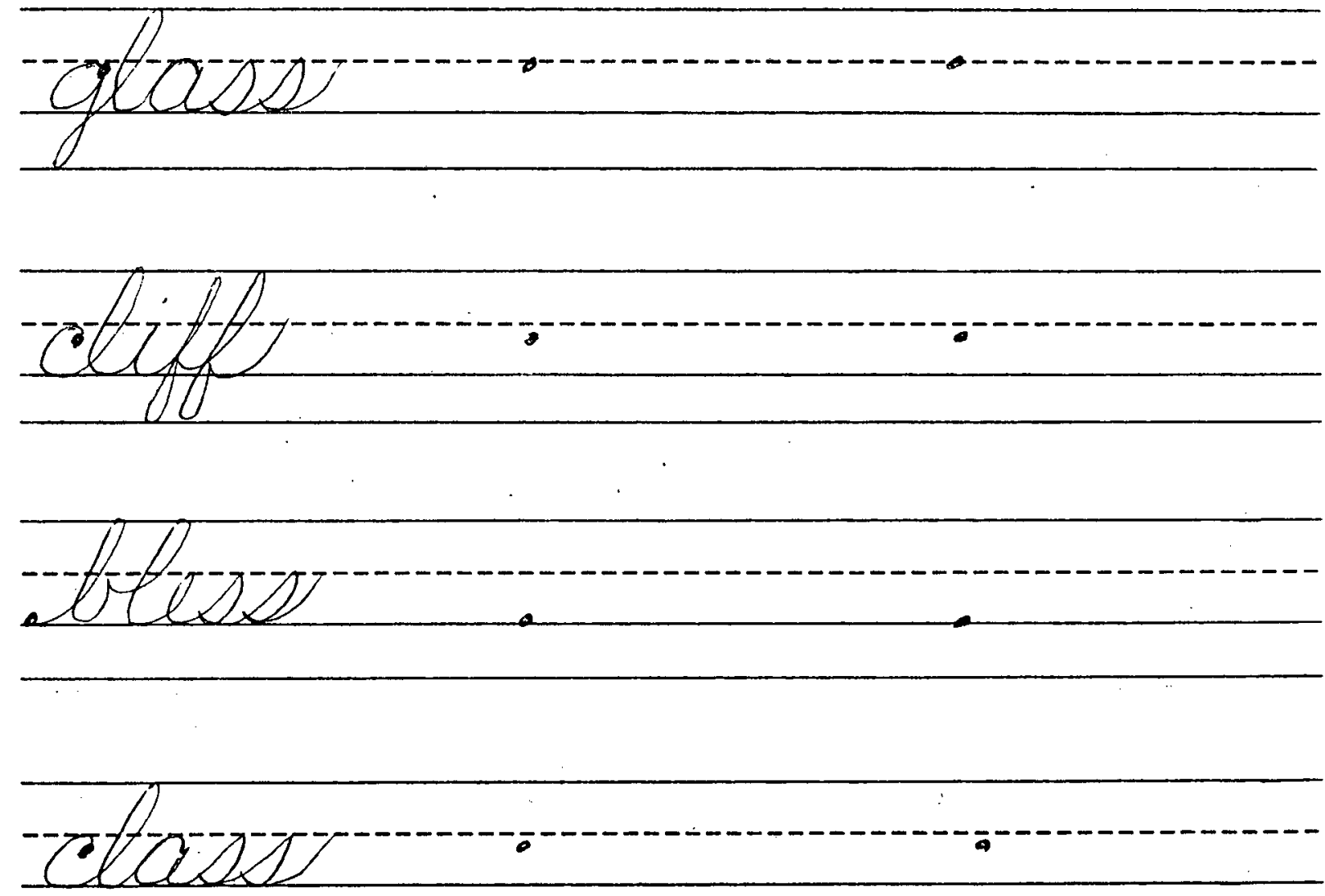
$2 \rightarrow+\infty=1 ;$

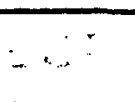


Write new words using the _l blends. 
_r Blends

bat brat rack crack rop drop

fog frog rip grip pop prop

rim trim rob throb rub

shrub rush crush rash trash

cash crash rush brush resh

fresh rass grass pess press

rill frill till trill rill

thrill

tretratutrit crecocrac gragigreg

brobafrack cogragucrap dridaprim 


$$
44 b_{1}^{*}
$$

1.

$$
\begin{aligned}
& b r \text { - brat } \\
& c r \text { - crack } \\
& d r \text { - drop } \\
& f r \text { - frog } \\
& g r \text { - grip } \\
& p r \text { - prop } \\
& \text { tr - trim } \\
& \text { the - throb } \\
& \text { shr - shrub }
\end{aligned}
$$

Initial Consonant

$B I$ ends

$r$

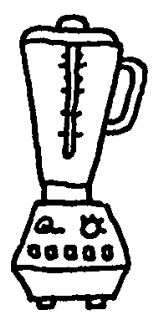

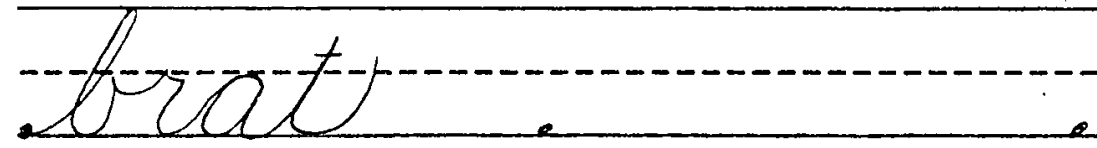

crater

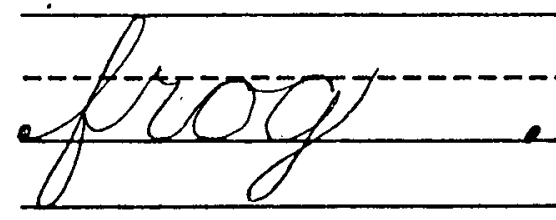


gripo

preop.

trions.

thorite.

ahoute. 
2. crush trash _ $r$ Blends crast brush fresh
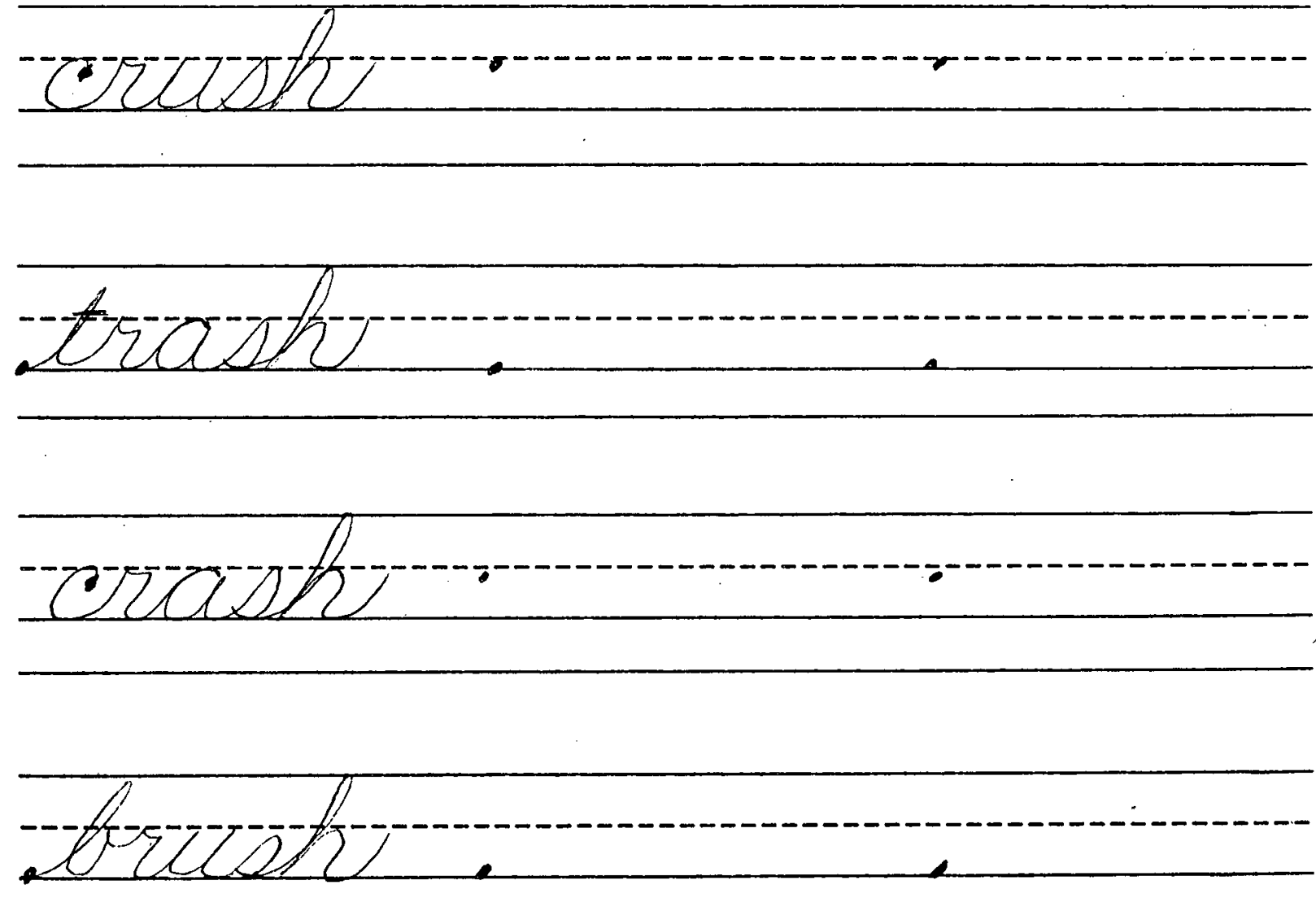
$\therefore i$

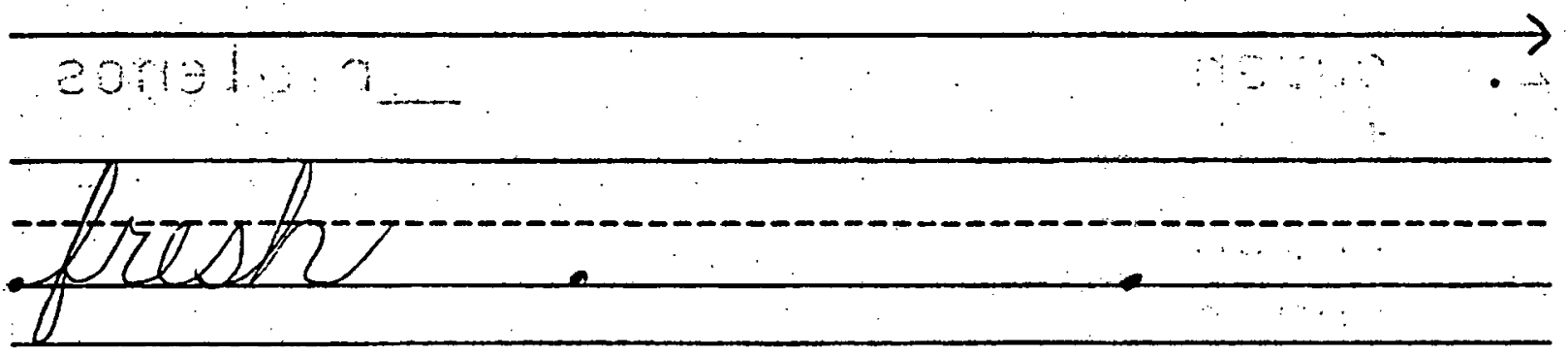

$$
\because \div
$$

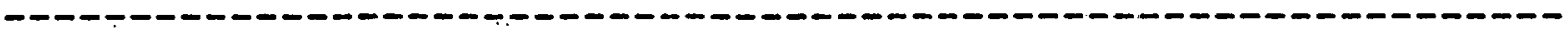

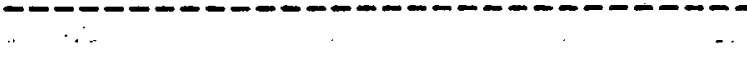

$$
\text { . }
$$

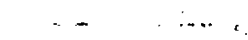

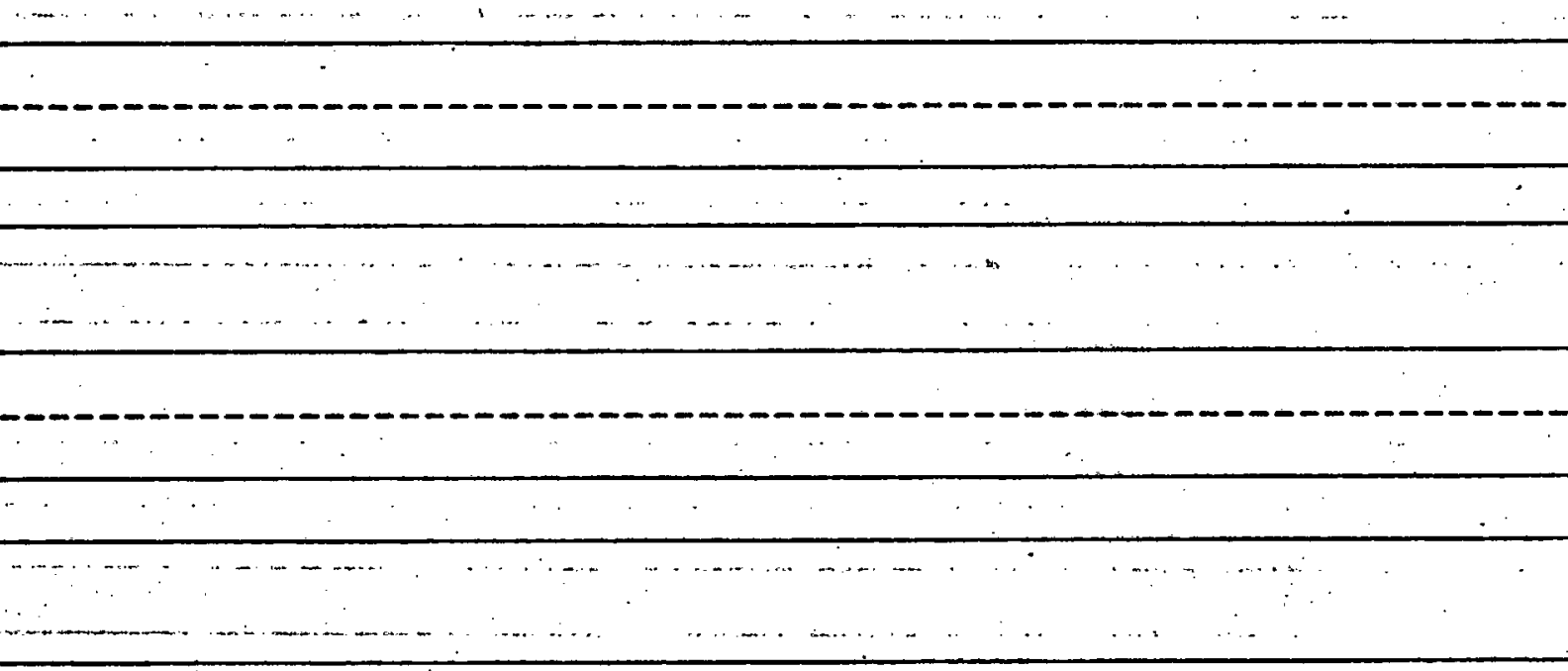

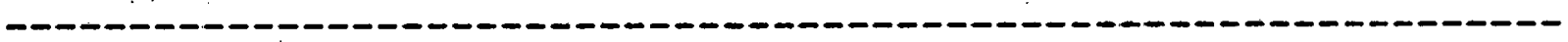




$$
44 b_{3}^{*}
$$

3. grass

r Blends

press

grill I

brass

dress

frill

trill

thrill

forts on.

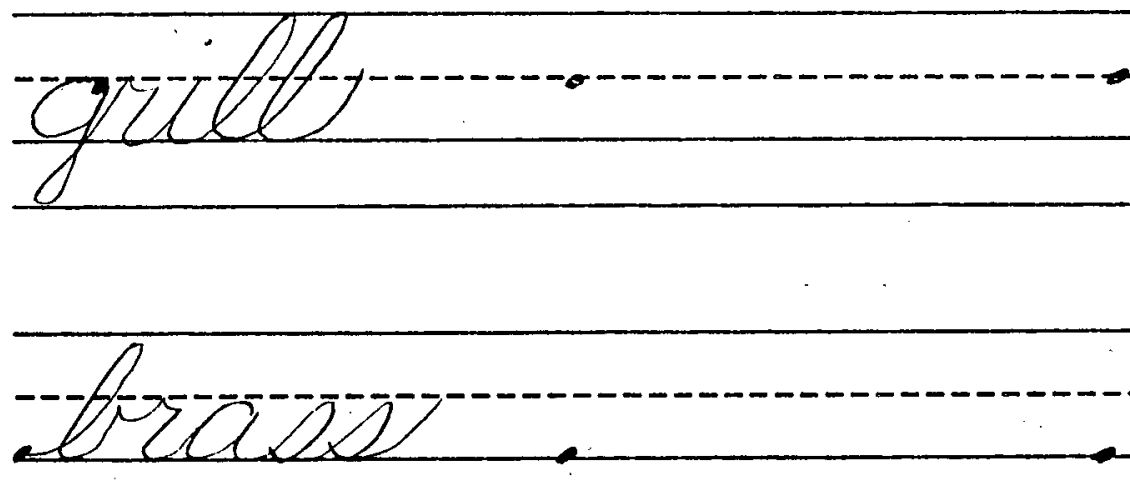


$\therefore \ldots$

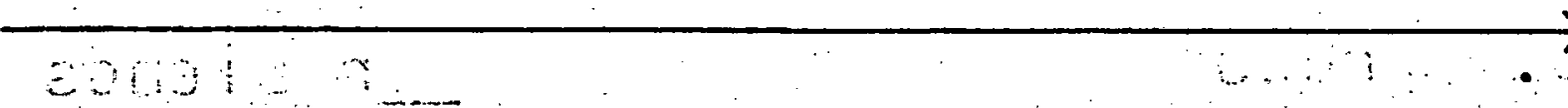

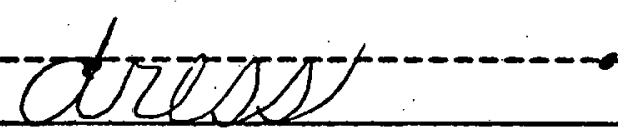

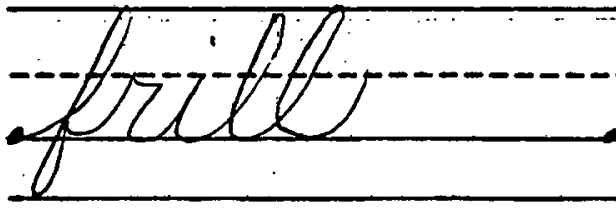

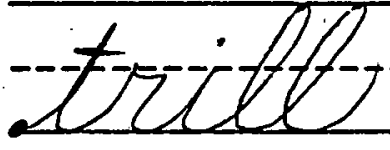

1727

$\therefore$

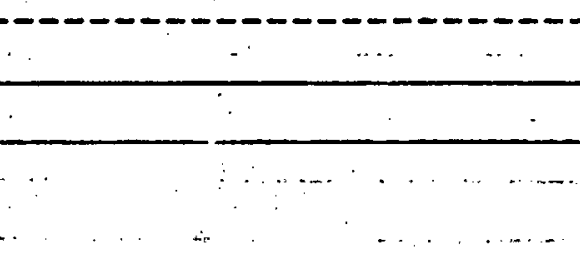


Write new words using initial _r blends. 
—w Blends

Sam swam wim swim sop swop

win twin (quit) wish swish

well dwell sell swell will.

twill

swapritwom dwemiprob twiplubub

quimislot swatix quagrass

plop rock lap rat fog

pop crock clap brat frog 


$$
45 b^{*}
$$

1.

$$
\begin{array}{r}
\text { sw - swam } \\
\text { swim } \\
\text { swap } \\
\text { two - twin } \\
(q u)-\text { quit }
\end{array}
$$

2. swish

3. dwell swell twill
Initial Consonant $B$ l ends

W

非

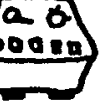

sitarist

ZTTEบ TH

$2010=5$

tern 
-

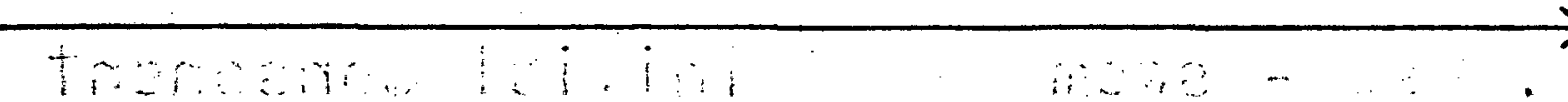

gouts

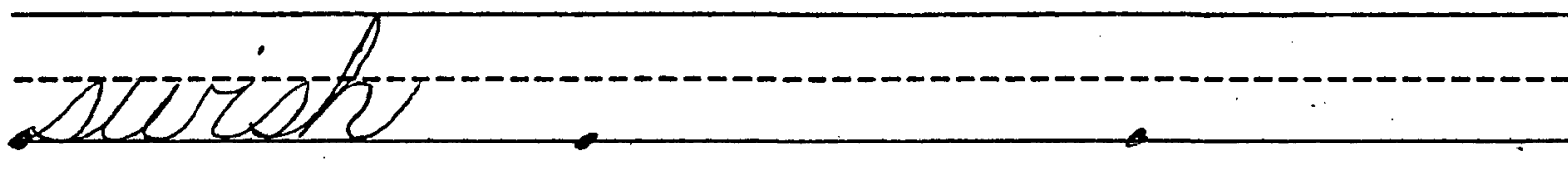

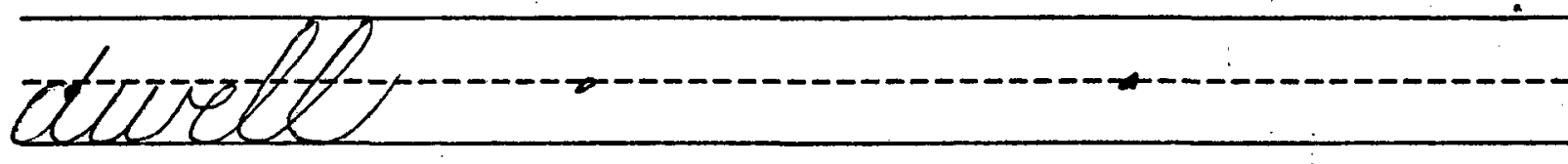
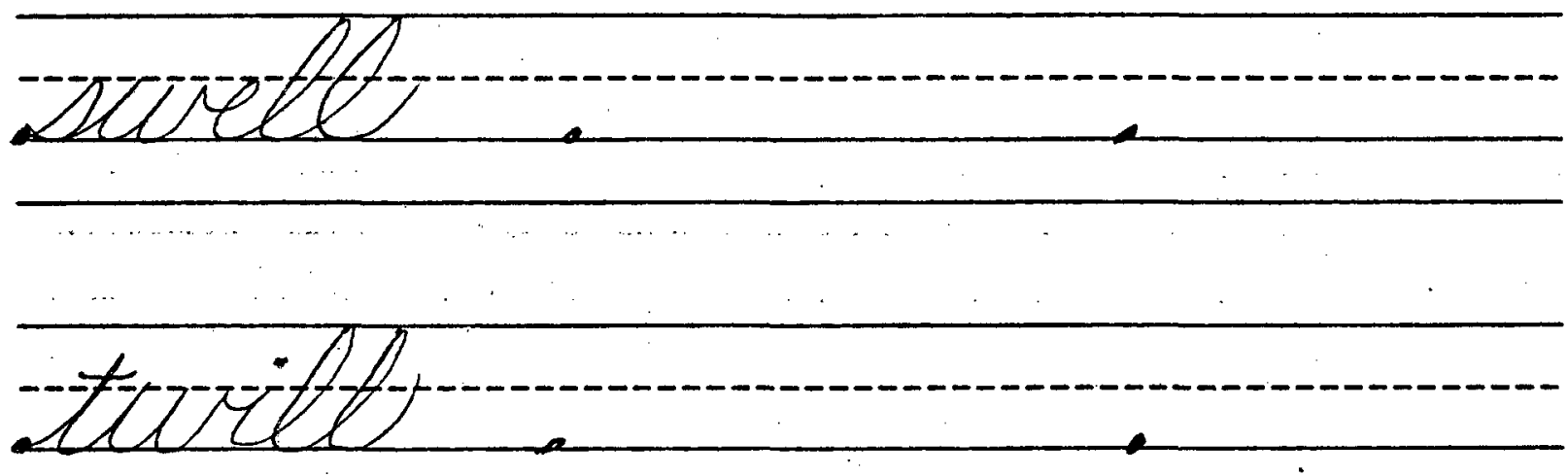
Write 5 more words with initial blends. 
Final Consonant $\mathrm{Bl}$ ends

lit lift wit wilt fod fond

chat chant hep help thup

thump Mick milk whis whisk

I ip lisp dut dust pin pinch

brick "brisk stam stamp truss

trust slat slant spen spent

Fren French

oftaltond whostuct shoptelk

swemimimp planimisk slutameft

Rick rush sack pant sash

brick brush sand chant slash 


$$
46 b_{1}^{*}
$$

1.

$$
\begin{aligned}
& \text { ft - lift } \\
& \text { It - wilt } \\
& \text { nd - fond } \\
& \text { nt - chant } \\
& \text { Ip - help } \\
& \text { mp - thump } \\
& 1 k \text { - milk } \\
& \text { sk - whisk } \\
& \text { sp - lisp } \\
& \text { st - dust } \\
& \text { neh - pinch }
\end{aligned}
$$

Final Consonant Blends
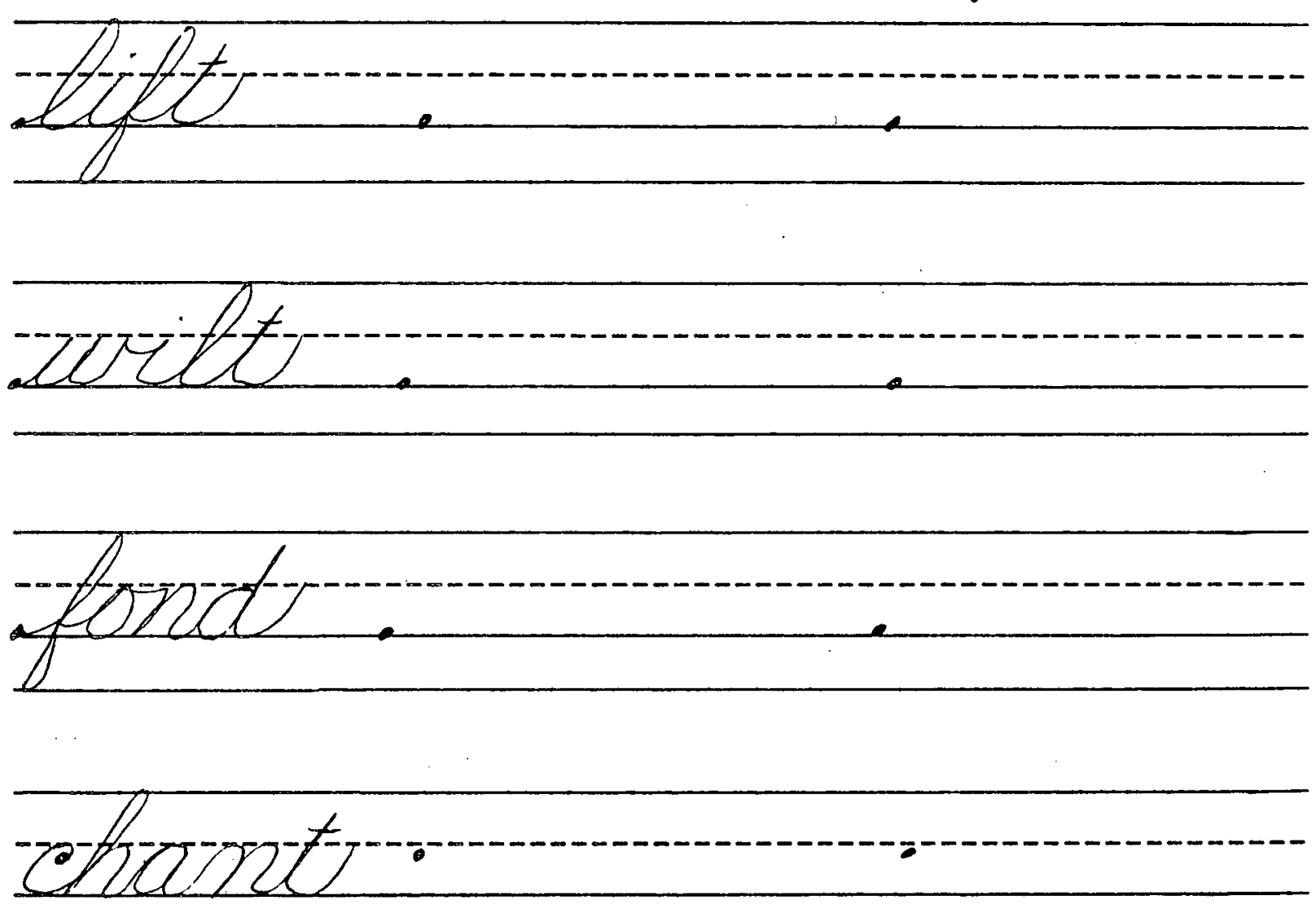


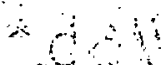

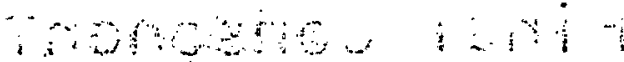

(4)

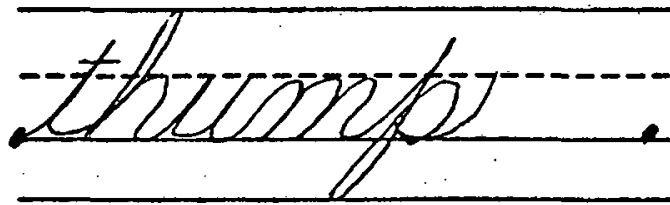

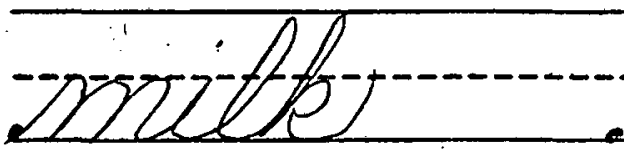

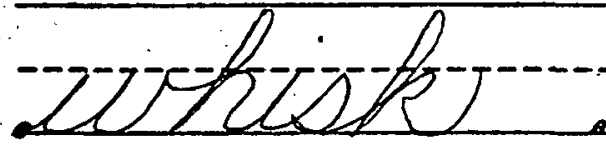

(2)

dust

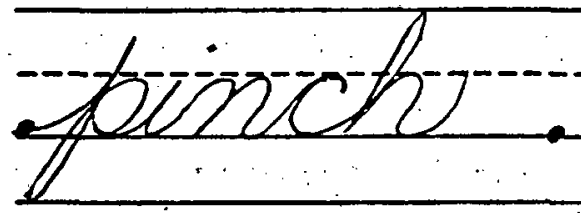


ct - duct

pt - wept

2. brisk

splint

grunt

stamp

trust

slant

spent

French
Final Consonant

Blends 
Tronoenou haid

grewnet

utanters.

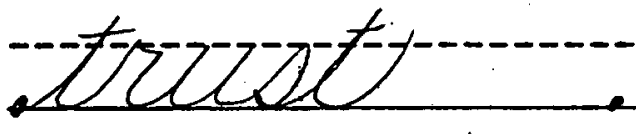

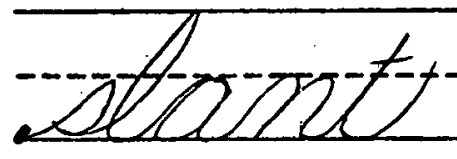

isferts

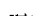

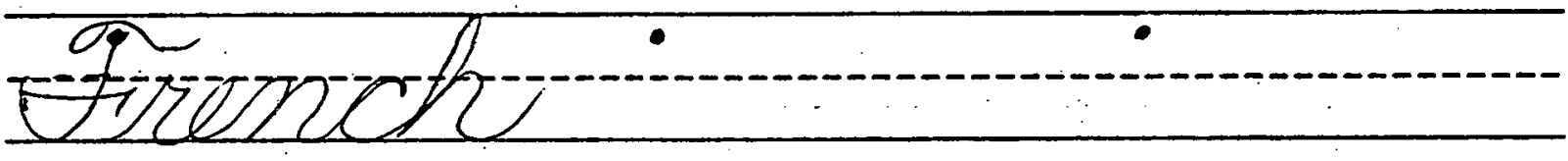


Look in any book and find words with final consonant blends. Have a "race" with a friend and see who can find the most.

Then complete these sentences.

1. The camp was on the $\overline{\text { (chant, sand, sing) }}$

2. The lamp has

(fond, dust, quench)

3. A big raft is in the

(wisp, tilt, pond).

4. Sam will spill the

(bump, milk, slept)

5. Stan can stand on the

(mend, trust, desk) 


\section{Adding $s$ and 's}
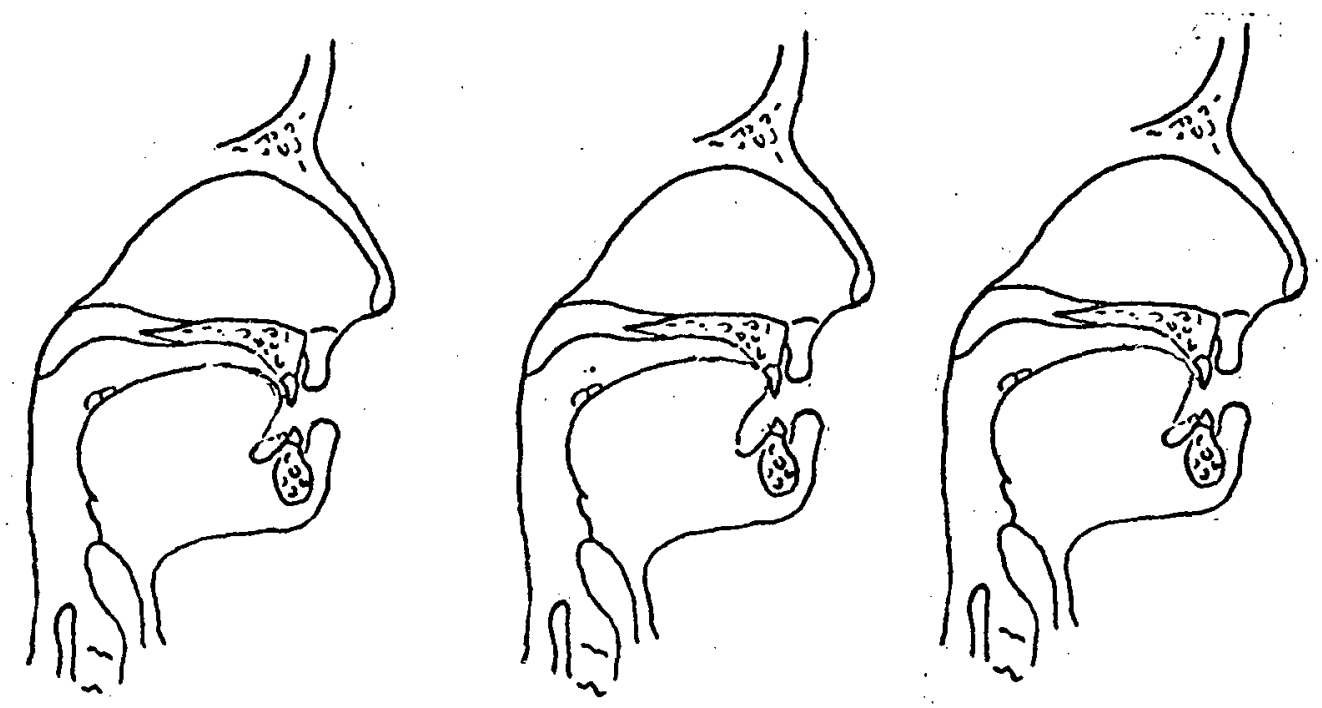

cat

cats

hat

hats

kick

kicks ship ships cuff cuffs

ham hams pad pads dog dogs

doll dolls rub rubs

stastsepsisksast twandestsaps

whimpesks vothimpafs chands 
$47 b *$

Unvoiced: cats

hats

kicks

ships

cuffs

Voiced: hams

pads

dogs

dolls

rubs
Adding $s$ and 's 
Singular and Plural - One of something is singular (one cat). Two or more of something is plural (two cats). Add an s to make the following words plural. Then read the words.

back

gun

cub

pi†

sack

bun

cup

ki†

Possessives - To show that somebody owns something, an ' $\underline{s}$ is added to the end of the owner's name. If there is more than one owner (as in boys' hats), and there is an $s$ on the word already, merely add the (') after the s. Add apostrophes (') or 's in these sentences.

1. This is Bob hat.

2. Frank has Jack dog.

3. The gals cats are big.

4. Dan dog has a sock. 


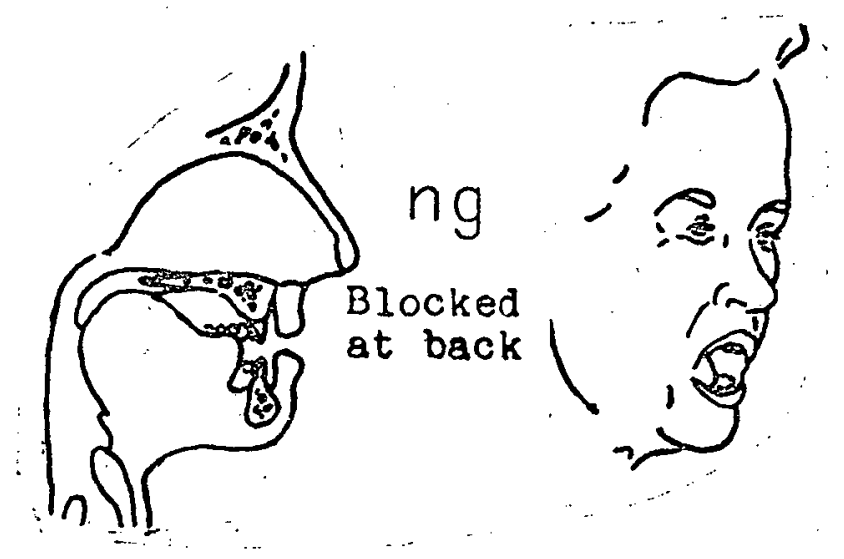

sing

clang

clung.

prong

swung

ban bang din ding thin thing

tapatong swemaming chubitwang
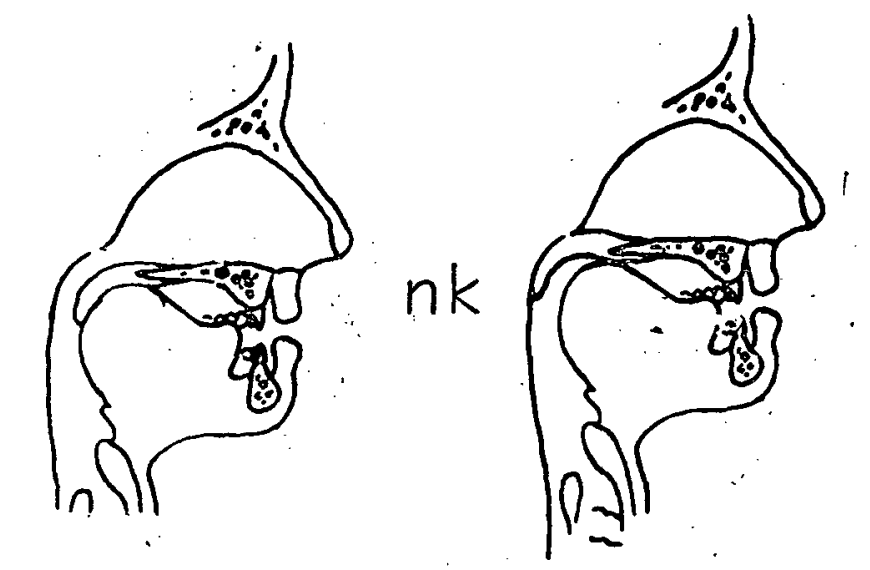

ink sink bank thank hunk

win wink bun bunk thin think

pununk saninink thoninonk 
/ng/ king

clang

clung

prong

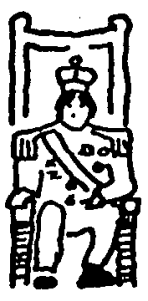

$n g$

swung

/nk/ ink

sink

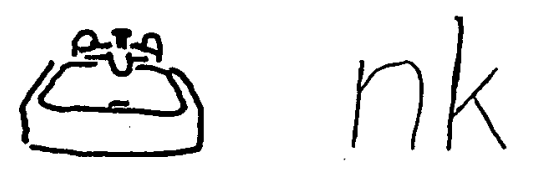

bank

thank

hunk

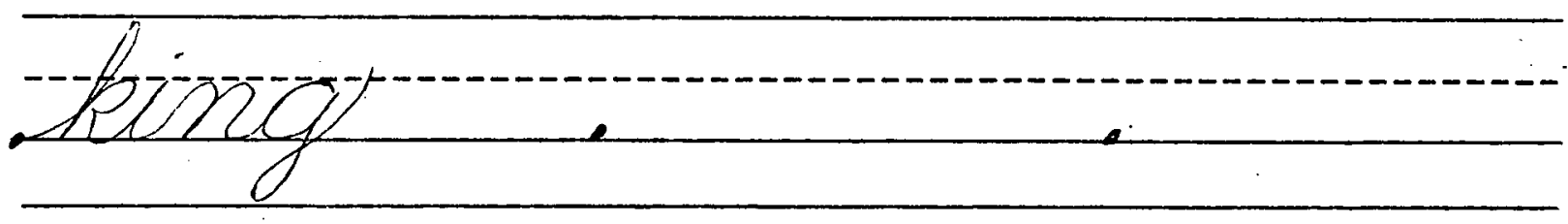

(1)
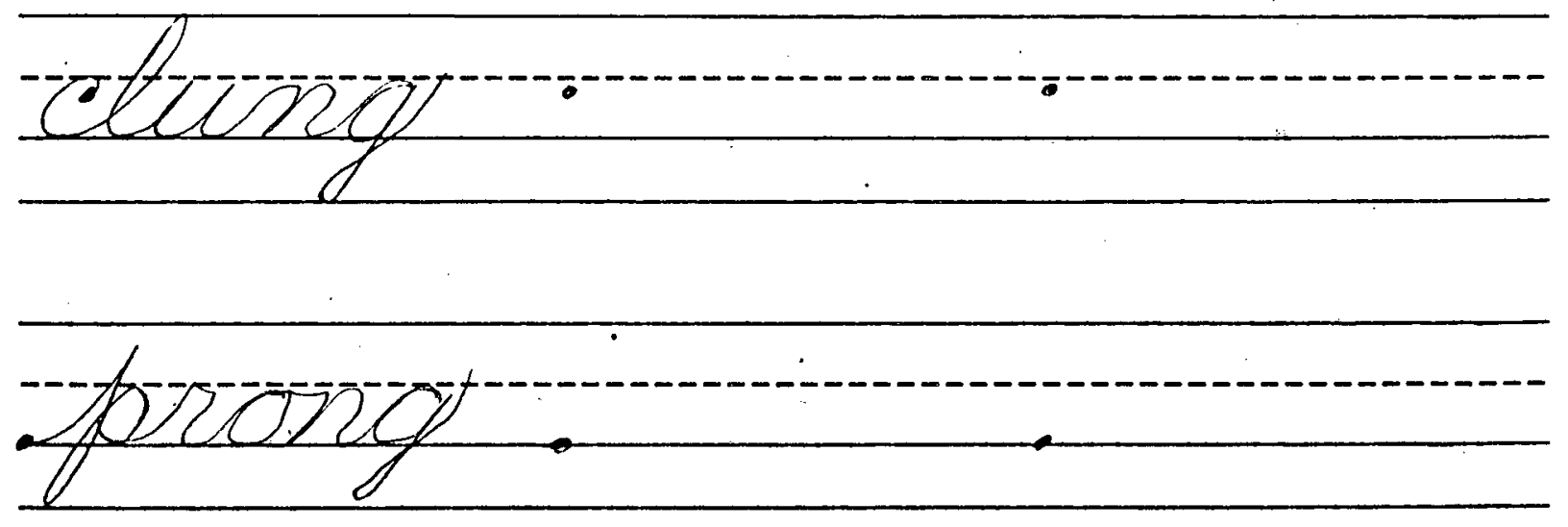
zwaney.

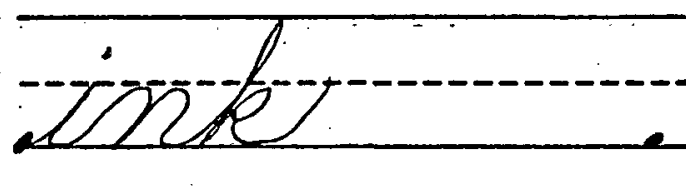

242825
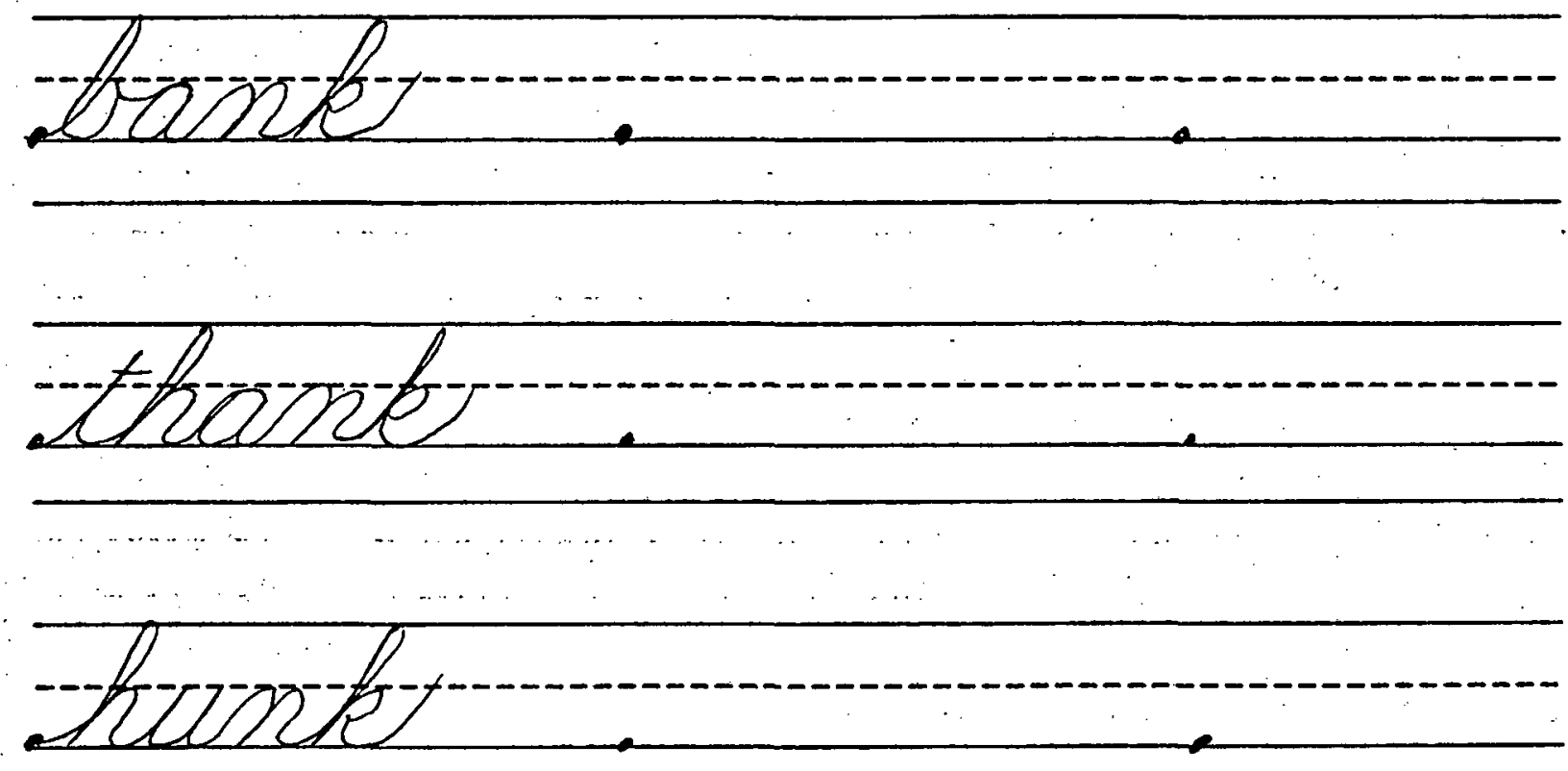
$48 c$

Draw a ring around the name of each picture below. There are four words per picture.

king

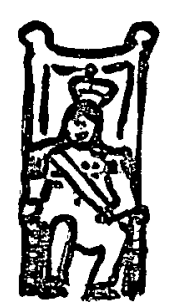

sink ring

junk

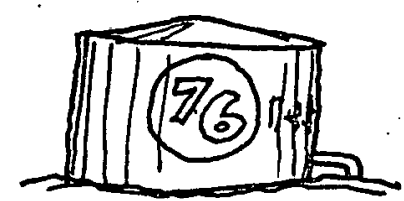

bunk

sink

honk

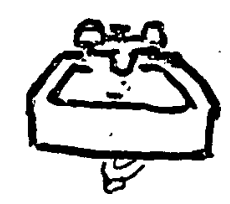

thank

tank

hung

pink

rink

swing

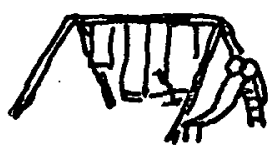

bank 
49

Review of Consonant Blends

Read and write the following words on a separate sheet of paper. Then your teacher will give them to you as spelling words.

swim smog plush strand

trunk grasp twist sinks

grunt tempt dress Jack's

strings twig swift dolls

black shrimp brush splash

Compare these words.

back - black tin - tint

sting - string cats - cast

sift - swift pack - pact

tip -trip mist -miss 


\section{Detached Syllables With Consonant Blends}

proboprob prob trafafatraf traf

trumumum trum plasaplas. plas

splenenen splen pepepend pend

sususult sult memement ment

jejeject rupupt rupt spectect

spect twiwist twist stracact

stract sweswept tranans trans

sthadzafnakish costanochigst

dzagmeptobyats scopacstempids

ptactesthich tsaflebgoftsip 
1. prob

traf

trum

plas

splen

2. pend

sult

ment

ject

rupt
Detached Syllables with Consonant

Blends
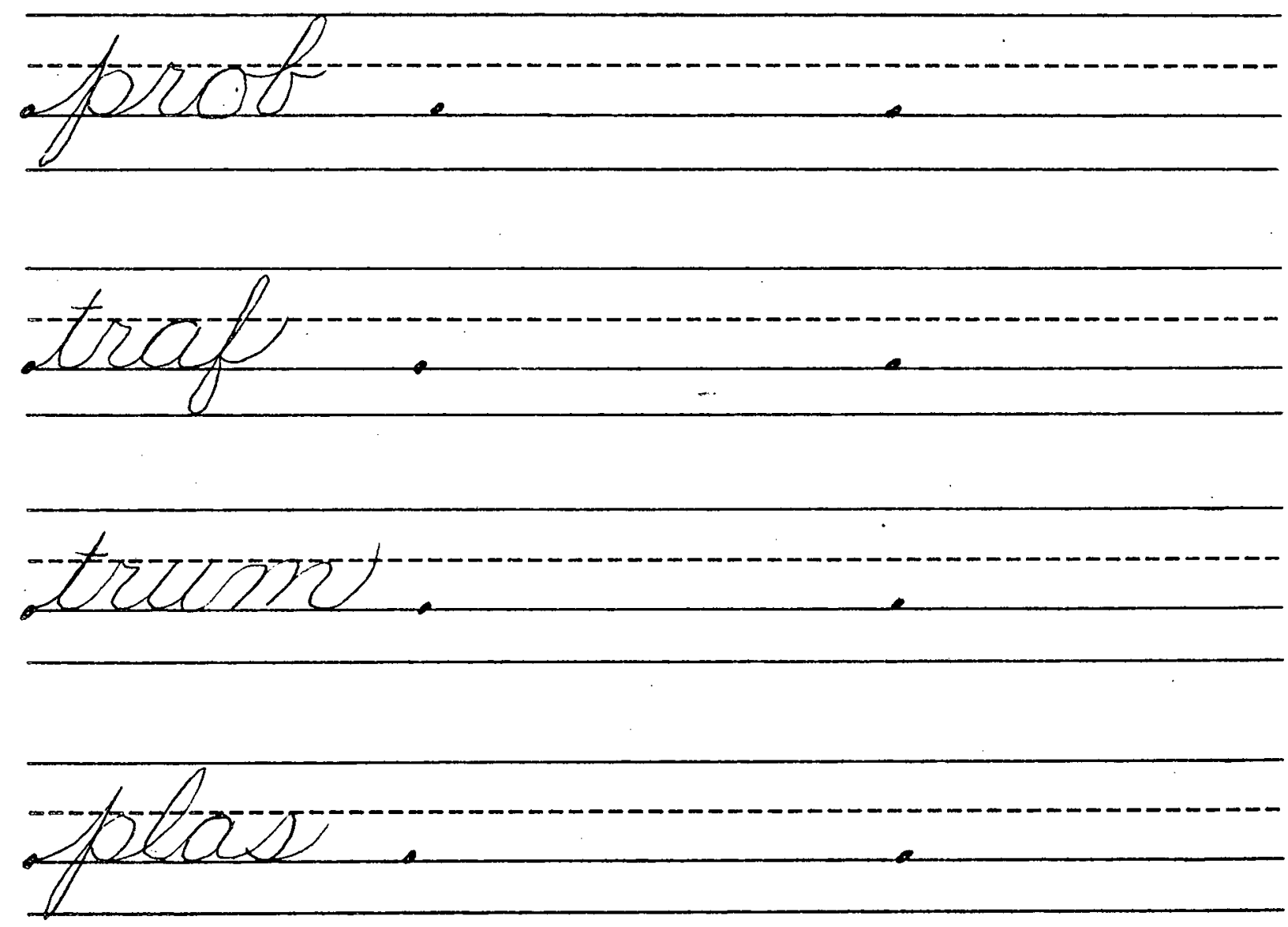


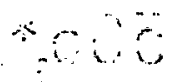

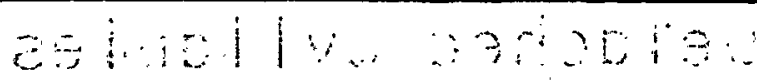

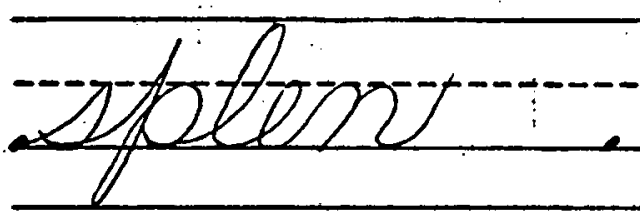


$50 b_{2}^{*}$

3. spect

twist

stract

swept

trans
Detached Syllables with Consonant

$B l$ ends

teresto,

stract.

extepty. 


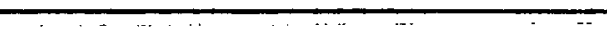

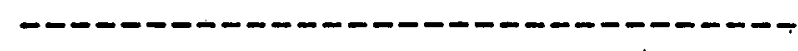


Make up your own detached syllables and pronounce them. They may be written below. 
$51 a$

Two-Syllable Words Using Consonant Blends

prob lem problem trap tic traffic tan trim tantrum plus tic plastic thrum pet trumpet splen did splendid aus pend suspend in suit insult com mont comment in jest inject dis rept disrupt in aspect inspect un twist untwist ab strict abstract wind swept windswept trans act transact

crack shrank plunk wish cracks crank skunk squish 
$5 \mid b_{1}^{*}$

1. prob lem traf fic tan trum plas tic trum pet splen did
Two-Syllable Words Using Consonant Blends

2. sus pend in sult com ment in ject dis rupt

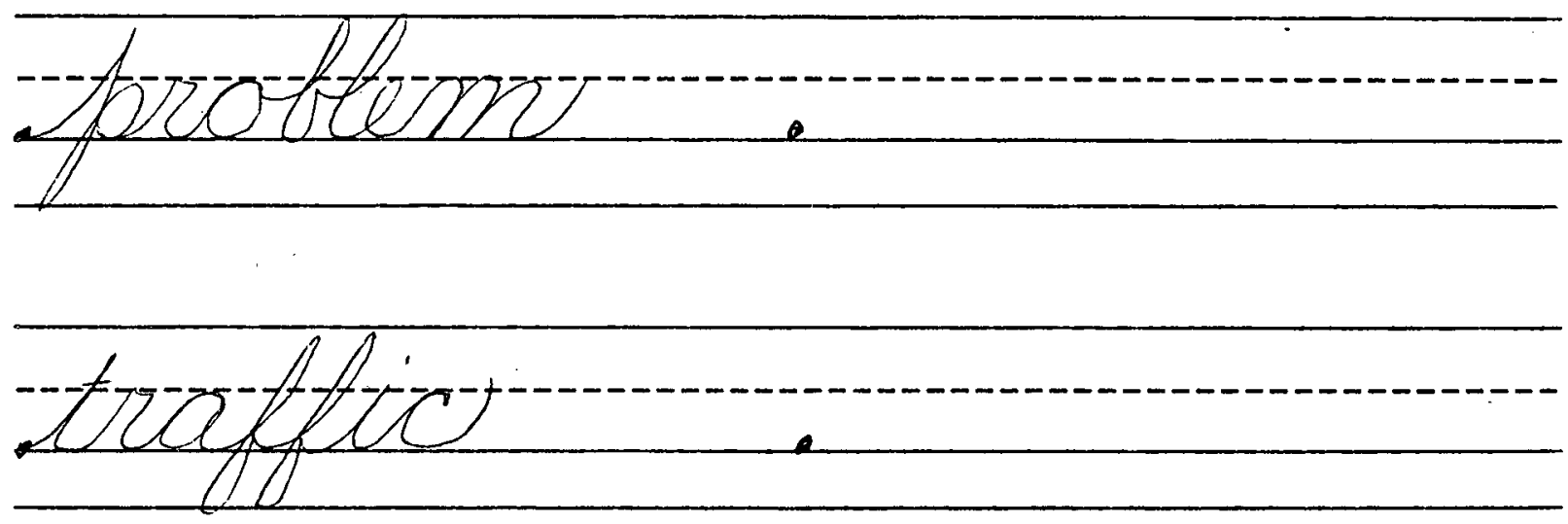

trentrume. 
trompets

ipplenediot..

zusponids

insult

comment

inject

distruptet 
3. in spect un twist ab stract wind swept trans act
Two-Syl Iable Words Using Consonant Blends

instoectom

zimturest.

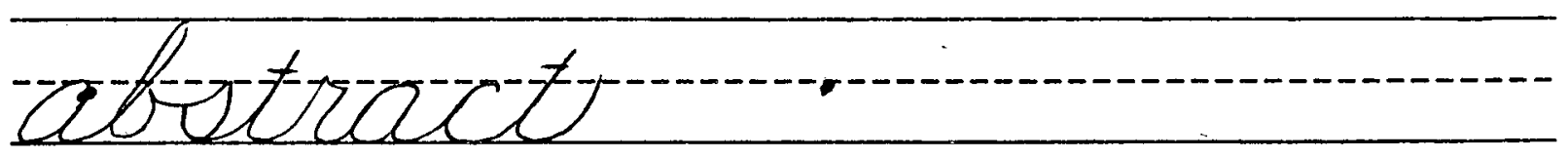


$\therefore \therefore$

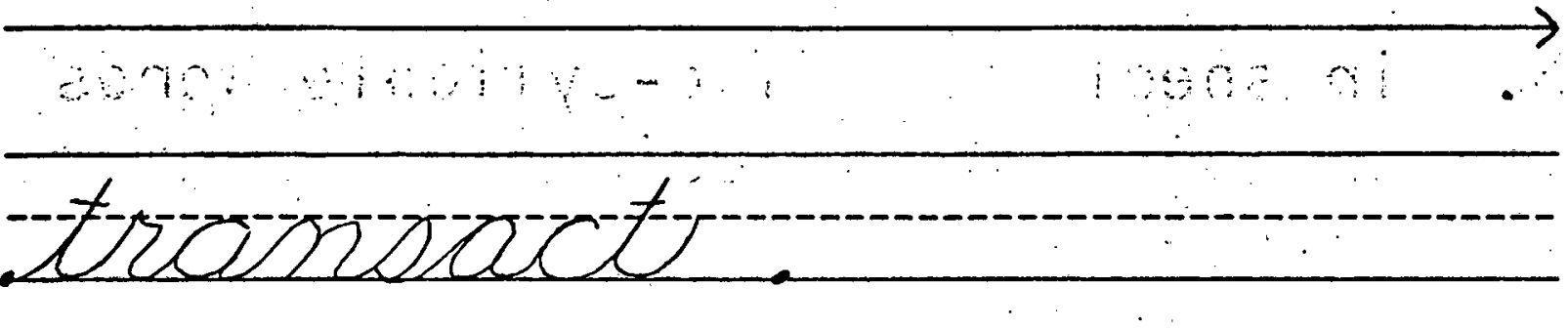


Find some 2-syllable words using consonant blends in a book. Write them below. Your teacher will help you to pronounce them. 
$52 a$
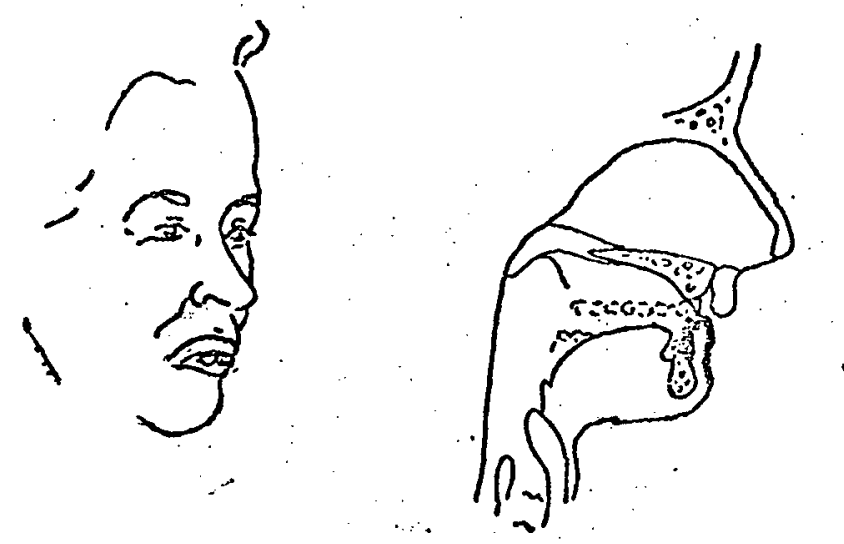

ph

phiphil Phil

graphaph

graph

ralalph

Ralph

proprop

phetet

prophet

pamapam

phletet

pamphlet

phank gagugant squonk strug

slisisiff phasasass prazazazz

twang plank fill staff squint

tang bank Phil graph hint 
$52 b *$

Phil

graph

pro phe

pro phet
pam phlet

ph

pam phlet

m

Prit

graph

Ratph

propthet 
+r $6=$

$m, \quad \cdots$

(2)

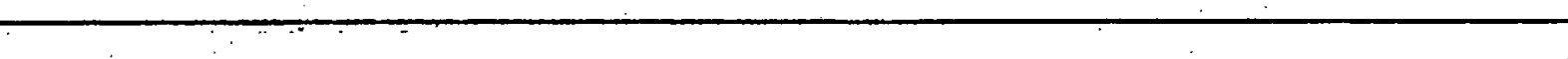

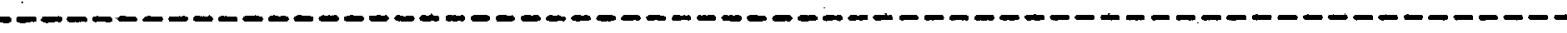


Circle the correct digraph for each. incomplete word.

Th

1. Ph _at is Dick's cat.

Sh

2. Jack can bring the lun__ ph. sh

ph

3. Ral_ sh will have the dog. th

4. The brush went swi

ph sh. ch

$\mathrm{Ph}$

5. Sh _onics is fun. Ch 
$53 a$

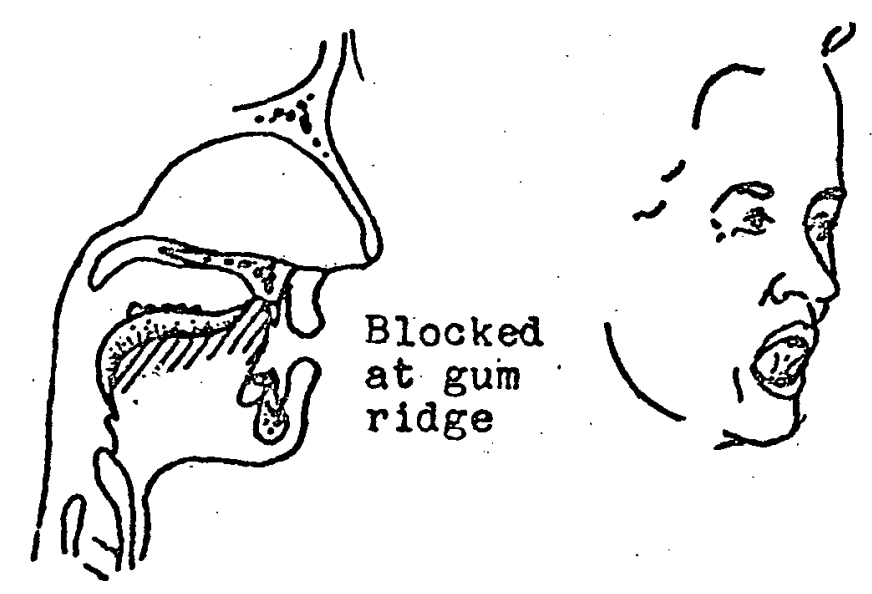

knititit knit knobob knob

knototot knot knacack knack

knapap sasack knapsack knocock

knock

phankophink knang phalifeft

twawang swenganins pluninks

knot knap shipment basket

not nap comment blanket 
knit

knob

knot
knack

knap sack

knock

$53 b *$

$k n$

Bonito

tote.

knot

Enact. 
Enropsocace.

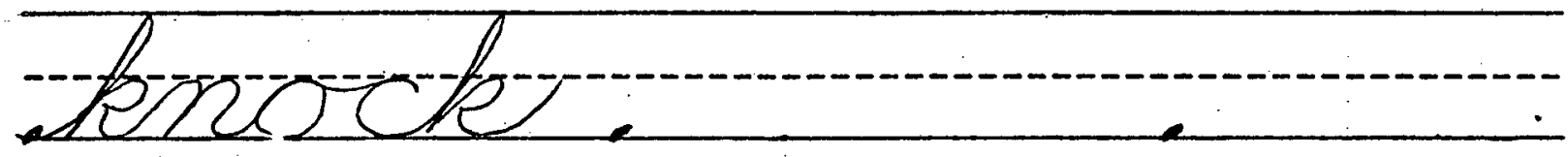


Write a story with your new words: (knit, knot, knack, knapsack, knock). 

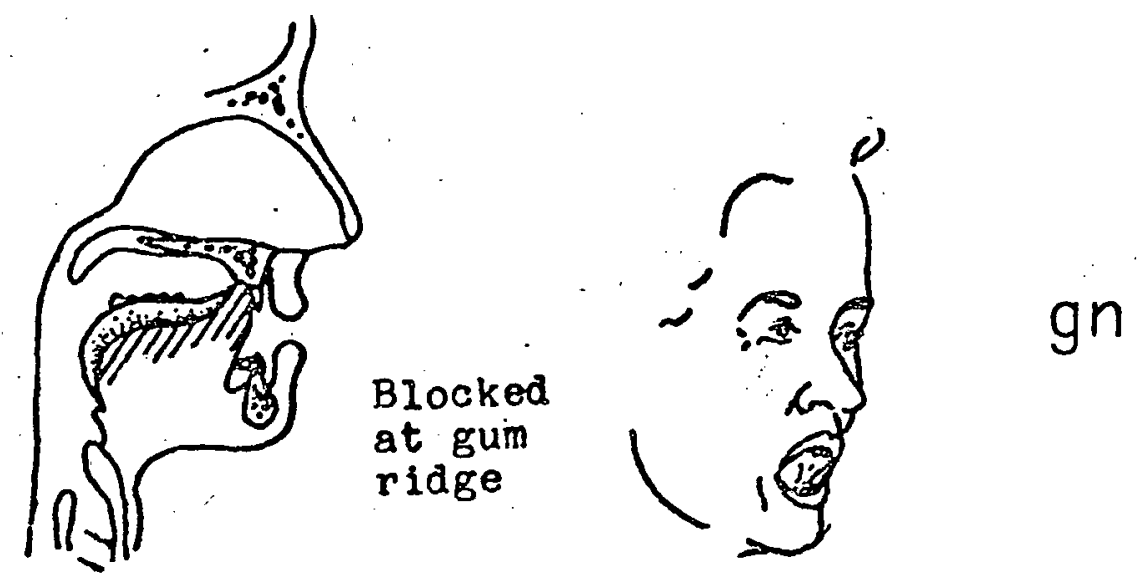

gnatatat

gnat

gnashash

gnash

phanant

knopli|l

slactemp

pruninant

twenung

gnanunink

camps

Phil

champs

until

Kim's

gash

Jim's

gnash 


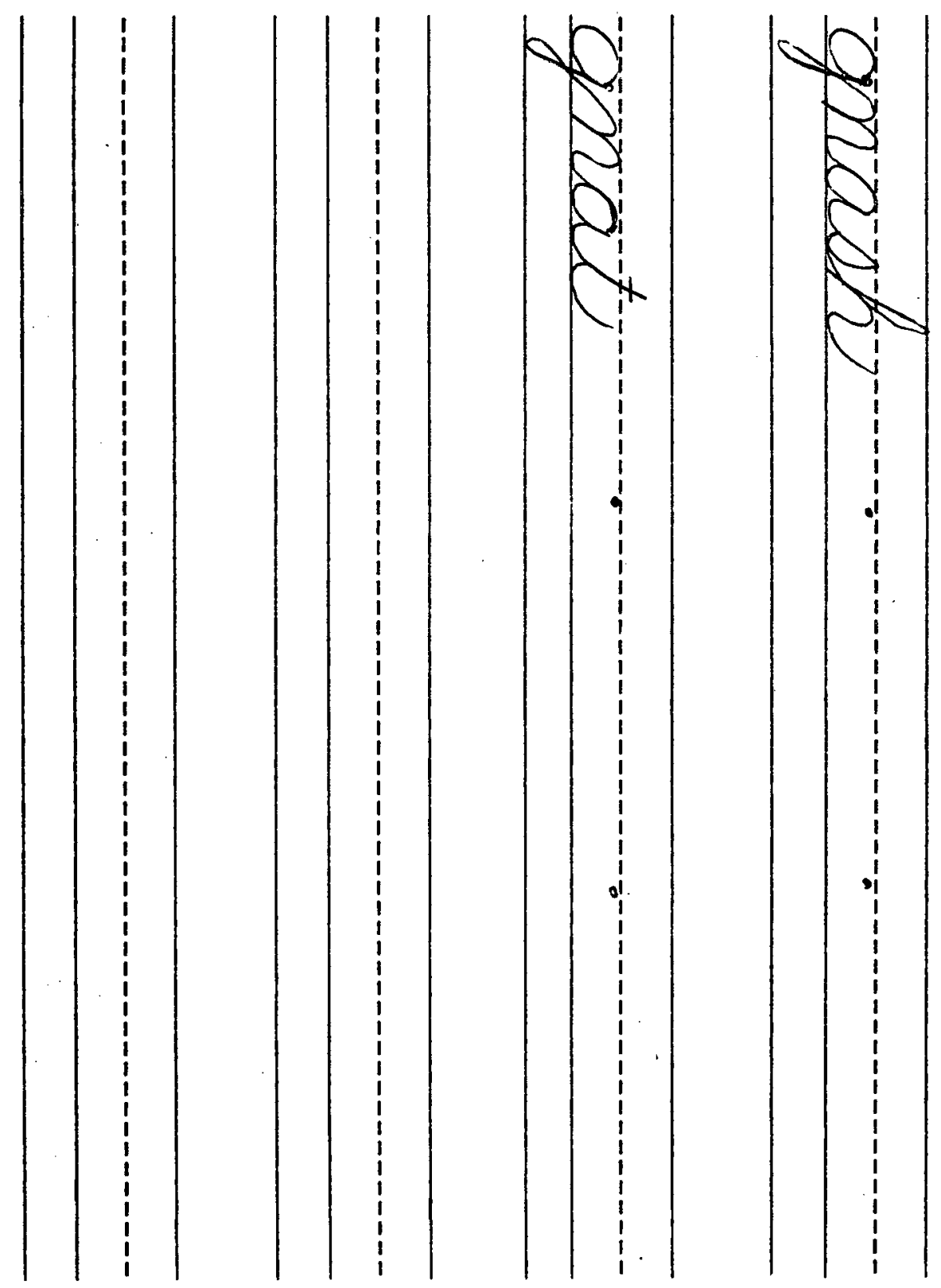




$$
\begin{array}{r}
0 \frac{\pi}{3} \\
0.0 \\
+\frac{\pi}{0}
\end{array}
$$

8

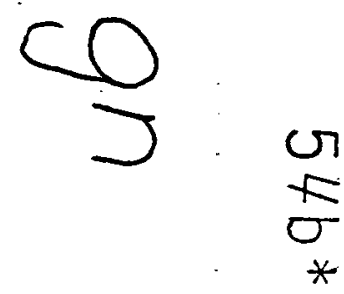


Choose the correct word for each sentence.

1. The man was bitten $\frac{\text { by a }}{\text { (knack, gnat, knit) }}$

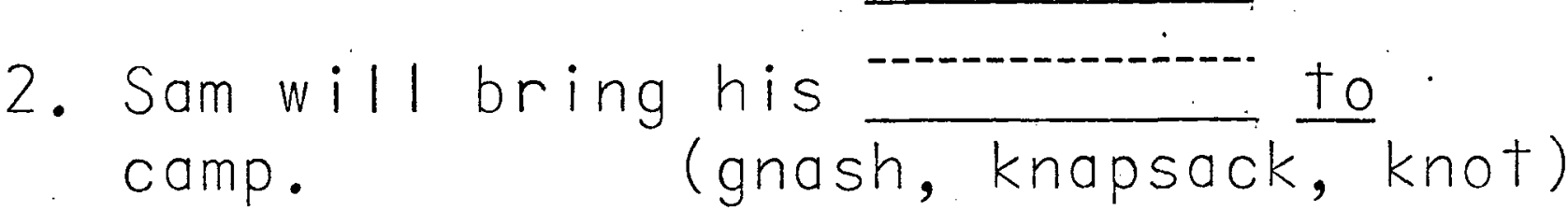

3. His mom will

(knit, Phil, tantrum)

4. Ralph can when it happens.

(knock, gnat, pumpkin)

5. Cal's dad will

(not, knot, gnat) 


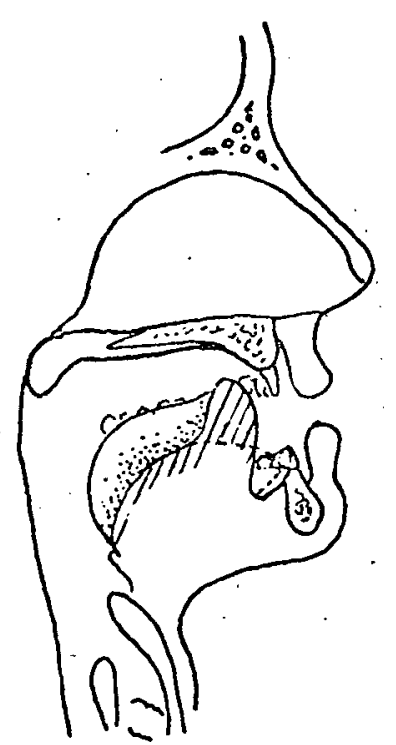

$55 a$

wrekekeck

wrapapap

wrap

wringing

wring

$w r i+i \dagger i \dagger$

writ

wrisisitist

wrist

writ

ten

written

wronong

wrong

gnamant

phomeff

tingong

stromp

truntemp slamongank wrenewant

plant

pant gnash slash clump

I ump strung

rung 
$55 b *$

wren

wrench

wreck

wrath

wrap

wring

writ

wrist

writ ten

wrong
Nr

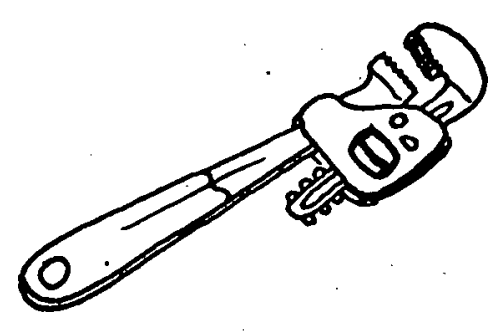

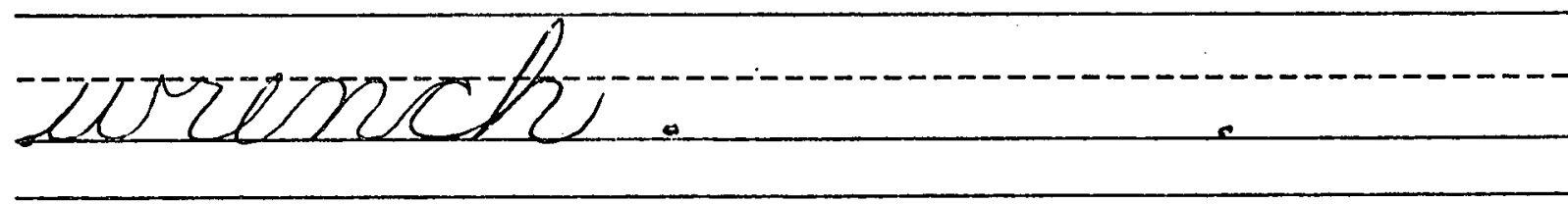

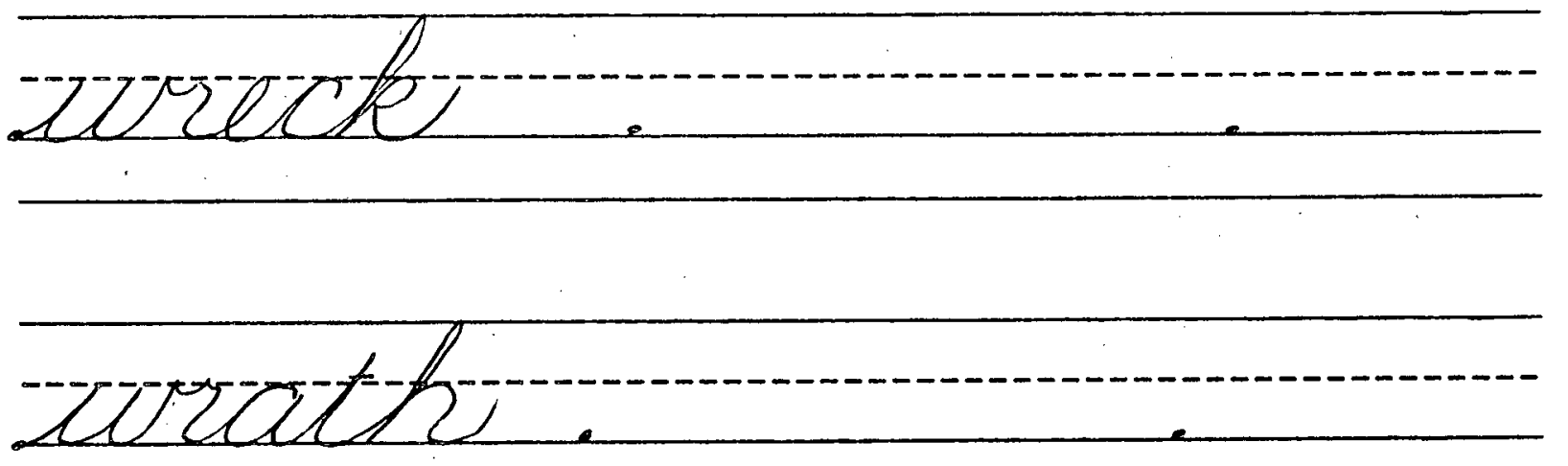


$\therefore \therefore$

zorafs. $-$

xusting.

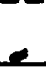

arrits

truste.

e

zorittern:

a

zorvinge. 
Which words have the same sound as wrench? Underline them.

rack

rap

trick

whack

Russ

rich

wet

with

wick

whip

rock

trap

ring

win

wrath

Rick

track

whim 
$56 a$
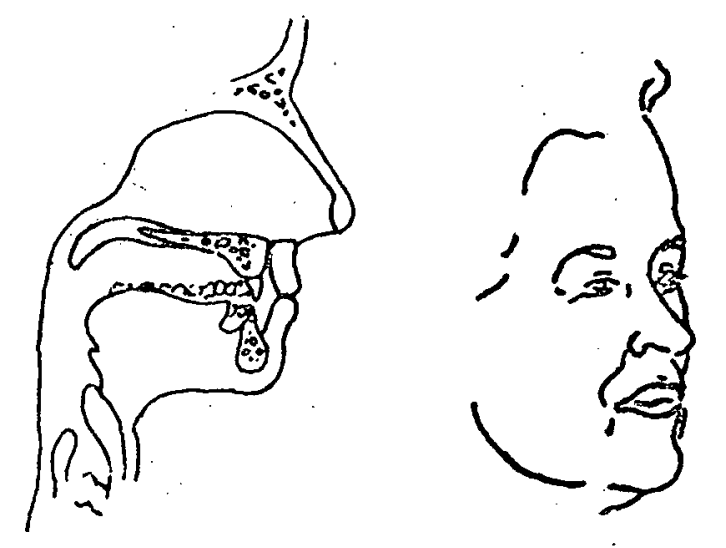

$m b$

dudumumb dumb nunumb numb

thuthumb thumb crucucrumb crumb

I imimimb limb lamamb lamb

bobobomb bomb

wrinocopt cromplank blimimumpt

phlamp gnaminimp glangonk
bl ink
whack
tracks
wring
slink
knapsack
smacks
ring 
dumb

numb

thumb

crumb

$1 \mathrm{imb}$

lamb

bomb

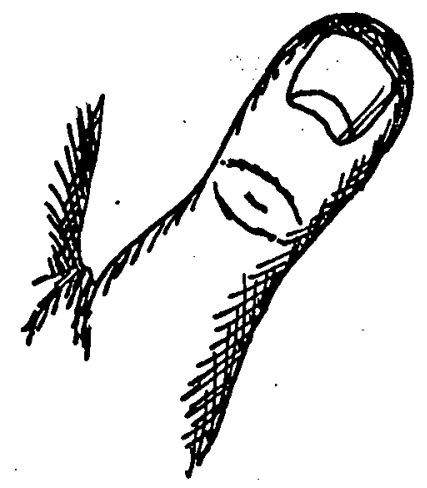

atrorefs=
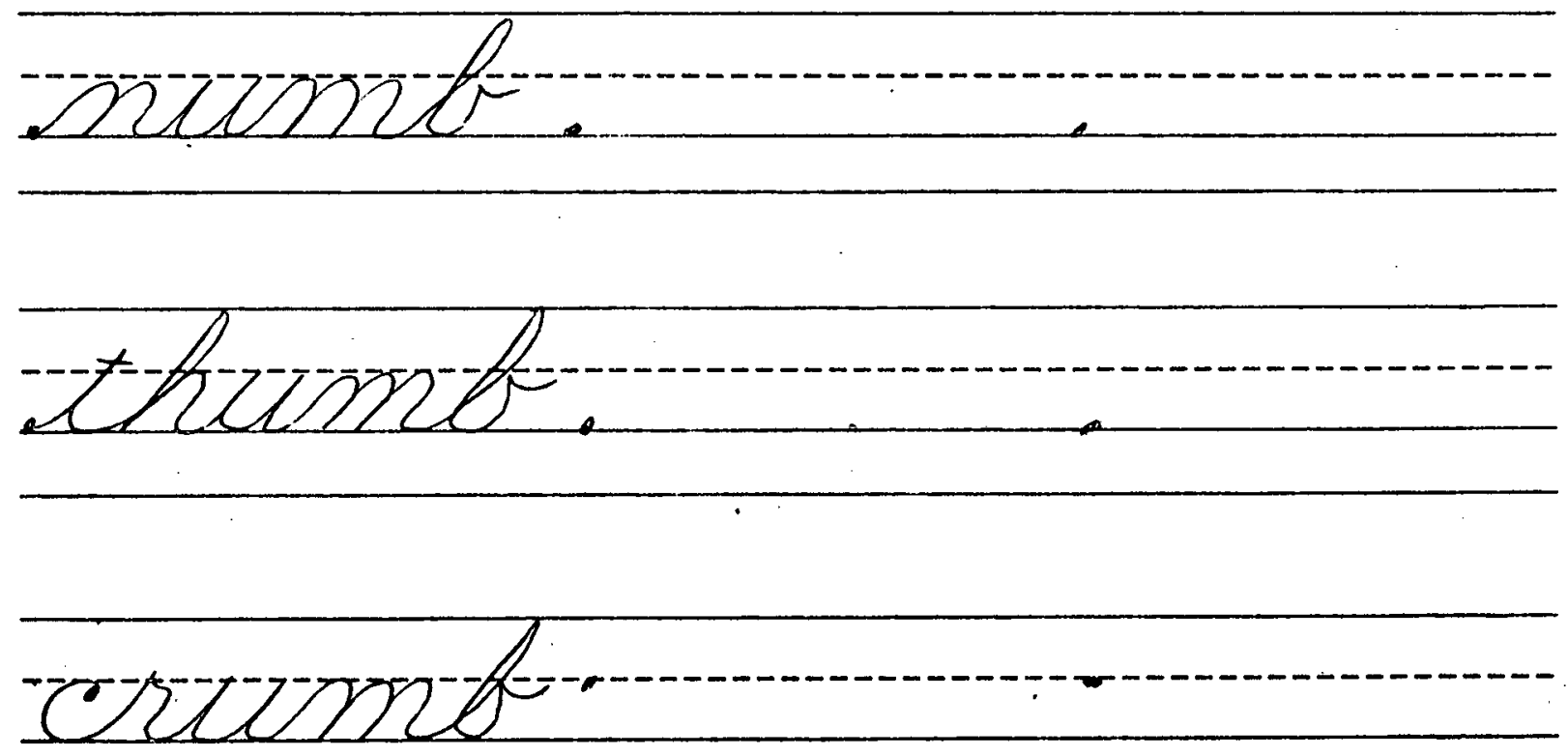
$\because \because$
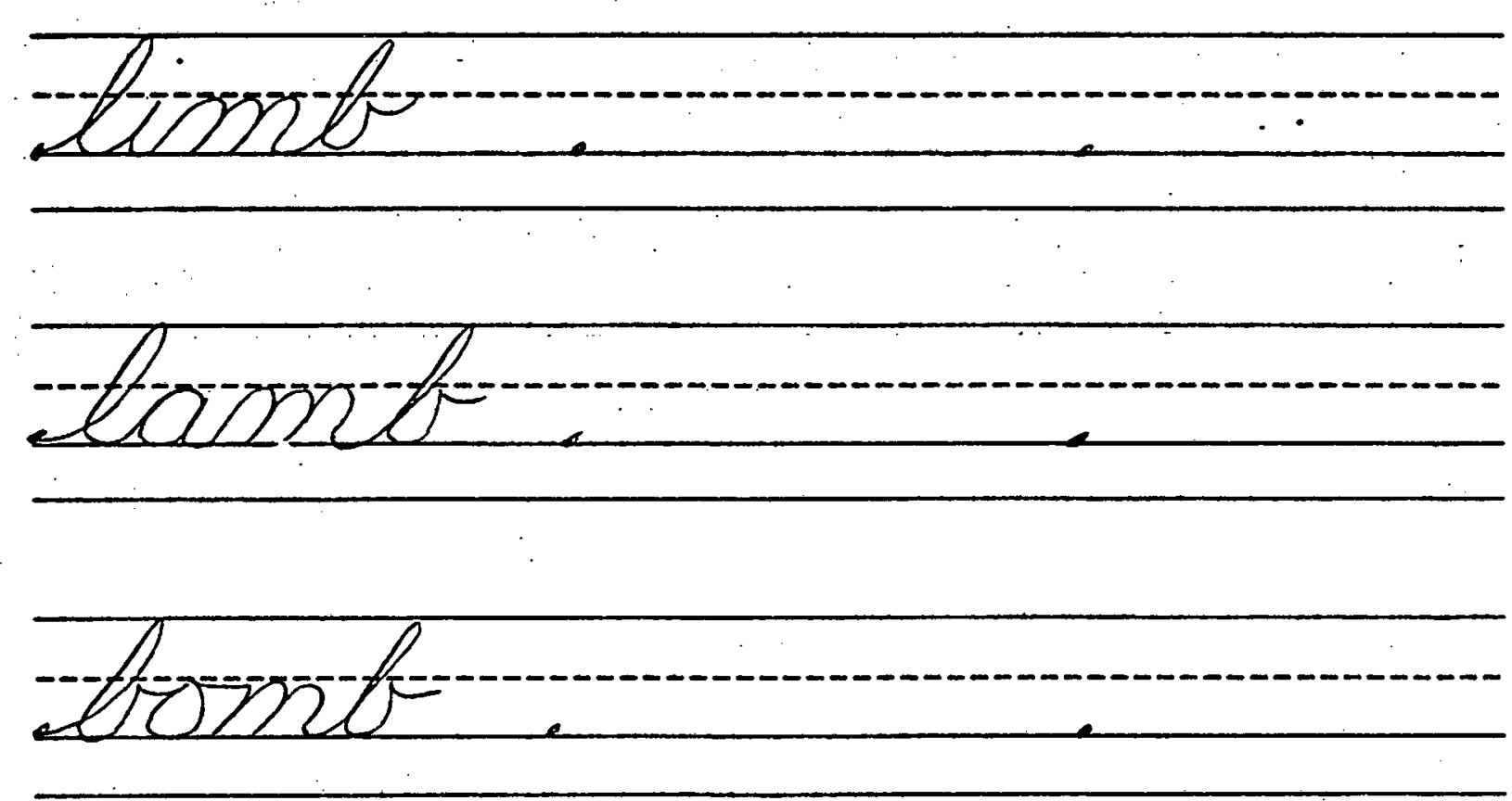


\section{$56 c$}

1. Underline the letters that make the "f" sound in these words:

pamphlet Ralph graph Phil

2. Underline the letters that make the "n" sound in these words:

knit knock gnat knot gnash

3. Underline the letters that make the "r" sound in these words:

wrap wrong wring written

4. Underline the letters that make the " $m$ " sound in these words:

lamb limb thumb bomb 


\section{Review}

Put a slash through the letters you do not hear in the words below. Then read the word. The first one is done for you.

gnat gnash. written thumb knapsack numb dumb knob wreck wrench knack wren knit wring wrath lamb crumb limb knock wrist

Write in the blanks the single sound that each letter combination produces. Your choices are $f, m, n, r$. Then say words containing each of these consonant twins.

$p h=$

$g n=$

$w r=$

$\mathrm{mb}=$

$k n=$ 


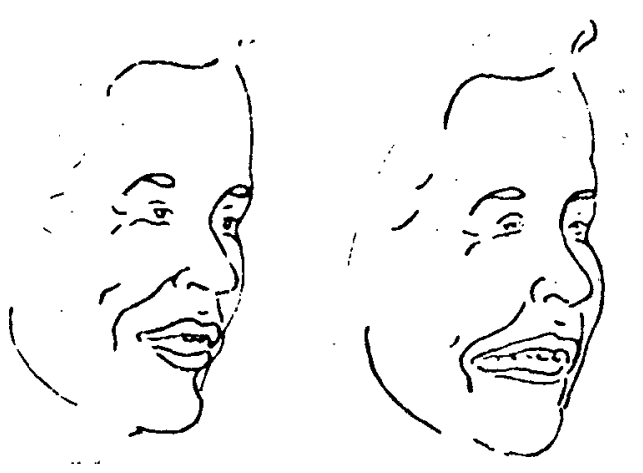

पave

at ate fat fate tap tape.

cap cape mad made fad fade

Jan Jane can cane gal gale

Sal sale

sate vant bane zape comman

plimpkan grumanane glanuman

abstract stand plane cake contract sand pane take 

made.

$\rightarrow$

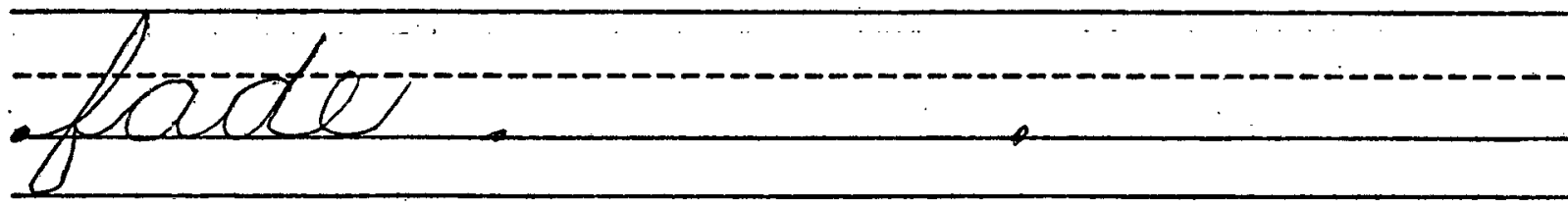

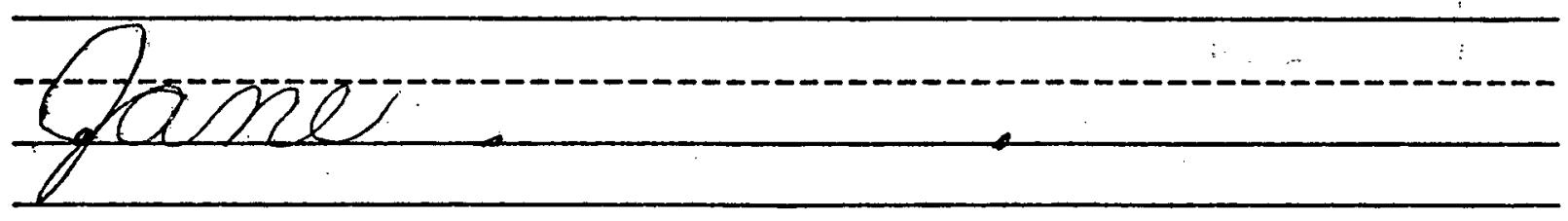

canet

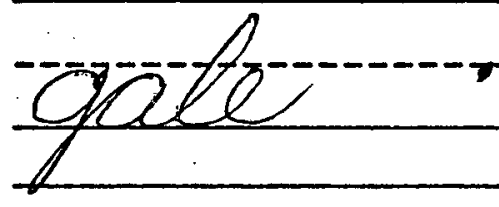

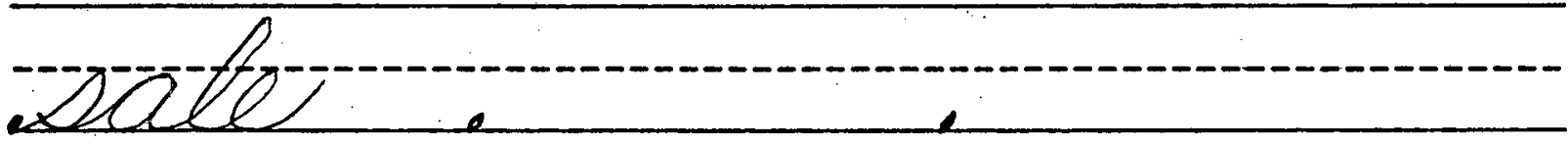


$58 c$

Underline the correct choice for each sentence.

1. The man has (tap, tape).

2. It will make Jack (mad, made).

3. Jimwill take a (hat, hate).

4. Jack will shake the (mat, mate).

5. The (sale, Sal) is on at the Smith's place.

6. James ate a snack when he was on the (plane, plan).

7. The gal will (back, bake) the cake. 
$59 a$

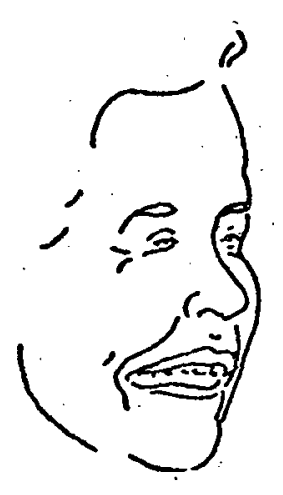

\section{aere}

Pete mete fete eke Zeke

here these Eve Steve

velplet Deke zedack brede

plefe plete kete grake vete

shame whack Pete grade mete sham wake pet grad met 


$$
59 b *
$$

Pete

mete

ere

fete

eke

Zeke

here

these

Eve

Steve
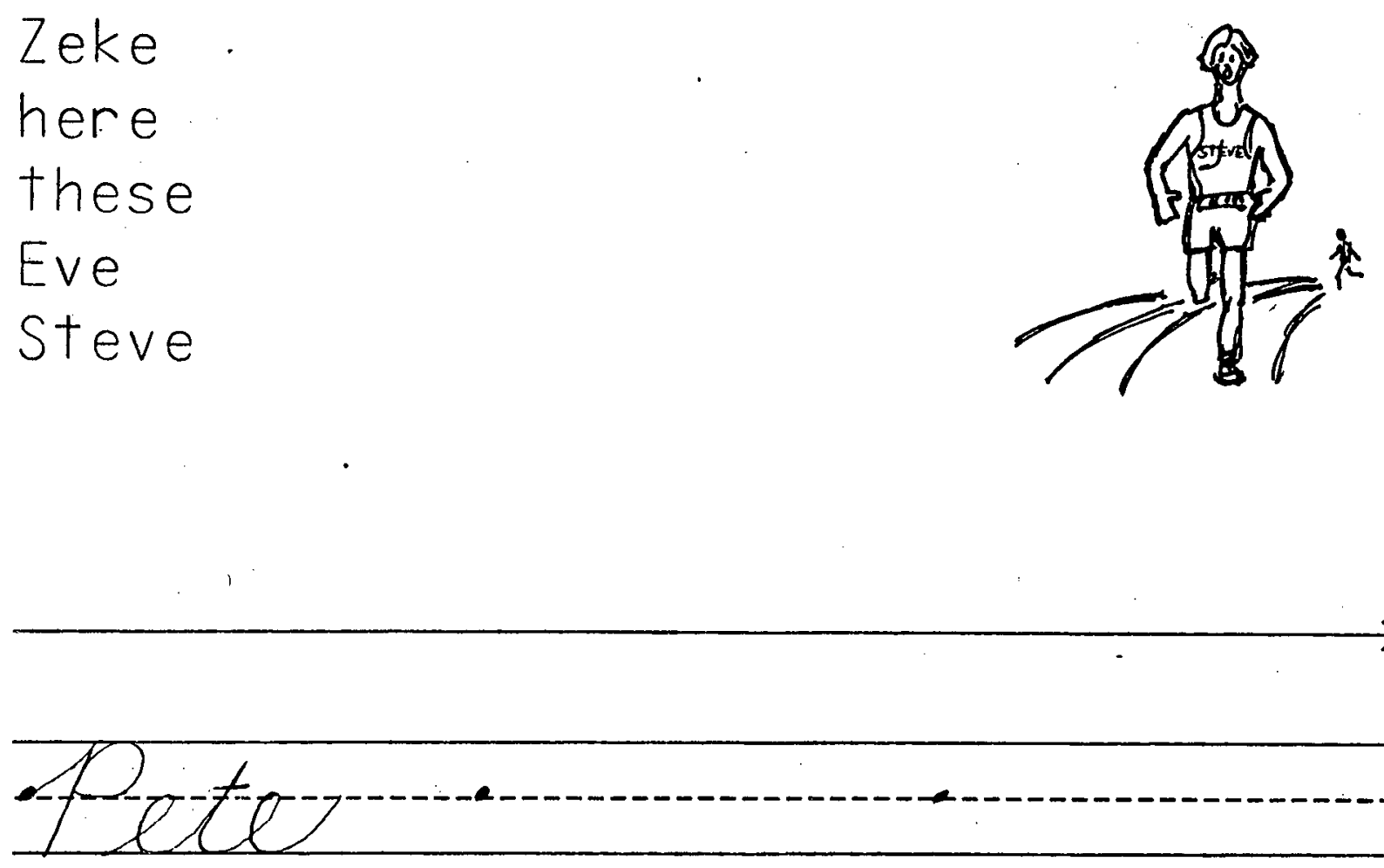

meter
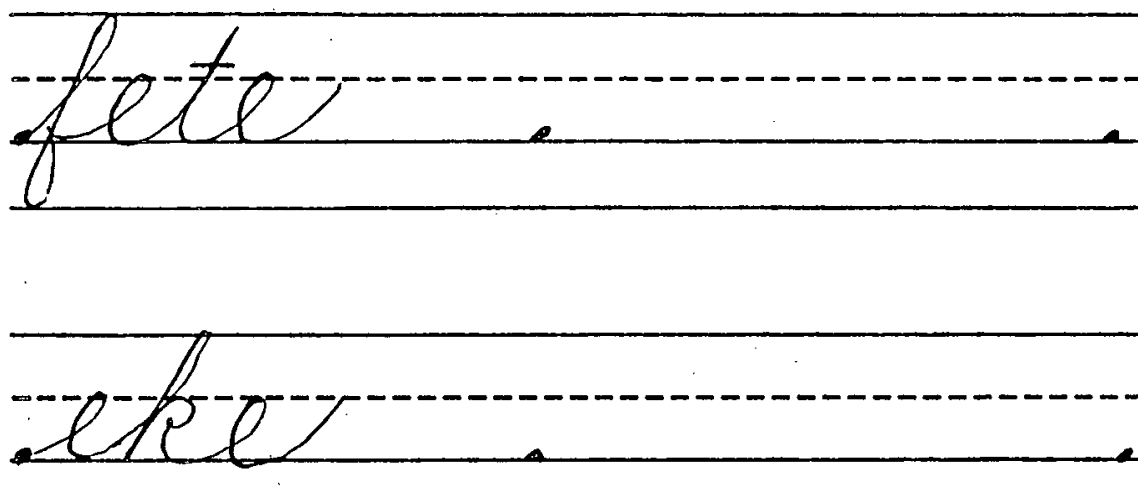

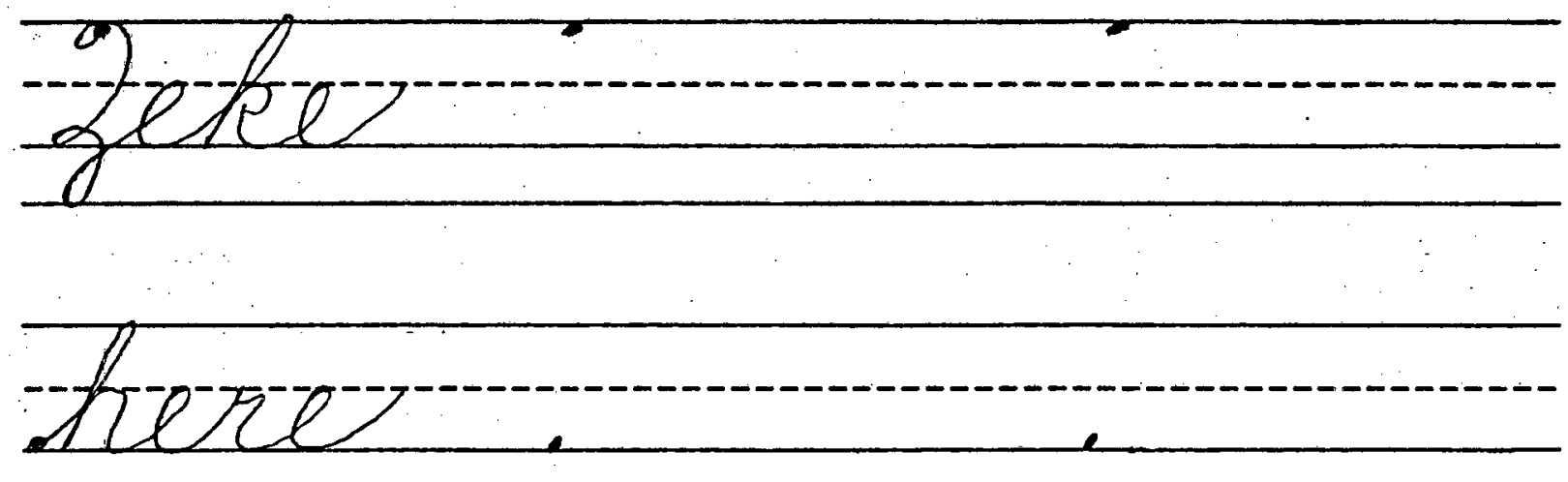

thest 2

Ever

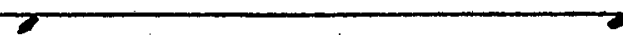

ztetver. 
Underline the best choice for each sentence.

1. James has a (Pete, pet).

2. His name is (ten, Zeke).

3. The dogs did nip (Eve, vent).

4. That man has much (stress, tell).

5. Beth can (mend, Eve) well.

6. Dick went with (set, Steve).

7. (Then, These) men came late. 
$60 a$

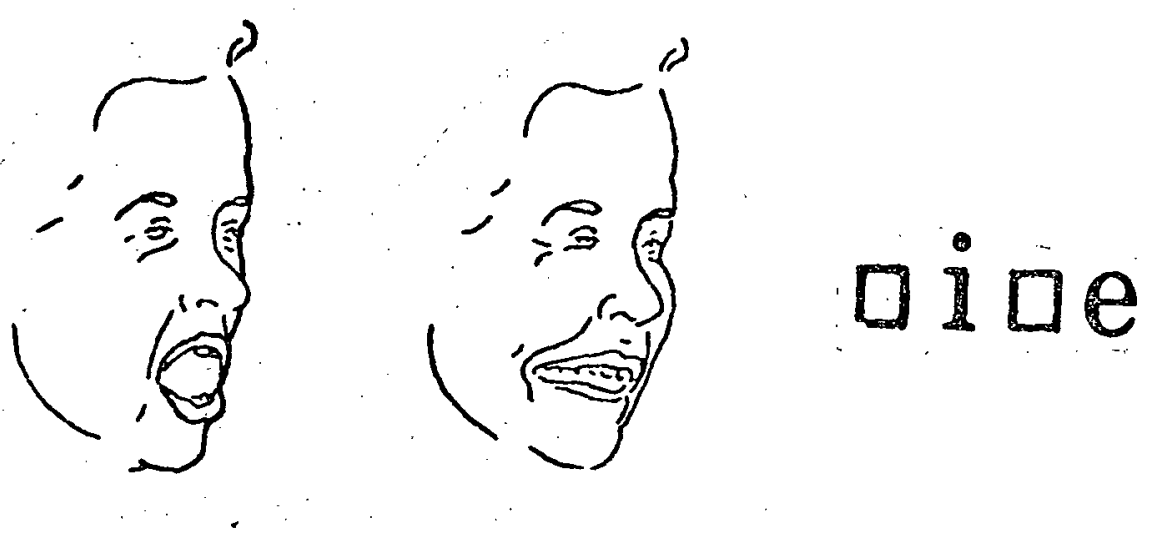

nine mine bite write ride

bride mile pile prize size

bit writ rid mill writ bit

knimdip changdap wrangth filampt

phantip tepe tete gninin rete

$\begin{array}{llll}\text { flame strike smile while } & \text { Eve } \\ \text { lame trike mile will } & \text { Steve }\end{array}$ 


$$
60 b *
$$

nine

mine

$1-e$

bite

write

ride

bride

mile

pile

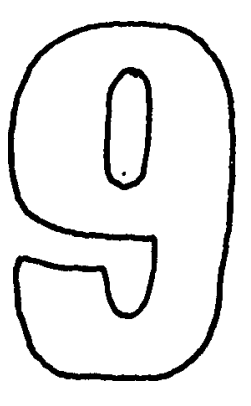

prize

size

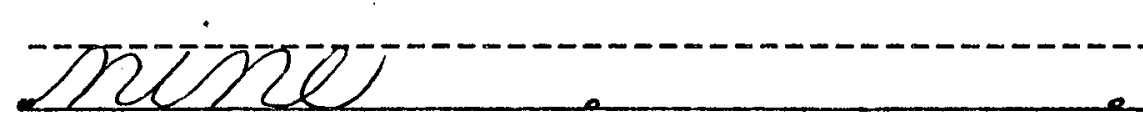

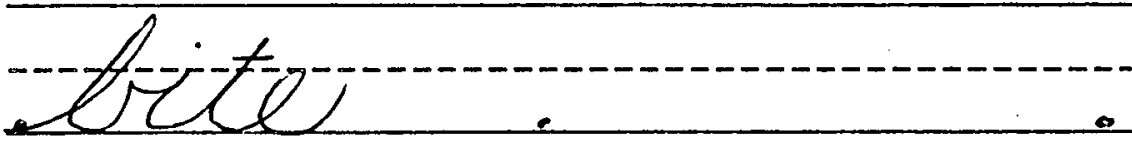


zicter

trides.

miles.

forter.

prouge.

zige 
Underline the best word choice for each sentence.

1. The dog (bit, bite) the man.

2. 1. (lick, like) that rug.

3. Jack will (rid, ride) the bike.

4. Dick did (wine, win) the game.

5. The dust will (pill, pile) up fast.

6. Mike is (still, stile) here.

7. Mom has (till, tile) in the kitchen. 


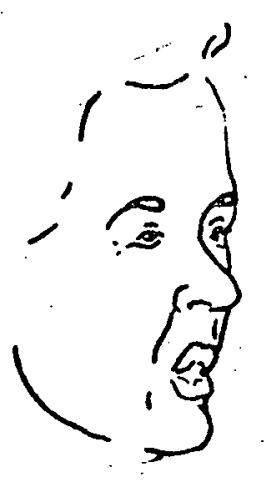

पoue

hope hop rope rode rod. Ross

strode froze doze rose close

note not quote stove hop

clogagut nonong seakamit prode

sistses tiviv tweminan slipe

$\begin{array}{llll}\text { split dime } & \text { grope } & \text { phantom } \\ \text { lit } & \text { dine rope } & \text { pamphlet }\end{array}$ 


$$
61 b^{*}
$$

hope

rope

rode

strode

froze

doze

rose

close

note

quote

stove
$O-e$

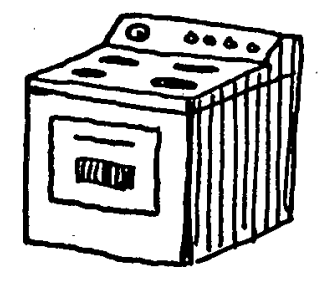

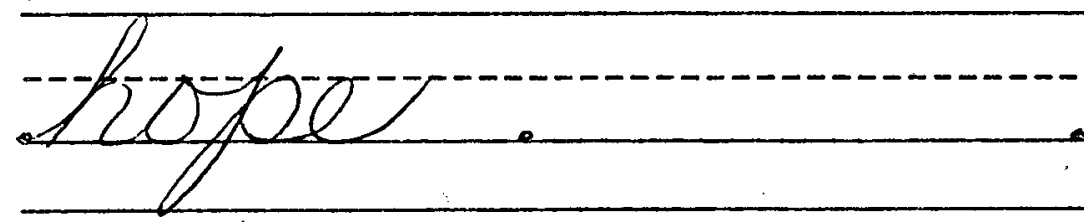

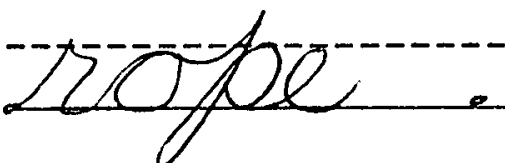

rooter.

etrooter: 
froze

toze

rooet.

ctooser.

note.

quontes

stowe. 
Underline the best word choice for each sentence.

1. Fire makes (smock, smoke).

2. Rick sang a bad (not, note).

3. The rabbit can (hop, hope) fast.

4. Jack has a (phone, fond).

5. Al will (choke, chock) on the core.

6. Sal has a map and a (globe, gob) in class.

7. The (bite, bit) made Jim sore. 
$62 a$

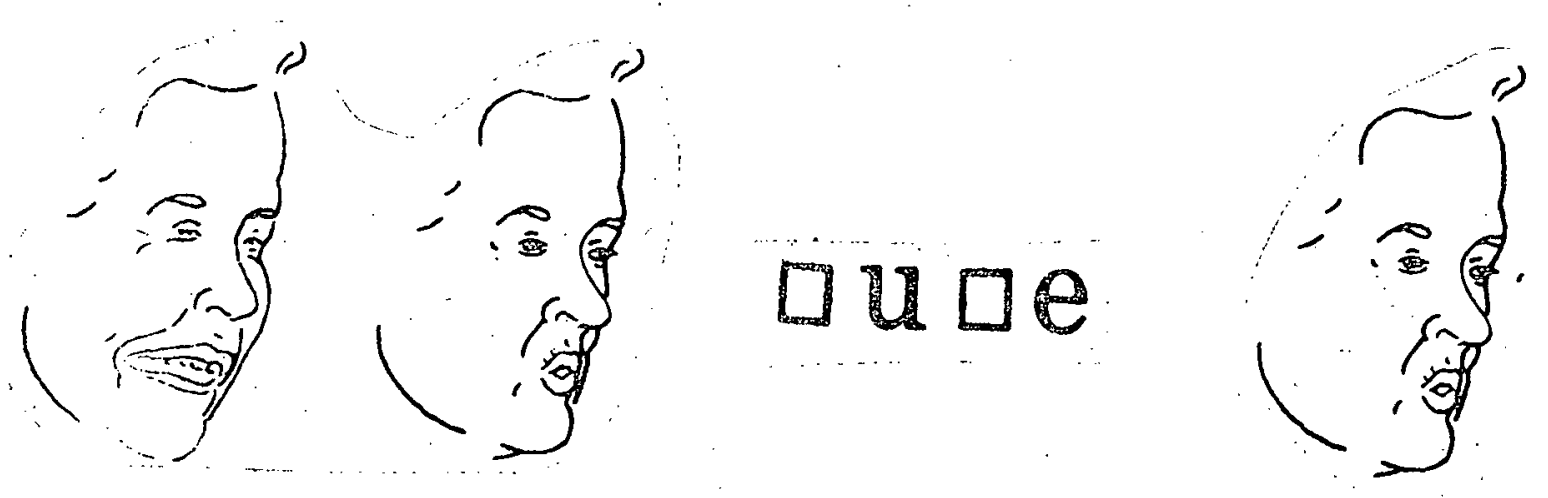

use us fuse fuss cute cut cube cub mule mull rule rude plume plum duke duck June

bake lake nunind sprite plonang jumampt kimumum stome wrench crude coke spite wren rude cock spit 


use
fuse
cute
cube
mule
rule
rule
rule
plume
duke
June

use

fuses:

cuter

cuter 

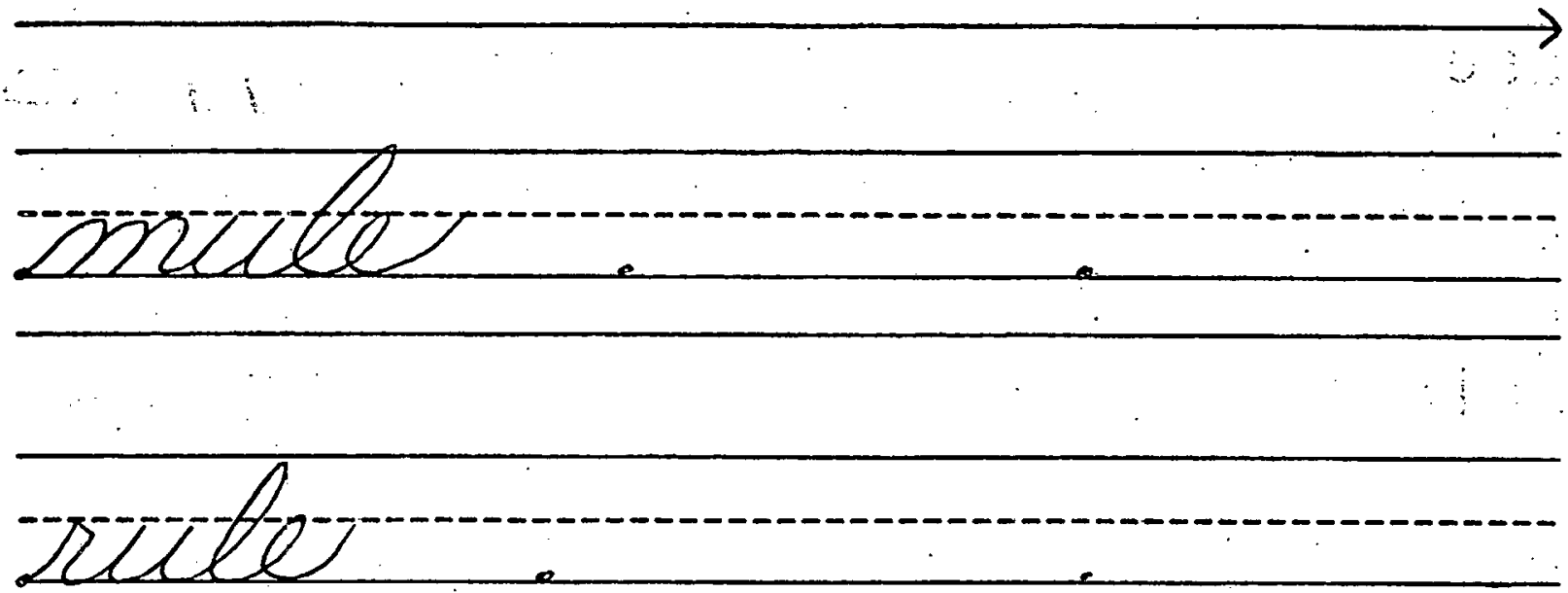

-radén
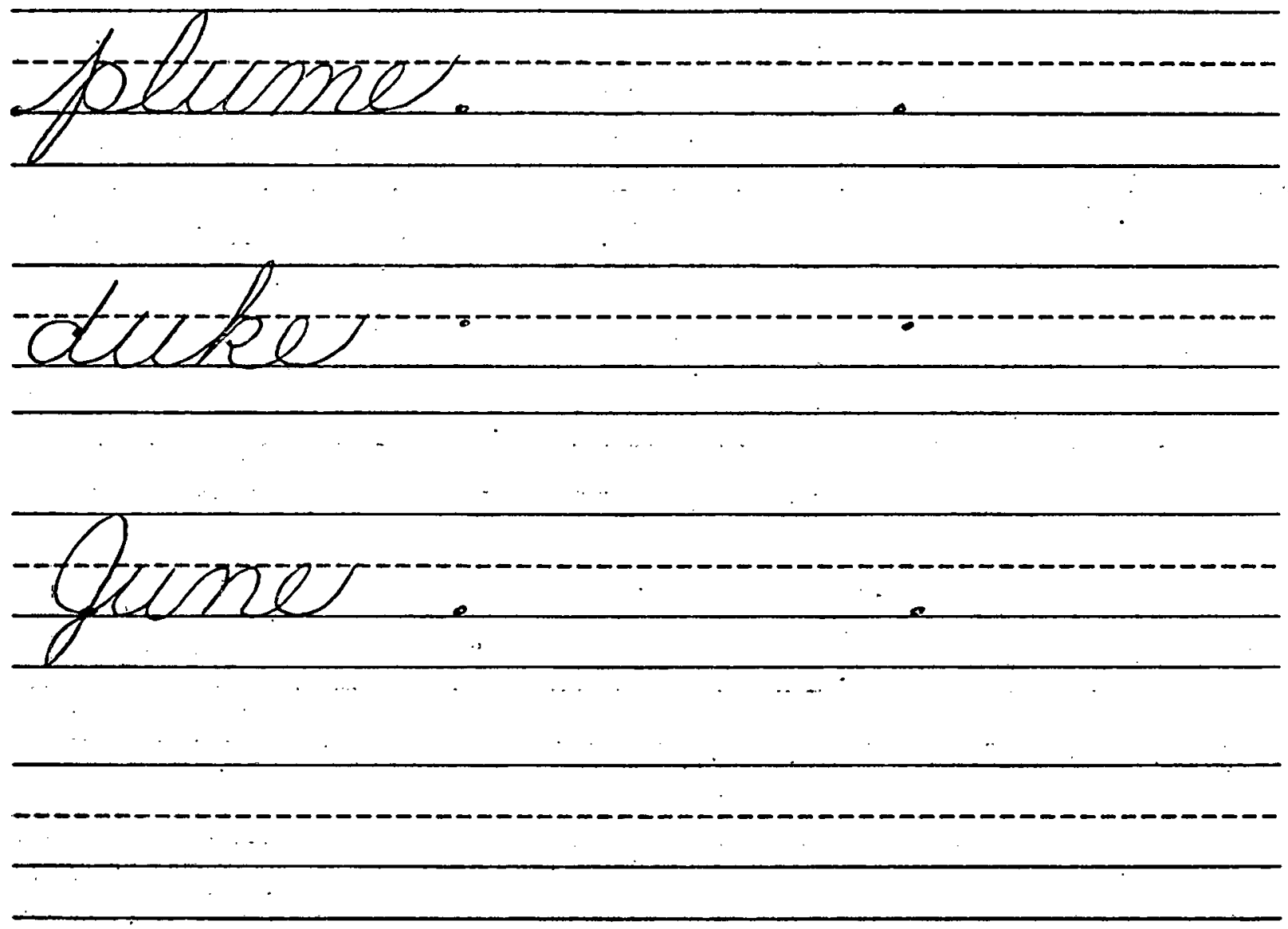
Underline the best word choice for each sentence.

1. That knife will (cute, cut) well.

2. The (duck, dukè) has wings and says,

3. A (cube, cub) is square and has 4 sides.

4. The man shot it with a (gun, June).

5. Do not (use, us) it up.

6. The (fuss, fuse) is in that box.

7. A (mull, mule) has 4 legs. 
$63 a$

\section{"Magic e" Detached Syllables}

nite knit buse bus pose

plete let tate tat pede ped

bine bin pire sane san tume

†um

sprant quire trank sprire vore

fluze bline hoke meme chuke

spring brink then square

ring rink when spare 
$63 b^{*}$

nite

buse

pose

plete

tate

pede

bine

pire

sane

tume
"Magic e" Detached Syllables
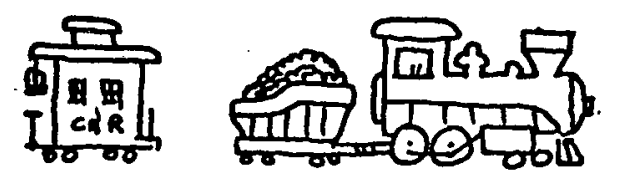

ancite-.-.

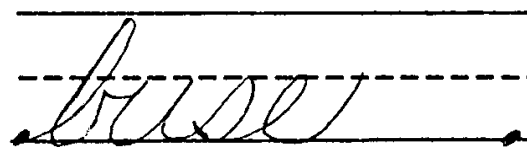

parey.

steter. 

Write the detached syllables below that your teacher dictates. 
Two-Syllable "Magic e" Words

tad pole tadpole sub lime

sublime im pure impure sup

pose suppose bag pipe bagpipe

dic tate dictate es cape

escape in side inside en

tire entire com pete compete

admire backbone upside compute entire wishbone inside dispute 
tad pole

sub lime

im pure

sup pose

bag pipe

dic tate

es cape

in side

en tire

com pete
Two-Sy| $|a b| e$

"Magic e"

Words
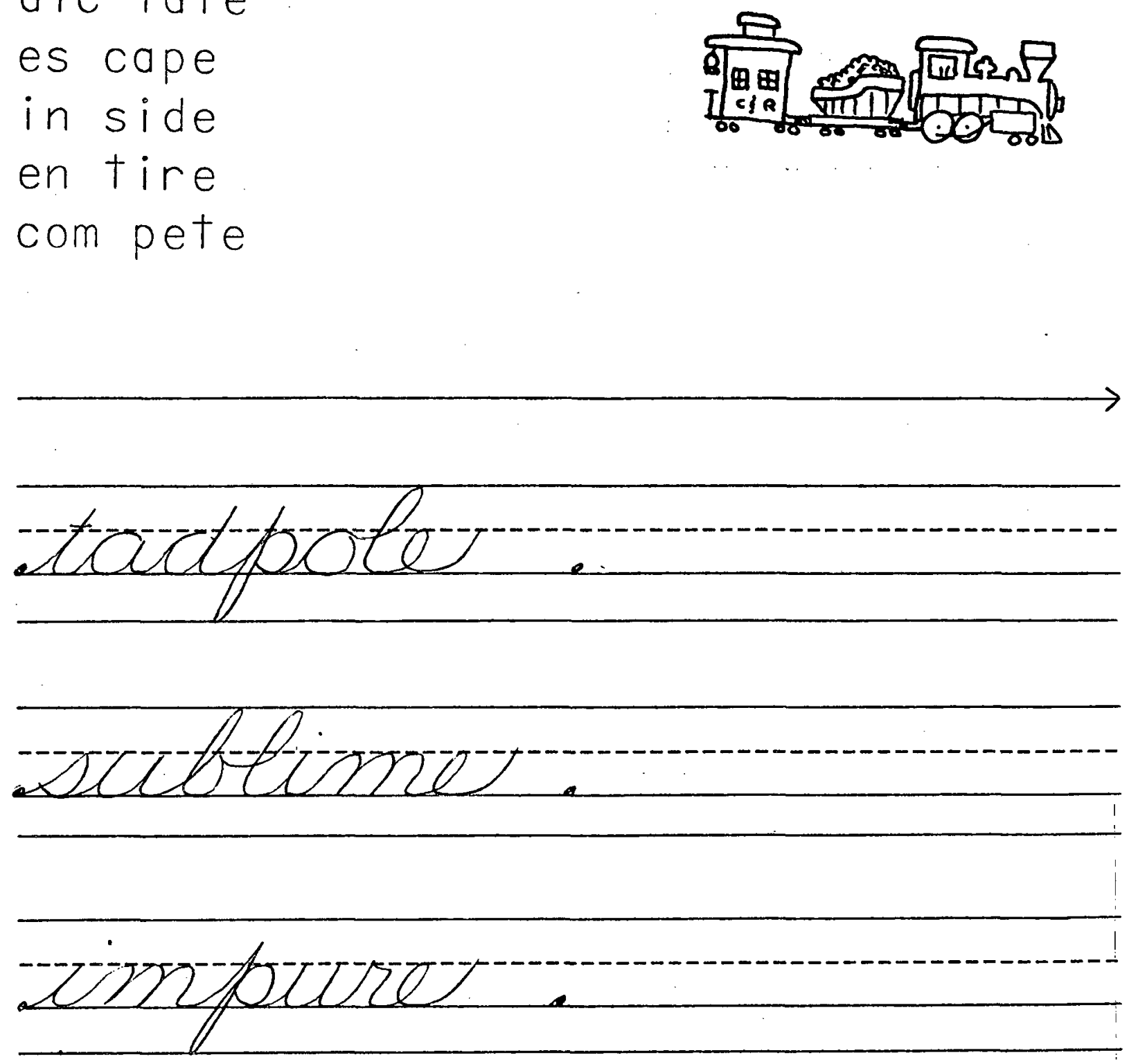

extppover. 
bagpiper.

dictate

escape

inside

entire

compete 
Match the best ending with each word beginning to make a two-syllable word.

in

plete

em

pire

com

dure

en

vade

con

sume

ad

nore

$\cos$

mire

ig

tume

Find other two-syllable "magic e" words in a book. 


\section{"Magic e" Review`}

Read these words.

rate

rat

bite

bit

Sal

sale

Pete

pet cute

cut

pin

pine

mete

met

rob

robe cloke

clock

duke

duck

kite

kit

tame

tam made

mad

file

fill

sake

sack

pile

pill

Read these words.

invite costume impede tadpole

inside confuse stampede suppose

Write the long vowel sound that you hear in each word that is read to you.

1.

2.

3.

4.

5. 

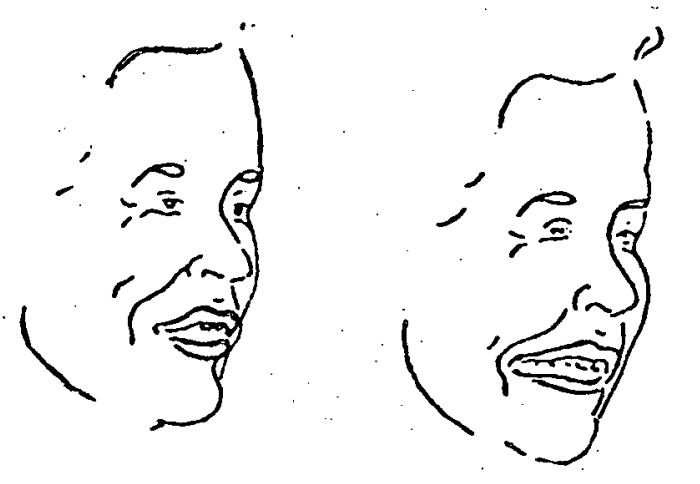

\section{aaic}

jail mail aid paid grain

train fail bail taint quaint

chair chairman claim exclaim

pair despair box mailbox

pane vane complain dumb wrote

pain vain complete thumb rote 
jail

mail

aid

paid

grain

train

fail

bail

taint

quaint

$66 b *$

$a i$

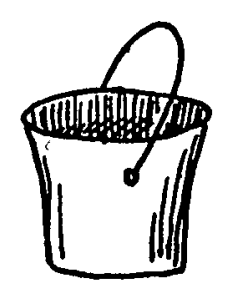

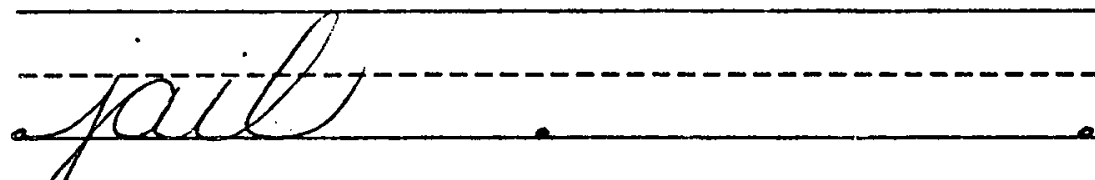

marie.

aid et

paid t. 
grain

tration.

faits...

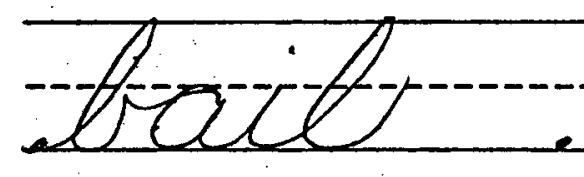

2

taint

gewaint 
Under l ine the correct. homonym.

1. The postman put the mail in the box.

2. That man fell and is in pane.

3. Fill the pail with milk.

4. The dog has a long tale

5. His dad will bail him out of jail.

6. The big shiphas a sale full of wind.

7. Much grass is on the flat plane plain.

8. That lad will not ail the man. 


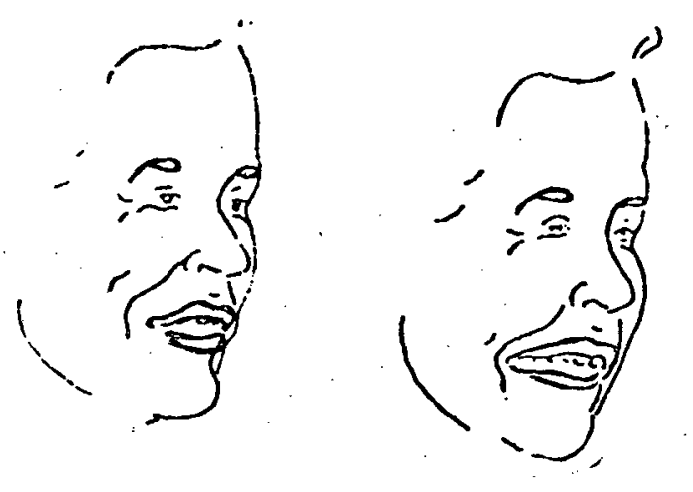

\section{aay}

may pay say slay clay ray

pray spray sub way subway

play mate playmate

fail chain came dome play

time playtime concrete inquire

sale male made stay gray

sail mail maid say grain 
$67 b *$

may

pay

say

slay

clay

ray

pray

spray

sub way

play mate day

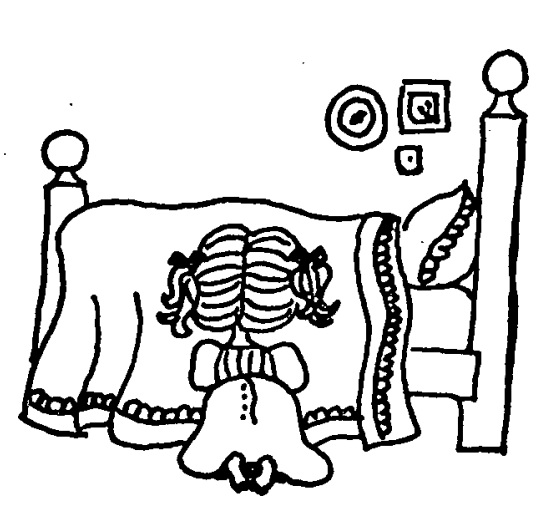

mary

zany

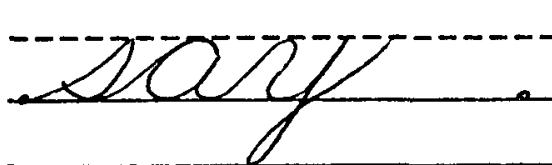

stray. 
ctany

roung

froong:

uprong:

xubuowy.

Zflarymate: 
Magic squares:
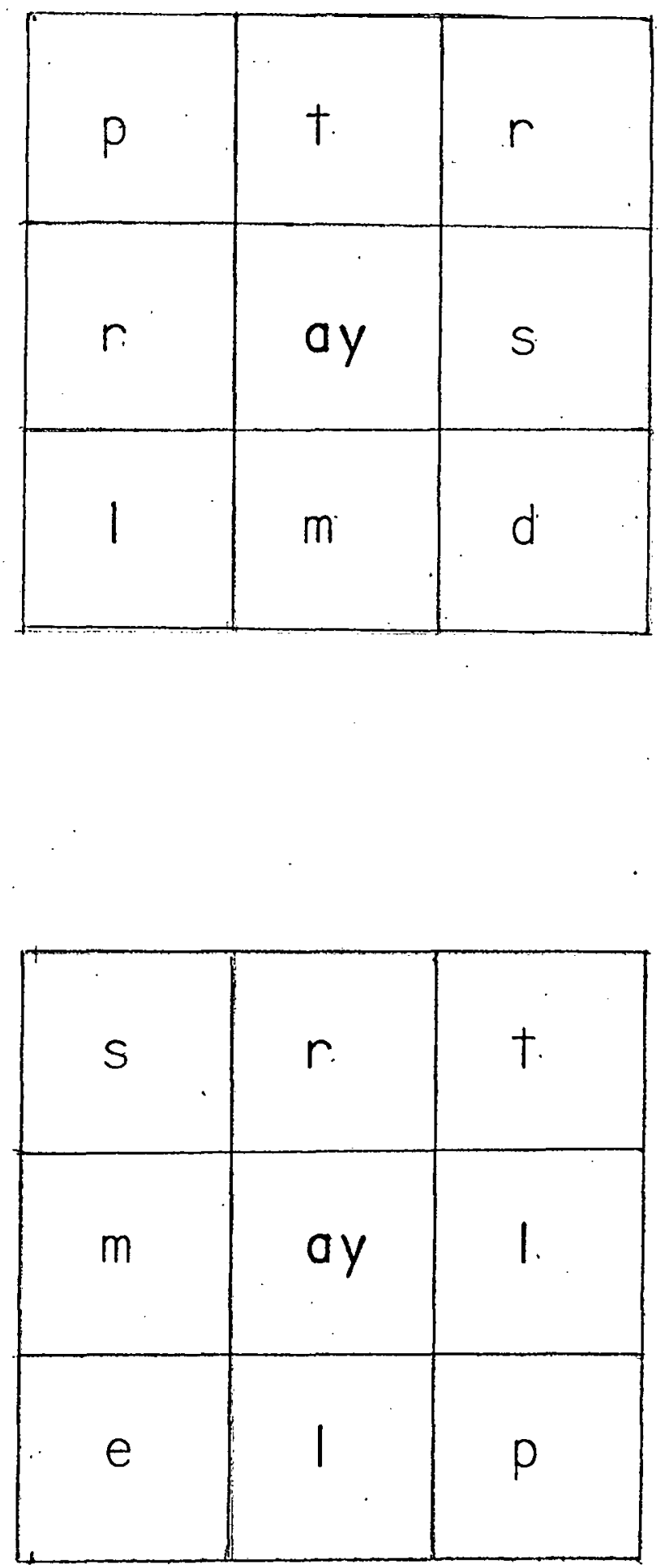


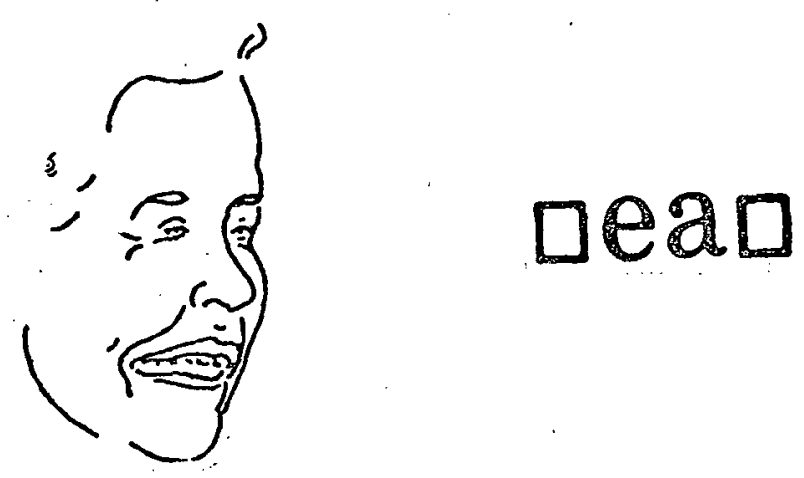

eat seat east yeast team

steam stream bean clean

squeak

daydream lead napkin stairs

gay paint tantrum despair

wail paid wane complete phone whale pay way pleat stone 


\begin{tabular}{l} 
eat \\
seat \\
east \\
yest \\
team \\
steam \\
bean \\
clean \\
squeak \\
\\
\hline eat
\end{tabular}


Underline what one can eat.
yeast
grape
clay
nail
train
peach
bean
dream
braid
wheat
grain
squeak
cream
stream 


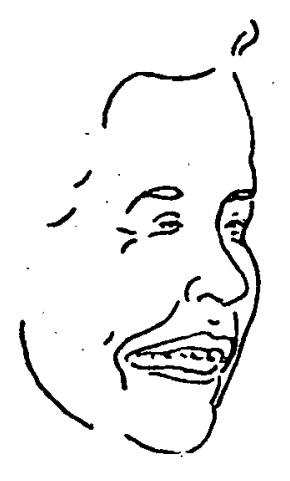

\section{oeer}

see bee bleed speed heel

peel green tree fleet street

seal sprain playtime quote

stray Ralph athlete compose

sea peal heal wail steel

see peel heel whale steal 

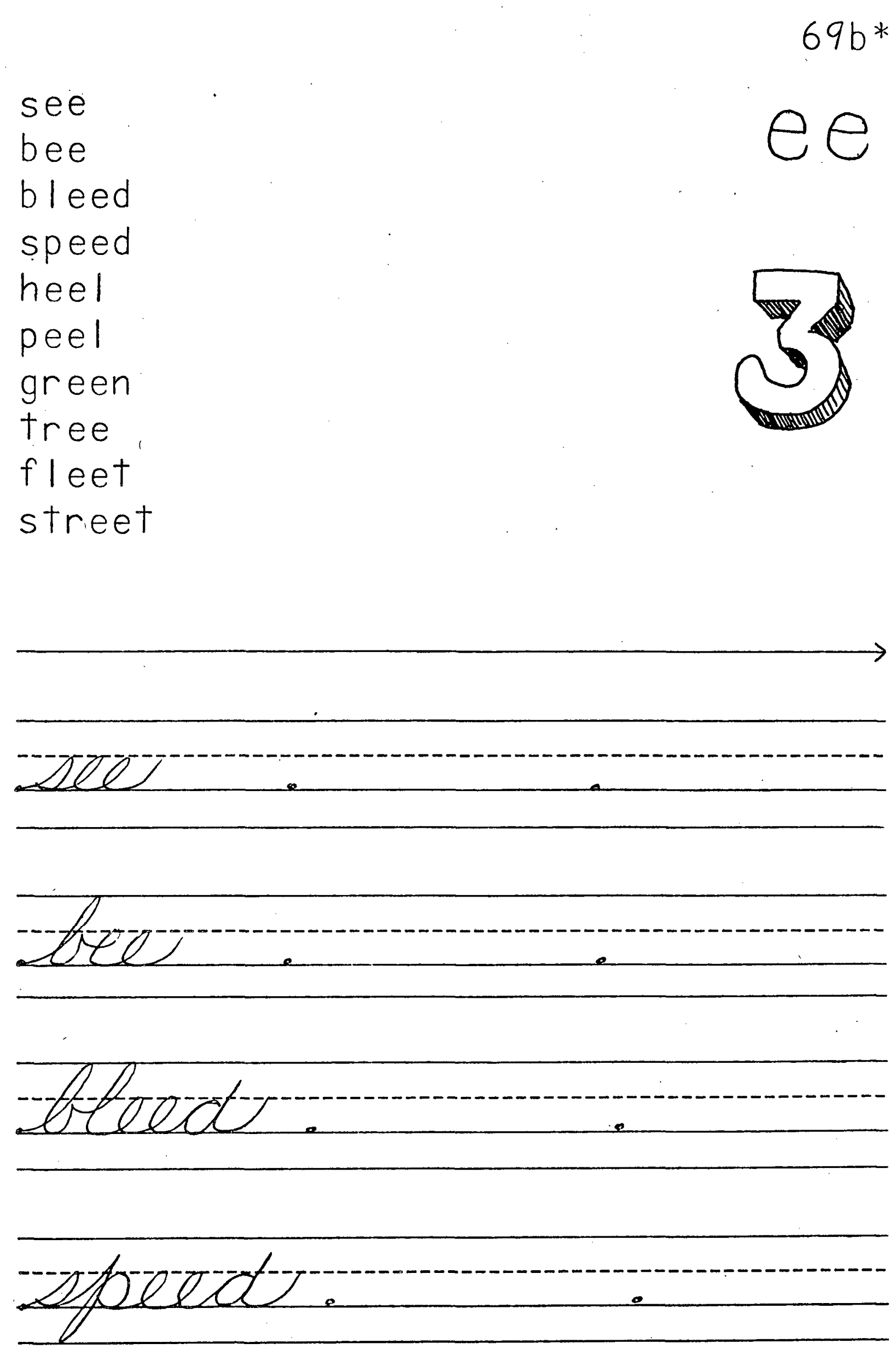


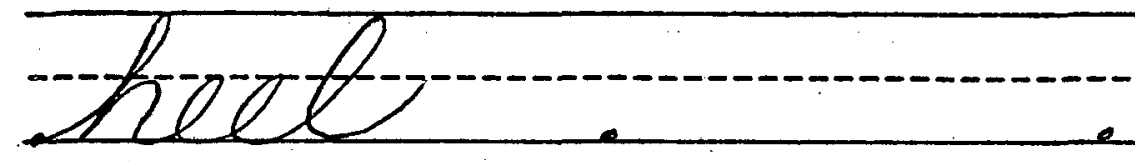

(2)

greter

treel

flett

atreet.

-

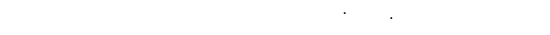


Which words below have the same vowel sound as wheel? Underline them.
beast
screech
Jack
cheap
Pete
cloak
basket
green
mate
complete
squeak
bite
athlete
mote 


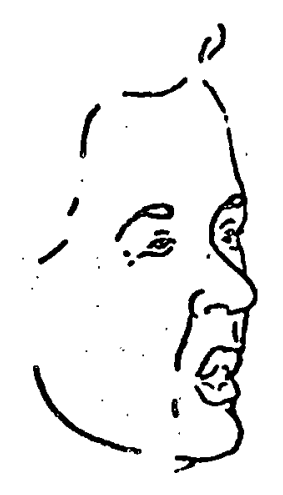

प0ar

Ioan oats boats soap coax

coach road load toast coast

sole shipshape dispute enclose

combine compete vampire raid

rode lone mote street meet

road loan moat treat meat 


$$
70 b *
$$

loan

oats

boats

soap

coax

coach

road

load

toast

coast

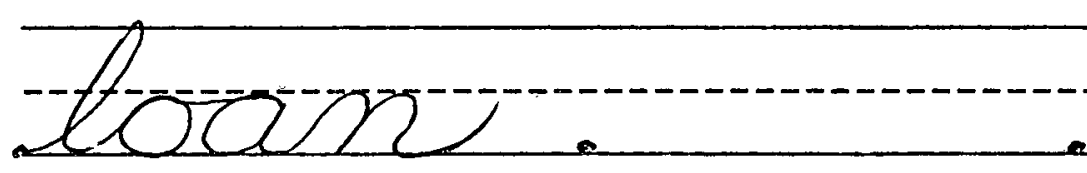

oates

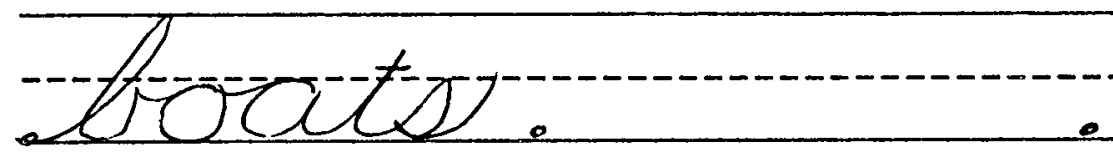

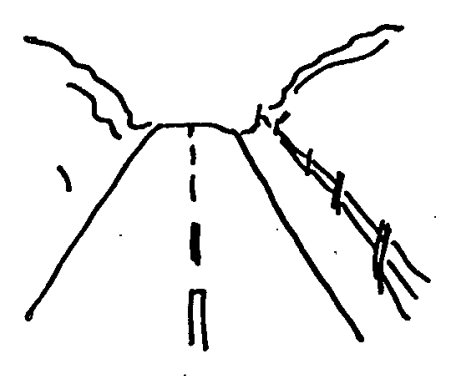



Magic squares:
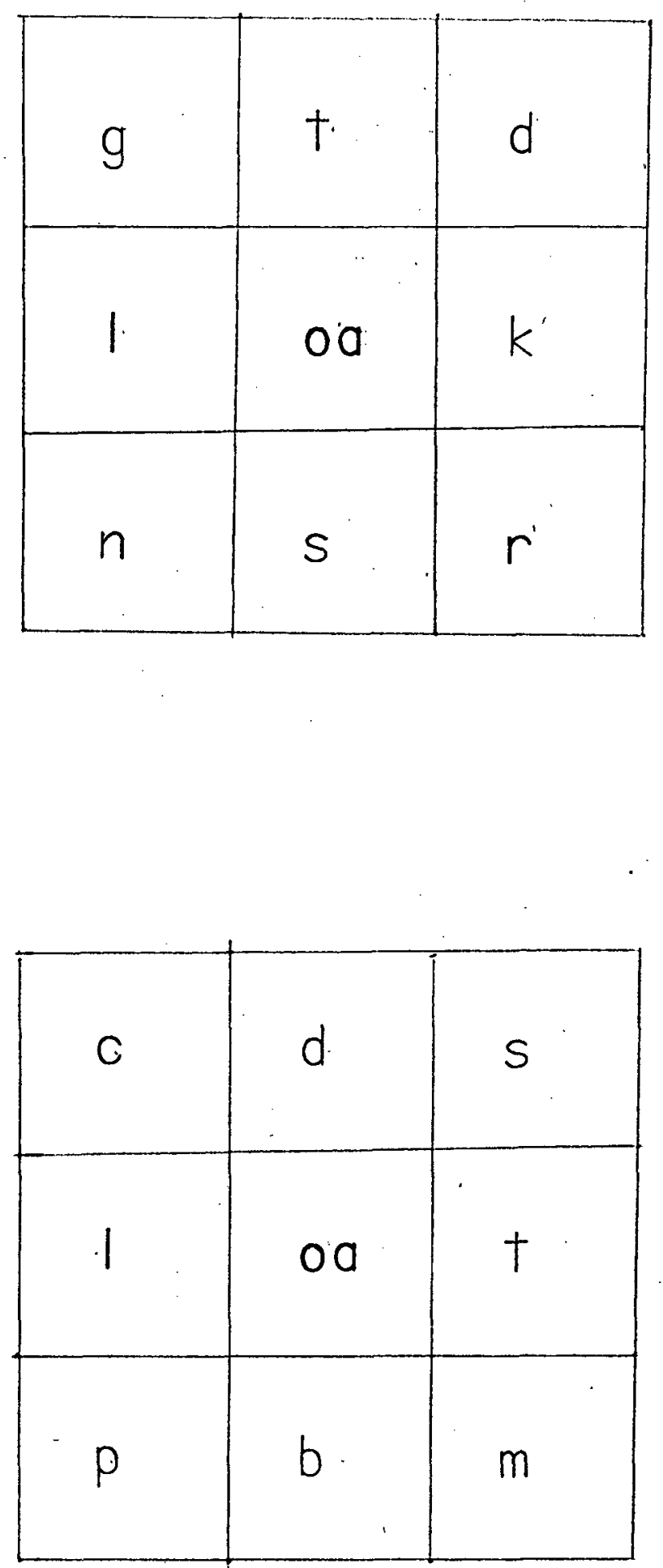


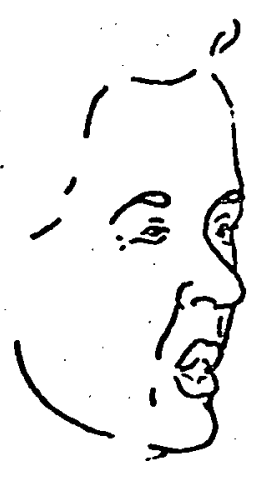

. $\mathrm{OO}$

woe toe Joe foe doe toe

nail toenail tip toe tiptoe

doe skin doeskin

screech throat peach dome

play coast stream plank

foe toe toast queen knee

foes toes toad ween tree 
woe

toe

oe

Joe

foe

doe

toe nail

tip toe

doe skin
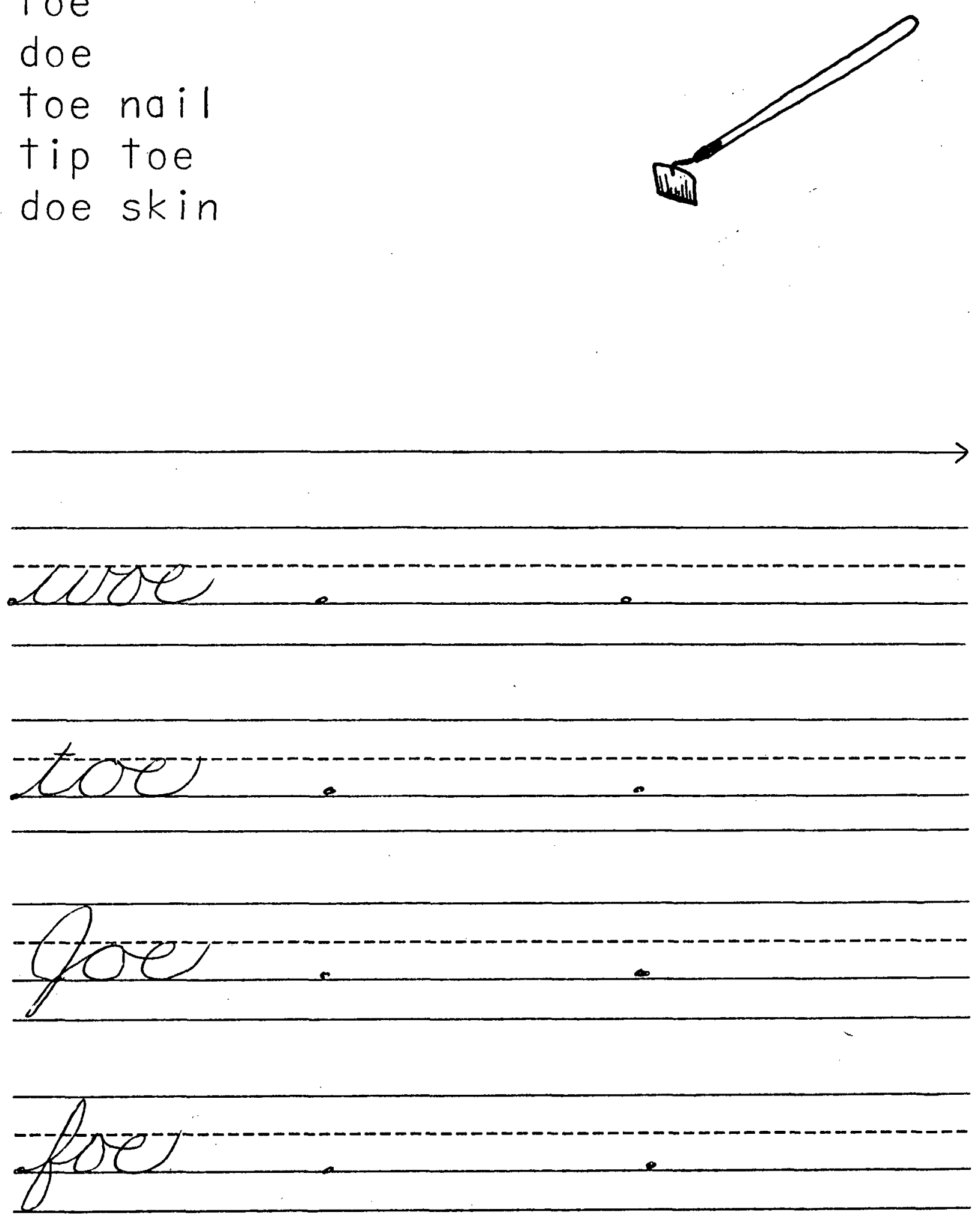
atar
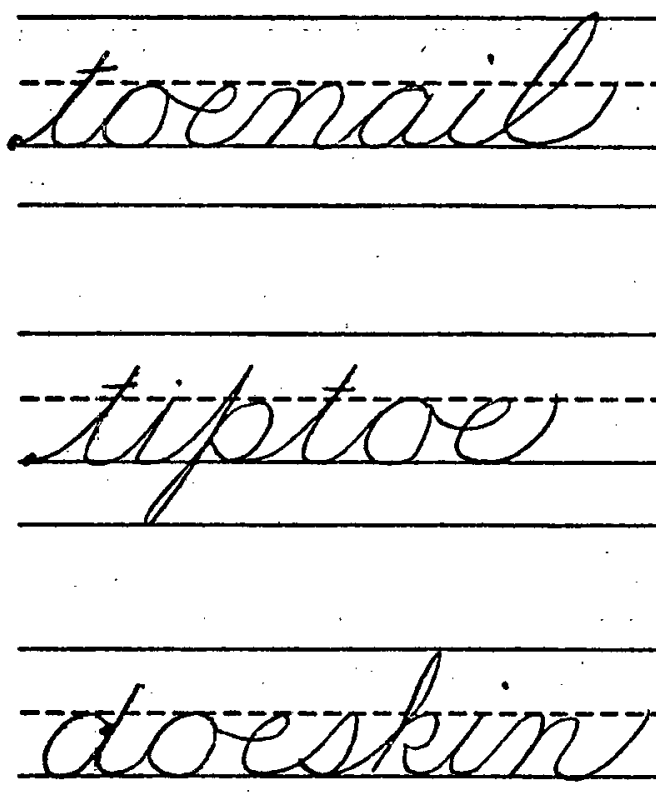
Which words below have the same vowel sound as in toe? Underline them.
load
not
sock
soap
mote
home
hole
dock
knot
chop
$\operatorname{coa} \dagger$
bomb

Ione

float 
$72 a$
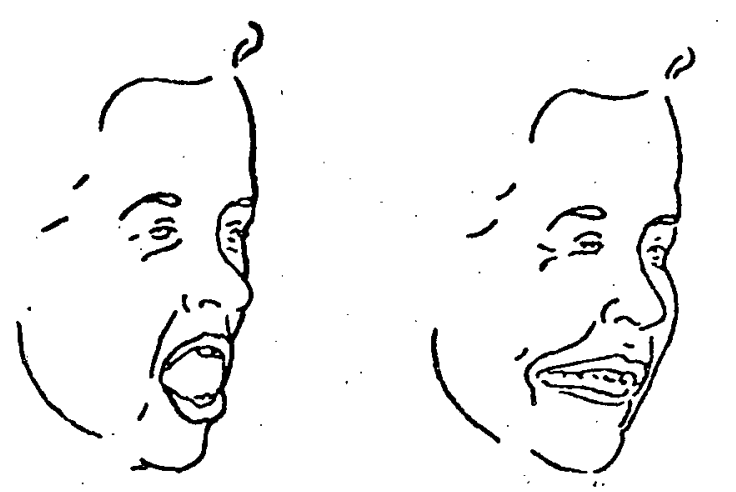

vier

die pie lie tie die lie tie lie die pie die tie

wilt sweep float file speak stray blank wring gnash jams tied contract bloat Glen's tide subtract float men's 

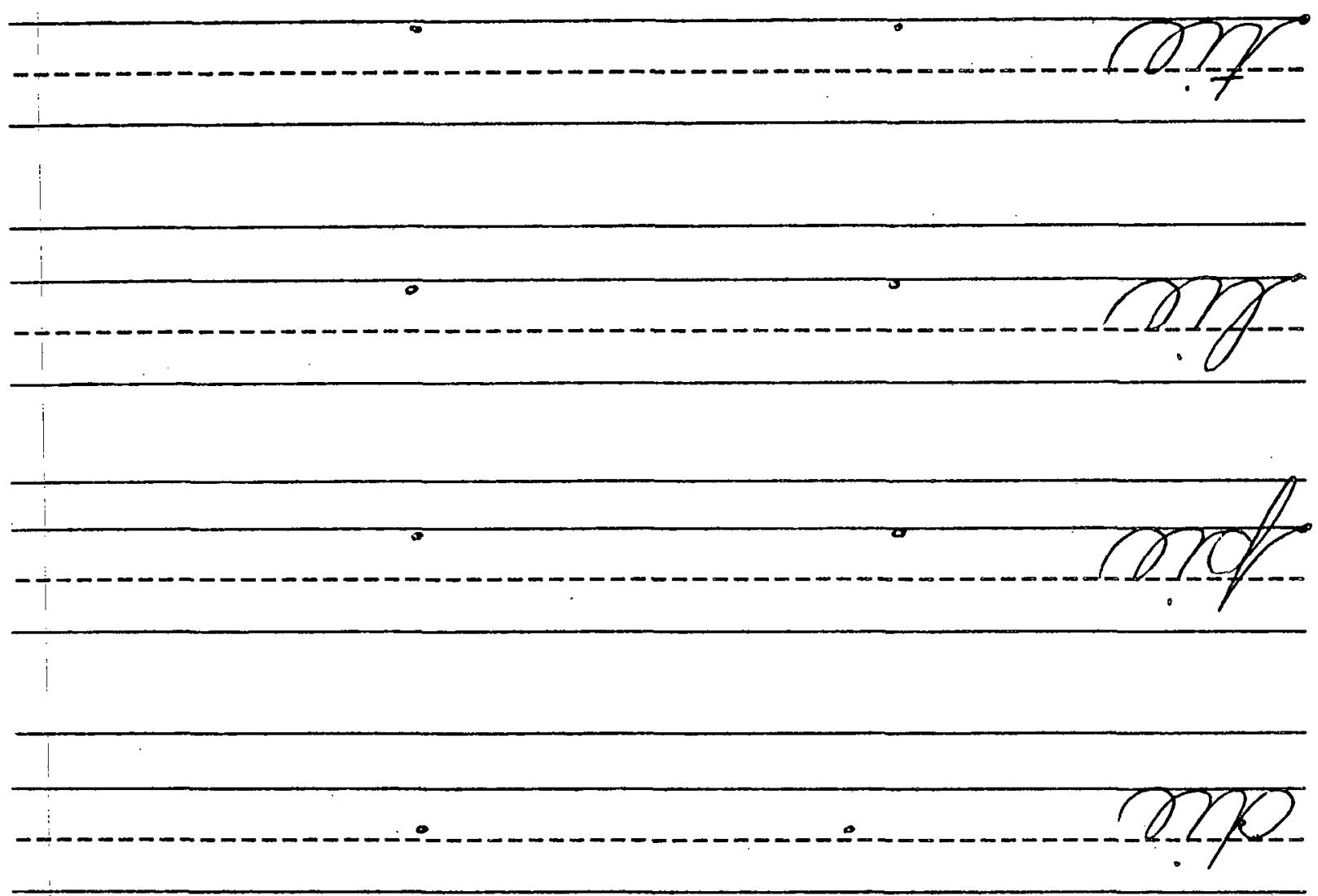

$\leftarrow$
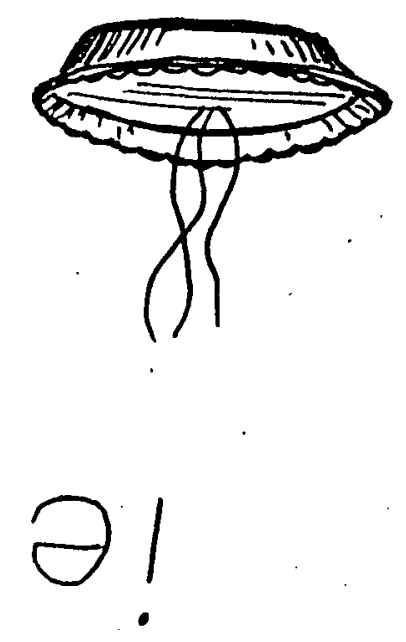

$\partial !+$

ə! 1

$\partial ! d$

$\partial ! p$

* 92L 
Which words below have the same vomel sound as in die? Underline them.
side
died
cried
children
this
fine
chicken
mite
white
inside
prize
slide
slid
†ie 
Review

Write the correct spelling of ( $\vec{a})$ in the blanks. Read the entire sentence. Choices: ai, ay, a-e

1. The s__ I is white.

2. Jack can pl_ with Dick.

3. The P_l is $P_{\text {_ }}$ I_ green.

Write the correct spelling of (e) in the blanks. Read the entire sentence. Choices: ea, ee, e-e

4. The s_t is black. 5. P_t_'s tr_fell. 6. Lunch is a m_l.

Write the correct spelling of (ō) in the blanks. Read the entire sentence. Choices: oa, oe, o-e

7. The r__ d is long. 8. Jack has a h__ and a p_l_. 9. $A$ b_t $\operatorname{can} \overline{f l}+$. 


\section{Syllable Division}

1. Underline the vowels in red.

2. When two consonants appear between the vowels, split the consonants with a red pericil.

3. Read the first syllable, the second syllable, and lastly, the word (Traub, p. 108).

tempest rabbit catnip suspect bonnet admit subject tennis bandit sublime tablet pigment complete hobnob bobbin concrete pulpit muffin 


\section{Syllable Division}

\section{1.}

1. Find the vowels but do not underline them.

2. Split consonants with a red pencil.

3. Read the word (Tbid., p. 109).

happen

commit

kitten

nutmeg

public

helmet contest

subtract

combust

pancake

dispute

stampede pollen

pumpkin

magnet

mandate

rostrum

fossil 


\section{Syllable Division}

\section{$|1|$}

1. Find vowels without underlining them.

2. Split consonants without marking them. Use the "rule of thumb.".

It is easy to read a twosyllable word when you use the "rule of thumb."-Cover the second syllable with your thumb. Read the first syllable, and then read the whole word.

3. Read the word (rbia.).

suffix

gossip

sudden

napkin

picnic victim

dentist

consent

dictate

vampire suppose

tandem

disrupt

s.plendid

conclude 


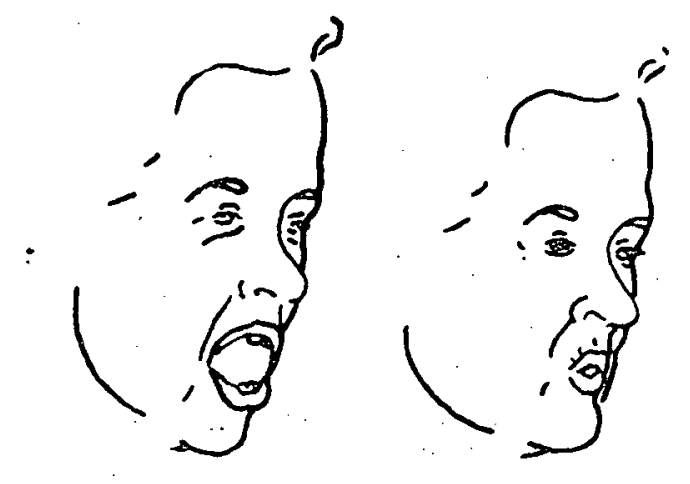

\section{DOUD}

out pout spout south mouth

out sour stout snout loud

joustin moumpen poumptan pleem

monoumap plame plostmimamp

toe loud moat pie sea

foe cloud float die tree 
out

pout

OU

spout

south

mouth

our

sour

stout

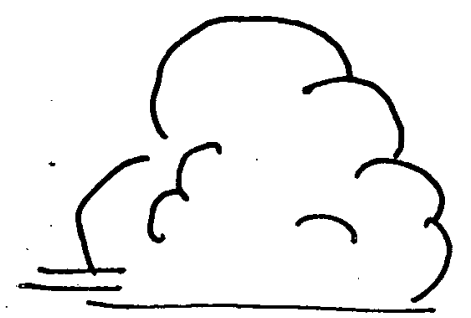

snout

l oud 


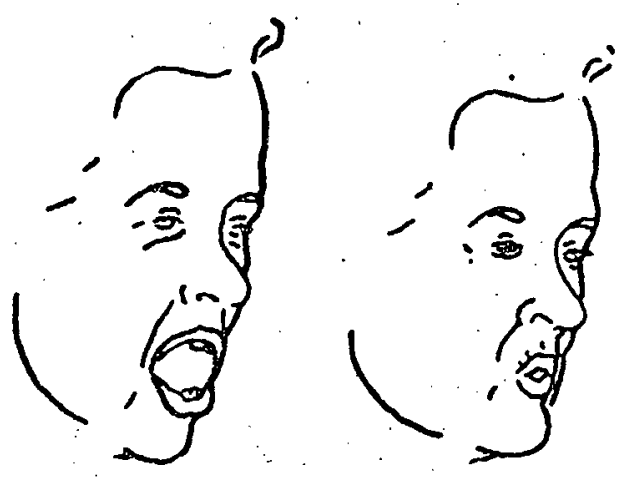

DOW

ow growl prowl vow plow

clown frown drown crowd prowl

powdened baidown meemeem bouboub

choatem pleday sleet squeak

found now paid beat moat

pound pow laid seat coat 
$76 b *$

ow 1

grow I

OW

prowl

vow

plow

clown

frown

drown

crowd

prow 1
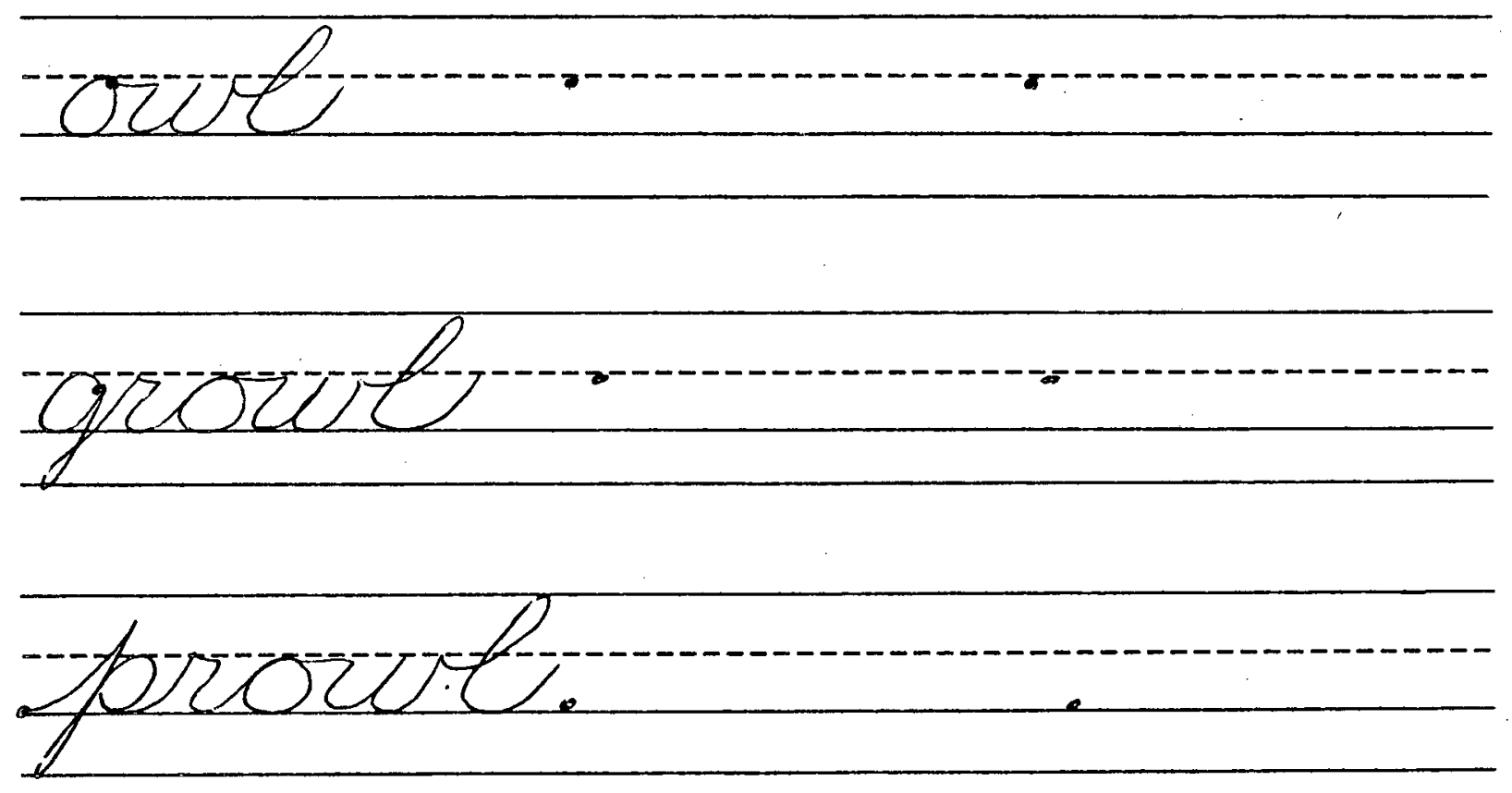

ZUYUCO 

Write ou or ow in the blanks.

1. That cl _n has a big, red nose.

2. The or__d can sh_t I_dly.

3. Jim $B r \ldots n$ is $d \ldots n$ in the + n.

4. His m__th will bleed.

5. Don went d_un S S_th.

6. The king wore a big or _ n

7. Do not $\mathrm{p} \ldots+$, or 1 will send you t. 
aer

her herb verb Bert pert term

perch her mit hermit Her

bert Herbert per haps perhaps

herperpert biebieb poapoat blump

deederday foufouf dowdowd slint

proud down meet tame slay
cloud clown fleet blame stay 


$$
77 b *
$$

her

herb

er

verb

Bert

pert

term

perch

her mit

Her bert

per hops
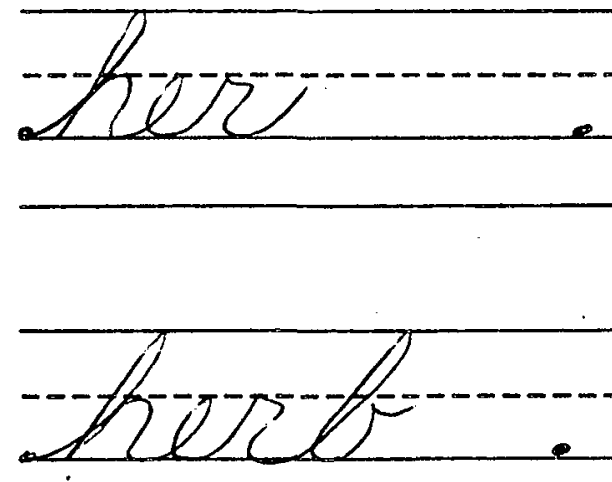

nets

Aet 


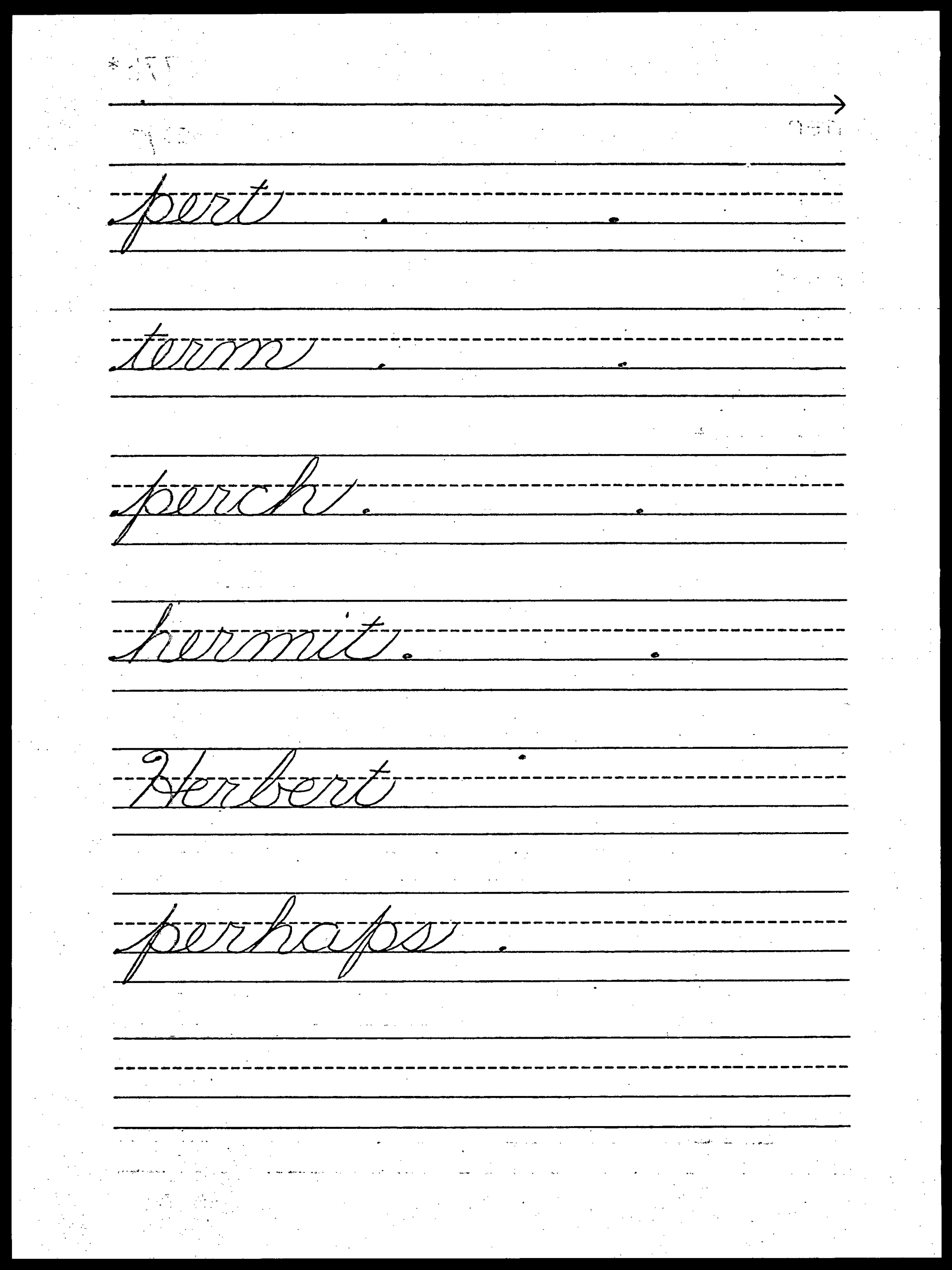


Put an appropriate er word in each blank. Answers will vary.

1. Jack rode home with

2. The man will shave his

3. Jim is a

4. The sang̀ well.

5. The dime is

6. I like

7. The did scare her. 


\section{air}

sir fir firm squirm first

thirst twirl swirl skirt dirt

pirpirp dowderd seaseas peedeed paipaip sersersert moump wown

round frown pert late lay found drown Bert Kate pay 


$$
78 b *
$$

sir

fir

firm.

squirm

first

thirst

twirl

swirl

skirt

dirt ir

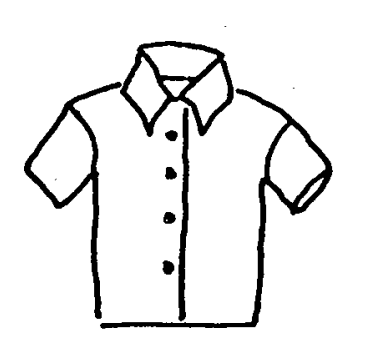

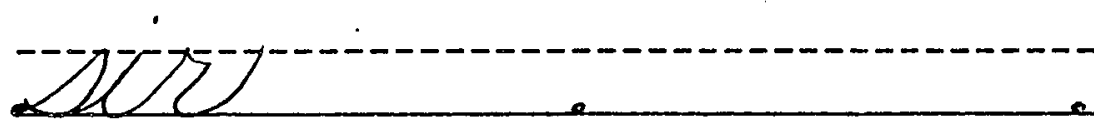
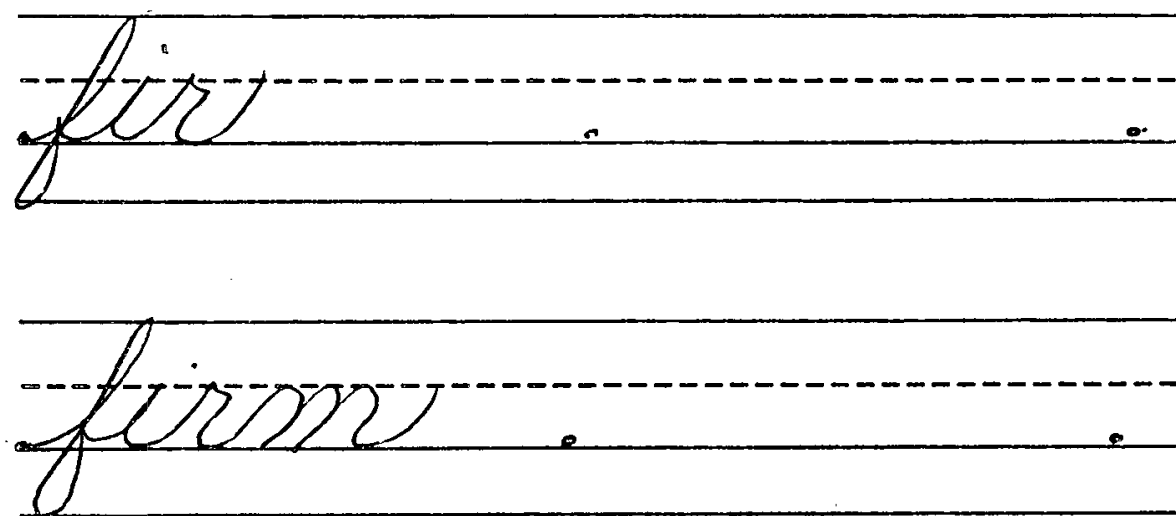

egutionv- 

$78 c$

Magic squares:
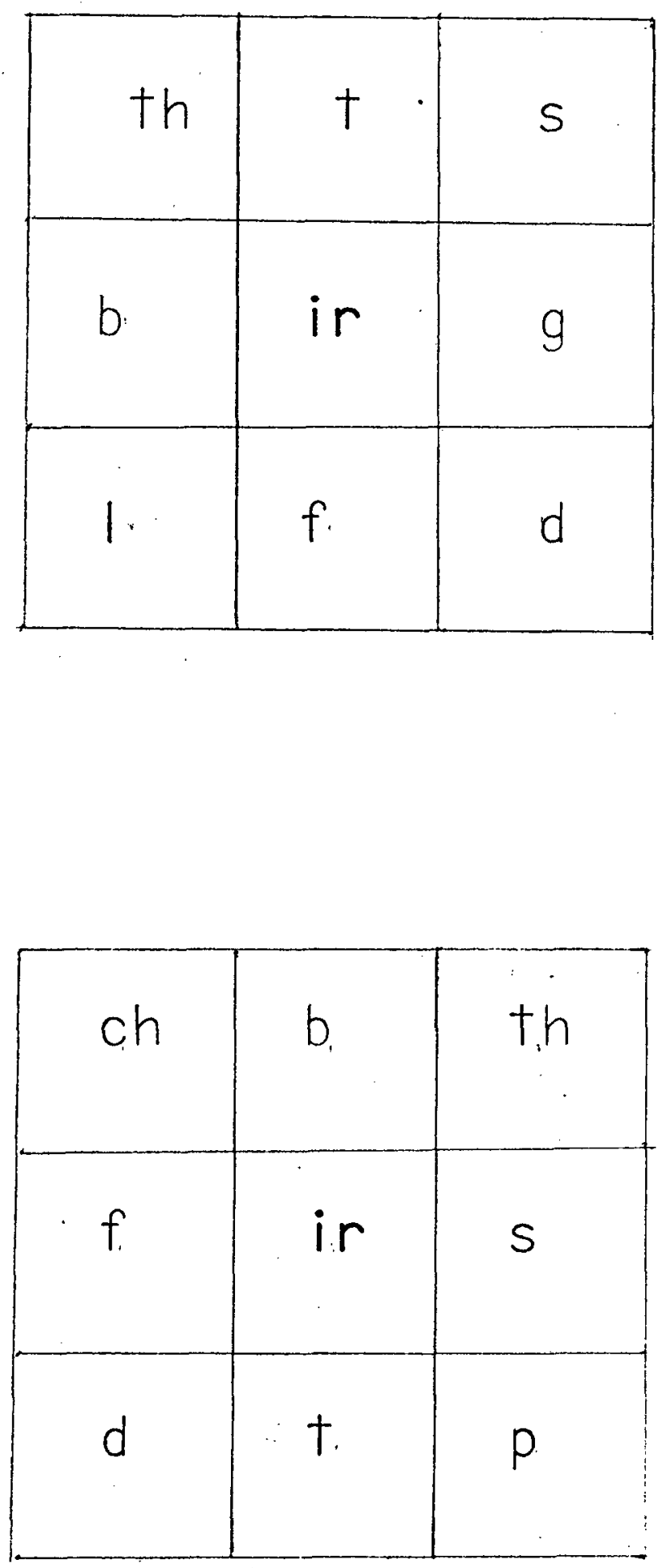
aur

fur spur curb curl burn

Turn dis turb disturb fur

nish furnish ur chin urchin

sur plus surplus

permit string plumpternk

smirk skirmish glownank

whirl Herbert churn crown

swirl hermit church brown 
fur

spur

curb

curl

burn

turn

dis turb

fur nish

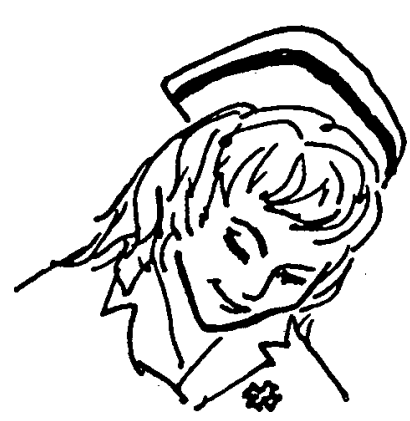

ur chin

sur plus

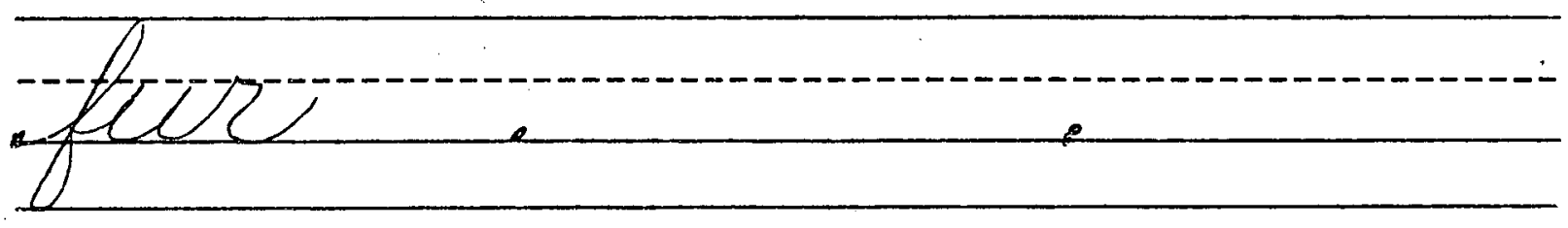

affortr-a-

aturte-a-n

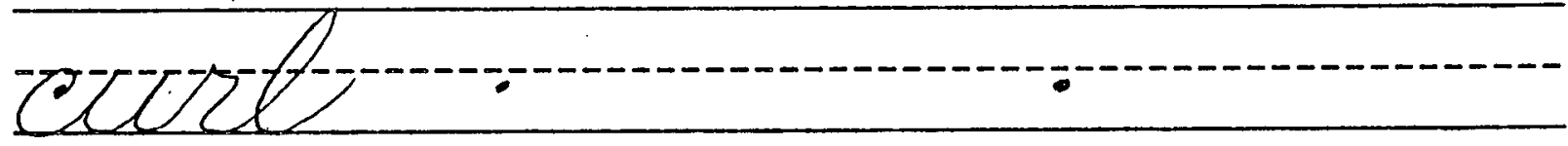




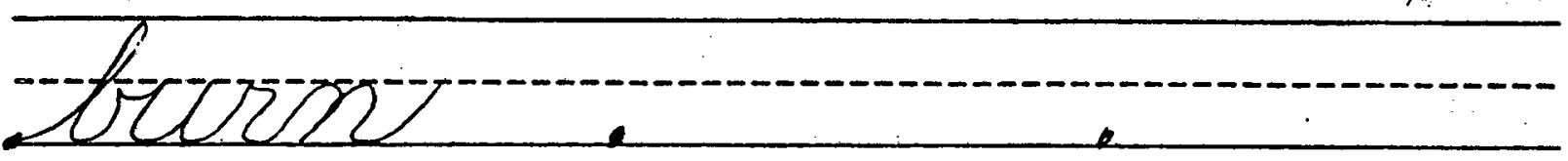

txum

a

a

distonte.

fownish:

auchine.

sorptrex. 
Read each sentence carefully. Underl ine the words that have the sound of ur as in fur.

1. The man in the third chair is Jeff Burns.

2. The bird said, "Chirp, chirp."

3. At first the girl could not see the birds.

4. Bert will hear it now.

5. The fern is under the tree.

6. That stern man is mean.

7. Please do not hurt the silver dish. 

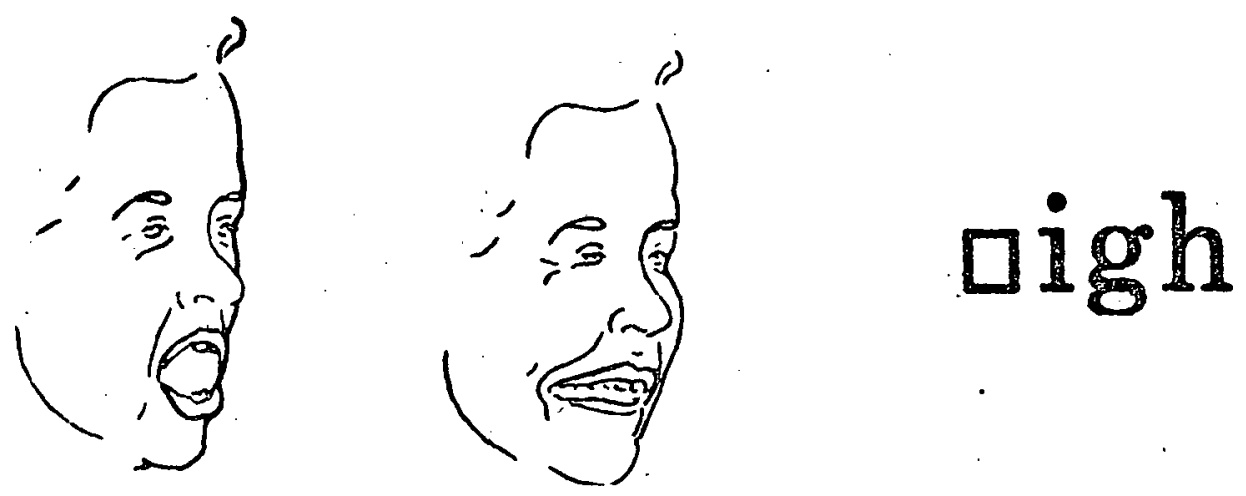

high

nigh

sigh

sight

tight

light

slight

plight

right

bright

insight

blonanonant

wound

grow I

micagamicuts

furnish

squirm

scow I

crouch

affright

squirt

how 1

grouch

I imelight 



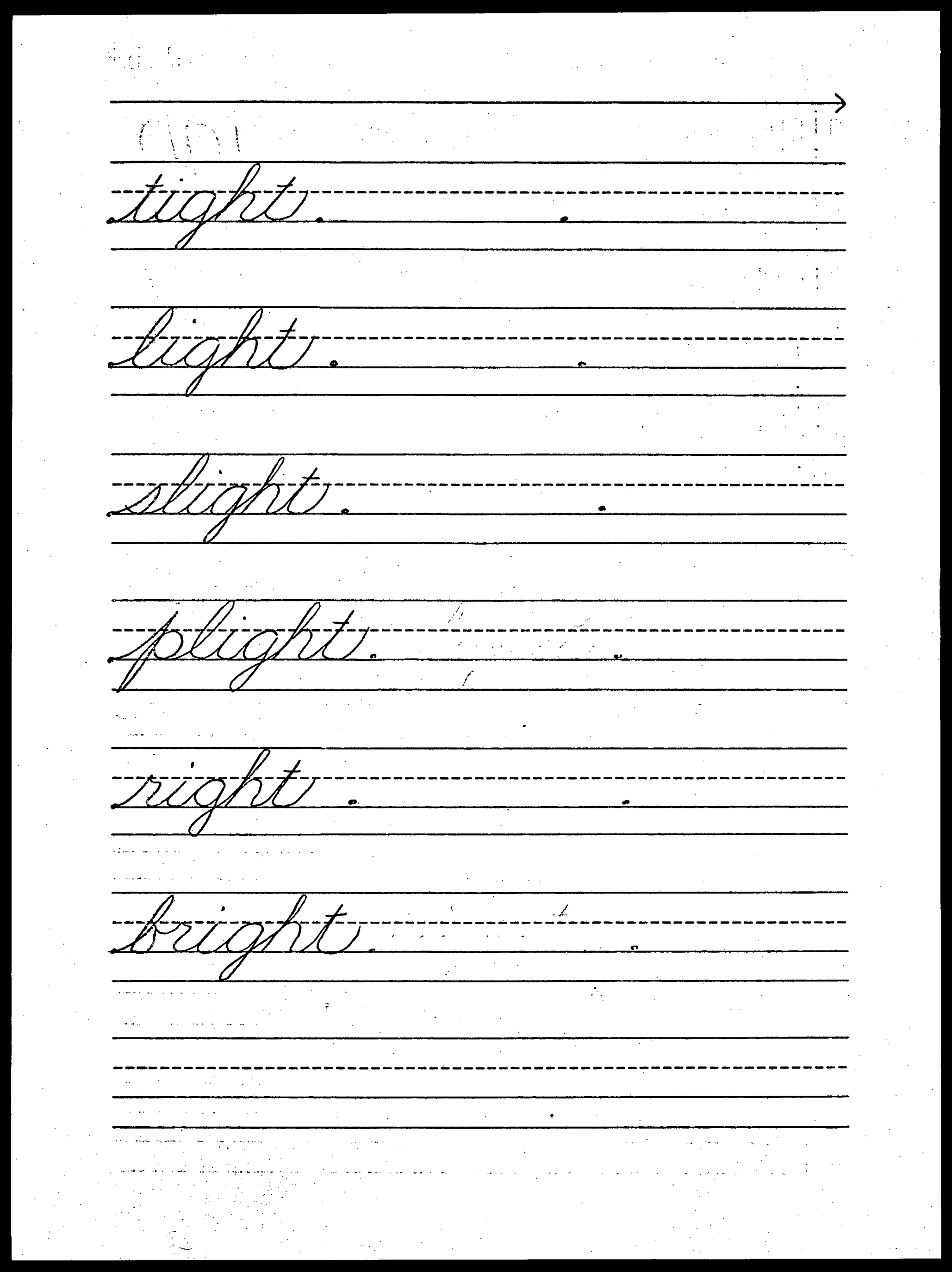


Circle the word that best fits each picture. There are four words per picture.

nigh

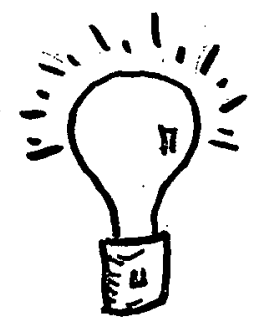

sight light

fight night

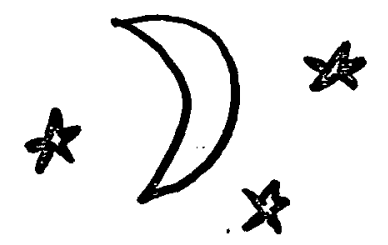

blight fright

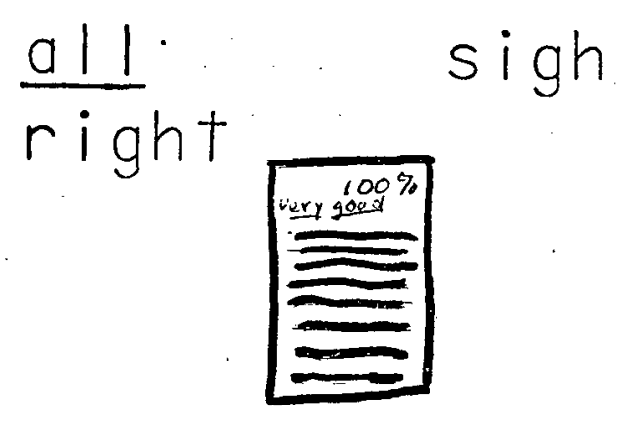

bright night

flight tight

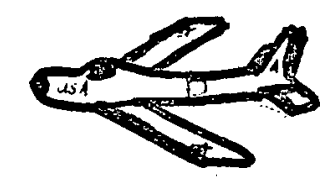

fight

might 
aar
art
arm
ark
jar
tar
harm.
bark
mark
harp
sharp

harmless

blomamomight

garlic

ground

frown

scaim

screech

art

arm

harm

bark

mark

a†

am

ham

back

Mack 


$$
81 b^{*}
$$

art

arm

ark

jar

tar

harm

bark

mark

harp

sharp ar

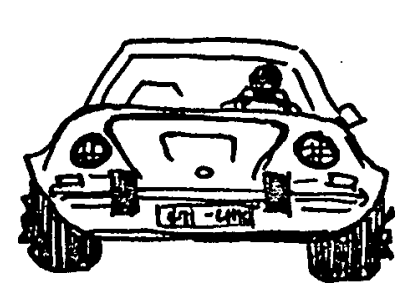

art

a)

arse

jars 


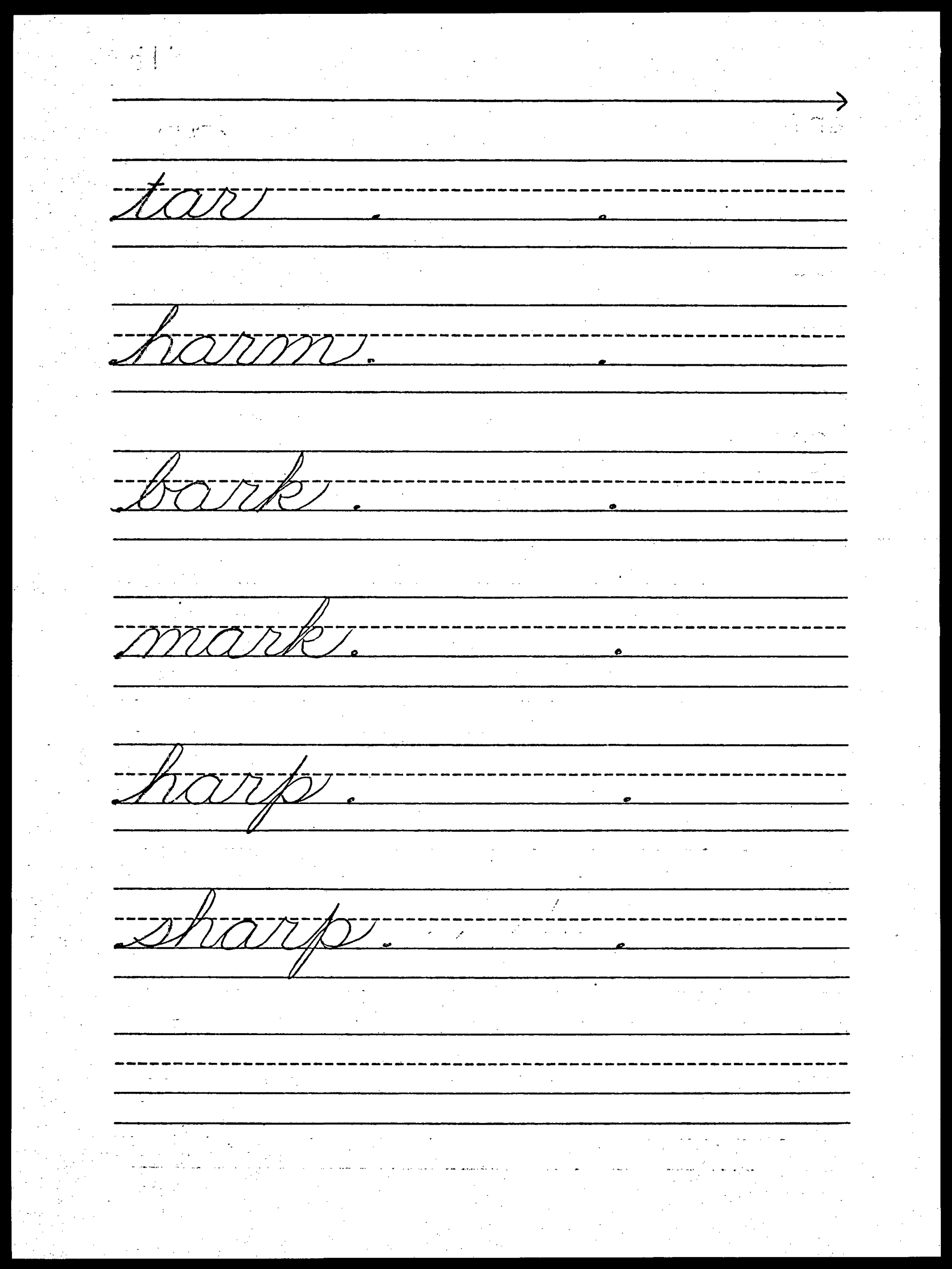


Choose the best word to complete each sentence.

1. The dog will at him. (snarl, farm, art)

2. Please $\frac{\text { do not }}{\text { (yarn, park, yard) }}$ here.

3. The lighter made a big (spark, lark, ark)

4. Most farms have a $\frac{\text { (barn, hard, scarf) }}{\text { har }}$

5. The scouts will now.

(chart, garlic, march)

6. That snake is

(charm, harmless, artist)

7. The apple is

(park, hard, start) 


\section{aor}

or for horn born fork cork

storm stork or bit orbit for

get forget

northwest forgave swoamimung

harness morbid brighten mouth

corn garden beech quaint

scorn sharpen beach saint 


$$
82 b *
$$

or

for

horn

born

fork

cork

storm

stork

or bit

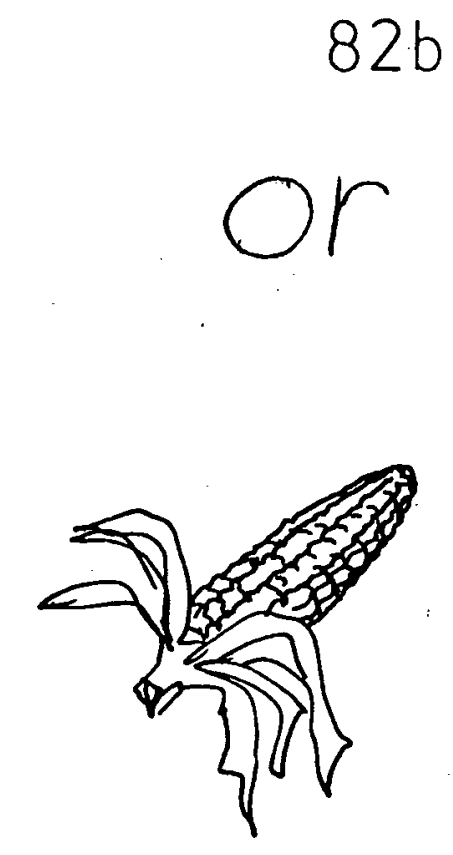

for get

QTS

for

frown

trover 

Finish each sentence with your own ending.

1. The storm

2. Jack's fork

3. Joe forgave

4. The short speech

5. Corn is

6. Hornets came

7. Sports are 
le

rum ble rumble bot tle

bottle sam ple sample snif

fle sniffle bun dle bundle

an kle ankle puz zle

puzzle tan gle tangle

humble bulb strurn pleamble

soublight stumble dimple

crumble ground disturb berth

grumble round blurb birth 


$$
\begin{aligned}
& \text { ble - rumble } \\
& \text { tle - botfle } \\
& \text { ple - sample } \\
& \text { fle - sniffle } \\
& \text { dle - bundle } \\
& \text { kle - ankle } \\
& \text { zle - puzzle } \\
& \text { gle - tangle }
\end{aligned}
$$$$
83 b *
$$$$
1 e
$$
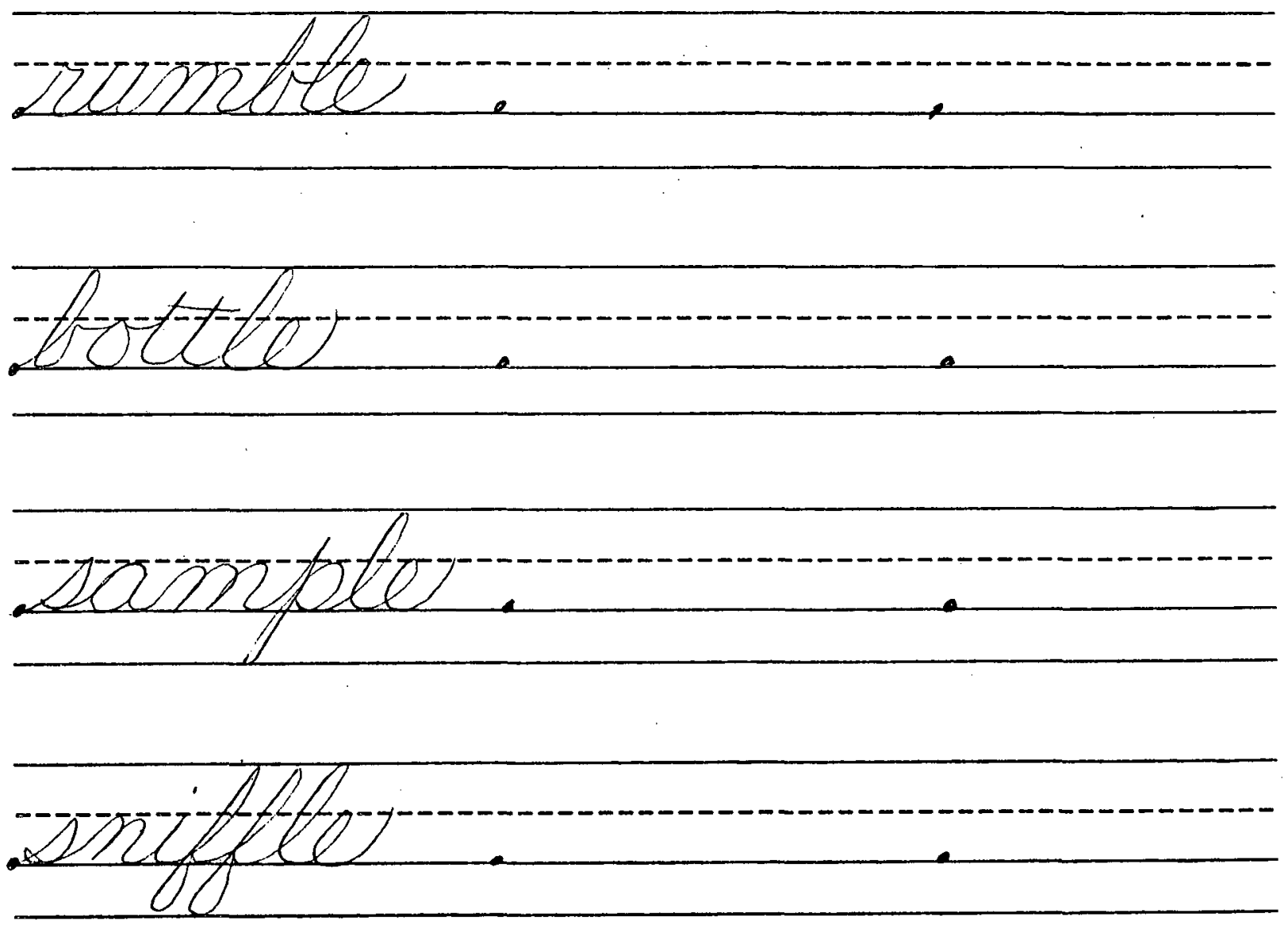


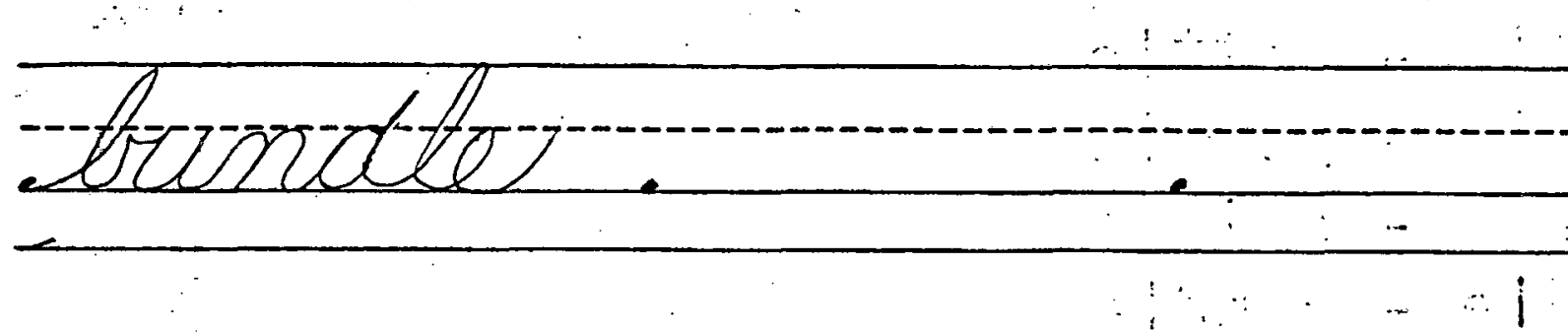

anteter

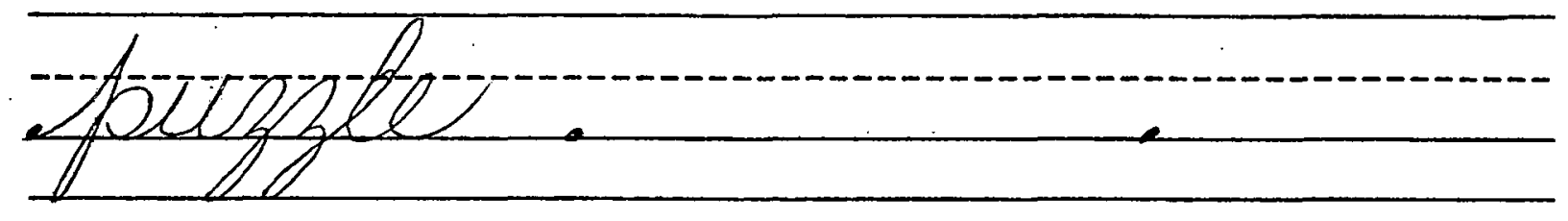

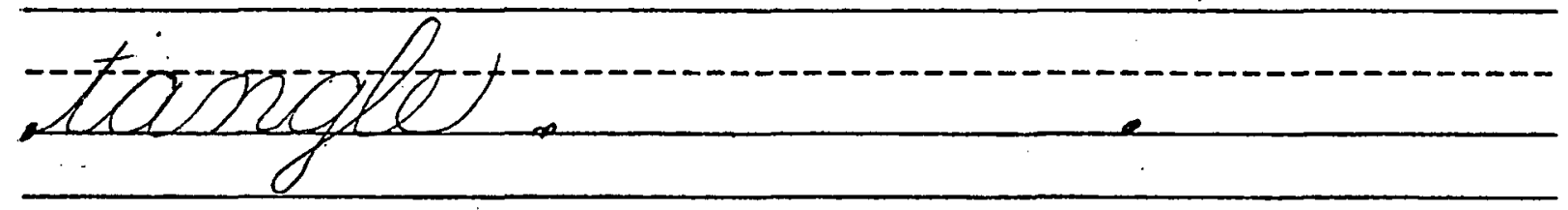


1. Using your thumb, cut off the ending of each word below.

2. Read the first syllable.

3. Read the word. (Some of the words have "twin" consonants.)

handle dazzle stumble crumble

ankle meddle candle spindle

guzzle grumble dimple hobble

Match the correct ending with each beginning syllable to make a word. The first one is done for you.

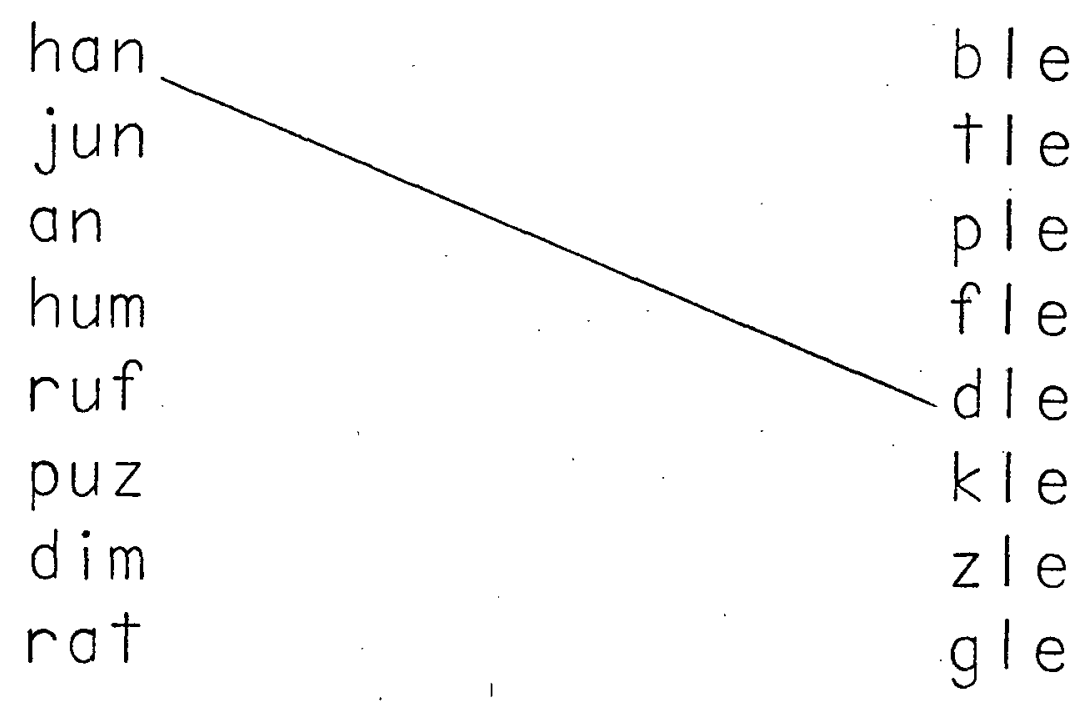




\section{Review}

Write in syllables each word that your teacher dictates. Then say the word. For example, if your teacher says the word, "sample," you write sam ple.
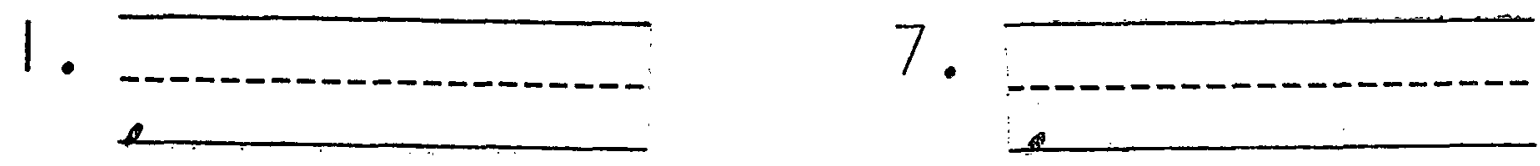

2.

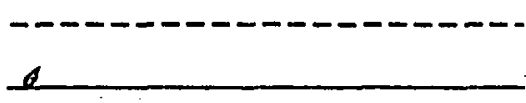

$Q$

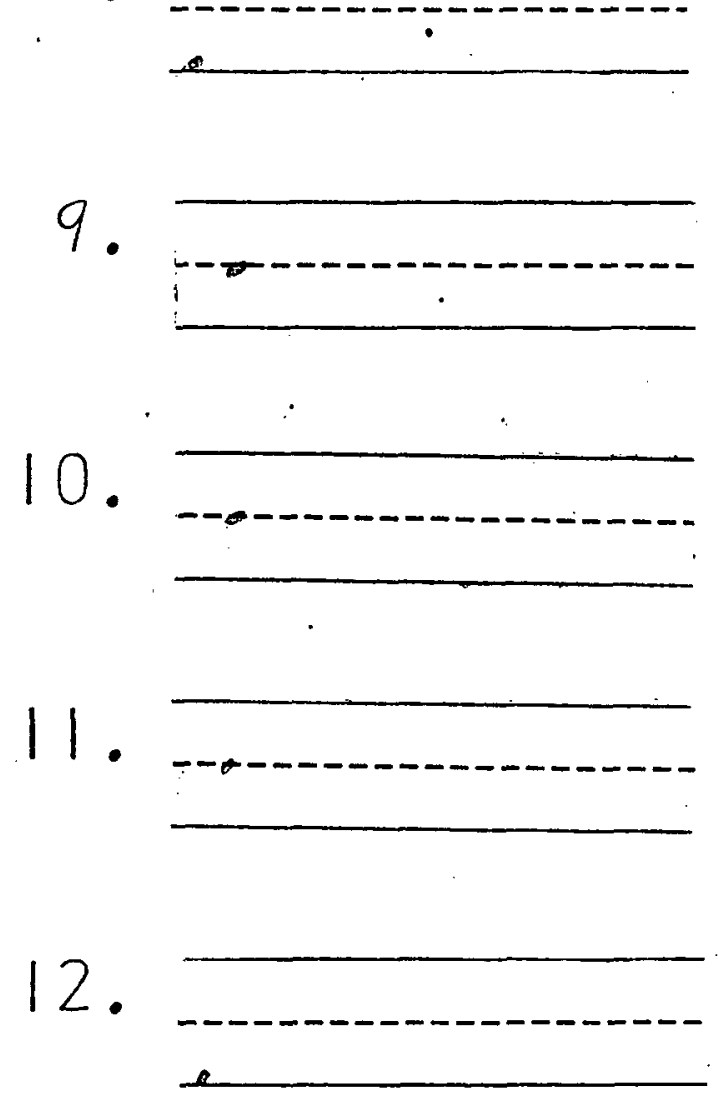

3.

9.

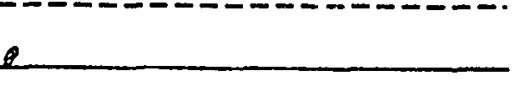

4.

10.

5.

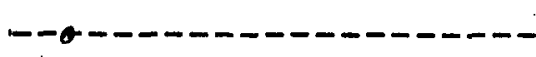

11.

6.

12.
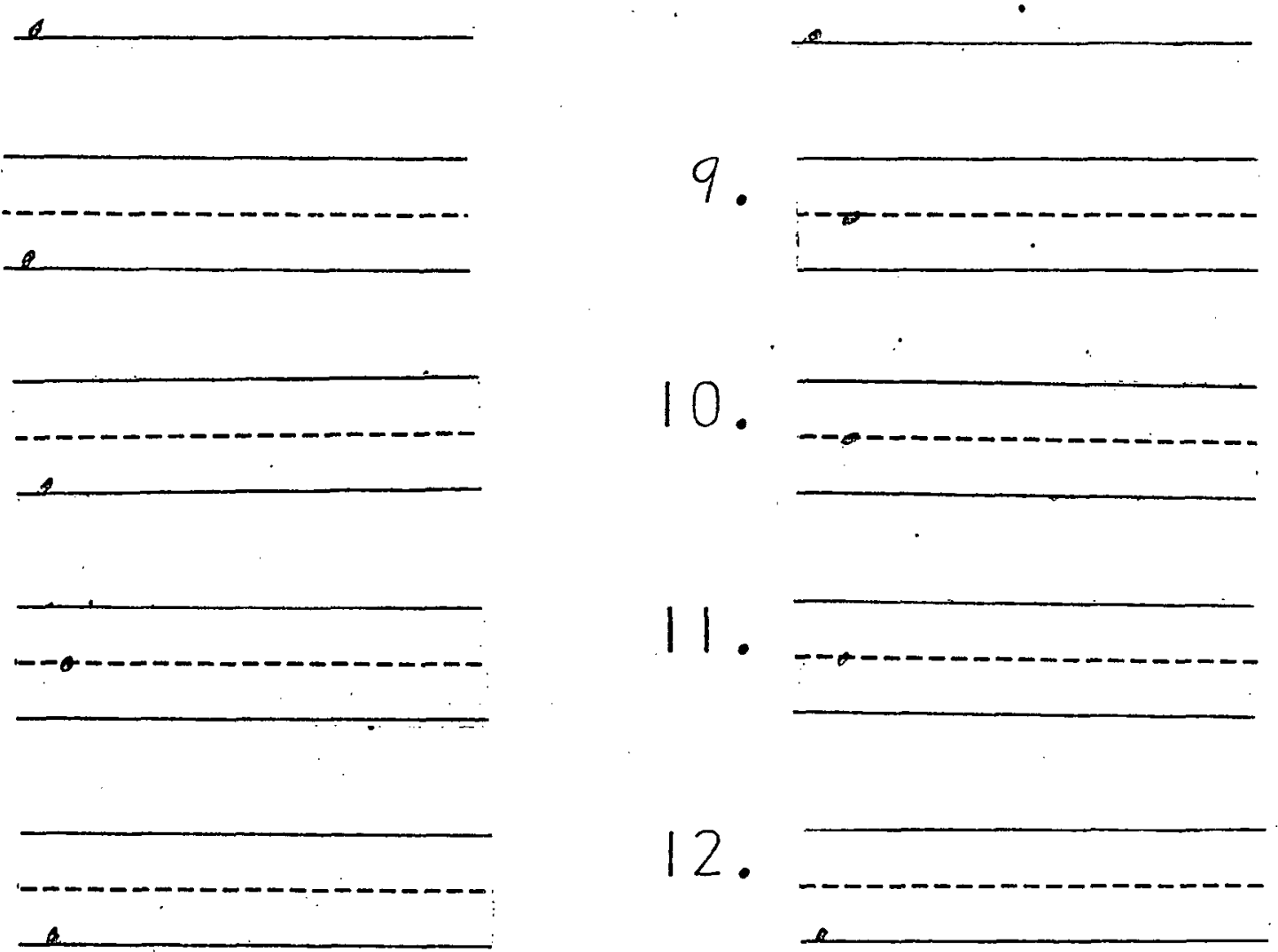
"Y" as an Ending

man Iy manly hob by hobby
en vy envy win dy windy
stuf fy stuffy fif ty fifty
mom my mommy pen ny penny
Pat sy Patsy pup py puppy
fris ky frisky

tangle bright forth tantrum

shirt verb proud stranger 


$$
85 b *
$$

man IV

hob by

en ry

win $d y$

stuff fy

fit ty

mom my

pen ny

Pat wy

pup ry

fris ky
"Y" as an Ending

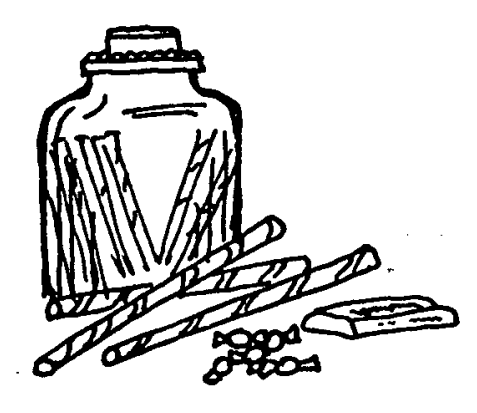

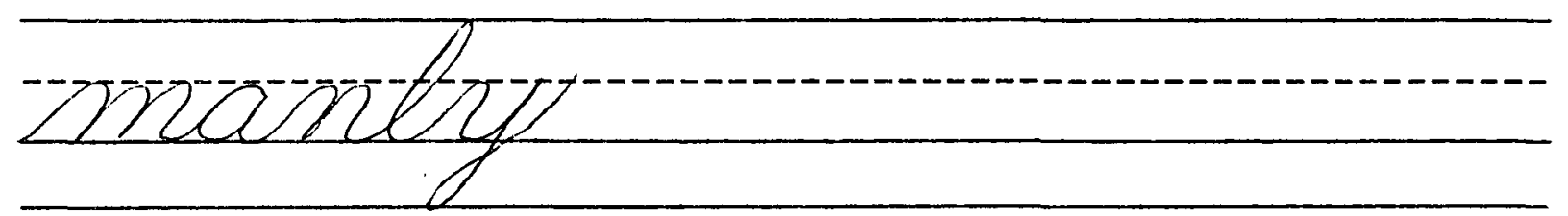

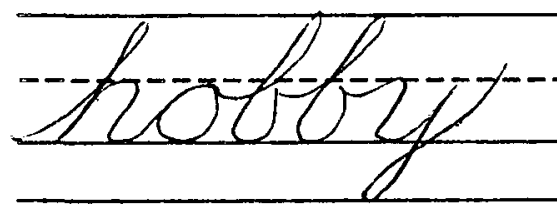

icreinedy 
$\therefore-\cdots$

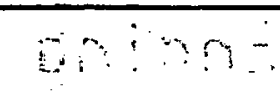

itteffy

fifty

$2 m 070000 y$

penmey

Fatory

purtery

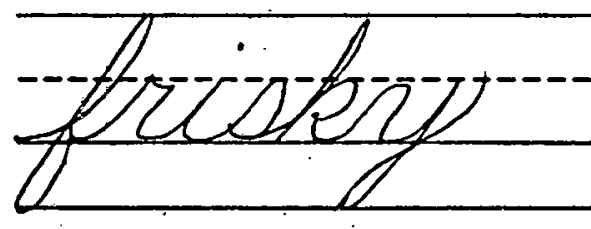


1. Using your thumb, cut off the ending of each word below.

2. Read the first syllable.

3. Read the word.

windy candy manly chunky

grumpy crusty sandy ninety

party Randy misty crispy

madly dusky sixty stately

sweetly forty puppy thirty

mommy snappy frisky hurry

grandly fifty nearly twenty

Think of one new word for each of the following endings: Iy, vy, by, dy, ty, fy, ny, sy, py, ky. 
$86 a$

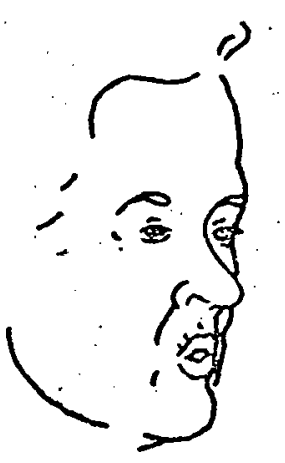

$\square 00 \square$

too zoo boom room mush
mushroom stool spool spoon

coon car toon cartoon.

mushroom poodle smorple gnafring

northwest sparkle insight pound

hurl swirl crown hound flight

curl twirl frown ground plight 
$86 b *$

too

$\mathrm{ZOO}$

00

boom

room

mush room

stool

spool

spoon

coon

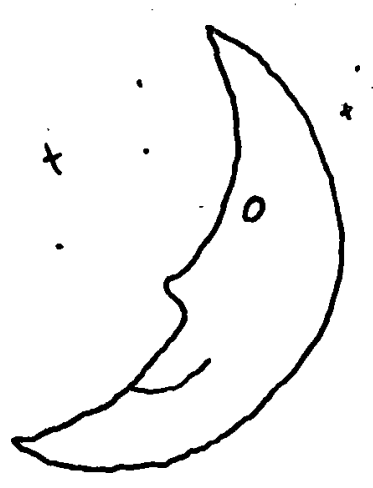

car tron

$t 00$

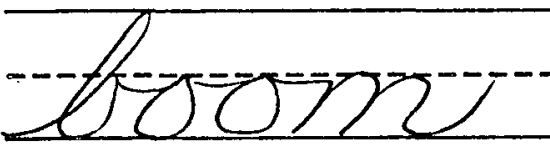




\section{ILOPOARS}

LCODO

\section{sundere}

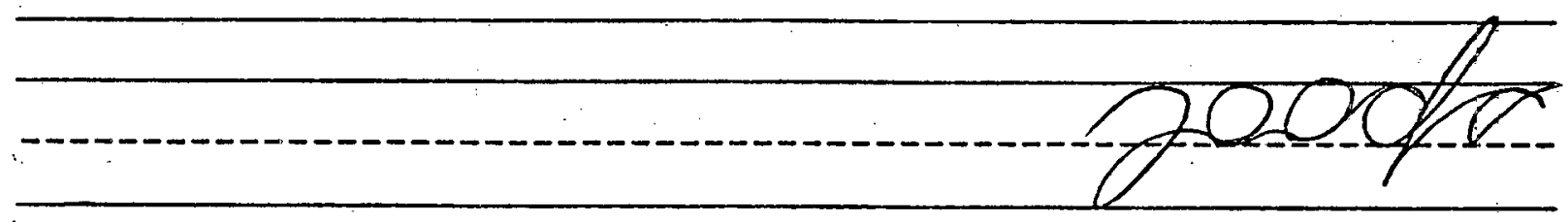


Circle the word that best fits each picture. There are four words per picture.

broom

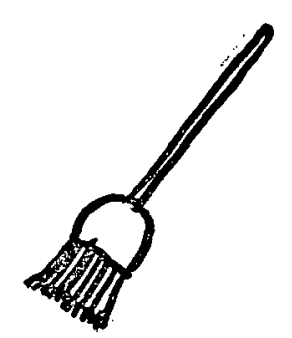

shoot hoot

scoop

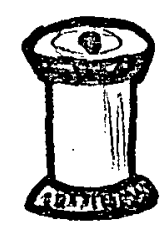

spool

stool

proof
I $00 \mathrm{~m}$

soon b loom

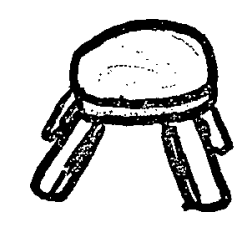

Ioop

poodles

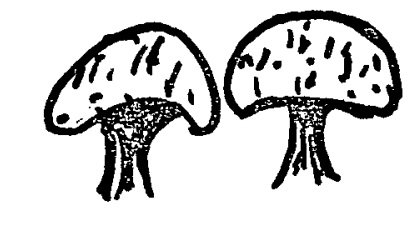

stool

$\operatorname{mood}$

roof mushrooms 


\section{Hard - Soft C}

Natural sound of "c" (hard "c"): can cot cash

class cliff crust cape cane

carpet canteen candy curl

Soft "c" words (followed by "e", "i", or "y"): cell cinch

face race fancy Nancy except

pencil advice circle thrice

cup cat cent rice crash

cave candle circus ice cob

clock nice center crash spruce 
$87 b^{*}$

cell

cinch

face

race

fan by

Nan by

ex cept

pen oil

ad vice

cir ole

thrice
Hard - Soft C
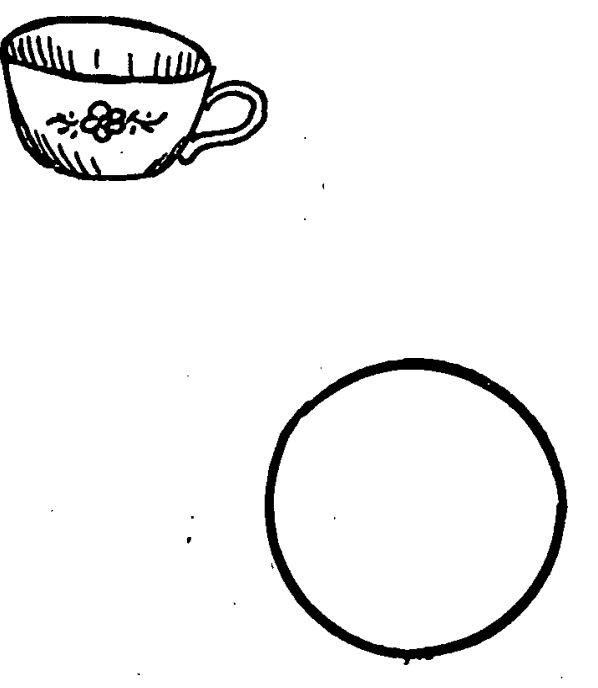

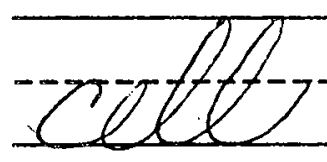

winch

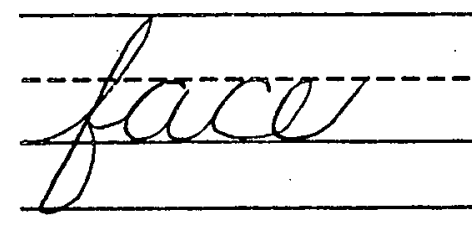

sTacte 
fancy

Fancy

Except ot

pencil

advice

circles

thrice 
In the beginning of a word, the (k). sound is usually spelled with a $\underline{c}$, except when it is followed by $\underline{e}$, or $\underline{x}$, and then $a \underline{k}$ is used (Traub, p. 235).

Example: cot, cut, key, kit Fill in the blanks with $\underline{c}$ or $\underline{k}$.
1. _ave
9. ick
17. ock
2.
in
10.
urd
18.
i te
3.
u†
11.
ord
19.
art
4.
een
12.
eel
20.
a Im
5. _ it
13.
$i \ln$
21.
ill
6.
all
14.
ent
22.
elp
7.
rib
15.
andle 23 .
raze
8.
16.
lear
24. eep 


\section{Hard - Soft G}

Natural sound of "g" (hard "g"): got Gus gate

gulf glide grape gull glad

grin gale gob globe grave

Soft "g" words (followed by "e", "i", or "y"): gem age

page cage stage huge congest

gentle margin ginger Roger

grab age grin stingy gust

grill edgy Glen gulf stage

Gale hinge single orange

Exceptions to the rule: ge $†$ gift girl give

giggle anger 


gem
age
page
cage
stage

huge

Hard - Soft G

con gest

gen tie

mar gin

gin ger

Rog er

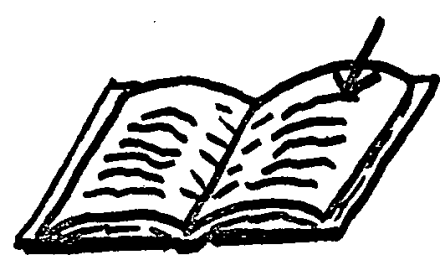

QUETEY

äge

parage

atige 

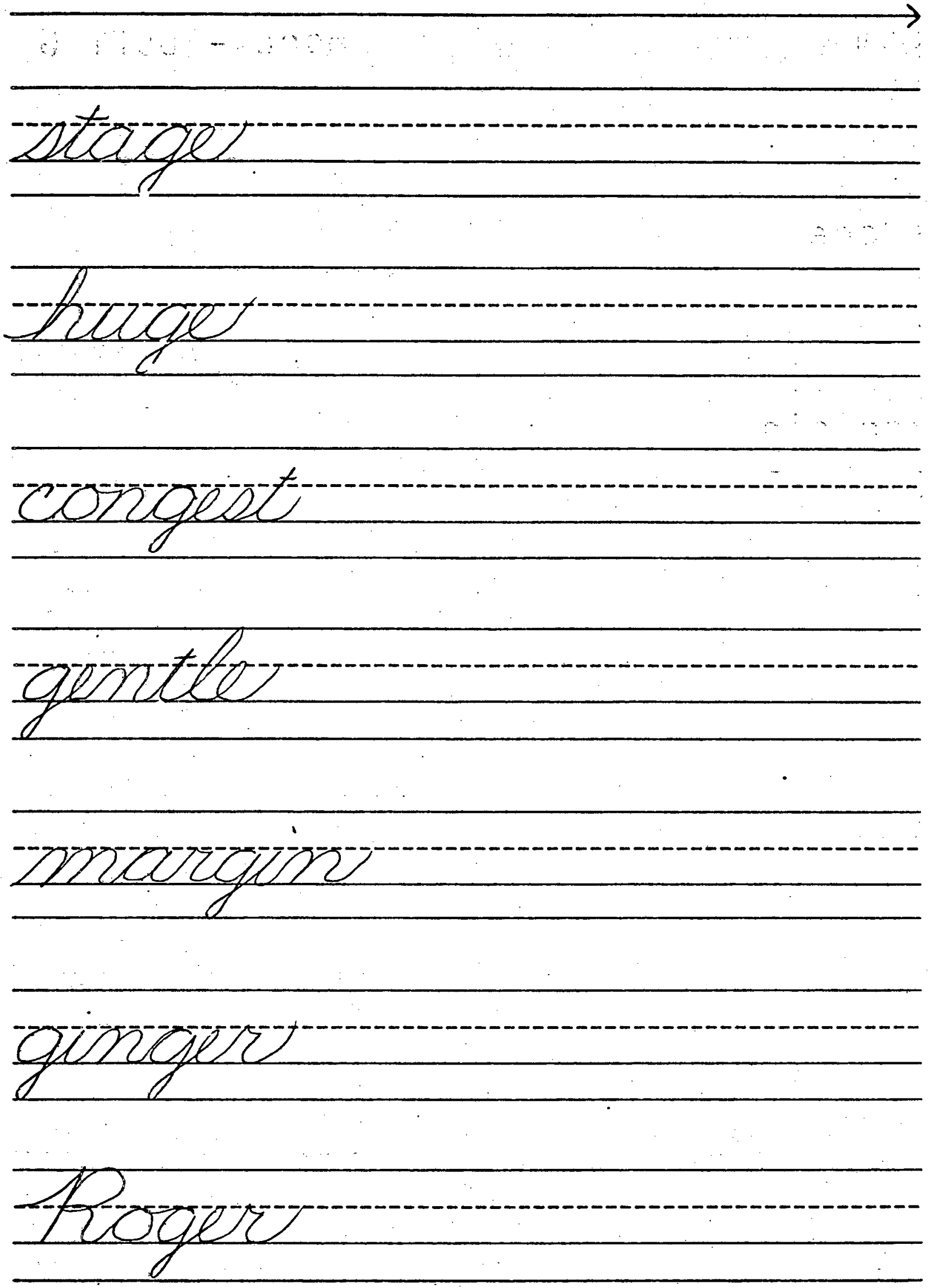
The $(j)$ sound is usually spelled with a g if it is followed by $\underline{e}$, i, or $y$ (Traub, p. 238).

According to the above rule, fill in the blanks with $g$ or $j$. All the words have the sound of $(j)$.
I. - a ii
9. $\mathrm{ca}$
2. _ent
10. ed e
3. _ack
11. _ $a b$
4. _ungle
12. _. ob
5. _inger
13. _ entle
6. _unk
14. _ust
7. _oke
15. _une
8. bar_e
16. _ane 


$$
\text { ge - dge }
$$

ge - When a consonant precedes the $(j)$ sound: barge large

cringe fringe plunge strange

ge - When a long vowel precedes the $(j)$ sound: wage stage

huge cage page rage gage

dge - When a short vowel precedes the $(j)$ sound: l edge fudge

judge edge lodge bridge smudge 
ge - When a consonant precedes the $(j)$ sound barge

cringe

ge - When a long vowel precedes the $(j)$ sound

stage

huge

dg - when a short vowel precedes the $(j)$ sound

ledge

judge
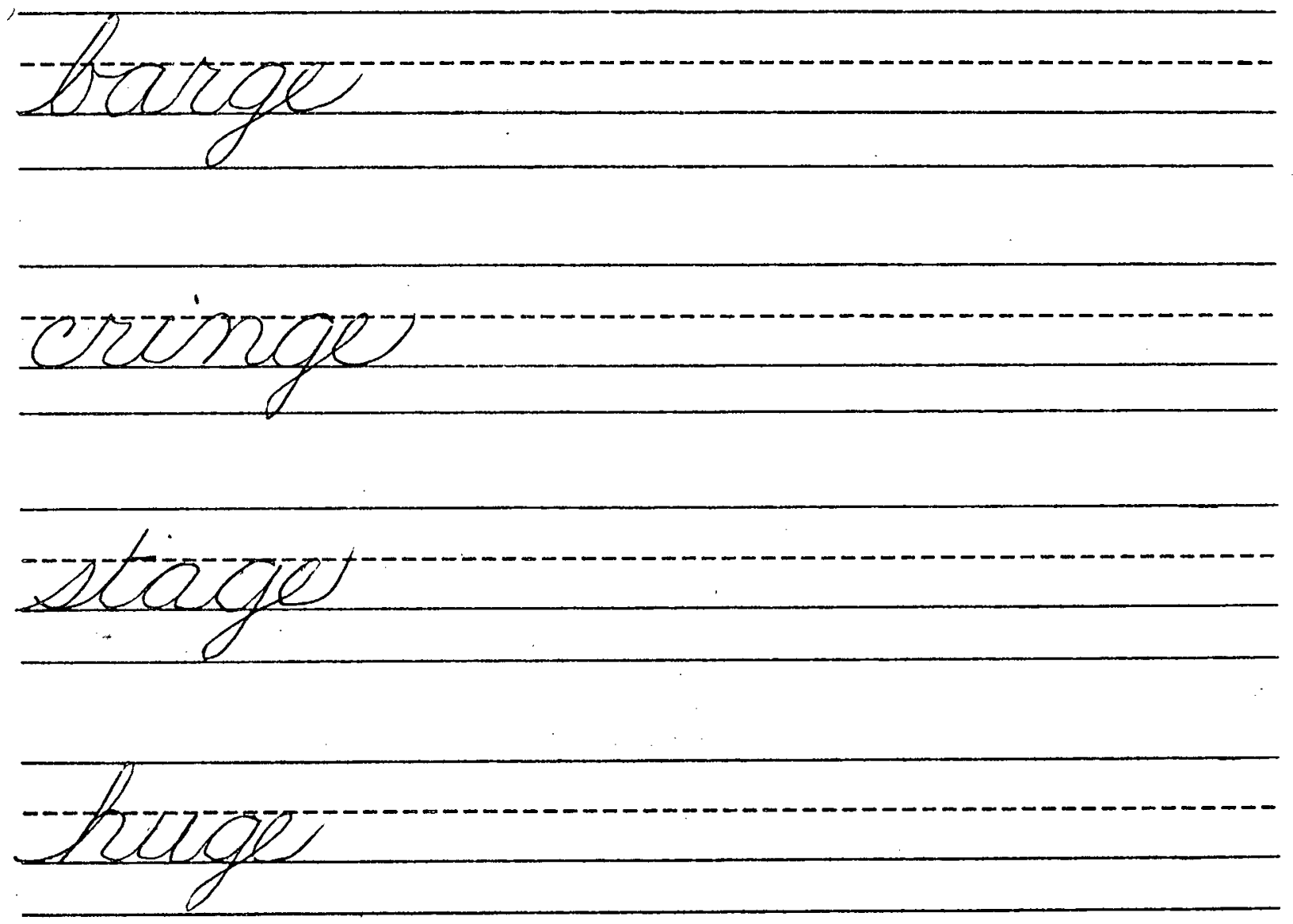


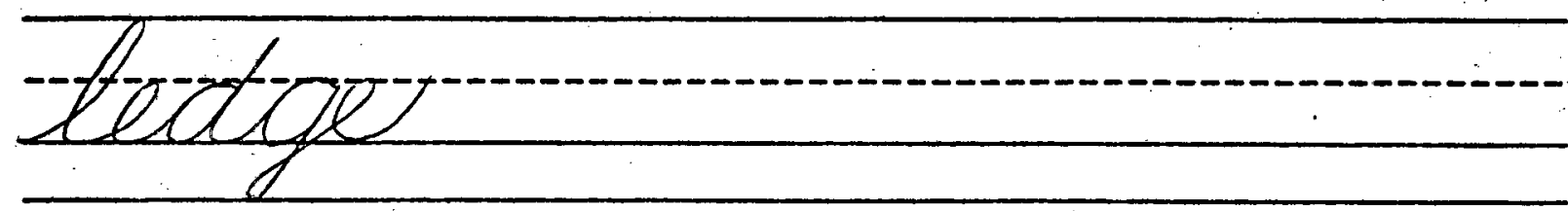

(2)

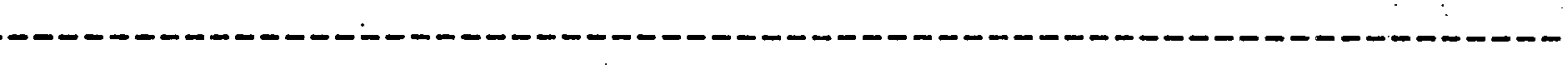

.

- 
Put dge or ge in the blanks.

I. The ink made a smu

2. Do not for checks.

3. The fu_ had a nice taste.

4. Take that bri__ and then turn right.

5. Dick had a ba___ on his shirt.

6. Jack is stran__ly happy now.

7. The lar cow is lost. 
Review - Hard-Soft $\underline{C}$ and $\underline{G}$

Read each word below.

trace

cell

cramp

change

crib

orange

brace

race

circus

crop

crust

gum

gulf

gull

Gus

crept

scat

scale

mice

gust

twice

price

cube

hinge

grip

strange

grate

glaze

Read these sentences.

Mac has an ice cream cone.

Grace keeps her mice in a cage.

The grape pie has a crisp crust. 
$91 \mathrm{a}$

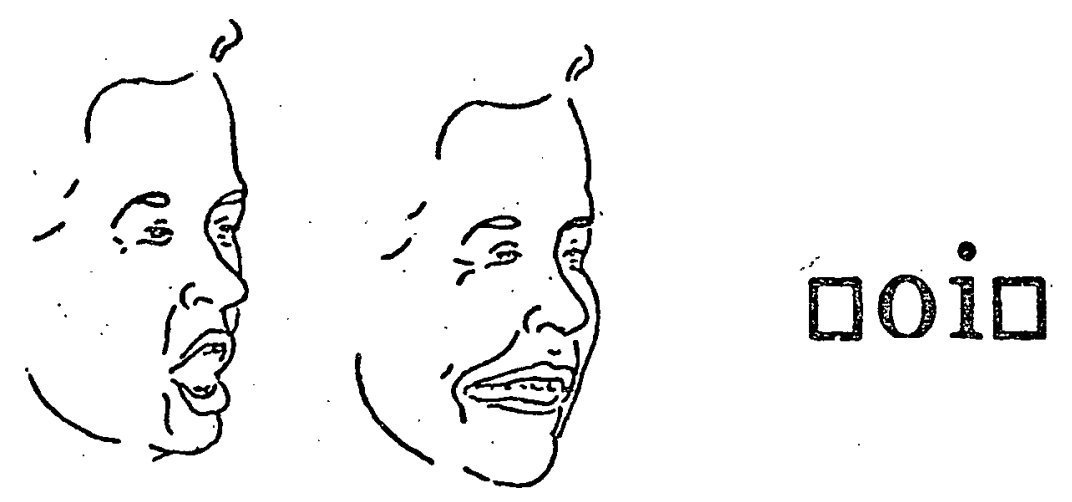

oil foil boil join loin joint point hoist moist tin foil tinfoil

spoil bright strompamg. goomp church furnish plow candle

toil point bird pout dangle soil joint birch out tangle 
oil

foil

boil

join

loin

joint

point

hoist

moist

tinfoil
$91 b^{*}$

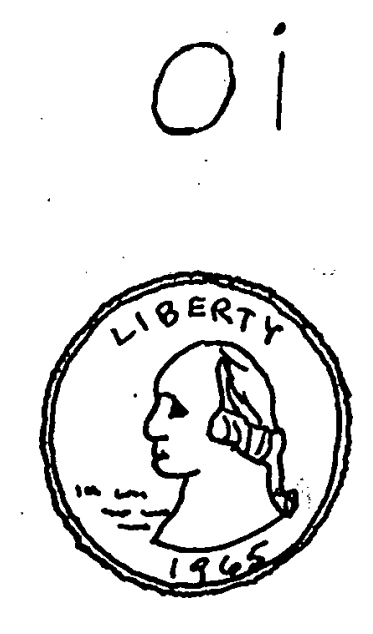

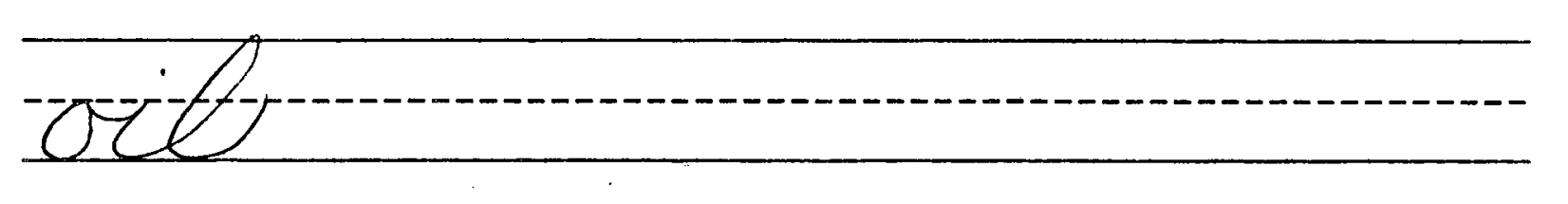
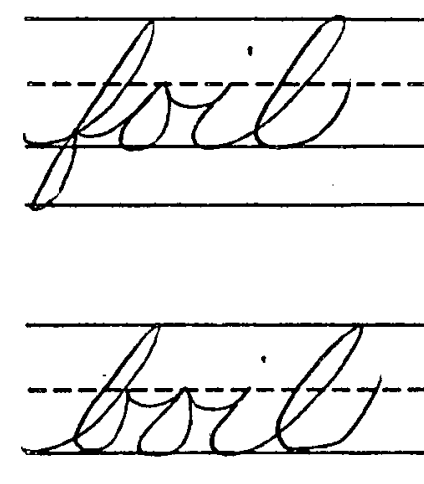

join 
toino

joint

porint

Froist

moist

tinfoits 
Fill in the missing letters.

1. Tin_oil is silver.

2. Jack will till the _oil in his garden.

3. The food might _ oil if it is not cool.

4. Pencils have _oints.

5. The ground is _oist since the rain.

6. Don did _oin the army.

7. The liquid in the pot might _oil too fast if you do not turn down the heat. 


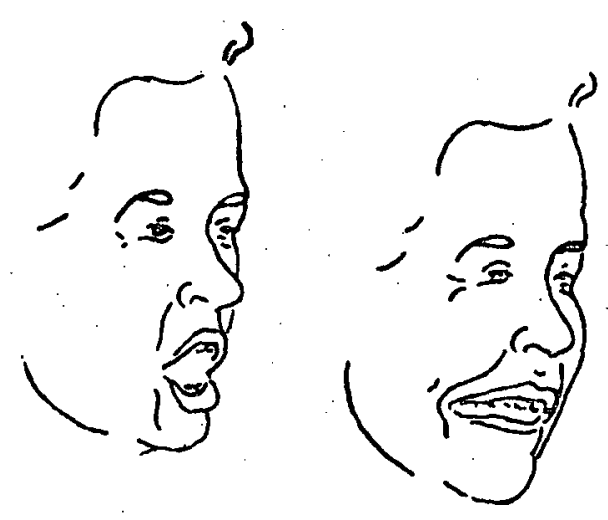

\section{口OY}

boy joy Roy soy en joy

enjoy en voy envoy con

voy convoy oy ster oyster

de coy decoy em ploy employ

soil voice cowboy destroy

hedge forth sigh dazzle

beach phones mirth judge car reach Jones birth fudge far 


$$
92 b *
$$

boy

joy

Roy

soy

en joy

en roy

con roy

ox ster

de coy

em ploy

or
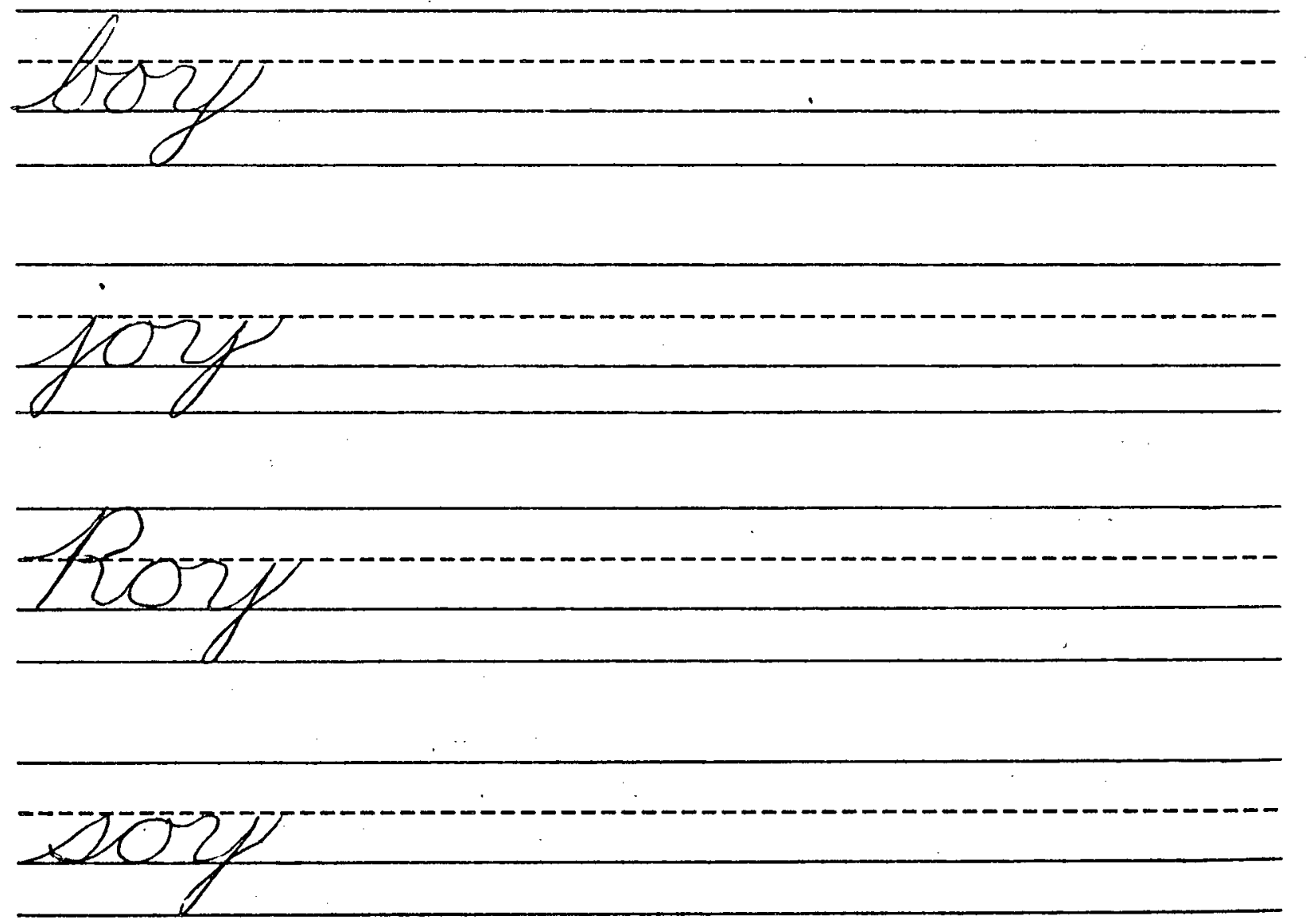
onvoy

conowoy

oypteri

tecory 
Read the following sentences. Underl ine the words containing the oy sound as in boy.

1. Roy has a toy in his classroom.

2. Mom will broil the meat.

3. Joyce made a bad choice.

4. That boy has a silver coin.

5. The coil is too hot.

6. Mr. Roy will employ the boy.

7. Dick found an oyster shell on the beach. 


\section{口aw}

law paw jaw thaw claw flaw

lawn pawn dawn drawn

squawk crawfish seesaw lobster

tangle destroy flight brow

candy wedge shawl spoon morn handy ledge sprawl soon horn 


row
pow
jow
low
clow
flow
lown
pown
down
drown

- 2010

fraw

10000

tawo 
ctaro

ftaw

tawn

pouver

dautr

drawn 
Write a short story or poem with the aw words on job sheet 93b. You may use other aw words if you like. 


\section{口aug.}

haul Saul paul fraud fault.

vault flaunt haunt haunch

I aunch

jaunty saucer squawk blight

fault gnaw outlaw spool paw

squaw nightless conform pawn straw flightless inform lawn 


$$
94 b *
$$

haul

Saul

Paul

fraud

fault

vault

flaunt

haunt

haunch

launch au

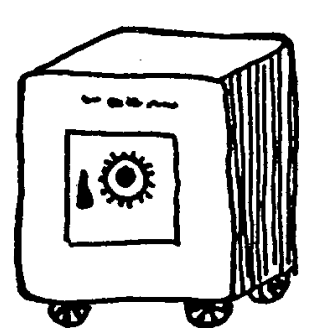

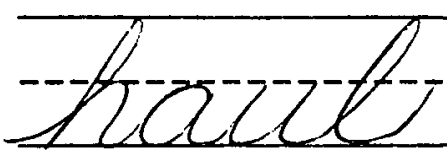
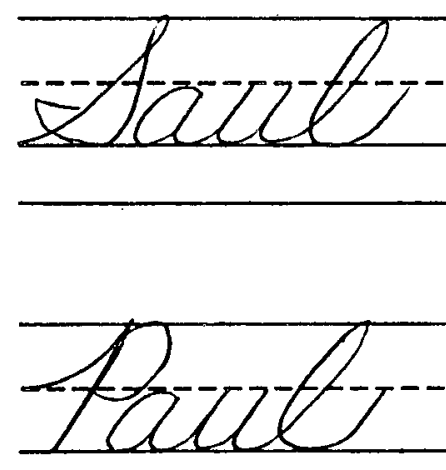

fraud 
fautt

woult

ftawint

haunt

haunch

tawnch 
Fill in the blanks with the proper spelling of the au sound. (Choices: aw or au)

1. The h_k hurt its wing.

2. That farmer sells a let of str

3. The mouse did gn_ on the wire.

4. It is not P_ l's f__ It.

5. The men will h_l the things to the I__n.

6. It is not r__. Mom did boil it.

7. P_l hurt his j_. 


\section{aaln}

call mall small salt malt

wal nut walnut talk chalk

stalk

tall snail false blurp fawn

plow birth starlight buckle

$\begin{array}{llll}\text { talk } & \text { rage stall } & \text { forlor } \\ \text { stalk gage install } & \text { forgot }\end{array}$ 


$$
95 b *
$$

all:

call

mall

al

small

al:

salt

malt

wal nut

Silent l: talk

chalk

stalk

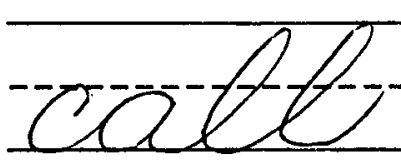

mate

vat 

Put the new words on job sheet 95b in the appropriate spaces below. Use each word only once.

A phone $\cdots \cdots-\cdots-\cdots$ when I was

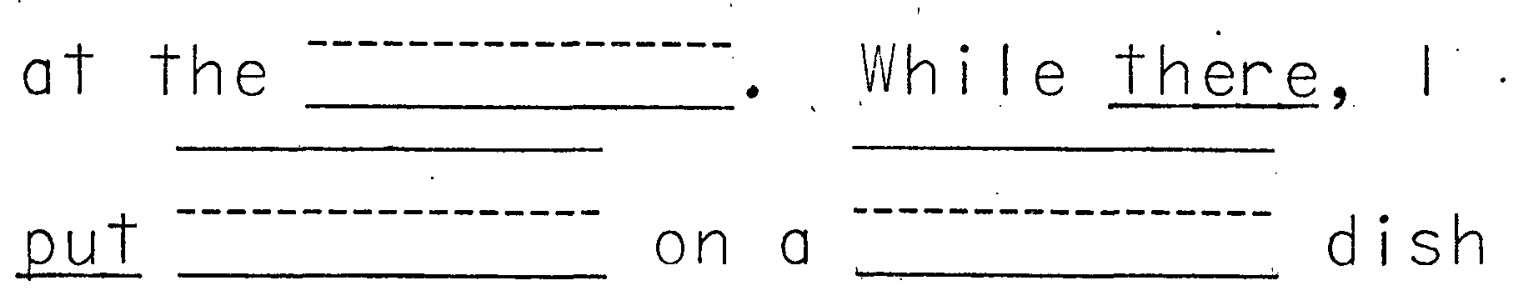

of French fries and ate them. After

I had a drink and some

s, I left for home. My

boy met me and told about the call.

I went in the house to return the

call, and had a nice

Now I will clean the of

my dress and sprinkle the corn s. 

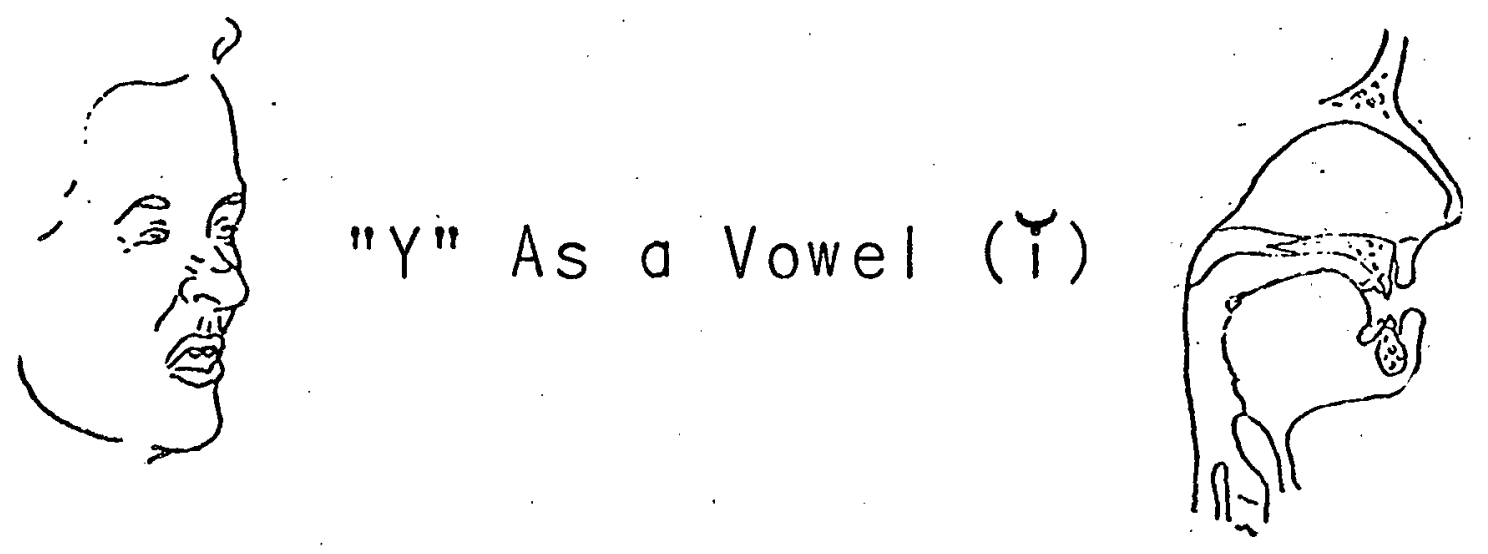

myth

cyst Iynx

my

stic

mystic

gyp

Iy

ric

Iyric

sys. tem

system

syn

$\operatorname{tax}$

syntax

cym bal

cymbal

ox

y gen oxygen

gym lyric gypsy hinge birch

strange happy haggle calls
$\mathrm{Jim}$
sits
$\sin$
links
simple
gym
cyst
cynic
Iynx
symbol 
myth

cyst

Iynx

my stic

gyp

ly ric

sys tem

syn tax

cym bal

ox y gen
"Y" as a Vowel ( $(\bar{i})$

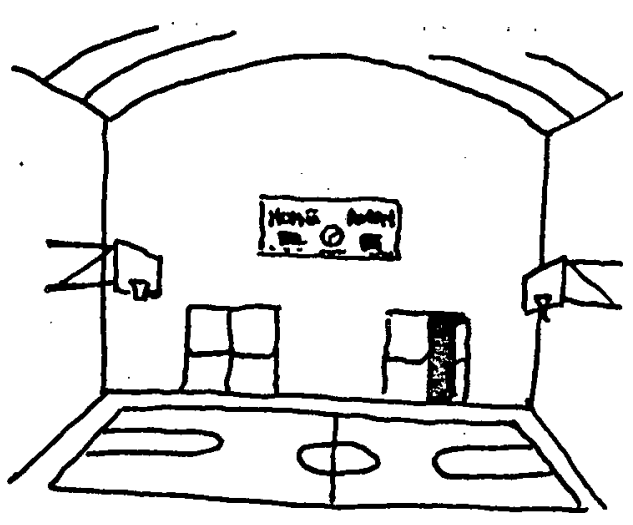

mongth

cypet

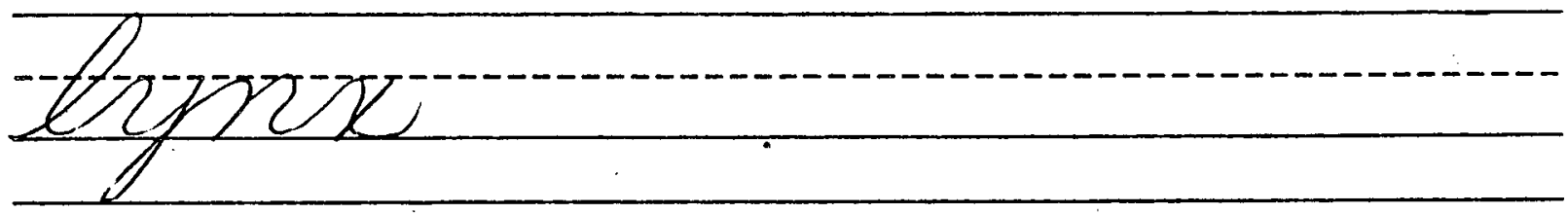

invipotic 


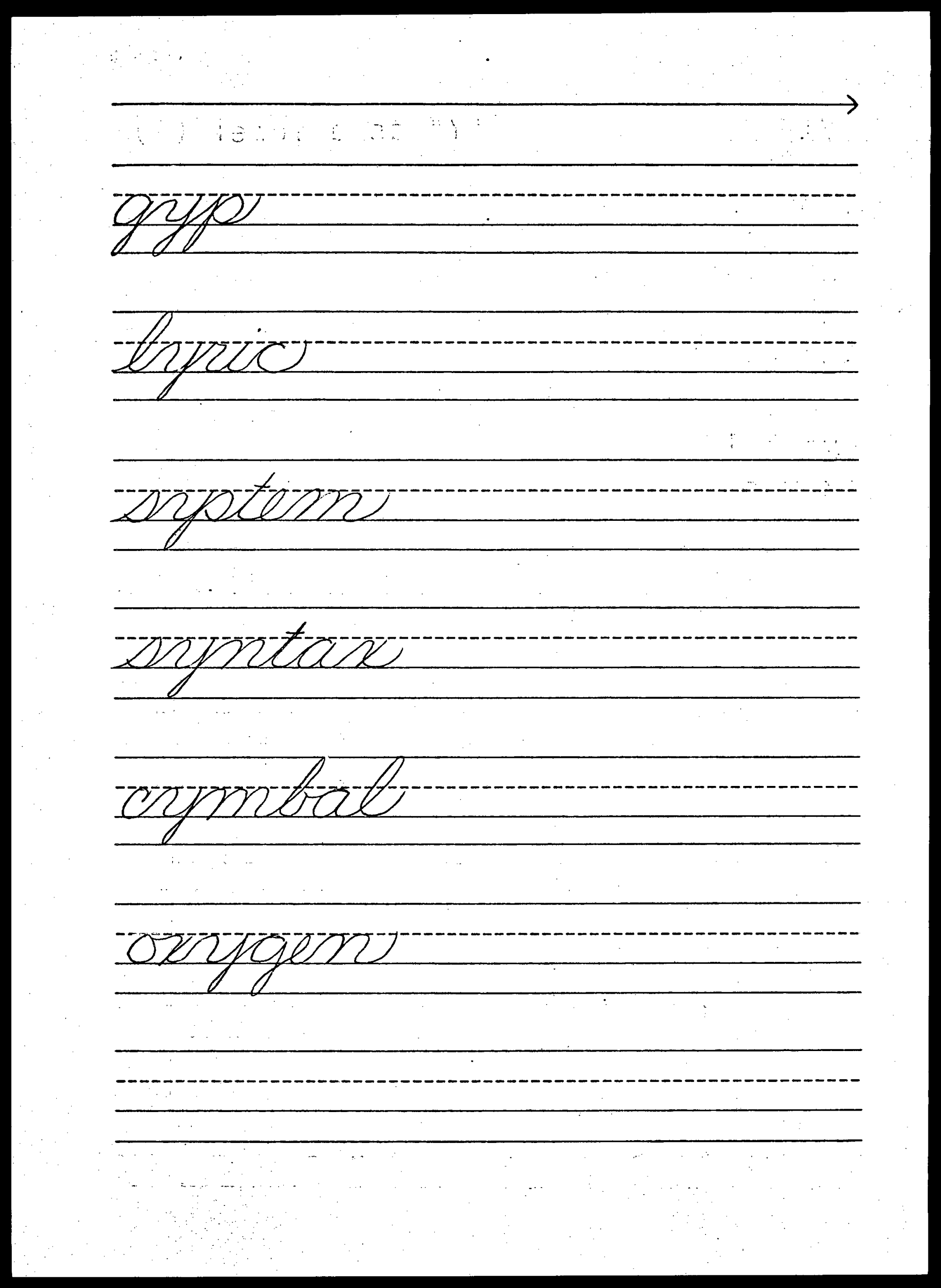




\section{$96 c$}

Read the following sentences. Find the words that have the $\stackrel{i}{\text { sound. Un- }}$ derline them.

1. It is a myth that Jack is in charge.

2. The Iynx had a cyst on his nose.

3. That man will gyp Dick on the P.A. system.

4. Syntax is part of the study of English.

5. The cymbals were too loud for Jill.

6. Oxygen is important for our lives.

7. The Iyric of the song is nice. 


\section{Long Vowels in Syllable Division}

mi nus minus pu pil pupil

be gin begin pa per paper

ho tel hotel ti ger tiger

ba sin basin ba sis basis

re joice rejoice o mit omit

moment agent recite call for crowd soon fudge city join

$\begin{array}{llll}\text { tangle } & \text { employ } & \text { saw dandy } \\ \text { strangle } & \text { destroy } & \text { jaw } & \text { handy }\end{array}$ 


$$
97 b *
$$

mi nus

pupil

be gin

pa per

ho tel

ti ger

ba $\sin$

ba sis

re juice

o mit
Long Vowels

in Syllable Division

minus
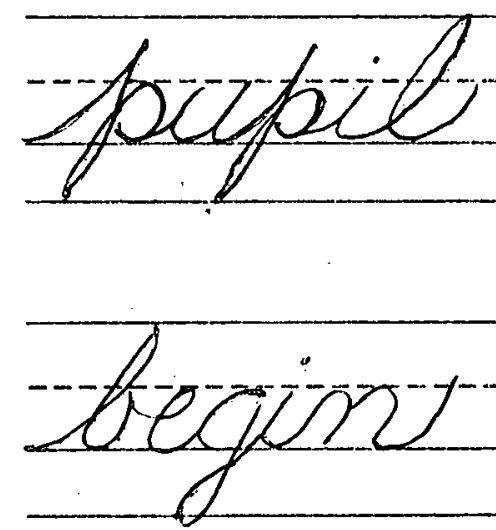

zappers 
hotet

trigers

basion

basids

Zejorce

omit 
Divide the following words into syllables following these rules: (1) Underline all vowels in red. (2) If there is only one consonant between the two vowels, divide in front of the consonant. (3) The vowel at the end of the syllable is a long vowel, (Traub, p. 143).

li lac

human spoken

broken

crisis erect

polite program donate

demand secret A jax

recite

behave

climax

protect

item

focus 


\section{"ing" as an Ending}

banging ringing mashing smashing

gushing swelling stuffing risking

honking tossing

fishing oiling stroimash raw

carmomim roomer bright furnish

$\begin{array}{lllll}\text { edge } & \text { prawl } & \text { *sour tower fir } \\ \text { ledge crawl *flour flower sir }\end{array}$ 
bang ing

"ing" as an Ending

ring ing

mash ing

smash ing

gush ing

swell ing

stuff ing

risk ing

honk ing

toss ing

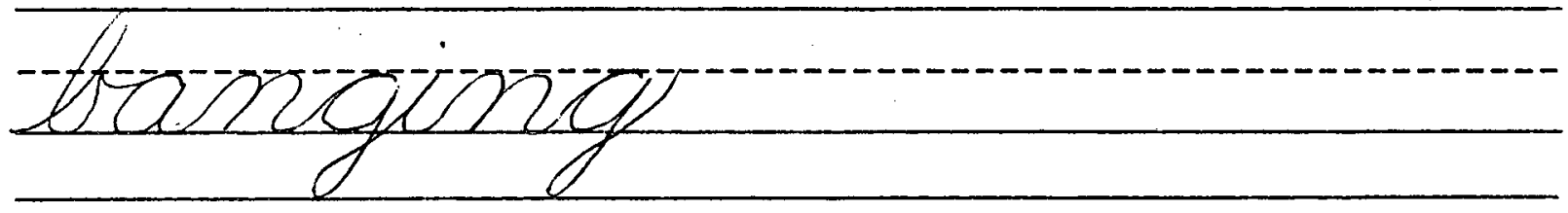

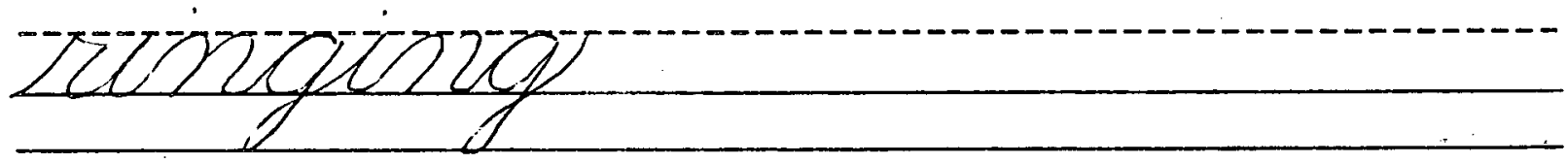

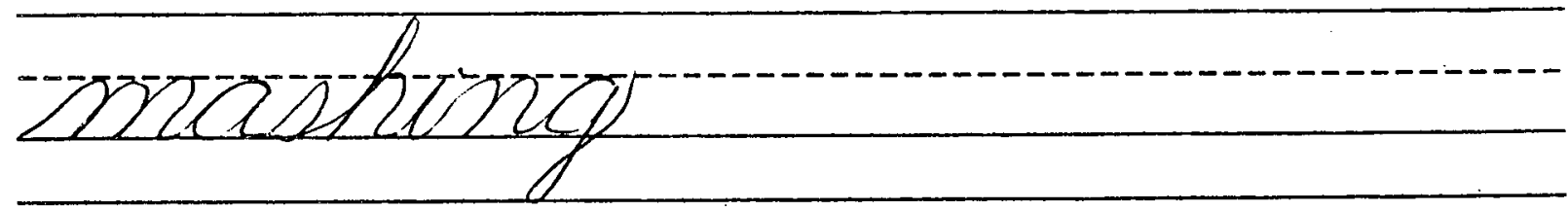

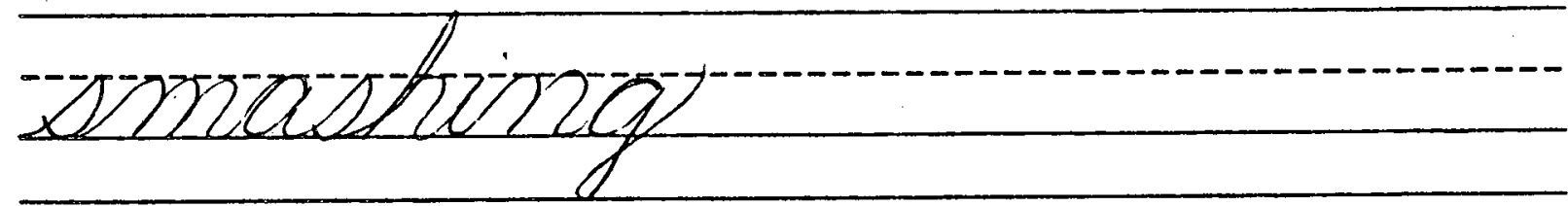




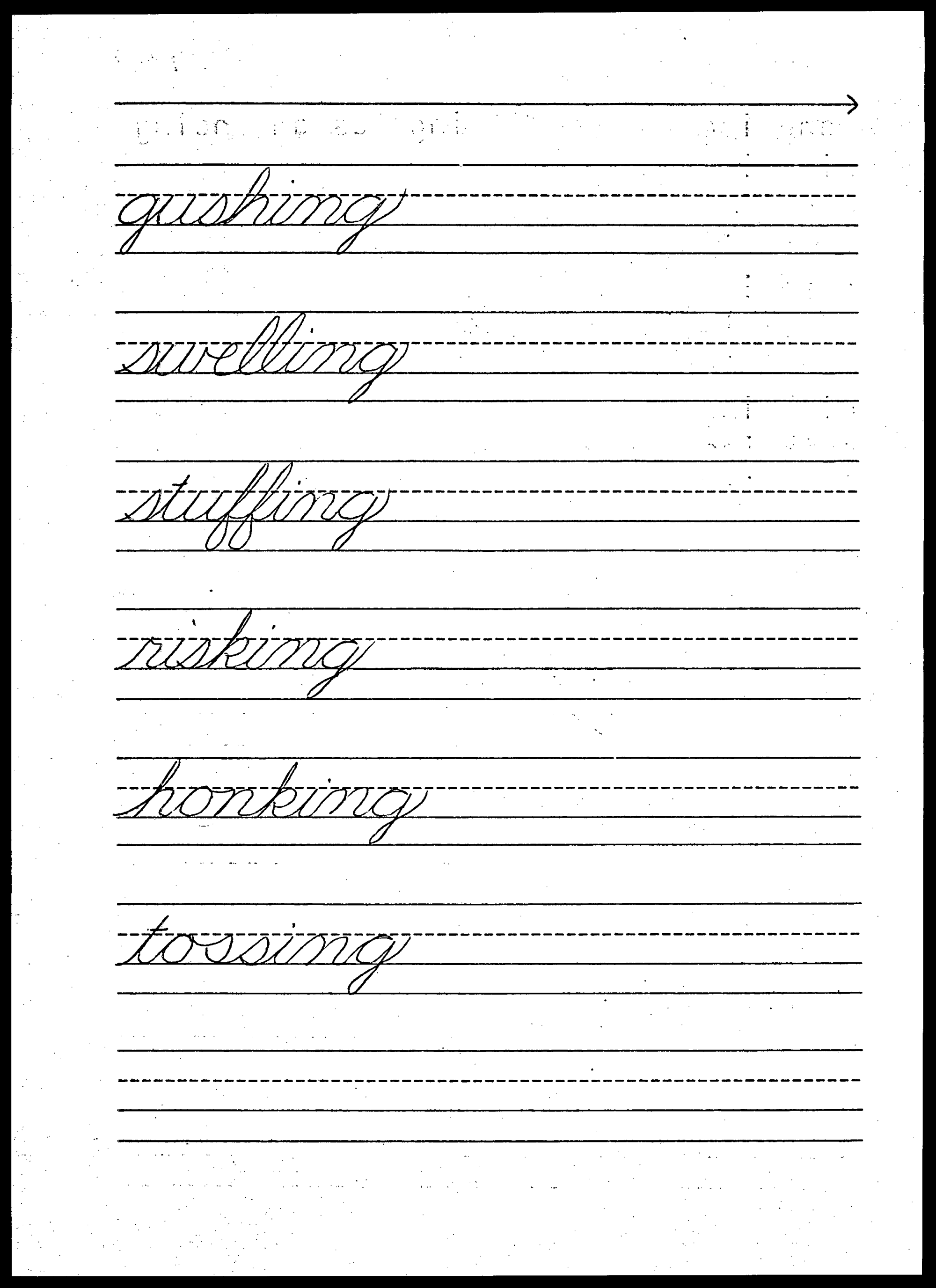


Add "ing" to the following words and then read each word.

salt

crash

smash

camp

swell

ring

scuff dress

honk

print

stand

plant

yell

bump brush

spell

flash

†ell

hiss

sniff

swing 
990

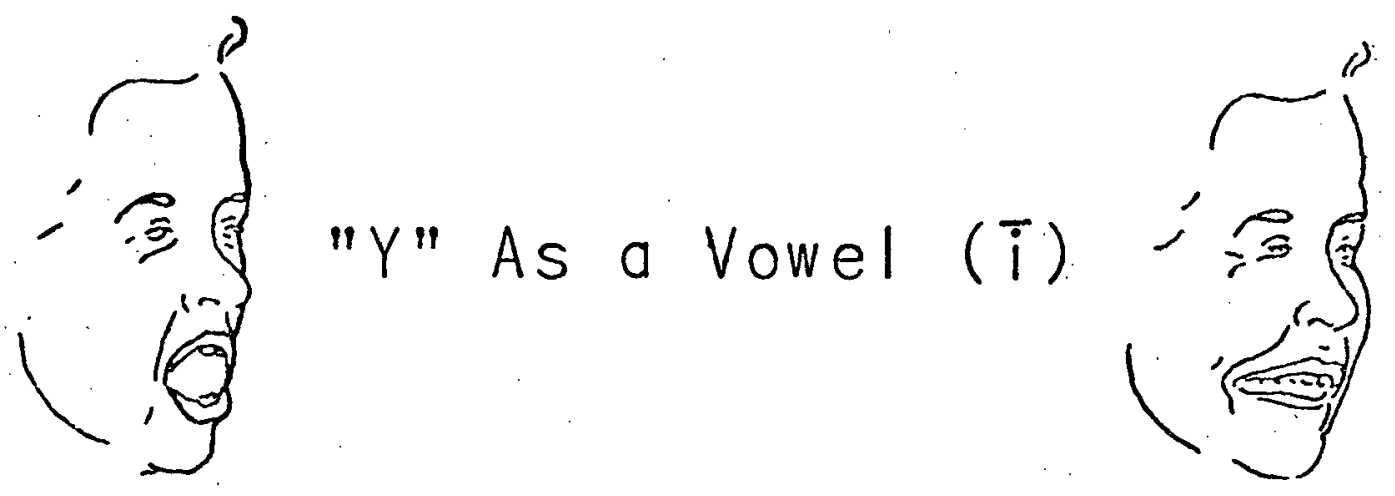

my spy spry style type du In July de ny deny sat is fy satisfy oc cu by occupy lu la by lullaby

sight type thy stall stalk fudge Randy signify foil shy lie boy star ripe
sky fly boil tar type 


$$
99 \text { b* }
$$

my

spy

spry

style

type

Jul IV

de ny

sat is fy

oc cu by

|ul la by
"Y" as a Vowel ( $\bar{i})$

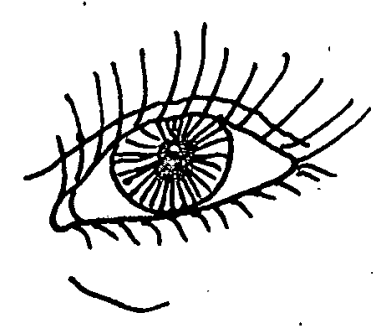

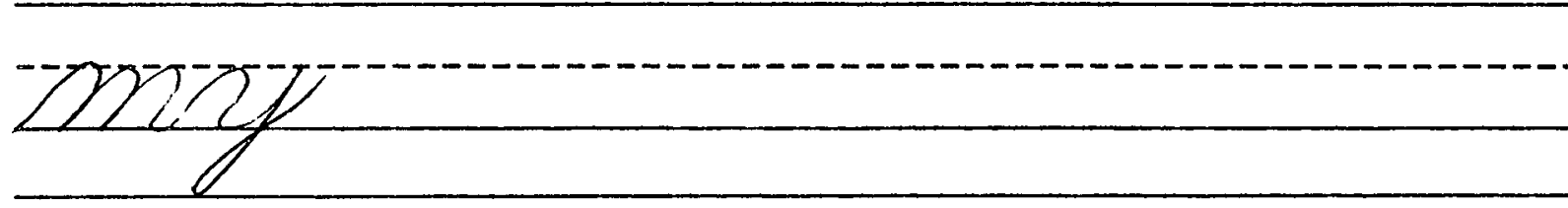
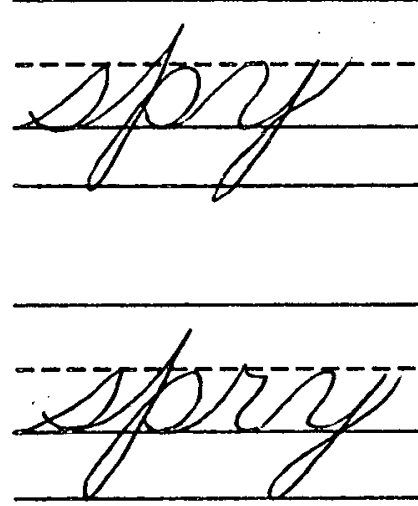
Geitry

tomy

satisfry

occoupry

tuttorty 
Underline the words that have the $\bar{i}$ sound.

my

Iyric

fly

satisfy

myth

Mike

glide

gym.

candy

pie

system

$\mathrm{Jim}$

try

why

deny

simmer

fancy

Mick

prime

hinge

stingy

sigh

tie

style

spry

type

I ight

shy 


\section{VCV Spelling Rule}

Write in colored pencil above the appropriate letters in each root and suffix the following:

V.- for vowel

$C$ - for consonant

$V$ - for vowel (above the initial vowel in suffix)

The first one is done for you.
1. rún
ing
2. big
est
3. $f i b$
er
4. $\operatorname{mad}$
es†
5. $\operatorname{scot}$
ish
6. drop
ing
7. sun
y
8. stun
ing 
Some one-syllable words do not double the final consonant when adding a suf fix since they do not follow the $V-C$ pattern (rún). Put $V$ or $C$ above the appropriate letters in each word. The first one is done for you.

9. bogc

10. dunk

11. blush

12. stain

13. creep
14. stop

15. plunk

16. 0.11

17. black

18. $\operatorname{load}$

Notice that there are three groups of short words: $\quad V C$ as in top

VVC as in feed

VCC as in must 
Suffixes can be divided into two groups: suffixes beginning with a vowel (as in "ing"), and suffixes beginning with a consonant (as in "ness").

Put $V$ or $C$ over the first letter in each suffix below.
19. 1y
26. er
20. ment
27. en
21. Iess
28. ish
22. ing
29. $a b / e$
23. ness
30. ed
24. y
31. est
25. ence
32. ent 
Now combine the roots and suffixes below. Remember to use the VCV rule (the "One-One-One Rule"). Put $V$ or $C$ above the appropriate letters if it will help. The first two are done for examples.

33. $t^{v} c h+Y$ ing

34. rusct $+\stackrel{v}{\text { ed }}$

35. clan + ish

36. $\operatorname{skin}+y$

37. $\operatorname{man}+1 y$

38. big + est

39. run + er

40. spoon + ed

41. claim + ing

42. drift + ed
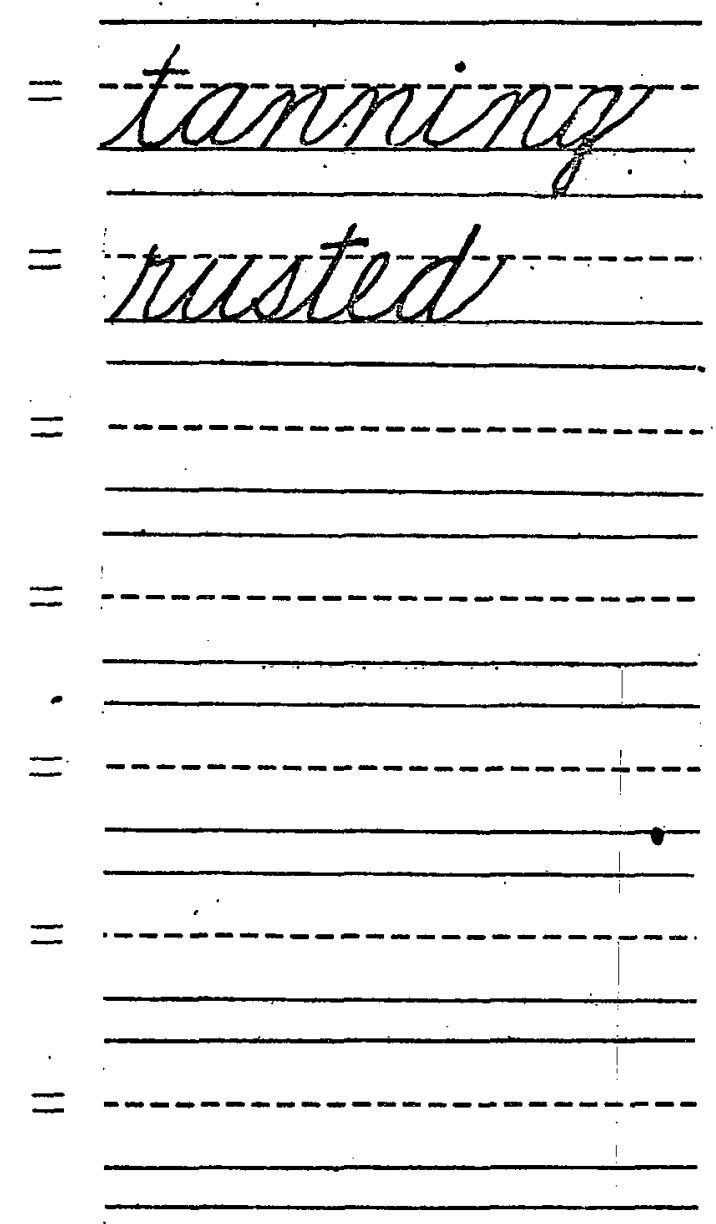

$=$

$=$

$=$ 


\section{Review}

Write oi or oy in each blank. Remember that oi is usually within a word, and oy is usually at the end of a word or syllable (Traub, 1973, p.I49).

S

b

j_n nt

f__ 1 emp 1

ster

conv

R

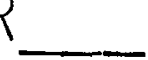

C n

S

$s p$

h__ st

Write aw or au in each blank below. Remember that aw is used for the final sound or before a consonant, and au is. used before a consonant (orton, 1964, p.88).

$h$

$1 \ldots$

I_n nch

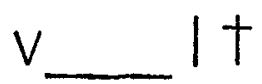

fl

cr
$P$

1

h 
Read these words:

call

stall

$$
\text { wal nut }
$$

mal† stalk.

walk

Write three words that have a short "i" sound spelled with a "y." e.g. system.

Write three words that have a long " $i$ " sound spelled with a "y." e.g. try.

Add "ing" to each word. Read the word. toss twist bang risk fall see

Divide the following words into syllables. Read the words.

paper basis return

hotel:

began

tiger 
Suffix es

pass passes grass grasses rush

rushes brush brushes ranch ranches

branch branches ax axes tax taxes

fizz fizzes quiz quizes

cyst oyster prawl hedge bicycle

bubble moon light table convoy

$\begin{array}{lllll}\text { mall } & \text { lable } & \text { edge } & \text { draw } & \text { soil } \\ \text { small fable } & \text { ledge } & \text { squaw } & \text { toil }\end{array}$


$102 b *$

$\begin{array}{ll}\text { pass } & \text { passes } \\ \text { grass } & \text { grasses } \\ \text { rush } & \text { rushes } \\ \text { brush } & \text { brushes } \\ \text { ranch } & \text { ranches } \\ \text { branch } & \text { branches } \\ \text { ax } & \text { axes } \\ \text { tax } & \text { taxes } \\ \text { fizz } & \text { fizzes } \\ \text { quiz } & \text { quines }\end{array}$

Suffix es 


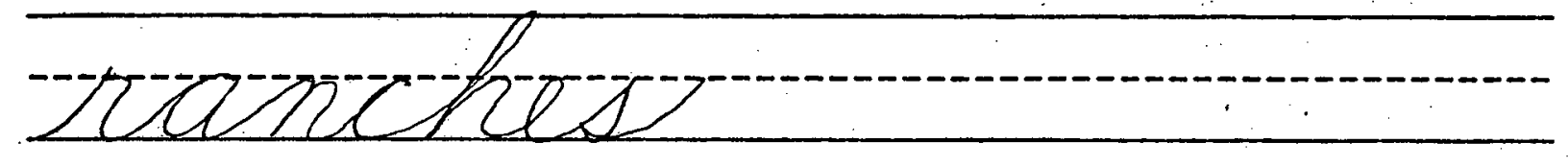

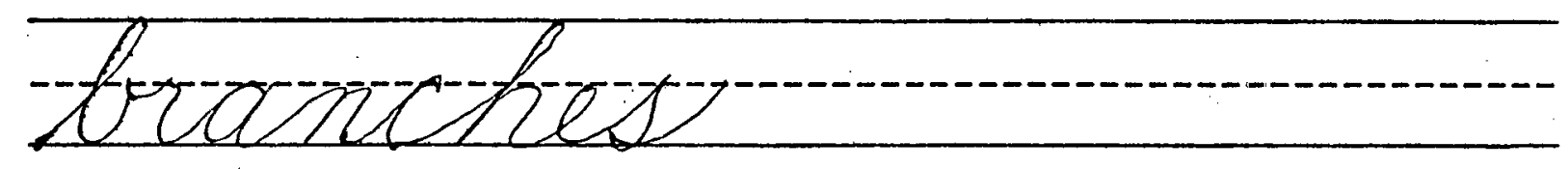

DUXET

ATATE

fizizesin

gutiges 
Add $\underline{s}$ or es to each word. Remember that es is added instead of $\underline{s}$ after $\underline{s}, \underline{z}, \underline{s h}$, $\underline{c h}$, and $\underline{x}$.

tack

bump

crutch

latch

wax

nest

dish

path

hiss

church

tree

-

ledge

bubble

clown bean

paw

miss

trip

I unch

p- 


\section{Suffix ed}

mend mended hunt hunted stay

stayed drag dragged check checked

toss tossed

churches minus candy cages walked

lightly support story hedges oily

clutches maple score tardy

crutches staple shore hardy 
1. Present

mend

hunt

2. stay

drag

3. check toss
Past

mended

hunted

stayed

dragged

checked

tossed 

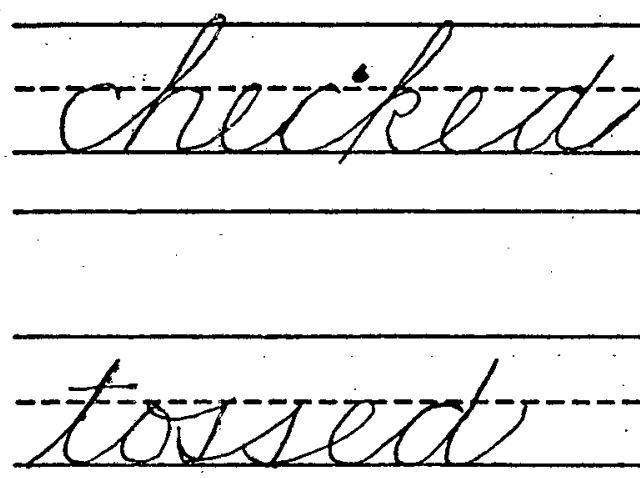
Write more words using each sound of ed. The first word in each catagory is done for you.

\section{led corrinted-}

$/ d /$
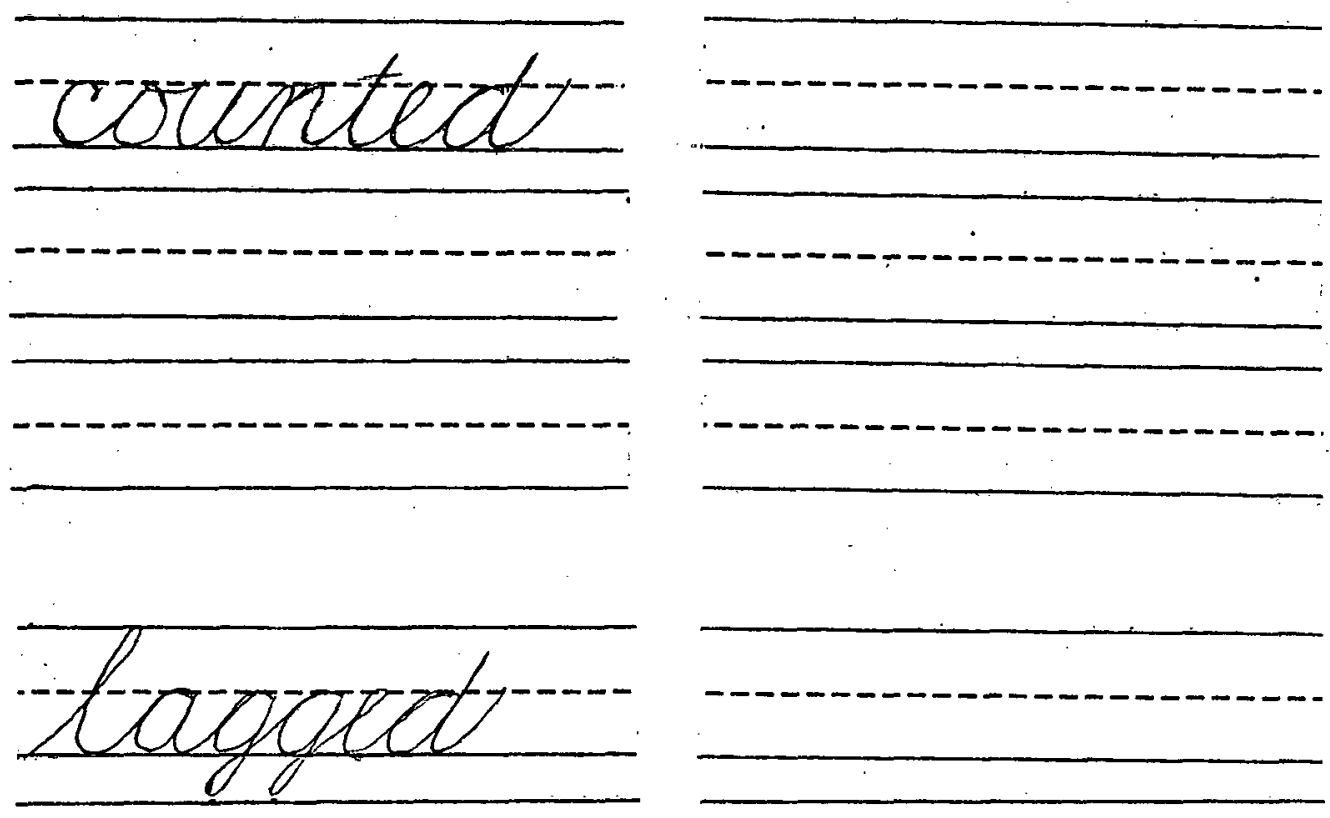

1+1 tatkect 
$104 a$

Suffix er

farm farmer big bigger hunt hunter pray prayer kind kinder sick sicker call caller lay layer boil boiler begin beginner

before barnyard program donate recite bridle shaky grudges city starch fir slight prevent parch sir light relent 
$104 b *$

farm farmer

Suffix er

big bigger

hunt hunter

pray prayer

kind kinder

sick sicker

call caller

lay layer

boil boiler

begin beginner
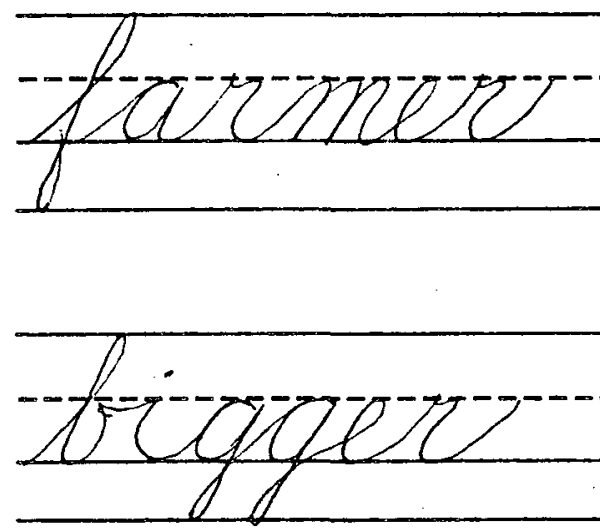

hunter

quraugert 


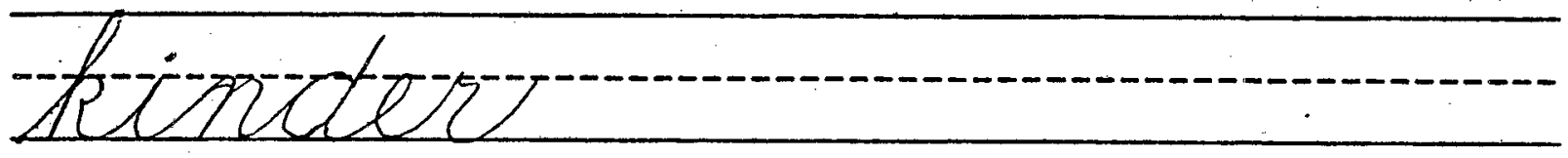

wichers

catters

taryen

bocter

begionenes 
See how many of these suffixes you can use with each word: es, ed, er, est, ness, less, ment, ish. Rewrite each word with its suffixes. The first one is done for you.

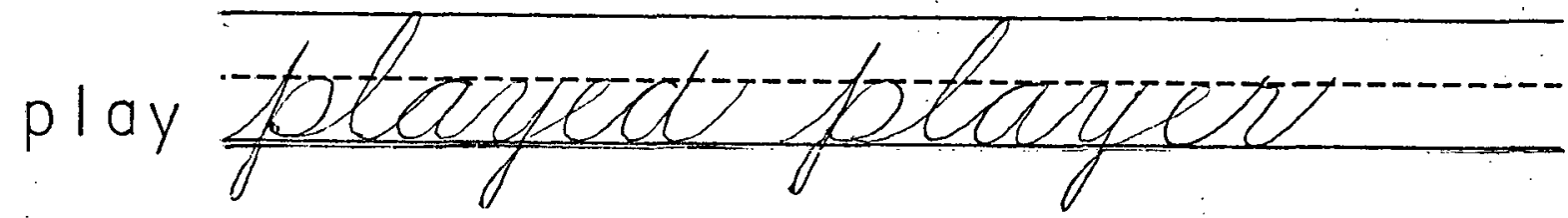

boy

settle

big

drink

complete

wax 


\section{Final i-e Unaccented Syllables}

active festive granite opposite engine doctrine notice practice missile fertile

ruffle toiler foggy provide moment

ringing running granted cloudy

$\begin{array}{lll}\text { furnish noon crumble melted } & \\ \text { burnish moon humble } & \text { belted }\end{array}$


$105 b *$

ive / iv/

ac tive

fes tive

ine $/ \mathrm{in} /$

en gine

doc trine

Final i-e Unaccented syllables

$\frac{\text { ice /iss/ }}{\text { notice }}$

prac tice

$\frac{i l e / \cdot 1 /}{\text { mis sile }}$

fer tile

active

festruer

granite 
xmigine

doctuines

motice

fratetice

missiter

fertite 
Fill in the blanks with an appropriate word from the following list: native, massive, examine, famine, exquisite, justice, office.

1. The wore a grass skirt and a mask.

2. The new party dress was

3. During the hard to find.

4. The brown desk is in the

5. The crowd had 32,000 men.

6. We stand for peace and , food was 


\section{Review}

Add a word to each suffix. Be sure that the word is appropriate for the suffix. e.g. player. er es est ment ed ness ish less

Read the following words. Remember that unaccented syllables sometimes have a short " $i$ " sound (sometimes $\theta$ ). The accented syllables will have a long " $i "$ sound.

engine survive' defile' entice' divine' nátive miśsile of'fice 
tch

itch witch catch latch Dutch

blotch Scotch sketch stretch

ketchup sandwich such rich much

which sandwich attach ostrich

active without imply walker order

powder cloudy scooner native edgy
cinch
enjoy
crumple
$\mathrm{mal}+$
finch
employ
rumple
salt 
itch

witch

catch

latch

Dutch

blotch

Scotch

sketch

stretch

ketch up

Exceptions: sandwich such rich attach much which ostrich

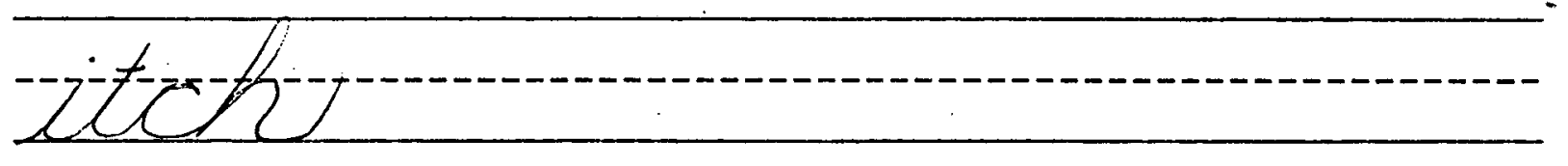

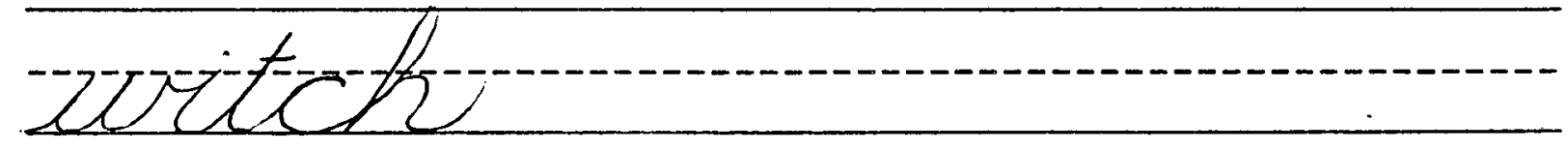

cuteth

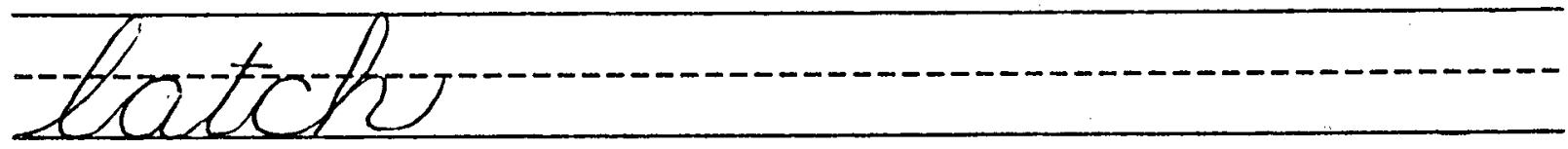


Futch

beotch

Ecotch

zketch

stretch

ketchupe 
Put ch or tch in each blank below. Your teacher will say each word for you.

is

1.

in

7. blo

2. pi

8. ou

3. mar

9. op

10. clu

5. pi_er

11. star

6. bran

12. tha 


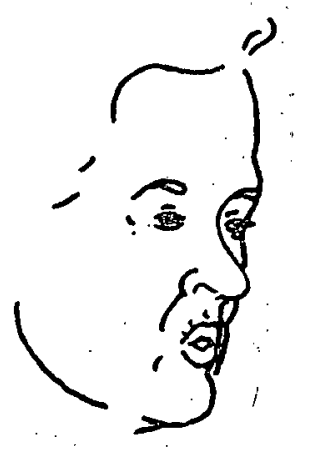

口eW

Jew blew crew screw brew flew.

chew slew strew threw

hitches napkin carpet except

advice hurry mushroom poodle

sweetly
plight
mound
spur
gray
tail
blight
found
slur
play
sail 
$108 b *$

Jew

blew

crew

screw

brew

flew

chew

slew

strew

threw en

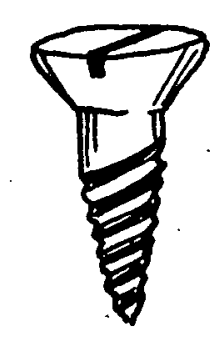

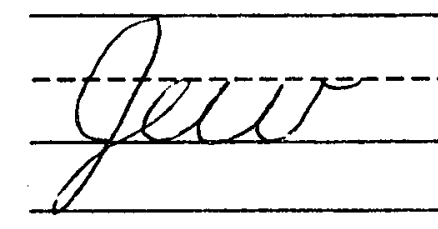

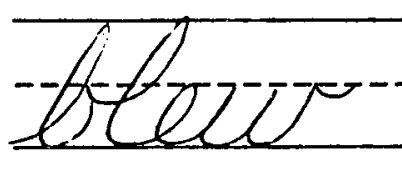

ret 
Complete each sentence, using all the words in the nearest box.

1. The player $-\begin{aligned} & \text { a } \\ & \text { threw } \\ & \text { ball }\end{aligned}$
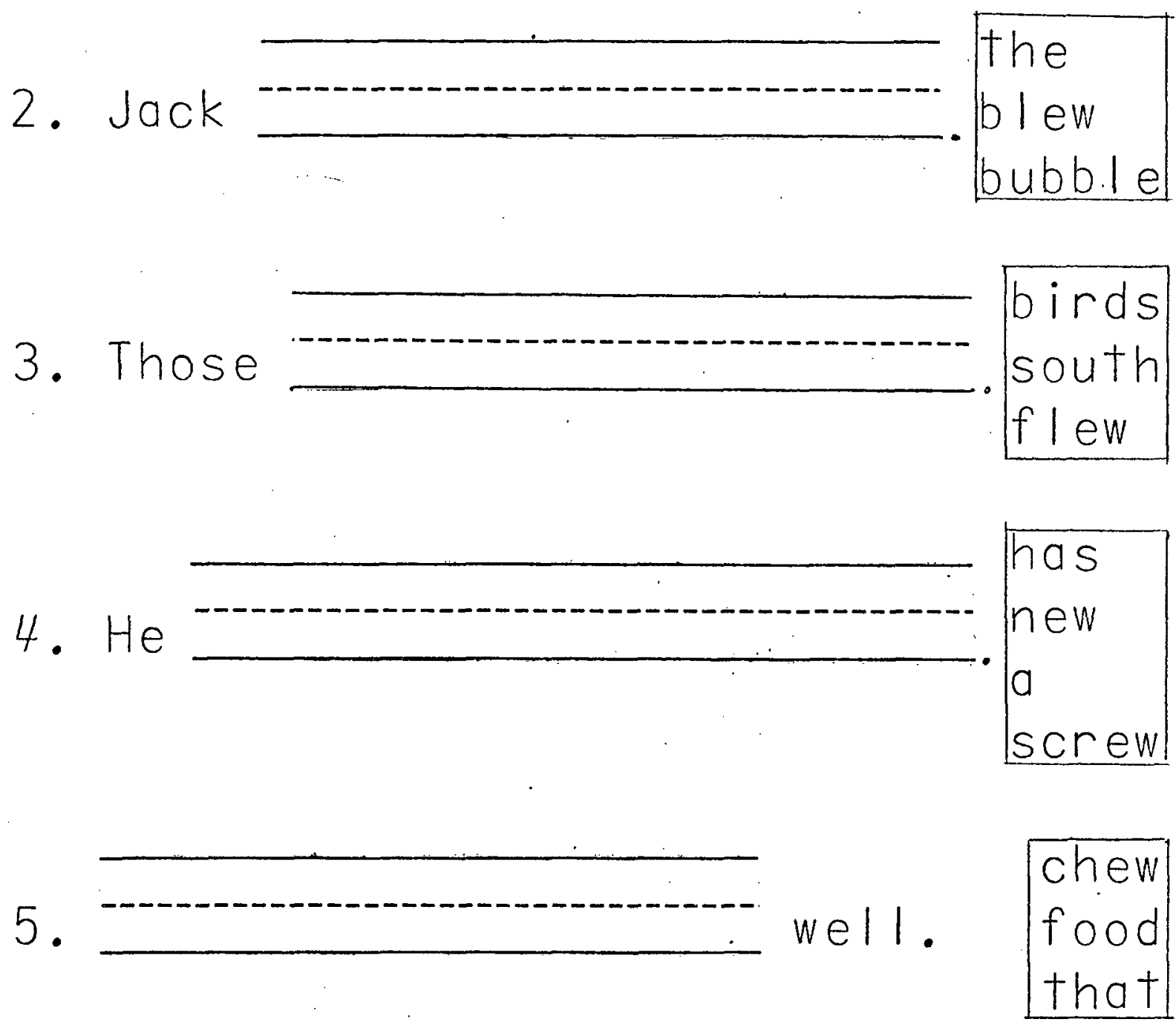


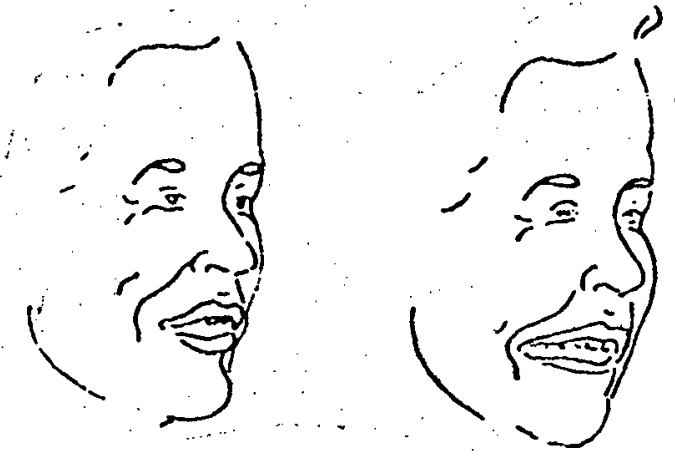

口eighr

eight eighth eighty eighteen weigh weight neigh freight sleigh notice missle mistake birthday kitchen farmer surplus counter crawl gym corn running pitch
brawl Jim born sunning hitch 
$109 b *$

e ight

eigh ty

eigh teen

weigh

neigh

freight

sleigh

eigh

(2)

wights

zighthe

vightory

exighterns 
weith

weight

meigh

freight

stexgh 
Circle each word with a long "a." sound.

I. weight

2. tail

3. batter

4. saw

5. freight

6. haul

7. eighth
11. weigh

8. walk

9. sleigh

10. apron

12. plate

13. cake

14. high 


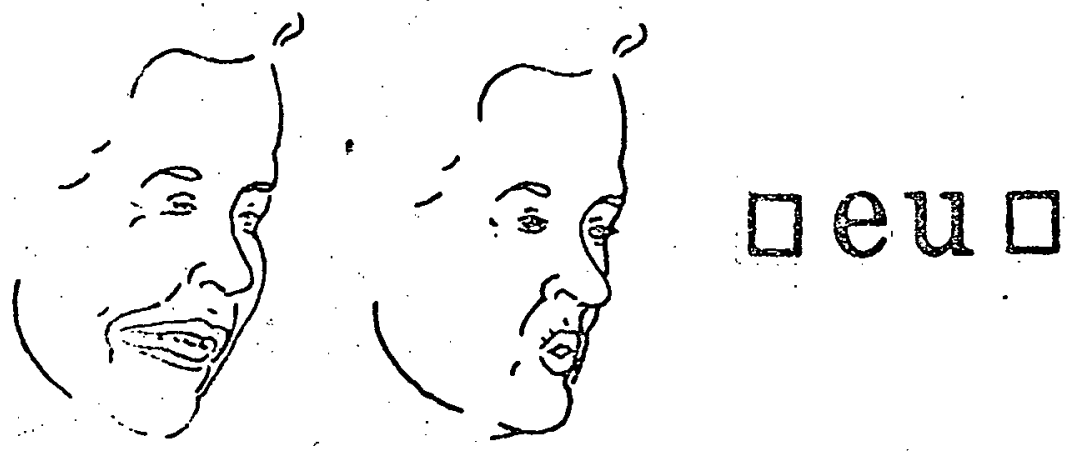

Europe eulogy euphony feud sleuth neutral

eighteen eighty gargle center basin pencil indulge pupil staple zipper dawn haunch point farmer dew drawn launch joint charmer new 
$110 b *$

Eu rope

eu lo gr

eu pho ny +

feud

sleuth +

neutral eu

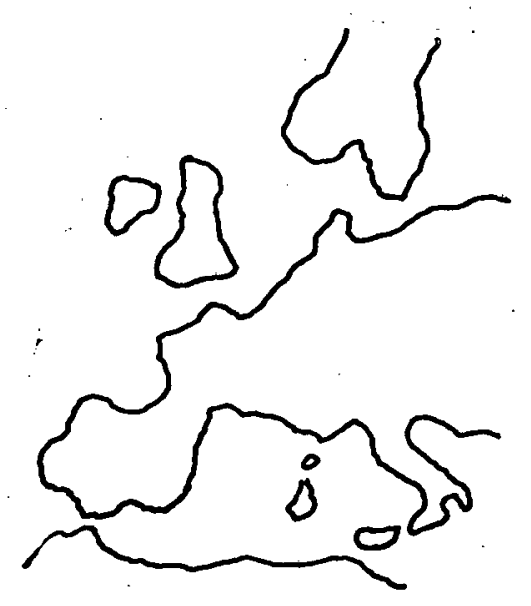

Europe
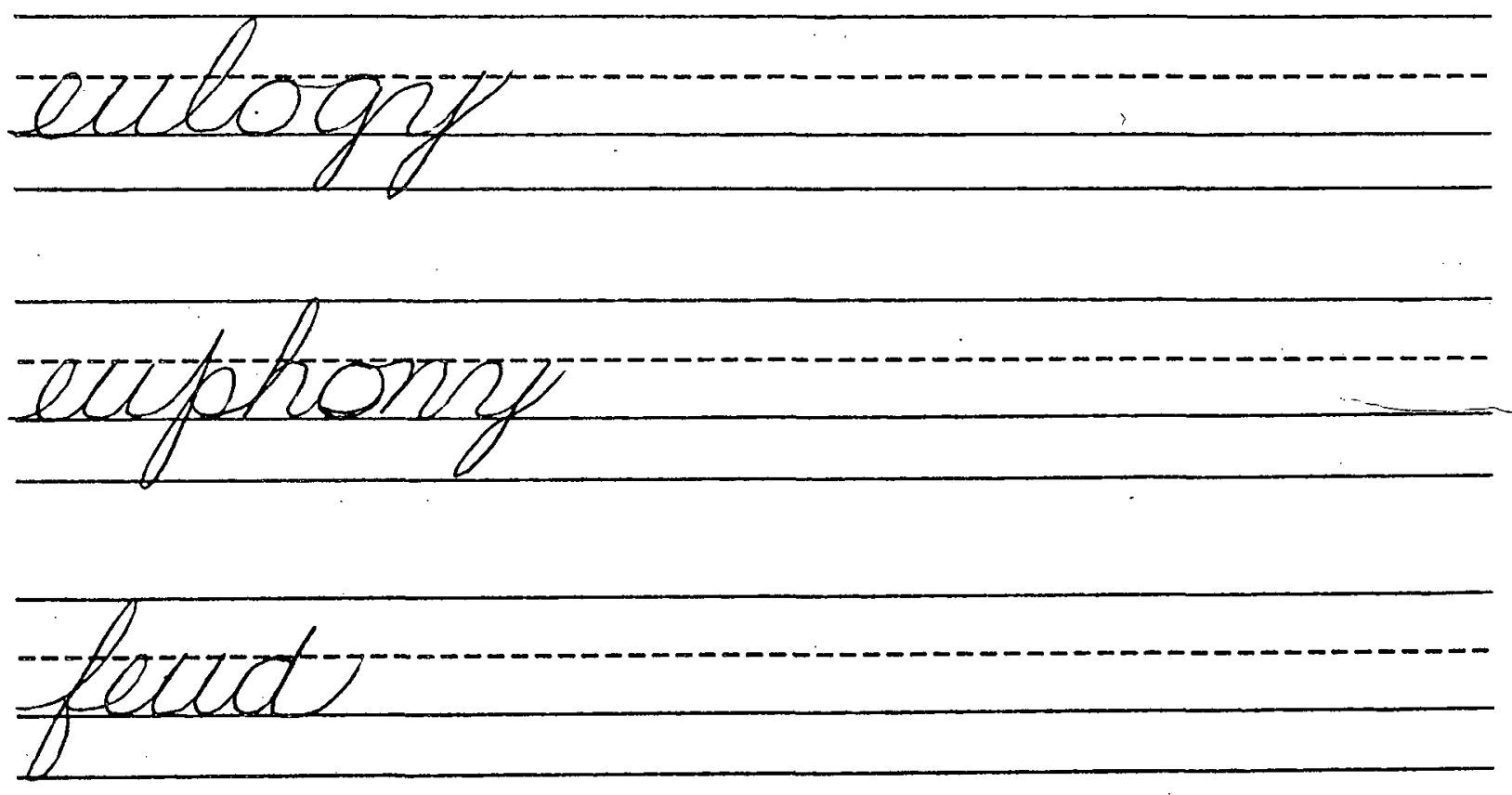
Circle each word with a long "u" sound.

1. cute

2. cut

3. feud

4. hurt

5. neuron

6. Paul

7. neutral
8. compute

9. bunch

10. feudal

11. confuse

12. euphony

13. flute

14. hur 1 


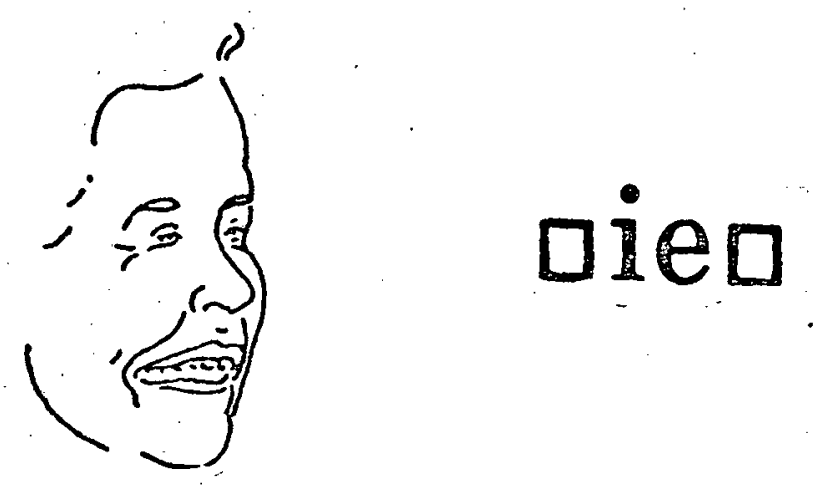

bier tier grief brief thief shriek

priest belief relief yield

Europe witches oyster squawking

eighty screwball system native

lightness chalk wrong crumb brightness walk wrung thumb 
bier

tier

grief

brief

thief

shriek

priest

be lief

re lief

yield
$11 \mid b *$

le

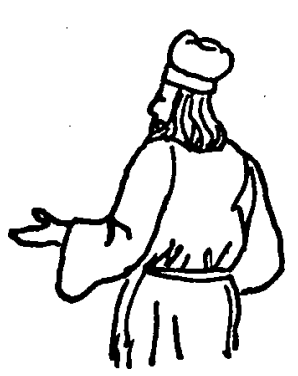

trover

tiers

grief

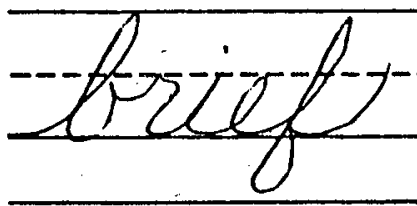


shriete

priest

betief

zietrif

zjietd 
Circle each word with a long "e" sound.

1. field

2. Pete

3. slept

4. seat

5. bat+le

6. yield

7. brief
8. whet

9. street

10. relief

11. wheat

12. sleep

13. chief

14. net 
tion

action traction diction junction.

question notion nation ration

vacation education

hungry saucer tinfoil jackknife

engine junction gentleman practice

$\begin{array}{lll}\text { lodge action } & \text { belief rushed } \\ \text { dodge fraction } & \text { relief crushed }\end{array}$ 


$$
112 b *
$$

ac tion

trac tion

dic tion

junc tion

ques tion

notion

nation

ration

va cation

ed $u$ ca tion tion

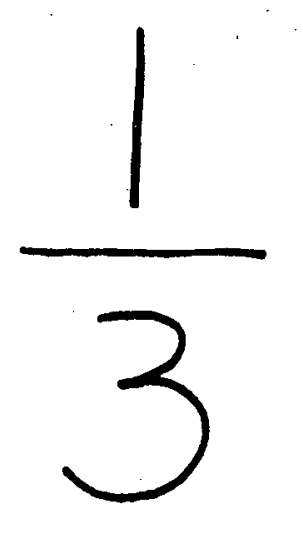

action

tractions

atictions

finnction 
gutestion

notion

mation

nation

wacation

ectucution 
Choose the best word from the following list to complete each sentence.

motion friction lotion plantation station section mention ration

1. During the famine citizens wili food.

2. Slaves planted all the cotton on the

3. A cof the apple was cuT out.

4. Dad did not problem to Mom.

5. When a car is on ice, there is not enough ---or---- to make good traction.

6. She has creamy. face.

7. The gas is crowded. 


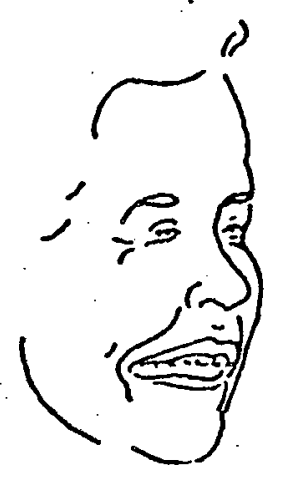

oein

ceiling receive deceive deceit

conceit conceive weird weize

either neither

section friction belief shielded

euphony eighty-eight feasted salted
threw
freight
cyst
icy
strew
eight
system
spicy 
ceil ing

re ceive

de ceive

de ceit

con ceit

con ceive

weird

seize

ei ther

nei ther

$$
113 b *
$$

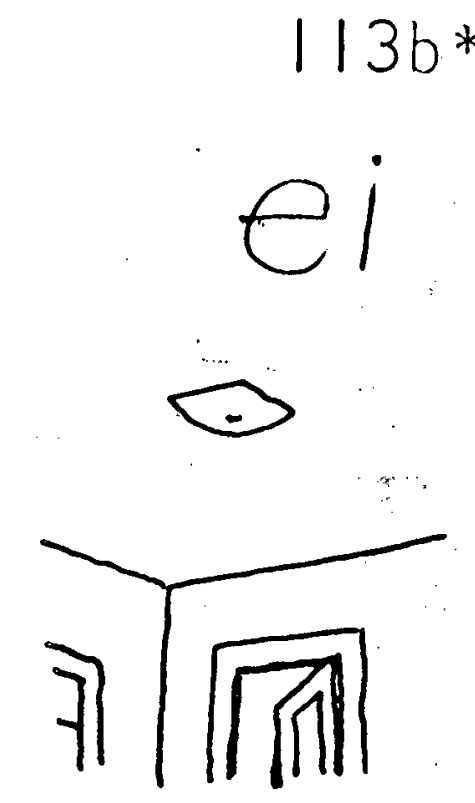

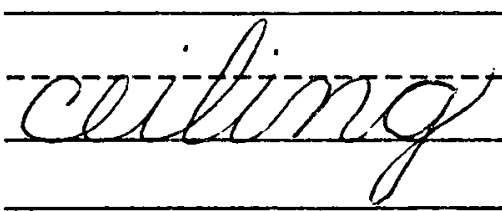

recente

atereines

decett 
concert

conceitue

utritrot

veizes

either

meithers 
Using the "i before $\underline{\mathrm{i}}$, except after $\underline{c}$ " rule, put ie or ei in the blanks to complete each word.

1. c__ ling

8. bel__f

2. ch_f $f$

9. conc__

3. rec ve

10. pr st

4. f_. Id

11. dec

5. cono

ve

12. y_ Id

6. th f

13. dec ve

7. $+[r$

14. gr f 
$114 a$

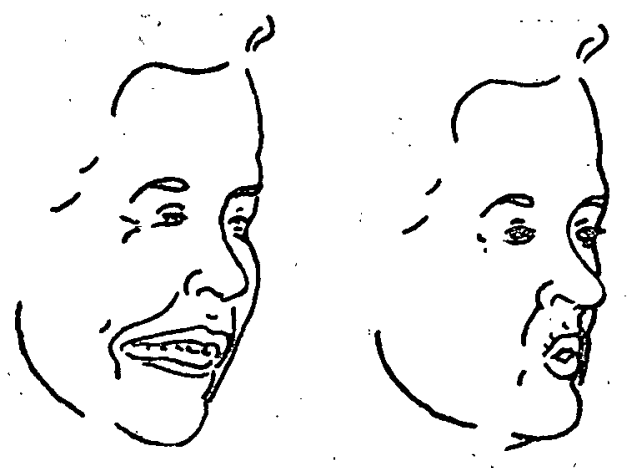

aue

hue cue argue value rescue

continue curlycue imbue

decide ceiling receive sleighbells

service neutral fraction practice
Alice
neural
fierce
neigh
office
neutral
pierce
weigh 
hue

cue

ar gue

val.ue

res cue

con tin ue

curl y cue

im bue
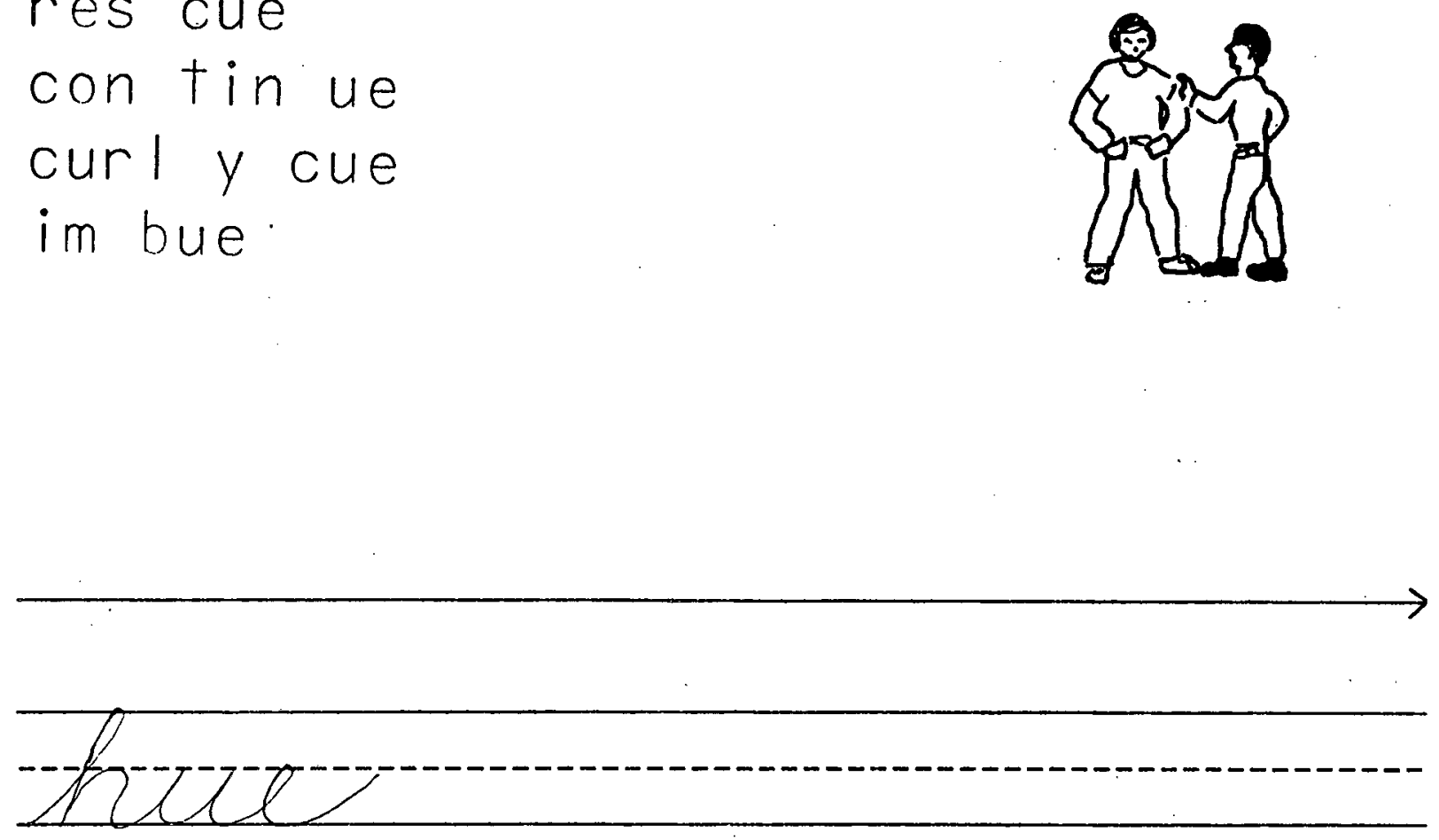

CUTU2

atgeter

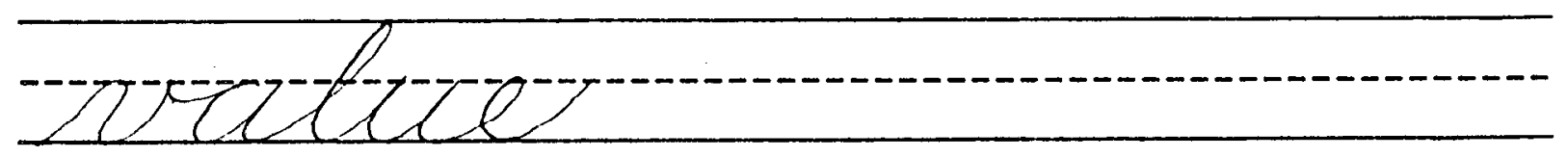


FeUCAT

continue

cuovtrucues

iontere 
Rearrange the scrambled sentences.

I. argue Mom Dad not did and.

2. Iater continue We that will.

3. Please drowning the rescue swimmer.

4. to cue Remember a me give. 


\section{Review}

Read these word families:

$\frac{t c h}{i+c h}$

witch $\frac{e i}{\text { receive }}$

deceive $\frac{i e}{\text { grief }}$

brief $\frac{e w}{f l e w}$

blew $\frac{\text { ue }}{\text { hue }}$

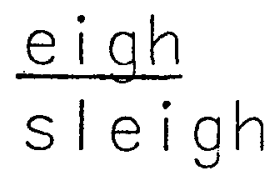

cue $\frac{\mathrm{eu}}{\mathrm{f} e u d}$

feud

sleuth tion

ration

nation

Put the following words into word families like above, using the same headings. You may do this on a separate sheet of paper. Read each word.
catch
euphony
weight
sketch
slew
threw
strew
Europe
freight eight
eulogy
priest
diction latch
belief traction
relief
notion
neither
value
action
either
argue
conceit 


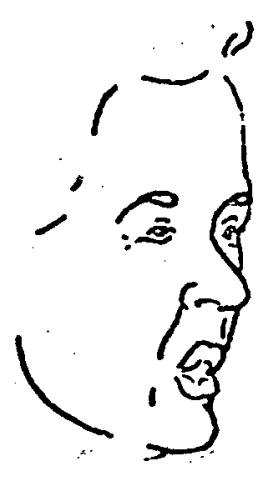

口OW

low blow row grow show throw bowl flown growth window

crowbar nation talker gymnastic

crutches slowly ledges cycle

mellow rescue suction either
fellow argue section neither 


$$
116 b^{*}
$$

low

b low

row

grow

show

throw

bow 1

flown

growth

win dow
OW

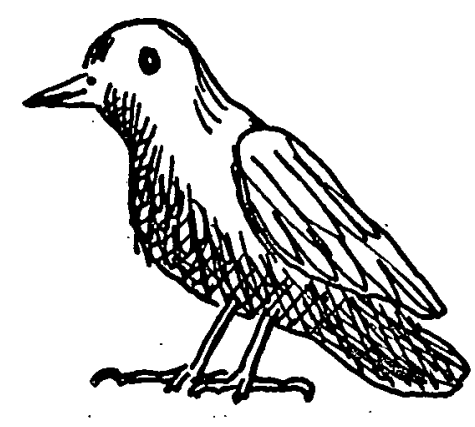

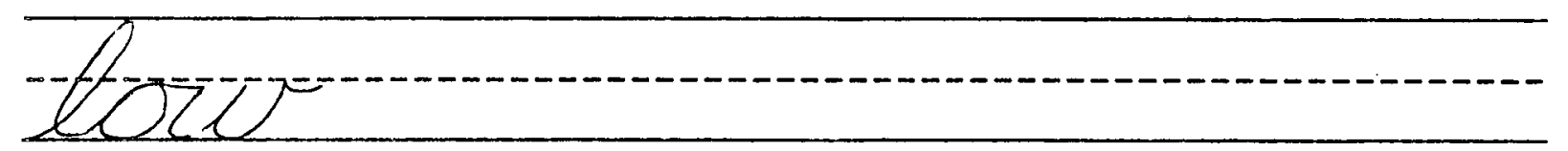

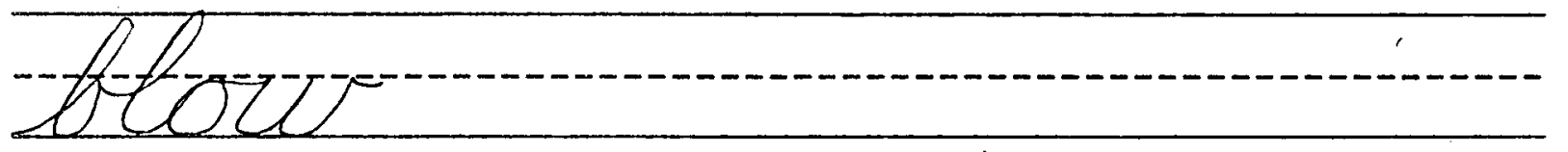

grow 
Thore

throw

trout

ftown

groveth

urindowe 
Circle each word that has Iong "o" sound.

1. load

8. hoe

2. note

9. rode

3. show

10. slow

4. shot

11. moon

5. drop

12. boy

6. know

13. oil

7. how

14. crow 
sion

division conclusion confusion

infusion intrusion inclusion

invasion transfusion

excursion avenue position deceive

feudal believe hunter plantation
vision
fence
rushed
notion
decision
hence
brushed
lotion 
di vi sion

con clu sion

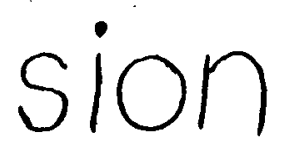

con fu sion

in fu sion

in tru sion

in clu sion

in va sion

trans fu sion

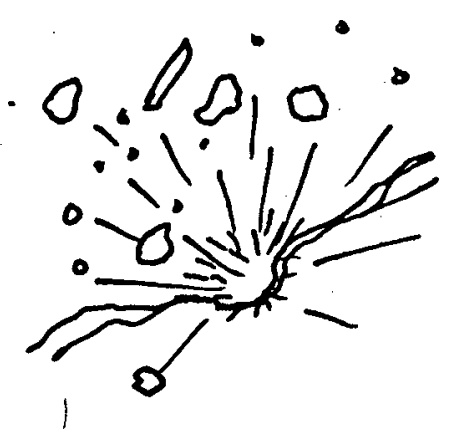

atrivisury

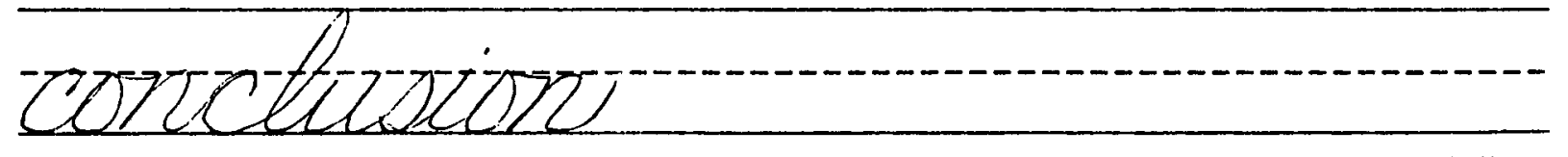

(20)

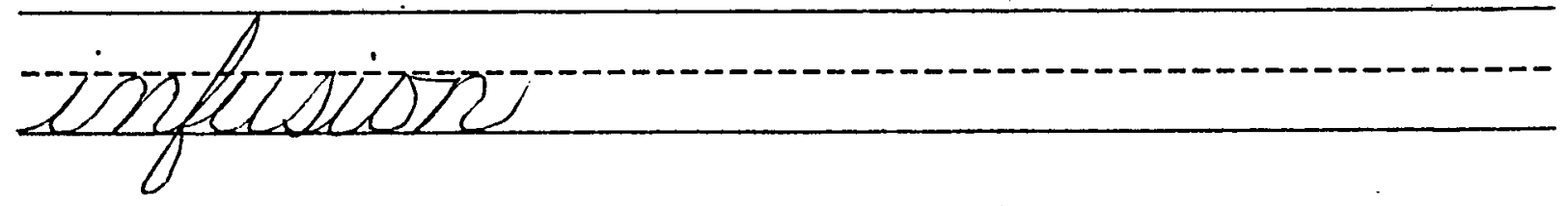


zintrexsions

(2)

सח

tranofersion 
Write the correct ending on the line after each word part. Use either tion or sion for endings. Read the complete word. The first one is done for you.

I. nafion

2. confu

3. rela

4. no

5. $a c^{-\cdots-\cdots}$

6. $v i^{\cdots \cdots}$

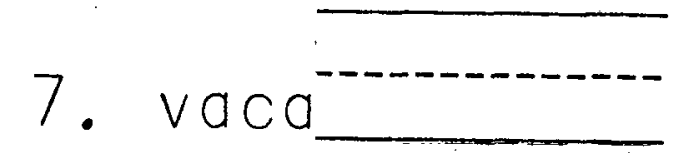

8. conclu

10. $\operatorname{explo}$

11. divi

12. inva 


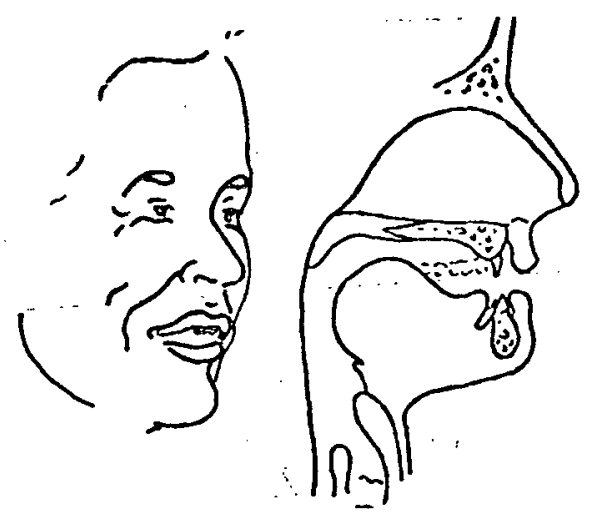

\section{口ean}

head dead tread death wealth

health meant heavy instead

feather widow heaven pillow

rescue conclusion weapon lunches

bread ouch grew car gnat

read couch new far gnash 


$$
118 b *
$$

head

dead

ea

tread

death

weal th

health

meant

hera ry

in stead
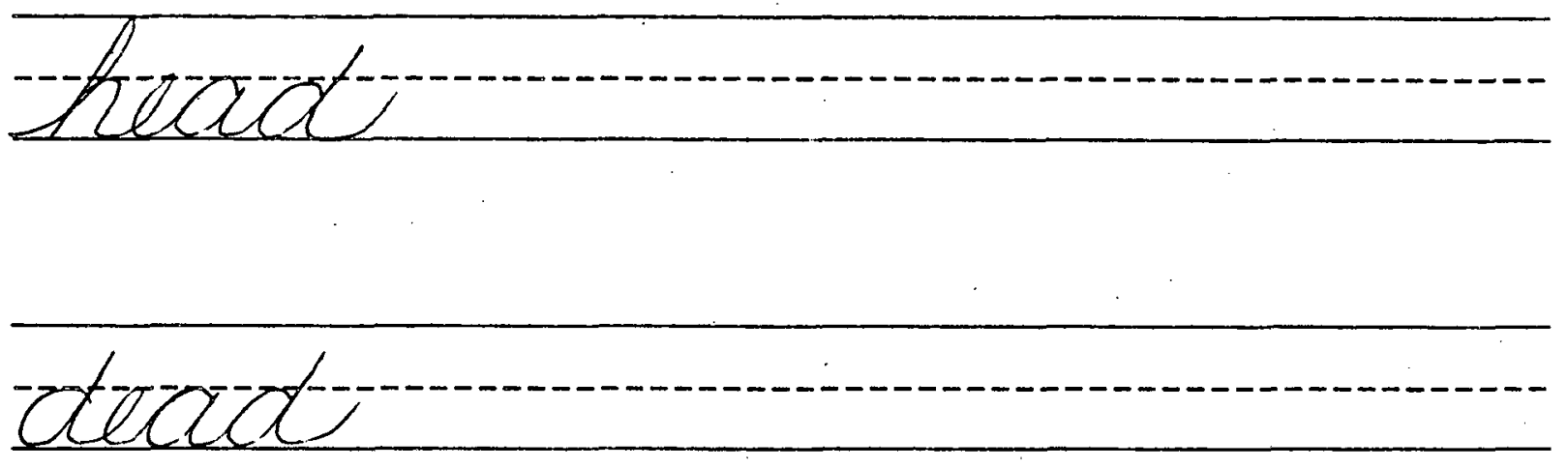

treat - - -

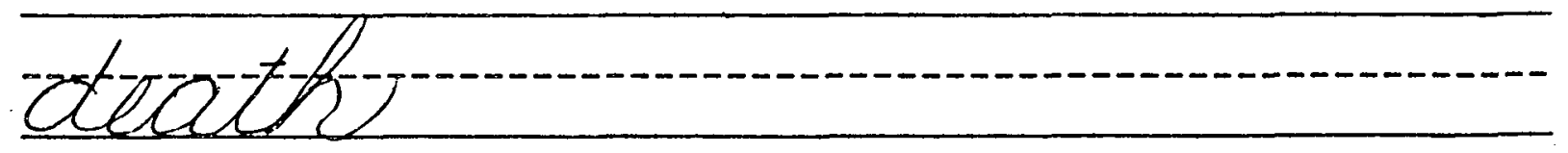


wealth

Featth

meornt

heratry

invitead 


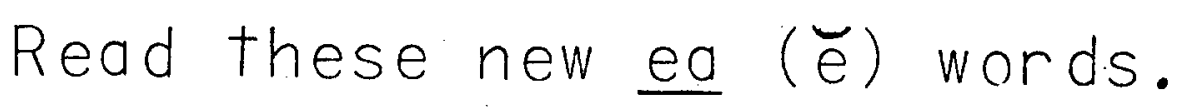

hea ven

realm deaf

rea dy bread

stea dy

Write some senterices using as many ea (こ) words as you can. 


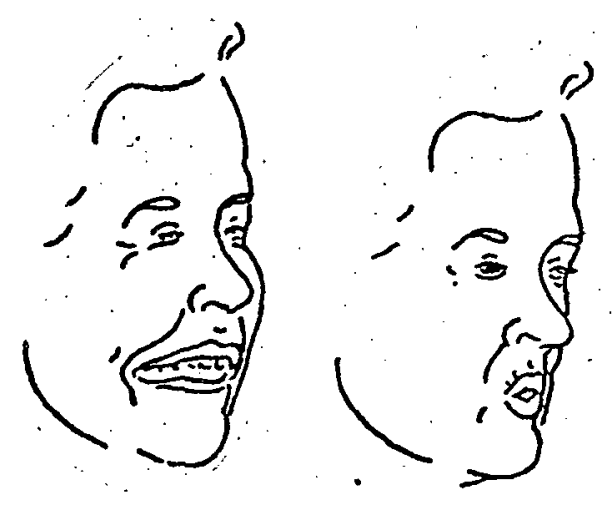

\section{口ew}

hew few mew pew skew nephew

sinew curfew pewter

weather instead nation eighteen

explosion ceiling elbow cargo

cattle fern shirt crow clown

rattle tern skirt know down 


$$
119 b *
$$

hew

few

mew

pew

skew

neph ow

sin ex

cur few

pew ter eq

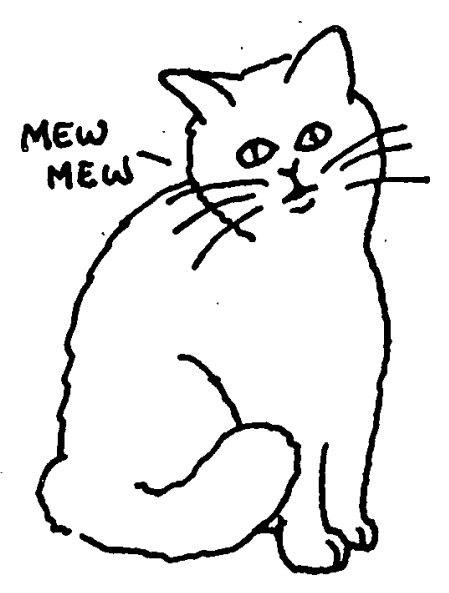

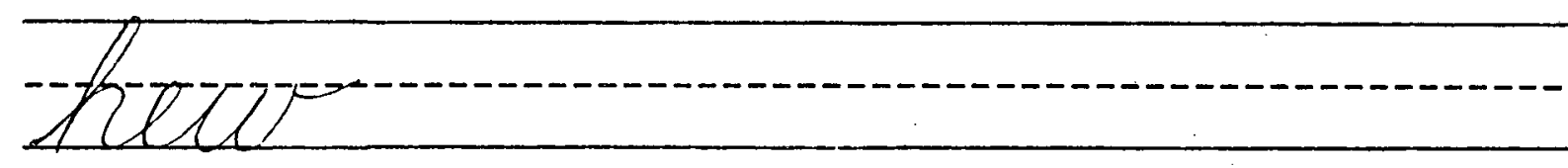

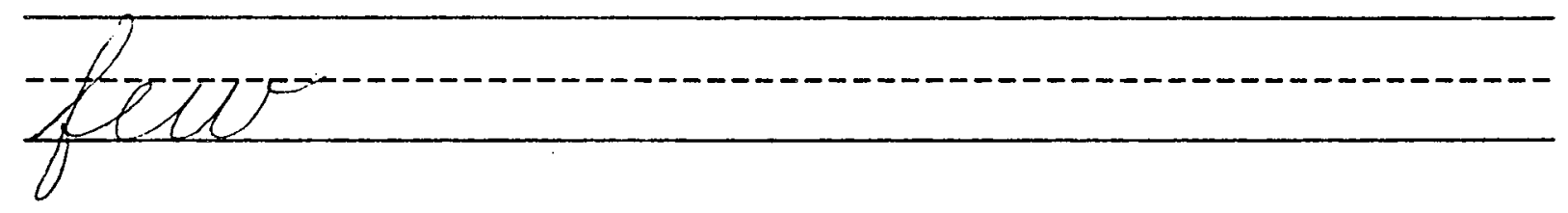

$27 n e t T^{-\cdots \cdots}$

aet 
atseur-and

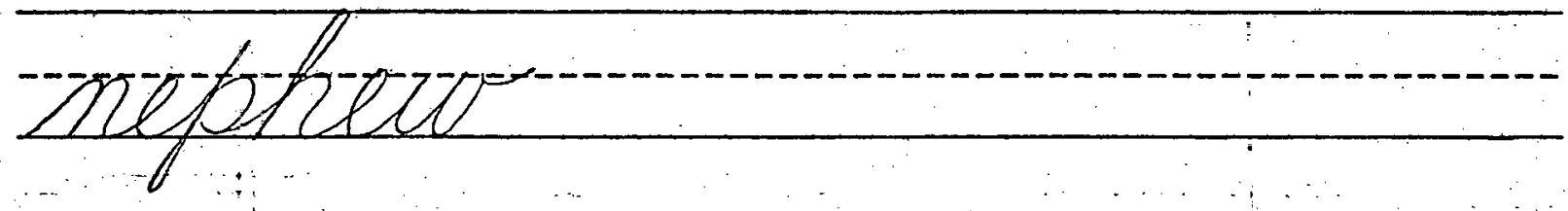

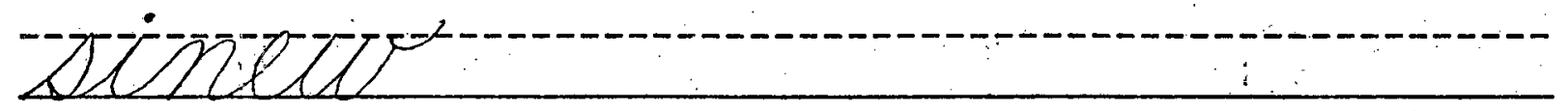

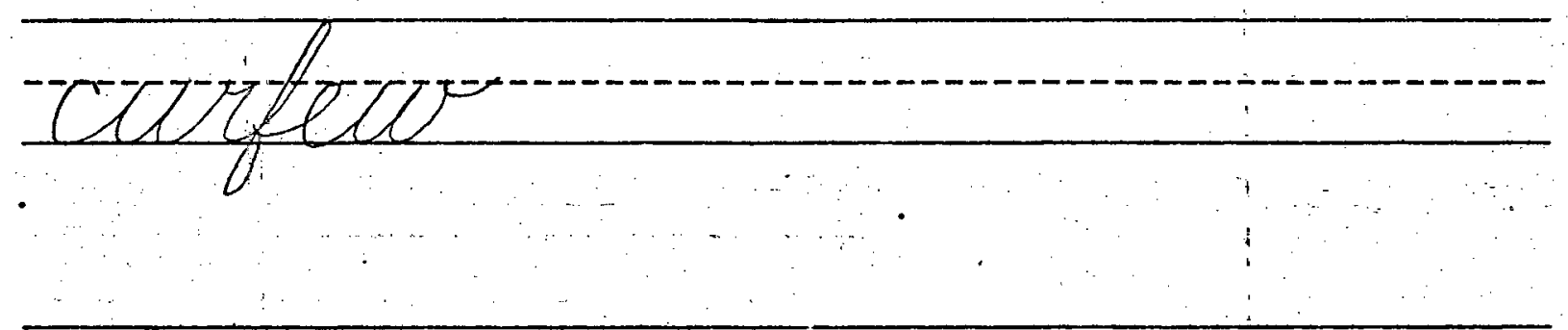
zoevotere 
$119 \mathrm{C}$

Read the sentences carefully. Draw a line under all the words that have ewe. You may want to write some senfences, yourself. (Include sw words.)

1. The lady will screw up her nose at the bad smelling brew.

2. At the sight of the crew, the bird flew to the yew.

3. Jane blew on the hot stew.

4. Do you like to chew gum?

5. The boy slew the ants and threw them in the hole.

6. Jack drew a picture.

Lines for writing sentences: 


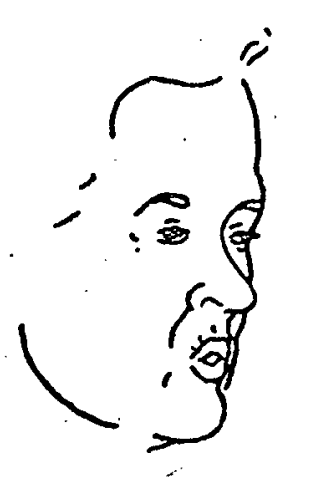

oue

true rue blue flue glue construe misconstrue due subdue sue pursue curfew mildew ready expulsion

slowly heavy angle charmer moon moonbeams shirtwaist
lowly
health
seat
rank
road
slowly
wealth
neat
sank
toad 
true

rue

blue

flue

glue

con sprue

wis con sprue

due

sub due

sue

pun sue
$120 b *$

le

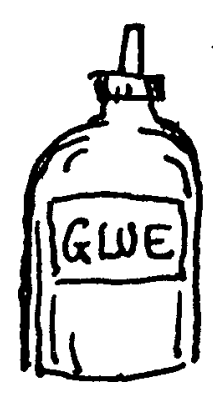

true

TUE
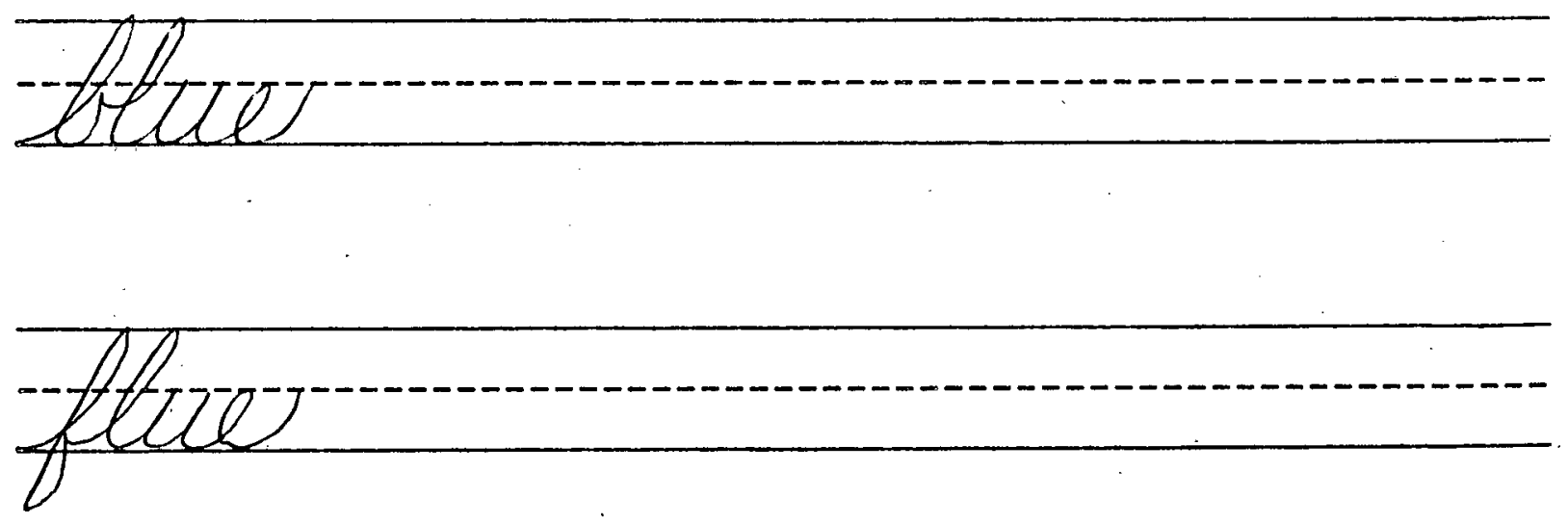
getue

conotrutes

mosonsotrue

dut

sutedue

XIXU 
$120 c$

Put these words with the we ( $\overline{0 O}$ ) sound in the order of the alphabet.

sue

sub due

true

glue blue

flue av e noe

pour sue

rue

con sprue
2

3

5

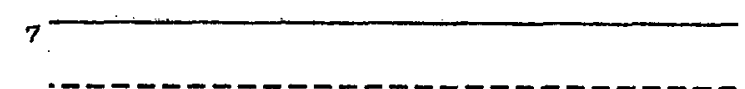

8

9

10

/I. 
ind ild

bind find kind hind grind blind wild mild pint climb

grinder tinfoil crowbar pewter

treadle corny conclusion feudal

hue chief feud hobble head

cue thief feudal gobble stead




$$
121 b^{*}
$$

ind
bind
find
kind
hind
grind
blind
ill
$\begin{array}{ll}\text { wild } & \\ \text { mild pint } & \text { climb }\end{array}$

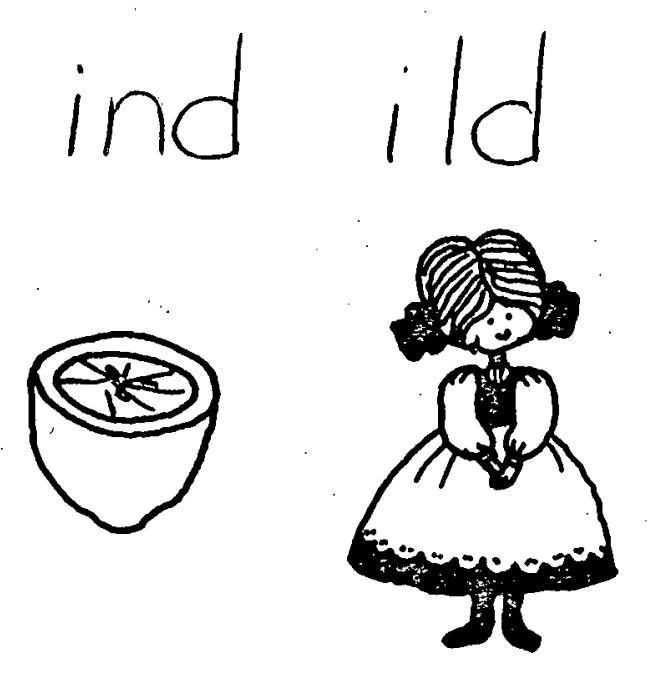


grimats

Btind

zorited

mitet

foints

cetimn of 
Match the first part of these words with the correct ending.

p

rind

cl

ild

b

ind

f

int

m

$\mathrm{imb}$

g

lind 


\section{old, olt, oll, ost}

old bold cold scold fold colt

jolt volt roll poll toll troll

stroll most host

foundation oldster holster cashier fiercely neuter pursue explode scold halt sleigh table niece
cold malt weigh fable piece 
$122 b_{1}^{*}$

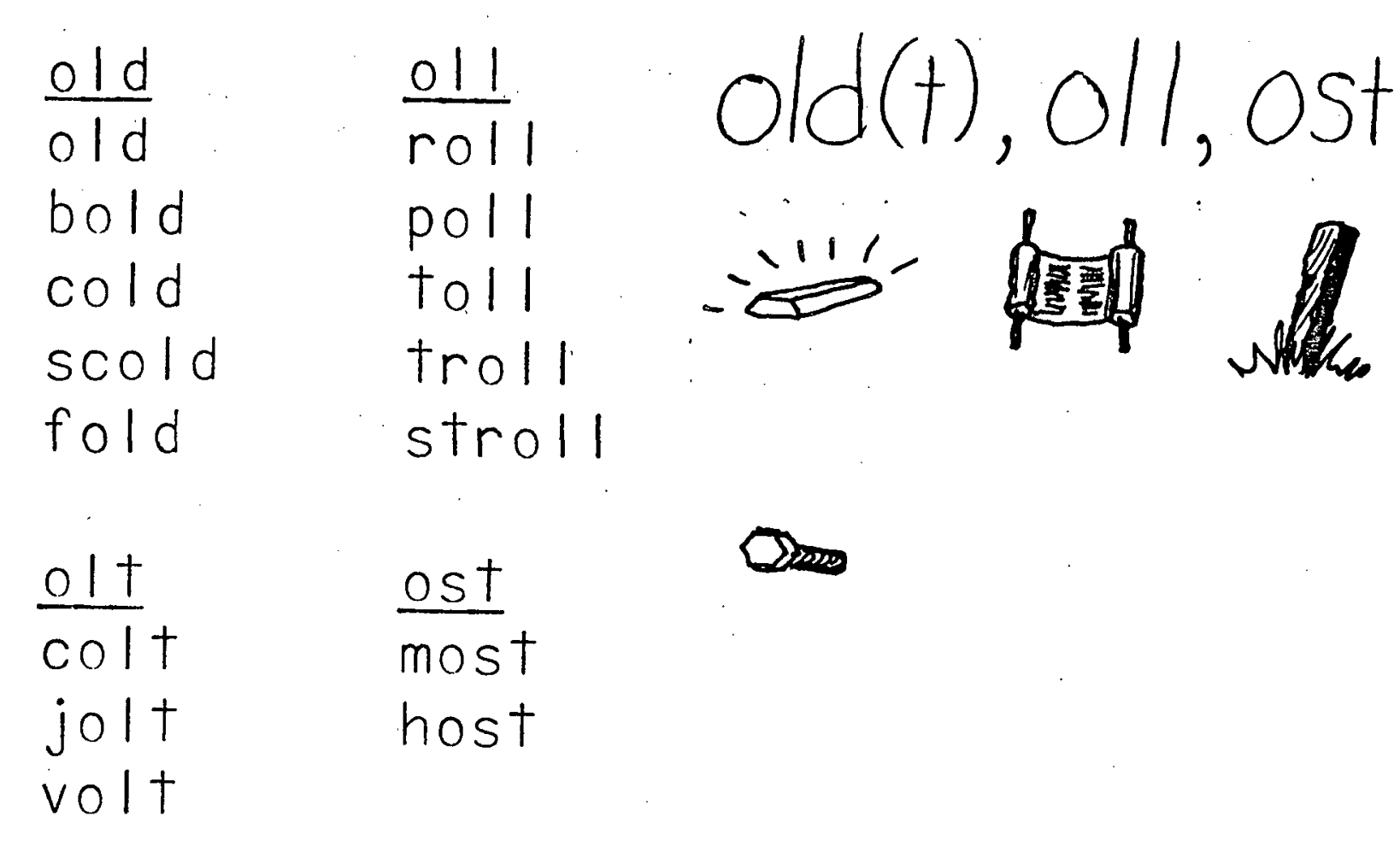





$$
122 b_{2}^{*}
$$
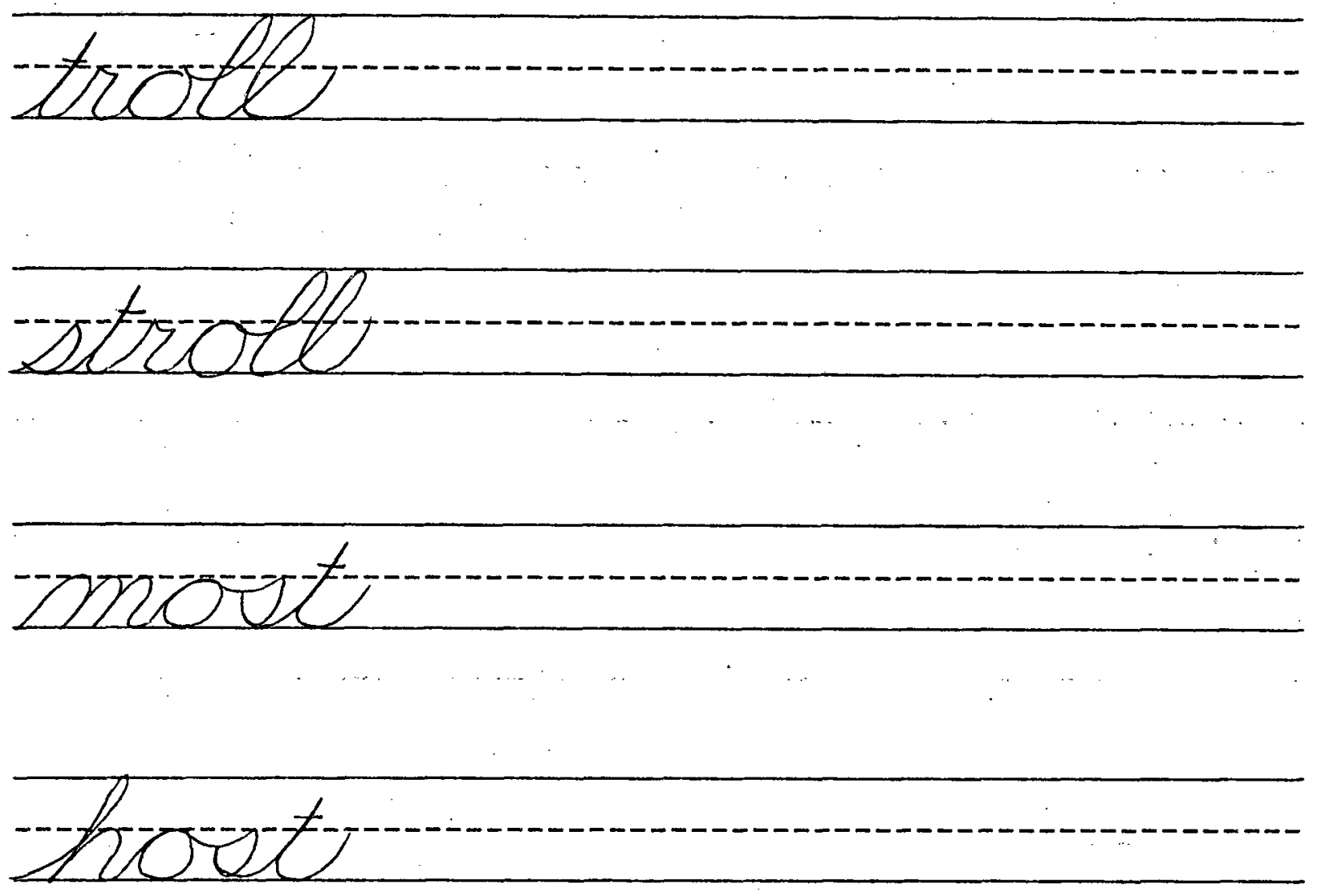
Fill in the blanks, using old, oll, olt, or ost.

The $\cdots$ man took a str $\bar{\cdots}$ down

the street. He met a b

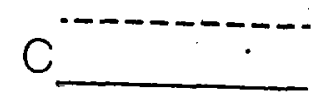

who ran by, giving the man a j-a.-

such a b men would Sc

man did not. 


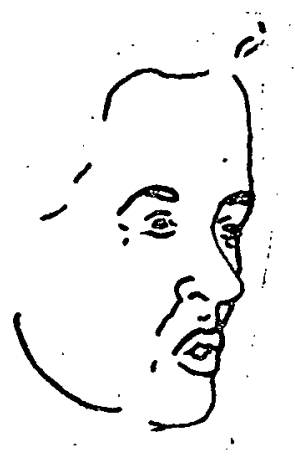

पOOD

took look shook good stood wool

foot cooking woodshed fishhook

cooker nephew pillow cunning

service ration without meadow
bolt crook
conclusion
good
colt
brook
exclusion
stood 

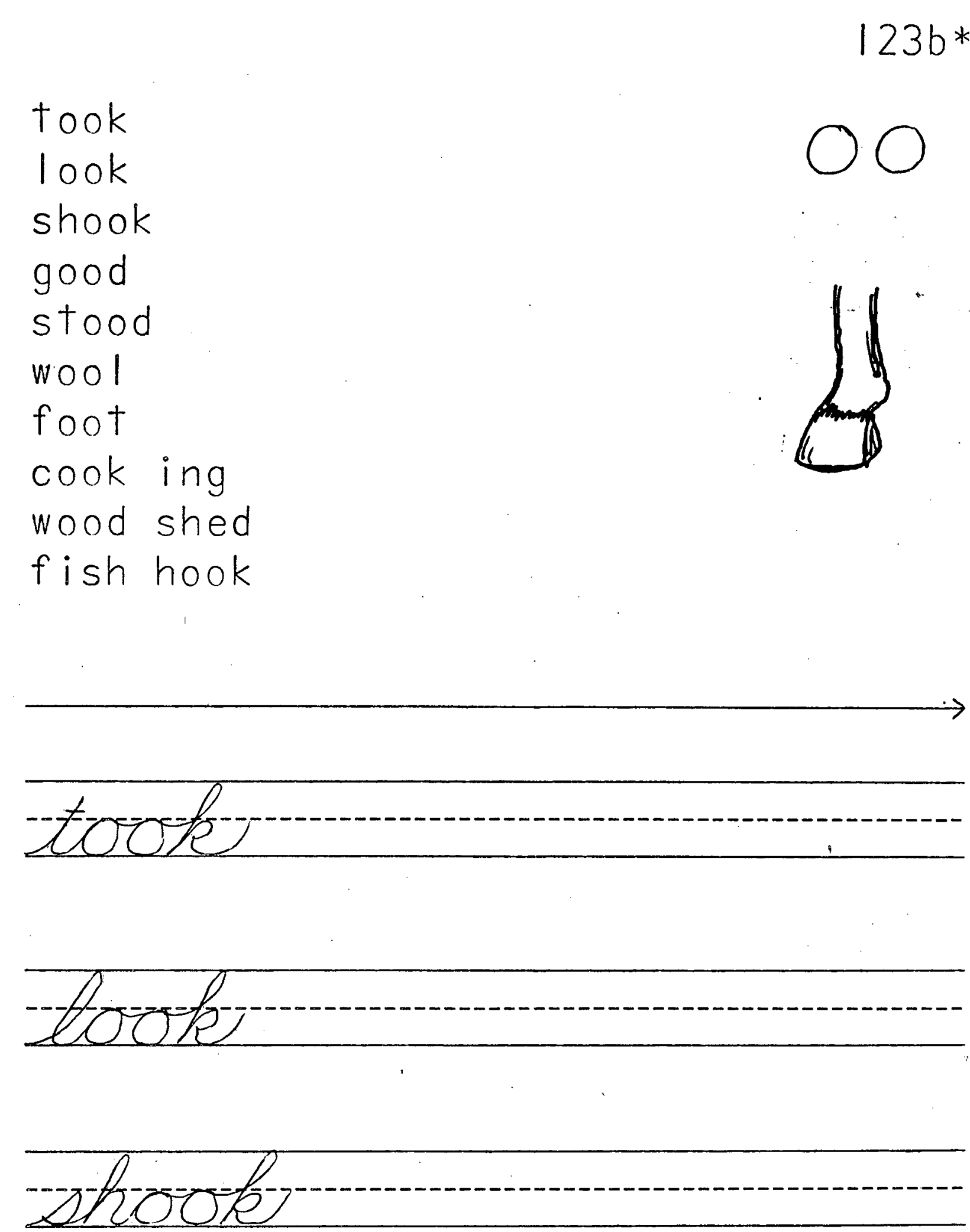

goods 
stood

$20000 t$

forot

cookingeg

zoroodsterds

fishtrook 
Match the words with an appropriate suffix. Write the suffix after the word.

1. book

er

2. good

3. hood

less

4. hook

5. look

6. foot

1

ed

7. wood

ness

8. crook 


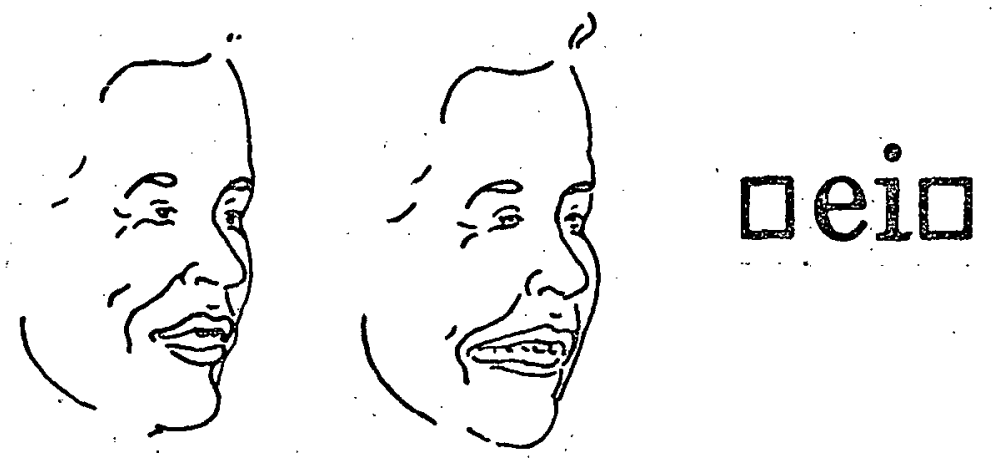

reins reindeer vein veil reign skein chowmein

bottle kinder postman cooking understood curfew woolen breaded
loud
corn
pry
me
screw
cloud
born
try he
crew 
reins

rein deer

vein

veil

reign

skein +

chow mein

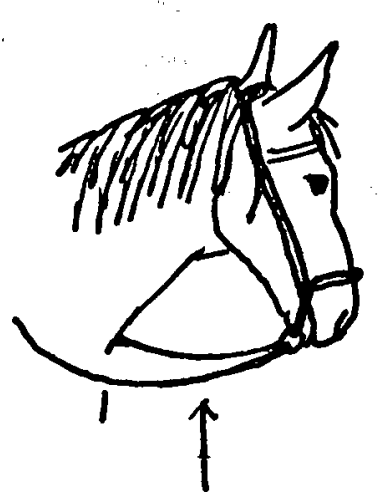

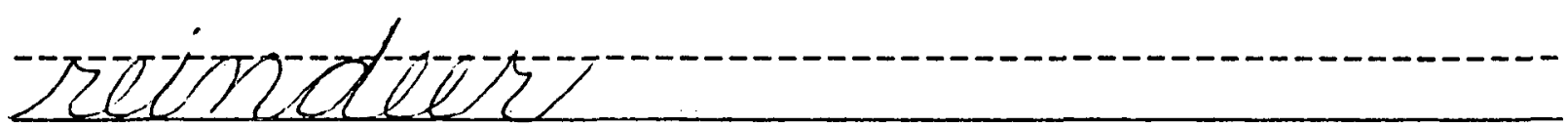

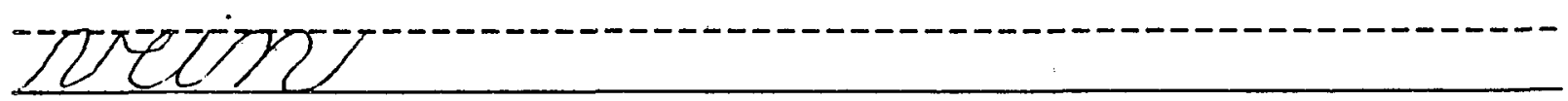

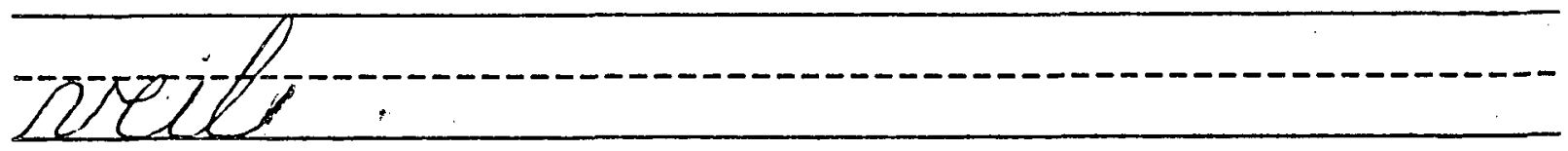


zreigntz

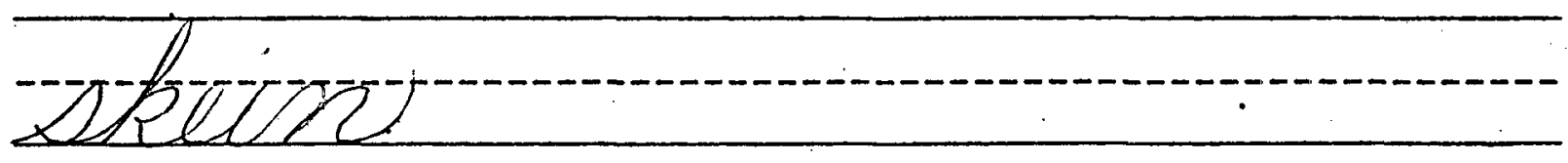

chrovornetint 
Write a story, using ei words with the long "a" sound. Use as many other words that spell the long "a" sound as you can. 


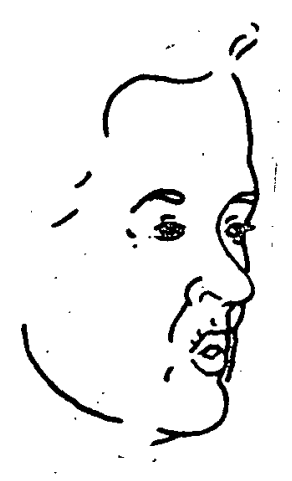

\section{वuin}

fruits suits juice juicy bruise

cruise recruit

misconstrue mildew undertook planter pheasant sweater follow hollow
$\operatorname{colt}$
vein
chief
missing
most
cold
rein
grief
hissing
post 
fruits

suits

juice

juic y

bruise

cruise

re cruit
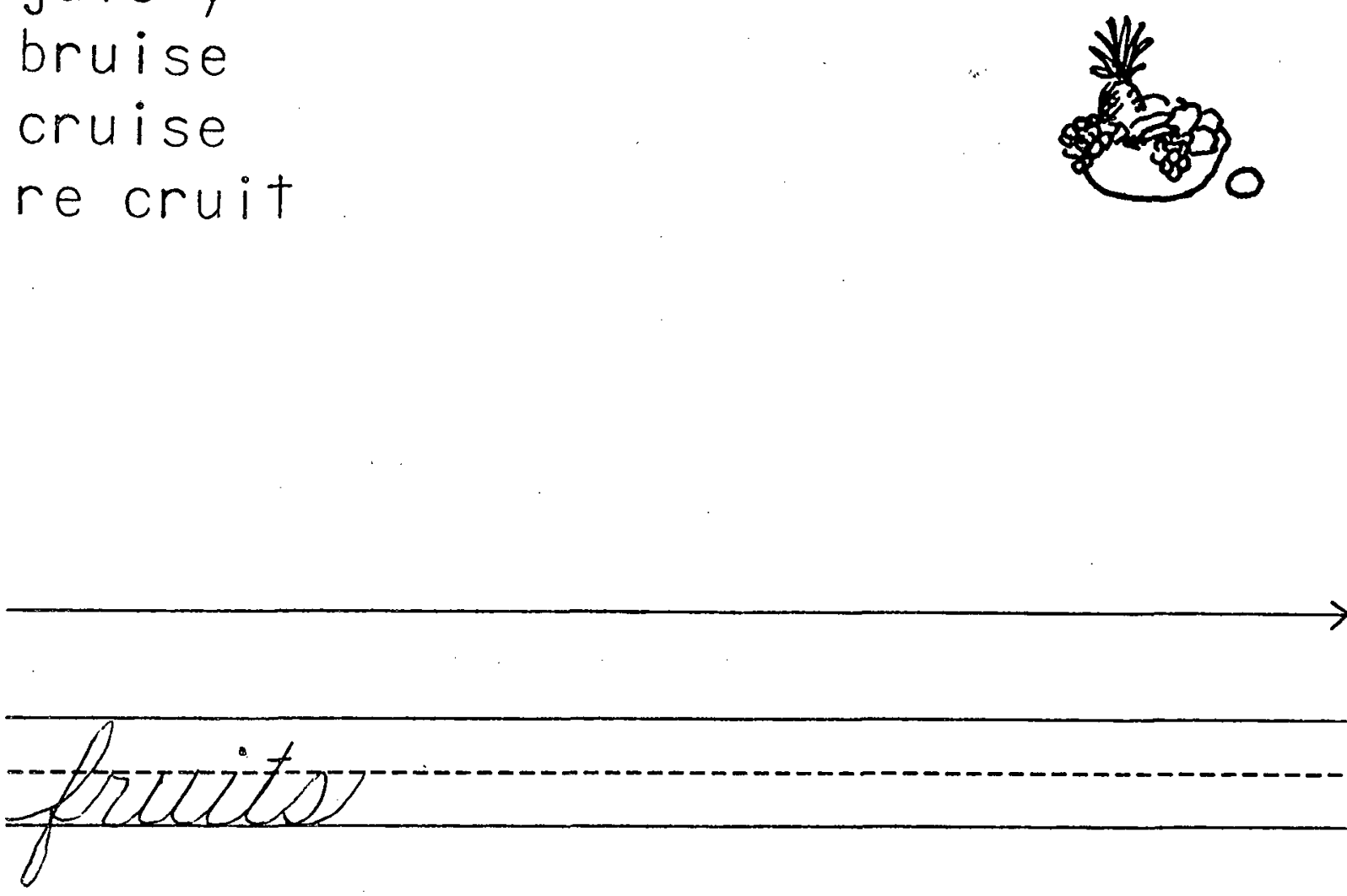

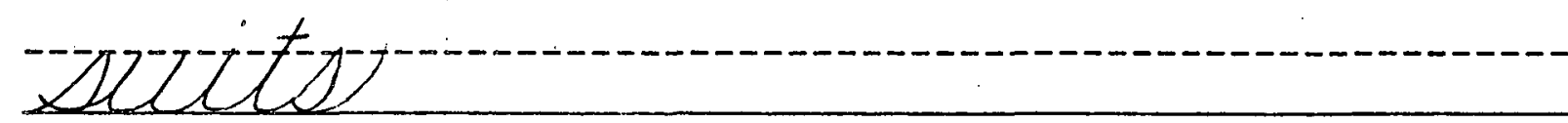

juitce

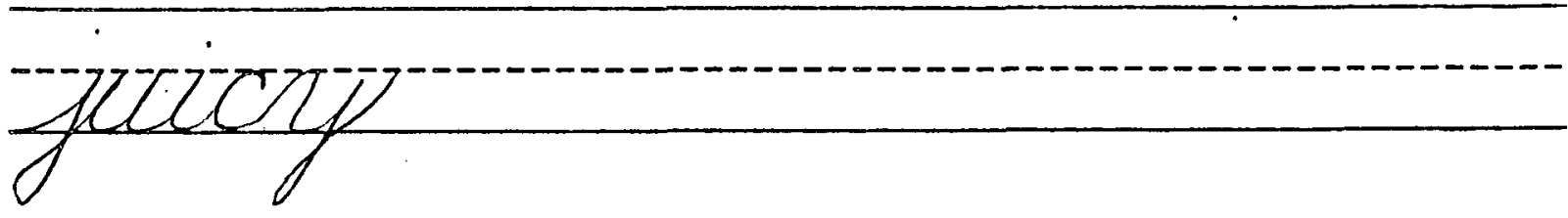


( crutse

recrute 
Write your own ending to these sentences.

1. The family took a cruise

2. The yellow juice

3. The recruit

4. The boy's new suits

5. Mark got a bruise

6. That fruit 


\section{sion}

tension pension pretension compulsion propulsion suspension extension expansion

alternate affliction tossing begun ketchup detach occupy pretension

Scotch strange fission suction splotch range mission section 
ten sion

pen sion

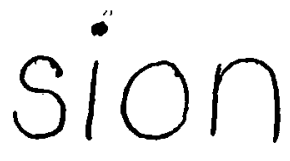

preten sion

com pul sion

pro pul sion

sus pen sion

ex ten sion

ex pan sion

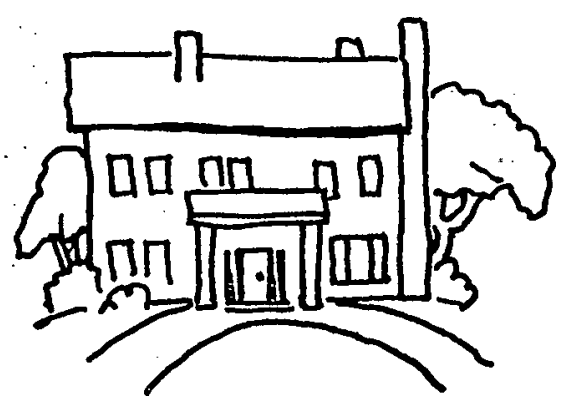

Zerrotion

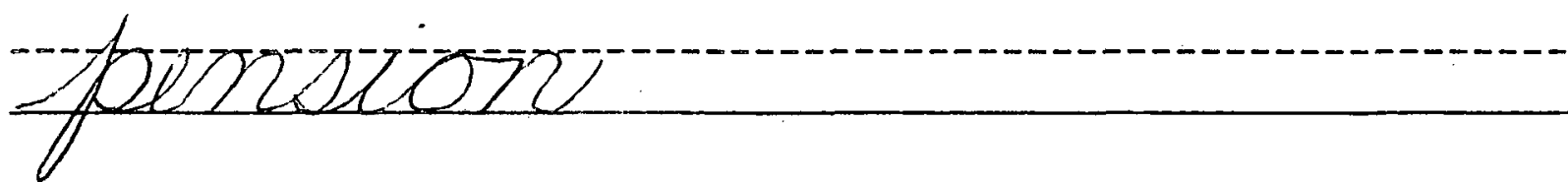

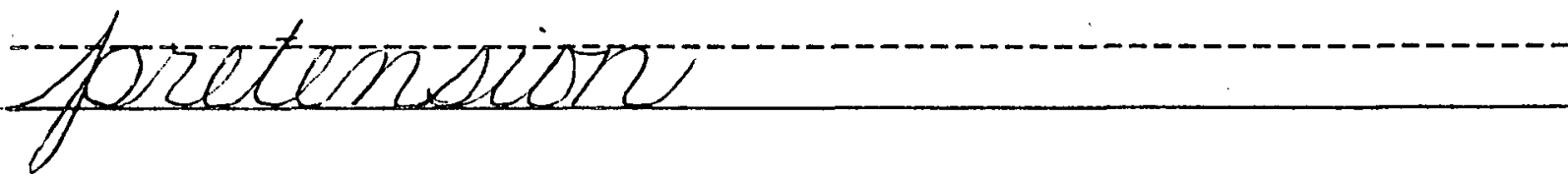

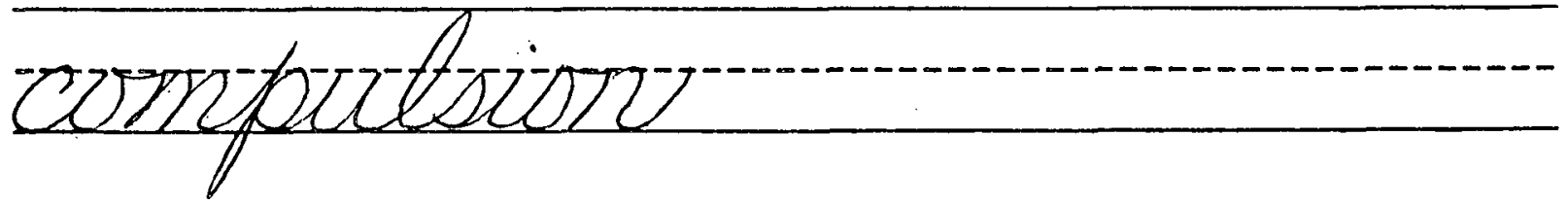


proputsions

exiofersions

exteraicis

exponanion 
$126 c$

Put these parts of words together to make the words from your reading list (job sheet 126b). Use each part once, except sion. Write the words below.

ten

pen

pan

sion

pro

com ex

pen

sis

pul

pres

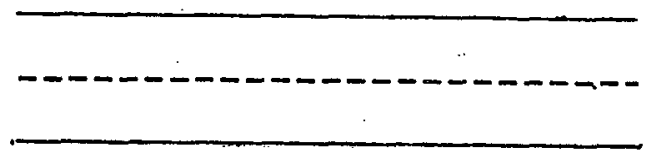




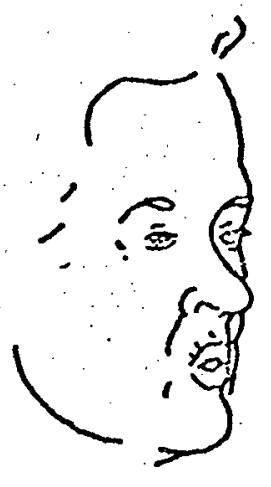

DOUL

Lou Louis soup soupy group croup

troupe route wound youth

reindeer kindness leather hooking

omission breaded wounded mansion

true fruit pension veil glue blue suit tension vale flue 
Lou

Lou is

$\mathrm{OU}$

soup

soup $y$

group

croup

troupe (silent e)

route (silent e)

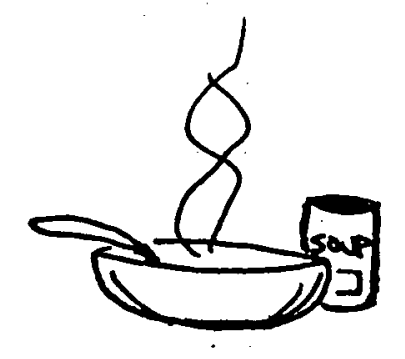

wound

youth

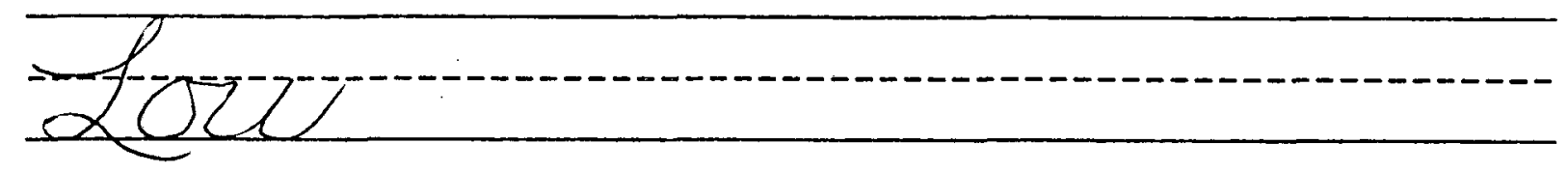

Loute-

zoteph

sorifory 
groutp

croverp

trouper

zouter

wownots

zyouth 
Fill in the missing letters in these sentences. You will make words you have learned in this lesson (job sheet 127b).

1. _ou_ joined the _ou__ou_.

2. Baby_ou has the _ou_.

3. The _ou_tastes good.

4. The salt water made the _ou_sting.

5. The circus _ou_followed the western _ou_.

6. The clay was _ou_. 
Review

Read these words:

dead nephew toll due meant find cold shook new glue most wild climb vein pension jolt wool pint reign soup bruise gruit tension croup

Write each of the above words in the appropriate column below. They are to be listed by vowel sounds. The first word in each column is done for you.

$\underline{\underline{e}} \underline{\ddot{u}}(\overline{00}) \quad \underline{0}$

tension bruise most
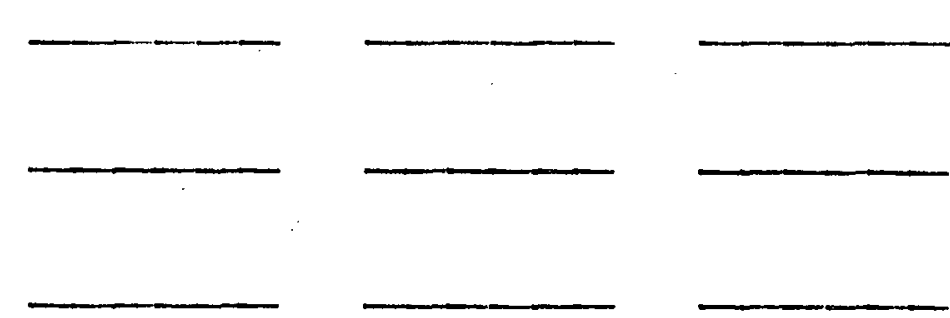

i.

climb

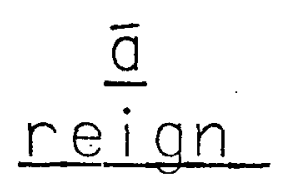

$\underline{\dot{u}}(\overline{00})$

wool 


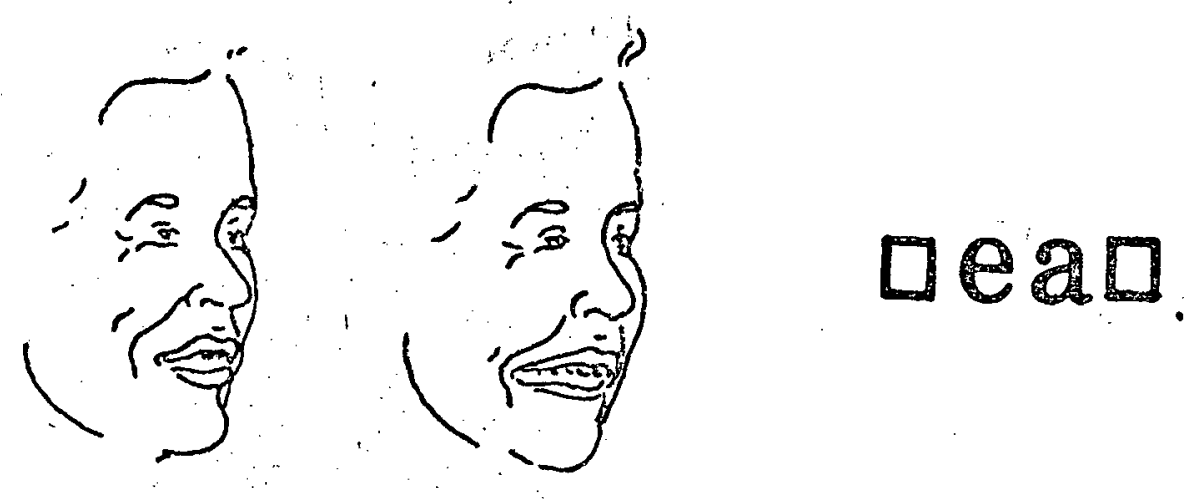

great greater greatest greatly

break breaks daybreak steak steaks

beefsteak.

greatness troupe permission taxes

expansion walnut quizes beginner

walk fizzes clowns ledge bruise stalk quizes plows hedge cruise 


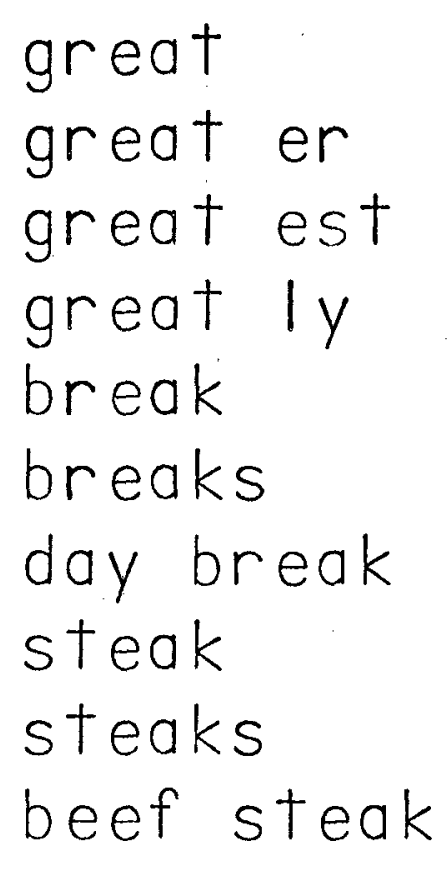

great greater greatest greatly break breaks daybreak 
steak

steaks

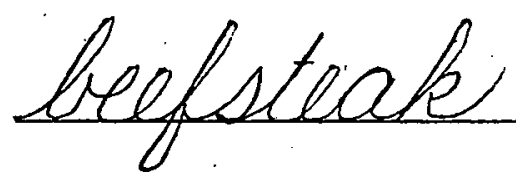


Use the new words on job sheet 1296 in a story. Read the story to the teacher after you write it below. 


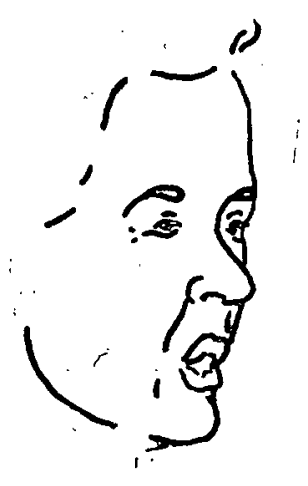

\section{पOUT}

four fourth fourteen pour court.

mourn course source soul poultry

convoy notice opposite sandwich

bottle fourteenth eulogy relief

conceit hue sleigh itch flew deceit cue weigh witch blew 
four

fourth

four teen

pour

court

mourn

course

source

soul

pour try 130b*

On

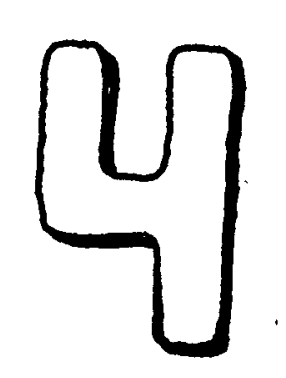

four

fourth

fourteen

pour

court

morns

corves es 
source

soil

poultry 
Magic squares:
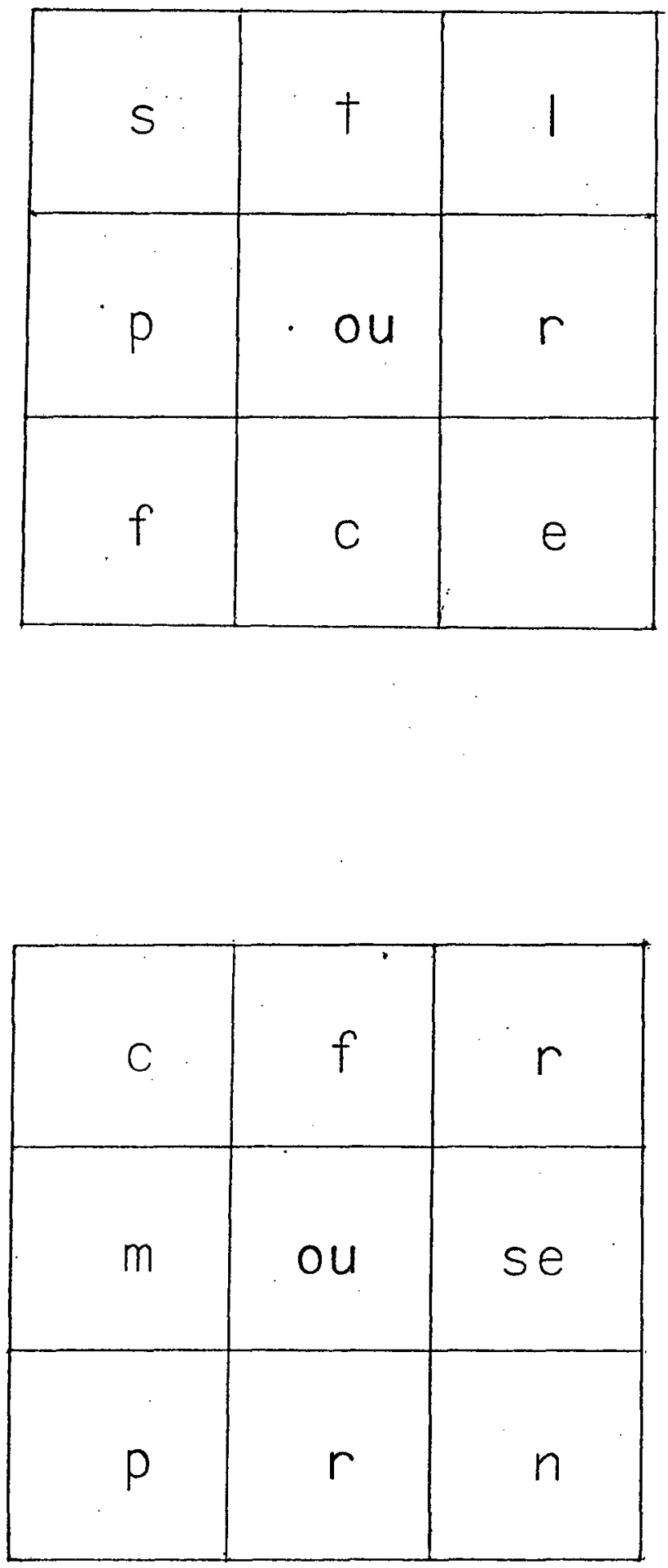


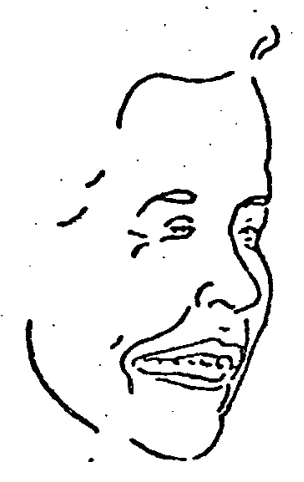

aie.

Millie Willie Winnie Dickie Richie Annie Frankie Kätie Süsie Brownie fourteen value euphony widow heaven transfusion intrusion instead fruity

bread skew sight eight due read pew sigh ate sue 


$$
131 b *
$$

Mill ie

Will ie

ie

Wen ie

Dick ie

Rich ie

Ann ie

Frank ie

Kat ie

Subs ie

Brown ie

Millie

Millie

Minnie

Sickie

Annie

Frankie

Katie 
Susie

Brownie 
See how many new names you can think of that can have the ie ending. (e.g. Billie, Freddie).

Write them below. 
Short Vowel Sounds

With_r or _rr

carry carrot barrel sparrow berry

ferry very heron irrigate irritable

iridescent

rounded climber coldest cherry

fishhook chowmein reindeer recruit
bruise
soup
break
pour
contract
cruise
croup
steak
four
abstract 


$$
132 b *
$$

Short a

car ry

car rot

bar rel

spar row

Short e

beer ry

fer ry

very $y$

her on
Short Vowel Sounds With _r or_ rr

Short i

ir ri gate

ir ri ta ole

ir i desc cent

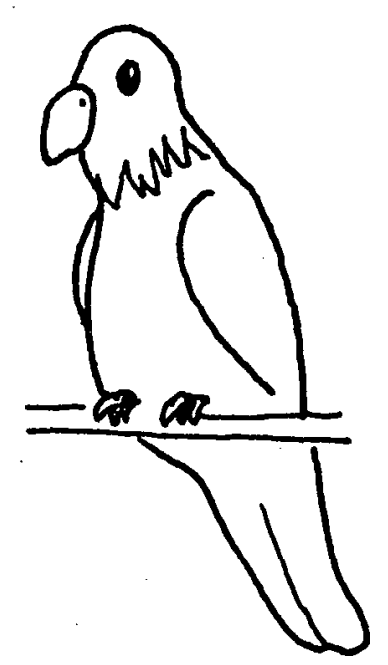

carry

carrot

barrels

sparrows

berry

ferry

very e 
heron

irrigates

irritable

iridescent 
$132 \mathrm{c}$

Choose an ending from the list to put with each word beginning. Each ending is used only once.

1. car

2. fer

on

3. spar

y.

4. ber

rel

5. car

ry

6. her

row

7. bar

rot

8. ver

ry

Unscramble these words:

ble ir rita

ri gate ir

i cent des ir 


\section{DOP}

words work worm worse worth world worst worry worship doctor mayor wordy daybreak poultry Brownie irrigate sparrow posted worship

$\begin{array}{lllll}\text { spoil dispute soup great } & \text { try } \\ \text { soil compute group grate } & \text { fry }\end{array}$




$$
\text { 133b* }
$$

words

work

r

worm

worse

worth

world

worst

work ry

wo ship

doc tor

may or

words

work

ceresin

worse

worth

world

worst 
woring urship doctor maypor 
Which words have the er sound as in work? Underline them.

worse

horn

arm

world

mayor

horse

sour

pour

worth

worst

worry

farm

our

word 


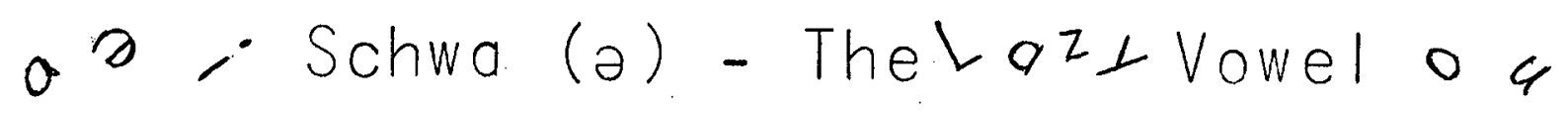

Read the following words. Put accent marks on the accented syllables. Then find the $/ \underline{a} /$ and draw a line under it.

sep a rate

e qual

$\bmod e 1$

dis tant

cab in

con fuse

a round dam age

hu man

ap ple

pick le

a bout

a pron

a Ione 


$$
\text { ou - Plus Silent I }
$$

could could n't should should n't would would $n^{\prime}+$

about carrot soupy confession greatly friction babble stubble word berry hawk soup bout work ferry gawk group about 
$135 b *$

could

could $n^{i} t$

should

should nit

would

would nit
OH

Plus Silent I

could

could nit

should

shouldn't

would

would nt 

Write sentences using the ou words that have a silent 1 . 


\section{DOD}

son ton Monday wonder cover dozen front month come done wondering coming extension construe bruised juicy education worded
could
worth
cold
stood
vein
should
worst
scold
hood
veil 
son

ton

Mon day

won der

cover

doz en

front

month

come (silen te)

done (silent e)

$$
136 b^{*}
$$

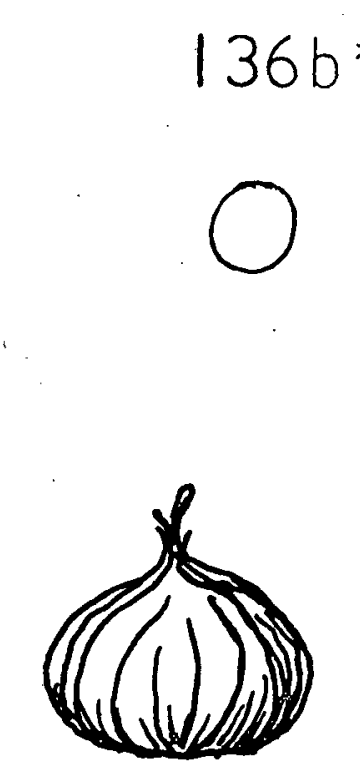

sone

ton

Ohonday

under

cover

dozen

front 
month

comel

dones 
Read the story carefully. Find and underline all the words that have the o as in son.

The month of May marks the time when summer begins to come. Early on a Monday morning a dozen sons meet in front of a house. All of them are going on a wonder trip to the beach. The sons will enjoy making a pile of sand that seems to weigh a ton. Before day is done, the sun will get hot, so the boys will need a cover. Mother will be happy when the children come home. 


\section{"ove" Words}

love glove shove shovel discover move remove prove reprove improve shoved covering discovering dozen Monday convert receive curlycue $\begin{array}{llll}\text { built head few } & \text { troll } & \text { jolt } \\ \text { guilt tread curfew stroll volt }\end{array}$ 


$$
137 b *
$$

$\bar{u}$ sound

love

glove

shove

shove el

dis cove er

$\overline{00}$ sound

move

re move prove
"OVen" Words

Sf?

re prove in prove

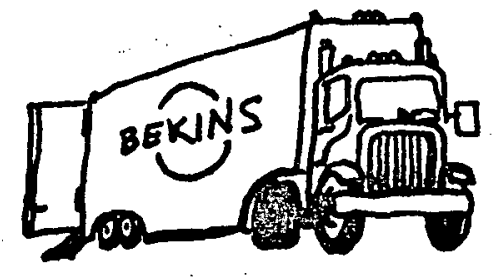

lower

glower

shore

shovel

discover

reveres 
prove

reprove

improve 
Read the "ove" words in this I ist. Underline each "ove" word that has the sound of $\vec{u}$. Circle each word that has the sound of $\overline{00}$.

improve
discover

move

prove

shovel

dove

lover glove

remove

shove

cover

reprove

Iove

grove 

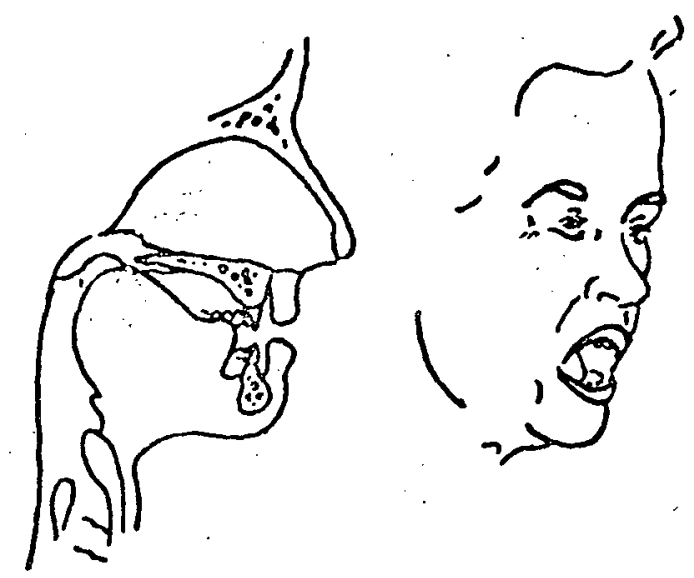

ch

chorus chrome christ Christmas

schools schoolboy schoolroom

scheme ache headache

improve discover schooling wonder

shouldn't separate distant ached

world Millie four steak coil worth Willie pour break oil 
cho rus

chrome

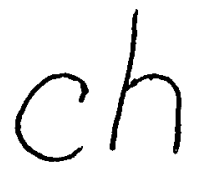

Christ

Christ mas

schools

school boy

school room

scheme

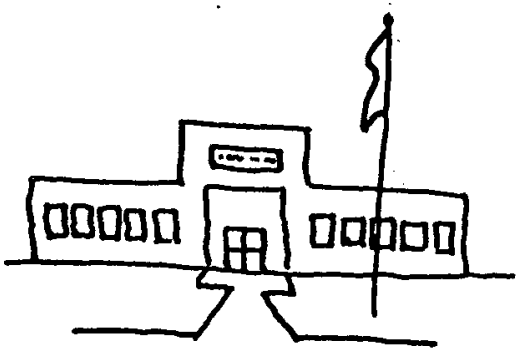

ache

head ache 
scheme

ache

headache 
Fill in the blanks with words from job sheet 138b.

1. The about the

play was child.

2. The sang in the

3. parts on a car glared in the sun and made the girl get a

4. Some are in the country and have only one

5. The boys made a to win ball games.

6. When Jane fell down, her knee began to 


\section{घeara}

earn learn earnest Earl early

pearl earth heard search

pearly earthly earning sparrow

berry reigning very iridescent

juice vein most wild justice juicy veil host mild notice 


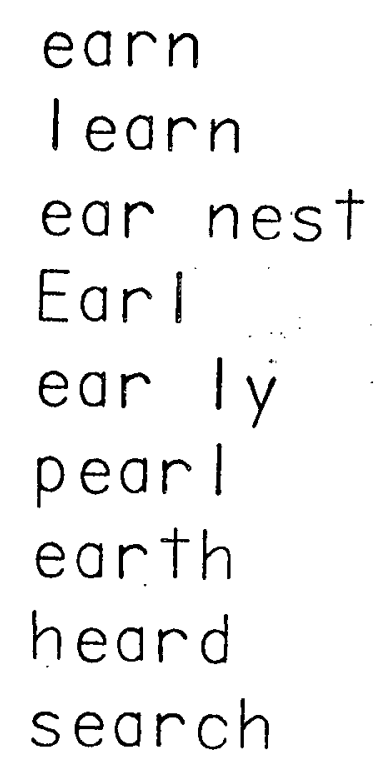$$
\text { earn }
$$$$
\text { learn }
$$$$
\text { ear nest }
$$$$
\text { Earl }
$$$$
\text { ear ty }
$$$$
\text { pearl }
$$$$
\text { earth }
$$$$
\text { heard }
$$$$
\text { search }
$$$$
139 b *
$$

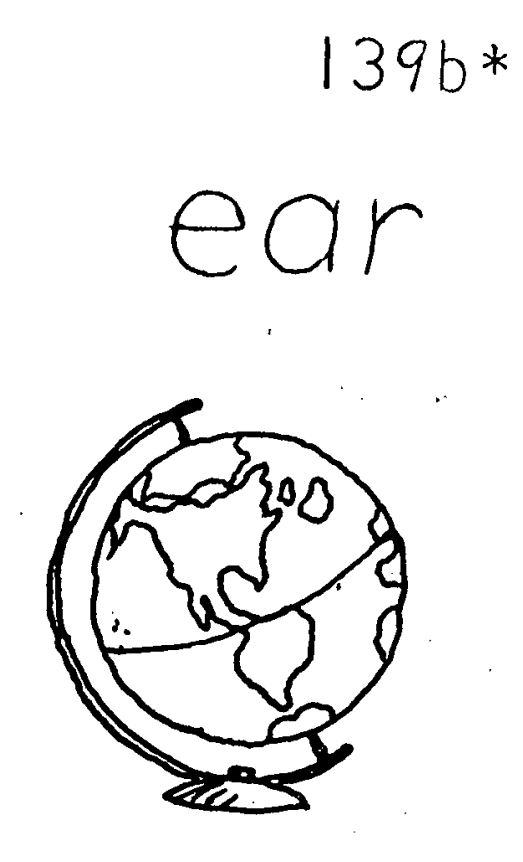

earns

learn

earnest

Earl

early

pearl

earth 
heard

search 
Unscramble these letters to make the ear words you have learned. You may look at the word list on job sheet $139 b$.

1. naer

2. hrade

3. pIrae

4. IEra

5. elary

6. raetsen

7. ear $\ln$

8. Thare

9. chreas 


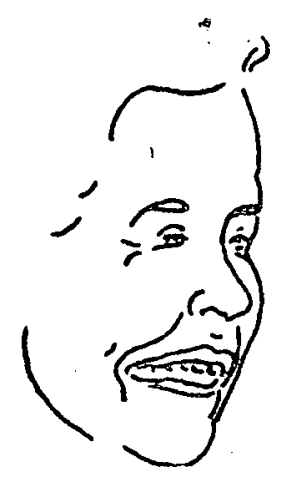

aey

honey money monkey donkey journey

sonny monkeyish handy crooked

steady transfusion itches Millie

relief eulogy squirm surface belief euphony squirt surfaced 


$$
140 b *
$$

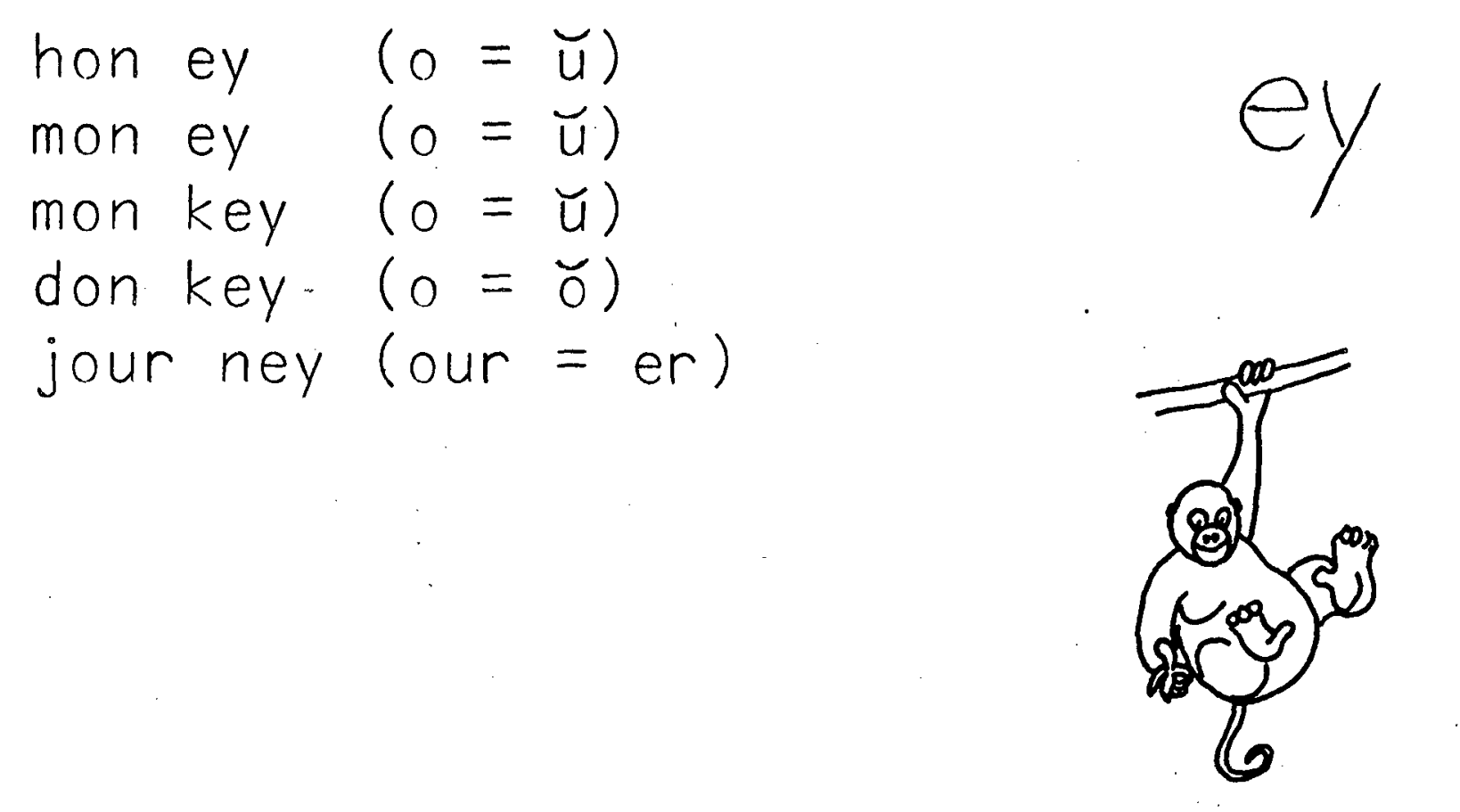

honery

miozrezp

monkery

dorkery

jouromery 


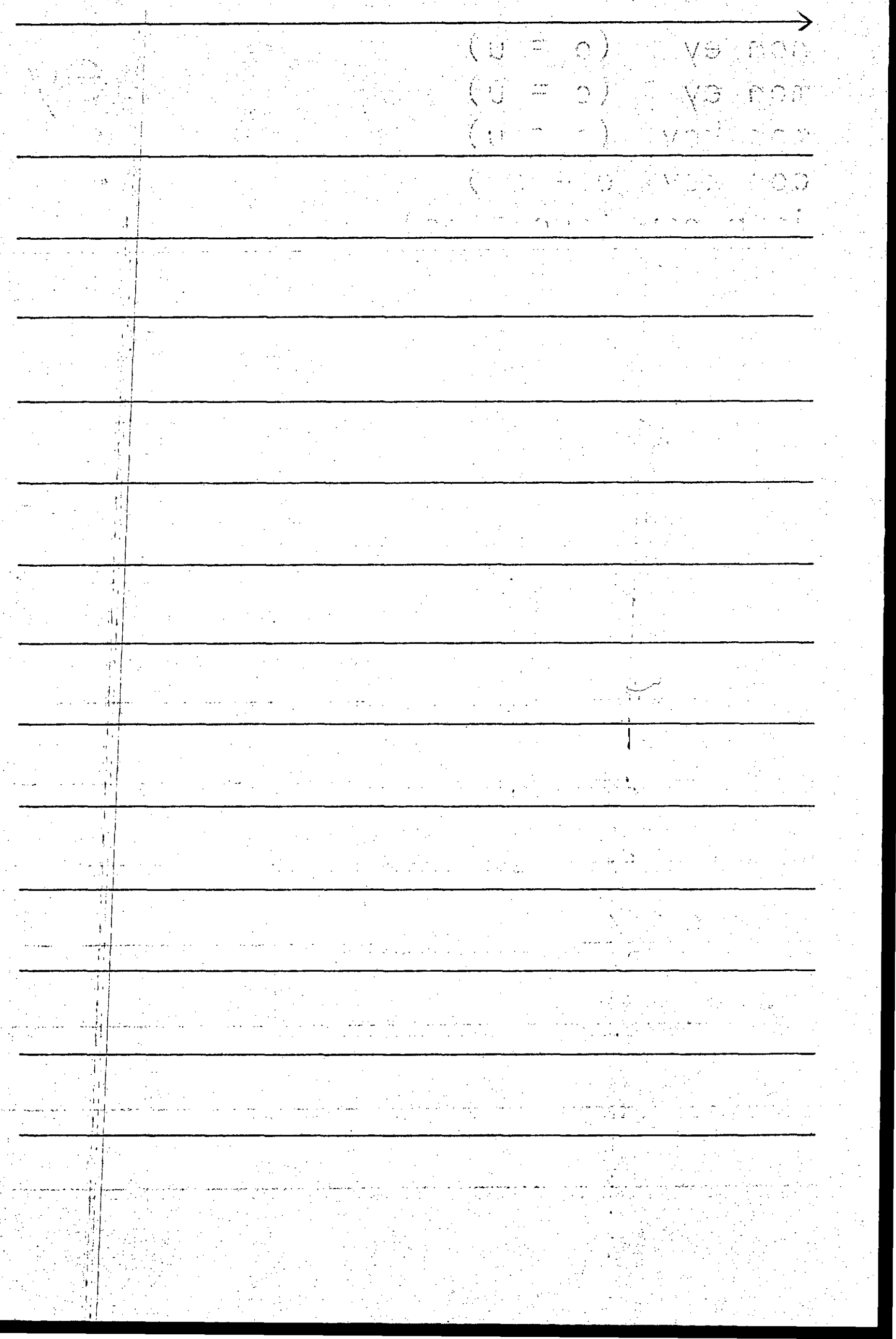


Use your new ey words to write a story below. 


\section{Review}

Read each of these words to your teacher. If the word has more than one syllable, draw a line between the syllables. You may use the dictionary if you need to.

greatest

poultry

irrigate

shovel

earnest

wonder

Christmos

Brownie sparrow

worry

early

improve

daybreak

honey

Annie

berry beefsteak

monkey

mayor

cover

fourteen

discover

headache

journey 


\section{oar}

collar dollar pillar beggar scholar poplar lizard custard standard backward

forward donkey earnest headache schooling remove searcher discover son should cable carrel Rickie ton would stable barrel Richie 
col lar

dol lar

pill lar

beg gar

schorl ar

pop lar

liz ard

custard

stand ard

back ward
$142 b *$

ar

.

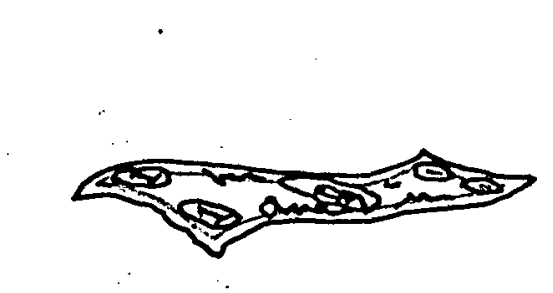

callow

dollar

pillar

beggar

scholar

poplar

ligand 
custard

stondard

bockuard 
Write the correct ending for each word part below. Use each ending in the left column only once.
1. stand
I ar
2. $p o p$
gar
3. $p i l$
ard
4. back
I ar
5. dol
ward
6. beg
Iar
7. cus
ard
8. col
Iar
9. $1 \mathrm{iz}$
tard 


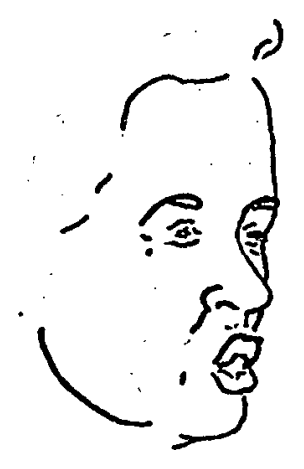

ch

chef chic Chicago Michigan chevron mustache chic Michigan Chicago chef scholar soupy Monday mustaches compulsion recruiter reindeer brushes

hook troll mil.d sold true cook stroll wild scold due 
chef

chic

Chi ca go

Mich i gan

chev ron

mus tache (silent e)

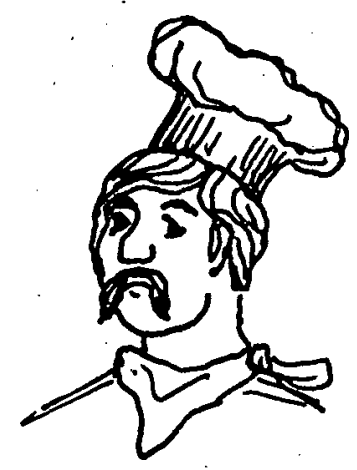

\section{chof}

Chicrgo

2hichignon

cherron

muetache 


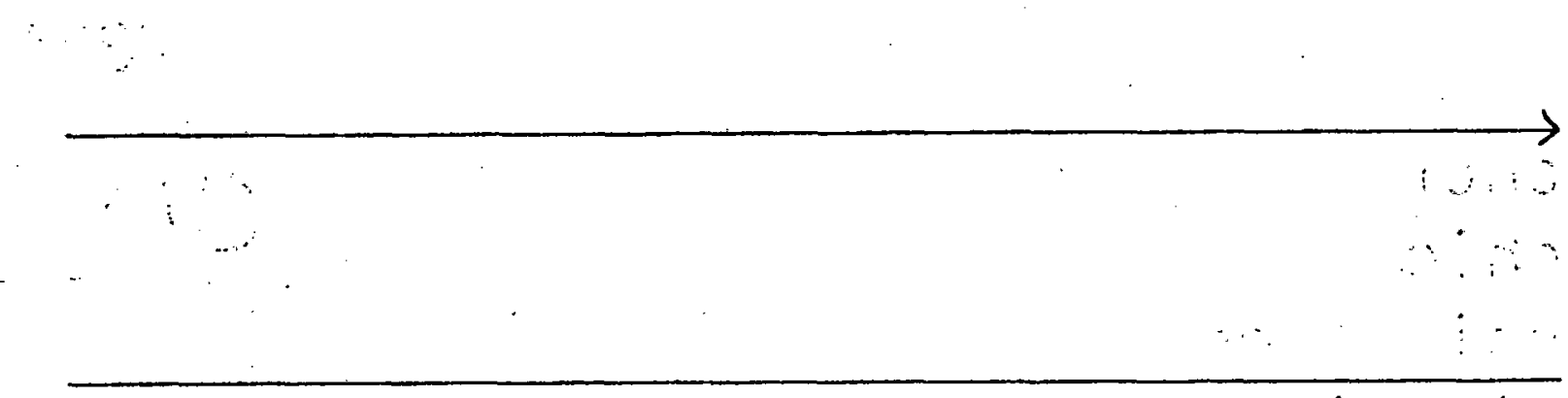

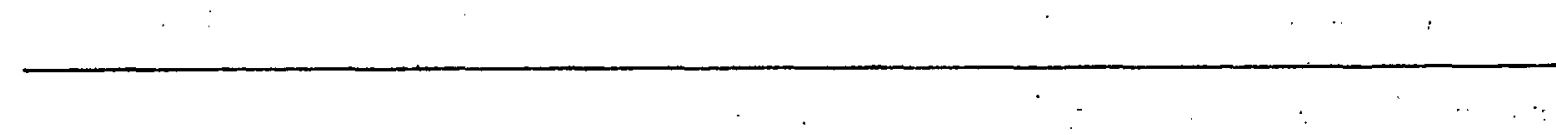


Write a story, using your new ch words and other ch words. 


\section{口OUD}

double trouble couple touch young youngster cousin country southern famous

continuous chevron mustache pewter instead division bowling faction

mew dead skater sleigh witch
few head cater weigh pitch


$144 b *$

dou ble

trou ble cou ple touch

young

young ster

cous in

coun try

south ern

fa mous
OU

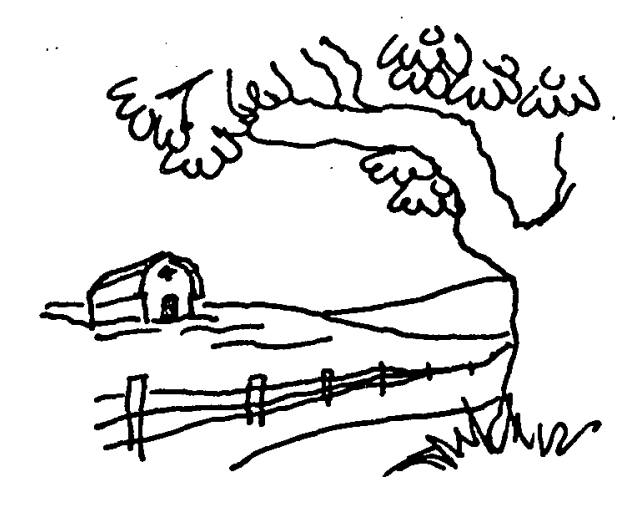

dozible

trozufle.

corpples

toruch

nowing

upoungeter

corsion 
country

southern

famores 
Write these ou words in the order of the alphabet.

famous

young

country

trouble

cousin

2.

3.

4.

5. southern

double

touch

youngster

couple

7.

8.

9.

10. 
gh

rough tough enough laugh ghost

ghetto ghastly dough though

al though

laughing throughout country continue

value neither conceive roughly

belief action neutral ghost

relief traction neural most 
$g h=|f|$

rough

tough

e nough

laugh $(a u=\breve{a})$

$g h=\mid g /$

ghost

Silent gh

ghet to

ghast Iy

dough

though

al though

rough
torugh

wrorugh

laugh

ghost

gietto 
donigh

though

althorigh 
In the blank beside each word, write the symbol for the sound each gh makes. Write f, g, or silent (for silent gh). The first one is done for you.

1. although silent 6. rough

2. laugh

7. ghost

3. ghetto

8. though

4. tough

9. ghastly

5. dough

10. enough

Write a sentence, using some of the words above. 
$146 a$
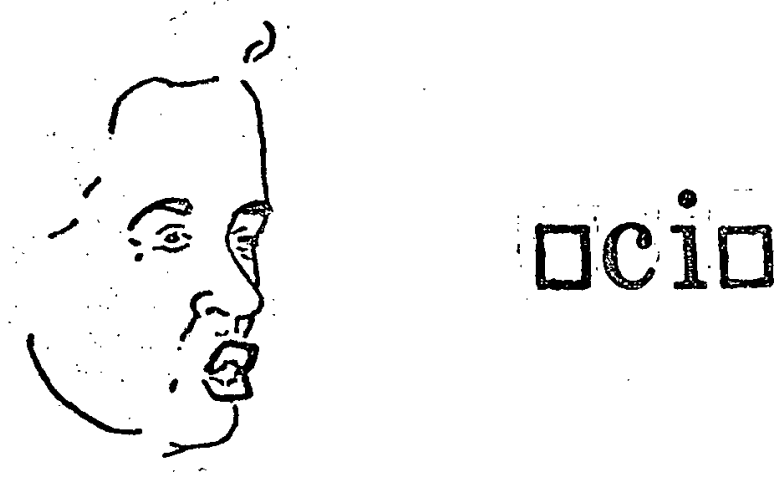

special social official financial

ancient sufficient appreciate

precious gracious conscience

commercial specially ghastly engine

although chewing blotched survive

passes kind decked axes sty
grasses mind checked taxes dry 
spe cial

so cial

of $f i c i a l$

fi nan cial

an cient.

suf $f i$ cient

ap pre ci ate

pre cious

gra cious

con science
$146 b *$

$\mathrm{Ci}$

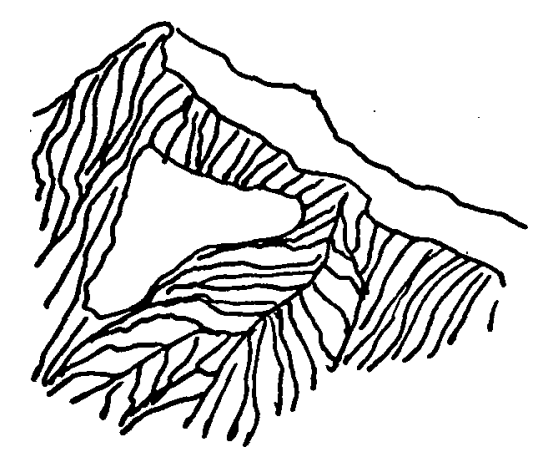

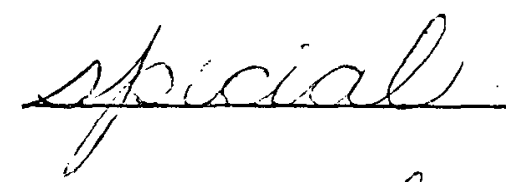

social

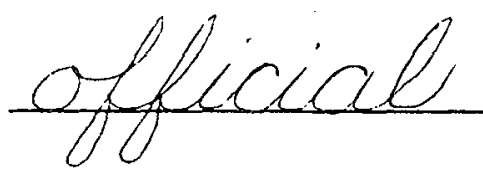

financial

encient,

sufficient

appreciate 

Read this story to your teacher. Underline your new ci words.

The Queen of England is a special person in her country. She is gracious and kind. At special times she wears an ancient crown that is made with precious jewels. At social parties the people appreciate her happy smile. It would be nice to have sufficient money to be able to visit her castle. The Queen must have a good conscience to handle the financial matters of her country. 

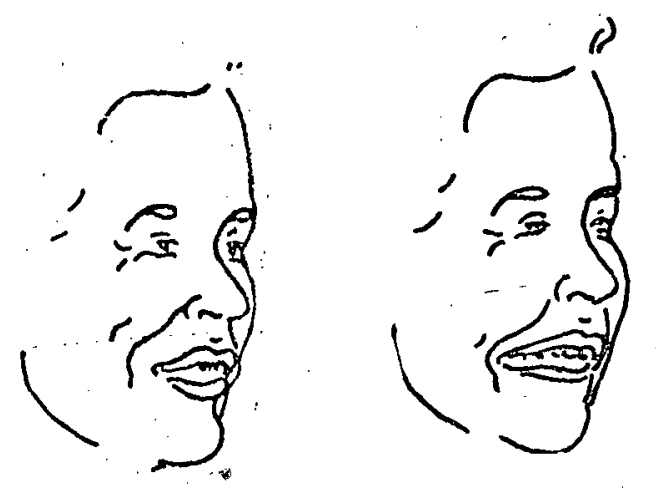

ney

hey whey they grey greyhound

prey obey convey survey

dollar worst obeyed surveying

mayor appreciate financial enough
early
convoy
ba $\mid l$
cold
hoist
earthly
employ
call
bold
choice 


$$
147 b *
$$

hey

whey

they

ty

grey

grey hound

prey

o bey

con very

sur very

hey

whey

they

grep

greyhound

prey

obey 
connery

survery 
Unscramble the words in these sentences and read the entire sentence. The first one is done for you.

1. yhey is what is left of milk when cottage cheese is made.

2. Some people say " yhe "when yeth want to get my attention.

3. An animal that will peyr

3. An animal that will on

smaller animals is a eygr nduoh

4. You can make a yevrus when you want to find out how many people eoyb safety rules. vyenoc

5. Please my thanks to her. 
$148 a$

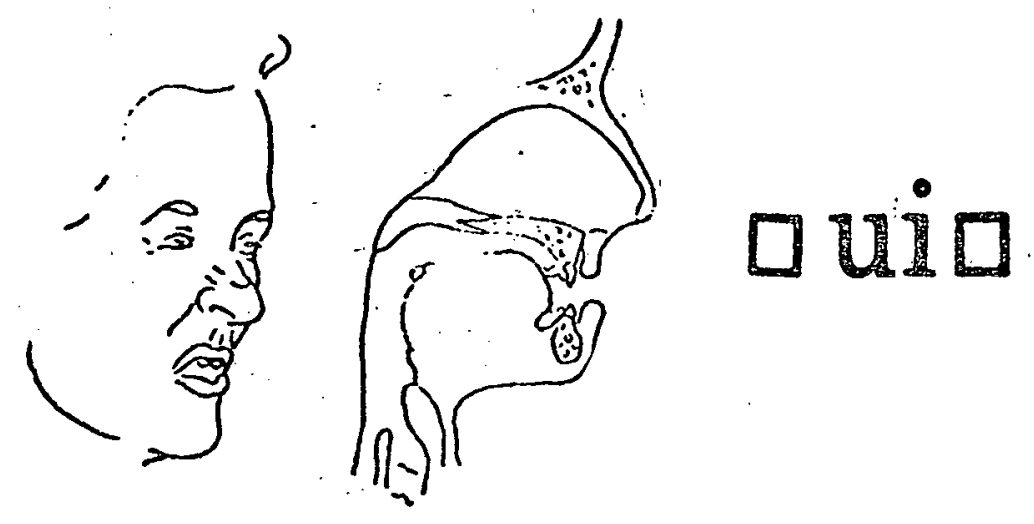

guild build building builder built

guilt guilty quilt.guitar

quilting weightless survey guilted children reindeer brighten auction
bl ind
bolder
shrew
soup
pie
wind
colder
drew
group
lie 
guild

build

build ing

build er

built

guilt

guilty

quilt

gui tar
$148 b *$

Mi

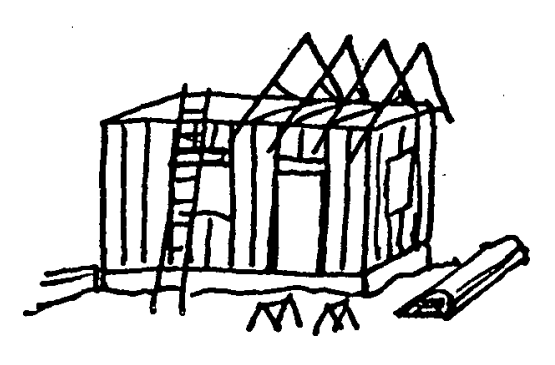

guild

build

building

builder

built

guilt

guilty 
quilt,

guitar 
Finish these sentences with your own words.

1. Grandmother's quilt

2. The man built

3. Building

4. Willie felt guilty

5.

with guilt.

6. Will you build

?

7. A guild is

8.

a guitar.

9. The new builder

10. This old building 

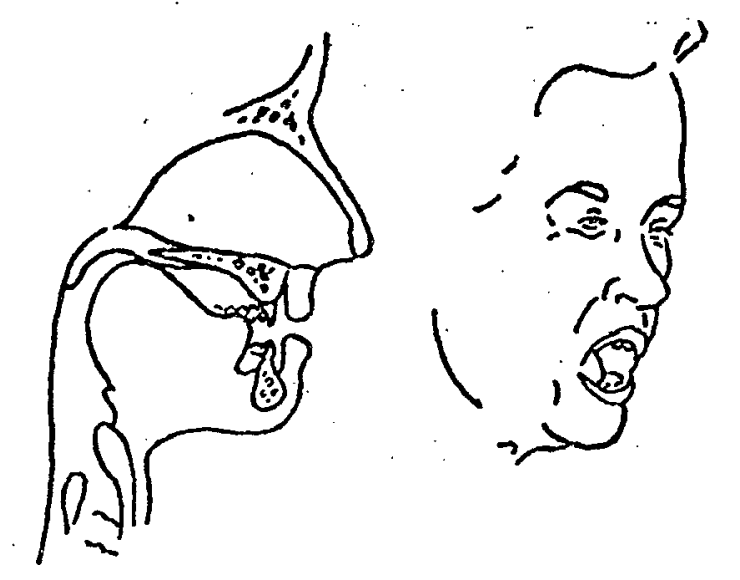

gu

guess guest guide guile guard

lifeguard guest guess guide

guitar builder fruity quickly

meadow priestess tryout cruising

brown boiled room good slay

town spoiled broom wood lay 
$149 b *$

guess

guest

guide

gu

guile

guard

life guard

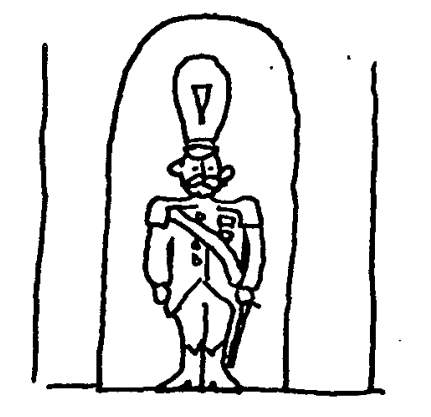

guess

guest

guide

guile

guard

lifegieard 
$\therefore \quad 4$
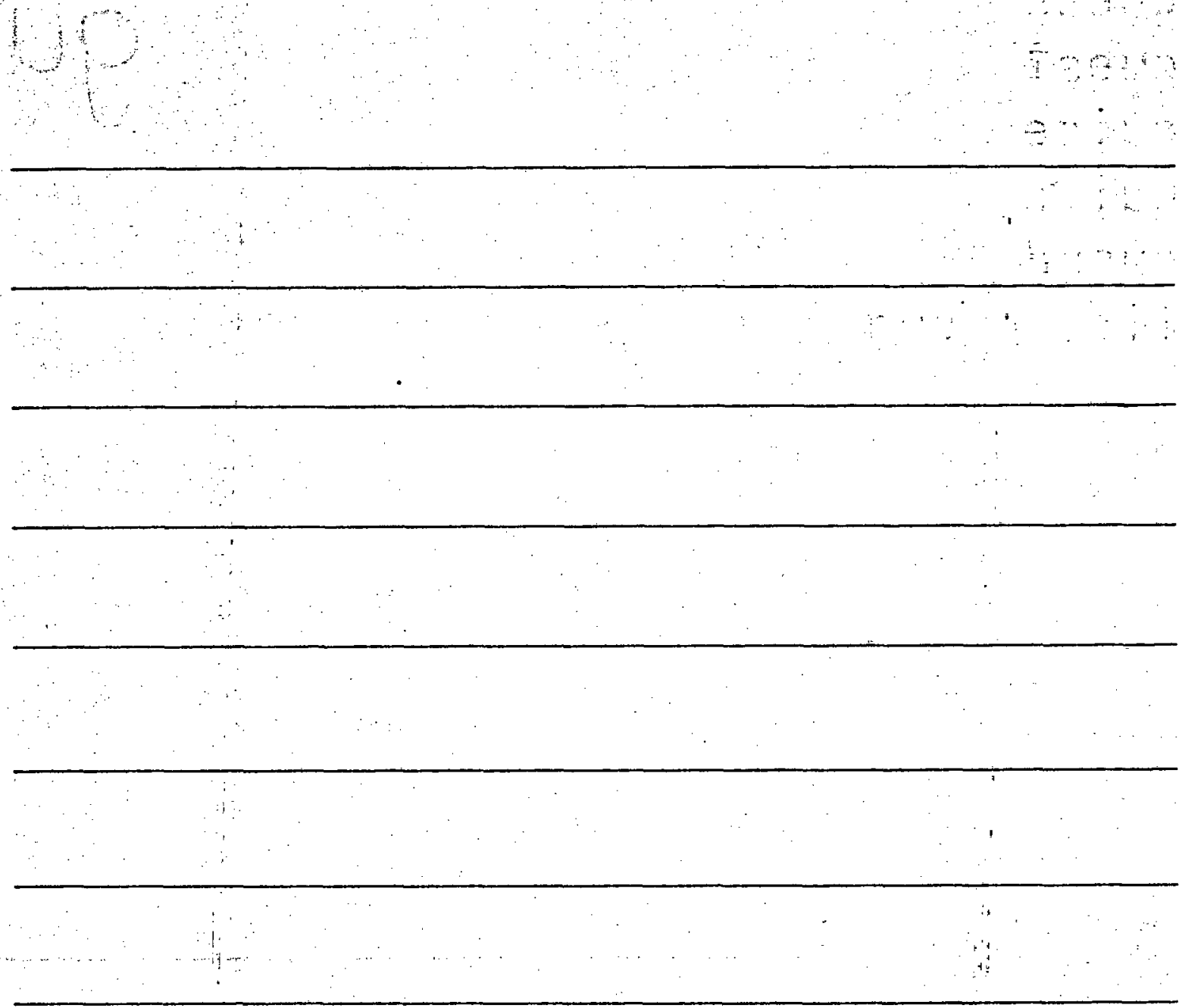
Draw a line under all the gu words in these sentences. The words are from this lesson and lesson 148.

1. The life guard plays the guitar and guards the swimming pool.

2. The guide will show you the new busilding.

3. The artists'guild is a group of men who paint pictures.

4. Guile is a word that means tricky or cunning.

5. You will not have to guess when you know the answer.

6. When you do something wrorig you feel guilty. 


\section{पa口}

wad want wand wander wash watch water swan swamp squash

washtub watchman watermelon watery waterproof Washington walker walled
shy
guile
guild
rolled
clue
try guide
build
roller
blue 
$150 b *$

wad

want

wand

wan der

wash

watch

wa ter

swan

swamp

squash a

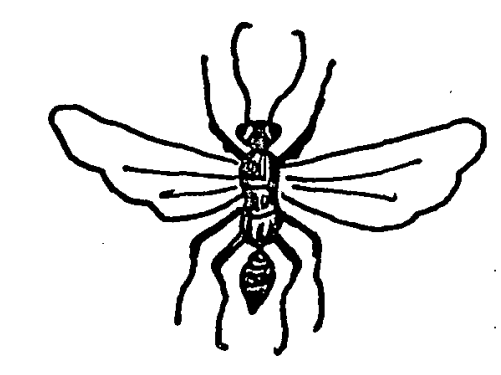

lad

rant

stand

under

wash

watch

water 
suan suramp sguash. 
Write a story using the a words that say the sound of aw or au (e.g. want, what). You may also use as many aw and au words as possible. 


\section{aught}

aught caught taught slaughter

daughter haughty naughty distraught

teacher slaughtering witness eater water turkey poplar jeweler undue

saw car far

salt

care

fare

though

rein

tough

rain 
$151 b *$

aught

caught

taught

slough ter

dough ter

haugh ty

naught ty

dis fraught aught

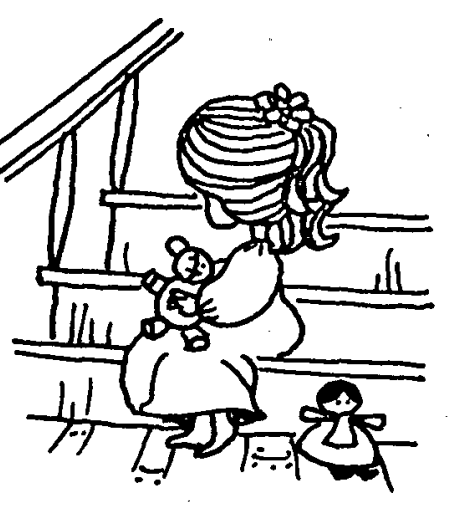

aught

caught

taught

slaughter

daughter

haughty.

naughty 
distraught 
Choose letters from the letter bank to make some aught words. The first one is done for you.

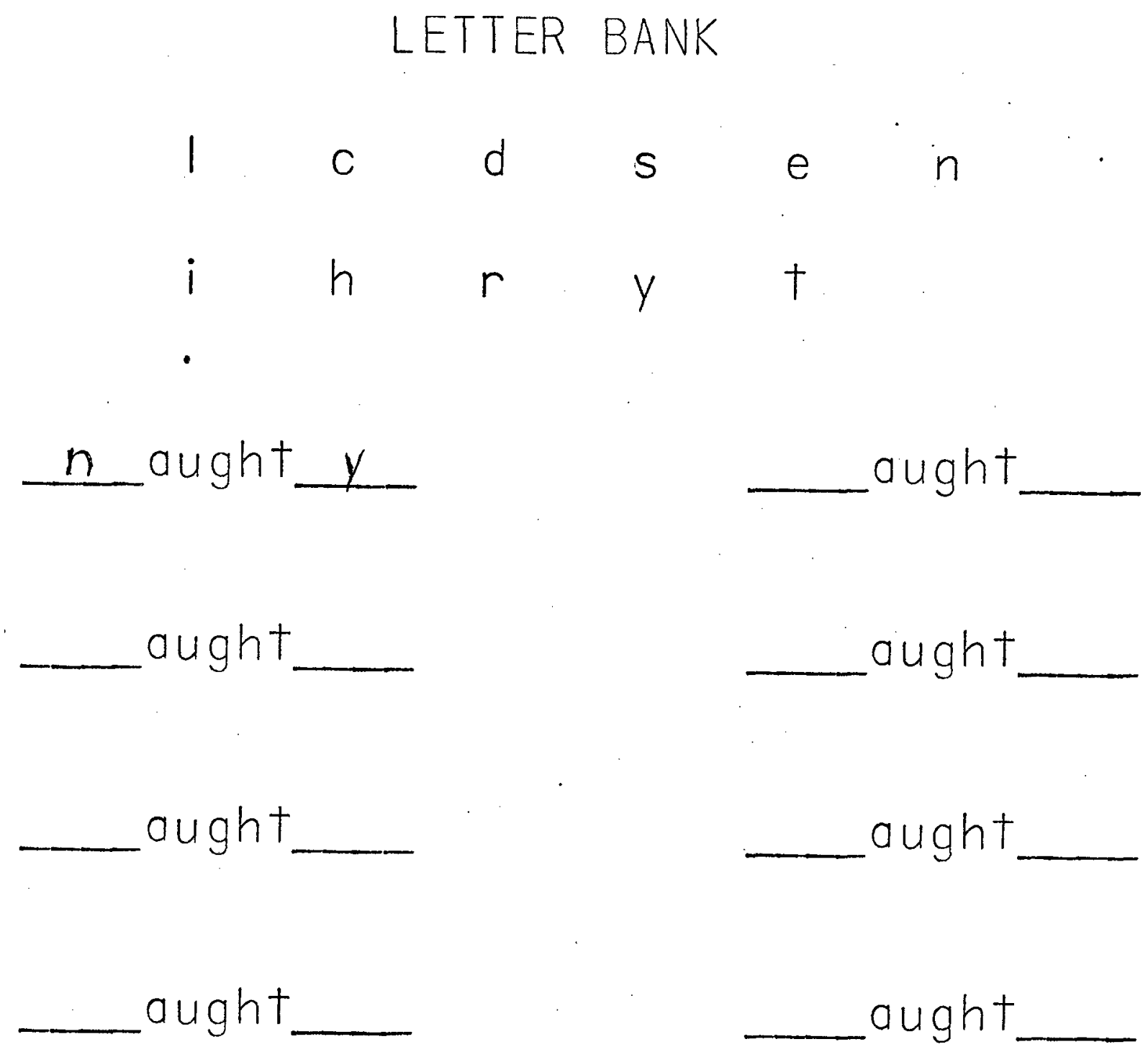




\section{ought}

ought bought brought fought sought

thought bought ought fought thought

daughter slaughter suitcase wander

building appreciate although wand

collar honey earn wad glove
dollar money learn wand love


152b*

ought

bought

brought

fought

sought

thought ought

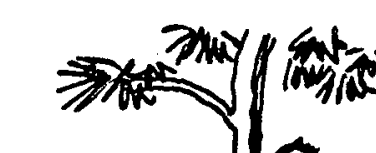

ought s

bought

brought,

fought

sought

thought 

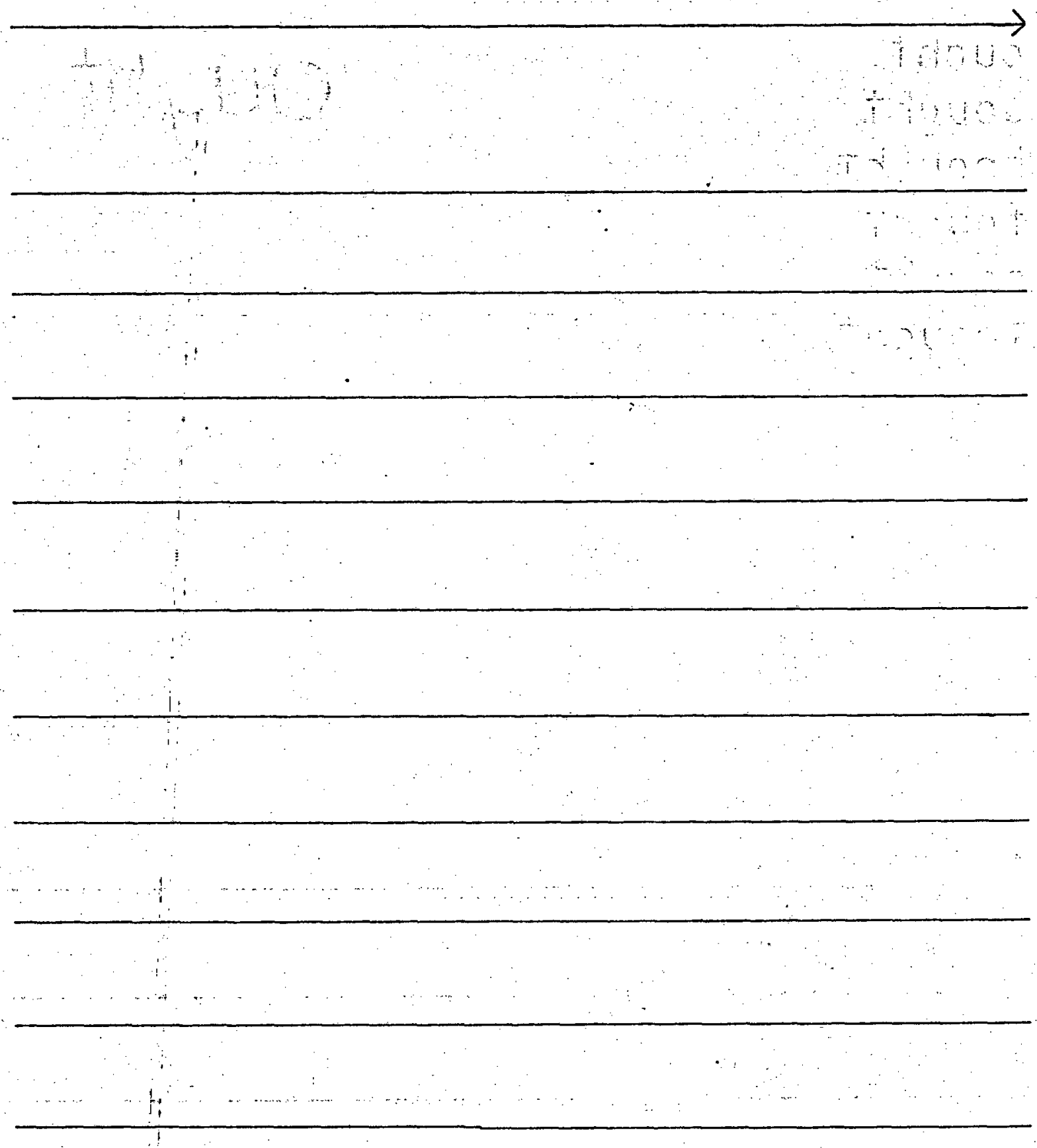
Write these ought and aught words in alphabetical order.
ought
slaughter
aught

distraught bought

sought

fought

daughter

naughty

haughty

thought

caught

taught

brought

1

2.

3.

10.

4.

8.

9.

11.

5.

12.

6.

13.

7.

14. 


\section{Review}

Read each of these words. Write the sound of the vowel that you hear in each word. Choice: $\breve{a}, \bar{a}, \breve{e}, \bar{e}, \bar{i}, \bar{i}, \check{o}, \bar{o}, \widehat{o}$, $\bar{u}, \bar{u}$. The first one is done for you.
young $\underline{\bar{u}}$
taught

guide

guest

though

sought

hey

prey

touch

guild

guile

bought

ghost

rough

laugh

wad

wand

whey

thought

$$
\text { - dough }
$$

guilt

built

: cqught

watch

guess

grey 